\title{
Plantas medicinales de los Andes y la Amazonía - La flora mágica y medicinal del Norte del Perú
}

\author{
Rainer W. Bussmann, Douglas Sharon
}

\section{Investigacíon}

\section{Resumen \\ El norte de Perú representa la "Eje de la Salud" de los Andes Centrales, con las raíces de las prácticas tradicionales remontandose a la cultura Cupisnique (1000 AC).}

Durante una década de investigaciones se realizaron entrevistas semi-estructuradas de curanderos, colectores y vendedores de plantas medicinales. Se ejecutaron bioensayos para evaluar la eficaz y toxicidad de las plantas encontradas.

La mayoría (83\%) de los 510 especies usadas eran nativos de Perú. El $50 \%$ de las plantas utilizadas en la época colonial desaparecieron de la farmacopea. En los mercados se agruparon vendedores de: plantas comunes y exóticas, plantas para enfermedades comunes, plantas solo utilizadas por curanderos, y plantas con fines mágicos. Unos 974 preparaciones con hasta 29 ingredientes trataron 164 afecciones. Casi 65\% de la flora medicinal se aplican en mezclas. Se confirmó la actividad antibacteriana en la mayoría de plantas utilizadas para infecciones. El $24 \%$ de extracto acuosos y $76 \%$ de extractos etanolicos mostraron toxicidad. Los métodos tradicionales de preparación toman este en cuenta al elegir el disolvente apropiado para la preparación de un remedio.

La creciente demanda no incrementó el cultivo significativo de plantas medicinales. La mayoría representa plantas recolectadas en la naturaleza, causando dudas sobre la sostenibilidad del comercio.
El enfoque de los estudios etnobotánicos y la participación de las partes interesadas locales han cambiado mucho en las últimas décadas. Desde el punto de vista científica, la investigación ha pasado de simples inventarios por ejemplo de plantas principalmente medicinales a estudios cuantitativos detallados, a menudo enfocados en todas las plantas útiles. Sin embargo, lo más importante es que la investigación finalmente se ha alejado de las investigaciones de estilo colonial a la etnobotánica moderna basada en los principios del Protocolo de Nagoya. Esto es de gran importancia para la comunidad etnobiológica. Sin embargo, estos cambios no han sido igual en todos los países Latinoamericanos, y hay grandes diferencias regionales.

El objetivo de esta publicación es brindar ejemplos de veinticinco años de investigación global, describiendo el cambio de actitud y metodología durante ese tiempo, destacando el papel cada vez mayor de los actores locales en la investigación etnobotánica y aportando ideas para el desarrollo futuro de la disciplina.

Con este número especial de IEthnobotany Research and Applications, intentamos llevar 20 años de investigación en el norte de Perú a una audiencia más amplia.

\section{Correspondencia}

Rainer W. Bussmann, Saving Knowledge, Avenida Principal 92, Chicani, Casilla 13092, La Paz, Bolivia,

Rainer.Bussmann@savingknowledge.org

Douglas Sharon, 2328 Dolphin Dr., Richmond, CA 94804, U.S.A.

Ethnobotany Research \& Applications 15(1):1-293 (2016) 


\section{Rainer W. Bussmann - Douglas Sharon}

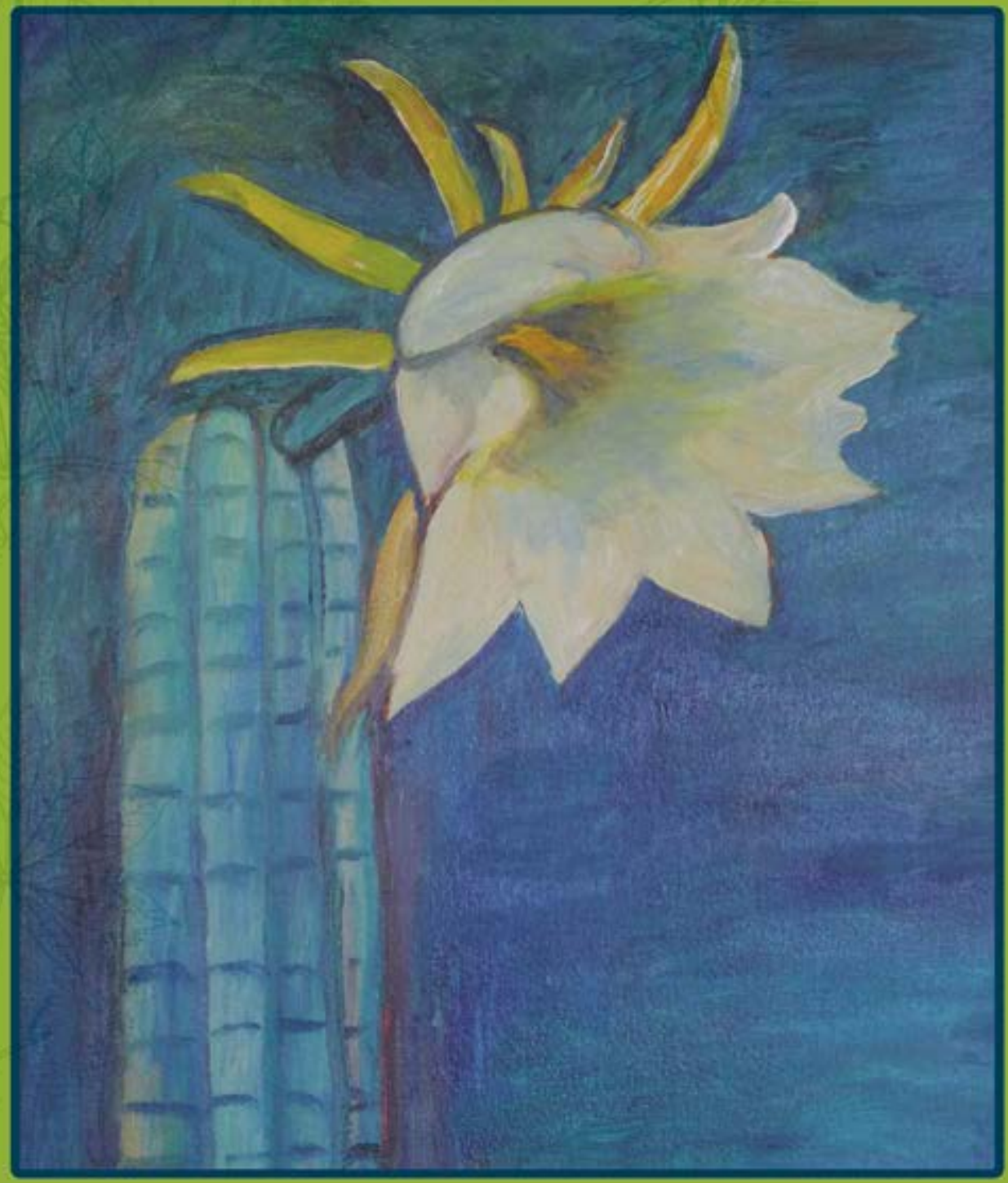

Plantas medicinales de los Andes

y la Amazonia

La Flora mágica y medicinal del Norte del Perú 


\section{Plantas medicinales de los Andes y la Amazonia}

La Flora mágica y medicinal del Norte del Perú 


\title{
Plantas medicinales de los Andes y la
} AMAZONIA

Rainer W. Bussmann - Douglas Sharon

\author{
La Flora mágica y medicinal del Norte del Perú
}

Esta publicación goza de los derechos de propiedad intelectual en virtud del protocolo 2 anexo a la Convención

Universal sobro Doza de los dechos de prop no se inerión de

información o trasmitir alguna parte de esta publicación, cualquiera sea el món

fotocopia, grabación, etc - sin permiso previo del autor intelectual.

\section{Rainer W. Bussmann - Douglas Sharon}

Centro William L.Brown - Jardin Botánico de Missouri 


\section{AdVertencia}

Las declaraciones contenidas en esta publicación representan una recopilación de la Medicina Tradicional Norperuana, a partir de entrevistas con en el mercado, con el fin de documentar y preservar este conocimiento tradicional. La información ha sido registrado en entrevistados.

Este libro no pretende contener, ni pretende ser, cualquier tipo de recomendación o guía de auto-tratamiento con las plantas o las prácticas tradicionales. Algunas de las especies reportadas son bastante tóxicas o podrían causar daño cuando se utilizan de forma inapropiada. Incluso las plantas que se consumen comunmente como alimentos que generalmente son reconocidos de ser seguros para consumir pueden tener efectos adversos, incluyendo las interacciones medicamentosas y la hipersensibilidad de algunas personas.

Los autores han consultado las fuentes que se consideran fiables para confirmar la fidelidad e integridad del contenido de este libro. Sin embargo, los autores, editores y titulares de los derechos de autores reclaman todas las garantías, expresadas o implícitas, en la medida permitido por la ley y afirman que los contenidos son en todos aspectos fidedignos y completos, y que no son responsables de errores, omisiones o las consecuencias de la aplicación del contenido de este libro. Ningún contenido de este libro debe ser interpretado de representar un intento de diagnosticar, prescribir o administrar de forma alguna cualquiera dolencia o condición física o psicológica, ni se debe utilizar la información de este libro en lugar de los consejos y cuidados médicos calificados.

Aunque la información proporcionada en este libro procura promover la educación y la investigación científica, nos damos cuenta que ciertos aspectos de este trabajo pueden contribuir a la comercialización. Todo el trabajo de este libro se llevó a cabo bajo las reglas del Protocolo de Nagoya sobre el acceso a los recursos genéticos y la participación justa y equitativa en los beneficios derivados de su utilización y del Convenio sobre la Diversidad Biológica. Además el derecho de propiedad intelectual de estos conocimientos es mantenido por los curanderos tradicionales y vendedores que fueron entrevistados que han desarrollado sus conocimientos a través de siglos de experimentación y experiencia. Cualquier uso comercial de la información presentada en esta publicación requiere el permiso previo de los informantes y sus comunidades y un acuerdo sobre la distribución de Los beneficios 


\section{Medicina Tradicional y Alternativa-Complementaria}

La Medicina Tradicional se utiliza globalmente y tiene una importancia económica que está creciendo rápidamente. En los países en vías de desarrollo la Medicina Tradicional a menudo es el único modo de tratamiento accesible y económicamente factible. Por ejemplo, en Uganda la proporción de practicantes de Medicina Tradicional en la población está entre 1:200 y 1:400 mientras que la disponibilidad de médicos occidentales típicamente es de 1:20,000 o menos. Además los médicos mayormente se encuentran en las ciudades y zonas urbanas y por eso no son accesibles a la población rural. En África, hasta $80 \%$ de la población usa la Medicina Tradicional como el sistema primario de tratamiento médico. En América Latina, la Oficina Regional de la Organización Mundial de Salud de las Américas (OMS/OPS) reporta que 71\% de la población de Chile y $40 \%$ de la población de Colombia ha usado la Medicina Tradicional. En muchos países asiáticos la Medicina Tradicional es usada ampliamente a pesar de que la medicina occidental frecuentemente está disponible. En Japón, 60 a 70\% de los médicos alopáticos usan medicamentos tradicionales para sus pacientes. En China, alrededor de $40 \%$ del tratamiento médico de todo el país es proveído por la Medicina Tradicional y se usa para tratar aproximadamente 200 millones de habitantes cada año. En Estados Unidos, el número de visitas a proveedores de Medicina Alternativa-Complementaria (MAC) ahora excede en una cantidad grande al número de visitas a médicos de atención primaria de salud (WHO 1999, 2002; WHO/PAHMA 1999).

La Medicina Alternativa-Complementaria (MAC) se está haciendo cada vez más popular en muchos países desarrollados. El 48\% de la población de Australia, $70 \%$ en Canadá, $42 \%$ en Estados Unidos, $38 \%$ en Bélgica y $75 \%$ en Francia han usado la Medicina AlternativaComplementaria por lo menos una vez (WHO 1998; Fisher y Ward 1994; Health Canada 2001). Una encuesta de 610 médicos suizos mostró que 46\% habían usado alguna forma de la MAC, principalmente homeopatía y acupuntura (Domenighetti et al. 2000). En Gran Bretańa, casi $40 \%$ de todos los practicantes alopáticos ofrecen alguna forma de acceso y se refieren a la MAC (Zollman y Vickers 2000). En Estados Unidos, una encuesta nacional reportó que el uso de por lo menos una de 16 terapias alternativas se incrementó de 34\% en 1990 a 42\% en 1997 (Eisenberg 1998; UNCTAD 2000).

Los gastos para el uso de la Medicina Tradicional y la Medicina Alternativa-Complementaria están creciendo exponencialmente en muchas partes del mundo. En Malasia, se gasta un estimado US \$ 500 millones anualmente en la Medicina Tradicional, comparado a cerca de US \$ 300 millones en la Medicina Alopática. En 1997, el gasto directo en Medicina AlternativaComplementaria en Estados Unidos se estimó en US \$ 2700 millones. En Australia, Canadá y Gran Bretańa el gasto anual en Medicina Alternativa-Complementaria se estima en US \$ 80 millones, US \$ 2400 millones y US \$2300, respectivamente. El mercado mundial para remedios a base de hierbas usadas en la Medicina Tradicional a fines de los años 90 se estimó en US \$ 60000 millones (Breevort 1998). Una década más tarde fue alrededor de US \$ 60 billones (Tilburt y Kaptchuk 2008) con estimaciones para 2015 alrededor de US 90 billones (Global Industry Analysts 2012). La venta de hierbas y suplementos nutricionales a base de plantas en Estados Unidos se incrementó en 101\% entre mayo de 1996 y mayo de 1998. Los productos más populares incluyeron el ginseng (Ginkgo biloba), ajo (Allium sativum), Echinacea spp. y St. John’s Wort (Hypericum perforatum) (Breevort 1998).

La Medicina Tradicional y la Medicina Alternativa-Complementaria están ganando más y más respeto de gobiernos nacionales y de proveedores de salud. El Programa Nacional de Medicina Complementaria de Perú y la Organización Panamericana de Salud recientemente 
compararon la Medicina Complementaria a la Medicina Alopática en clínicas y hospitales trabajando dentro del Sistema de Seguro Social de Perú (EsSalud). Los investigadores realizaron el seguimiento con un total de 339 pacientes durante un año - 170 tratados con la Medicina Alternativa-Complementaria y 169 con la Medicina Alopática. Analizaron tratamientos para osteoartritis, dolor de la espalda, neurosis, úlceras gastro-duodenales, tensión, migrañas y obesidad. Los resultados en un $95 \%$ mostraron que el costo del uso de la Medicina AlternativaComplementaria fue menos que el costo de la terapia occidental. Además, para cada criterio evaluado - eficacia clínica, satisfacción de usuarios y reducción de riesgos futuros - la eficacia de la Medicina Alternativa-Complementaria fue más alta que los tratamientos convencionales, incluyendo menos efectos secundarios, percepción de una eficacia más alta de parte de los pacientes en las clínicas de EsSalud y una eficacia de costo de 53 a 63\% de la Medicina AlternativaComplementaria que la de los tratamientos convencionales para las condiciones seleccionadas (EsSalud/OPS 2000).

Según la Organización Mundial de la Salud (2002), los retos más importantes para la Medicina Tradicional/Medicina Alternativa- Complementaria para en el futuro son:

- La investigación de MT/MAC deberá encontrar tratamientos eficaces y seguros para enfermedades que representan la mayor carga, particularmente entre los pobres del mundo.

- Reconocimiento del papel que desempeñan los practicantes de la MT en proveer asistencia médica en paises en vías de desarrollo.

- Destreza mejorada de practicantes de la MT en países en vías de desarrollo.

- Protección y conservación de los conocimientos indígena de la MT.

- Cultivo sostenible de plantas medicinales.

- Información fidedigna para los usuarios en cuanto al uso apropiado de terapias y productos de la MT/MAC.

Dr. Manuel Fernández (2009), subdirector del Instituto Nacional de Medicina Tradicional

(INMETRA) en los años 90, esboza los retos relacionados con la producción de "fitofarmacéuticos" en Perú:

- Falta de una política nacional.

- Ausencia de una politica sectorial del recurso de las plantas medicinales.

- Falta de apoyo estatal.

- Falta de apoyo de la clase médica.

- Desconocimiento de los beneficios de esta industria.

- Limitados recursos humanos y técnicos.

- Falta de conocimiento tecnológico para la fabricación de productos herbarios.

- Inexistencia de métodos y procesos de control de calidad y estandarización.

- Problemas para obtener materia prima de calidad y en cantidades adecuadas.

- Ausencia de una política de conservación que cultive especies en mejores condiciones.

- Limitaciones de investigación etnobotánica, agrotecnológica, farmacéutica y validación.

- Aspectos legales relacionados con el registro sanitario y comercialización.

- Intereses de las industrias farmacéuticas que minimizan la importancia de fitofármacos, a no ser que sean de sus propios programas de investigación y desarrollo.

El Dr. Fernández habla de una diminución en América Latina del consumo de productos medicinales de $8 \%$ del consumo global en 1980 a 5\% en 1990. El atribuye esta diminución a una reducción de medicinas gratuitas de gobiernos a los pobres, una concentración de la renta en pocas manos y la ampliación de la pobreza. Otro factor es el hecho que los países desarrollados gastan un porcentaje más alto de su PIB en medicamentos (6-8\% de PIB) que los países en vías de desarrollo ( $1-2 \%$ de PIB), donde se estima que $2 / 3$ de las medicinas compradas son pagadas por los pacientes. Y el gasto per cápita es mucho más alto en los países desarrollados en comparación con los países en vías de desarrollo, por ejemplo, Japón: US \$ 276; Alemania: US \$ 148; EE.UU: US \$ 128; Argentina: US \$ 42; Uruguay: US \$ 40: ParaguayUS \$ 18; Brasil: US \$ 10.5; Bolivia: US $\$ 4$. No hay cifras para Perú, pero se estima que es un poco más alto que el número para Bolivia. En general, se estima que $50 \%$ de la población de América Latina tiene poco a ningún acceso a productos médicos y que un gran porcentaje de ellos usa plantas medicinales.

Una respuesta innovadora a los retos arriba mencionados ha sido desarrollada durante casi tres décadas por el Centro de Medicina Andina (CMA) fundado en Cuzco en 1984 como un departamento autónomo del Instituto de Pastoral Andino (IPA). Inaugurado por trabajadores católicos de salud con experiencia extensiva en comunidades quechuas, la metodología pragmática de CMA involucra "capacitación mutua" entre profesionales, curanderos y parteras. Su interrogativa retórica es: "Quién conoce mejor toda la riqueza de la medicina andina, sino el propio campesino y especialista practicante de esta medicina?"

Objetivos del Centro hasta 1992 incluyeron: "1) Avanzar hacia un sistema de salud que favorezca a las mayorías del pueblo donde se complementan la Medicina Natural-Popular y la moderna. 2) A través del estudio y la aplicación de la Medicina Natural-Popular crear una base científica para su desarrollo ". Objetivos desde 1992 incluyen: "1) Revalorar y rescatar la Medicina Andina para contribuir a su mejor utilización y reconocimiento dentro del sistema de salud alternativo al alcance de la mayoría de la población. 2) Investigar, experimentar, sistematizar y difundir las experiencias y conocimientos de la Medicina Andina. 3) Fomentar el debate, intercambio y coordinación entre personas e instituciones que trabajan en el campo de la Medicina Natural-Popular. 4) Rescatar los alimentos andinos para elaborar una propuesta y así mejorar la alimentación” (Garrafas R \& R 2009).

Objetivos del CMA incluyen: 1) Educación-Capacitación "campesino a campesino" a promotores de salud de la comunidad y grupos de mujeres en colaboración con universidades locales y el Ministerio de Salud (MINSA); 2) Medicina y Antropología Médica-Epidemiología regional y evaluaciones clínicas de tratamientos naturales además de etnografías y publicaciones sobre aspectos culturales y cosmovisión de la Medicina Andina; 3) Etnobotánica y FitoterapiaColección e identificación de 3,740 plantas además del desarrollo de un Herbario y Laboratorio certificado que ha llevada a la producción y comercialización de seis medicinas naturales (Garrafas R \& R 2009: 373-384).

Otro proyecto innovador fue organizado por el R.P Dieter Wacker (MSC), Presidente de la Asociación Huitco en 1997 en Puquio (Ayacucho). Incluye un jardín botánico; un herbario; ambientes de secado; depósitos; maquinaria de procesamiento; cadenas de oferta (regional e internacional) para ungüentos de huitco, camasol, molle y eucalipto además de jarabe de eucalipto; certificación de calidad y sanidad, investigación etnobotánico y educación todo administrado por personal local (Pietrellini 2007: 3-4).

El estudio actual es un intento a analizar y ofrecer sugerencias en cuanto a temas tocadas arriba. Subvencionado por el Fondo 54112B, Programa MHIRT (Capacitación Internacional de Disparidades de Salud para Grupos Minoritarios), Becas G000613 y 5 T37 MDOO144218 es financiado por los Institutos Nacionales de Salud, Washington, D.C., inicialmente por 
medio del Centro Internacional Fogarty de Estudios Avanzados y, en la actualidad, por el Centro Nacional para la Salud Minoritaria y de Disparidades de Salud. MHIRT-Perú es coordinado por la Universidad Estatal de San Diego (SDSU, Drs. Roberto Pozos y Dena Plemmons PD's). Incluye cooperación con la Universidad de California-Berkeley (UCB), la Universidad de CaliforniaSan Diego (UCSD), Linfield College (LC) en Oregón, la Universidad Estatal de Nueva York en Búfalo (UB-SUNY) y el Jardín Botánico de Missouri (MOBOT) - en Estados Unidos - y la Universidad Nacional de Trujillo (UNT), la Clínica Anticona-Trujillo (CAT) y el Centro de Atención de Medicina Complementaría (CAMEC) EsSalud-Trujillo - en Perú.

El enfoque principal de este proyecto ha sido la etnobotánica de plantas medicinales usadas en la costa norte de Perú. Perú Septentrional representa el "eje de salud" de la antigua área cultural de los Andes Centrales extendiéndose de Ecuador a Bolivia (Camino 1992). Evidencia gráfica del uso tradicional de plantas mágicas y medicinales en esta región data del primer milenio AC (Cultura Cupisnique) y durante la época Moche (100-800 DC) hay cerámicas mostrando escenas de curación.

Precedentes para este estudio fueron establecidos por cronistas de la época colonial temprano (Monardes 1574; Acosta 1590; Cobo 1653), las colecciones de flora (293 plantas en cajones 11 y 12 de 24) enviados en 1789 al Palacio Real de Madrid bajo el título Trujillo del Perú (vols. 3, 4 \& 5 de 9 volúmenes de acuarelas) por Obispo Baltasar Jaime Martínez Compañón; los trabajos de Ruiz y Pavón (1798, 1799, 1802); los estudios del naturalista italiano Antonio Raimondi (1857); el análisis etno-arqueológico del cacto alucinógeno San Pedro (Sharon 2000), curandera Representaciones en la Cerámica Moche(Glass-Coffin, Sharon y Uceda 2004) y la investigación de plantas medicinales en Ecuador Meridional (Béjar, Bussmann, Roa y Sharon 1997, 2001; Bussmann y Sharon 2006a, 2007a).

El trabajo de campo para el estudio actual comenzó el 2001 en los mercados de Trujillo (Mayorista y Hermelinda) y Chiclayo (Modelo y Moshoqueque). En nuestro base de datos proveemos los datos norperuanos y fotos digitales de 510 plantas medicinales organizada bajo los subtítulos: nombres científicos, nombres vernáculos, partes de las plantas usadas, administración, preparación y usos (www.olorien.org/ebDB; Skoczen y Bussmann 2006b; Bussmann y Sharon 2007b).

\section{Antecedentes - Investigación de Plantas Medicinales y la Medicina Tradicional en Perú}

Con 84 de los 107 eco-egiones del mundo, se ha estimado que Perú tiene 17,143 taxa de espermatofitas en 2485 eco-regiones y 224 familias con 7\% de las plantas del mundo (Brako y Zarucchi 1993). León et al. (2006) encontraron 18650 taxa. Se considera que sólo se ha estudiado $60 \%$ de la flora peruana habiéndose descrito 1400 especies de uso medicinal (Brack 2004).

La importancia de la biodiversidad para la economía peruana es enorme, considerando que $25 \%$ de las exportaciones son recursos vivos y que su uso es esencial para las poblaciones locales en el abastecimiento de leńa, carne, madera, plantas medicinales y muchos otros productos. De interés particular son las especies vegetales, con 5000 plantas aplicadas en 49 usos distintos de los cuales 1400 son medicinales. De las 5000 plantas en uso 4000 son nativas; sólo 600 son introducidas. La mayoría de especies nativas útiles no son cultivadas; solamente 222 pueden ser consideradas domesticadas o semi-domesticadas (Brack 1999).
La transculturación ha resultado en una pérdida grande del conocimiento tradicional de plantas silvestres de gran valor para la ciencia y la tecnología del país. La flora representa un $10 \%$ del total mundial, del cual un 30\% es endémico. Perú es el quinto país en el mundo en número de plantas conocidas y usadas por la población; es el primero en especies domesticadas nativas (182 especies) (Brack 1999).

En todos los grupos étnicos de Perú el conocimiento vegetal es de gran importancia porque reafirma la identificación y los valores nacionales que se pierden en los procesos complementarios de la modernización y la globalización. En la actualidad el emergente reconocimiento y aplicación incipiente de estos recursos y los conocimientos relacionados enfáticamente subrayan la necesidad crítica para la investigación etnobotánica, ante los siguientes hechos:

- Absorción y devalorización de culturas nativas a raíz de la modernización y globalización.

- Al mismo tiempo, recuperación/revalorización del conocimiento florístico por la ciencia.

- Reconocimiento del valor terapéutico de plantas medicinales en el "primer mundo".

- Crecimiento reciente de investigaciones etnobotánicas por investigadores peruanos.

En Sinopsis histórico de la Etnobotánica en el Perú, La Torre y Albán (2005) esbozan la historia de estudios florísticos formales en Perú comenzando en el siglo XVIII con los trabajos de Hipólito Ruiz, José Pavón y Joseph Dombey seguido por Alexander von Humbolt, Aime Bonpland y Antonio Raimondi en el siglo XIX. Etnobotánicos en el siglo XX incluyeron Fortunato Herrera, Hermilio Valdizán y Angel Maldonado, Juan Lastres, Jaroslav Soukop, Julio López y Irma Kiyán, Felipe Chávez, Emma Cerrate de Ferreira, James Duke y Rodolfo Vásquez y Joaquina Albán. Sin embargo, fue John Harshberger en 1896 que acuñó el término etnobotánica por primera vez en Perú y Juana Infantes que estableció la disciplina formal en la Universidad Nacional Mayor de San Marcos en 1945.

Se ha realizado progreso considerable en el estudio taxonómico de la flora de Perú durante las últimas décadas (Brako y Zarucchi 1993). Sin embargo, mientras que los bosques de la Amazonía recibieron mucha atención científica, los bosques montañosos y las áreas remotas de la sierra quedaron relativamente inexplorados. Hasta la última parte de los ańos 90 poco trabajo había sido realizado en la estructura de la vegetación, la ecología y la etnobotánica de los bosques montañosos y de la costa del Norte. A pesar del hecho que esta área formaba lo que la antropóloga peruana Lupe Camino (1992) llama el "eje de salud" de la etnomedicina de los Andes Centrales, poco trabajo etnomédico y etnobotánico se había publicado sobre la rica flora de esta región.

Los estudios etnobotánicos a mediados del siglo XX enfocaron principalmente en la famosa flora peruana con propiedades "mágicas" y "mente-alterantes". El primer estudio de la "cimora" - otro nombre vernáculo para el cacto San Pedro - data de los años 40 (Cruz Sánchez 1948). El primer estudio detallado de un alucinógeno en Perú fue enfocado en el San Pedro (Echinopsis pachanoi) (Dobkin de Rios 1968, 1969). Otros trabajos sobre la planta, incluyendo algunos sobre "Daturas" (Brugmansia spp.) siguieron (Bristol 1969; Crosby y McLaughlin 1973; Dobkin de Rios 1977, 1980; Pummangura et al. 1982). Coca (Erythroxylon coca) también atrajó la atención científica (Martin 1970; Naranjo 1981; Plowman 1981, 1984 a, b) además de la Ayahuasca de la Amazonía (Banisteriopsis caapi) (Rivier y Lindgren 1971; McKenna, Luna y Towers 1968; Schultes y Raffauf 1992; Bianchi y Samorini 1993). Chiappe, Lemlij y Millones (1985) fueron los primeros en escribir una reseña del uso de los alucinógenos en el shamanismo de Perú. Estudios más comprensibles siguieron (Alarco de Zandra 1988; Cabieses 1990; Schultes y Hofmann 1992; Schultes y Raffauf 1990). 
En su análisis crítico de la Uńa de Gato, el defensor principal de la Medicina Tradicional en Perú y el director-fundador del Instituto Nacional de la Medicina Tradicional (INMETRA) del Ministerio de Salud, el Dr. Fernando Cabieses (2000) recalca que el trabajo de Hermilio Valdizán y Ángel Maldonado (1922) fue el esfuerzo pionero en el estudio de la Medicina Tradicional llevando a la emergencia de la antropología médica casi cinco décadas más tarde. Mientras tanto la exploración botánica de la flora peruana y plantas medicinales en particular incluyó estudios por Yakovleff and Larco-Herrera (1935), Weberbauer (1945), Towle (1961) y Valdivia (1975). La mayoría de los autores (Larco Herrera 1940; Herrera 1941; Lira 1985; Soukup 1970, 1987; Franquemont, Plowman et al. 1990; De Ferreyra 1978, 1981) enfocaron en la herbolaria quechua de la región de Cuzco. Otros estudios comprensivos se centraron en la región fronteriza de Perú y Bolivia alrededor del Lago Titicaca (Girault 1987; Bastien 1987; Roersch 1994; Macia et al. 2005) y la Amazonía (Prance 1972; Vásquez 1989; Rutter 1994; Duke y Velásquez 1994; Jovel 2005). Cabieses (1993) escribió un tratado mayor sobre la medicina tradicional y Ugent y Ochoa (2006) y Fernández H. y Rodriguez R. (2007) smmarized pre-Hispanic ethnobotany. Estudios de la Uña de Gato (Obregón 1996), Maca (Cabieses 1997) y Sangre de Grado o del Drago (Meza 1999) también se llevaron a cabo.

Inicialmente, el norte de Perú fue en la sombra de otras áreas estudiadas y atraía poca atención académica hasta finales del siglo XX. Gran parte del trabajo hasta ahora se ha hecho en los bosques montańosos del norte, incluyendo los estudios de la diversidad florística y estado negativo de la conservación del departamento de Cajamarca y parte del departamento de Amazonas (Sagástegui et al. 1999 y 2003), mientras que el Museo Nacional de Dinamarca ha colocado la etnobotánica de partes de los departamentos de Amazonas y San Martín en el contexto cultural y ecológico (Schjellerup et al. 1999, 2003, 2005). En el Distrito de Ayabaca del departamento de Piura, De Feo (1992, 2003) registró 46 especies de plantas medicinales y mágicas y sus usos en particular en relación con las prácticas de adivinación. En el Callejón de Huaylas (Ancash), Hammond et al. (1998) han realizado un estudio de las plantas medicinales tradicionales complementado con la colección de 178 plantas medicinales y sus usos por (Gonzales de la Cruz et al. 2014). En la provincia de Bolívar (La Libertad) Monigatti, Bussmann y Weckerle (2012) y Monigatti, Bussmann, Tellez y Vega (2013) recolectaron 2,776 reportes de uso de remedios de plantas en dos comunidades. En los mercados de Trujillo y Chiclayo, Evans, Telles y Vega (2014) llevaron a cabo una encuesta de la trazabilidad de las plantas medicinales que demostró que los vendedores tienen poco conocimiento de los origenes y las identificaciones de las plantas medicinales. Schjellerup $(1991,2009)$ ha ampliado nuestro conocimiento de la etnobotánica colonial tardio con su trabajo con las obras del Obispo Martínez Compañón.

Durante los años 70 la Organización Mundial de la Salud (OMS) tomó la iniciativa de abogar por la integración de la Medicina Tradicional en los programas de salud pública en países del tercer mundo (WHO 1977). Este esfuerzo culminó en la Declaración de Alma Ata de 1978 que proclamó "salud para todos en el año 2000" (WHO 1978, Farnsworth et al. 1985). Cabieses (2000) describe su lucha para implementar los principios de la OMS en Perú junto con el Dr. Carlos Alberto Seguín $(1979,1982,1988)$, un mundialmente reconocido psiquiatra social quien abogó por la incorporación de la psicoterapia tradicional del curanderismo en la estructura institucional moderna. En 1979, ellos organizaron el Primer Congreso de Medicina Tradicional para fundarse sobre los principios de la Declaración de Alma Ata. Como resultado de tal noción tan "descabellada", los pioneros casi fueron expulsados del prestigioso Colegio Médico del Perú. Además, el Ministro de Salud declinó la invitación a participar en la inauguración del evento.

A pesar de estos contratiempos, el congreso fue un éxito sorprendente con participantes de
23 países y sesiones en Lima, Iquitos y Cuzco. Sin embargo, pocos médicos asistieron. A partir del éxito del primer congreso en 1988, el Dr. Cabieses presidió en Segundo Congreso Mundial de Medicina Tradicional. Esta vez fue diferente, con 4,000 participantes de 41 países del mundo. El Ministro de Salud Pública, el Decano del Colegio Médico y el Alcalde de Lima participaron en la ceremonia de inauguración, junto con una larga delegación de autoridades universitarias. Las actas publicadas del congreso incluyeron contribuciones importantes sobre la flora médica de Perú (Pallardel 1988; Rimiche y Valderrama 1988) y los Andes Meridionales (Roersch 1988). Publicaciones importantes posteriores incluyeron la sierra sur del Perú (Franquemont, Plowman et al 1990. Roersch 1994) y la región amazónica peruana (Duke 1994; Rutter 1994).

Un resultado importante del segundo congreso fue una propuesta presentada para crear un Instituto para el estudio de la medicina tradicional en el Ministerio de Salud del Perú. Esto dio lugar a la inauguración del Instituto de Medicina Tradicional (INMETRA) en 1991, con el Dr. Cabieses como su primer director para la próxima década. Mientras que fue el director de INMETRA él realizó una serie de innovaciones incluyendo: conferencias internacionales sobre Medicina Tradicional, monografías sobre plantas medicinales, coordinación de 16 jardines botánicos en centros urbanos, programas educativos sobre MT en centros culturales por todo el país, investigaciones científicas publicadas, un programa nacional de parteras nativas y esfuerzos constantes abogando por legislación reconociendo el valor de MT.

En los últimos años de su vida, desde su puesto como rector de la Universidad Científica del Sur, Cabieses (2007) publicó su magnum opus sobre la medicina en el Perú antiguo. También fue un crítico fuerte de la apatía de las instituciones gubernamentales en cuanto a la protección de los biorecursos de la nación. En su libro Hoy y Ayer: Las Plantas Medicinales (2003) esbozó la historia lamentable de la legislación peruana referente a las plantas medicinales durante los años 90. Mostró que Perú siguió las recomendaciones de la Administración Federal de Alimentos y Drogas de EE.UU (USFDA) que el sustentó fueron totalmente inaplicables, una situación trazable a la naturaleza "bicultural" de la sociedad peruana donde la visión del mundo de la ciencia moderna predomina sobre la "cosmovisión" tradicional. Eso ocurrió a pesar del hecho que, desde los años 70, la Organización Mundial de Salud (OMS) repetidamente había formulado y refinado pautas para la protección apropiada y desarrollo sostenible de plantas medicinales y los conocimientos indígenas asociados. La mayoría de estas recomendaciones fueron sistemáticamente ignoradas por el gobierno peruano. Enfocando una perspectiva personal a este asunto, Cabieses (p. 118) citó un ministro de salud que decía que la medicina tradicional y las plantas medicinales "no valen nada", y que el estudio de ellas fue "una pérdida de dinero y esfuerzo". Terminó su libro (p. 120) contrastando el interés renovado de los europeos en cuanto a las plantas medicinales con la actitud peruana:

Pero aquí en Perú es distinto. La falta de información y una deficiencia de investigación, educación y práctica médica en cuanto al uso de plantas medicinales agravía el hecho de que más que nueve millones de seres humanos, una tercera parte de nuestra población, de hecho tienen como su único recurso médico...los recursos vegetales que los rodean. El gran incógnito en nuestro sistema de salud pública es porque tantos médicos hacen tanto esfuerzo para excluir de su actividad terapéutica el único recurso que puede controlar el sufrimiento-para no mencionar los males-de un sector tan importante de nuestra población.

Durante los últimos años cuando Fernando Cabieses fue director de INMETRA, emergió otra iniciativa en cuanto a un acercamiento entre aspectos de la medicina tradicional y la medicina oficial. En 1999, el sistema del seguro social peruano, EsSalud, con apoyo de la OMS y la OPS, 
desarrolló el Programa Nacional de Medicina Complimentaria (PRONAMEN). Fundaron tres Centros de Atención en Medicina Complimentaria (CAMECs) ubicados en los centros urbanos más poblados de Perú (Lima, Arequipa y Trujillo). En 2012, hubo 26 centros en el país y 25 unidades médicos menores. Ya hemos visto que, en 2000, PRONAMEN realizó un estudio que demostró que la medicina complementaria tuvo menos efectos secundarios y mejores resultados que la medicina alopática, además de ser más rentable que la terapia convencional (EsSalud/OPS 2000).

La primera modalidad de tratamiento de 12-inspirados por la medicina tradicional chinafue la fitoterapia, la cual es descrito en el Manual de Fitoterapia (2001) compilado por Martha Villar, la directora nacional de PRONAMEN, y Oscar Villavicencio bajo los auspicios de la OMS. Resume la literatura científica sobre la botánica, la fitoquímica y la farmacología de 76 plantas medicinales. Expone las categorías de enfermedades tratables por especies vegetales además del control de calidad y normas bioagrículas sostenibles. En 2009, un programa piloto usando 20 de las 76 plantas medicinales estudiadas se inició en las clínicas de Lima, Arequipa y Trujillo (Fernández 2009). EsSalud también ha establecido el Instituto de Medicina Tradicional (IMET) en Iquitos donde colabora con curanderos nativos en investigar las propiedades de plantas medicinales. Y, en 2010, Dra. Villar colaboró con el Colegio Médico del Perú en organizar el VII Congreso Nacional de Medicina Tradicional/II Congreso Mundial de Medicina Natural/I Congreso Andina de Medicina Tradicional, Natural y Alternativa, apropiadamente nombrado "Dr. Fernando Cabieses Molina” por el pionero peruano que abogó por la Medicina Tradicional.

\section{Asuntos de Actualidad en la Etnobotánica}

Moran, King y Carlson esbozan la emergencia de la bioprospección. El 5 de junio de 1992, para aliviar la pérdida de la flora y fauna de la tierra, la Convención de Diversidad Biológica (CDB) fue inaugurada durante la Cumbre de la Tierra en Río de Janeiro, Brasil. Los objetivos de la CDB son: 1) Conservación de la biodiversidad, 2) Uso sostenible de los componentes de la biodiversidad y 3) Participación equitativa en los beneficios derivados del uso comercial de recursos genéticos.

Para los países en vías de desarrollo que son ricos en cuanto a la biodiversidad, el componente más crítico de la $\mathrm{CDB}$ es la soberanía sobre biorecursos por gobiernos nacionales ya que el tratado reconoce su derecho a regir y cobrar para acceso a su biodiversidad a agentes de afuera. El componente referente a la soberanía intenta reemplazar el paradigma de la "herencia común" que provee acceso ilimitado a los biorecursos. El ideal buscado por este cambio de paradigma debiera balancear la manera en que todos los grupos interesados involucrados puedan ganar del uso de la biodiversidad por medio de un reconocimiento de los valores económicos, socioculturales y ambientales de los biorecursos y el costo de su conservación.

En el transcurso del tiempo desde el inicio de la CDB, pocas de las naciones signatarias han introducido en su legislación el requerimiento de recompensa para acceso comercial foráneo a sus biorecursos nacionales a pesar de que algunas sugerencias para la implementación de la CDB se han propuesto (Iwu 1996; Buitron 1999). A pesar de la recepción bastante tibia a la CDB por las naciones del mundo, el cambio de conciencia en cuanto a la deforestación de los trópicos proveyó una oportunidad para los etnobotánicos de afirmar que todo el mundo tiene un interés en conservar las selvas tropicales porque podían contener compuestos que podían curar el cáncer, el SIDA y otras enfermedades, una aserción afirmada por varios autores (Schultes y Raffauf 1990; Elisabetsky y Castilhos 1990; Plotkin 1993; Schultes 1994; Brown 2003). Además, ingresos derivados de la Medicina Tradicional fueron percibidos como un instrumento para aliviar la pobreza y para financiar la conservación (Reid 1993; Mooney 1993; Baker et al.
1995). Sin embargo, en unos cuantos años, para sus críticos, la etnobotánica - visto al principio como un instrumento que podía salvaguardar contra la disminución de la biodiversidad y de los conocimientos tradicionales - sencillamente había llegado a ser un facilitador del robo cometido por la "biopiratería".

En su libro Who Owns Native Culture? el antropólogo Michael Brown (2003) tiene un capítulo titulado "The Ethnobotany Blues" que documenta proyectos de alto perfil en África y América Latina en los primeros ańos de la década de 1990. Fueron organizados bajo la iniciativa norteamericana llamada International Cooperative Biodiversity Group (ICBG, Grupo de Cooperación Internacional sobre Biodiversidad) administrada por el Fogarty International Center for Advanced Study in the Health Sciences (Centro Internacional Fogarty para Estudios Avanzados de las Ciencias de Salud) de los National Institutes of Health (NIH, Institutos Nacionales de Salud), con financiamiento adicional del National Science Foundation (NSF, Fundación Nacional de las Ciencias) y la U.S. Agency for International Development (USAID, Agencia Internacional para el Desarrollo). Los proyectos involucraron asociaciones entre científicos norteamericanos y de los países anfitriones tanto como empresas farmacéuticas mayores incluyendo Monsanto, Bristol-Myers Squibb y American Cynamid. En el ICBG-Perú, Brown describe la relación problemática entre Washington University (St. Louis) y los Aguarunas, criticando "intervenciones paternalistas que dejan a la comunidad indígena al margen del los procesos de tomar decisiones y de recibir ganancias" (p. 114). En México, él documenta como ICBG-Maya fue clausurado por una organización de curanderos indígenas y sus aliados activistas que reclamaron que fue un esfuerzo a robar recursos y conocimientos indígenas, es decir, un caso de "biopiratería". Y él traza el fracaso de Shaman Pharmaceuticals (una empresa de California que fracasó en 1999) cuando trató de adaptar la bioprospección etnobotánica al paradigma de la "bala mágica" de la industria farmacéutica.

La antropóloga norteamericana Cori Hayden (2003: 113-116) en su etnografía sobre la bioprospección y el ICBG en México traza el impacto de la Declaración de Alma Ata de la OMS sobre la etnobotánica mexicana. En 1975, el Presidente Echevarría estableció el Instituto de Plantas Medicinales (IMEPLAM), inaugurando una era de reconocimiento oficial de la medicina tradicional como un recurso legitimo para la investigación integrada de la ciencia y la terapia. Fue un esfuerzo para revigorizar el Instituto Nacional Médico (1888-1910) que intentó fomentar una industria farmacéutica en México a base de conocimientos indígenas y populares. Abigail Aguilar, directora jubilada del herbario nacional, subrayó el impacto positivo de la OMS:

Lo que sucede es que nadie estudia lo que tiene. Todos devalúan lo que tienen, especialmente en países como México, donde hemos sido conquistados y tenido otra cultura impuesta, hablando históricamente. Por eso, en el caso de México, hay un complejo histórico en que todo lo que olía de plantas no valía nada. Investigadores médicos modernos no tuvieron mucho interés en ese tipo de recurso... hasta que oían lo que la OMS decía en los años 70. Eso pegó en muchos países, definitivamente pegó aquí, especialmente porque IMEPLAM ya estaba establecida (Aguilar en Hayden 2003:114).

Cuando Echevarría cesó su presidencia, IMEPLAM fue absorbido dentro del Instituto Mexicano del Seguro Social (IMSS), la agencia gubernamental encargada de salud pública. IMSS estableció el herbario de muestras de plantas medicinales encabezado al principio por Abigail Aguilar quien coordinó proyectos para educar médicos y otros profesionales de salud en cuanto a plantas medicinales. Mientras tanto el nombre del instituto fue cambiado varias veces terminando con el nombre actual, Centro Biomédico del Sur (CIBIS) con su sede principal en Cuernavaca donde su enfoque es la producción de medicinas herbolarias o fitomedicinas por medio de la 
investigación interdisciplinaria. Estos remedios son de "baja tecnología" que no requiere el aislamiento de componentes "activos", usando, en cambio, la mayor parte de la planta natural.

Hayden describe un convenio de "bioprospección" inaugurado en 1993 entre la Universidad de Arizona (EE.UU.) y sus socios farmacéuticos (que solo contribuyeron un descuento en el uso de sus equipos modernos!) y un equipo de investigadores interdisciplinarios en materia de plantas medicinales de la Universidad Nacional Autónomo de México (UNAM) encabezado por el etnobotánico Robert Bye. Bajo los términos de este convenio, investigadores de UNAM enviaron extractos de plantas medicinales mejicanos a Estados Unidos en cambio por fondos para la investigación y promesas de un porcentaje de las ganancias 10 a 20 años en el futuro—si una droga eficaz saliera de la colaboración. Impulsado por el CDB de las Naciones Unidas el proyecto también fue diseñado para juntar conocimientos etnobotánicos y dirigir una porción de las ganancias posibles a las comunidades que proveyeron las plantas medicinales. El proyecto colaborativo concluyó en 2003 cuando la UNAM optó por no revalidar el convenio una segunda vez.

Situaciones complejas surgieron durante el proyecto ICBG-UNAM, en particular los efectos paradójicos de las normas para compartir beneficios abogados por la metodología de la bioprospección que es fuertemente influenciada por la ideología de neo-liberalismo tan arraigada en Estados Unidos. Para la NIH, las normas exigieron que los investigadores científicos tuvieron la obligación de firmar contratos con cada individuo que proveyó plantas. Proveedores-y, implícitamente, sus comunidades - fueron considerados como presumidos "autores" y "conservacionistas" del recurso plantas tanto como beneficiarios.

Los etnobotánicos de la UNAM--fundamentándose en una metodología de investigación científica bien establecida por más de100 años además de 500 años de hibridación que produjeron "la herbolaria mexicana" sincretizada y mestizada - interpretaron las normas de la NIH de tal manera que indicaba que la colección inicial de plantas tuve que ocurrir en mercados urbanos y a los lados de los caminos rurales. Esta interpretación iba en contra a una asunción fundamental de la bioprospección que presume que plantas y conocimientos asociados "vienen con" claramente identificados autores, conservacionistas y beneficiarios. Contrastando marcadamente con esta visión, el equipo de Bye usaba una combinación de estudios de mercados, reseńas de la voluminosa literatura etnobotánica mexicana, el Atlas de Plantas Medicinales del Instituto Nacional Indigenista (INI) en cinco tomos y sus propios estudios históricos y etnobotánicos para buscar plantas potencialmente "activos".

Contrastando fuertemente con la manera de proceder de la ICBG, hay el modelo del Instituto Mexicano del Seguro Social (IMSS) aplicado en su Centro de Investigación Biomédica del Sur (CIBIS) en Cuernavaca y enfocado en la producción de medicinas naturales de plantas. El 20 de febrero de 1977, Hayden (p. 115) tenía una entrevista con Miguel Antinori, una autoridad eminente de CIBIS quien denigró los convenios de bioprospección por usar los químicos mejicanos como "labor barato" que envía extractos al extranjero para realizar trabajo "más sofísticado". Agregó que: "Es difícil ver una aserción de identidad nacional en estos contextosen el norte, solamente ven a México como una fuente de materiales crudos y decididamente no como colaboradores o socios en la investigación. ¿¿Por qué no ubican mucho más del proceso de desarrollo aquí? Porque no confían en la ciencia mexicana".

Ex-empleados de Shaman Pharmaceuticals Moran, King y Carlson (2001) discuten la ironía de esta situación indicando que la mayoría de la industria biotecnológica no está involucrada en la bioprospección ya que muchas empresas favorecen el uso de tecnologías sintéticas porque estas son baratas y rápidas en comparación con el complicado proceso involucrado en la exploración para la obtención de productos naturales. A pesar de esta realidad, la biotecnología genera debates éticos, sociales y jurídicos al margen de la bioprospección farmacéutica, por ejemplo, la colaboración entre los negocios grandes y la ciencia grande, la ética de la ingeniería genética y el proceso de patentar las formas de la vida además de ideas acerca de la genética y el racismo, cultura y etnicidad, etc. Sin embargo, es significativo notar que, desde la inauguración de la CDB, ningún producto de la bioprospección desarrollado usando los conocimientos tradicionales ha generado una ganancia económica. (Pero eso no quiere decir que no impiden o co-optan esfuerzos de hacer llegar productos naturales al mercado.) También, solamente un número pequeńo de expediciones de investigación y bioprospección comienzan usando la etnobotánica como una metodología de descubrimiento, con el trabajo rápidamente evolucionando hacia la botánica económica en la cual en enfoque del laboratorio enfatiza la química, la bioactividad y la farmacología/toxicología de las plantas. Durante el proceso de descubrimiento de drogas, componentes químicos activos son aislados, frecuentemente modificados y patentados. Entonces la información patentada llega a ser un producto en si mismo.

El investigador peruano en el campo farmacéutico Pedro Angulo (2009) discute sobre nuevos planteamientos en la investigación de plantas medicinales contrastando metodologías occidentales y orientales. Por ejemplo, mientras Occidente despreció la información y la sabiduría popular desarrollados durante siglos por las culturas locales, Oriente utilizó estos conocimientos como base paradigmática de su modelo de ciencia. Mientras Occidente recurrió exclusivamente al modelo cartesiano de escepticismo científico, Oriente recurrió a su pragmatismo característico y, apoyándose en la tradición, formalizó el uso y después lo investigó. Mientras Occidente usó el camino de la investigación básica ignorando los conocimientos tradicionales en el diseño de estudios artificiales donde aísla compuestos químicos y evalua toxicidad y modo de acción para después llevar los productos a la clínica, Oriente usó una estrategia inversa valorando la tradición popular y aplicando remedios y terapias originales en la clínica médica para luego investigar y refinarlos para el uso general. Mientras Occidente planteó como paradigma básico el análisis de los componentes de las plantas por separado para la posterior extracción, síntesis y estudio de las propiedades, Oriente reconoció la acción de los medicamentos herbolarios "como un todo" y buscó industrializarlos recurriendo a la tecnología moderna.

Resultando de los factores arriba mencionados, en el estudio de plantas medicinales la ciencia occidental ha desarrollado una metodología de quimiotaxonomia augurando que solo mediante el conocimiento químico de las especies se descubre la distribución de principios activos. Eso ha llevado al énfasis corriente en los procedimientos de la química sintética para el desarrollo de medicinas modernas. Angulo indica que, al seguir el modelo occidental para la investigación farmacéutica promovido por las empresas europeas y norteamericanas, Perú ha accedido a la noción que países como Perú y México no se cuenten con los recursos técnicos y económicos suficientes para competir con los consorcios farmacéuticos extranjeros en el desarrollo de nuevos medicamentos. Como resultado, estos países, con pocas excepciones, han menospreciado el conocimiento popular de las sociedades indígenas sobre las propiedades y usos de las plantas medicinales. Al mismo tiempo han descuidado el desarrollo nacional de la investigación viable de la etnobotánica y la etnofarmacología. De acuerdo con la opinión de Eliana Elisabetski (1988), Angulo (p. 363) sugiere que:

Medicina Tradicional debe ser la base para el desarrollo de drogas, ya que esto incluye el conocimiento del valor terapéutico de la flora. Por lo tanto, el conocimiento de las prácticas médicas tradicionales juega un rol crucial para la selección de especies a ser posteriormente consideradas como fuentes potenciales de drogas universalmente aplicables. Elisabetski concluye que la interacción entre la antropología y la etnofarmacología es la base sobre la cual se debe desarrollar la investigación holística sobre plantas medicinales en particular, y el cuidado de la salud en general. 
Sólo queremos añadir que la investigación aplicada sobre los recursos naturales de las plantas también debe estar establecida en las agendas nacionales de Perú y las repúblicas vecinas.

Manek y Lettington en Cultural Survival Quarterly (2001) recalcan que cuando la CDB se enfocó en los conocimientos tradicionales e indígenas relacionados con el ambiente, hicieron posible esquivar algunos de los aspectos más políticamente cargados de la polémica de derechos de propiedad intelectual indígena (DPII). El impacto mayor sobre preocupaciones por los derechos de comunidades indígenas y locales se puede trazar al ascenso voluble de la biotecnología en el mercado internacional y la versión de 1995 del Convenio de Aspectos Comerciales de Derechos de Propiedad Intelectual (TRIPS) de la Organización de Comercio Internacional (WTO). Estos dos factores han creado un potencial mercado grande para los conocimientos y recursos locales e indígenas mientras que al mismo tiempo causan preocupaciones en cuanto al riesgo que estos recursos sean sujetos a una malversación. Por eso los conocimientos tradicionales están recibiendo una atención internacional aumentada en términos de su relación a los derechos humanos además de su relevancia a la ciencia moderna. Paradójicamente esta situación ha creado presiones opuestas abogando por los derechos de pueblos indígenas y locales por un lado y la explotación en el otro. Junto con Moran, King y Carlson (2001), Greaves (1995), y Brush y Stabinsky (1996) los autores indican que el problema más grande con el sistema de propiedad intelectual es su enfoque en los aspectos materiales de los conocimientos tradicionales a costo de los aspectos culturales. Abogan por el reconocimiento de visiones del mundo alternativas en la formulación de nuevos derechos para los conocimientos indígenas que son locales, relevantes y eficaces.

En su artículo en Cultural Survival Quarterly, Bannister y Barrett (2001) afirman que la bioprospección es un tipo de botánica económica que puede ir en contra a los objetivos etnobotánicos de proteger la diversidad biológica y cultural. El enfoque de esta actividad subraya la problemática en relación con los derechos indígenas, los conocimientos culturales y los recursos tradicionales, asuntos donde las normas de protección de la propiedad intelectual no son adecuadas o apropiadas. Sin embargo, comunidades indígenas con mayor frecuencia se encuentran obligadas a emplear los derechos de la propiedad intelectual para proteger estos recursos. Asuntos de protección deberían ser abordados mucho antes del momento en que el empleo de mecanismos de propiedad intelectual parecen ser la única alternativa. Un control considerable ocurre en el momento de tomar la decisión acerca de la publicación de los conocimientos pertinentes y su diseminación al sector público en general lo que plantea cuestiones importantes acerca de la facilitación de la apropiación de los conocimientos culturales. Los autores abogan por un modo de proceder más "precavido" en cuanto a la investigación etnobotánica con el fin de ayudar a las comunidades indígenas y locales a proteger su herencia cultural y sus derechos de propiedad intelectual.

Probablemente la mayor preocupación en muchas comunidades tradicionales es que sus legados espirituales serán secularizados y profanados por el mundo externo con su ética de consumismo. Sin embargo, frecuentemente consideraciones económicas muy legítimas también desempeñan un papel importante en las reacciones defensivas de estas sociedades al deseo bien intencionado pero ingenuo del mundo académico de poner sus conclusiones al alcance del sector público. Brush y Stabinsky (1996) y otros (Greaves 1995; Bannister and Barrett 2001) advierten que el peligro inherente de esta forma de proceder es que un "archivo colonializador" puede ser "minado" para obtener pistas en la búsqueda de nuevas drogas sin la molestia de realizar trabajo de campo o incluir la comunidad local en los beneficios de los productos finales de la investigación. Sin embargo, en el otro lado, publicando en el sector público puede rendir "nopatentable" a las plantas y remedios de uso en la medicina tradicional.
Aunque reconocemos las preocupaciones genuinas acerca del neocolonialismo y la biopiratería, sustentamos que cada situación tiene que ser considerada por sus propios méritos, especialmente en cuanto a su contexto cultural específico. Un primer paso en el proceso de evaluación debe involucrar la distinción importante entre una comunidad "indígena" y una comunidad "local" (Moran, King y Carlson 2001). Una comunidad local incluye agricultorescampesinos que hablan el idioma nacional, practican la religión de la mayoría y se identifiquen con el gobierno nacional, especialmente en cuanto a sus aspiraciones socioeconómicas mientras que una comunidad indígena tiende a incluir grupos minoritarios (étnicos y/o tribales) que buscan derechos colectivos y autodeterminación para sus recursos biológicos y culturales. Aunque frecuentemente es el caso que en ambas comunidades conocimientos y recursos tradicionales no son documentados y corren el riesgo de desaparecer, este peligro tiende a ser más apremiante en comunidades locales dado que sus miembros siguen adaptándose a la privatización y a la globalización. Este peligro es más agudo en comunidades locales que ya son integradas a la cultura nacional y por eso sienten menos necesidad de afirmar y proteger sus conocimientos y recursos tradicionales. En tales casos la intervención etnobotánica requiere una metodología que combina la "etnografía de rescate" con el "asesoramiento rápido". Esta metodología es lo que hemos aplicando en Perú Septentrional y proveyó la razón principal para nuestro trabajo inicial. Para motivarnos tenemos la experiencia profesional de haber trabajado en Ecuador Meridional donde los conocimientos tradicionales de plantas medicinales son muy similares a los de Perú y donde parece que están en vías de desaparecer. Sin embargo, ahora que hemos elaborado la base de datos, podemos enfocar en facilitar la conservación y desarrollo sostenible del uso de las plantas medicinales.

India provee un ejemplo positivo para la aplicación activista de esta metodología. Sacando provecho del criterio de "novedad" en las leyes internacionales de patentes en cuanto a la documentación científica de la medicina popular y ayurvédica, textos milenarios en sánscrito juntos con publicaciones modernas se incluyen en una base de datos de conocimientos tradicionales que posteriormente se provee a la oficina de patentes. La expectativa es que, por poner los conocimientos y precedentes culturales para usos tradicionales en el dominio público, estas investigaciones probarán que aplicaciones contemporáneas derivadas de los conocimientos médicos locales no son originales, es decir, no son suficientemente "novedosas" para calificar como "invenciones" que merecen protección bajo las leyes internacionales de patentes y, por eso, no son patentables.

Afortunadamente en el 2002, con el apoyo del Instituto Internacional de Recursos FitoGenéticos (Roma, Italia), el Perú promulgó la Ley 27811 para la protección de los conocimientos colectivos de pueblos indígenas relacionados a los recursos biológicos. El artículo 17 de la ley establece un Registro Nacional Público para incluir los conocimientos que se encuentran en el dominio público. Este registro es administrado por el Instituto Nacional de Defensa de la Propiedad Intelectual (INDECOPI), con la obligación de enviar la información a las oficinas principales de patentes de todo el mundo, una protección defensiva que tiene la intención de prevenir la asignación de patentes que no cumplen con los requisitos de novedad y grado de invención (Venero 2005b: 32-36)

En la primera década de 2000 - a pesar de que poco se había hecho para proteger y desarrollar sosteniblemente estos valiosos recursos naturales--acceso sin límites a la rica flora médica peruana fue cedido a empresas farmacéuticas extranjeras. En 2004, un foro organizado por el Congreso Peruano y la Sociedad Peruana de Derecho Ambiental (SPDA, un ONG de abogados especializados en los leyes del medio ambiente) mostró que solicitudes para patentes realizados por empresas extranjeras fueron pendientes o aprobadas para 19 plantas peruanas, y 
Un ejemplo clásico de una mano no sabiendo lo que la otra está haciendo fue revelado el 16 de julio de 2009 cuando Zoraida Portillo de SciDev.Net reportó que Perú había negado patentes a Francia, Japón, Corea del Sur y Estados Unidos porque sus nuevos productos fueron desarrollados utilizando conocimientos de la Medicina Tradicional. Los rechazos emanaron de la Comisión Nacional Contra la Biopiratería que fue advocado en el Foro del Congreso Peruano de 2004 y activado bajo Ley 28216. Sin embargo, el reporte de Portillo terminó citando Michel Pimbert del Instituto Internacional del Desarrollo y del Ambiente: "Sería ingenuo pensar que gobiernos nacionales automáticamente compartirán con comunidades locales cuando la biopiratería es prevenida o la compensación es obtenida". Dicho eso, en 2010, peticiones para 69 plantas estuvieron bajo investigación, 17 casos de biopiratería habían sido identificados y siete peticiones fueron desaprobadas (Smallwood 2011:36-37).

En el foro del Congreso de 2004 que resultó en la formación de la Comisión una variedad de asuntos importantes fueron discutidos, incluyendo la propiedad intelectual (Bazán 2005: 2135); la biopiratería norteamericana de la Quinua, un cereal de alta proteína (Caillaux 2005: 3647)); la ley para la protección de la biodiversidad peruana y los conocimientos colectivos de los pueblos indígenas (2005: 48-49); y los esfuerzos para anular el patente norteamericano para la Maca que se usa contra la impotencia (Venero 2005a: 50-55). Brevemente notado fue el asunto de alimentos genéticamente modificados (Agurto 2005: 71-72), un asunto preocupante que el foro anticipó iba a salir como un resultado del Tratado de Libre Comercio con Estados Unidos que Perú estaba negociando en ese tiempo. Se espere que durante todas estas deliberaciones, hoy y en el futuro, las palabras siguientes del panelista Jorge Agurto (2005: 71) sean recordadas:

El problema que subyace de la biopiratería es el del reconocimiento de los derechos de los pueblos indígenas y comunidades. Muchas veces éstos han quedado excluidos y marginalizadas de las políticas de los Gobiernos. Incluso el día de hoy podemos encontramos con congresistas que desconocen la existencia de los pueblos indígenas o no los reconocen como titulares de derecho. Es imposible hablar de biopiratería si no defendemos a los titulares de muchos de los recursos genéticos, a aquellos que han logrado la domesticación, el conocimiento, la tecnología para utilizar sosteniblemente la biodiversidad. Ellos son titulares también del consentimiento informado previo, derecho fundamental para conocer cuáles son los objetivos de la exploración y la explotación de sus recursos y conocimientos tradicionales y las consecuencias o beneficios potenciales que puede traer el uso industrial, comercial o científico.

La antropóloga española Luisa Abad (2003: 274) en su libro Etnocidio y Resistencia en la Amazonia Peruana concluya que el desarrollo nacional e internacional contribuye a la marginalización de pueblos indígenas:

Subdesarrollados, en vías de desarrollo, Tercer Mundo, Norte-Sur..., quizá el lenguaje ha ido cambiando en estos tiempos y la terminología ha ido adaptándose a hábitos parcialmente nuevos, pero la realidad desigual, jerárquica, permanece igual, puesto que quienes ejercen el poder siguen siendo los mismos. La ayuda internacional también sigue fomentando un desarrollo desigual entre los pueblos.

Conservación de Biodiversidad y Medicina Tradicional

Un informe, Biodiversidad, Conocimientos Tradicionales y Salud Comunitaria: Reforzando Lazos, publicado por la Universidad Naciones Unidas - Instituto de Estudios Avanzados en Yokohama, Japón se dirige a muchos de los asuntos actuales arriba mencionados (Unnikrishnan y Saneetha 2012). Basándose en la Declaración Alma Ata de la Organización Mundial de Salud (1978) que se trata de medicina tradicional y atención primaria de salud, la Convención sobre Diversidad Biológica de las Naciones Unidas (1992) y Metas Nivel Medio de las Naciones Unidas (2011), este documento indica que los lazos entre medicina tradicional y la biodiversidad son reforzados por tres procesos: 1) Un acercamiento médico que implica esfuerzos nacionales para integrar la medicina tradicional en el sistema institucional de entrega de salud que incluye retos relacionados a seguridad, calidad, eficacia, acceso y regulación; 2) Un acercamiento orientado al mercado enfocado en el desarrollo de drogas o la promoción turística de productos y servicios biomédicos como mercancía vendible; y 3) Un acercamiento enfocado en la comunidad local activado por organizaciones civiles de conservación que utilizan un proceso de movilización de las bases con la ayuda de profesionales de salud, botánicos, conservacionistas y activistas locales.

El acercamiento a nivel de salud de la comunidad se alinea con el modelo de atención primaria de salud Alma Ata. Ejemplos incluyen la estrategia de "doctores descalzos" en China y programas de salud tipo activista-social en India. Dado la centralidad de la biodiversidad en la vida humana, todavía hay una necesidad para desarrollar estrategias sostenibles para mantener la salud combinado con la conservación de recursos biológicos y vinculados con conocimientos y prácticas locales.

Al principio del informe UNU en el "Mensaje del Director", Govindan Parayil (p. 6) evalúa el progreso hacia la agenda CDB de definir y seguir un camino de desarrollo sostenible, equitativo, de justicia medioambiental y económicamente viable. El ve que el pronóstico no es bueno. Se ha realizado progreso, pero todavía no estamos realizando el desarrollo necesario para sostener niveles corrientes de bienestar. "Tendencias medioambientales negativas sigan siendo exacerbadas por intervenciones humanas-principalmente conducidas por un modelo de consunción conspicua y no sostenible". El agrega: "El énfasis extraordinaria en fomentar capital producido parece haber aplastado todos los otros aspectos de la capital natural requerido para nuestro bienestar".

En el lado positivo, Parayil nota una conciencia aumentada de la brecha entre planificación e implementación. Indicios de cambios bienvenidos incluyen: "resolución aumentada para alinear actividades de producción con consideraciones medioambientales de equidad" además de "esfuerzos con el fin de reformar estructuras institucionales para crear más sinergias e implementación eficaz de políticas relevantes". El concluye:

Patrones corrientes aceptables de práctica y normas de negocios deben de ser reorientados para incluir un ambiente político más consultiva con todos los actores representativos. [Esto] requerirá el diseńo de regulaciones que reconocen la necesidad para una balanza entre todos tipos de capital e incentivos que proveen acceso equitativo a recursos y servicios.

El informe de la UNU documenta treinta exitosos proyectos comunitarios de todas partes del mundo. A pesar de su éxito en encontrar soluciones viables para satisfacer necesidades de conservación y atención primaria de salud, la escala de operación de estos programas no ha sido mejorada o ampliada. Este hecho es a causa de varios factores relatados en el informe, algunos 
de los cuales son:

- Hay una clara necesidad para incluir factores ecológicos, conseracionales y sociocultuales en cuanto a programas de salud y desarrollo.

- Altos niveles de dependencia externa, especialmente en productos farmacéuticos y tecnología médica, desincentivan innovaciones locales en medicina tradicional y atención primaria de salud.

- Por medio de una metodología desde arriba hacia abajo, sociedades se han organizado para ser más enfermedad-céntrico en lugar de ser bienestar-céntrico. Un cambio de paradigma al bienestar general (prevención/promoción) es esencial.

- Promoción de salud tradicional y esquemas de conservación que se enfocan principalmente en plantas medicinales son percibidos como caminos hacia el desarrollo económico. Para ser autosostenible, los costos de colección de recursos hasta la distribución e infraestructura para identificar y apoyar curanderos tienen que ser incluidos.

- En el nivel politico, hay una tendencia hacia un proceso de definir objetivos no realistas. Implementación por especialistas apropiadamente entrenados al nivel de promotores de salud de la comunidad local puede apurar los procesos para realizar varios objetivos a bajo costo.

- Intentos de documentar y proteger los conocimientos médicos tradicionales en inventarios digitalizados son insuficientes. Intentos a abrir tales inventarios para fines de la investigación todavia apoyan los procesos del desarrollo de drogas—más que para apoyar la entrega de servicios de salud.

- Alta corrosión de conocimientos tradicionales y una percibida falta de apoyo para los practicantes de la medicina tradicional han traido como consecuencia un decremento en la receptividad a $y$ transferencia de todos aspectos de tales conocimientos entre generaciones.

- Frecuentemente los sistemas dominantes de educación e investigación tiendan a mejorar tecnologias y conocimientos usando normas universales, sin mucha atención a las capacidades y necesidades de regiones y poblaciones especificas resultando en una falta de comprensivos acercamientos teóricos para evaluar los conocimientos tradicionales que se cree es la clave al desaire en cuanto a culturas tradicionales. Métodos pedagógicos culturalmente apropiados con una inclinación intercultural e multidisciplinario de aprender son necesarios.

- Hay una necesidad de un acercamiento radical e innovador para integrar la Medicina Tradicional en los sistemas de salud necesitando un total respaldo institucional de agencias gubernamentales y no-gubernamentales que enlazan cadenas de oferta de recursos medicinales con profesionales de salud y consumidores y teniendo altos estándares de calidad, seguridad y eficacia.

En cuanto a un plan de acción, el informe de la UNU aboga por el uso de protocolos integrados de evaluación rápida similares a esos usados en algunos de los estudios esbozados en el informe-apropiadamente adaptados a circunstancias culturales e ambientales a nivel de las comunidades locales involucrados. Provee un ejemplo de un marco de evaluación y estrategias potenciales:

- Métodos de evaluación para inventariar recursos y conocimientos de salud pública.

- Valorización, generación y uso de conocimientos tradicionales.

- Construcción de capacidad para todas las partes interesadas.
- Complementariedad equitativa entre distintos sistemas de conocimientos.

- Mecanismos para proteger recursos y conocimientos tradicionales.

- Vinculación con objetivos de desarrollo económico.

- Expansión de asociaciones civiles con distintos tipos de socios.

- Estrategias de comunicación eficaces.

- Sinergia de iniciativos de comunidades locales con organizaciones de sociedad civil.

Complementando los ejemplos positivos del informe de la UNU hay las lecciones aprendidas de un proyecto fracasado en India que procuró desarrollar una cadena de oferta entre agricultores locales de las Himalayas y una empresa holandesa (Ayurvedic Health) en un proyecto emprendido por el Royal Tropical Institute (KIT) y el Centro de Desarrollo Sostenible (CSD) de Holanda en cooperación con agencias gubernamentales locales (Alam y Belt 2009). Los autores señalan que mundialmente las plantas medicinales se merman a un paso rápido a causa de la colección no-sostenible en gran escala de sus ambientes naturales. La conservación de estas especies es crítico para cuatro razones: 1) son una fuente de ingredientes naturales usadas en la fabricación de farmacéuticos modernos resultando en una demanda grande y creciente (Lambert et al. 1997; Balick y Mendolsohn 1992; FAO 1997); 2) las plantas medicinales forman la base para homeopatía y medicinas tradicionales y, junto con los conocimientos tradicionales, son cruciales para curanderos tradicionales que juegan un papel vital en la vida de los pobres y sus animales en países en vías de desarrollo; 3) la colección y venta de plantas medicinales es un recurso valioso en el sustento de grandes cantidades de pobres en países en vías de desarrollo (WHO 1999; Hamilton 2008); 4) plantas medicinales forman un componente esencial de la diversidad biológica y su conservación (SCBD 2001).

En cuanto a lecciones aprendidas, los autores dan tres razones para el fracaso del proyecto: (1 baja calidad de la materia prima proveído a los agricultores causando un alto nivel de mortalidad de las plantas; 2) demasiado agricultores no-coordinados sembrando parcelas no-económicas en tierras descuidadas resultando en baja motivación y expectaciones demasiado altas no-realizadas; y 3) baja comprensión de las dinámicas de la agricultura local y la emergencia de un cultivo comercial alternativo más viable que plantas medicinales. Estos son factores que deben de ser evaluados en esfuerzos de desarrollar una cadena de oferta exitosa para CAMEC-EsSalud.

\section{Trabajo hasta la Fecha}

Nuestro trabajo hasta le fecha_además de desarrollar una base de datos de 510 plantas medicinales (Bussmann y Sharon 2006, 2007a, 2009a) y 974 remedios de mezclas (Bussmann, Glenn, Meyer, Kuhlman y Townesmith 2010)—ha demostrado que el comercio de hierbas en Perú es un recurso económico de mayor importancia (Bussmann, Sharon, Vandebroek, Jones y Revene 2007) que se aplica extensivamente junto con el uso de productos farmacéuticos modernos, pero que es amenazado por la disminución de conocimientos tradicionales (Bussmann, Sharon y Lopez 2007; Bussmann, Sharon y Garcia 2009; Fajardo y Sours 2012). La investigación en el laboratorio de la mayor parte de la base de datos ha incluido concentraciones inhibitorias mínimas (Bussmann, Malca et al. 2010) análisis de toxicidad (Bussmann, Malca et al. 2011), ensayos de actividad antibacteriana (Bussmann, Sharon et al. 2008; Bussmann, Glenn et al. 2009a; Bussmann, Glenn et al. 2011) y análisis fitoquímico (Bussmann, Glenn et al. 2009b; Pérez, Rodríguez et al. 2012) con estudios enfocados de tratamientos herbales para la acné (Bussmann, Sharon et al. 2008), la malaria (Bussmann y Glenn 2010) y enfermedades renales e infecciones urinarias (Bussmann y Glenn 2011). Otros trabajos han tratado de la 
identificación de una planta ceremonial de la cultura pre-Hispánica Moche llamado Ulluchu (Bussmann y Sharon 2009b) y una reseńa de fuentes coloniales sobre plantas medicinales en Perú Septentrional y Ecuador Meridional (Bussmann y Sharon 2009a). Una etnografía de hierbateros campesinos y aspectos de la cadena de oferta mostró que los proveedores de plantas no son adecuadamente remunerados para su labor y que la oferta es amenazado por la sobreexplotación y una falta de medidas de conservación (Revene, Bussmann, Sharon 2008). Carrillo (2012) criticó la metodología reduccionista de la ciencia moderna en cuanto a una valorización apropiada de remedios tradicionales. Smallwood (2010) escribió una etnografía sobre la interacción entre empresas fitofarmacéuticas y la Comisión Nacional Contra la Biopiratería. Analices antropológicos de curanderos tradicionales y sus mesas de curanderismo incluyen trabajos de Sharon (2009), Sharon y Gálvez (2009), Sharon, Glass-Coffin y Bussmann (2009) y GlassCoffin, Sharon y Uceda (2004).

Vale notar que, durante la década que hemos estado trabajando en el campo y el laboratorio, ha ocurrido un cambio llamativo en actitudes y percepciones de la Medicina Tradicional (Sánchez Garrafas, eds. 2009; Vergara y Vásquez, eds. 2009). En Trujillo, un programa piloto de prescribir plantas medicinales científicamente evaluadas ha sido iniciado por el Programa Nacional de Medicina Complementaria (PRONAMEN) de EsSalud (Fernández 2009; Villar y Villavicencio 2001). También el programa "Semillas Sagradas" del Jardín Botánico de Missouri ha coordinado un jardín de plantas medicinales en el museo de sitio del centro urbano pre-Hispánica Chan Chan. Y un equipo de biólogos de la Universidad Nacional de Trujillo ha compilado un volumen de 774 plantas medicinales que abarca su taxonomía, ecogeografía, fenología y etnobotánica (Mostacero, Castillo, Mejía, Gamarra, Charcape y Ramírez 2011). En Huamachuco, un programa de etnobotánica y conservación manifestado en jardines y semilleros comunitarios de plantas medicinales está luchando para recubrr vida por medio de una colaboración entre una comunidad campesina, la Beneficencia Pública, el hospital regional, EsSalud, el programa "Semillas Sagradas" del Jardín Botánico de Missouri (MOBOT), MHIRT y el Cuerpo de Paz. Esperemos que trabajo futuro involucrará el desarrollo de una cadena de oferta entre la comunidad de Huamachuco y el Centro de Atención de Medicina Complementaria (CAMEC)EsSalud de Trujillo respaldado científicamente por MHIRT, Universidad de Búfalo (SUNY)Escuela de Medicina y Ciencias Biomédicas, el Jardín Botánico de Missouri y la Universidad Nacional de Trujillo.

\section{Nomenclatura de Plantas en el Norte de Perú}

La denominación de las especies de plantas sigue tres patrones generales. Los nombres de las plantas ya utilizados por las poblaciones indígenas originales se mantienen a menudo aunque ligeramente modificado. Las plantas similares a las especies ya conocidas, o con habitus similares, a menudo reciben el mismo nombre (transposición). En otros casos, se crean nombres completamente nuevos (neología) (Van den Eynden et al. 2004)

Los nombres vernáculos de las plantas utilizadas en el norte de Perú reflejan el desarrollo histórico del uso de plantas en la región. Las especies introducidas (por ejemplo, Apium graveolens - Apio, Foeniculum vulgare - Hinojo), especies nativas similares a las especies que se encuentran en España (por ejemplo, Adiantum concinnum - Culantrillo, Matricaria frigidum - Manzanilla), así como especies creciendo sobre todo en las regiones costeras de la área (por ejemplo, Alternanthera porrigens - Sanguinaria) a menudo tienen nombres derivados de raíces españolas. Las plantas de los bosques montanos y sobre todo el altiplano andino o el Amazonas son a menudo conocidos por sus nombres quechuas (por ejemplo, Pellaea ternifolia - Cuti Cuti, Amaranthus caudatus - Quihuicha, Banisteriopsis caapi - Ayahuasca), y algunos nombres de plantas se remontan a
Mochica (el idioma original indígena hablada en la costa del norte de Perú) (por ejemplo, Nectandra spp - Espingo) (Bussmann y Sharon 2009c). Van den Eynden et al. (2004) observaron patrones similares en el sur de Ecuador, aunque su estudio se centró sólo en especies comestibles.

En la región norte de Perú se registraron novecientos treinta y ocho nombres vernáculares entre 510 especies de plantas. Alrededor de un tercio de todos los nombres representaron nombres quechuas o tenían raíces mochicas, mientras que el $66,5 \%$ de todos los nombres eran de origen español o tuvieron al menos componentes españoles. En comparación, el 41\% de los nombres vernáculos de las plantas comestibles en el sur de Ecuador resultaron ser de origen español. Más de la mitad de las especies indígenas sólo tenía un nombre vernáculo, con las especies restantes teniendo una variedad de nombres indígenas, que a menudo se derivaron de la misma raíz. En comparación, casi el $75 \%$ de las especies eran conocidos por un solo nombre. Las ligeras diferencias en los nombres de las plantas indican que las especies se han utilizado en la región por largo tiempo y que sus nombres reflejan pequeñas variaciones en los dialectos locales.

\section{Dos décadas de Etnobotánica en el norte de Perú y el sur de Ecuador}

Desde 1995 recogimos datos etnobotánicos en el norte de Perú y el sur de Ecuador (Fig. 1) de los proveedores de la plantas, comprando materiales vegetales en los mercados locales, acompañando curanderos locales a los mercados cuando compraron las plantas para sesiones de curación y en el campo cuando cosecharon plantas. Además, muestras de todas las plantas fueron recogidas por los miembros del proyecto en el campo y - junto con el material comprado en los mercados - llevados a los hogares de los curanderos para dialogar sobre propiedades curativas, aplicaciones, la metodología de recolección y orígenes. La región del proyecto representa un punto florístico híperdiverso en Perú, con gradientes de desiertos costeros y bosques secos a algunos de los páramos más húmedos conocidos, así como a las tierras bajas del Amazonas (Fig. 2). En las casas de los curanderos los autores también observaron la preparación de remedios y participaron en rituales de curación. Usos de las plantas fueron discutidos en detalle con los informantes, con consentimiento informado previo de cada encuestado. Siguiendo una técnica de entrevista semi-estructurada, se pidió a los encuestados proporcionar información detallada sobre el nombre vernáculo de la planta, propiedades de las plantas (frío/caliente), región de la cosecha, las dolencias para que se utilizó una planta, el mejor tiempo y la estación de la cosecha, partes de las plantas utilizadas y el modo de preparación/applicación, incluyendo la adición de otras plantas. Todas las entrevistas se realizaron en español con al menos uno de los autores presentes. Ambos autores hablan español y no se necesitaron intérpretes para llevar a cabo las entrevistas. También se registraron datos sobre las especies de plantas, familias y nombres vernáculos adicionales.

Muchas de las especies reportadas desde el norte de Perú son ampliamente conocidas por los curanderos y los vendedores de hierbas, así como la población en general de la región y se emplean para un gran número de condiciones médicas. Ciento cinquenta a doscientos especies de plantas, incluyendo la mayoría de las especies introducidas se venden comúnmente en los mercados locales (Bussmann y Sharon 2006b). Especies autóctonas raras fueron colectadas por los curanderos mismos o las pidieron de recolectores o vendedores de hierbas especializados. Las mismas plantas se utilizaron con frecuencia para los mismos fines por la mayoría de los curanderos con sólo ligeras variaciones en las recetas. Sin embargo, diferentes curanderos pueden dar preferencia a diferentes especies para el tratamiento de la misma condición médica. Todas las especies encontradas fueron bien conocidas por los curanderos y los vendedores de hierbas que participaron en el estudio a pesar del hecho que a veces ellos mismos no utilizaron o vendieron una especie en cuestión. Muchas especies a menudo fueron reconocidas fácilmente por sus nombres vernáculos por otros 
miembros de la población. Esto indica que estos remedios han estado en uso durante mucho tiempo por muchas personas. El uso de algunas especies, lo más prominentes siendo San Pedro (Echinopsis pachanoi), Maichil (Thevetia peruviana) y Ishpingo (varias especies de Nectandra), se remonta a la cultura Moche (100-800 D.C.). Las representaciones de estas plantas se encuentran con frecuencia en la cerámica Moche, y los restos de algunos fueron encontrados en una variedad de entierros de individuos de alto rango de la élite Moche, por ejemplo, el Señor de Sipán (Bussmann y Sharon 2009c).

\section{Usos Medicinales}

Quinientos diez plantas con propiedades medicinales se registraron en el norte de Perú. Las mismas especies se suelen utilizar para diversas condiciones médicas y se aplican de diferentes maneras para la misma condición. Por ejemplo, los trastornos nerviosos pueden ser tratados con diferentes partes de una planta en diferentes aplicaciones, por ejemplo, tópica (como cataplasma o baño), oral (ingestión de extractos de plantas) y por la aplicación a la paciente de un Seguro, una botella llena de hierbas y perfumes que sirve como amuleto protector. Dos mil cuatrocientos noventa y nueve usos distintos se registraron para las 510 especies encontradas. A continuación, se da el número total de los usos/aplicaciones y el número de especies utilizadas, en lugar de sólo el número de especies de plantas que se utilizan para tratar una enfermedad, con el fin de destacar la importancia del tratamiento de condiciones específicas.

El mayor número de especies $(207,40,4 \%)$ se utiliza para el tratamiento de dolencias "mágicas", con $682(27,3 \%)$ de todas las condiciones. Los problemas respiratorios (91 especies, $18,5 \%)$ fueron mencionados como $233(9,3 \%)$ de todos los usos; 98 especies $(19,1 \%)$ se utilizan para tratar los problemas psicosomáticos y nerviosos, con 176 usos (7\%). Enfermedades renales y del tracto urinario se tratan con 69 especies $(16,6 \%)$, de 111 condiciones $(4,4 \%)$. Reumatismo y artritis se mencionaron en 103 usos $(4,1 \%)$, con 55 especies $(8,8 \%)$ utilizadas para los tratamientos. Infecciones de los órganos femeninos son tratados con 105 especies $(20,9 \%)$ y 100 $(4,4 \%)$ de todas las condiciones.

Los tratamientos se realizan con más frecuencia en los hogares de los curanderos individuales, que normalmente tienen sus mesas (altares de curación portáteles) establecidas en sus patios (Fig. 3). Los curanderos también tratan a los pacientes al frente de altares en las cámaras de consulta en sus hogares, en sitios sagrados en el campo o en lagunas sagradas en la sierra. Altares curativos que llevan un gran número de objetos de poder (artes) son más frecuentemente empleados (Fig. 4). Una ceremonia de curación normalmente implica la purificación del paciente soplando por vía oral extractos de hierbas benditas en todo el cuerpo para defenderlo de los malos espíritus además de la ingestión nasal del jugo de tabaco y perfumes. Suministros de plantas provienen principalmente de los mercados locales (Fig. 5).

Se registraron doscientos setenta y ocho condiciones médicas diferentes. La mayoría de las plantas se utilizaron para el tratamiento de múltiples enfermedades. La gran variedad de condiciones se agrupa en 72 categorías principales.

\section{Usos Mágicos}

Los trastornos mentales, neurológicos y psicosomáticos son altamente prevalentes en una escala global. La carga de los problemas de salud mental ha sido seriamente sub-estimado. Aunque los problemas neurológicos sólo son responsables de aproximadamente el $1 \%$ de las muertes a nivel mundial, contribuyen a más del $11 \%$ de la carga mundial de morbilidad. Se estima que este porcentaje se elevará al 15\% en 2020 (WHO 2009). La medicina occidental a menudo ofrece poca ayuda para los pacientes afectados por estos trastornos.

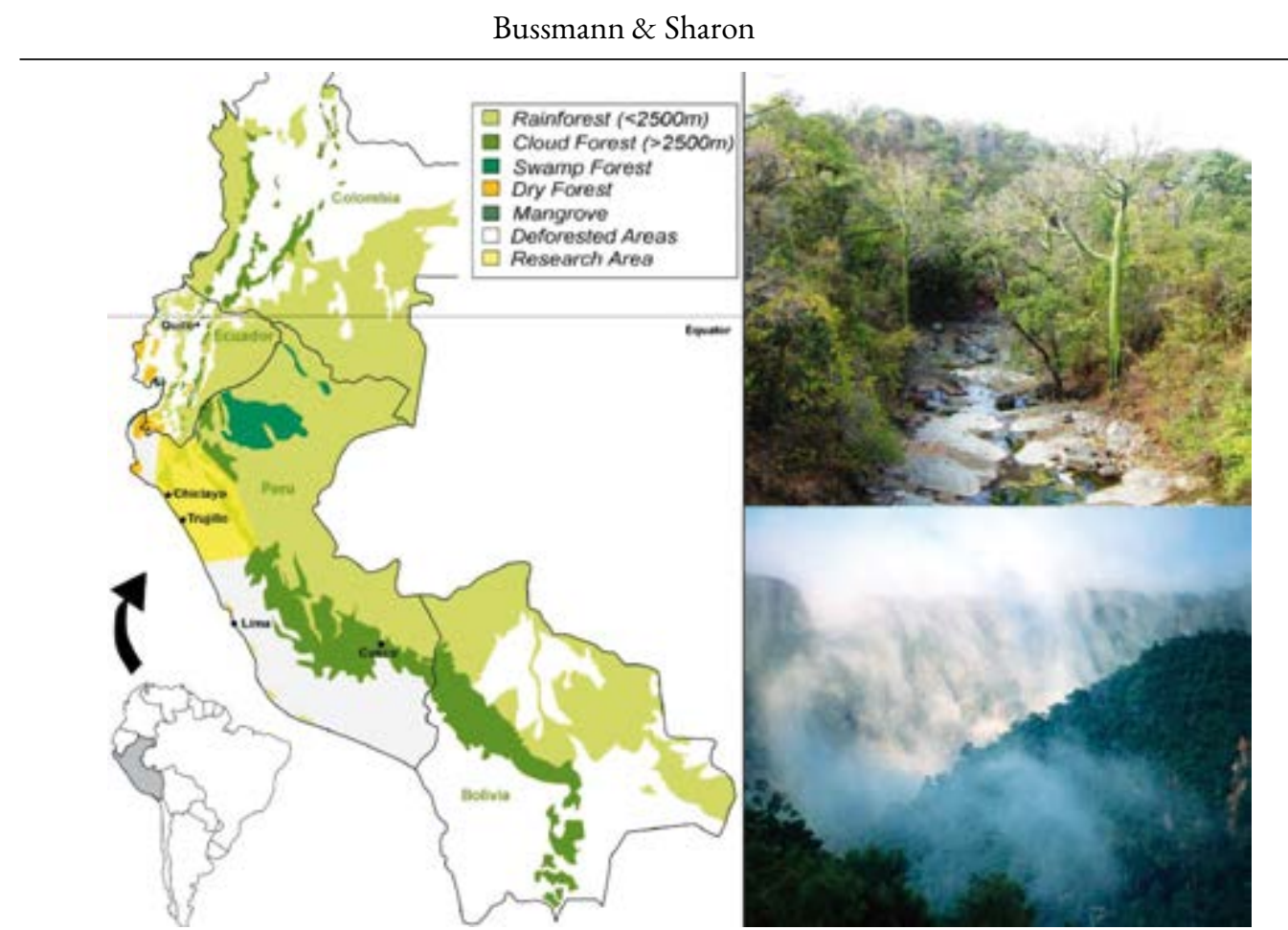

Figura 1: Área de estudio: Departamentos peruanos de Amazonas, Piura, Lambayeque, La Libertad, Cajamarca, San Martín y la provincia ecuatoriana de Loja. Bosque seco (arriba) y Bosque nublado (abajo) que indica el gradiente de humedad sorprendente.

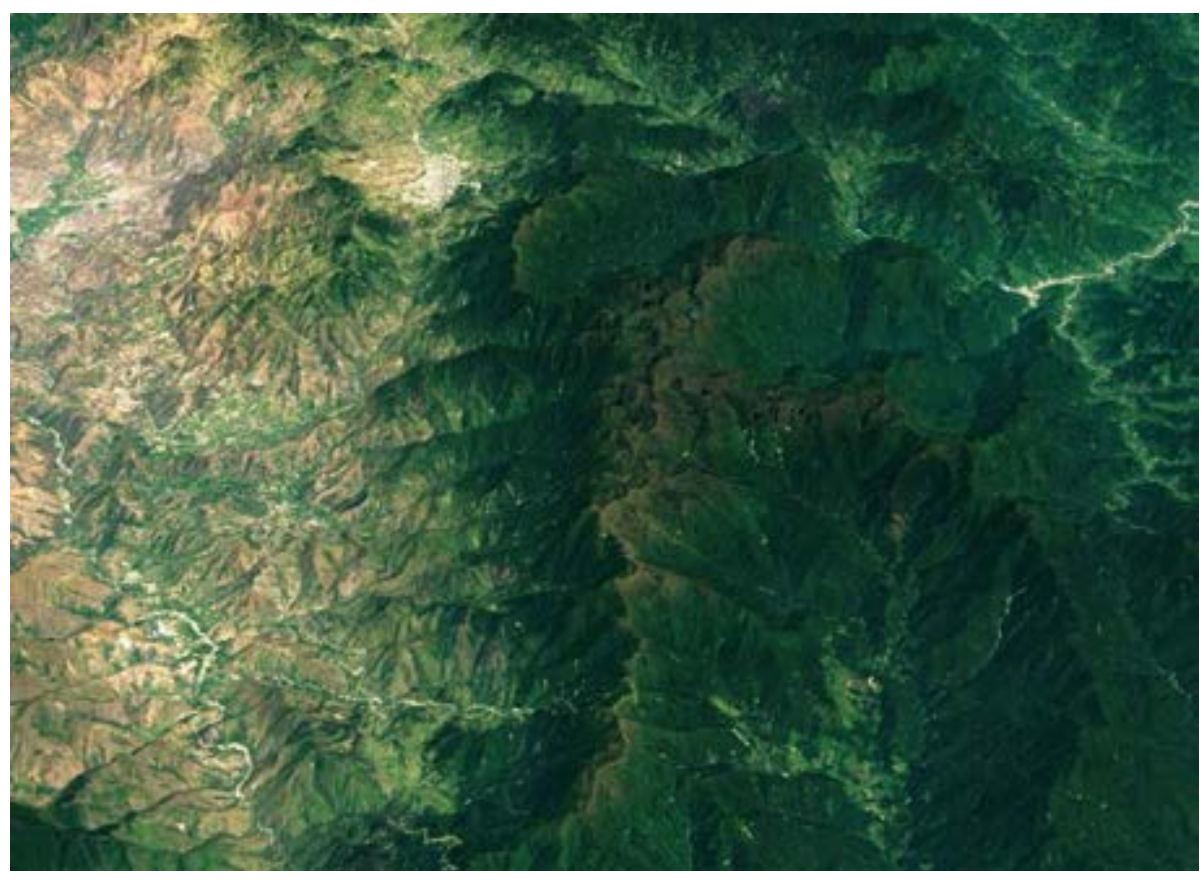

Figura 2: Transecto de 50 kilometros en el sur de Ecuador desde el bosque seco $(250 \mathrm{~mm}$ de precipitación, izquierda) hacía el Parque Nacional Podocarpus Páramo (precipitación $10000 \mathrm{~mm}$, medio) a las tierras bajas del Amazonas (derecha) 
Altares curativos (mesas) en el norte de Perú a menudo siguen las antiguas tradiciones mediante la inclusión de una gran variedad de "objetos de poder," con frecuencia con un fondo "pagana”. Los objetos como conchas, cerámicas pre-Hispánicas, varas, piedras, etc., son muy comunes en mesas peruanas y se mezclan con iconos cristianos como cruces e imágenes de santos. Los tratamientos se realizan con más frecuencia en los hogares de los curanderos individuales, que normalmente tienen sus mesas establecido en sus patios. Los curanderos también tratan a los pacientes en altares ubicados en los consultorios de sus hogares, en sitios sagrados en el campo, o en lagunas sagradas en las montañas. Una ceremonia de curación normalmente implica la purificación del paciente soplando extractos de hierbas benditas en todo el cuerpo para defenderse de malos espíritus seguido por baños de florecimiento. En la mayoría de los casos, "la limpia" del paciente también incluye tomar jugo hervido de San Pedro y la ingestión nasal del jugo de tabaco y perfumes. A veces extractos de Brugmansia spp. se utilizan para purificar el paciente. Invocaciones de los curanderos durante sus sesiones de curación incluyen componentes cristianas (por ejemplo, la invocación de Cristo, la Virgen María y una variedad de santos) y referencias a la cosmología andina (por ejemplo, a los Apus o espíritus de las montañas). El uso de cobayas como instrumentos de diagnóstico es muy común en el norte de Perú (Sharon 1978, 1980, 1994, 2000; Joralemon y Sharon 1993).

Mal Aire, Mal Viento, Susto o Espanto, Mal de Ojo y Daño o Brujería son percibidos como enfermedades muy comunes en la sociedad andina. Las causas incluyen cambios repentinos en la temperatura corporal (Mal Aire, Mal Viento), cualquier tipo de choque (Susto, Espanto), humores negativos emitidos por ciertas personas (Mal Ojo) y comida envenenada, maldiciones, etc. (Daño, Brujeria). Problemas médicos causados por influencias externas se reportan en varios estudios (Girault 1987; Oblitas 1992). El concepto occidental de "trastornos psicosomáticos" se acerca más a la caracterización de estos males.

Estas categorías de enfermedad están profundamente arraigadas en la sociedad andina, y la medicina occidental no ofrece alternativas eficaces al tratamiento tradicional. Esto podría explicar por qué todavía tienen una importancia excepcional entre la población. El tratamiento en muchos casos implica la participación del paciente en una ceremonia de limpieza o "limpia". Esto podría ser un tratamiento relativamente sencillo con perfumes y agua bendita o una ceremonia (mesada) de toda la noche enfocado en el altar (mesa) del curandero. Depués de la

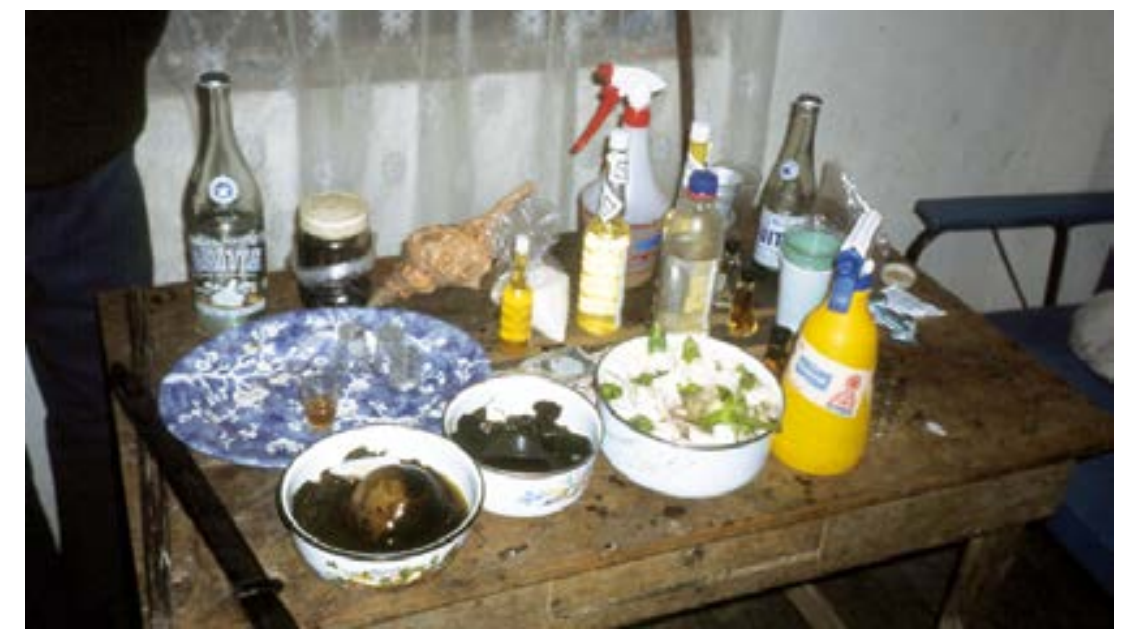

Figura 3: Mesa curandera contemporánea en el Sur de Ecuador. ceremonia el paciente es normalmente tratado con un "baño de florecimiento espiritual" con el fin de liberarlo de cualquiera síntoma o "espiritu" restante. Además, el paciente con frecuencia recibe un "seguro" o amuleto a base de hierbas para la protección contra futuras malas influencias y para la buena suerte. Seguros son frascos o botellas llenas de hierbas mágicas, así como perfumes, imágenes de santos y el cabello y las uñas del paciente.

El enorme número de especies de plantas utilizadas para el tratamiento de los trastornos psicosomáticos indica que los curanderos del norte de Perú son valorados como especialistas

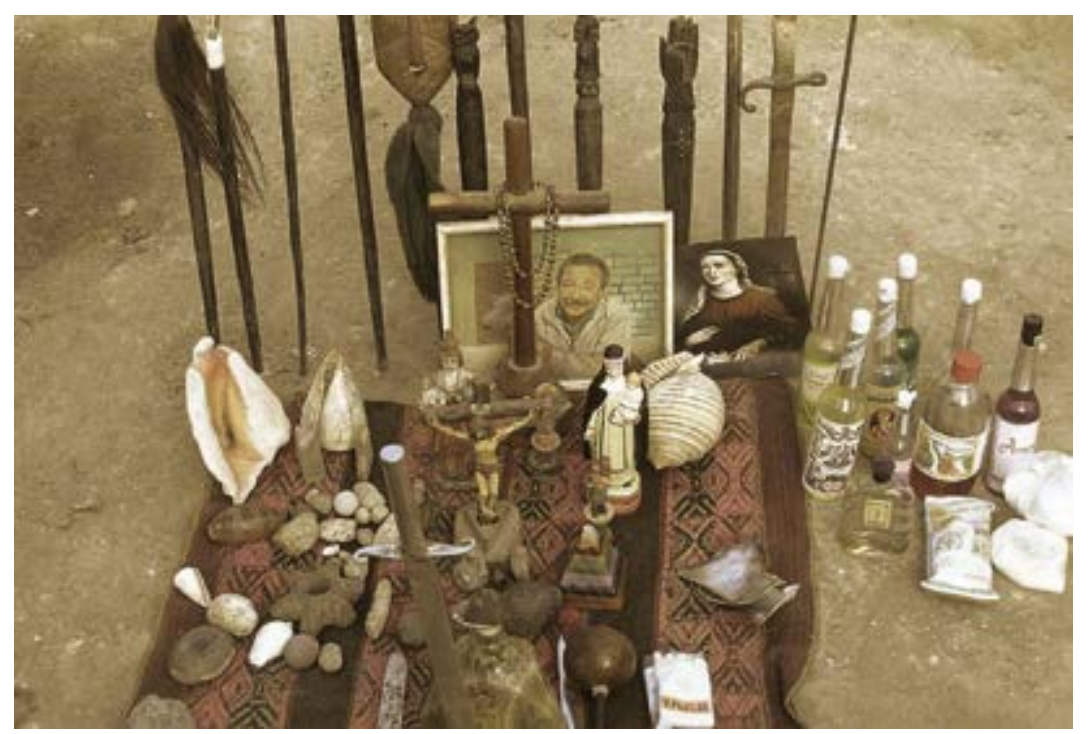

Figura 4: Mesa curandera contemporánea en el norte de Perú.

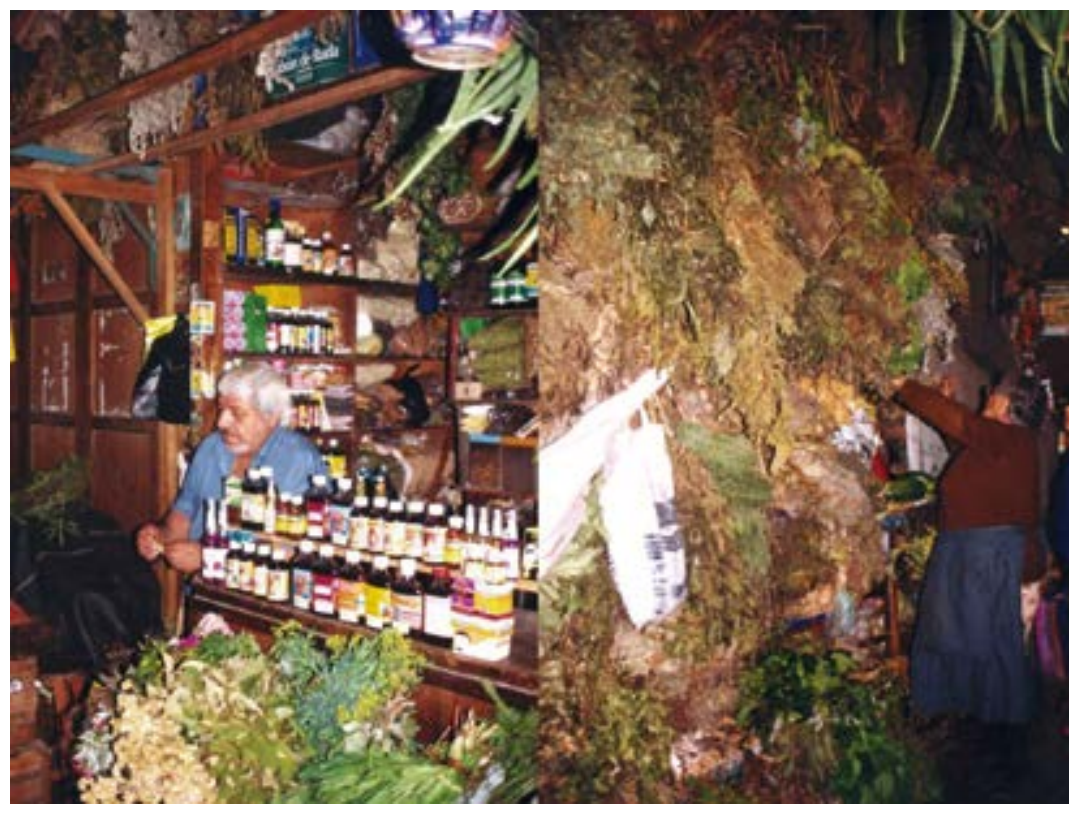

Figura 5: Preparaciones vegetales y plantas crudas para la venta en el Mercado Mayorista, Trujillo. 
que se consultan principalmente para estas condiciones. Esto es un punto importante, ya que la medicina occidental todavía no ha encontrado tratamientos eficaces para los trastornos psicosomáticos. Las especies de plantas utilizadas para la "mágica" provienen principalmente de las partes altos de los Andes, sobre todo desde las inmediaciones de los lagos sagrados, ya que las plantas de esas regiones se consideran especialmente "poderosas". Esto vincula las prácticas actuales de los curanderos directamente a la antigua cosmología andina. El uso de purgantes y laxantes, que literalmente "expulsan" espíritus malignos también es muy común.

En total, 198 especies de plantas pertenecientes a 172 géneros y 78 familias fueron registradas e identificadas como remedios utilizados para tratar problemas del sistema nervioso en el norte de Perú. La mayoría de las especies utilizadas fueron Asteraceae (36 especies, 16,21\%), seguido por Solanaceae (15 especies, 6,76\%) y Lamiaceae (14 especies, 6,31\%). Las familias más importantes relacionadas con el sistema nervioso son altamente representados en comparación con la flora medicinal en general, mientras que algunas otras familias terapeúticamente importantes (por ejemplo, Poaceae, cucurbitáceas, Euphorbiaceae) son completamente ausentes o insuficientemente representadas en la categoría de trastornos nerviosos (Bussmann y Sharon 2006b).

La mayoría de las preparaciones de hierbas se prepara con la planta entera $(31,56 \%)$, mientras que las hojas $(24,48 \%)$, tallos $(21,24 \%)$ y flores $(8,55 \%)$ se utilizan con menos frecuencia. Las plantas enteras y tallos se utilizan con más frecuencia de lo característico de los preparativos medicinales generales que se encuentran en la región (Bussmann y Sharon 2006b). Esto indica que los curanderos locales cuentan con un conocimiento muy bien desarrollado sobre las propiedades de diferentes partes de la planta. En más del 60\% de los casos se utilizó material vegetal fresco para preparar remedios, que difiere ligeramente del promedio de modo de preparación de hierbas en el norte de Perú. Curiosamente, sólo alrededor del 36\% de los recursos se aplicaron por vía oral, mientras que la mayoría se aplica por vía tópica $(46,65 \%)$, a menudo como un baño, y los restantes se utilizaron como protectores espirituales ("seguros"). Esto es diferente del promedio de aplicación regional de aplicación y subraya la importancia de los tratamientos de orientación espiritual. Más de $79 \%$ de todos los recursos se prepararon como mezclas hervidas con múltiples ingredientes, ya sea en el agua o en alcohol de caña de azúcar (aguardiente),

\section{Sistema Respiratorio}

La OMS (WHO) informa que las enfermedades respiratorias son una prioridad en la lista de importancia como causas de muerte y morbilidad a nivel mundial y por lo tanto ha elaborado una Estrategia para la Prevención y el Control de las Enfermedades Respiratorias Crónicas (CRD) (WHO 2002). Los problemas respiratorios son una causa importante de muertes infantiles en Perú (Weil 1978).

En total, 91 especies de plantas pertenecientes a 82 géneros y 48 familias fueron registradas e identificadas como remedios para el sistema respiratorio en el norte de Perú. La mayoría de las especies utilizadas fueron Asteraceae (15 especies, 16,67\%), seguidos de Lamiaceae y Fabaceae $(8,89 \%$ y $5,56 \%)$. La mayoría de las otras familias contribuyeron sólo una especie cada uno a la farmacopea. Las familias más importantes están bien representadas en comparación con la flora medicinal en general, aunque algunas otras familias medicinalmente importantes (por ejemplo, Euphorbiaceae, Lycopodiaceae, Cucurbitaceae) están completamente ausentes de la categoría respiratoria (Bussmann y Sharon 2006b)

La mayoría de los remedios para problemas respiratorios se preparan con las hojas de las plantas $(27,69 \%)$, mientras que la planta entera $(18,46 \%)$, flores $(13,85 \%)$ y los tallos $(17,69 \%)$ se usan con menos frecuencia. Esto indica que los curanderos locales cuentan con un conocimiento bien desarrollado de las propiedades de diferentes partes de la planta. En casi el 55\% de los casos se utilizó material vegetal fresco para preparar remedios, que difiere poco del modo promedio de preparado de hierbas en el norte de Perú. Alrededor del 86\% de los recursos se aplicaron por vía oral, mientras que los preparativos restantes se aplican por vía tópica. Más de la mitad de todos los recursos se prepararon como mezclas de varios ingredientes hirviendo material vegetal, ya sea en el agua o en alcohol de caña de azúcar.

Problemas respiratorios son tan comunes en todo el mundo y remedios libremente disponibles, tanto alopáticos y complementarios, se venden con tanta frecuencia que se ha puesto mucho esfuerzo en la verificación de los remedios tradicionales. Casi $50 \%$ de las plantas y sus congéneres que se encuentran en la farmacopea respiratoria del norte de Perú se han estudiado por sus propiedades medicinales. La hipótesis original aplicado en estos estudios fue que muchas especies empleadas para las enfermedades respiratorias fueron no-nativas y se introdujeron para tratar enfermedades que fueron originalmente introducidas por los colonizadores. Sin embargo, esta hipótesis no se probó. Al contrario, muchos remedios para enfermedades respiratorias son nativos de la zona del estudio. Desde esta perspectiva, es sorprendente ver cuántas especies realmente se han estudiado al menos de manera preliminar.

\section{Sistema Urinario (Riñones, Vejiga)}

El informe de la WHO (2005) sobre las infecciones del tracto urinario (UTI) indica que se encuentran entre las infecciones bacterianas más comúnmente visto, sobre todo en los niños. Se ha estimado que las infecciones urinarias son diagnosticados en el $1 \%$ de los varones y $8.3 \%$ de las niñas. En el primer año de vida UTI es más frecuente en los niños con tasas de 2,7\% en comparación con $0,7 \%$ en las nińas. La tasa de notificación de UTI recurrente es alrededor de 12 a $30 \%$, con mayores riesgos en los lactantes $<6$ meses de edad. Los estudios han demostrado una mayor prevalencia de la UTI de $8-35 \%$ en niños desnutridos, con el riesgo de bacterias aumentando significativamente de acuerdo con la gravedad de la malnutrición.

Un total de 69 especies de plantas pertenecientes a 61 géneros y 43 familias fueron documentadas para problemas del riñón y del tracto urinario en el norte de Perú. La mayoría de las especies utilizadas fueron Asteraceae (8 especies, 11,43\%), seguido por Fabaceae y Poaceae (ambos 5 especies cada una, 7,14\%). Todas las demás familias contribuyeron una sola especie cada una a la farmacopea. Las familias más importantes están representados de manera similar como en la flora medicinal en general, mientras que algunas otras familias importantes medicinalmente (por ejemplo Lycopodiaceae, Cucurbitaceae) están completamente ausentes de la categoría del riñón (Bussmann y Sharon 2006b).

La mayoría de las preparaciones de hierbas renales se prepara con toda la planta $(27,78 \%)$, mientras que las hojas de las plantas $(25,56 \%)$, flores $(12,22 \%)$ y los tallos $(16,67 \%)$ se utilizan con menos frecuencia (Bussmann y Sharon 2006b). Esto indica que los curanderos locales cuentan con un conocimiento muy bien desarrollado de las propiedades de diferentes partes de la planta. En casi el $64 \%$ de los casos se utilizó material vegetal fresco para preparar remedios, que difiere poco del promedio de modo de preparado de hierbas en el norte de Perú. Alrededor del 88\% de los recursos se aplicaron por vía oral, mientras que los restantes se aplicaron tópicamente. Más de la mitad de todos los recursos se prepararon como mezclas de varios ingredientes hirviendo material vegetal, ya sea en el agua o en alcohol de caña de azúcar.

Problemas renales y del sistema urinario son muy comunes en todo el mundo, pero los tratamientos alopáticos, en particular con respecto a los cálculos renales, se centran principalmente en la dilatación del uréter y de la gestión el dolor. Aunque un gran número de 
plantas se utilizan en la Medicina Tradicional para tratar este problema, menos de 35\% de las plantas que se encuentran en el Perú o sus congéneres se han estudiado por sus propiedades medicinales. Enfermedades renales y del tracto urinario son desafíos importantes de salud en todo el mundo. Muchas especies de plantas se utilizan tradicionalmente para el tratamiento de la enfermedad renal, y algunas han sido investigadoas para su eficacia con resultados positivos. Un factor limitante en estas investigaciones es la falta de datos etnobotánicos integrales para ayudar a elegir candidatos para las pruebas de potencia de plantas/eficacia. Este estudio puede servir como un guía de las especies que necesitan mayor evaluación sobre su estado de regeneración.

\section{Problemas reumáticos}

Los Institutos Nacionales de Salud (NIH) informan que se estima que 23,5 millones de estadounidenses sufren de enfermedades autoinmunes y que se estima que este número va a crecer. La investigación médica ha identificad 80-100 enfermedades autoinmunes, y se sospecha que 40 enfermedades adicionales que tienen una base autoinmune. Enfermedades autoinmunes colectivamente están en los primeros 10 principales causas de muerte entre las mujeres de edades comprendidas desde la adolescencia hasta la edad de 64. En la medicina occidental, los tratamientos más comunes son inmunodepresores, que se sabe tienen efectos secundarios devastadores a largo plazo (Gillett et al. 2000).

Condiciones de vivienda con corrientes de aire, así como las condiciones de trabajo difíciles, llevan a un amplio espectro de los problemas músculo-esqueléticos, incluyendo el reumatismo, la artritis y óseo- y muscular-dolor. En total, 55 especies de plantas pertenecientes a 53 géneros y 43 familias fueron documentadas e identificadas como remedios a base de hierbas autoinmunes en el norte de Perú. La mayoría de las especies utilizadas fueron Fabaceae (4 especies, 7,27\%), seguidas de las Rosáceas y Myrtaceae (ambos 3 especies cada uno, 5,45\%). Todas las demás familias contribuyeron sólo una o dos especies cada uno al total. Las familias más importantes están claramente representados en comparación con la flora medicinal en general, mientras que algunas otras familias medicinalmente importantes (por ejemplo, Asteraceae, Lamiaceae, Euphorbiaceae, Apiaceae, Lycopodiaceae, Cucurbitaceae) se utilizan con menos frecuencia para el tratamiento de problemas autoinmunes y dolor o están completamente ausente de la categoría (Bussmann y Sharon 2006b).

La mayoría de las preparaciones de hierbas se prepararon con las hojas de las plantas (35\%), mientras que toda la planta $(21,25 \%)$ y tallos $(17,5 \%)$ se usan con menos frecuencia. Esto indica que los curanderos locales cuentan con un conocimiento muy bien desarrollado sobre las propiedades de diferentes partes de la planta. En el 60\% de los casos se utilizó material vegetal fresco para preparar remedios, que difiere poco del modo promedio de preparado de hierbas en el norte de Perú. Sólo alrededor del $55 \%$ de los recursos se aplicaron por vía oral, mientras que los restantes se aplicaron tópicamente. Esto difiere poco del promedio regional de aplicación. Más de la mitad de todos los recursos se prepararon como mezclas de varios ingredientes hirviendo material vegetal, ya sea en el agua o en alcohol de caña de azúcar.

Existe muy poca evidencia científica para probar la eficacia de las especies empleadas como remedios para el tratamiento de problemas autoinmunes. Menos de $22 \%$ de las plantas o sus congéneres se han estudiado por sus propiedades medicinales.

\section{Órganos Internos (Higado, Vesícula)}

Enfermedades de los órganos internos son tratadas muy poco entre las condiciones médicas más comúnmente tratadas por los curanderos (Bussmann y Sharon 2006b). Esto es una indicación de que los curanderos en el norte de Perú en gran medida se especializan en el tratamiento de trastornos psicosomáticos, y que las enfermedades "corporales" son tratados más como una actividad secundaria. Sin embargo, un gran número de especies de plantas fueron utilizadas por los curanderos locales para tratar enfermedades del hígado y la vesícula biliar.

En total, 51 especies de plantas pertenecientes a 43 géneros y 31 familias fueron registradas e identificadas como remedios herbales para el hígado y la vesícula biliar en el norte de Perú. La mayoría de las especies utilizadas fueron Asteraceae (9 especies, 17,66\%) seguido de Euphorbiaceae (4 especies, 7,85\%) y Gentianaceae (3 especies, 5,89\%). Todas las demás familias contribuyeron sólo una o dos especies cada uno a la farmacopea. Asteraceae son claramente sobrerrepresentadas en comparación con la flora medicinal en general, mientras que algunas otras familias medicinalmente importantes (por ejemplo, de las Solanáceas, Lycopodiaceae, Cucurbitáceas, Rosaceae) están completamente ausentes de la categoría dolencia hepática (Bussmann y Sharon 2006b).

La mayoría de las preparaciones de hierbas empleadas para las dolencias hepáticas se prepara de la planta entera $(35,38 \%)$, mientras que las hojas $(24,61 \%)$, flores $(9,23 \%)$ y tallos $(12,32 \%)$ se usan con menos frecuencia. Plantas enteras fueron más frecuentemente utilizados que era característico para los preparativos medicinales generales que se encuentran en la región, mientras que los tallos de las plantas se empleaban con mucho menos frecuencia (Bussmann y Sharon 2006b). Esto indica que los curanderos locales tienen un conocimiento menos bien desarrollado sobre los constituyentes de las partes de plantas individuales en el caso de los tratamientos del hígado y de la vesícula biliar que para otras aplicaciones. En casi el 65\% de los casos se utilizó material vegetal fresco para preparar remedios, que es diferente del modo promedio de preparado de hierbas en el norte de Perú. La mayoría de los remedios fueron aplicados por vía oral (más del $90 \%$ ), mientras que los restantes fueron aplicados por vía tópica. Esto es diferente del promedi regional de aplicación. Más del $71 \%$ de todos los recursos se preparon como mezclas herviendo múltiples ingredientes hirviendo, ya sea en el agua o en alcohol de caña de azúcar. Esto indica que los curanderos locales tienen un conocimiento muy profundo acerca de los efectos sinérgicos de las plantas en forma de preparados de ingredientes múltiples.

Existe casi ninguna evidencia científica hasta la fecha para demostrar la eficacia de las especies empleadas como remedios del hígado y de la vesícula biliar en el norte de Perú. Sólo $8 \%$ de las plantas o las especies relacionadas en el mismo género se han estudiado.

\section{Diarrea, Problemas del Estómago y otras Enfermedades de los}

\section{Intestinos}

Enfermedades transmitidas por alimentos son un grave problema de salud pública en todo el mundo. Algunas enfermedades transmitidas por los alimentos son bien conocidas, pero se han vuelto más comunes. Los brotes de salmonelosis se han reportado durante décadas, pero dentro de los últimos 25 ańos estas enfermedades han aumentado en muchos continentes. Mientras que el cólera ha devastado gran parte de Asia y África durante muchos años, su introducción por primera vez en casi un siglo en el continente de América del Sur en 1991 indica que sea otro ejemplo de una enfermedad infecciosa que es a la vez bien reconocida y emergente. Mientras que el cólera es a menudo transmitido por el agua, muchos alimentos también transmiten la infección. La infección con Escherichia coli serotipo O157: H7 (E. coli) fue descrita por primera vez en 1982. Posteriormente, se ha surgido rápidamente como una causa importante de diarrea sanguinolenta y falla renal aguda. Los brotes de infección, generalmente asociadas con carne de res, han sido reportados en Australia, Canadá, Japón, Estados Unidos, en varios países europeos y en el sur de África (WHO 2002). 
En total, 75 especies de plantas pertenecientes a 62 géneros y 39 familias fueron registradas e identificadas como remedios a base de hierbas para las dolencias intestinales en el norte de Perú. La mayoría de las especies utilizadas fueron Lamiaceae (13,33\%), seguido por Asteraceae y Rutaceae (ambos 5 especies cada una, 6,67\%). La mayoría de las otras familias contribuyeron sólo una especie cada uno a la farmacopea. Las más importantes familias anti-infecciosas son claramente sobre-representadas en comparación con la flora medicinal general, mientras que algunas otras familias importantes medicinalmente (por ejemplo, Asteraceae) son mucho menos importantes (Bussmann y Sharon 2006b).

La mayoría de las preparaciones de hierbas anti-infecciosas se prepararon con las hojas de las plantas $(29,25 \%)$, toda la planta $(22,64 \%)$ y tallos $(16,04 \%)$. Esto indica que los curanderos locales cuentan con un conocimiento muy bien desarrollado sobre las propiedades de diferentes partes de la planta. En casi $60 \%$ de los casos se utilizó material vegetal fresco para preparar remedios, poco diferente del modo promedio de preparados de hierbas en el norte de Perú. Curiosamente, sólo alrededor del $83 \%$ de los recursos se aplicaron por vía oral, mientras que los restantes se aplicaron tópicamente. Más de la mitad de todos los recursos se preparan como mezclas de varios ingredientes hirviendo el material vegetal, ya sea en el agua o en alcohol de caña de azúcar.

Gran parte de las especies utilizadas para las enfermedades intestinales en el norte de Perú son introducciones de otras partes del mundo, especialmente de Europa. Muchos de ellos son bién conocidas, y casi el 50\% de las plantas que se encuentran en este estudio han mostrado eficacia en estudios científicos.

\section{Problemas Reproductivos y Salud Femenina}

Según la WHO (1999), problemas reproductivos - incluyendo 340 millones de nuevos casos de enfermedades de transmisión sexual (ITS) como la sífilis, la gonorrea, la clamidia y tricomoniasis - se producen anualmente en todo el mundo en adultos de 15 a 49 ańos de edad. En los países en vías de desarrollo, las ITS y sus complicaciones se clasifican en los primeros cinco categorías de enfermedades para las que los adultos buscan atención médica. La infección con enfermedades de transmisión sexual puede conducir a síntomas agudos, infecciones crónicas y consecuencias retardadas graves, como infertilidad, embarazo ectópico, cáncer cervicouterino y la muerte prematura de los niños y adultos (WHO 2007)

En total, 105 especies de plantas pertenecientes a 91 géneros y 62 familias fueron registrdas e identificadas como remedios a base de hierbas para problemas de reproducción en el norte de Perú. La mayoría de las especies utilizadas fueron Asteraceae (9,52\%), seguido por Lamiaceae y Fabaceae $(8,57 \%$ y $6,67 \%)$. Otras familias eran menos importantes, y 44 contribuyeron una sola especie cada uno a la farmacopea. Las familias más importantes están representados de una manera similar a su importancia global en la farmacopea local (Bussmann y Sharon 2006b).

La mayoría de los preparados a base de hierbas para problemas reproductivos se preparan a partir de las hojas de las plantas $(22,72 \%)$, la planta entera $(21,97 \%)$ y los tallos $(21,21 \%)$, mientras que otras partes de la planta se utilizan con mucho menos frecuencia. Esto indica que los curanderos locales cuentan con un conocimiento muy bien desarrollado sobre las propiedades de diferentes partes de la planta. En casi $62 \%$ de los casos se utilizó material vegetal fresco para preparar remedios, que difiere poco del modo promedio para preparados de hierbas en el norte de Perú. Más del $70 \%$ de los recursos se aplicaron por vía oral, mientras que los restantes se aplicaron tópicamente. Muchos remedios se prepararon como mezclas de varios ingredientes por ebullición material vegetal, ya sea en agua o en alcohol de cańa de azúcar.
Existe poca evidencia científica para probar la eficacia de las especies empleadas como remedios reproductivos en el norte de Perú. Sólo el 34\% de las plantas se encontró o sus congéneres se han estudiado en absoluto por sus propiedades medicinales.

\section{Corazón y Sistema Circulatorio}

Las enfermedades cardiovasculares son colectivamente la primera causa de muerte en el mundo, representando más del 30\% de todas las muertes en el mundo, el $80 \%$ de las cuales se producen en países de ingresos más bajos, con poca frecuencia de atención médica occidental disponible. Grupos de más bajos ingresos suelen tener una mayor prevalencia de factores de riesgo (WHO 2009). La Medicina Tradicional se utiliza a nivel mundial y está creciendo rápidamente en cuanto a su importancia económica. En los países en vías de desarrollo, los curanderos tradicionales son consultados con frecuencia para tratar problemas del corazón y enfermedades del sistema circulatorio. Los curanderos encontradas en este estudio utilizan una amplia variedad de términos relacionados con problemas del corazón que en parte generaliza las condiciones (por ejemplo, "enfermedades del corazón"), incluyendo referencias a condiciones como causas de los problemas del corazón subyacente (por ejemplo, “colesterol") o, simplemente, el uso de términos para indicar las opciones de tratamiento (por ejemplo, "riego sanguíneo" como un término que se refiere al "adelgazamiento" de la sangre de un paciente, "purificación de la sangre" o "refrescar el corazón", un término que indica un proceso de limpieza de la sangre de presuntos toxinas, y "sangre circulación ", que indica un tratamiento que mejora la circulación). El uso de términos biomédicos de estilo occidental no es sorprendente, dado que todos los informantes son de origen mestizo y viven en un entorno urbano.

La mayoría de los tratamientos del sistema circulatorio implican la purificación de la sangre con el fin de mejorar el estado general del paciente. Además, el concepto de moda de "control de peso" y las condiciones relacionadas con la obesidad han entrado en el dominio de los curanderos peruanos. Todos los curanderos fácilmente reconocen la influencia negativa de los niveles altos de colesterol y el uso de remedios vegetales para reducir el colesterol, así como terapias de pérdida de peso, mientras que las plantas utilizadas para el aumento de peso son insignificantes.

En total, 60 especies de plantas pertenecientes a 52 géneros y 33 familias fueron registradas e identificadas como remedios herbales para el corazón en el norte de Perú. La mayoría de las especies utilizadas fueron Asteraceae (7 especies, 11,67\%), seguido por Lamiaceae (6 especies, $10 \%$ ) y Solanaceae (4 especies, 6,67\%). Fabaceae, Amaranthaceae y Cucurbitaceae contribuyeron con 3 especies cada uno $(5 \%)$ a la farmacopea del corazón. Todas las otras veinte y siete familias contribuyeron sólo una o dos especies cada uno a la farmacopea. Asteraceae son en general poco representadas como remedios cardiácos en comparación con la flora medicinal utilizada en el norte de Perú. Lamiaceae y Euphorbiaceae están claramente representadas en comparación con la flora medicinal en general, mientras que algunas otras familias medicinalmente importantes (por ejemplo, Poaceae, Lycopodiaceae, Rosaceae) están completamente ausentes de la categoría del corazón (Bussmann y Sharon 2006 a, b).

a mayoría de los remedios del corazón se prepararon con plantas enteras $(37,18 \%)$, mientras que las hojas (24,36\%), tallos (15,38\%) y flores $(7,69 \%)$ se utilizan con menos frecuencia. Plantas enteras fueron más frecuentemente utilizados que lo que es característico para los preparativos medicinales generales que se encuentran en la región (Bussmann y Sharon 2006b). En casi el $70 \%$ de los casos se utiliza material vegetal fresco para preparar remedios, que es poco diferente del principal modo de preparación a base de hierbas en el norte de Perú. Más de $90 \%$ de los recursos se aplicaron por vía oral, mientras que los restantes se aplicaron tópicamente. Esto es muy diferente del promedio regional de aplicación. Más del $65 \%$ de todos los recursos se preparan 
como mezclas con múltiples ingredientes hirviendo el material vegetal, ya sea en el agua o en alcohol de cańa de azúcar. Esto indica que los curanderos locales tienen un conocimiento muy profundo acerca de los efectos sinérgicos de las plantas en forma de preparados de ingredientes múltiples.

Existe escasa evidencia científica hasta la fecha para probar la eficacia de las especies empleadas como remedios del corazón en el norte de Perú. Sólo el 33\% de las plantas que se encuentran o especies relacionadas en el mismo género se han estudiado.

\section{Inflamación e Infecciones Bacterianas}

Las infecciones bacterianas y la inflamación son algunas de las enfermedades responsables de un gran número de muertes en el mundo y a menudo son tratados por curanderos tradicionales (Bussmann y Sharon 2006a, b; WHO 2009).

En total, 96 especies de plantas pertenecientes a 84 géneros y 46 familias fueron registradas e identificadas como remedios a base de hierbas anti-infecciosos en el norte de Perú. Veinte por ciento de las especies fueron introducciones, mientras que el $80 \%$ pertenecen a la flora nativa de Perú. La mayoría de las especies utilizadas pertenecen a Asteraceae (18,95\%), seguido por Fabaceae y Euphorbiaceae (7,37\% y 5,26\%, respectivamente). La mayoría de las otras familias contribuyeron sólo una especie cada uno a la farmacopea. Las más importantes familias anti-infecciosas eran altamente representadas en comparación con la flora medicinal general, mientras que algunas otras familias medicinalmente importantes (por ejemplo, Lycopodiaceae, Cucurbitaceae) están completamente ausentes de la categoría anti-infeccioso.

La mayoría de los preparados a base de hierbas se preparan con las hojas de las plantas $(31,34 \%)$, mientras que la planta entera $(18,66 \%)$, flores $(12,69 \%)$ y los tallos $(17,16 \%)$ se usan con menos frecuencia. En casi $67 \%$ de los casos se utilizó material vegetal fresco para preparar remedios. Sólo alrededor del $55 \%$ de los recursos se aplicaron por vía oral, mientras que los restantes se aplicaron tópicamente. Más de la mitad de todos los recursos se preparan como mezclas de varios ingredientes hirviendo el material vegetal, ya sea en el agua o en alcohol de cańa de azúcar. Las infecciones, en particular, por las cepas de Staphylococcus aureus son muy comunes y cada vez más difíciles de tratar debido a la formación generalizada de resistencia a los medicamentos. Las infecciones por hongos, debido a la estructura de los organismos implicados, han sido siempre difícíl de tratar. Dada la gran importancia de las infecciones, no es de extrañar que los agentes anti-infecciosos tienen un alto rango en la lista de plantas a ser desarrollas como fármacos y que un gran número de especies utilizadas tradicionalmente han sido objeto de análisis. Casi el $43 \%$ de las plantas utilizadas en el norte de Perú para tratar las infecciones o sus congéneres se han estudiado por sus propiedades medicinales.

\section{Paludismo y Fiebre}

La malaria sigue siendo un importante problema mundial de salud pública en la mayoría de los países tropicales. Se piensa que la malaria es la enfermedad tropical más grave que causa uno a dos millones de muertes al año y desempeńa un papel importante en la alta mortalidad observada en los lactantes y niños (El Kamali et al. 1997; Milliken 1997). También es responsable de abortos involuntarios, partos prematuros, retraso del crecimiento, bajo peso al nacer y la anemia (Connally 1996; Gbile 1984; Minakawa et al. 2002; Hay et al. 2003).

La Organización Mundial de la Salud (WHO) ha estimado que alrededor de dos millones de personas en más de 100 países están expuestos a la malaria, con 247 millones de casos en 2006 La mitad de la población mundial está potencialmente expuesta a la enfermedad (WHO 2009). El empeoramiento de la situación económica mundial hace difícil ampliar los servicios modernos de salud. Por lo tanto, un sistema médico de entrega a bajo costo efectividad se necesita con urgencia (El Kamali et al. 1997).

Esto es aún más apremiante debido a que el uso y abuso de remedios contra la malaria como la cloroquina para prevenir y tratar la malaria falciparium ha dado lugar a aparición generalizada de parásitos resistentes (Milliken, 1997). Esto se complica por el hecho de que el calentamiento global puede llevar a la expansión de las áreas en las que la temperatura ambiente y las condiciones climáticas son adecuadas para la transmisión de Plasmodium. La variabilidad climática se ha asociado con algunas de las epidemias recientes (Minakawa et al. 2002).

En total, 17 especies de plantas pertenecientes a 17 géneros y 13 familias fueron registradas e identificadas como remedios a base de hierbas contra la malaria en el norte de Perú. La mayoría de las especies utilizadas fueron Asteraceae ( 3 especies, 17,66\%), seguido por Fabaceae y Solanaceae (ambos dos especies cada uno, 11,77\%). Todas las demás familias contribuyeron una sola especie cada una a la farmacopea. Las más importantes familias contra la malaria están altamente representadas en comparación con la flora medicinal general, mientras que algunas otras familias medicinalmente importantes (por ejemplo, Lamiaceae, Euphorbiaceae, Poaceae, Apiaceae) están completamente ausentes de la categoría contra la malaria (Bussmann y Sharon 2006b). En el contexto de las encuestas, los curanderos y los vendedores a menudo hacen referencia a "la fiebre" cuando se habla de la malaria. Fiebre sin embargo incluye una variedad de condiciones, de la fiebre de la gripe a la fiebre como resultado de la malaria. La malaria es reconocida como una infección parasitaria, mientras que otras especies de plantas se utilizan para tratar la fiebre como síntoma, centrándose principalmente en la reducción de la temperatura corporal.

La mayoría de las preparaciones de hierbas contra la malaria se preparan con las hojas de las plantas $(38,46 \%)$, mientras que la planta entera $(26,92 \%)$, flores $(15,38 \%)$ y los tallos $(11,54 \%)$ se usan con menos frecuencia. Las hojas y tallos son utilizados con más frecuencia para los tratamientos contra la malaria que lo que se habría esperado en comparación con los otros preparativos medicinales que se encuentran en la región, mientras que se emplean las semillas de las plantas con mucho menos frecuencia y otras partes de la planta no se usan (Bussmann y Sharon 2006b). Esto indica que los curanderos locales cuentan con un conocimiento muy bien desarrollado sobre las propiedades de diferentes partes de la planta. En casi $70 \%$ de los casos se utiliza material vegetal fresco para preparar remedios, que es poco diferente del modo promedio de preparado de hierbas en el norte de Perú. Curiosamente, aproximadamente 55\% de los remedios se aplican por vía oral, mientras que los restantes fueron aplicados por vía tópica. Esto es poco diferente del promedio regional de aplicación. Más de la mitad de todos los recursos son preparados como mezclas de varios ingredientes hirviendo el material vegetal, ya sea en el agua o en alcohol de caña de azúcar.

El número muy limitado de plantas empleadas en la costa peruana para tratar la malaria y la fiebre a primera vista puede parecer sorprendente si se compara con los estudios de otras regiones en el país (Kvist et al. 2006; Roumy et al. 2007). Sin embargo, la malaria siempre ha tenido una importancia relativamente menor en las zonas desérticas costeras. Por lo tanto, no es sorprendente que se emplean pocos remedios. Hay indicios de que las prácticas de salud están en el proceso de cambio y los curanderos están empezando a tratar a los pacientes con remedios modernos preparados (por ejemplo, aspirina, primaquina, malaraquin o lariam) a pesar de que los preparativos de plantas siguen siendo importantes (Bussmann y Sharon 2006b, 2007b, 2009a ).

Existe poca evidencia científica para probar la eficacia de las especies empleadas como remedios contra la malaria en el norte de Perú. Sólo el $41 \%$ de las plantas que se encuentran o sus congéneres se han estudiado por sus propiedades medicinales. 


\section{Cancer y Diabetes}

Cuarenta y siete especies de plantas pertenecientes a 42 géneros y 30 familias se utilizan por los curanderos en el norte de Perú para tratar afecciones cancerosas y síntomas de la diabetes. La mayoría de las especies utilizadas son Asteraceae (9 especies, 19,15\%), seguidos por Gentianaceae (3 especies, 6,37\%) y siete familias con dos especies de cada uno (4,25\%). Todas las demás familias contribuyeron una sola especie cada una a la farmacopea. Asteraceae como la familia más importante contra el cáncer y la diabetes es claramente sobre-representada en comparación con la flora medicinal en general, mientras que la mayoría de las otras familias medicinalmente importantes son subrepresentadas o completamente ausente de la categoría (Bussmann y Sharon 2006b).

La mayoría de las preparaciones de hierbas anti-cancerosas y anti-diabéticos se preparan con las hojas de las plantas $(30,77 \%)$, mientras que toda la planta $(20 \%)$, tallos $(20 \%)$ y flores $(6,15 \%)$ se usan con menos frecuencia. Las hojas y los tallos se utilizan con más frecuencia de lo característico de los preparativos medicinales generales que se encuentran en la región, mientras que plantas enteras se emplean con menos frecuencia (Bussmann et al. 2006b). Esto indica que los curanderos locales cuentan con un conocimiento muy bien desarrollado sobre las propiedades de diferentes partes de la planta. En casi $60 \%$ de los casos se utiliza material vegetal fresco para preparar los remedios, poco diferente del modo promedio de los preparados de hierbas en el norte de Perú. Más del 90\% de los recursos se aplican por vía oral, mientras que los restantes se aplican tópicamente. Esto es significativamente diferente del promedio regional de aplicación. Más de 50\% de los remedios incluyen múltiples plantas.

Existe muy poca evidencia científica hasta la fecha para probar la eficacia de las especies empleadas como anti-cancerosas y anti-diabéticos en el norte de Perú. Sólo $38.71 \%$ de las plantas que se encuentran como tratamientos para la diabetes y 17,65\% empleadas como remedios contra el cáncer o especies relacionadas en los mismos géneros han sido estudiados.

\section{Partes Usadas de las Plantas Medicinales y Modos de Aplicación}

Los curanderos del norte peruano prefieren utilizar las hojas (en el 25\% de todos los usos) o toda la planta (24\%) para la preparación de sus remedios. En 19\% de los casos los tallos de las plantas se utilizan, más comúnmente junto con las hojas. Flores (10\%), semillas (7\%), frutas y raíces ( $4 \%$ cada uno), corteza $(3 \%)$, cáscara de fruta $(2 \%)$ y látex y madera ( $1 \%$ cada una) son utilizadas para un número pequeño de las recetas.

Casi 64\% de los remedios empleados en el norte de Perú se preparan usando material vegetal fresco. Muchas de las especies introducidas se cultivan en los campos y jardines, pero la mayoría de las especies autóctonas se recogen silvestres. Esto indica que se necesita un sistema generalizado de coleccionistas de plantas para suministrar el material vegetal fresco necesaria para la Medicina Tradicional. La mayoría de los curanderos indicaron, sin embargo, que en la mayoría de los casos material secado se podría utilizar si las plantas frescas no estaban disponibles. En 36\% de todos los casos los remedios se preparan usando material vegetal seco. Material fresco no se utiliza en estas situaciones (Bussmann y Sharon 2006b).

Los curanderos en el norte de Perú a menudo emplean mezclas muy complejas de mucha variedad de plantas en sus tratamientos. El uso de una sola especie para tratamientos es raro. Más comunmente, el material vegetal se hirvió en agua, o en algunos casos en alcohol de caña de azúcar (aguardiente) para extraer los compuestos activos. En algunos casos, el material vegetal se macera en alcohol de caña de azucar o vino por períodos más largos de tiempo antes de su uso.

Todos los curanderos tenían recetas sorprendentemente bien medidas para el tratamiento, con cantidades muy específicas del material vegetal utilizado para preparar los remedios. Estas cantidades no fueron muy diferentes de un curandero a otro. Además, la cantidad de un recurso específico que se dio a un paciente fue muy similar entre diferentes curanderos.

La forma más frecuente de administrar remedios era preparar una decocción e ingerirla por vía oral $(52 \%$ de todos los usos) seguido por la aplicación en forma de cataplasma (38\%, planta triturada y/o hervida y aplicada). Siete por ciento de todos los usos de plantas implicaban la preparación de un seguro, una botella o frasco pequeño lleno de material vegetal junto con diversos perfumes. Este amuleto tiene que ser llevado por el paciente en su persona o se coloca en la casa y se utiliza para bendiciones periódicas. Seguros contenían desde un puñado de más de tres docenas de ingredientes diferentes. En dos por ciento de los casos las plantas se utilizaron para fabricar seguros, y en un por ciento de todas las aplicaciones el material vegetal fue quemado como incienso con el humo inhalado en el tratamiento.

Muchos curanderos tradicionales usan preparados a base de plantas - que a menudo consisten en ingredientes complejos y de preparaciones muy específicas -- para tratar las enfermedades de sus pacientes, en lugar de sólo emplear extractos de plantas individuales. Sin embargo, estudios que documenten estas preparaciones y análisis de la composición de las mezclas son casi inexistentes. La mayoría de los estudios etnobotánicos hasta la fecha han documentado la "utilización" de las especies individuales, sin hacer la pregunta importante si las plantas en cuestión son realmente empleadas solas, o si en realidad son parte de una preparación más compleja. Cano et al. (2004) estaban entre los primeros autores que respondieron a este desafío, investigando las mezclas de plantas empleadas en Cuba y el Medio Oriente, mientras que Vandebroek et al. (2010) demostraron la gran complejidad de los preparados de plantas en la República Dominicana. Sin embargo, no hubo información sobre la farmacopea andina tan rica en especies.

Nuestro trabajo intenta proveer una visión detallada sobre las mezclas de hierbas empleadas por los médicos tradicionales en el norte de Perú y las aplicaciones específicas con el fin de proporcionar una base para más estudios profundos sobre la eficacia y seguridad de estos preparativos, como así como las posibles aplicaciones en el sistema de salud pública.

La investigación de las mezclas de plantas utilizadas en la Medicina Tradicional en el norte de Perú encontró un total de 974 preparaciones de hierbas que se utilizan para tratar 164 aflicciones diferentes (Bussmann, Glenn, Meyer, Kuhlman y Townesmith 2010). La clasificación de las enfermedades siguió la terminología de los curanderos. Para permitir una mejor visión, los diferentes conceptos de enfermedades se agruparon en categorías de enfermedades comprensivos de acuerdo a sus similitudes. Trastornos psicosomáticos son las aflicciones más destacados tratados con mezclas de plantas, con casi $30 \%$ de todas las recetas aplicadas, seguidas por las enfermedades respiratorias, problemas femeninos, problemas renales y problemas del corazón. Susto, problemas del sistema nervioso, la inflamación sistémica general y bronquitis juntos representaron casi $25 \%$ de todos los recursos utilizados. En muchos casos, los curanderos utilizaron sólo una o dos plantas comunes para el tratamiento de una enfermedad y esta coincidencia entre curanderos diferentes muestra la gran sofisticación de los tratamientos. Al contrario, cuando se trata del tratamiento de categorías de enfermedades que no son específicas como "inflamación" o "bronquitis", cada curandero parecía usar su propia mezcla específica para tratar el problema. Esto fue particularmente evidente en el tratamiento de problemas neurológicos y psicosomáticos, que emplean la mayoría de plantas y mezclas. Hasta 49 preparaciones diferentes se utilizan para tratar la misma enfermedad. Esto parece indicar un alto grado de experimentación con el fin de encontrar curas para síntomas que no son específicos y que hay muy poco consenso entre los curanderos individuales en cuanto a qué cura hay que emplear en estos casos. Este bajo 
consenso, sobre todo cuando se trata del sistema nervioso y trastornos psicosomáticos, también podría indicar que los curanderos individuales son reacios a intercambiar conocimientos sobre sus protegidas metodologías y tratamientos específicos para ciertas categorías, mientras que el conocimiento acerca de los tratamientos "simples" es mucho más generalizado.

En total, 330 especies de plantas, lo que representa casi $65 \%$ de la flora medicinal utilizada en la región (Bussmann et al. 2010a) se aplicaba en mezclas. De ellas, 64 especies $(19,39 \%)$ fueron introducciones, cayendo dentro del rango de las especies introducidas como porcentaje de la flora medicinal total. Entre las plantas empleadas, Asteraceae sobresalió como era de esperar, y el número de especies utilizadas en esta familia fue comparable al porcentaje de Asteraceae en la flora medicinal de la región (Bussmann y Sharon 2006). La inmensa mayoría de las mezclas de plantas contenía dos a siete especies de plantas diferentes, aunque en el caso más extremo se incluyó 27 especies distintas. Un gran número de especies apareció en diversas mezclas. Las especies de plantas para cada mezcla se enumeran en el orden dado por los curanderos a fin de expresar la importancia de las especies individuales, en lugar de proporcionar una lista alfabética. (Para una descripción detallada de las cantidades y partes de cada planta utilizadas ver Bussmann y Sharon 2006b).

El análisis de "clusters" confirma que las mezclas utilizadas para aplicaciones como enfermedades respiratorias (tos, resfriado, bronquitis, etc.) inflamaciones, infecciones (renales/ urinarias, etc.) y purificación de la sangre tenían una composición florística similar. Sin embargo, algunos grupos de interés se destacaron, por ejemplo, mezclas utilizadas para los trastornos del sistema nervioso, la ansiedad y los problemas del corazón a menudo tenían una composición similar al igual que las mezclas para los problemas de la próstata y la vejiga; problemas renales, trastornos de la vejiga biliar, diabetes y colesterol fueron tratados con las mismas preparaciones como enfermedades reumáticas y la asma. Nuestra investigación sugiere que esto indica que los curanderos locales tienen un conocimiento muy detallado de los conceptos de enfermedad y están eligiendo sus remedios con mucho cuidado a base de la causa diagnosticada. Es decir, problemas cardíacos son tratados de manera diferente si son causados por el estrés versus un agente físico, mientras que infecciones renales reciben un trato diferente de problemas del rinón relacionados con la diabetes y/o obesidad.

La composición florística, así como la fitoquímica compleja de las mezclas tradicionales a base de plantas sigue siendo lamentablemente poco estudiada. Esto es tanto más sorprendente, ya que los esfuerzos de descubrimiento de fármacos tradicionales a base de una sola planta/ compuestos individuales han dado muy pocos resultados en las últimas décadas, lo que podía ser una explicación de por qué tantas especies de plantas que se han documentado para un uso determinado resultan "ineficientes" o "tóxicos" cuando se someten a ensayos clínicos.

Nuestra investigación indica que un gran número de plantas utilizadas en la Medicina Tradicional en el norte de Perú se emplean en mezclas sofisticadas, en lugar del uso de las plantas individuales. Curanderos peruanos parecen emplear pautas muy específicas en la preparación de estos "cocteles" y parecen tener una clara comprensión de los conceptos de enfermedad cuando diagnostican a un paciente. Esto a su vez los lleva a aplicar mezclas específicas para condiciones específicas. Parece que hay un intercambio generalizado de conocimiento sobre las mezclas para el tratamiento de las enfermedades corporales, mientras que las mezclas para el sistema nervioso y trastornos psicosomáticos parecen estar más estrechamente protejidos por los curanderos individuales. Mezclas tradicionales de hierbas, con su gran cantidad de fragmentos de compuestos y nuevos compuestos que se originan en el proceso de preparación, podían dar nuevas pistas para el tratamiento de una amplia variedad de enfermedades. El presente libro ofrece información detallada sobre la composición y el uso de mezclas tradicionales en el norte de Perú. Estudios adicionales para comparar la composición de estas preparaciones frente a extractos de una sola planta, así como las investigaciones que comparan la eficacia y la toxicidad de las preparaciones de hierbas en comparación con los ingredientes de una sola planta están progresando.

\section{¿Funciona la Medicina Tradicional? Una Mirada a Plantas Antibacterianas en el Norte}

Plantas con potencial actividad medicinal han llegado recientemente a la atención de los científicos occidentales, y los estudios han informado de que algunas son bioactivas (Perumal Samy et al. 2000). Componentes potencialmente activos se han aislado de algunas de las plantas de prueba (D’Agostino et al. 1995 a, b; Okuyama et al. 1994, Rodríguez et al. 1994).

Con el fin de evaluar la actividad antibacteriana de especies usadas en la Medicina Tradicional en el norte de Perú, 525 muestras de plantas de al menos 405 especies se ensayaron usando agar-bioensayos para la actividad antibacteriana contra Staphylococcus aureus, Escherichia coli, Salmonella enterica Typhi y Pseudomonas aeruginosa. Un número mucho mayor de extractos etanólicos de plantas mostró actividad antibacteriana en comparación con extractos de agua. Ciento noventa y tres extractos de etanól y 31 extractos de agua fueron activos frente a $S$. aureus. En 21 casos, sólo el extracto de agua mostró actividad (para todas las especies bacterianas) en comparación con el etanól sólo. Ninguno de los extractos acuosos se activaron contra las otras tres bacterias, con la actividad de los extractos de etanól también muy reducidos, ya que sólo 36 mostraron alguna actividad contra E. coli y tres cada uno contra S. enterica Typhi y P. aeruginosa. Diez y ocho extractos de etanól fueron eficaces tanto contra E. coli y S. aureus, mientras que en dos casos, el extracto de etanól mostró actividad contra E. coli y el extracto de agua contra $S$. aureus. El extracto de etanól de Dioscorea trifida era eficaz contra E. coli, S. aureus y P. aeruginosa. Caesalpinia spinosa fue la única especie que mostró alta actividad contra todas las bacterias, incluyendo Salmonella enterica Typhi y Pseudomonas aeruginosa cuando se extrayó en etanól (Bussmann et al. 2010).

Doscientos veinte y cinco extractos vinieron de especies de plantas que se emplean tradicionalmente contra las infecciones bacterianas. Ciento sesenta y seis $(73,8 \%)$ de ellos eran activos contra al menos una bacteria. De los trescientos extractos de plantas sin uso antibacteriano tradicional, solamente $96(32 \%)$ mostraron alguna actividad. Esto demuestra claramente que las plantas utilizadas tradicionalmente como agentes antibacterianos tenían una mayor probabilidad de tener actividad antibacteriana que las plantas sin usos anti-bacterianos. Sin embargo, la eficacia de las plantas usadas tradicionalmente para aplicaciones antibacterianas varia, lo que demuesta la necesidad de realizar estudios encaminados a comprender con claridad los conceptos de enfermedades tradicionales.

Plantas utilizadas para enfermedades respiratorias, inflamación/infección, heridas, diarrea y la prevención de infecciones post-parto fueron eficaces en el 70-88\% de las pruebas. Las plantas utilizadas para la "inflamación del riñón" tenían una eficacia mucho menor contra bacterias, poniendolas dentro del rango de las especies que tradicionalmente se utilizan para tratar otras enfermedades corporales. Sólo las especies utilizadas para tratamientos espirituales/rituales tuvieron peor rango. De ellas sólo $22 \%$ mostraron alguna actividad antibacteriana. Sin embargo, entre las plantas "espirituales" $38 \%$ de las especies utilizadas para baños de florecimiento mostraron actividad, mientras que sólo $15 \%$ de las plantas de uso frecuente en los amuletos de protección (en su mayoría especies dentro de las familias de Lycopodiaceae y Valerianaceae) mostraron actividad antibacteriana. 
Varias especies mostraron mayor eficacia que los antibióticos de control utilizados en los experimentos. Por ejemplo, Ambrosia peruviana, Iresine herbstii, Niphogeton dissecta, Opuntia ficus-indica y Smilax kunthii fueron particularmente eficazes contra Escherichia coli. Berberis buceronis, Caesalpinia paipai, Caesalpinia spinosa, Cestrum strigilatum, Cydista aequinoctialis, Dioscorea trifida, Escallonia pendula, Escobedia grandiflora, Eucalyptus citriodora, Eucalyptus globulus, Eugenia obtusifolia, Eustephia coccinea, Gallesia integrifolia, Geranium sessiliflorum, Hedyosmum racemosum, Iresine herbstii, Lycopersicon hirsutum, Mauria heterophylla, Phyllanthus niuriri, Porophyllum ruderale, Salvia cuspidata, Senecio chionogeton, Smilax kunthii, Tagetes erecta y Taraxacum officinale mostraron alta actividad frente a Staphylococcus aureus. Lo mismo es válido para la Ephedra americana, Gentianella bicolor y Mandevilla cf. trianae. Sin embargo, los extractos de estas tres especies fueron altamente inconsistentes en su eficacia.

La comparación de especies estrechamente relacionadas tradicionalmente empleadas para diferentes propósitos (por ejemplo, diferentes Alternanthera spp., Passiflora spp., Senecio spp. y Salvia spp. para fines espirituales y contra las infecciones bacterianas) mostró que especies "espirituales" normalmente no eran eficaces contra las bacterias, mientras que las especies estrechamente relacionadas y utilizadas como agentes antibacterianos eran eficaces. Ejemplos incluyen Plantago sericea var. sericea (utilizado en seguros sin eficacia) y Plantago sericea var. lanuginosa (utilizado para las infecciones vaginales con una alta eficacia contra $S$. aureus), casos particularmente convincentes que indican la sofisticación de los conocimientos tradicionales. Sin embargo, hay el ejemplo de Chuquiragua spp. donde sólo una de las especies mostró una eficacia. Esto indica claramente que en este caso el conocimiento tradicional no produjo resultados fiables.

Por otra parte, los extractos de la misma especie tradicionalmente utilizada para tratar infecciones a menudo produjió resultados muy divergentes cuando fue colectada en diferentes localidades. Buenos ejemplos son Iresine herbstii, Schinus molle, Eustephia coccinea, Oreopanax eriocephalus, Myroxylum balsamum, Spartium junceum y Gentianella dianthoides. La mayoría de estas especies no produjo particularmente altas tasas de inhibición y no eran la primera opción de los curanderos cuando se trataba de encontrar remedios para las infecciones bacterianas. Muchos remedios tradicionales para conceptos como "inflamación del riñón" no produjeron ningún resultado antibacteriana, lo que indica que la investigación sobre la eficacia no necesita tomar de cerca conceptos tradicionales de enfermedades en cuenta.

Muchos remedios utilizados para florecimiento espiritual u otros fines no relacionados a infecciónes sí mostraron eficacia antibacteriana in vitro, pero no se describieron como tal por los curanderos locales. Esto podría explicarse por el hecho de que, o bien son muy inconsistentes en su actividad (por ejemplo, Mandevilla trianae, Loricaria spp., Lonicera japonica, Hypericum laricifolium, Hyptissidifolia, Mentha piperita, Brachyotum naudinii, Cydonia oblonga), o están tan estrechamente relacionados que la identificación, especialmente cuando se seca, puede ser un problema, por ejemplo, en el caso de Baccharis spp., Gentianella spp. y Valeriana spp. Otra posibilidad es que pueden ser propensos a los efectos secundarios tóxicos como en el caso de Ephedra americana y Brugmansia spp.

Casi todos los remedios se preparan tradicionalmente como extractos de agua, aunque etanól (en forma de alcohol de caña de azúcar) es fácilmente disponible. A primera vista esto podría parecer sorprendente, dada la baja eficacia de los extractos de agua que se encuentran en este estudio. Sin embargo, los resultados iniciales de los ensayos de toxicidad salmuera-camarón indican que los extractos de etanól son mucho más tóxicos que los extractos de agua en el caso de muchas especies. Por lo tanto los extractos de etanól en muchos casos podían ser inadecuados para la aplicación terapéutica. Otra vez esto indica la considerable sofisticación y cuidado con el los curanderos tradicionales en el norte de Perú eligen sus recursos para fines específicos.

Si la documentación botánica de plantas medicinales peruanas se ha descuidado, las investigaciones de la composición fitoquímica de plantas útiles están rezagadas. La mayoría de los estudios sobre la fitoquímica de las plantas peruanas se concentran en unas pocas especies "de moda" que han sido comercializadas en una escala global, especialmente Maca (Lepidium meyenii), Sangre del Drago o del Grado (Croton lechleri) y Uńa de Gato (Uncaria tomentosa y Uncaria guianensis). El número de otras plantas peruanas para las que existen al menos algunos estudios fitoquímicos sigue siendo mínimo y la mayoría de los esfuerzos se alimentan de las modas y tendencias del mercado internacional de los suplementos a base de hierbas. Los estudios que incluyen múltiples especies solamente se iniciaron en la década de los años noventa.

Las concentraciones inhibitorias mínimas encontrados para extractos de plantas peruanas variaron de 0,008 a $256 \mathrm{mg} / \mathrm{ml}$. Los altos valores en muchas especies indican una eficacia antibacteriana muy limitada. Los extractos de etanól exhiben actividad más fuerte y un espectro mucho más amplio de acción que los extractos de agua. La actividad más interesante con $E$. coli se obtuvo a partir de extractos de etanól de Baccaris sp., Ochroma pyramidale, Croton lechleri, Banisteriopsis caapi, Miconia salicifolia y Eugenia obtusifolia. Sólo esta última especie también mostró una fuerte actividad en el extracto acuoso. Una gama mucho más amplia de especies, incluyendo la mayoría de especies activas contra $E$. coli mostró inhibición de $S$. aureus.

Poropohyllum ruderale, Senecio sp., Corynaea crassa, Dioscorea trifida, Senna monilifera, Spartium junceum, Pelargonium odoratissimum, Satureja pulchella, Cuphea sp., Malva parviflora, Brosmium rufescens, Syzygium aromaticum, Sanguisorba minor, Citrus limetta, Verbesina sp. y dos especies no identificadas mostraron valores de MIC entre $1-4 \mathrm{mg} / \mathrm{ml}$. La mayoría de ellos, sin embargo no mostró ninguna eficacia en el extracto acuoso. Hypericum laricifolium, Hura crepitans, Caesalpinia paipai, Cassia fistula, Hyptis sidifolia, Salvia sp., Banisteriopsis caapi, Miconia salicifolia y Polygonum hydropiperoides mostraron los valores más bajos de MIC y podian ser candidatos interesantes para futuras investigaciones (Bussmann et al. 2010).

La mayoría de las especies eficaces contra $S$. aureus son tradicionalmente utilizadas para tratar infecciónes de heridas, infecciones de garganta, inflamaciones graves de infecciones posparto. Curiosamente, muchas especies utilizadas en los baños de florecimiento también mostraron alta actividad contra esta bacteria. Muchas de estas especies se emplean ya sea por vía tópica o en mezclas sinérgicas de manera que sea posible que toxicidad no parece ser un problema. Las especies eficaces contra E. coli fueron empleadas principalmente para condiciones que los curanderos tradicionales identifican como "inflamación".

La mayoría de las plantas utilizadas por los curanderos tienen actividad antibacteriana, pero sólo siete de las 141 plantas (5,6\%) examinados en este estudio muestran valores de MIC de 200 o menos $\mathrm{mg} / \mathrm{ml}$ de extracto. De estas plantas, cinco se utilizan para tratar enfermedades que se consideran de origen bacteriano por la Medicina Tradicional, y una se utiliza para propósitos de tratamiento no definidos.

Nueve de 141 plantas probados $(6,3 \%)$ no fueron utilizados para las enfermedades que se consideran de origen bacteriano por la Medicina Tradicional. Cinco mostraron alta actividad antibacteriana con valores de MIC debajo de $16 \mathrm{mg} / \mathrm{ml}$. Cuatro de ellos se encuentran entre las plantas más potentes con valores de MIC de 2 o menos $\mathrm{mg} / \mathrm{ml}$, incluyendo un alucinógeno y extractos utilizados para tratar la diabetes y la epilepsia. Enfermedades como la diabetes a menudo enpeligran la salud del paciente y tratamientos antibacterianos pueden ser necesarios para complicaciones secundarias de la enfermedad. 


\section{Toxicidád en la Medicina Tradicional}

Eficacia medicinal básica ha sido investigada para una amplia variedad de plantas. Sin embargo, mientras que los ensayos de toxicidad están disponibles para un gran número de países, no existen datos sobre la toxicidad potencial de las especies medicinales peruanas.

Crustaceas del género Artemia se utilizan con frecuencia como un agente en ensayos de laboratorio para determinar los valores de toxicidad mediante la estimación de los valores de la LC50 (concentración letal media). La actividad letal de artemia en 501 extractos acuosos y etanólicos de 341 especies de plantas pertenecientes a 218 géneros de 91 familias que se utilizan en la medicina tradicional peruana se puso a prueba (Bussmann, Malca, Glenn et al. 2011). Los extractos acuosos de 55 especies mostraron valores altos de toxicidad (CL50 a continuación 249 $\mathrm{g} / \mathrm{ml}$ ). Diez y ocho especies mostraron toxicidad mediana (LC50 $250-499 \mathrm{~g} / \mathrm{ml}$ ) y 18 mostraron baja toxicidad (LC50 500-1000 g/ml). Los extractos de etanól demostraron ser mucho más tóxicos: 220 especies mostraron valores altos de toxicidad (LC50 a continuación $249 \mathrm{mg} / \mathrm{ml}$, con 37 especies que tienen niveles de toxicidad de> $1 \mu \mathrm{g} / \mathrm{ml}), 43$ especies mostraron toxicidad mediana (LC50 250-499 g ml) y 23 especies mostraron baja toxicidad LC50 500-1000 g/ml). Más de $24 \%$ de los extractos acuosos y el $76 \%$ de los extractos de etanól mostraron niveles de toxicidad elevados a salmuera de camarón. Métodos de preparación tradicionales están tomando esto en cuenta. La mayoría de los remedios se preparan como extractos de agua simples, evitando así los efectos tóxicos potenciales. Excelentes ejemplos donde se producen los extractos de agua no son tóxicos, mientras que los extractos de etanól que muestran alta toxicidad son Ocimum basilicum L., Salvia sp. o Laccopetalum giganteum (Wedd.) Ulbrich. En contraste, los extractos de etanól de Cinchona officinalis L. no eran tóxicos y se utilizan tradicionalmente, mientras que el extracto de agua altamente tóxico no tiene ningún uso tradicional.

Las especies que mostraron mayores niveles de toxicidad eran Bejaria aestuans L., Erodium cicutarium (L.) L'Her., Brachyotum naudinii Triana, Miconia salicifolia (Bonp. ex Naud.) Naud., Cuscuta foetida Kunth, Caesalpinia spinosa (Molina) Kuntze y Phyllactis rigida (Humb. y Bonpl.). Pers. Achillea millefolium L., Artemisia absinthium L. y Eucalyptus globulus Labill, utilizado frecuentemente como tés medicinales, también entran en este grupo tanto como Lupinus mutabilis Sweet y Ilicium verum Hook. f. Varias Solanáceas (por ejemplo, Nicotiana tabacum L. y Solanum americanum Mill. resultaron ser altamente tóxicas, mientras que otras especies conocidas por ser altamente tóxicas cuando están ingeridas (por ejemplo, Datura sp. y Brugmansia spp.) no mostraron toxicidad en Artemia.

Múltiples extractos de diferentes colecciones de la misma especie en la mayoría de los casos mostraron valores de toxicidad muy similares. Sin embargo, en algunos casos, la toxicidad de extractos de diferentes colecciones de la misma especie varió de no-tóxica hasta altamente tóxica. No se encontraron ejemplos de tal variación en la toxicidad para Chersodoma deltoidea MO Dillon y Sagast., Satureja sericea (C. Presl. Y Benth.) Briq., Eugenia obtusifolia Cambess., Epidendrum sp., Capparis crotonoides Kunth, Sambucus peruviana Kunth y Malva sp. Para estas especies que se utilizan con frecuencia, tiempo de cosecha, localidad de recopilación o el uso de partes específicas de la planta podían ser importantes para una reducción de la toxicidad.

\section{Mercados y Sostenibilidad \\ Las Farmacopoeae del Sur de Ecuador y el Norte de Perú - Regímenes coloniales y su Influencia en el Uso de las Plantas}

Las diferencias en el uso de plantas medicinales entre el sur de Ecuador y norte de Perú son sorprendentes. Ambas regiones comparten las mismas antecedentes culturales, y tienen una flora muy similar con un número comparable de especies de plantas que en gran medida se superponen. Muchas plantas mencionadas en Martinez Compañón (1789) todavía se encuentran hoy día en los mercados locales (Fig. 6). Sin embargo, la flora medicinal del sur de Ecuador incluye sólo 40\% de las especies utilizadas en el norte de Perú. Las diferencias en el uso de Medicinal Tradicional pueden explicarse mediante la comparación del desarrollo de las farmacopoeae en ambas áreas desde el principio del período colonial hasta hoy. Cronistas coloniales a menudo se incluyen descripciones detalladas de plantas útiles en sus informes. Monardes (1574), Acosta (1590), y Cobo (1653/1956), proveen los primeros relatos más completos de la flora económicamente interesante del norte de Perú y sur de Ecuador. Tratamientos posteriores fueron incluidos en Alcedo (1776). Martínez de Compañón (1787), Arzobispo de Trujillo, ordenó la preparación de un inventario completo de su diócesis. Por último, Ruiz y Pavón presentaron el primer inventario botánico real de la región (1777-1788).

El relato de Martínez Compañón ofrece la mejor base para la comparación de la flora medicinal colonial con la flora contemporánea de la región. Su obra incluye acuarellas minuciosas para cada especie, lo que permite una comparación detallada con la flora medicinal de hoy y indicando que los nombres vernáculos de las plantas útiles no han cambiado significativamente desde la época colonial. El relato contiene 526 especies de plantas útiles. Un examen preliminar de este trabajo parece indicar que el número de plantas que se utilizan hoy no ha cambiado significativamente desde 1789, con más de 500 especies de plantas disponbles en los mercados peruanos modernos. Sin embargo, una comparación más cercana muestra que sólo $41 \%$ de las especies publicadas por Martínez de Companón todavía se vende hoy en el Perú. Un adicional 32\% todavía se utiliza en el departamento o región de Amazonas, pero ya no llega a los mercados de la costa. Veinte y siete por ciento ha desaparecido por completo hoy. Esto significa que $59 \%$ de las especies que se venden en los mercados de Perú y el $41 \%$ de las especies utilizadas en Ecuador se han agregada a la farmacopea dentro de los últimos 200 años (Fig. 7).

Un análisis del agrupamiento de los inventarios de plantas coloniales y modernas mostró una explicación sorprendente de las diferencias de uso entre Ecuador y Perú, y ayuda a explicar por qué los inventarios de plantas cambiaron de manera significativa en el siglo diez y ocho. La farmacopea actual de la flora útil de Ecuador es más similar a la flora colonial temprano mencionada en Monardes (1574), Acosta (1590), Cobo (1653/1956) y Alcedo (1776). Esto indica que la flora medicinal ecuatoriana no se desarrolló mucho entre los tiempos coloniales tempranos y tardíos. En contraste, la flora medicinal peruana es mucho más similar a colecciones posteriores (Fig. 8). Una explicación de esto radica en la diferencia de trato de las prácticas tradicionales en Ecuador y Perú. En Ecuador, los practicantes de la Medicina Tradicional fueron perseguidos de inmediato una vez que la administración colonial fue instalada, mientras que la administración peruana era mucho más tolerante. Esto también refleja la creación del Instituto Nacional de Medicina Tradicional (INMETRA) en Perú en la década de 1990, mientras que la Medicina Tadicional era ilegal en Ecuador hasta que fue incluido en la Constutución de 1998. Esto significaba que los curanderos ecuatorianos no tuvieron la oportunidad de experimentar con nuevas especies para curar enfermedades introducidas por los europeos, mientras que los 
curanderos peruanos fueron capaces de explorar la rica flora de la región con el fin de encontrar nuevos remedios. Esta experimentación se extendió también a los conceptos "mágicos" de enfermedades como Mal Aire, Mal de Ojo, Susto y Envidia que se introducieron desde Espańa durante el régimen colonial. Curanderos peruanos desarrollaron una amplia gama de productos medicinales para el tratamiento de estas condiciones, que, en gran medida explica el cambio en la flora medicinal entre finales de 1700 y los tiempos modernos. Experimentación en Ecuador se mantuvo restringido para el tratamiento de enfermedades comunes, mientras que los tratamientos espirituales fueron prohibidos hasta que la revisión constitucional de 1998 reconoció el derecho de la población a utilizar la Medicina Tradicional (Fig. 9) (Bussmann y Sharon 2009a).

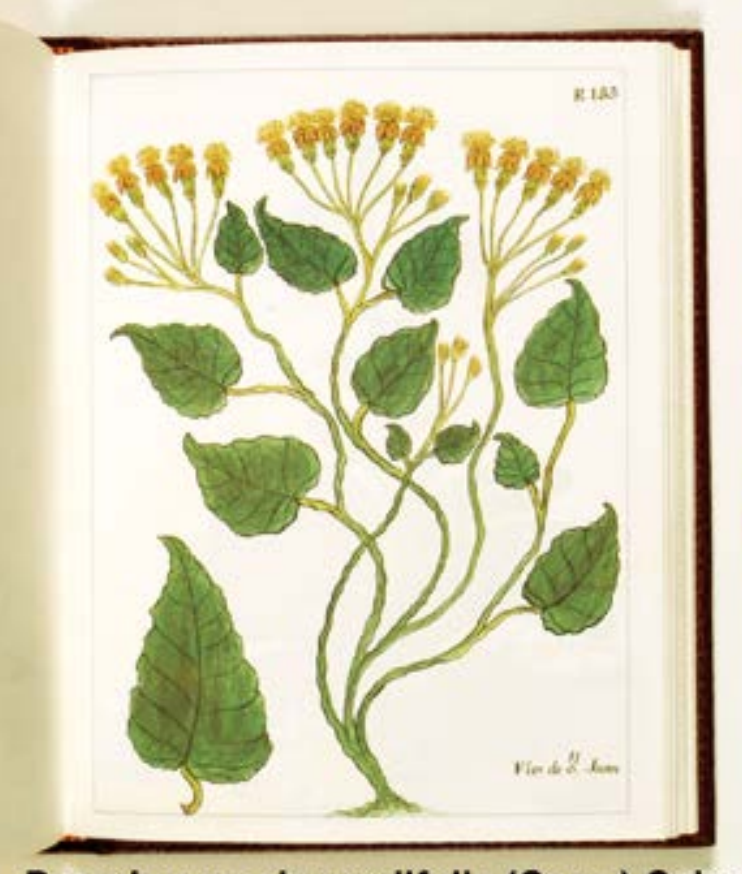

Pseudogynoxis cordifolia (Cass.) Cabr.

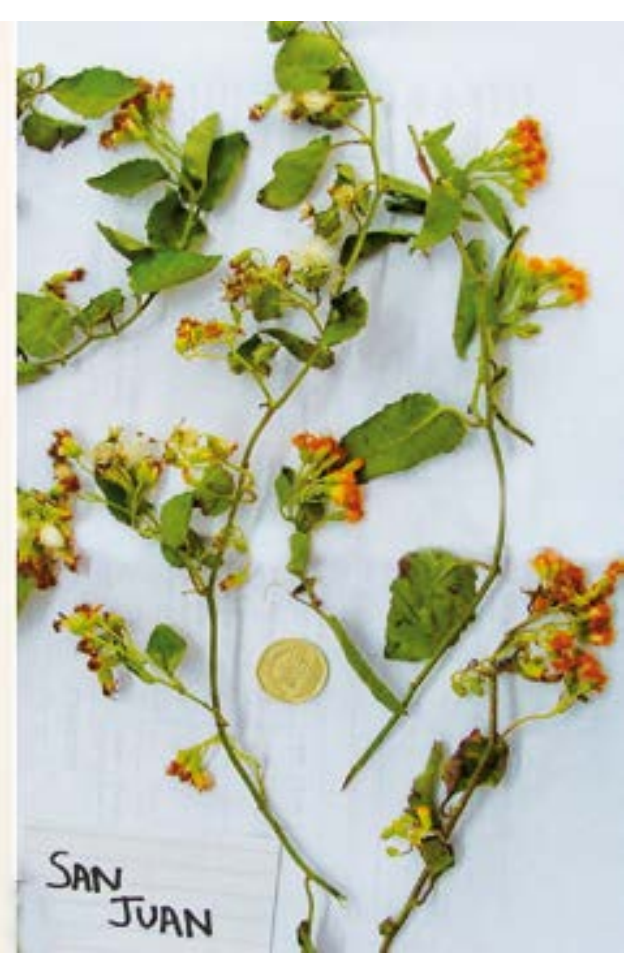

Figura 6: : Flor de San Juan desde el dibujo en Martínez de Compañón (1789) y la reciente compra de mercado.
Matrix correlation: $\underset{(=n}{\mathrm{r}=} \mathbf{0 . 8 9 6 5 8}$
$(=$ nomalized Mantel statistic Z $)$

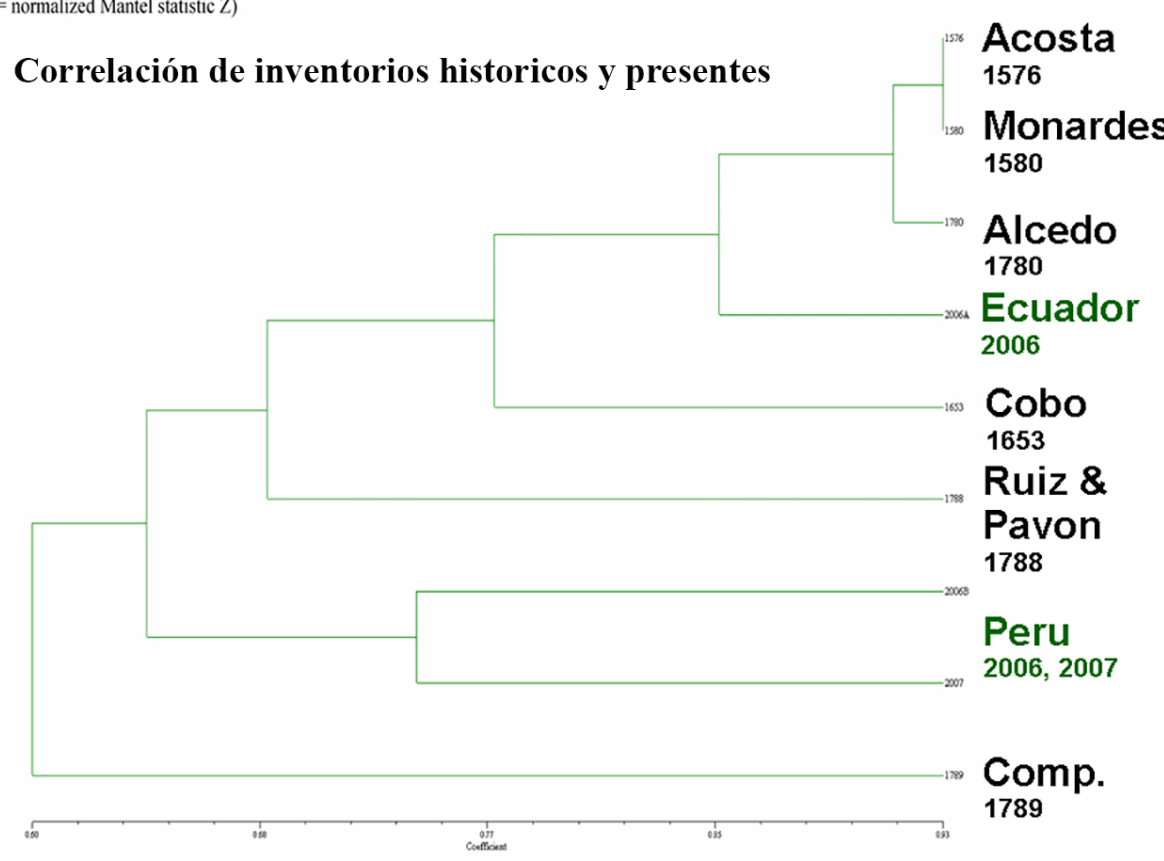

Figura 7: Cladograma de la vinculación de las fuentes históricas y farmacopeas actual.

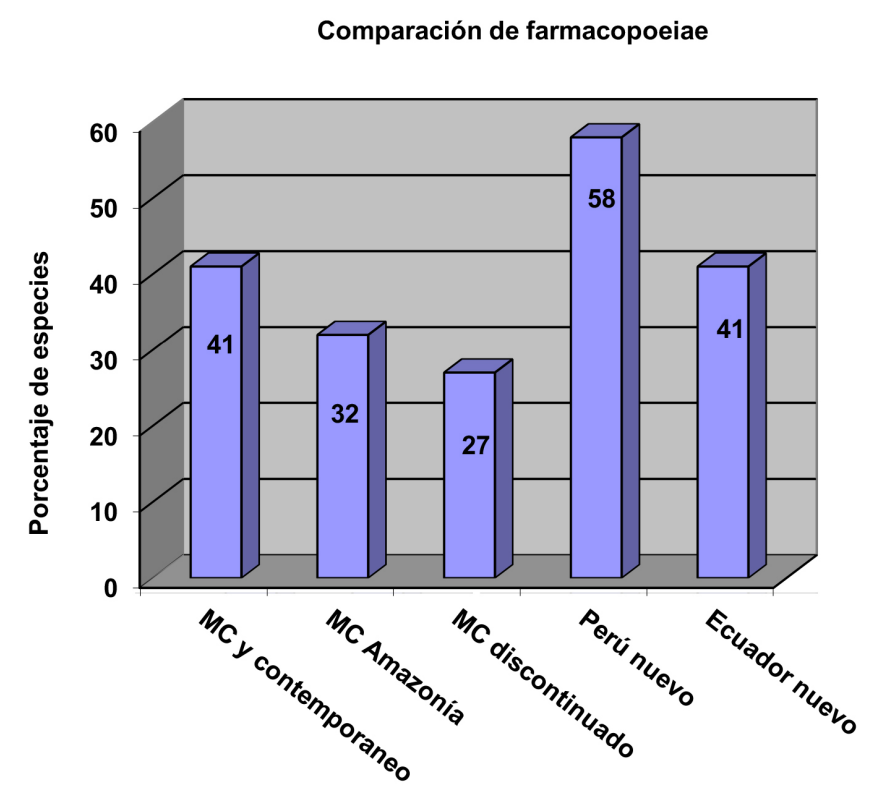

Figurz 8: Las diferencias en el uso de plantas entre Perú y Ecuador. 
Plantas usadas en Perú y Ecuador - Porcentaje

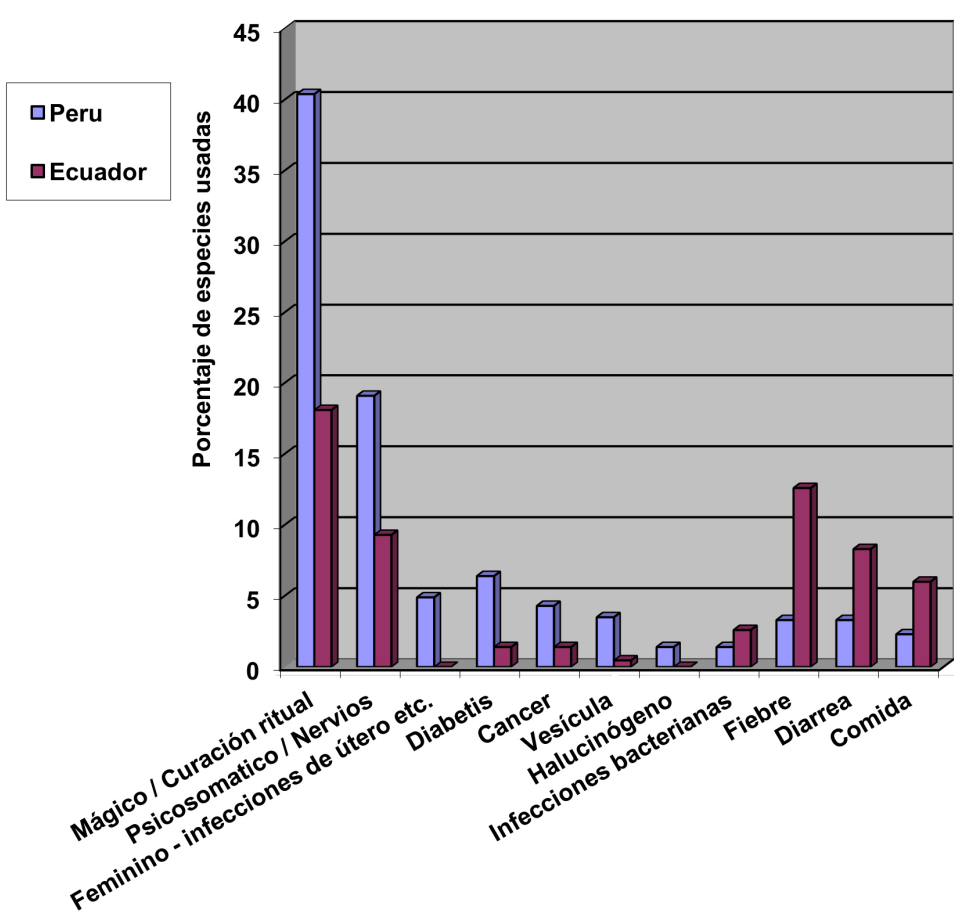

Figura 9: Diferencias de uso de plantas en Ecuador y Perú.

\section{El Caso de Ulluchu}

Ulluchu es el nombre común asignado a una planta que con frecuencia se representa en el arte de la cultura Moche (100-800 d.C.). Se trata de una acanalada fruta en forma de coma con calix grande dibujada en la cerámica Moche (Fig. 10). El termino apareció por primera vez sin explicación linguística en la labor del pionera de la Cultura Moche Rafael Larco Hoyle (1939: Fig. 58; 1940: 98, Figs. 166 y 167). En su publicación de 1939, informó que los pueblos de la sierra y la costa (valles de Moche y Virú) creyeron que la fruta tuvo que ser recogida de manera silenciosa para evitar que amargara. Preguntó si la planta simbolizaba el silencio y la discreción de los mensajeros Moche ricamente ataviados, algunos de los cuales usaban cinturones decorados con Ulluchus. Identificó Ulluchu como Phaseolus sp. (un frijól). Larco reconoció que el Ulluchu no tenía nada en común con "ulluco" (Ullucus tuberosus), tubérculo andino ampliamente cultivado y consumido en Perú en este día.

La importancia simbólica de Ulluchu en la iconografia Moche fue establecido firmemente por Donna McClelland (1977), estudiosa de la Cultura Moche del Museo de História Cultural de la Universidad de California-Los Angeles (UCLA). Basándose en un estudio minucioso de los Archivos de la Cultura Moche en UCLA, demostró que su distribución no fue al azar y que su uso variado mostró patrones bien definidas con la mayor variabilidad en los elementos de fondo y que la representación más frecuente fue encontrada en las correas de los guerreros y los corredores. Ella demostró que "las hojas de la Phaseolus no se parecen a las representaciones de las hojas de ulluchu" (McClelland 1977: 43). Pepino (Solanum muricatum) y ají (Capsicum annum), que están claramente representadas en el arte Moche y no se parecen a Ulluchu también fueron eliminados "dado que la fruta ulluchi (sic.) cuelga de la planta por su lado puntiagudo menor, mientras que estos dos se cuelgan de la parte mayor" (McClelland 1977: 437). Indicó que la planta no se había identificado botánicamente, señalando que, si resultó ser una planta mítica, no sería posible identificarla.

Una década después del artículo original de McClelland, S. Henry Wassen (1987) del Museo Etnográfico de Gotemburgo, eliminó Persea americana Miller var. americana (un pariente silvestre de aguacate) como candidato, y concluyó que el Ulluchu fue Carica candicans A. Gray (una especie de papaya silvestre). Tambien fue co-autor de un artículo que describe la enzima papaina, que puede ser extraida de la papaya verde para usar como anticoagulante en la sangre (Hulten et al. 1987). En el último artículo, los autores proponen que la papaina se utiliza en la ceremonia de sacrificio de los Moches para evitar la coagulación de la sangre sacada de los guerreros sacrificados para su posterior consumo por los sacerdotes.

En un trabajo presentado en la Conferencia Sibley en la Universidad de Texas en Austin, en noviembre de 2003, McClelland (2008)--además de ampliar su trabajo científico de 1977 a la luz de un archivo Moche ampliamente expandido y a la luz de descubrimientos arqueológicos del verdadero Ulluchu—refutó la hipótesis de la papaya. También examinó la presencia en el arte de las semillas de adelfa amarilla (Thevetia peruviana) usadas como sonajas tobilleras, así como semillas espingo (Nectandra sp.), que Wassen (1976) había sugerido anteriormente podían haber sido agregado a la chicha de maíz para fines medicinales y psicotrópicos. McClelland concluyó que el mayor reto para la investigación fue la identificación de Ulluchu.

\section{Cuestiones relacionadas con el nombre Ulluchu}

El nombre Ulluchu parece haber siudo acuñado por Larco (1939). Según su descripción, el nombre se originó en el valle del río Virú, y se supone que es de origen Mochica. Sin embargo no hay evidencia lingüística que tal término existío en el idioma Muchic o Yunga. El más completo diccionario mochica-español disponible, compilado a partir de los estudios de la Cultura Moche realizados por el estudioso E. Brüning (2004), no contiene tal palabra. Además, la población local, así como vendedores del mercado, los coleccionistas de plantas y curanderos entrevistados, no tenían conocimiento absoluto de Ulluchu, excepto los que lo derivaron de Larco. Desde esta primera publicación, el término ha sido copiado por todos los autores siguientes (McClelland 1977, Wassen 1987), sin confirmar su validez. Es poco probable que Brüning (2004) no hubiera descubierto el nombre al realizar su investigación a principios del siglo veinte, si de hecho estaba todavía en uso. Brüning lista bastantes nombres de plantas mochicas, algunas de los cuales todavía están en uso hoy, por ejemplo "faik" = Acacia macracantha (faique, espino), de "fáçek, fáçke" = espino.

La única lengua que tiene palabras similares de que pudiera derivarse Ulluchu es quechua: "uchu" que se traduce a "ají," y "ullu" que se traduce como "pene". El término "ullu uchu" se utiliza a veces como nombre para Columellia ovata R. \& P. (Columelliaceae), una pequeńa planta de la sierra, que se decribe como "un árbol muy grueso y su madera es nuy adecuado para diversos fines, y sus hojas tienen propiedades para la fiebre y son muy amargas" (Ruiz 1777). Sin embargo, esta planta no tiene semejanza alguna con el Ulluchu de Moche. Por lo tanto, debemos concluir que el término Ulluchu fue de alta probabilidad acuñado por Larco (1940: 98), basándose en un 
$1 \mathrm{~cm}$
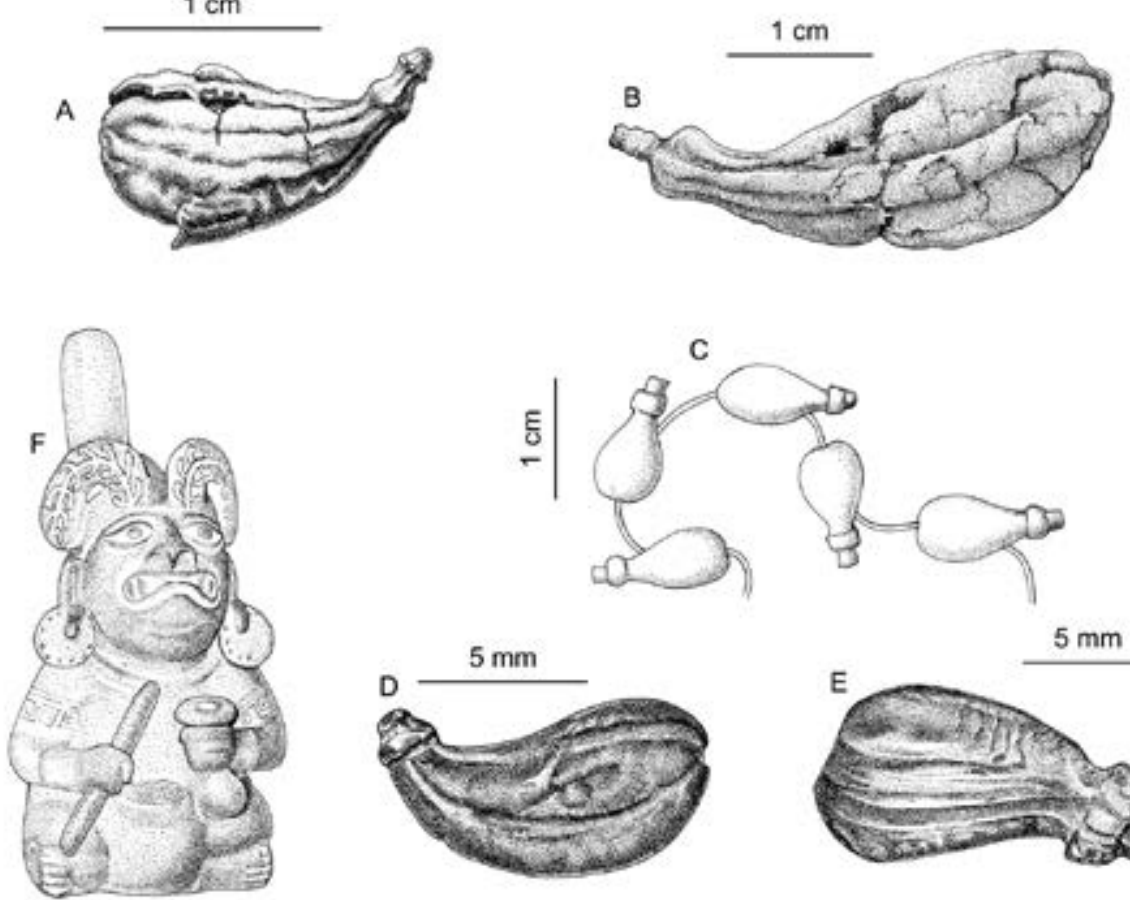

$5 \mathrm{~mm}$
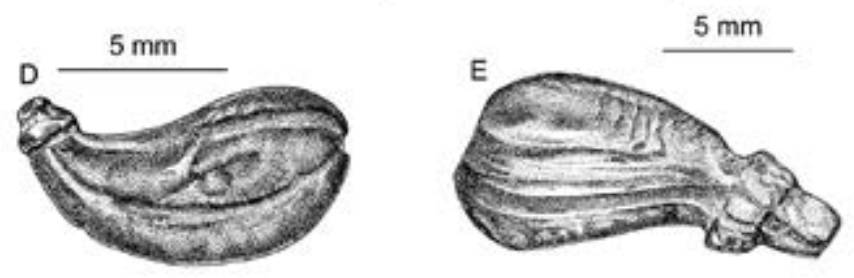

Figura 10: Ulluchu en Arqueología.

A. Fruto de Ulluchu de la tumba de Sipán. Dibujado de fotografía de Christopher B. Donnan. B. Fruto de Ulluchu de entierro de Dos Cabezas. Dibujado de fotografía de Donald McClelland. C. Perlas de hueso en forma de Ulluchu de Huaca de la Luna. Dibujado de fotografía de Donald McClelland. D. Ulluchu hecho de oro. Dibujado de fotografía de Donald McClelland. E. Cáscara de Spondylus tallado en forma de Ulluchu. Dibujado de fotografía de Donald McClelland. F. Figura supernatural asentada, agarrando una calabaza que posiblemente contiene semillas Ulluchu. Ulluchus pintados en el tocado. Colección privada. Dibujado de fotografía de Christopher B. Donnan, de McClelland (2008). G. Corredores halcón anthropomorphizados con Ulluchu en sus cinturones y semillas de Ulluchu flotando por encima. Corredor lleva tubo de inhalación. Instituto de Arte de Chicago. Dibujado de dibujo por Donna McClelland (2008). H. Cosecha de Ulluchu. Nota árbol con hojas opuestas y semillas extraídas en la parte inferior derecha. Dibujado de McClelland (2008), colección privada. término quechua para una especie de fruta algo similar que no tiene ninguna relación con las especies utilizadas por los Moche.

\section{Identificación Botánica - ¿Porqué Ulluchu no es Carica candicans?}

Carica candicans es un pariente silvestre de la papaya (Carica papaya L.). Aunque las frutas no se comercializan, son conocidas ocasionalmente por la población local y algunos vendedores del mercado y curanderos entrevistados sabían de la planta bajo su nombre vernaculár "mito". Larco $(1939 ; 1940)$ nunca menciona la planta en relación con Ulluchu. Asumiendo que de véras se encontró una planta con ese nombre, no podía haber sido $C$. candicans, porque esta especie hubiera tenido el nombre "mito".

McClelland (2004) sostiene que Ulluchu "no puede ser una papaya, que pertenece a un grupo de plantas llamadas 'Cauliflores' (es decir, con flores que provienen del tallo)... Las flores y frutas de un cauliflor crecen en el tronco del árbol y no en las ramas...Sin embargo en los Ulluchus representado en el arte Moche, cuelgan de las extremidades. Las hojas de la papaya no se parecen a las hojas del ulluchu, que son triangulares, ovalados, 'boomerang', o formas que cuelgen de las ramas. Cada una de las grandes hojas palmeadas de la papaya crecen en un tallo de la parte superior del árbol”. Sin embargo, complicando aún más este asunto, resulta que $C$. candicans es una de las pocas papayas que no son caulifloras, que tienen hojas triangulares con margen entero, y los frutos cuelgan de las ramas. Así pues, a juzgar solo por la iconografía, $C$. candicans en realidad podía ser Ulluchu.

Sin embargo, basado en la reciente evidencia arqueológica (Alva et al. 1993, Alva 1994, Donnan et al. 1994, McClelland 2008), ha quedado claro que la fruta que se encuentra en los entierros no se parece a $C$. candicans (Fig.11). Ademas, la explicación de que la papaya pudiera haber sido extraida por los Moche de la papaya verde para ser usado como anticoagulante de la sangre (Hultin et al. 1987), a pesar de ser razonable, no tiene mucho sentido desde una perspectiva de la fitoquimica. La Papaya cultivada ( $C$. papaya) es a menudo representada en la cerámica Moche, y las especies contienen grandes cantidades de papaina. Por qué los Moche hubieran recurrido a una rara especie silvestre cuando podían utilizar un cultivo con las mismas propiedades que creció en sus propias huertas? También, las frutas de $C$. candicans son a menudo de $10 \mathrm{a} 15 \mathrm{~cm}$. de largo y, a pesar de que algunos de los Ulluchus en la iconografía tienen tal tamaño, es mucho más grande que muchas de las frutas representadas y es mucho más grande que las frutas que se encuentran en los entierros. Por último, la anatomía de C. candicans simplemente no correlaciona con las frutas encontradas en los entierros excavados.

\section{Qué es Ulluchu y para qué se usó?}

Los dibujos Moche de Ulluchu normalmente representan las vainas de semillas o semillas flotando en el aire en escenas de sacrificio (McClelland 2008: Fig. 3.14), en relación con los corredores y mensajeros (por ejemplo, McClelland 2008: Fig. 3.1) o sacerdotes intoxicados (por ejemplo, McClelland 2008: Fig. 3.6). Las frutas de Ulluchu varian enormemente en tamańo desde $1-15 \mathrm{~cm}$. Normalmente son en forma de coma, a menudo con "exagerados caliches redondos" (McClelland 2008: 43), con lineas en el cuerpo de la fruta, (por ejemplo, McClelland 2008: Fig. 3.4). Algunas ilustraciones muestran Ulluchu cosechado por monos, y en la mayoría de los casos la fruta se muestra creciendo a lo largo de los ejes de las hojas de la planta (por ejemplo, McClelland 2008: Figs. 3.27 y 3.28). 
En 2002, basándonos en el trabajo de Donna McClelland y las excavaciones arqueológicas de Sipán en el valle de Lambayeque (McClelland 2008; Alva 1994; Alva et al. 1994) y en Dos Cabezas en el valle de Jequetepeque en la década de 1990 (McClelland 2008; Donnan 1994), hemos tratado de proveer una identificación científica para Ulluchu. Botánicamente, todas estas representaciones tienen cápsulas o frutas drupas similares. Se hizo evidente que en un "hot spot" de biodiversidad como Perú con una flora de más de 18000 especies, un gran número de familias de plantas tienen frutas que recuerdan vagamente a dibujos Moche de Ulluchu. Y muchas de estas familias contienen más de un género con frutas similares. Ejemplos incluyen: (Apocynaceae: Ambelania; Caricaceae: Carica; Celastraceae: Maytenus; Chrysobalanaceae: Chrysobalanus, Hirtella, Licania; Convolvulaceae: Dicranostyles; Fabaceae: Aldina, Alexa, Andira, Dipteryx, Dussia, Ormosia; Guttiferae: Tovomita; Hippocrateaceae: Cheiloclinum, Salacia; Icacinaceae: Calatola; Meliaceae: Guarea; Menispermaceae: Abuta, Curarea, Elephantomene, Telitoxicum; Myristicaceae: Virola; Olacaceae: Cathedra; Quinaceae: Lacunaria; Sabiaceae: Meliosma; Sapindaceae: Cupania, Paullinia; y Sapotaceae: Pouteria. Algunas de éstas son todavía muy importantes en las sociedades tradicionales. Por ejemplo, Ambelania se consume con frecuencia. Ormosia contiene compuestos venenosos potentes, pero ahora se utiliza sobre todo en la artesanía. Curarea es un ingrediente de "curare", el famoso veneno de flechas de la Amazonía. Especies de Virola todavía se utilizan como rapé potente en la Amazonía. Finalmente, Paulliniaes el recurso para "yopo", es un estimulante importante. Sin embargo, ninguna de ellas lleva el nombre vernáculo Ulluchu.

Afortunadamente, la evidencia arqueológica ofrece buenas pistas para la identificación botánica. Los Ulluchus encontrados en entierros en la década de 1990 son claramente cápsulas

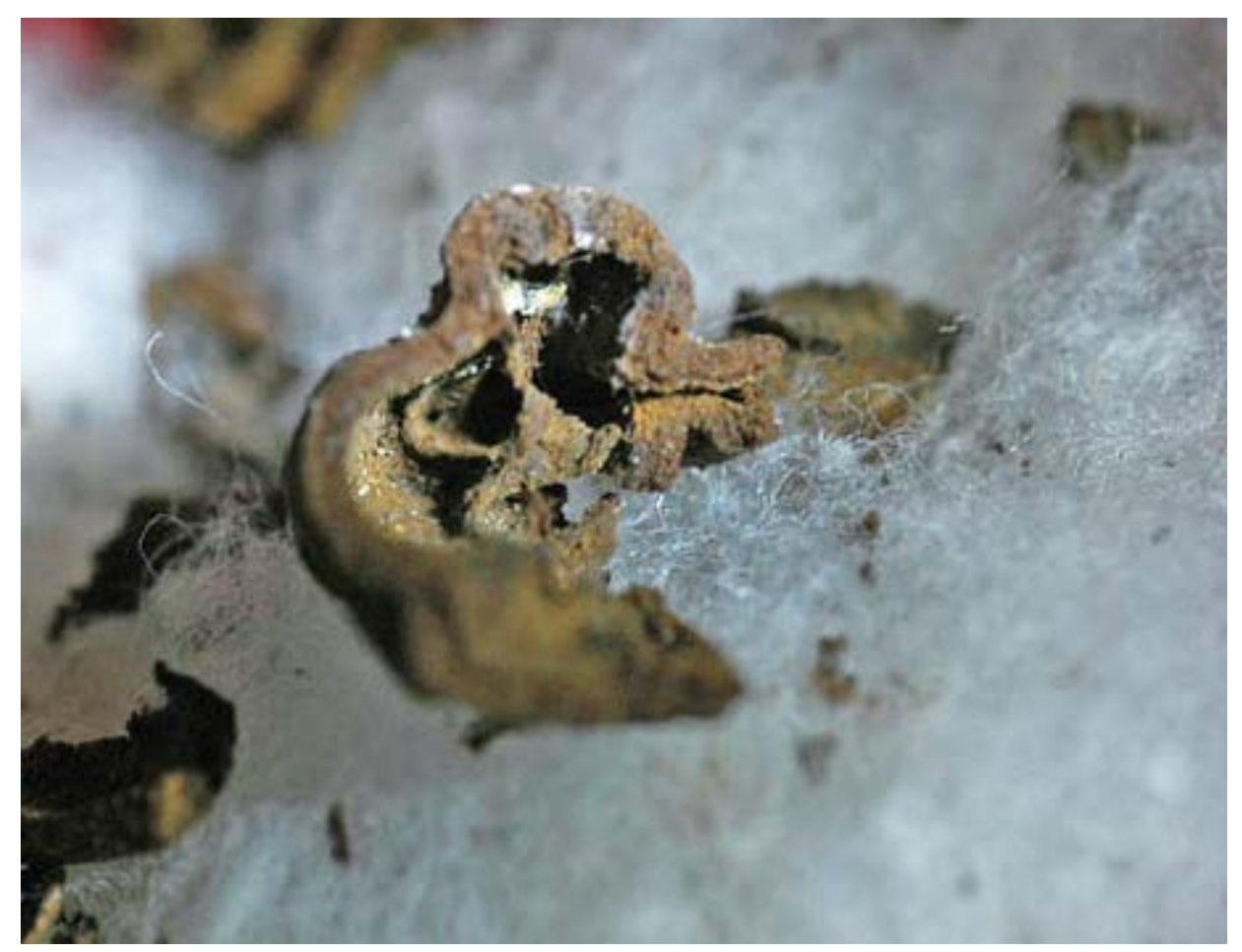

Figura 11: Vista frontal de Ulluchu triturado. Foto: Donald McClelland. o drupas, en forma de coma, entre 1,5 y $5 \mathrm{~cm}$. de largo y ligeramente acanaladas. El tamaño, la forma y la textura de ellos se asemejan a chaquiras de hueso, oro y Spondylus encontradas in situ. En la iconografía, las frutas se representan a menudo ubicadas en ambos lados de ramas dibujadas sobre los tocados de corredores y mensajeros. Es importante tener en cuenta que la persona que lleva el tocado tiene sus fosas nasales ampliamente abiertas, algo que se ve a menudo en las personas que inhalan rapé alucinógeno. McClelland (2008: Fig. 3.18) identifica lo que los mensajeros llevan en la mano como una calabaza de cal utilizada para la masticación de la coca. Sugerimos que también pudiera ser una calabaza utilizada para moler las semillas de Ulluchu al prepararlas para la inhalación. La evidencia iconográfica apoya esta hipótesis. Corredores y mensajeros asociados a menudo con Ulluchu tienen alas y metafóricamente vuelan, es decir, la inhalación de Ulluchu les da alas. Por lo tanto, parece posible que uno de los usos de Ulluchu pudiera haber sido para realizar una alteración de la mente. Otra razón para la identificación de las semillas en la iconografía como Ulluchus alucinógenos es subrayada por una famosa escena de Moche (McClelland 2008: Fig. 3.34), donde monos estan recogiendo las frutas de un árbol Ulluchu. Es importante señalar que el árbol tiene hojas opuestas y semillas que se extraen de la fruta, posiblemente para asar en un horno típico que se ve en la parte inferior derecha del dibujo. Las semillas asadas pudieran haber sido molidas e inhaladas. Las frutas parecen tener cinco válvulas. La función alucinógeno de Ulluchu se ve reforzada por otras imágenes (por ejemplo, McClelland 2008: Fig. 3.6) donde personas rodeadas de frutas de Ulluchu se encuentran caidos sobre la tierra en lo que claramente parece ser un estado intoxicado. Además, los presos en las escenas de sacrificio (por ejemplo, Hocquenghem 2008: Figs. 2.2, 2.3, 2.12 y 2.24). Y las "líneas de presos" en Huaca El Brujo y Huaca de Ia Luna (Fig. 12) muestran reacciones claramente visibles de erección, lo que pudiera ser visto como otro indicio de la ingestión de alguna sustancia que causa este efecto. Desde este punto de vista la palabra Ulluchu de Larco (Larco 1940), de verás es derivado del quechua "ullu-uchu" - "pene-ají". De hecho tiene sentido dada la descripción de los efectos de la planta mencionada. Asimismo, la asociación con la excitación sexual se ve reforzada por escenas míticas-eróticas en las que un Ulluchu surge de la espalda de un personaje masculino teniendo relaciones sexuales con una mujer.

En vista de lo anterior, Ulluchu es un árbol con hojas opuestas y frutas o drupas entre 1 a $15 \mathrm{~cm}$. de largo posiblemente conteniendo psico-activos que elevan la presión arterial y causan erecciones. La única familia de plantas en la lista arriba que tiene representantes que cumplen con todos estos criterios es Meliaceae, y el género Guarea es el que más se acerca a la descripción. Mayormente incluye árboles con hojas pinnadas (lo cual no es usual para Meliaceae) y frutas que tienen de 3 a 5 cápsulas valvuladas, con gran número de semillas pseudo-arillates. El género Guarea se encuentra en todo Perú, pero generalmente se limita a los bosques tropicales de la selva, con algunas especies llegando al bosque nublado. Ninguna especie se encuentra a lo largo de la costa seca de Perú, lo que indica que el material debe haber sido ampliamente comercializado en los tiempos Moche. Un representante típico es Guarea grandifolia DC. (Fig. 13). La especie tiene hojas claramente pinnadas y las frutas muy claramente se asemejan a las muestras arqueológicas. Además Guarea contiene gran número de especies con diferentes tamańos de la fruta $(1-15 \mathrm{~cm}$.), cáliz hinchado y ranurados en el cuerpo de la fruta, lo que correlaciona con la variedad de Ulluchu dibujado por los Moches en su cerámica. Las semillas de las especies Guarea con ombligo blanco son muy similares a las semillas dibujadas en la cerámica Moche.

Muchas especies de Guarea son conocidas por una amplia variedad de nombres vernáculos, como por ejemplo, Guarea spec.: requia, kushimsakish; G. glabra: yecheñor, yechemor; $G$. 
grandifolia: bola requia; G. guidonia: atapio, latapi, latapi caspi, requia colorada, requia latapi, xoro; G. kunthiana: requia, paujil ruro; G. purusana: latapi, requia. La madera de muchas especies se utiliza para la construcción. La madera, corteza y hojas contienen compuestos que actúan como agentes abortivos, eméticos, purgantes y antibacterianas, y la corteza suele ser vendida como Coccilliana en preparados de expectorantes (Kraemer 1915; Rätsch 1998). Las frutas y las semillas contienen una gran variedad de alcaloides que son muy rara vez utilizados debido a su alto nivel de toxicidad (Kraemer 1915). Algunos de los alcaloides encontrados, por ejemplo, rusbyine, tienen una estructura y resultados similares a emetina, un alcaloide encontrado en Psychotria ipecacuana (Brot.) Stokes, que ha sido ampliamente utilizado como emético y expectorante. Otras especies de Psychotria son componentes bien conocidas de los preparativos de la ayahuasca debido a su alto contenido de N, N-DMT (Rätsch 1998). En grandes dosis los preparados de ipecac causan alta presión arterial, arítmias, espasmos y la ampliación de los vasos sanguíneos. Si bien la literatura sobre los compuestos de las semillas de Guarea es bien fragmentaria, parece claro que una dosis concentrada de semillas de Ulluchu aumentaría los latidos del corazón de un prisionero Moche, elevando la presión arterial y abriendo los vasos sanguíneos, provocando así una erección. Todo esto haría mucho más fácil extraer la sangre para el sacrificio. Además, cuando fueron inhalado por sacerdotes, los compuestos activos pudieron haber tenido el efecto de alterar la mente, que no necesáriamente conduce a altos niveles de toxicidad y pudieron haber inducido alucinaciones muy rápidos y a corto plazo.

Concluimos que Ulluchu puede ser identificado entre un grupo de especies del género Guarea (Meliaceae), basado en características morfológicas. Además, la composición química de los compuestos de la planta apoya las tesis que fue utilizada en un contexto de sacrificio para mejorar la extracción de sangre de las víctimas de los sacrificios. También sugerimos que una preparación a base de semillas de Guarea, cuando fue inhalada, pudiera haber sido utilizada como alucinógeno. Sin embargo, se necesita una investigación fitoquímica más detallada para corroborar esta última hipótesis.

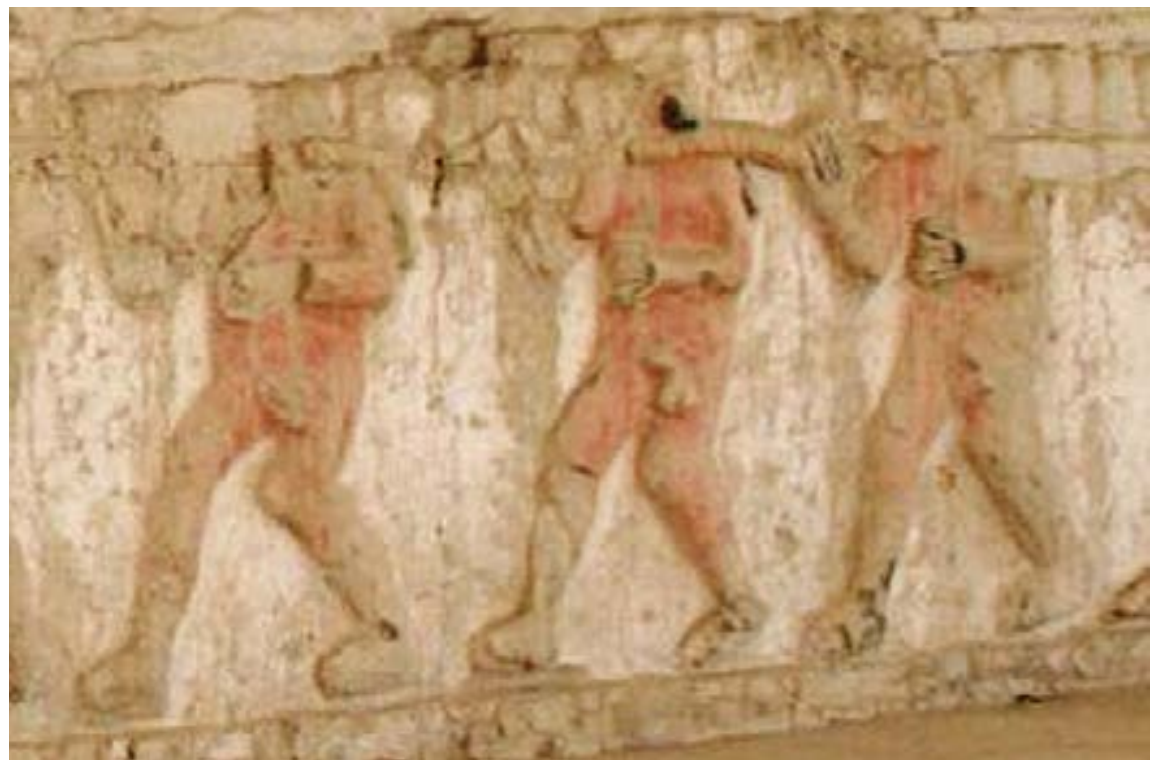

Figura 12: Línea de prisioneros en Huaca El Brujo. Foto: Rainer W. Bussmann.

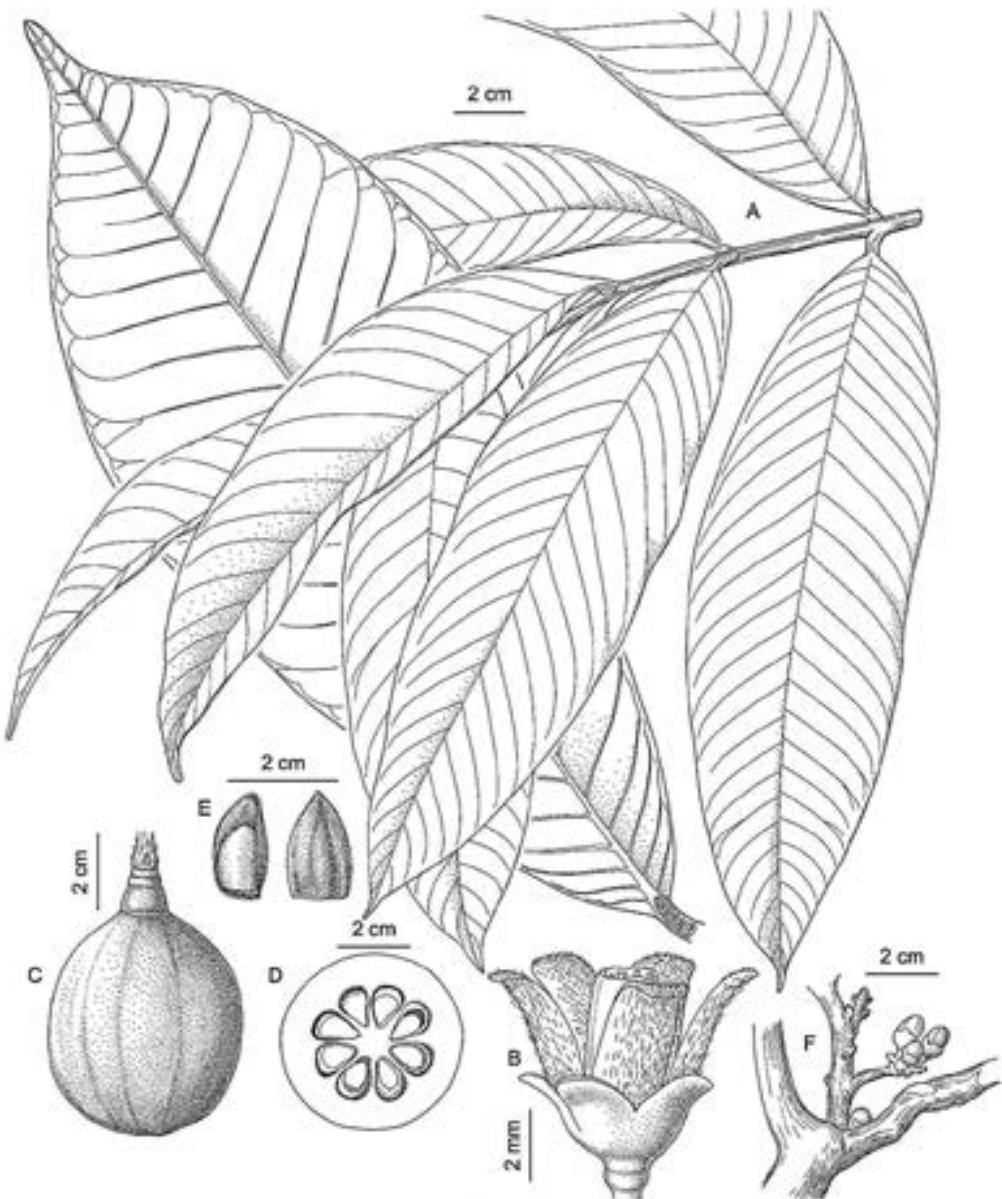

Figura 13: Guarea grandifolia

A. Rama madura, B. Flor, C. Fruto maduro, D. Sección de fruto, E. Seeds, F. Patrón de ramificación

\section{Mercados cambiantes}

Las especies exóticas jugaron un papel importante entre las plantas que se venden en los mercados norperuanos. Cincuenta y nueve especies (15\%) encontradas en todos los mercados eran exóticas. Sin embargo, entre las especies más comúnmente encontradas en los inventarios, 40-50\% eran exóticas. Matricaria recutita (manzanilla) se encontró en el inventario de aproximadamente $70 \%$ de los vendedores. Las siguientes especies más populares vendidas en estos mercados incluyen Equisetum giganteum sp., Phyllanthus urinaria, Phyllanthus stipulatus, Phyllanthus niruri (Chanca Piedra), Eucalyptus globulus (Eucalipto), Piper aduncum, Uncaria tomentosa (Uńa de Gato), Rosmarinus officinalis (Romero), Peumus boldus, Bixa orellana (Achiote) y Buddleja utilis. Sin embargo, cuando se toma en cuenta el volumen de ventas, Croton lechleri (Sangre de Drago), Uncaria tomentosa y Eucalyptus globulus eran claramente las especies más importantes (Bussmann y Sharon 2009c).

Mientras que era muy fácil para todos los proveedores nombrar sus especies más importantes y vendidas con frecuencia, resultó imposible obtener información detallada acerca de las especies que los vendedores consideraron "raros" o "desapareciendo". En la mayoría de los casos, los 
especies fueron mencionadas como raras por vendedores porque ellos mismos no los vendieron, y en tales casos estas plantas eran frecuentemente muy comunes fuera del mercado (por ejemplo, Plantago major) o porque la demanda era tan baja que no tenía sentido tenerlas en sus inventarios. Vendedores pequeños tenían inventarios que representaban las plantas medicinales más comunes disponibles y excluyeron la mayoría de las especies de "brujería" de su farmacopea. Por otro lado, los grandes vendedores bien establecidos fueron especializados en suministros para los curanderos, incluyendo las plantas "mágicas", amuletos, perfumes, etc.

Los inventarios de los cuatro mercados tenían más de 50\% de todas las especies de plantas incluidas en el inventario, pero carecían de muchas de las plantas "generalizadas" vendidas por vendedores más pequeños. El inventorio de puestos grandes se centró casi exclusivamente en las especies "mágicas" que son necesarias para curar enfermedades como el "susto", "mal aire", "daño" (brujería), "envidia" y otras dolencias "mágicas" o psicosomáticas. Al mismo tiempo, los cuatro mercados atendieron a la demanda del turismo esotérico, levando una variedad de plantas no utilizados por los curanderos para satisfacer las demandas turísticas.

\section{La sostenibilidad - ¿Qué cantidad de planta y a qué precio?}

Más de dos tercios de todas las especies que se venden en el norte de Perú proceden de la sierra, es decir, los valles interandinos que son muy usados para la agricultura y el pastoreo. El valor global de las plantas medicinales en estos mercados fue de US \$1,2 millones por año. Esta cifra sólo representa el porcentaje destinado a los vendedores del mercado y no incluye la cantidad usada por curanderos locales. Por lo tanto, las plantas medicinales contribuyen significativamente a la economía local. Este hecho plantea cuestiones de la sostenibilidad de este comercio, sobre todo porque el análisis del mercado no toma en cuenta las ventas informales.

Lo más sorprendente fue el hecho de que siete especies indígenas y tres exóticas, es decir, el $2,5 \%$ de todas las especies comercializadas, representaron más del $40 \%$ del volumen total de ventas. Además, 31 especies nativas representan $50 \%$ de todas las ventas, mientras que sólo 16 plantas introducidas contribuyeron a más de $25 \%$ de todo el material vendido. Esto significa que un poco más del $11 \%$ de todas las plantas en el mercado representan alrededor de $75 \%$ de todas las ventas. Alrededor de un tercio de este volumen de ventas incluye todas las especies exóticas. Ninguno de estos son raras o en peligro de extinción. Sin embargo, la demanda creciente del mercado podría llevar a un aumento de la producción de estas especies exóticas, que a su vez podía tener efectos negativos en la flora local (Bussmann y Sharon 2007b)

Una mirada a las especies indígenas comercializadas destaca amenazas importantes para la conservación. Croton lechleri (Sangre de Drago) y Uncaria tomentosa (Uña de Gato) son inmensamente populares en el ámbito local y cada una contribuye a alrededor de $7 \%$ del valor total de mercado. Ambas especies son también objeto de un amplio comercio internacional. El látex de Croton se cosecha descortezando todo el árbol. Uncaria también se comercializa principalmente como corteza y normalmente toda la planta se destruye. Croton es una especie pionera y, aparte de C. lechleri, algunas otras especies del género están llegando al mercado. Una producción sostenible de este género parece posible, pero este proceso tiene que ser implementado. Sin embargo, la práctica actual no es sostenible ya que la mayoría de Croton es cosechado de recursos forestales. En el caso de la Uńa de Gato, el comercio es tan grande que hace ańos los coleccionistas de esta liana del bosque primario empezaron a quejarse de la escasez (Cabieses 2000). Durante los años de este estudio otras especies de Uncaria, e incluso especies de Acacia, han aparecido en el mercado como "uña de gato" (observación personal). Bajo tales condiciones el comercio de Uncaria claramente no es sostenible.

Algunas de las otras especies "más importantes" son malezas comunes (por ejemplo, Desmodium molliculum) o son parte de poblaciones de gran tamaño (por ejemplo, Equisetum giganteum). Sin embargo, algunas especies son muy vulnerables. Tillandsia cacticola crece en pequeñas áreas de la costa como epífita (Downer 2006). El hábitat, bosque seco y vegetación arbustiva costera, está fuertemente afectada por la urbanización y la agricultura mecanizada, este último agravado por el actual auge de los biocombustibles.

Gentianella alborosea, G. bicolor, G. graminea, Geranium ayavacense y Laccopetalum giganteum representan especies de altitud con una distribución muy limitada. Su colección en gran escala es claramente insostenible y, en el caso de Laccopetalum, coleccionistas indican que la planta es cada vez más difícil de encontrar. El destino de un número de especies con requerimientos similares de hábitat plantea preocupaciones comparables. Las únicas especies cultivadas están por el momento las exóticas y algunas especies autóctonas muy comunes.

Con el fin de determinar si los peruanos tienen una preferencia para las plantas o productos farmacéuticos medicinales y las razones porque, llevamos a cabo tres encuestas en clínicas ubicadas en Trujillo: una clínica privada de estilo occidental convencional (Bussmann, Sharon y López 2007), un consultorio privado de hierbas y "laboratorio" homeopático (Bussmann, Sharon y García 2009), y un centro del seguro social para la medicina complementaria (Fajardo y Sours 2013). Los resultados indican que las principales razones son bastante obvias. Aquellas personas que preferieron el uso de plantas más a menudo lo hicieron porque el uso de las plantas que han estado en uso durante siglos parecía ser una alternativa más segura y más saludable. $\mathrm{Al}$ ser entrevistado, estas personas reconocieron que los productos farmacéuticos se utilizan para enfermedades específicas, pero a menudo tienen efectos secundarios que resultan en impactos negativos en otras partes del cuerpo. Sin embargo, la mayoría de los encuestados coincidieron en que los productos farmacéuticos parecían ser más eficazes que las plantas medicinales, al menos al corto plazo. A pesar de que todavía se utilizaban plantas, tendían a no depender de ellos por completo.

Se registró una gran cantidad de acuerdo para el uso de las recetas de un médico. Mucha gente tenía fé en su médico. Si su médico recomendaba el uso de un determinado medicamento, se cumplieron. Esta fé se basaba en la confianza que la gente tenía en la medicina científica que produce una gran cantidad de investigaciones científicas disponibles al público. Además de la investigación, los encuestados sabían que la medicina tiene efectos notables que se puede obtener con mayor rápidez que las que resultan del uso de las plantas. Remedios vegetales toman más tiempo y son más sutiles en sus efectos. Estas razones fueron dadas por aquellos que utilizan productos farmacéuticos más a menudo. Aunque el número era mínimo, había encuestados que dicieron que utilizaban los dos tipos de medicamentos en las mismas cantidades. Lo interesante fué que la mayoría dijo que usaron los dos juntos. Por ejemplo, los encuestados a menudo dijeron que bebian una taza de té de hierbas mientras que toman píldoras. Aunque la gente sentía que cada tipo de medicamento tiene su papel, la mayoría estuvieron de acuerdo que los productos farmacéuticos proporcionaron la mejor ruta para el tratamiento de muchas enfermedades biomédicas. Un dato interesante que surgió de nuestro estudio de la medicina complementaria es que las estadísticas anuales del gobierno para sus 26 clínicas miden "la reducción o eliminación de productos farmacéuticos" como uno de sus puntos de referencia de los resultados terapéuticos éxitosos. 
A pesar de la confianza pública en la medicina moderna, la Medicina Tradicional en Perú está experimentando un aumento de la demanda indicado por el hecho de que el número de vendedores de hierbas, sobre todo en las periferias de los mercados principales, se ha incrementado en los últimos años. Además, una gran variedad de plantas medicinales del norte de Perú se puede encontrar en los supermercados urbanos y también en el mercado global. Por el lado positivo esta tendencia podía ayudar a mantener las prácticas tradicionales y dar los conocimientos tradicionales el respeto que merecen. Pero por el lado negativo podía plantear una amenaza grave según lo indicado por los signos de sobre-explotación de especies importantes.

Hoy día la amenaza más seria a esta tradición milenaria es la destrucción de hábitats de plantas medicinales. La expansión urbana y la agro-industria ya han cambiado en gran medida las llanuras costeras alrededor de Trujillo y Chiclayo. El cambio climático y la deforestación amenazan los sistemas forestales de montaña que son el origen de muchas especies medicinales. Además, los ecosistemas alto-andinos y lagunas sagradas donde se encuentran muchas especies medicinales están en peligro de ser destruidos por las actividades mineras en gran escala (Downer 2007, Zamora 2007). Para contrarrestar estas influencias, es necesario un extenso trabajo con los curanderos para documentar el conocimiento local con el fin de aplicar los resultados en el desarrollo de material vegetal procedente de fuentes sostenibles y científicamente identificadas para los mercados locales. Afortunadamente, se está persiguiendo este tipo de trabajo actualmente (Fig. 14). Los conocimientos tradicionales también están siendo repatriados en forma bilingüe (Fig. 15).

Por lo general, los encuestados en las tres encuestas utilizaron hierbas medicinales con más frecuencia que los medicamentos farmacéuticos, pero sólo en un pequeńo grado. Asumieron que las plantas fueron más saludables y más seguras para utilizar porque fueron naturales y creyeron que no tienen ningún efecto secundario. Fue difícil determinar a partir de estos estudios si el conocimiento de la utilización de plantas medicinales estaba creciendo o disminuyendo. Sin embargo, nuestros estudios indicaron que los encuestados creían que la última generación sabía más que el presente. No obstante, la mayor parte de la generación actual no enseńaba a sus hijos sobre el uso de plantas medicinales. Nuestros estudios también mostraron qué plantas medicinales los encuestados utilizaron y para qué fines. Del mismo modo, el conocimiento de plantas de los pacientes en las tres clínicas fue en gran medida idéntico, con un solapamiento de especies comunes, en su mayoría introducidas. Esto indica que los conocimientos de la Medicina Tradicional forman una parte importante de la cultura local que se mantiene mientras que el pueblo también está adoptando los beneficios de la medicina occidental.

Sin embargo, esta situación conduce a profundos desafíos cuando se trata de la seguridad de las plantas empleadas, en particular para aplicaciones que requieren uso a largo plazo. Bussmann et al. (2013) encontraron que varias especies se venden a menudo con los mismos nombres comunes. Algunas de las diferentes especies frescas eran fácilmente identificables botánicamente, pero ni los colectores ni los proveedores hacen una distinción directa entre especies (Fig. 16). Para complicar las cosas aún más, el material se vende a menudo en forma de polvo fino o en extractos líquidos, lo que hace imposible la identificación morfológica de la especie en el mercado y en gran medida aumentando el riesgo para el comprador. La mejor manera de asegurar la identificación correcta sería códigos de barras de ADN. Sin embargo, la infraestructura técnica necesaria no está disponible localmente. El uso de códigos de barras de ADN como una herramienta de control de calidad para comprobar la composición de especies de las muestras a gran escala requerirá una cuidadosa toma de muestras de cada lote de material vegetal que se vende en el mercado. La volatilidad de los mercados hace esta tarea logística imposible. A menudo las

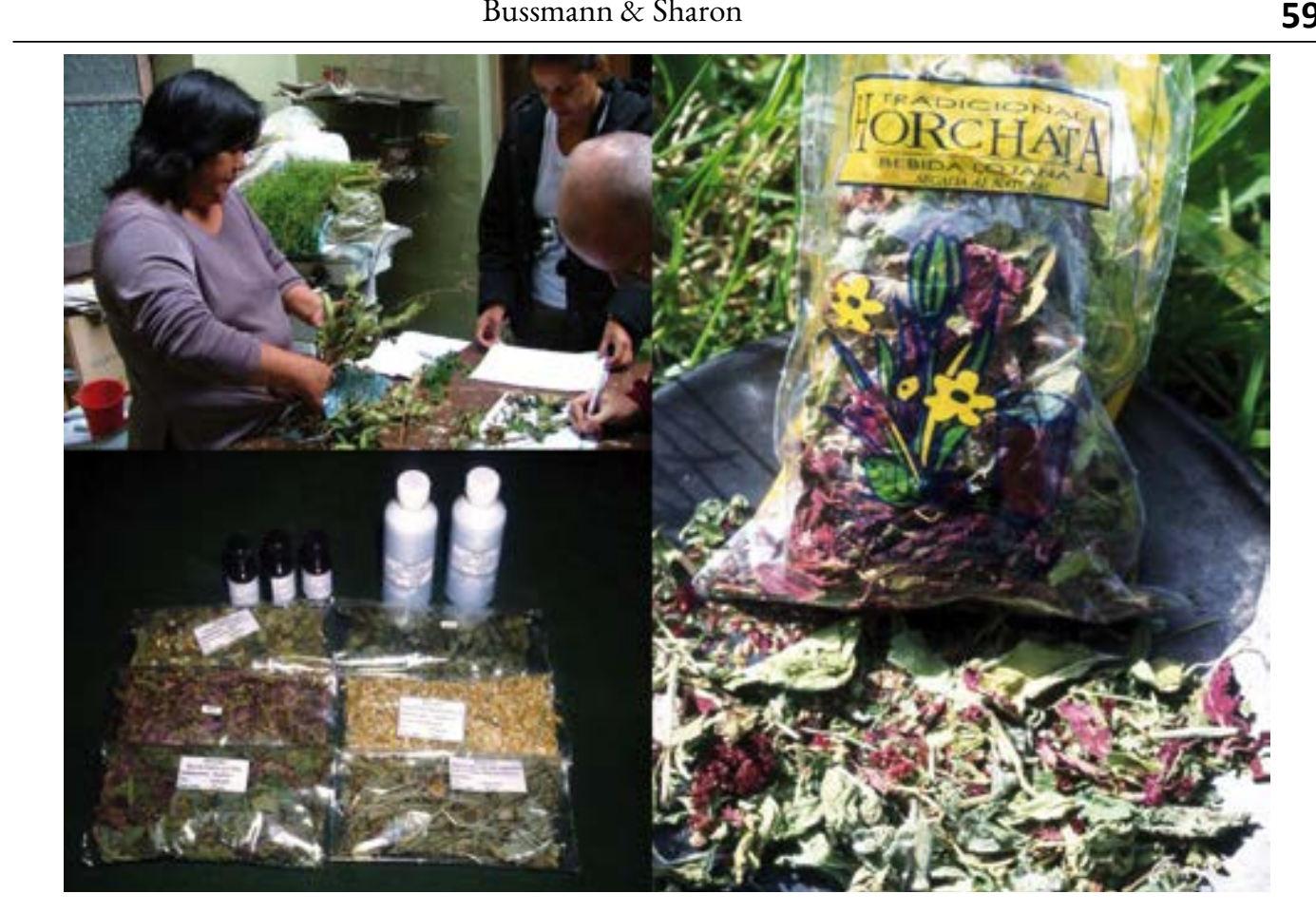

Figura 14:: El uso sostenible de plantas desde la documentación de la planta con los curanderos locales, hasta la producción de paquetes de hierbas a granel correctamente identificados y tés para los mercados locales.

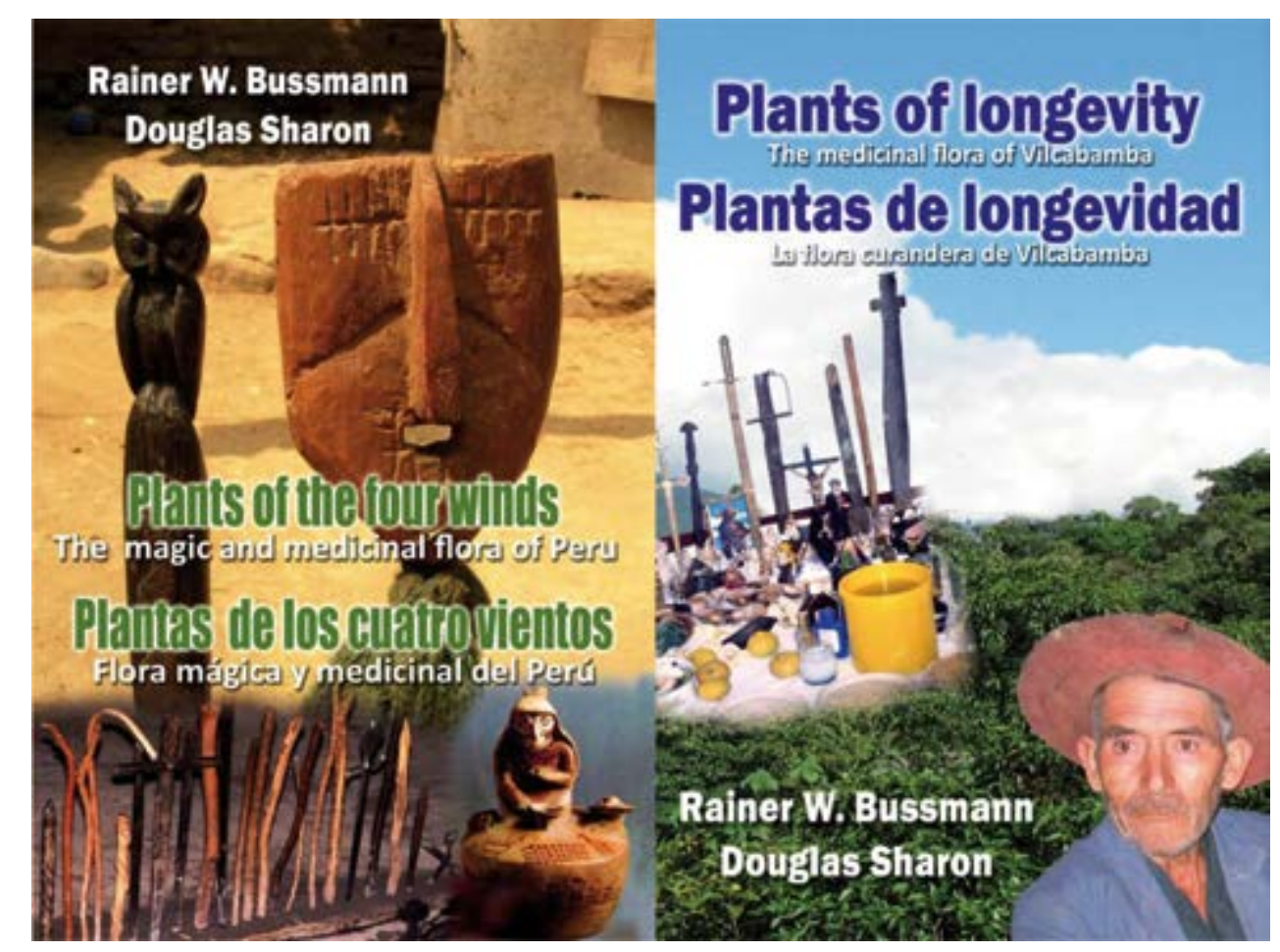

Figura 15: Difusión de los conocimientos tradicionales en los libros bilingües. 
mismas o estrechamente relacionadas especies mencionadas en la literatura venden bajo una amplia variedad de nombres comunes. Por lo tanto, una de las especies podía ser vendida como "Hercampuri" en un puesto del mercado mientras que se vende con un nombre diferente en un puesto vecino. Como era de esperar, no hay coherencia en la dosificación de las plantas utilizadas; ni los vendedores tienen una idea de posibles efectos secundarios.

En el curso de una evaluación de la modalidad de tratamiento de fito-terapia del Centro de Atención de Medicina Complementaria-Es Salud (CAMEC) en Trujillo (Gaucksheim, Narváez, Pons y Sharon 2013) encontramos una innovación importante en materia de control de calidad. Una parte integral de la prescripción de las plantas medicinales en la "farmacia natural" del Centro es un conjunto de cinco normas de control de calidad que se requieren de sus proveedores, incluyendo la identificación botánica de las especies, análisis microbiológico, la certificación de la falta de contaminación metálico, requisitos de embalaje sanitárias y documentación del valor cultural.

Nuestros estudios indican que el uso de las plantas en el norte de Perú, aunque basado en una tradición milenaria, ha cambiado considerablemente, sobre todo en las últimas décadas. Incluso en los casos de especies de plantas utilizadas para aplicaciones muy claramente circunscritos, los pacientes corren un riesgo considerable al comprar sus remedios en los mercados locales y los posibles efectos secundarios pueden ser graves. Se necesita más regulación y la identificación rigurosa del material que se vende en los mercados públicos y en la cadena de suministro global a través de las ventas por Internet para superar estas dificultades. En este sentido, el modelo de control de calidad requerido para la modalidad de tratamiento de fitoterápia de EsSalud es un paso adelante muy positivo.

\section{Semillas Sagradas, el Protocolo de Nagoya y la Repatriación de los Conocimientos Tradicionales}

Semillas Sagradas es uno de los programas de la William L. Brown Center (WLBC) en el Jardín Botánico de Missouri (MOBOT). Formando un modelo global de desarrollo sostenible a través de programas de investigación botánica, Semillas Sagradas trabaja en estrecha colaboración con las comunidades en los países afiliadas para promover el éxito a largo plazo en la búsqueda de soluciones prácticas a los problemas de conservación (Fig. 17). El programa tiene como objetivo establecer las colecciones in situ de las especies de plantas de importancia local utilizados en la Medicina Tradicional como alimentos y herramientas terapeúticas. Centros participantes reciben orientación, retroalimentación y asesoramiento del equipo WLBC, vinculando experiencias en la botánica, la antropología, la curación y la conservación tradicional con la experiencia colectiva de todos los centros de Semillas Sagradas. Semillas Sagradas también facilita la formación de almacenes de semillas, con la posibilidad de desarrollar relaciónes con grandes instalaciones de almacenamiento, capacitación en taxonomía vegetal y asistencia editorial para la creación de literatura educativa y científicamente válida además de la creación de un "Libro de Semillas Sagradas" en el idioma local para cada jardín con distribución en todo el mundo (Fig. 18). El programa Semillas Sagradas actualmente cuenta con casi 40 jardines principales, con una red de cerca de 1500 jardínes participantes.

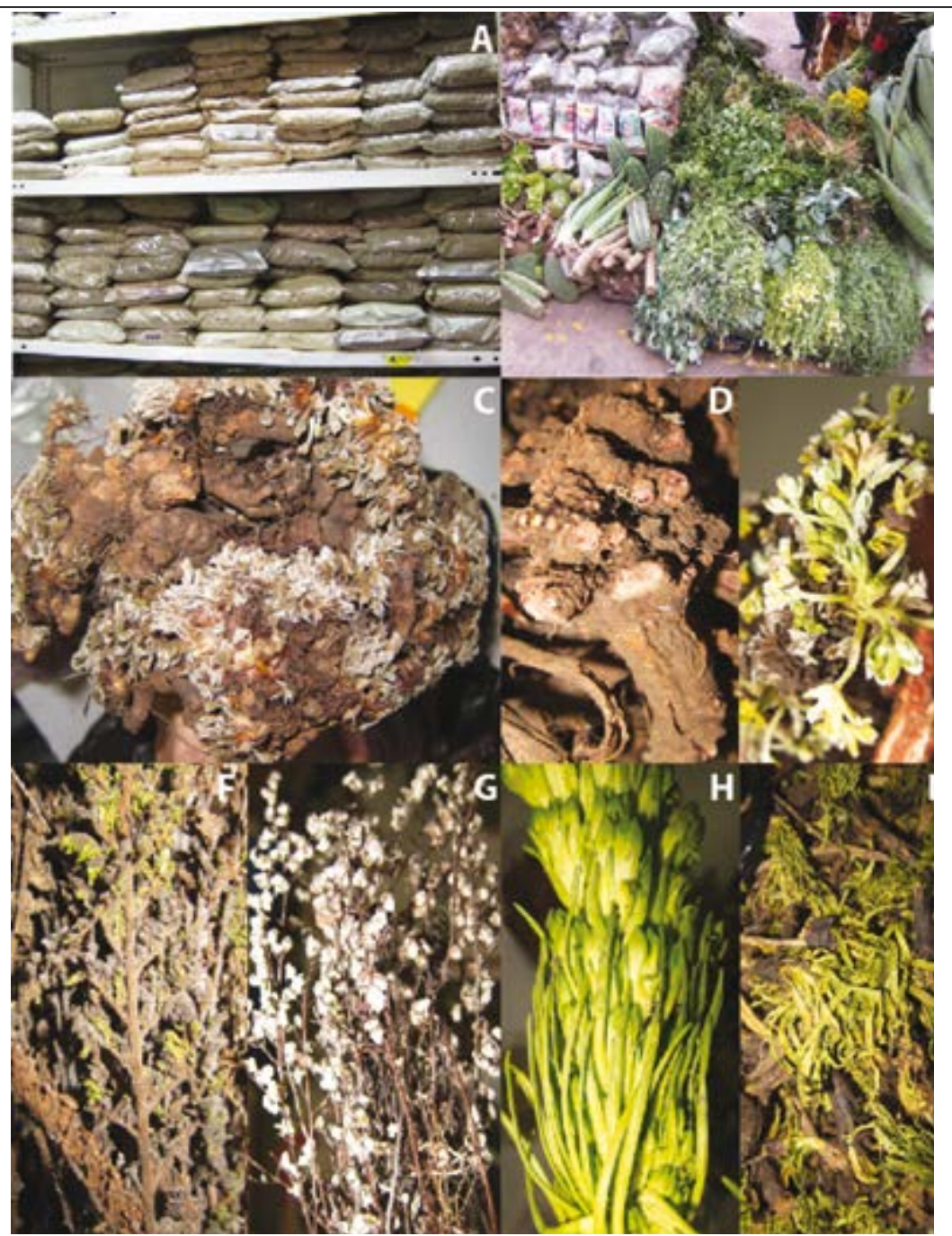

Figura 16: Presentación de plantas medicinales en el Mercado Aviación Lima. A. material molido y empaquetado, B. presentación tradicional, C y E. Geranio sessiliflorum, fragmento D. Geranium no identificado, F. Cheilanthes bonariensis, G. Argyrochosma nivea, H. Gentianella thyrsoidea, I. Gentianella nitida.

\section{Protocolo de Nagoya y la Repatriación de los Conocimientos}

Tradicionales

La aprobación definitiva del Protocolo de Nagoya sobre acceso a los recursos genéticos y participación justa y equitativa en los beneficios que se deriven de la utilización de la Convención sobre la Diversidad Biológica (CDB) ha proveído un gran impulso para los derechos de las comunidades indígenas y locales.

El principal objetivo del protocolo es "la participación justa y equitativa en los beneficios derivados de la utilización de los recursos genéticos, incluyendo un acceso adecuado a esos recursos y una transferencia apropiada de las tecnologías pertinentes, teniendo en cuenta todos los derechos sobre esos recursos y a esas tecnologias y, mediante una financiación apropiada, contribuyendo asi a la conservación de la diversidad biológica y la utilización sostenible de sus componentes. Un requisito 
importante es que "se accede a los conocimientos tradicionales asociados a los recursos genéticos que están en manos de las comunidades indígenas y locales con el consentimiento previo e consentimiento informado o aprobación y con la participación de estas comunidades indígenas y locales bajo condiciones mutuamente acordadas que se han establecido".

Este último requisito es de gran importancia. Afortunadamente, el establecimiento de consentimiento previo e informado ya ha sido ampliamente aplicado por la mayoría de las principales instituciones científicas. Sin embargo, todavía hay proyectos que ponen un énfasis limitado en los permisos y el consentimiento, ya que el proceso es a menudo largo y tedioso. Bajo el Protocolo de Nagoya consentimiento previo y la provisión de beneficios a los titulares de los conocimientos ya no es sólo una buena ética, es también un derecho internacional. Es de esperar que las principales agencias de financiamiento, ya sea privada o gubernamental, pronto harán prueba del consentimiento previo e informado un requerimiento para su financiación.

El concepto que los "beneficios" podían ser el resultado de la documentación de los conocimientos tradicionales es algo nuevo para muchos colegas. En la ciencia globalizada, donde los datos se circulan con facilidad, es justo asegurarse de que los conocimientos que nuestros homólogos comparten con nosotros no son apropiados por partes no involucradas en los estudios originales, ya sea para fines científicos o comerciales. En la práctica, esto significa que el establecimiento de consentimiento previo e informado, válida en virtud del Protocolo de Nagoya, debe incluir una declaración explícita en el sentido de que "cualquier trabajo realizado en una comunidad se lleva a cabo en virtud del Protocolo de Nagoya sobre acceso a los recursos genéticos y participación justa y equitativa en los beneficios derivados de su utilización, y que el derecho del uso y la autoría de cualquier conocimiento tradicional por todos los informantes se mantiene, asi como cualquier uso de la información obtenida y la publicación científica requiere el consentimiento previo adicional de los propietarios tradicionales, asi como un consenso sobre el acceso a los beneficios derivados de su uso posterior".

Desde nuestra perspectiva en el William L. Brown Center del Missouri Botanical Garden, el Protocolo de Nagoya se aplica de inmediato. No sólo abarca la investigación futura, pero los datos anteriores obtenidos por nuestra institución, a menos que exista un acuerdo diferente con los propietarios originales.

Participación en los beneficios en este contexto debe también incluir no solamente la repatriación de los nuevos datos reunidos, en un lenguaje y forma accesible a los propietarios tradicionales, sino también la traducción y la repatriación de los resultados de estudios anteriores realizados en la misma comunidad indígena o local - si esto no se ha hecho los investigadores originales. Además, si así lo desean, a los informantes se les debe permitir la plena participación como autores en todas las publicaciones de un estudio, en lugar de ser simplemente mencionados en los agradecimientos como una actividad secundaria

En este sentido WLBC ha editado una serie de libros escritos por los miembros de las comunidades locales como parte de la repatriación de los conocimientos sobre el uso de las plantas a los titulares de los conocimientos originales, publicados en los idiomas locales y en formatos que piden las comunidades. Éstos se dan a todos los miembros de la comunidad que participan, así como las escuelas locales. La primera reacción de la mayoría de las comunidades cuando se les presenta los resultados de una investigación de este tipo de colaboración es el asombro que los investigadores volvieron y de hecho trajeron material útil publicada en el idioma local. Este es normalmente seguido por una gran satisfacción por parte de los participantes a ser autores del material (Fig. 19). Todas las publicaciones reconocen la propiedad intelectual

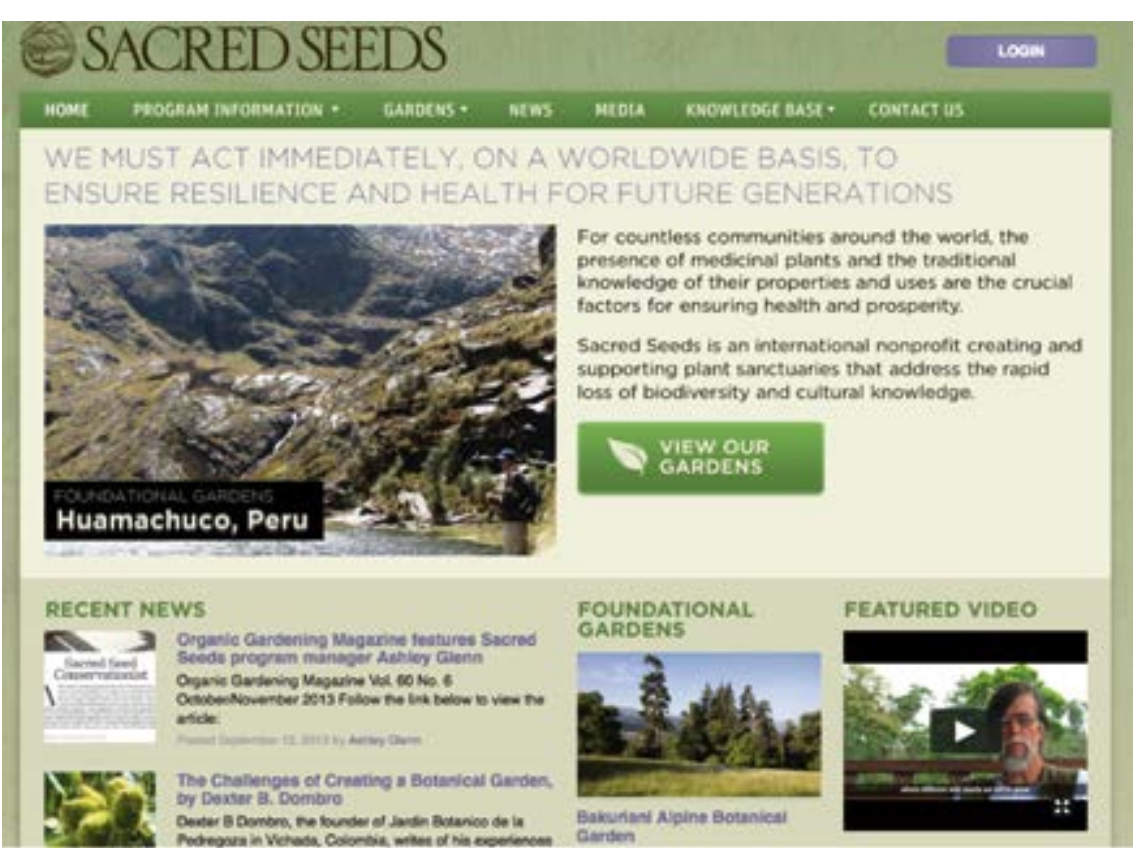

Figura 17: Página web de la Red de Jardínes Etnobotánicos Semillas Sagradas.

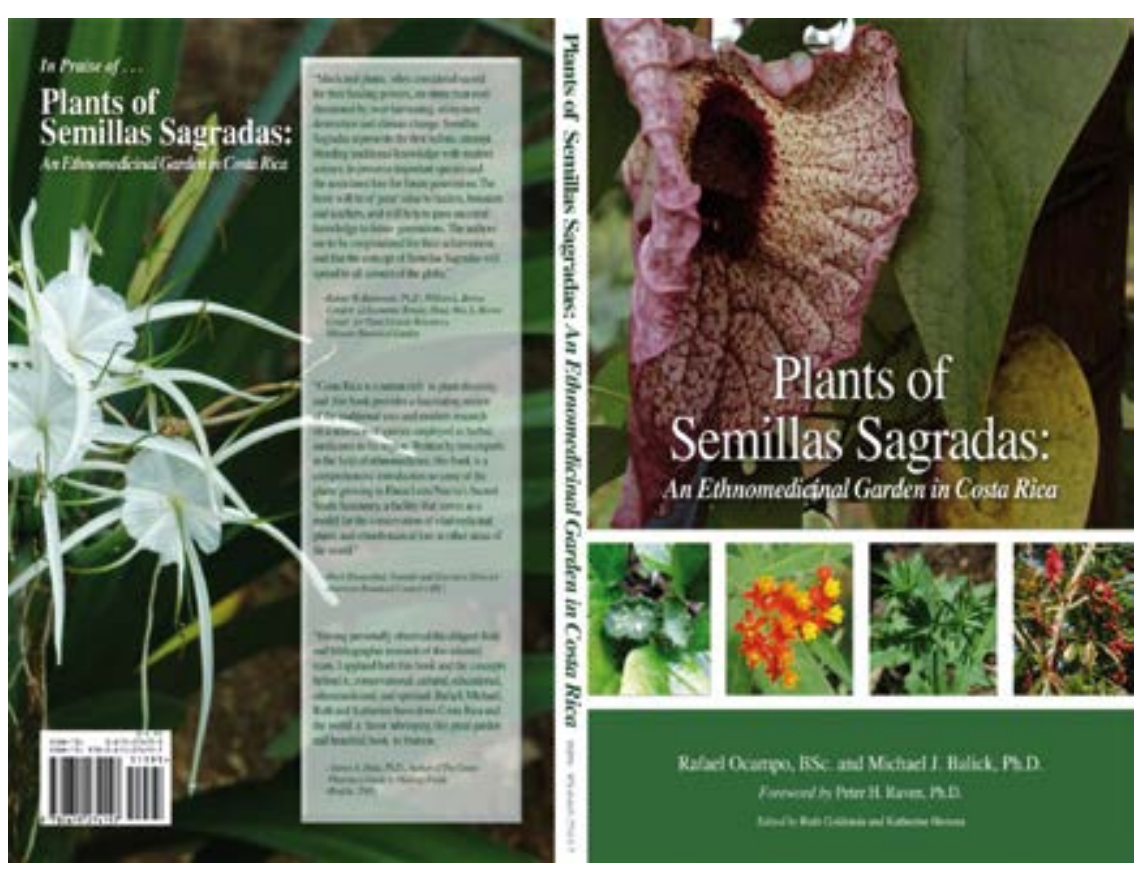

Figura 18: Guía de Jardínes Semillas Sagradas 
de la comunidad local dentro del marco del Protocolo de Nagoya (Fig. 20), así como la autoría de los colaboradores locales (Fig. 21). En el caso de las publicaciones sobre el uso de palmas, el WLBC desarrolló, en colaboración con las comunidades, símbolos para las categorías de usos y las partes usadas de las plantas fáciles de entender (Fig. 21). Los libros incluyen descripciones gráficas de partes de la planta (Fig. 23), con ejemplos en color de diferentes fases de crecimiento de hojas y frutas (Figs. 24 y 25), seguido por descripciónes detalladas e ilustradas de las especies individuales (Fig. 26) y de los usos (Fig. 27). Además de estos proyectos, WLBC se esfuerza por traducir los estudios publicados anteriores sobre los conocimientos tradicionales, haciéndolos disponibles para el beneficio de las comunidades que participaron en la investigación original. Un buen ejemplo es Bussmann y Paniagua Zambrana (2011), "La etnobotánica de los Chacobo: Traduccion de Ethnobotany of the Chacobo Indians, Beni, Bolivia" de B. Boom (Fig. 28).

\section{Un Programa Global de Conservación de las Plantas Útiles y los Conocimientos Tradicionales: Una Llamada a la Acción}

Entre el 1-2 de mayo del 2013, un grupo de expertos internacionales en el estudio de las plantas utilizadas por la humanidad se reunieron en St. Louis, Missouri para considerar como abordar una crisis mundial contemporánea: la pérdida de decenas de miles de especies de plantas. Estas plantas amenazadas incluyen especies vitales para la vida de la gente de todo el mundo y incluyen las plantas utilizadas para la alimentación, para la medicina, para fines culturales y espirituales y las que permiten generar medios de vida para que son necesarios para reducir la pobreza, garantizar la seguridad alimentaria y de esta manera apoyar una gestión sostenible en el desarrollo de muchos países. Las plantas y su conocimiento biocultural asociado, desempeñan un papel esencial al servicio de los ecosistemas que sustentan la vida en la Tierra.

Esta afirmación no sólo es una llamada a la comunidad internacional para hacer frente a la trágica pérdida de la diversidad vegetal de nuestro planeta, sino una llamada para el desarrollo de un esfuerzo común y coordinado a nivel mundial para hacer frente a la pérdida de los conocimientos esenciales sobre las plantas y sus usos, particularmente a nivel de las comunidades locales.

La reunión se centró específicamente en los objetivos de la Estrátegia Global para la Conservación Vegetal (GSPC), una iniciativa adoptada por la Convención sobre la Diversidad Biológica (CDB) de las Naciones Unidas de 2002 actualizada en el 2010, así como en los objetivos del GSPC relacionados al mantenimiento y conservación de plantas útiles y con significación cultural. Los participantes llegaron a la conclusión de que existe la inminente necesidad de hacer frente a la vital importancia de los conocimientos tradicionales de las plantas, su utilidad, manejo y conservación. Estos conocimientos únicos, antiguos y detallados son frecuentemente conservados y mantenidos por las comunidades locales e indígenas del mundo.

Los participantes del taller exhortaron la elaboración de un programa mundial para la conservación de las plantas útiles y los conocimientos asociado a ellas, tomando en cuenta la necesidad de:

- Instar a la comunidad internacional y a los gobiernos locales el reconocimiento de la importancia de la diversidad de las plantas silvestres y cultivadas, así como los conocimientos asociados a sus usos como recursos vitales actuales y futuros. Esto debe llevarse a cabo a través de la implementación exitosa de los objetivos y metas del GSPC en 2020.

- Destacar la necesidad de un esfuerzo internacional concertado para establecer un catálogo

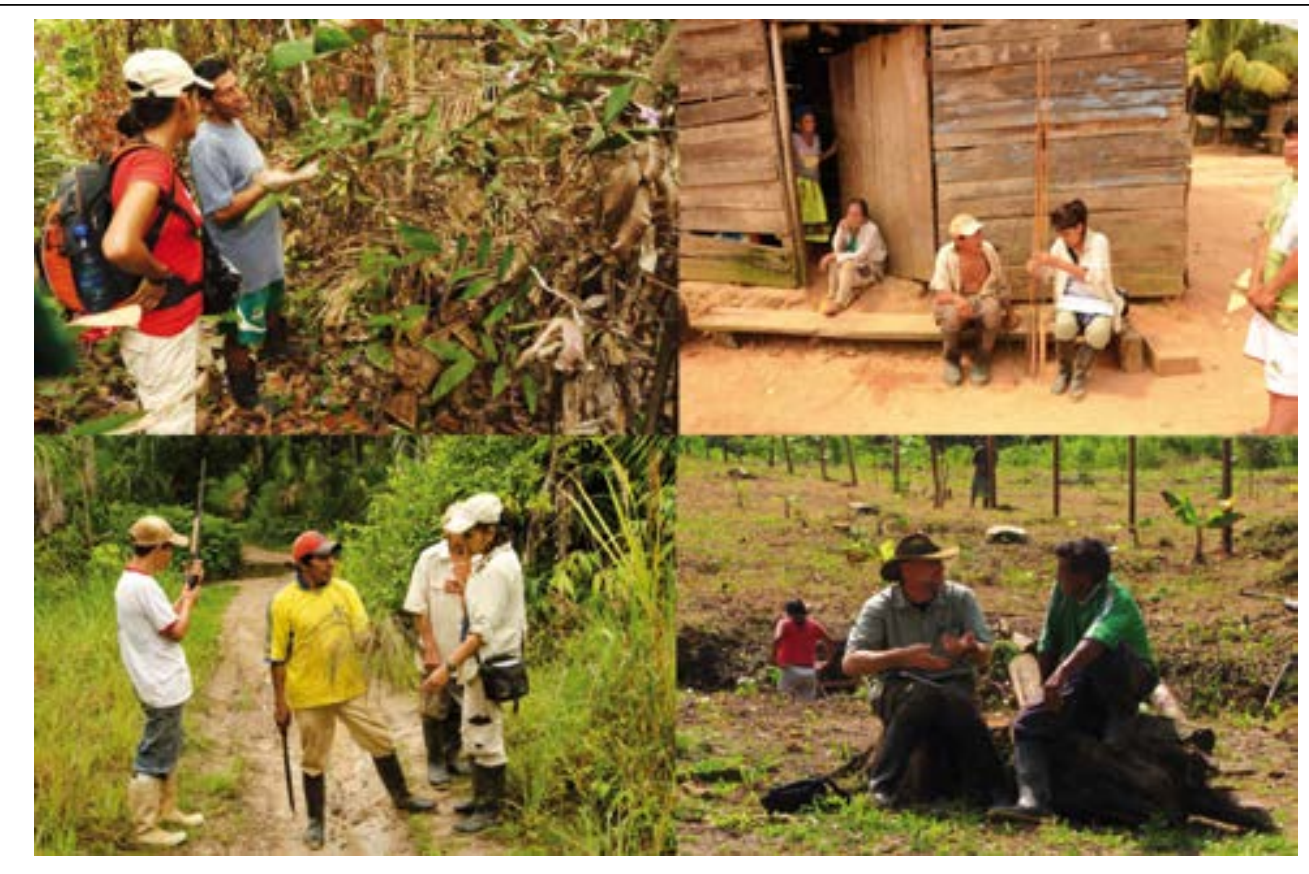

Figura 19: La repatriación de los conocimientos - Presentación de libros de palma a las comunidades locales.

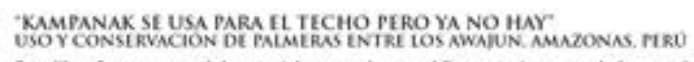

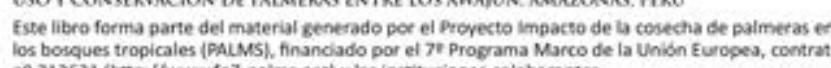

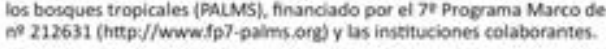

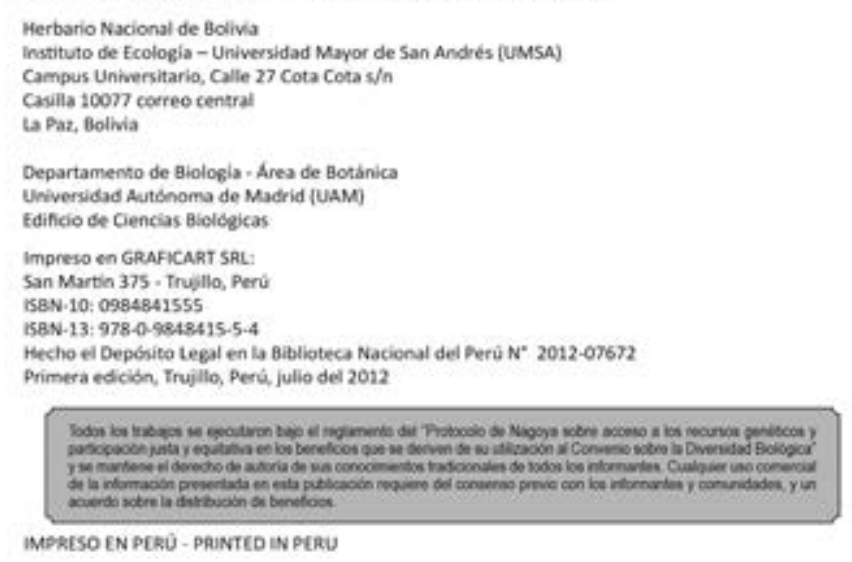

Figura 20: Página del libro reconociendo la propiedad intelectual local y el Protocolo de Nagoya. 


\section{AUTORES POR COMUNIDAD}

\begin{tabular}{|c|c|c|}
\hline Adela Shanocua & Florentino Montesinos & Maris kisela \\
\hline Aide Chetu & German Biaja & 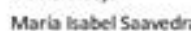 \\
\hline Alejandro Mohahe & German Biaeja & Marba Naj \\
\hline Aforsa Sethua & Glotia Salvedra & Markruz Shanoce \\
\hline Affredo Biacis & Graciela Huchehua & Mateo Bizeja \\
\hline Ailda Sasvedra & Gregorio Mejia & Melchor Vurinehew \\
\hline Alina Shoe & Hetor loshi & Mercedes Shasocur \\
\hline Ana Elinei: & Menry Postho & Mercedes Shethua \\
\hline Asunta 2apsata & Iness Meshi & Midio Huare \\
\hline Bento Huane & Asunta Bigeja & Miguel Dominguez \\
\hline Betrt Bizeja & Jescis Meniti & Nina Saspodra \\
\hline Cartitos Tirina & Jesusa Hudomels & Pastora Husqubeline \\
\hline Corritos Tirina & Jordsn Kioshi & Pilar Vildivia \\
\hline Carmen Machuquia & Jorge Shanoqua & Pio Meshi \\
\hline Cecilio Yoraje & Jose Gangora & Raü Meshi \\
\hline Celestina Hejasha & Jose Liaqui & Ricando Yovaje \\
\hline Zenón Yohuthe & Geovars Che ta & Roger Matio \\
\hline Clementino Meshi & Juan Shanooua & Rosa Paketaroj \\
\hline Dali Tipuna & Juanita Ekinei & Rosario Soria \\
\hline Dorida Porho & Julia Huane & Rosy Vasteno \\
\hline Doris Elinei & Lidia Meshi & Rudi setus \\
\hline Elida Hudenda & Lidia Stretua & Runh Tilihus \\
\hline Elisa Huajohuzho & Lorenzo Shoe & Sara Sayveda \\
\hline Eliseo Meshi & Lucio Yohathe & Segundo Savivedra \\
\hline Eliser Biaja & Luis Biaeja & Teoflla Samedra \\
\hline Elvira Sazvedra & turmas Shanokua & Verornica Beshov \\
\hline Esperanza Heyahijia & Marcela Biaeja & Victoria Meshil \\
\hline Exilda Shanoqua & Marcial Saria & Waitter Areas \\
\hline Felipe Vauhehua & Mardilina Biaja & Wilma Huabojehua \\
\hline Felix Huali & Margerita Meshi & Paira Shethes \\
\hline
\end{tabular}

Figura 21: Autores de la comunidad

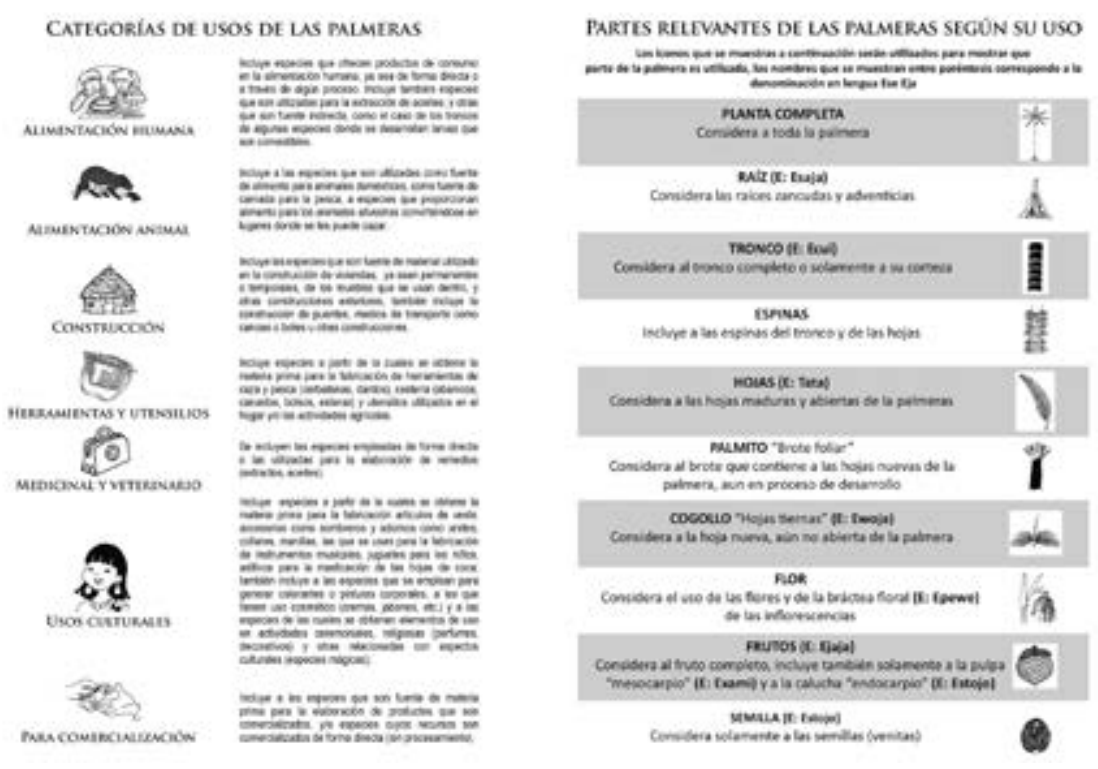

Figura 22: Símbolos para explicar los usos de plantas y partes de plantas desarrolladas en cooperación con las comunidades locales.
CONCEPTOS PREVIOS

LA ESTRUCTURA DE LAS PALMERAS

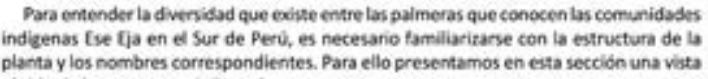

(a)

ripida de la estructura de las paimeras

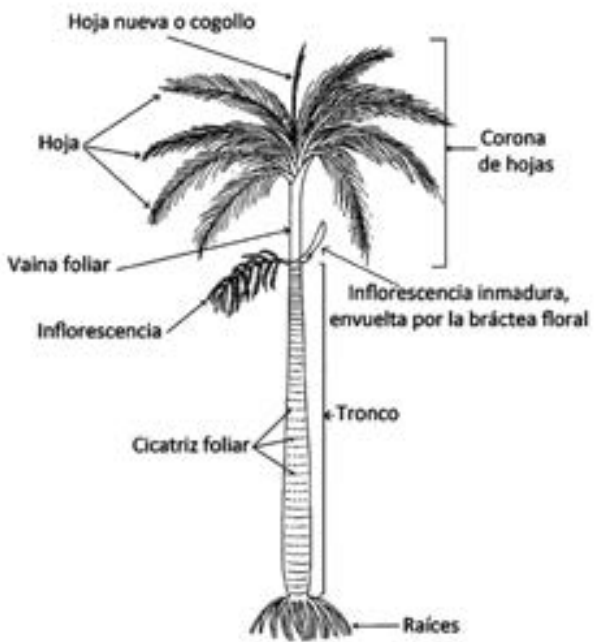

Figura 23: Perfil de Palmera - partes de la planta en el idioma local.
TAMANO DE LAS PALMERAS
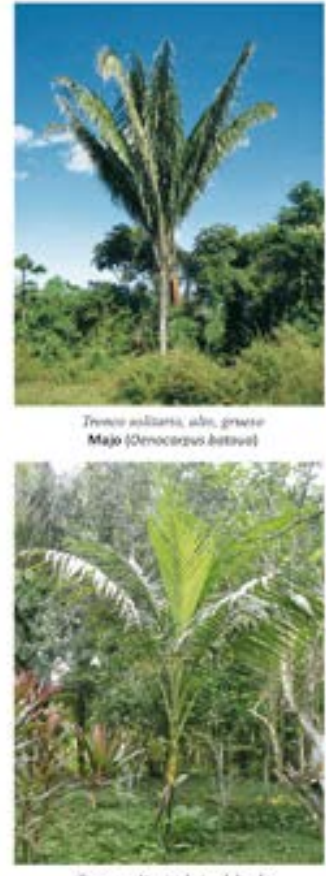

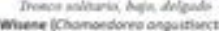
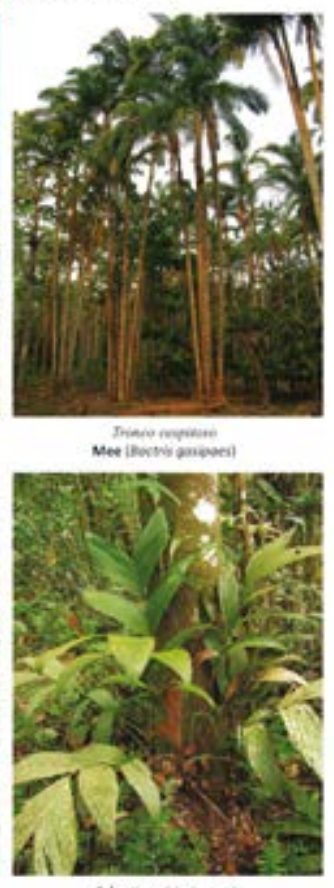

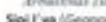

LAS HOJAS

Figura 24: Ejemplos de diferentes formas de hojas y de crecimiento de palmeras. 

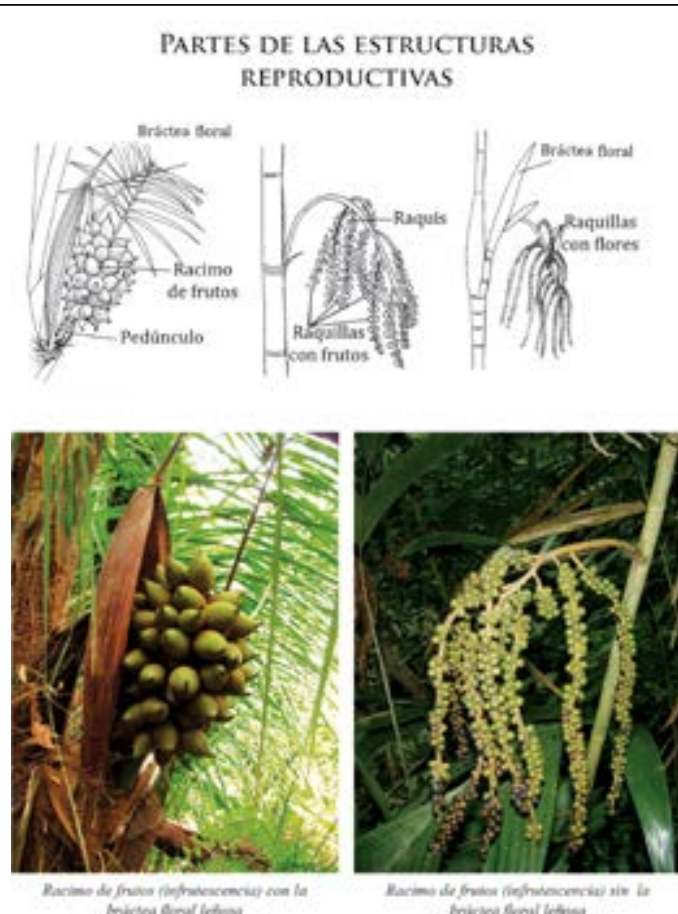

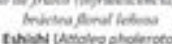

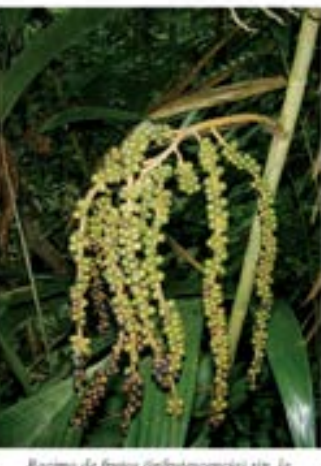

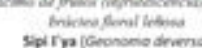

DIVERSOS TIPOS DE FRUTOS DE LUS PALMERUS

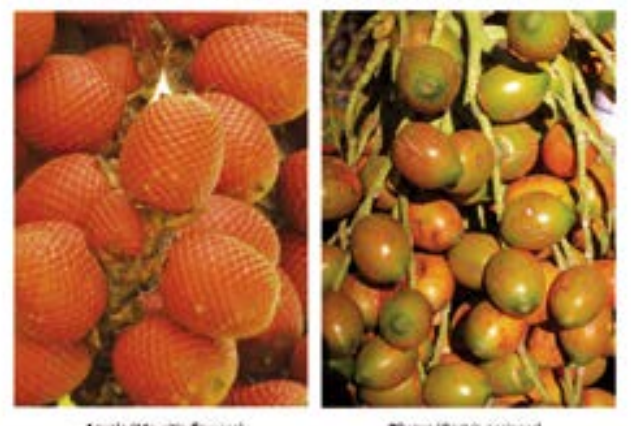

Figura 25: Ejemplos de frutenton
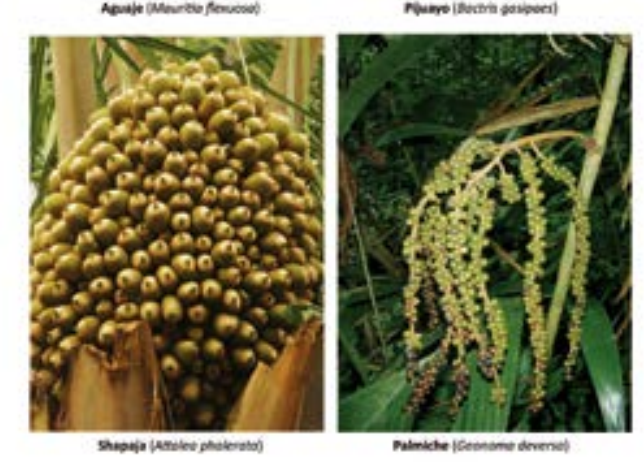

(usos

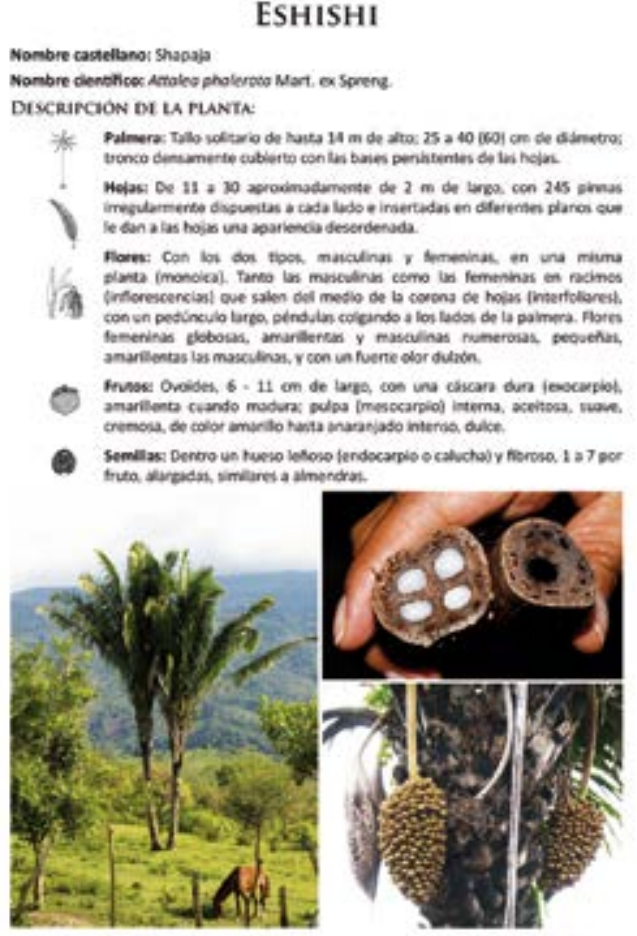

vose

1 1

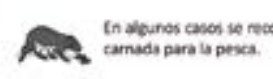

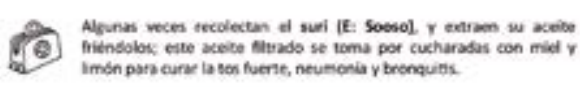

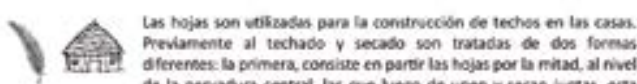

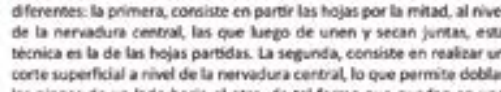

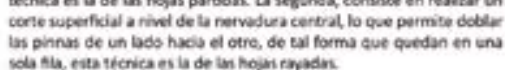

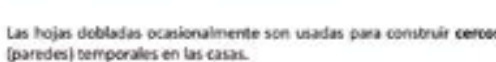

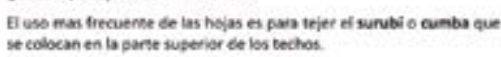

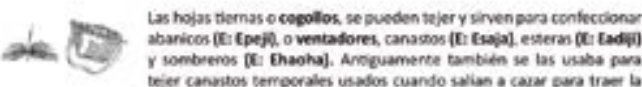

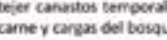

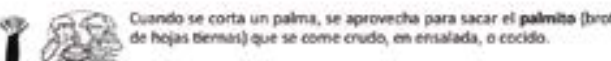

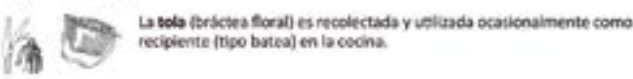

Figura 26: Descripción ilustrada de palmera.
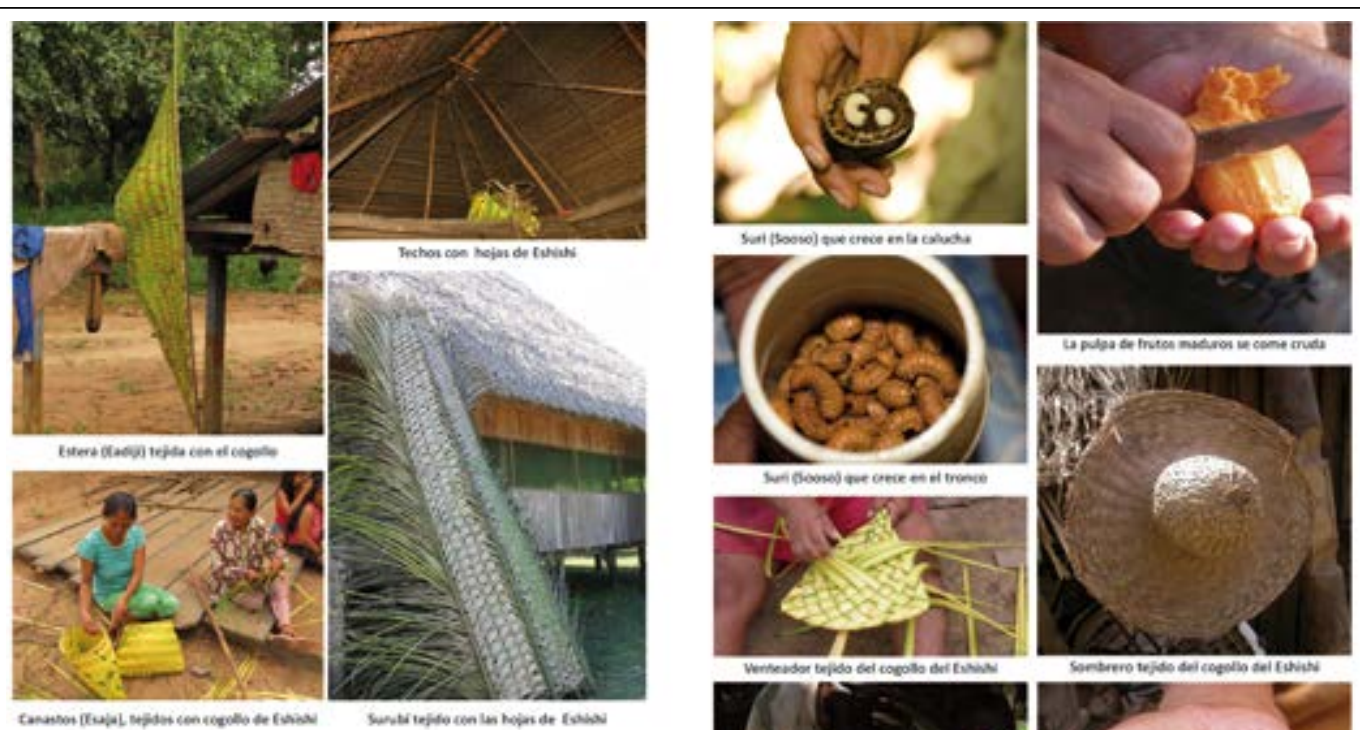

orit

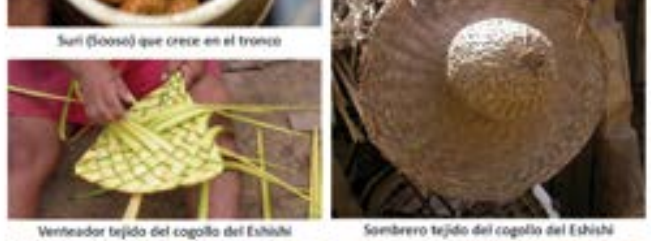

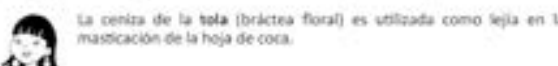
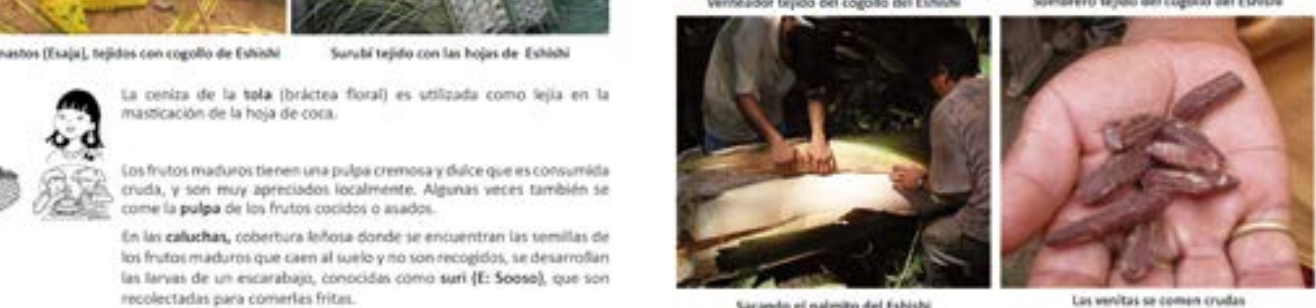

Figura 27: Descripción ilustrada de uso de la planta, incluyendo los términos en el idioma local y la traducción española.

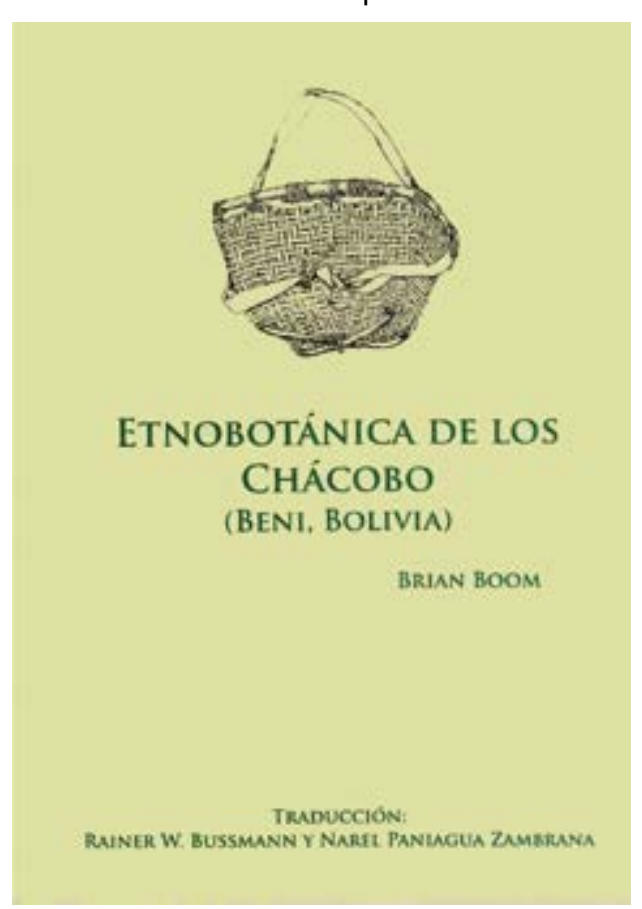

Figura 28: La repatriación de los conocimientos locales en el idioma local: Traducción de Boom "Ethnobotany of the Chacobo Indians" 
mundial, ampliamente accesible, de plantas útiles de importancia para la humanidad, respetando los derechos de propiedad intelectual, la propiedad local de los conocimientos tradicionales y la distribución de los beneficios de una forma adecuada y equitativa.

- Apoyar a las poblaciones locales e indígenas con la preservación y mantenimiento de sus conocimientos tradicionales de una manera culturalmente apropiada.

- Insistir en la necesidad de asociaciones culturales y de multiniveles en el esfuerzo de construir y compartir experiencias sobre la conservación de las plantas de importancia cultural, su uso sostenible y de los conocimientos tradicionales asociados a ellas.

- Desarrollar una plataforma internacional de investigación para hacer frente a los vacíos en los conocimientos científicos de las plantas útiles.

- Facilitar la creación de capacidades y de oportunidades para la capacitación en la etnobotánica, particularmente en los países y regiones con importantes vacíos de dichos recursos.

- Apoyar y fomentar la transmisión de los conocimientos bioculturales y su custodia.

- Desarrollar las instalaciones adecuadas, metodologías y técnicas para apoyar la curación culturalmente adecuada de las colecciones bioculturales (artefactos, muestras de herbario, productos, colecciones vivas, etc.) y de los conocimientos tradicionales asociados.

- Elaborar y difundir materiales educativos y recursos en los idiomas pertinentes para apoyar y promover el estudio y el uso de los conocimientos tradicionales, asegurando su inclusión en las currículas educativas.

- Desarrollar un conjunto de herramientas metodológicas, estudios de campo, manuales y sistemas de buenas prácticas con el fin de apoyar a la conservación de las plantas útiles y los conocimientos asociados a ellas.

- Destacar la necesidad de indicadores fáciles de medir que permitan monitorear los avances en la conservación de las plantas útiles y los conocimientos tradicionales asociados a ellas.

- Trabajar dentro el marco establecido por el Protocolo de Nagoya sobre el acceso a los recursos genéticos y la distribución justa y equitativa de los beneficios provenientes de su utilización (ABS), establecido en el Convenio sobre la Diversidad Biológica y el Tratado Internacional sobre los Recursos Fitogenéticos para la Alimentación y la Agricultura de la FAO, con el fin de gestionar y alcanzar los estándares éticos para el acceso, la distribución de beneficios justos y equitativos y la seguridad de los recursos tradicionales y los derechos de los agricultores, así como la protección de la propiedad intelectual.

\section{Conclusiones}

Perú Septentrional ocupa el sector superior del "eje de salud" del área cultural Andes Centrales. Pocos lugares en el planeta tienen una flora médica tan rica como esta región. La evidencia arqueológica demuestra el uso de plantas en la Medicina Tradicional y para la divinización en esta área hace 3000 años o más. La investigación contemporánea indica que la composición de la farmacopea local ha cambiado durante la época de la colonia (Sharon y Bussmann 2006) y que la cantidad total de plantas medicinales empleadas parece haber incrementado. Esto indica que la Medicina Tradicional Norperuana todavía siga siendo fuerte y que los curanderos constantemente están experimentando con nuevos remedios. Una indicación reciente de este hecho es la aparición de productos Noni (Morinda citrifolia) en cantidades grandes en fitofarmacias y mercados de la región. Esto lo hace bien obvio que hierbateros locales cuidadosamente sigan tendencias internacionales de salud para incluir especies prometedoras en sus propios repertorios.

El uso de psicoactivos sagradas (entheogens), en particular el cacto San Pedro (Echinopsis pachanoi) es un componente vital en las prácticas andinas de salud que ha persistido por milenios (Camino 1992; Polia 1998; Sharon 1978; Sharon 1980; Sharon 1994; Joralemon y Sharon 1993). La evidencia arqueológica más temprana para este cactus sagrado es de la Cueva Guitarrero (8200-6800 a.C.) en la sierra Lynch (1980: 102), Las Aldas (2000-1500 a.C.) en la costa norcentral (Fung 1969: 43, 120, 195) y Garagay (1643-879 a.C.) en la costa central (Burger 1992: 63-64). Y el San Pedro a menudo se encuentra en la iconografía Cupisnique, Chavín, Moche, Nasca y Lambayeque (Polia 2000; Sharon 2000; Glass-Coffin, Sharon y Uceda 2004; Franco 2009). Quinientos años de represión de prácticas curanderiles comenzando en la época colonial y continuando a manifestar en los prejuicios de administraciones nacionales contemporáneas no han podido destruir esta tradición. El uso del San Pedro, junto con aditivos como Floripondio (Brugmansia spp.) y Tabaco (Nicotiana tabacum, Nicotiana rústica) todavía desempeña un papel central en las ceremonias de curación de curanderos en Perú Septentrional. Sin embargo, los curanderos están experimentando con nuevos alucinógenos y algunos han comenzado a incluir pócimas de Ayahuasca (Banisteropsis caapi) en sus rituales.

Las mesas o altares de curanderismo en Perú Septentrional sigan la tradición antigua incluyendo artes o "objetos de poder" de origen "pagano". Objetos como caracoles del mar, cerámicas pre-Hispánicas, varas, piedras, etc., son muy comunes en las mesas peruanas y se armonizan con símbolos cristianos como crucifijos e imagines de santos. Los pacientes son limpiados soplándolos con agua bendita y perfumes y "baños de florecimiento" son componentes importantes de la tradición de curanderismo. En muchos casos la "limpia" del paciente involucra la ingestión por la nariz del jugo de tabaco macerado en perfumes. Las canciones o tarjos usadas por los curanderos durante sus sesiones de curanderismo incluyen componentes cristianos (por ejemplo, la invocación de Cristo, la Virgen María y una variedad de santos) además de referencias a la cosmología andina (por ejemplo, a las lagunas sagradas y los Apus o espíritus de los cerros). Además, el uso de cuyes como instrumentos diagnósticos es un elemento normal en Perú Septentrional.

Los conocimientos tradicionales de plantas medicinales todavía se enseñan verbalmente, sin ningún registro escrito. Esperemos que nuestro trabajo ayude mantener vivo los extensivos conocimientos tradicionales del norte similar a nuestra guía de campo ilustrada para Ecuador Meridional (Bejar, Bussmann, Roa y Sharon 2001; Bussmann y Sharon 2006a, 2007a). Sin embargo, la Medicina Tradicional está experimentando una demanda incrementada evidenciada por el hecho que la cantidad de hierbas, en particular en los mercados de Trujillo, ha aumentado recientemente. Además, una gran variedad de plantas medicinales de Perú Septentrional se puede encontrar en el mercado global (por ejemplo, www.rain-tree.com). A pesar de que esta tendencia podía ayudar a mantener prácticas tradicionales y garantizar a los conocimientos tradicionales el respeto que merecen, plantea una amenaza seria de excesiva colección de especies en el futuro.

Hoy día, la amenaza más seria a esta tradición milenaria es la destrucción de los hábitats de las plantas medicinales. La urbanización y las agro-industrias de azúcar, arroz y algodón han alterada en escala grande los llanos de la costa alrededor de Trujillo, Chiclayo y Piura y cambios de clima y la deforestación amenazan los bosques montańosos que son una fuente de muchas especies de plantas medicinales. Más importante aún, los ecosistemas y lagunas de la sierra alta de los Andes donde se encuentran muchas especies médicamente activas están en peligro de ser destruidos por actividades mineras de escala mayor (Downer 2006; Zamora 2007). 
Últimamente parece que una amenaza a la Medicina Tradicional-el prejuicio-va disminuyendo poco a poco. Evidencia de esto es el hecho que el Colegio Médico del Perú-que resistió un acercamiento con la Medicina Tradicional (MT) durante décadas--está organizando talleres y conferencias sobre esta materia tan importante. Ya hemos notado la posición proactiva de EsSalud en cuanto a la prescripción de plantas medicinales y el volumen sobre Medicina Tradicional publicado por el museo de la Universidad Nacional de Trujillo-el último parcialmente basado en un simposio ("Medicina y Cultura") organizado en 1999 por el antropólogo trujillano Rafael Vásquez. Vale notar que en 1994 y 1995 arqueólogos trujillanos organizaron dos simposios ("Chacmas") al aire libre que incluyeron curanderos, autoridades locales, académicos y el público que, desafortunadamente, no fueron publicadas (pero el evento de 1994 fue revisado por Segura y Miranda (1995) y Morales (2012). Hubo dos simposios más, Puemape 2004 y 2005. Y, en 2011, la Universidad Privada Antenor Orrego en Trujillo organizó un encuentro internacional sobre curanderismo que incluyó curanderos, académicos, comuicadoes y profesionales de salud (Paz, ed. 2012). Durante el tiempo que este libro va a la imprenta, un gran paso adelente se está realizándose. El Ministerio de Cultura, Dirección Desconcentrada de Cultura de la Libertad está preparando un expediente reconociendo el curanderismo norteńo usando el San Pedro como patrimonio cultural de la nación basada en el hecho de que, en 2003, Perú ratificó el Convenio sobre Salvaguardia del Patrimonio Cultural Inmaterial de UNESCO y que la Ley General del Patrimonio de la Nación reconoce valores medicinales, folclóricos y religiosos transmitidos oralmente.

César Gálvez (2013: 169-210) nos relata que las Chacmas arriba mencionadas "se articularon el aspecto académico y el práctico (demostrativo), mediante el trabajo conjunto de los maestros curanderos y los investigadores, en un escenario de mutuo respeto y colaboración" que incluyó la participación de las comunidades y autoridades locales además de estudiantes de antropología y medicina. Para elaborar las conclusiones de estos encuentros, se formó una comisión interdisciplinaria que redactó un resumen de las características y aportes a la sociedad de los practicantes del curanderismo. Entre los puntos de este documento sobresalen los siguientes:

-- Todo alcance de la Medicina Tradicional en su aproximación con la medicina convencional tendrá que darse con mutuo respeto, con mayor razón si la primera ha venido transmitiendo un conocimiento milenario en su propio territorio. Se reconoce que el encuentro entre el Centro Nacional de Salud Intercultural y los maestros curanderos sigue esta perspectiva.

-- La Medicina Tradicional es una alternativa seria para el problema de la salud, porque en nuestra sociedad, insertada en un mundo globalizante, no se ha resuelto este problema y han surgido nuevas enfermedades. Su ventaja radica en el hecho de que el maestro curandero trata al individuo, a su familia y a la comunidad en su conjunto, y busca el equilibrio de la ecología y el mundo en que vivimos.

-- Los maestros curanderos y otros terapeutas tradicionales (herbolarios, hueseros, parteras), en tanto intermediarios entre la naturaleza y el desequilibrio de la salud, representan una cultura viva que nunca ha cedido su lugar sino que persiste a través del tiempo; se entiende que en el contexto de la modernidad, los maestros curanderos tienen la alternativa de asociarse y tender a una integración, interactuando para la solución de enfermedades.

Tenemos la esperanza de que las iniciativas arriba mencionadas se lleven a innovaciones adicionales, especialmente la inclusión de practicantes tradicionales como iguales en la terapia oficial y entrega de servicios. Para modelos de la incorporación equitativa de curanderos indígenas en el sistema de salud moderna solo tenemos que mirar a los vecinos de Perú. Al norte en Ecuador, donde la Constitución de 2008 garantiza los derechos de la población indígena para usar la Medicina Tradicional dentro del sistema moderno, un yachak (curandero indígena) trabaja en un hospital en Riobamba al lado del personal de la salud pública moderna (Caselli 2012). Al sur en Bolivia, los yatiris y kallawayas están organizados en gremios profesionales (G. Fernández 2012: 330-334). En Chile, donde el pueblo Mapuche administra su propio hospital regional, también han organizado farmacias naturales que reparten remedios de plantas medicinales a la comunidad local y al nivel internacional (Nuestra Farmacia 2004). No creemos que sea demasiado esperar que pase lo mismo en Perú.

\section{Agradecimientos}

El trabajo de campo de este proyecto comenzó inicialmente en 2001 como una colaboración entre el programa MIRT/MHIRT de la Universidad Estatal de San Diego (SDSU, Dr. Robert Pozos, PD; desde 2014 PD es Dr. Dena Plemmons), el San Diego Museum of Man (Dr. Douglas Sharon) y la Universidad de Bayreuth, Alemania (Dr. Rainer W. Bussmann). A partir de 2003 se continuó con el auspicio de SDSU (Pozos), el Museo Phoebe Hearst de Antropología de la Universidad de California- Berkeley (Sharon) y la Universidad de Hawai en Manoa (Bussmann). A partir de 2007 el trabajo botánico se trasladó al William L. Brown Center en el Jardín Botánico de Missouri (Bussmann). Desde 2010 hemos tenido la suerte de contar con la colaboración del Dr. Thomas Love (Linfield Coll) y la Dra. Gail Willsky (Universidad de Buffalo-SUNY).

El trabajo de campo para este proyecto fue apoyado por la asistencia de los estudiantes MHIRT María Brodine, Marisa Alvarez, Christina Dennis, Gabriel Chait, David Dubose, Vanessa Feregrino, Mirna García, Gabriel Guerrero, Erika Hernández, Douglas Highfill, Kasee Houston, Brit Nilsen, Antonio Olea y James Saleda (San Diego SU); Guadalupe Ochoa (San Fran SU); Grace Kim (U CA SD); Tahamara Ibarra (Truman SU); Lorena Alvarez y Susana Fajardo (Linfield Coll); Ricardo González, Gletys Montoya y Tamia Souto (U Hawai-Manoa)); Guy Banner (Utah SU); Cynthia Aguirre, Abelardo Arellano, Yasmin Barrocio, Rosalie Cárdenas, Lucy Carrillo, Mayra Castro, Rosa Chan, Rigoberto Del Toro, Taisha Ford, Rubi Galarza, Mirna García, Margarita González, Gladys Guardado, Ana Jones, Cindy Lau, Alexis López, Jennifer Ly, Mariana Martínez, Ryan Martínez, Mariela Nevarez, Jessica Ortiz, María Pérez, Tahirah Rasheed, Samuel Regalado, Giselle Rodríguez, Daniel Ruiz, Jaime Sarria, Roberto Silva y Melinda Soriano (U CA Berkeley); Javier Blanco y Shant Tamazian (U Buffalo SUNY).

Los siguientes estudiantes de medicina prestaron un inestimable servicio como asistentes de enseñanza: Brian Jonat, Kamron Pourmand, Brent Parris y Keith Willner (SUNY Stony Brook) y Abby Besch, Rachel Ochotney y Rachel Simpson (U Buffalo - SUNY). Voluntarios de Bioquímica incluyen: Kristen Brooks, Lauren Carnevale, Thomas Cleland, Canaan Coppola, Russell Van Coevering, Lauren VanGelder y Brian Zylinski (U Buffalo-SUNY) así como Emily Bakaj (Barnard Coll), Alegría Barranis (U Chicago), Emily Frisch (Chapman Coll), Carolyn Gigot (Harvard) y Elizabeth Pon (Brown U); Voluntarios de Antropología/Sociología (Linfield Coll) Sandra García, Sam Gauksheim, Katelyn Henson, Joshua Ness, Kiana Ringuette, Ana Sours y Charlotte Trowbridge - tutorizadas en el campo por su jefe de departamento, Dr. Thomas Love y el Botánico Dr. John Syring.

Se completaron tres tesis de Maestría en temas relacionados con el proyecto esritos por Erika Hernández (Lat Am Stud, SDSU), Zachary Revene (Anthro, Utah SU) y Ashley Smallwood (LAS, SDSU). Tésis fueron escritas por Jay Chicoine (Anthro, Univ S Dakota) y Guadalupe Ochoa (Anthro, SFSU) y un ensayo analítico de Maestría fue presentado por Amanda Zenick

(LAS, SDSU). Ninguno de los trabajos hubieron sido posibles sin la inestimable colaboración 
de nuestros colegas peruanos, curanderas Julia Calderón, Isabel Chinguel y Olinda Pintado; curandero Leoncio Carrión; curandero Germán Santisteban; y herbolarios Manuel Bejarano, Elmer Cruz e Iván Cruz. En especial queremos agradecer el apoyo de todos ellos.

Durante tres temporadas de campo tuvimos la suerte de tener la experiencia antropológica de nuestro colega de SDSU, Alan Kilpatrick. Colaboradores del proyecto incluyeron: Biólogos Carolina Téllez y Carlos Vega (INBIA); Microbiólogos Marisela Aguilera y Doris Díaz (Clínica Anticona); Bioquímicos Inés Castro, Gonzalo Malca y Alan Mayanga (Universidad Nacional de Trujillo), Técnico de laboratorio Lai-Har Chi (U Buffalo-SUNY); Los botánicos Ashley Glenn, Jessica Griffard, Karen Meyer, Alyse Kuhlman, y Andrew Townesmith (William L. Brown Center, Missouri Botanical Garden); voluntarios Jay Chicoin, Genevieve Gilbreath, Pablo Lozano, Carlos Reyes, Jason Schoneman y Selma Somogny; y especialistas en TI John Effio y Steven Scokzen. Una deuda especial de gratitud a nuestros voluntarios dedicados Kaye Sharon, Tucker Sharon y René Summerfield. Desde 2010, hemos tenido la suerte de tener la profesionalidad del Dr. Gail Willsky (U Buffalo-SUNY) que ha transformado nuestra metodología de laboratorio y capacitación en UNT con el firme apoyo del Decano de la Facultad de Ingeniería Química Manuel Vera, Ingeniero Químico Alberto Quezada y Químico-Farmacéutico Mayar Ganoza. Desde 2013, contamos con el apoyo de UB Antropólogas Médicas las Dras. Ana Mariella Bacigalupo y Linda Kahn.

Gracias también a Eric Rodríguez (Herbario Truxillense, HUT) y Segundo Leiva, Mario Zapata, y el fallecido Dr. Abundio Sagástegui (Herbario Antenor Orrego, HAO) para el uso de sus instalaciones y la asistencia en la identificación de plantas. El Dr. Fredy Pérez (UPAO) ha sido un pionero fitoquímico y tutor incansable de nuestros estudiantes. MD Sarah Cohen (Lakenau PA Salud) proporcionaba valiosos evaluaciones de laboratorio. Desde el principio, hemos podido contar con la incansable buena voluntad de nuestros colegas MD Noé Anticona (Clínica Anticona), Luis Fernández (EsSalud/CAMEC-Trujillo) y el fallecido Hernán Miranda (UNT).

Reconocemos el apoyo de este trabajo bajo el programa de subvenciones MIRT/MHIRT (\# G0000613, Fondo 54112B MHIRT y NIH/NIMHD \# 5 T37 MDOO1442-18) de los Institutos Nacionales de Salud (NIH), la Deutsche Forschungsgemeinschaft (DFG) y el William L. Brown Center del Missouri Botanical Garden.

Principalmente queremos expresar nuestro agradecimiento sincero a la gente del Norte de Perú por ser asequibles en compartir sus conocimientos etnobotánicos con nosotros.

LISTA DE PLANTAS 


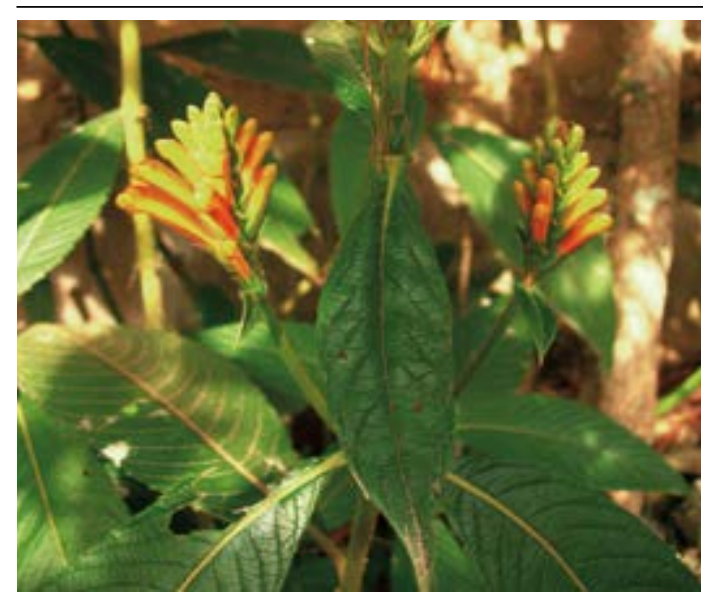

Aphelandra cirsioides

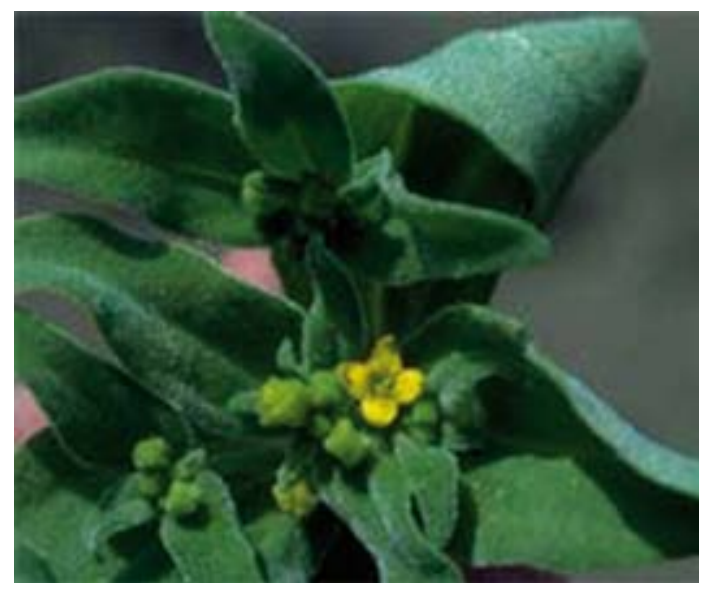

Tetragonia crystallina

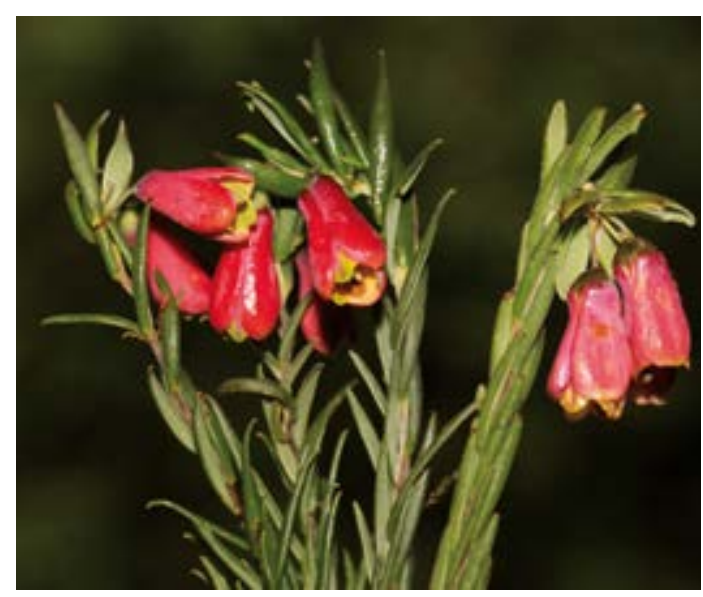

Bomarea dulcis

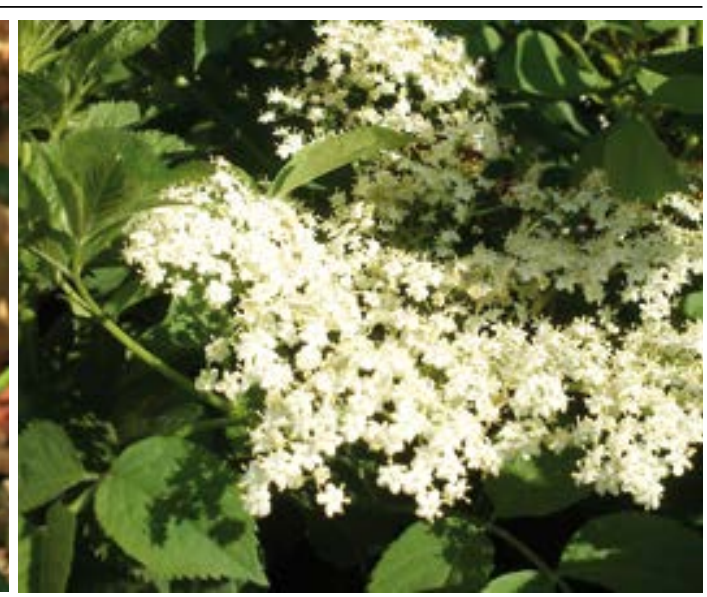

Sambucus peruviana

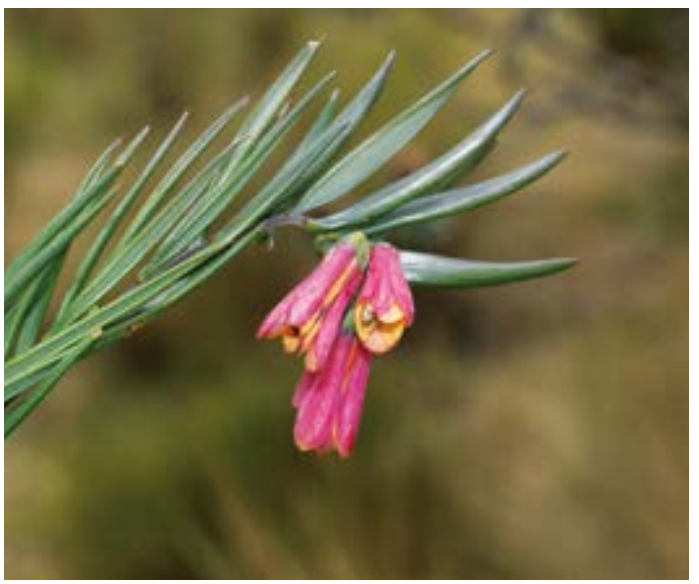

Bomarea angulata

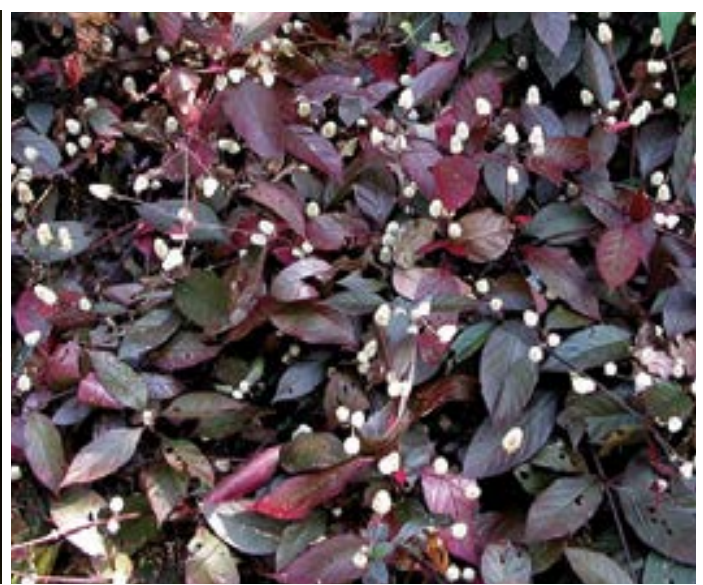

Alternanthera brasiliana

\section{ACANTHACEAE - Aphelandra cirsioides Lindau}

Espina de Hoja

Arbusto, Andino, 2000-3500m

Uso: Bronquitis / Planta entera, seco / Oral / 2 cucharas con 1 litro de agua caliente, 3 tazas por día, 3-4 días

ADOXACEAE - Sambucus peruviana Kunth

Cinta de Novia, Sauco, Saucotillo, Tilo

Árbol, Andino, 2000-4000m, cultivado

Uso: 1. Hinchazón, Riñones, Tos, Contusiones, Próstata, Fiebre, Bronquitis, Fiebre Amarilla / Hojas, Flores y Tallos, fresco o seco / Té: 5-20g en 1 litro de agua hervido 1 minuto y combinado con Aguardiente. Tomar 3 veces por semana, a 1 litro, hasta la fiebre pasa. Tomar frío. 2. Susto, Fiebre, Fiebre Amarilla / Hojas, fresco / Tópico / Baño: combinar con Nogal, Hierba del Susto, Manzanilla Blanco y Timolina en un frasco, 2-4 veces al mes. No usar demasiado porque esta muy frio. 3. Inflamación de Rińones, Gastritis / Hojas, fresco / Tópico / Emplasto, una vez al mes. 4. Nervios, Tos, Resfrío, Fiebre, Insomnio / Flores y Hojas, fresco / Oral / Hervir 1 litro de agua, añadir 10g de Sauco, Manzanilla, Hinojo, Coleo, Ajenco, Toronjil, Pimpinela y Claveles. Cubrir y dejar por 2-3 minutos. Paciente debe tomar caliente, 3-4 tazas por día por 1 mes. 5. Amuleto. Para amarrar alquilen en magia de amor / Hojas, fresco / Tópico / Amarrar una foro en los tallos y envolatar el paquete. Rezar y foguear perfume con nombres propios. Repetir si se necesita. Amarres rituales.

AIZOACEAE - Tetragonia crystallina L'Héritier

Hierba de la Sonrisa, Señorita, Ulluco de Gentil, Hierba de la Señorita

Hierba, Costa, $0-500 \mathrm{~m}$, introducido

Uso: 1. Felicidad, Tranquilidad, Fragancia, Buena Suerte, Florecimiento, Protección, Buena Salud, Buena Fortuna, Buenos Negocios / Tallos, Hojas, Flores, fresco / Seguro / Mezcla Estándar para Seguro. 2. Inflamación de molares / Tallos, Hojas, Flores, fresco / Tópico / Emplasto, machucar Hoja y Tallos, aplicar 2 horas, 2 veces al día. 3. Felicidad, Tranquilidad, Fragancia, Buena Suerte, Florecimiento, Protección, Buena Salud, Buena Fortuna, Buenos Negocios / Tallos, Hojas, Flores, fresco / Tópico / Mezcla Alternativa para Florecimiento.

ALSTROEMERIACEAE - Bomarea angulata Benth.

Cachujillo

Hierba, Andina, 300-3500m

Uso: Infertilidad en mujeres / Planta entera, seco / Oral / $5 \mathrm{~g}$ en 1 taza de agua hervida, 1 taza por día para 8 meses.

ALSTROEMERIACEAE - Bomarea dulcis (Hook.) Beauv.

Espuela de Gallo

Hierba, Andina, 3000-4500m

Uso: Protección, Éxito, Buen consejo / Planta entera, fresco / Seguro / 3 Tallos por frasco

AMARANTHACEAE - Alternanthera brasiliana (L.) Kuntze

Hierba del Oso, Veronica (Hembra), Moradilla de Cerro

Hierba o Arbusto, Amazónico, 0-500m, maleza

Uso: 1. Dislocación de huesos, Bronquitis, Asma, Hematomas, Fracturas, Hinchazones / Planta entera, fresco o seco / Oral / 5-10g en 1 litro de agua hervida. Mezclar con Muyaca, Huamanripa, Brochamelia. 4 tazas por día, 1-2 semanas. 2. Susto de altura / Susto de la cumbre / Planta entera, fresco o seco / Tópico / Limpia o Bańo. $5 \mathrm{~g}$ en 3 litros de agua hervida. También usado con Hierba del Susto, Zanahoria de Gentil, Poleo de Gentil. 1-2 veces por mes. 


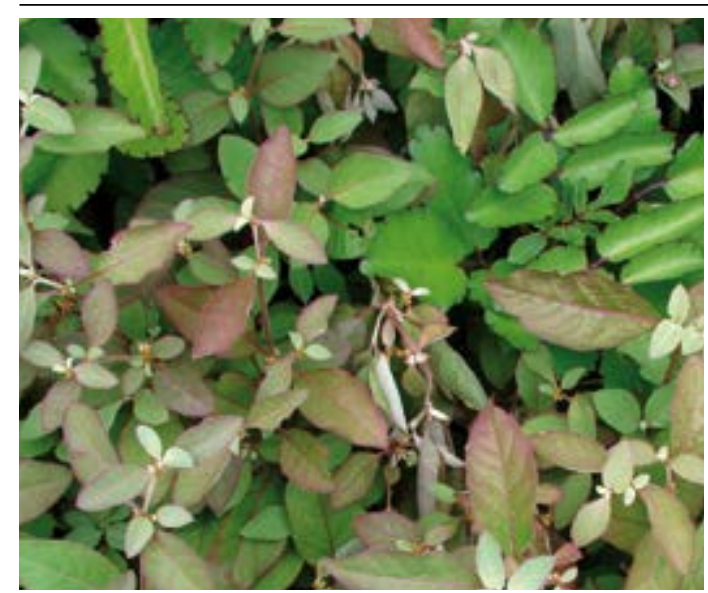

Alternanthera halimifolia

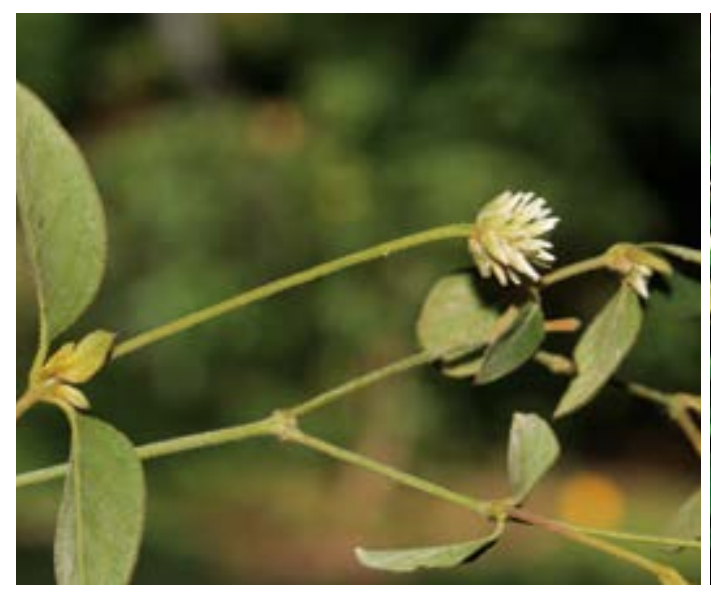

Alternanthera villosa

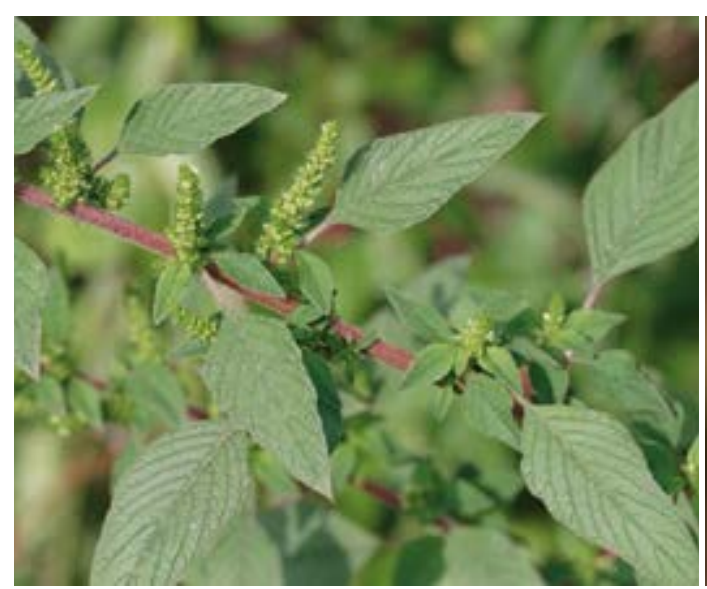

Amaranthus hybridus

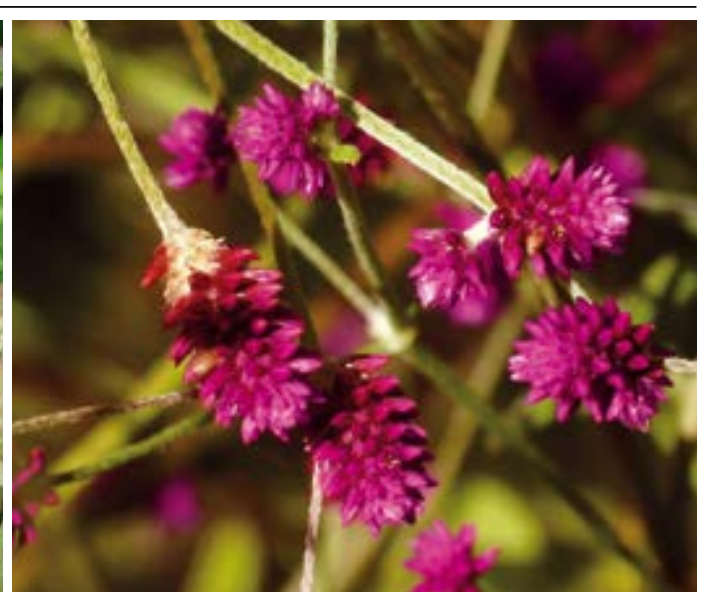

Alternanthera porrigens

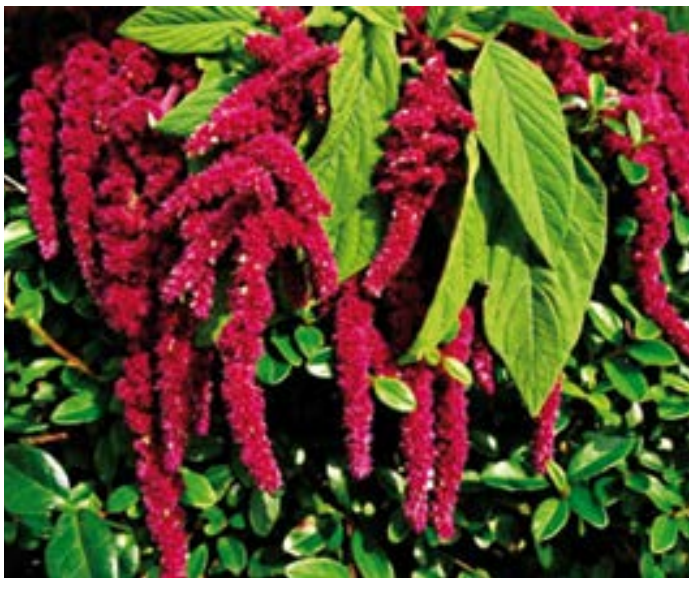

Amaranthus caudatus

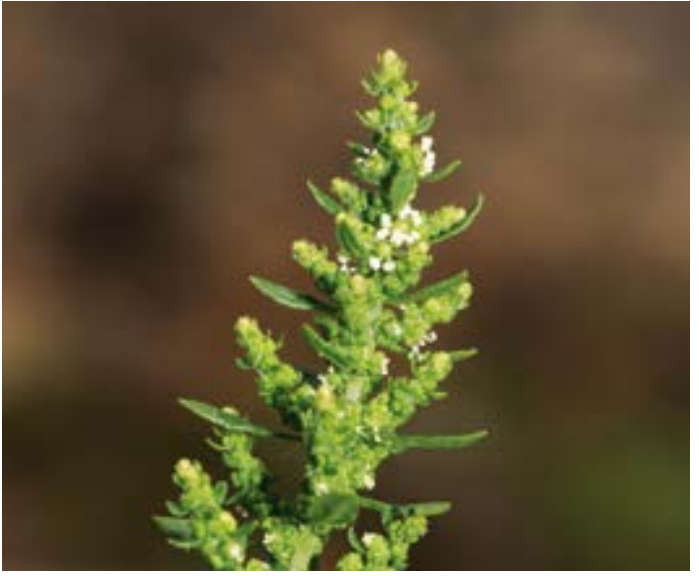

Chenopodium ambrosioides
AMARANTHACEAE - Alternanthera halimifolia (Lam.) Standley \& Pittier

Paja Morada (Colores), Lenguetilla, Sanguinario, Lengua de Pájaro, Sanguinaria, Moradilla, Hierba Morada

Hierba, Amazónica y Andina, 0-2500m, maleza

Uso: 1. Inflamación / Planta entera, fresco / Oral / Hervir 1 litro de agua, tomar y usar para lavarse, ańadir 10g Paja Morada. Combinar con Malva, Pie de Perro, Cola de Caballo, Chacur y Sombrerito. Tomar y usar para lavarse, 3 veces por día como se necesita. 2. Inflamación / Planta entera, fresco / Tópico / Hervir 1 litro de agua, ańadir 10g Paja Morada. Combinar con Malva, Pie de Perro, Cola de Caballo, Chacur y Sombrerito. Tomar y usar para lavarse, 3 veces por día como se necesita. 3. Nervios, Corazón, Ansiedad, Enfermedad cardíaca, Relajación / Planta entera, fresco / Oral / Hervir 1 litro de agua, añadir $10 \mathrm{~g}$ total de Toronjil, Manzanilla, Romero, Hinojo, Chanca de Comida, Cascorade y Membrillo. Dejar mezcla por 2-3 minutos. Tomar templado 3-4 veces al día durante comidas, o como se necesita. Paciente debe tomar cocción fría. importante de tomar 6 de mańana y 6 de la tarde.

AMARANTHACEAE - Alternanthera porrigens (Jacquin) Kuntze

Sanguinaria, Moradilla, Lancetilla

Arbusto, Amazónico, Andino y Costa, 0-2500m, maleza

Uso: 1. Circulación de sangre, Verrugas, Resfrío, Sangre, Alergias / Planta entera, fresco o seco / Oral / $5 \mathrm{~g}$ en 1 litro de agua combinado con Conchalagua, Moradilla, Colores, Lancetilla, Culantrillo, Hierba del Toro y Zarza Parilla. Tomar 3 veces al día hasta un año. 2. Limpiar útero después del parto, Fragancia, Suerte en amor y trabajo, Mal Aire, Amor, Negocios, Protección, Buena Fortuna, Buena Salud / Planta entera, fresco o seco / Tópico / Mezcla Alternativa para Florecimiento. Tomar 3 bańos al mes. 3. Buenos Negocios, Protección, Buena Fortuna, Buena Salud / Planta entera, fresco o seco / Seguro / Mezcla Estándar para Seguro.

AMARANTHACEAE - Alternanthera villosa Kunth

Hierba del Oso

Andina, $1000-2000 \mathrm{~m}$, maleza

Uso: 1. Mal Aire, Hechicería (protección de) / Flores, Hojas y Tallos, fresco o seco / Oral / Hervir 20g de Hierba del Oso en $1 / 2$ taza de agua por 5 minutos. Hervir $20 \mathrm{~g}$ de Hierba del Oso en 1/2 taza de agua por 5 minutos. Tomar frío, 1/8 taza, solo una vez 2. Protección del mal / Flores, Hojas y Tallos, fresco o seco / Tópico / Mixtura para baño de protección del mal.

\section{AMARANTHACEAE - Amaranthus caudatus L.}

Quihuicha, Kiwich

Hierba, Costa, Andina, 0-3500m, cultivado

Uso: Suplemento de nutrición/ Semillas, secas / Oral / 150g del grabo en 1 litro de agua. Hervir por 10 minutos o hasta grano esta blando. Ańadir Canela, Manzanas y Membrillo. 1 taza 1-2 veces al día como necesario.

AMARANTHACEAE - Amaranthus hybridus L.

Yuyo

Hierba, Amazónico, Andino, 0-3500m, maleza

Uso: Inflamación (general) / Hojas y Tallos, fresco / Oral / 100g de Yuyo y 1/2 taza de agua hervido por 5 minutos. Tomar frío, $1 / 4$ taza 2 veces por día por 3 días.

AMARANTHACEAE - Chenopodium ambrosioides $\mathrm{L}$.

Paico

Hierba, Amazónico, Andino, Costa, 0-4000m, maleza

Uso: 1. Parásitos / Hojas y Tallos, fresco / Oral / Extraer jugo de las hojas. El aceite de semillas y fruta tienen un ingrediente que mata a parásitos. Usar una vez al mes. 2. Tos / Hojas y Tallos, fresco / Oral / Añadir $10 \mathrm{~g}$ de material de la planta a $1 / 2$ litro de agua. Tomar caliente, 1 taza 2-3 veces por día por 1 semana. 


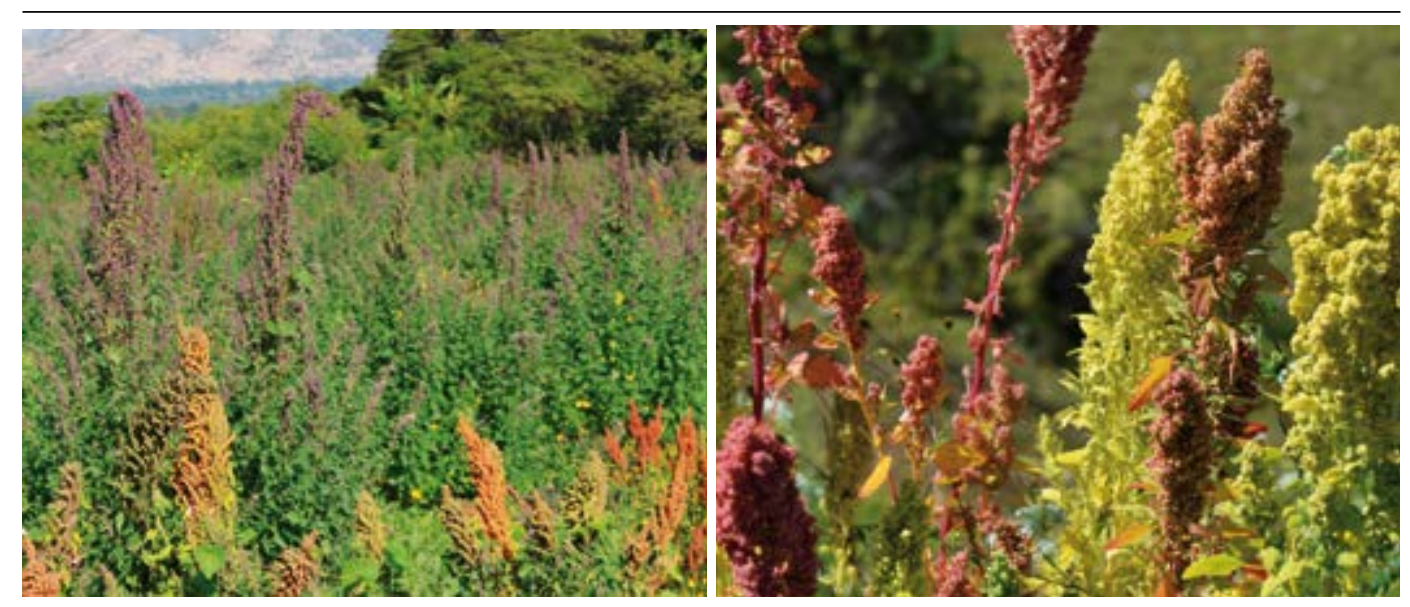

Chenopodium quinoa

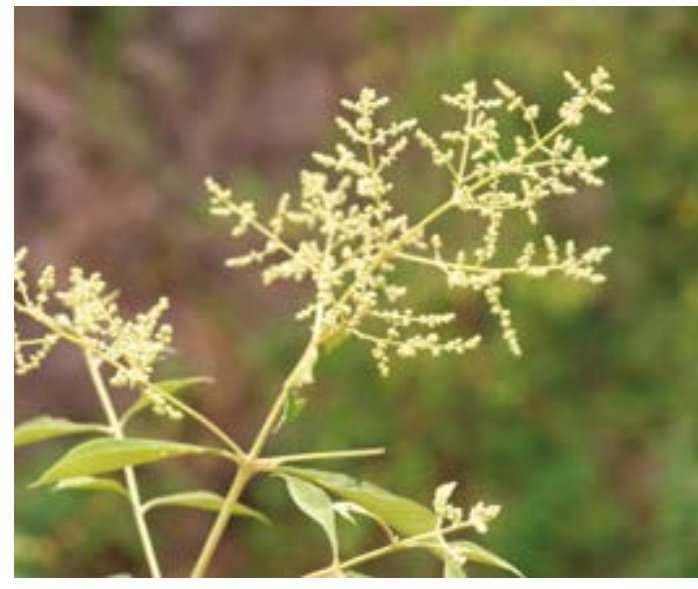

Iresine diffusa

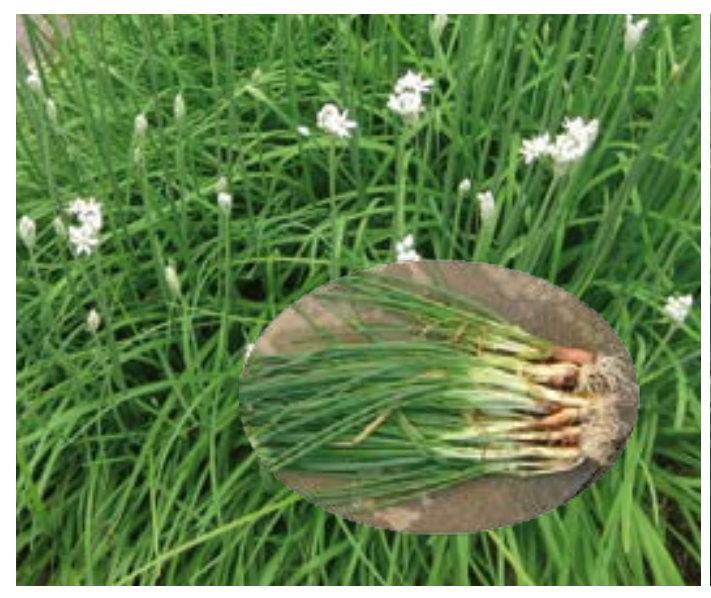

Allium odorum
Chenopodium quinoa

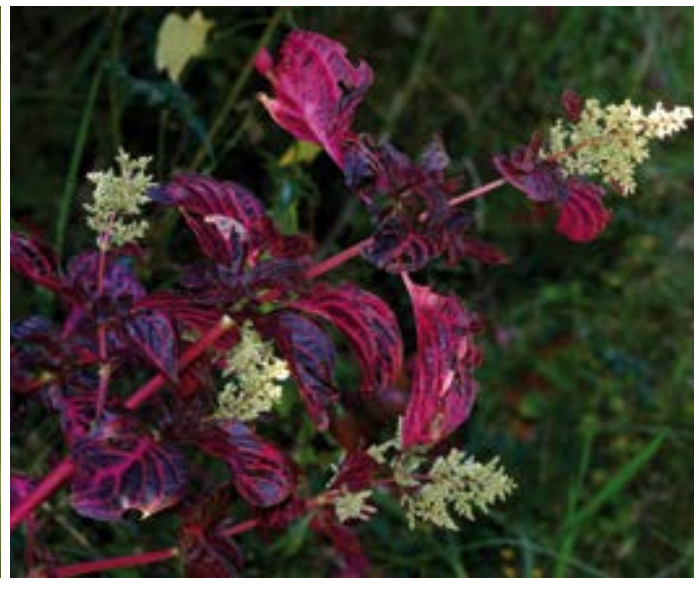

Iresine herbstii

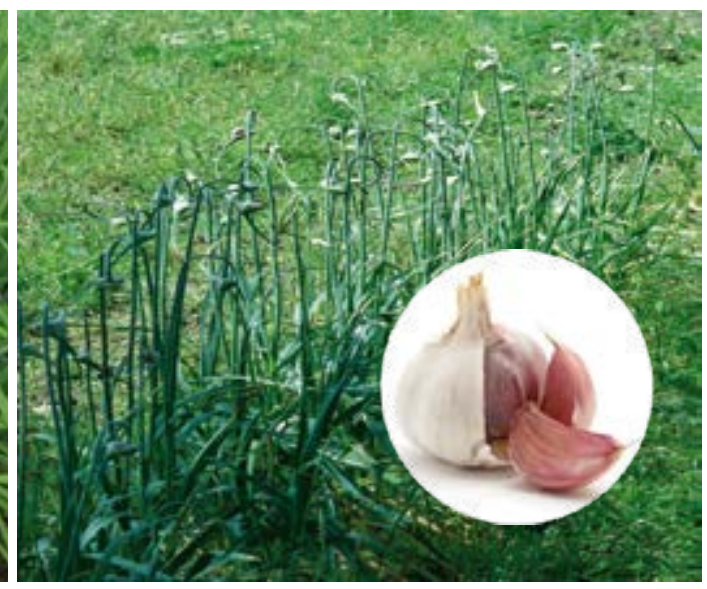

Allium sativum
AMARANTHACEAE - Chenopodium quinoa Willd. (wild form)

Quinua Amarga

Hierba, Andina, 2000-4000m, maleza

Uso: Intestinos (limpieza), Estómago (limpieza) / Semillas, fresco / Tópico / 5g seco o 5g en 1 litro de agua mezclado con Chocón, una vez al mes como enema.

AMARANTHACEAE - Chenopodium quinoa Willd.

Quinua

Hierba, Andina, Costa, $0-4000 \mathrm{~m}$, cultivado

Uso: Suplemento nutritivo / Semillas, fresco o seco / Oral / A 1 litro de agua añadir 150g de Quinua y hervir por 10 minutos o hasta grano esta suave. Añadir un pedacito de canela y manzana. Tomar 1 taza 1-2 veces por día como se necesita.

AMARANTHACEAE - Iresine diffusa Humb. \& Bonpl. ex Willd.

Paja Blanca, Sanguinaria

Hierba o Arbusto, Amazónico, Andino, 0-3500m, maleza

Uso: Hígado, Riñones, Inflamación de Ovarios, Sangre, síntomas de menstruación en adolescentes / Planta entera, fresco / Oral / Hervir 10g en 1 litro de agua, y mezclar con Ambarina, Lancetilla, Hierba de la Rabia y Palo de Sangre. Tomar 3 veces al día o como se necesita, 1 litro por día, por 1 año.

\section{AMARANTHACEAE - Iresine herbstii Lindley}

Colores, Timoras, Zangurache

Amazónico, 0-500m, cultivado

Uso: 1. Hígado, Riñones, Cáncer de la sangre, Circulación de sangre, Intoxicación de la sangre, Corazón, Sistema nervioso, Sangre, Inflamación del estómago, Inflamación (general) / Hojas, fresco / Tópico / Fresco solo hojas, se puede mezclar con Aguardiente, Vinagre y Contrahierba. Como emplasto, 3 veces por semana. 2. Hígado, Rińones, Cáncer de la sangre, Circulación de sangre, Intoxicación de la sangre, Corazón, Sistema nervioso, Sangre, Inflamación del estómago, Inflamación (general) / Hojas, fresco / Oral / Hervir $5 \mathrm{~g}$ en 1 litro de agua con Lancetilla, Contrahierba, Cachorillo y comer fresco. Tomar una vez al día por 1 semana a 1 mes, siempre antes del desayuno.

AMARYLLIDACEAE - Allium odorum L.

Cebolla China, Cebolla

Hierba, Andina, Costa, 0-3500m, introducido y cultivado

Uso: 1. Bronquitis, Asma / Planta entera, fresco / Oral / Cortar 15 cebollas en un recipiente. Añadir un vaso de agua y $1 / 4 \mathrm{~kg}$ azúcar blanco. Añadir un pedacito de jengibre (también se puede añadir grasa de pollo). Hervir y agitar hasta esta denso. Tomar jarabe, $5 \mathrm{~g}$ cada 6 horas por 1 semana. También se puede tomar jugo natural. 2. Hematomas, Mal Aire, Coágulos de sangre / Planta entera, fresco / Tópico / Machucar $11 / 2 \mathrm{~kg}$ de Cebolla y estrujar en tela para sacar extracto. Botar jugo y usar el resto. Poner en área afectada y cubrir con tela, cada segundo día en la mañana por 3 días.

\section{AMARYLLIDACEAE - Allium sativum $\mathrm{L}$.}

Ajo

Hierba, Andino, Costa, 0-3500m, introducido y cultivado

Uso: 1. Tos, Bronquitis, Resfrío / Tubérculo, fresco / Oral / Poner 3 dedos de ajo, 1 cebolla china, Matico, Escorcionera, Eucalipto, Vira Vira, azúcar blanco y $1 / 2$ litro de agua o leche de vaca en olla y hervir por 3 minutos. Tomar caliente, 2 cucharas dos veces al día por 1 semana. Se puede comer crudo. 2. Hematomas, Artritis, Reumatismo, Mal Aire / Tubérculo, fresco / Tópico / Machucar 250g de ajo. semana. Masajear y friccionar en área afectada. Friccionar 1-2 veces por día como se necesita 3. Mal Aire, Remover espíritus malos de la casa / Cáscara, fresco / Incienso / Quemar 1 kg de cáscara sobre carbón. Ahumar la casa una vez por semana durante 3 semanas, solo Martes y Jueves. 


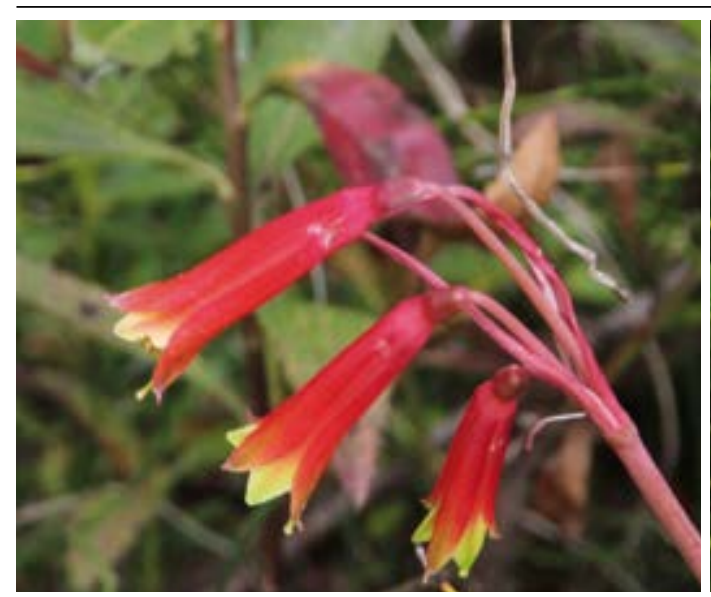

Eustephia coccinea

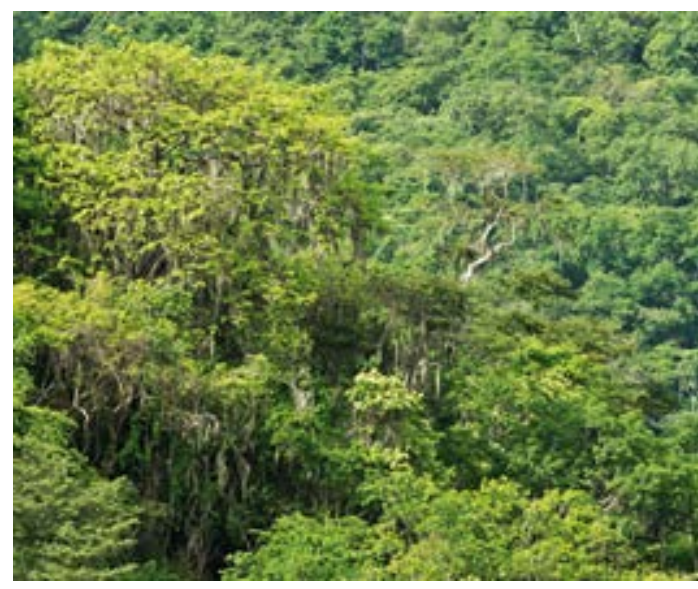

Loxopterygium huasango

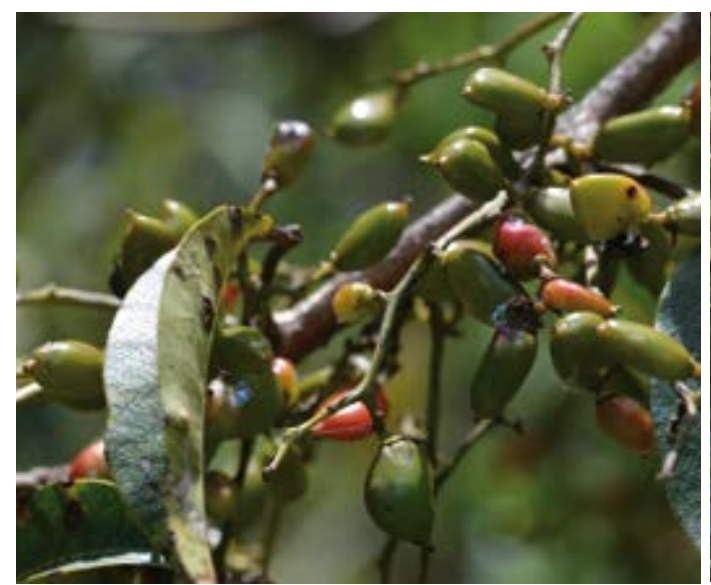

Mauria heterophylla

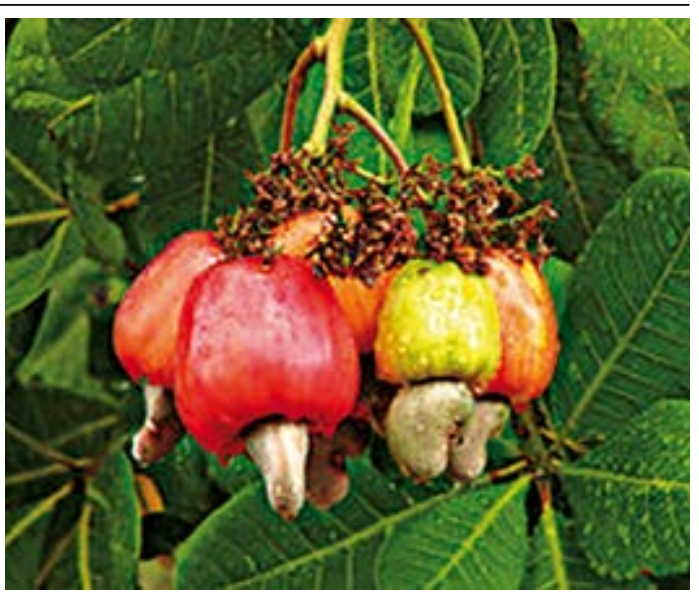

Anacardium occidentale

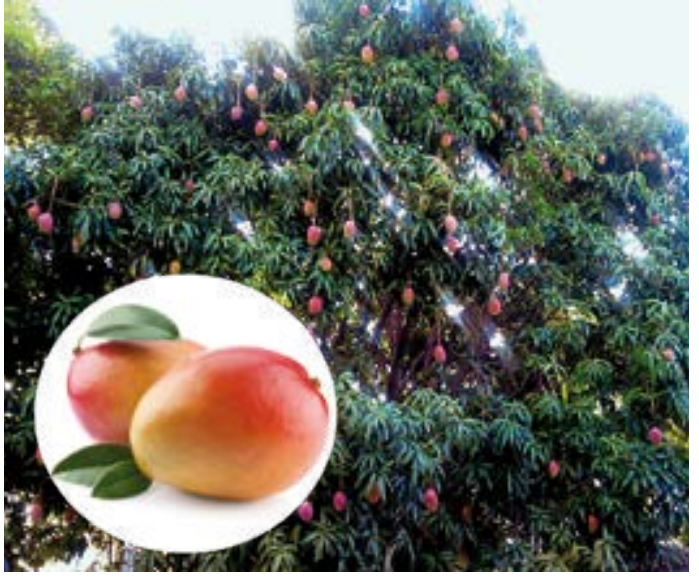

Mangifera indica

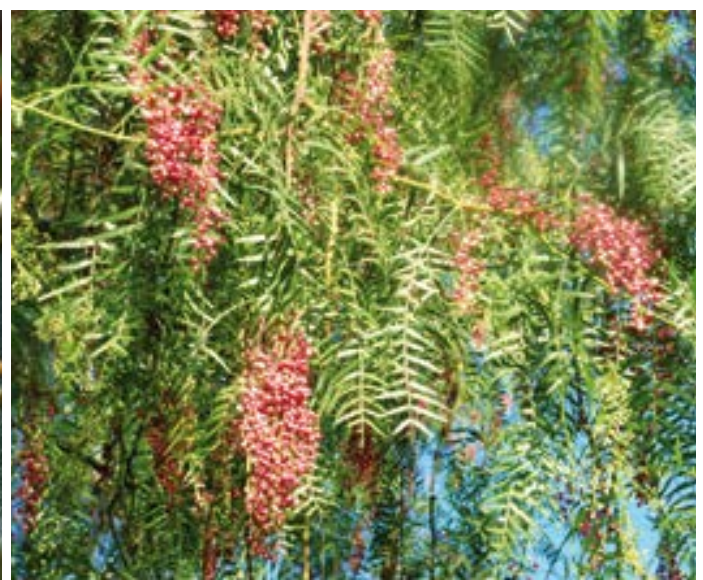

Schinus molle
AMARYLLIDACEAE - Eustephia coccinea Cav.

Tumapara, Pomanpara, Puma Para, Para Para

Hierba, Andina, $2000-400 \mathrm{~m}$, cultivado

Uso: 1. Artritis, Reumatismo / Corteza, fresco o seco / Oral / Macerar en botella de Vino, 3 vasos pequeños por día. 2. Inflamación del estómago, remover hechicería / Corteza, seco / Oral / Hervir 200g de Pomanpara en 1 litro de agua por 10 minutos. Tomar frío, 1 taza cada 3 días por 1 mes. 3. Heridas / Corteza, seco / Tópico / Machucar y polvorizar con una piedra, para hacer polvo. Poner polvo sobre la herida, una vez al día hasta se sana. Hervir por 20 minutos, $20 \mathrm{~g}$ de Hierba en 1 litro de agua mezclado con Matico, Malva y Talla. Lavar herida una vez al día por 8 días. 4. Inflamación, Hemorragias, Inflamación de Úterus, Úlceras, Quistes, Heridas Carcinógenas / Corteza, fresco o seco / Oral / Hervir 3-5 minutos, 5-10g en 1 litro de agua mezclado con Flor Blanca, Purenrosa, Malva Olorosa. Tomar 3 veces al día por 8 días.

ANACARDIACEAE - Anacardium occidentale L.

Marañon, Cayu

Árbol, Amazónico, Andino, 0-1000m, cultivado

Uso: Cicatrices, Lunares, Quistes, Manchas en la piel / Semillas, fresco / Tópico / Machucar Semillas y colectar "sangre." Aplicar a área afectada.

ANACARDIACEAE - Loxopterygium huasango Spruce ex Engl.

Hualtaco

Árbol, Amazónico, Andino, 0-1000m

Uso: Dolor de huesos o muscular después de accidente, dolor de fracturas / Madera, seco / Oral / Hervir $20 \mathrm{~g}$ de Hualtaco con Diego Lope, Suelda con Suelda, y 1 litro de agua por 30 minutos. Paciente debe tomar frío. No sobrepasar 3 dosis porque esta muy fuerte. 1/2 taza por día cada segundo día o como se necesita.

ANACARDIACEAE - Mangifera indica L.

Mango

Arbol, introducido y cultivado

Uso: Bronquitis, Resfríos, Inflamación (tórax) / Hojas, seco / Oral / Hervir 5 Hojas de Mango con 10 Hojas de Moy, 10 Hojas de Eucalipto, 5 Tallos de Pájaro Bobo y 1 Hoja de Limón en 1 litro de agua por 30 minutos. Tomar frío, 2 cucharas dos veces por día por 3 días.

ANACARDIACEAE - Mauria heterophylla Kunth.

Shimir, Tres Hojas, Trinidad, Chacur, Ahimir, Feregreco

Árbol, Andino, 500-4000m

Uso: 1. Daño/Hechicería, Susto, Irritación de piel por Daño/Hechicería / Hojas, fresco / Tópico / Hervir 50g con Lailambo, Nogal, Ajenco, Timolina. Limpia: una vez por semana. 2. Inflamación, Hígado, Rińones, Heridas, Inflamación de Utero, Limpia (externa), Limpia (interno), Ülceras (interno), Úlceras (externo), Inflamación de Ovarios, Quistes, Fibroids / Hojas, fresco / Oral / 10g por taza, combinado (ex Colo con Cola de Caballo, Veror 1 mes. y meter solución en vagina por 10 minutos. Ir al baño y contraer músculos hasta el liquido ha salido. Repetir si se necesita, dos veces al mes.

ANACARDIACEAE - Schinus molle L.

Molle, Moy

Arbol, Amazonico, Andino, Costa, 0-3500m

Uso: 1. Artritis, Reumatismo, Dolor de huesos, Bronquitis, Tos, Resfrío, Escalofríos, Inflamación (externo) / Flores, Hojas y Tallos, fresco / Tópico / Macerar material en alcohol y soplar al patient en la noche, una vez por dia por 5 dias, o aplicar como emplasto o frota el cuerpo del paciente con la mezcla durante el baño Avisar al paciente de descancar y no salir de la casa 2 Artritis, Reumatismo, Dolor de huesos, Bronquitis, Tos, Resfrío, Escalofríos, Inflamación (externo) / Flores, Hojas y Tallos, fresco / Oral / 20g 


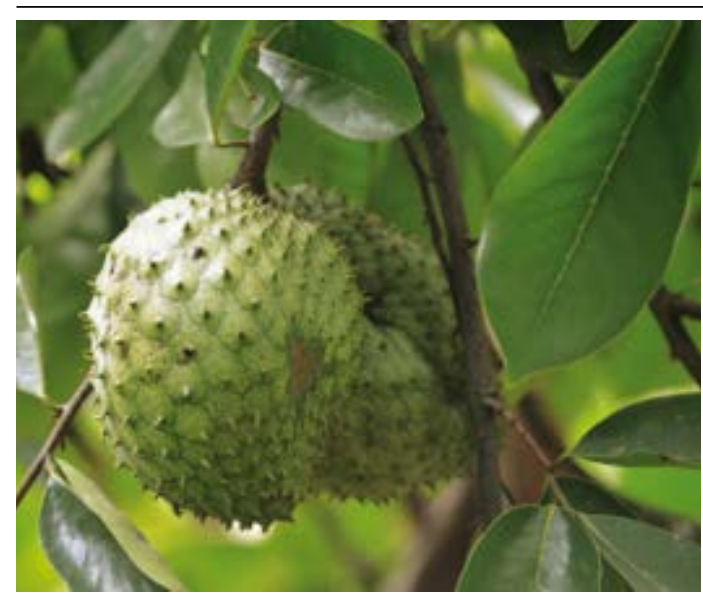

Annona muricata

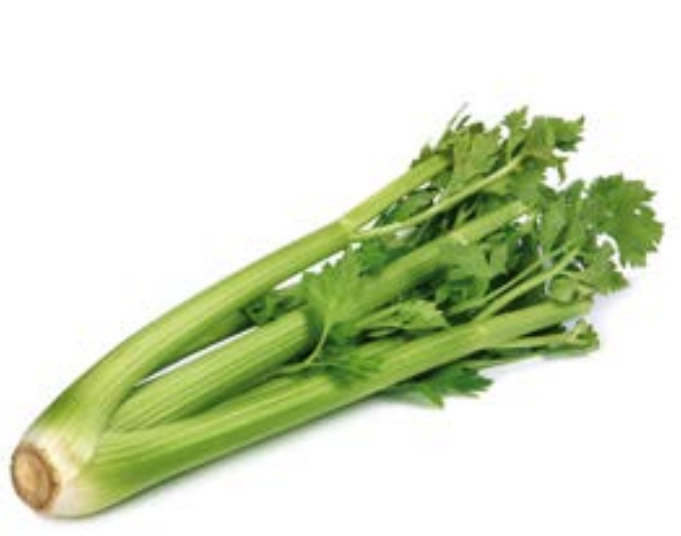

Apium graveolens

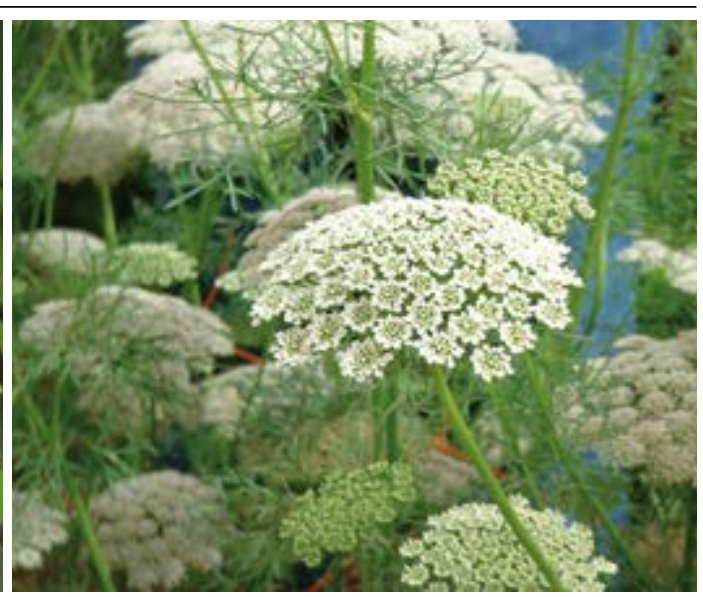

Ammi visnaga

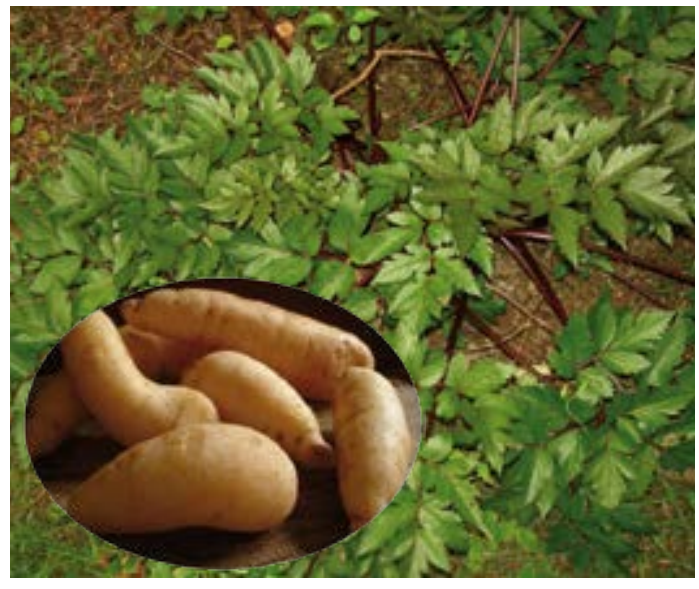

Arracacia xanthorrhiza

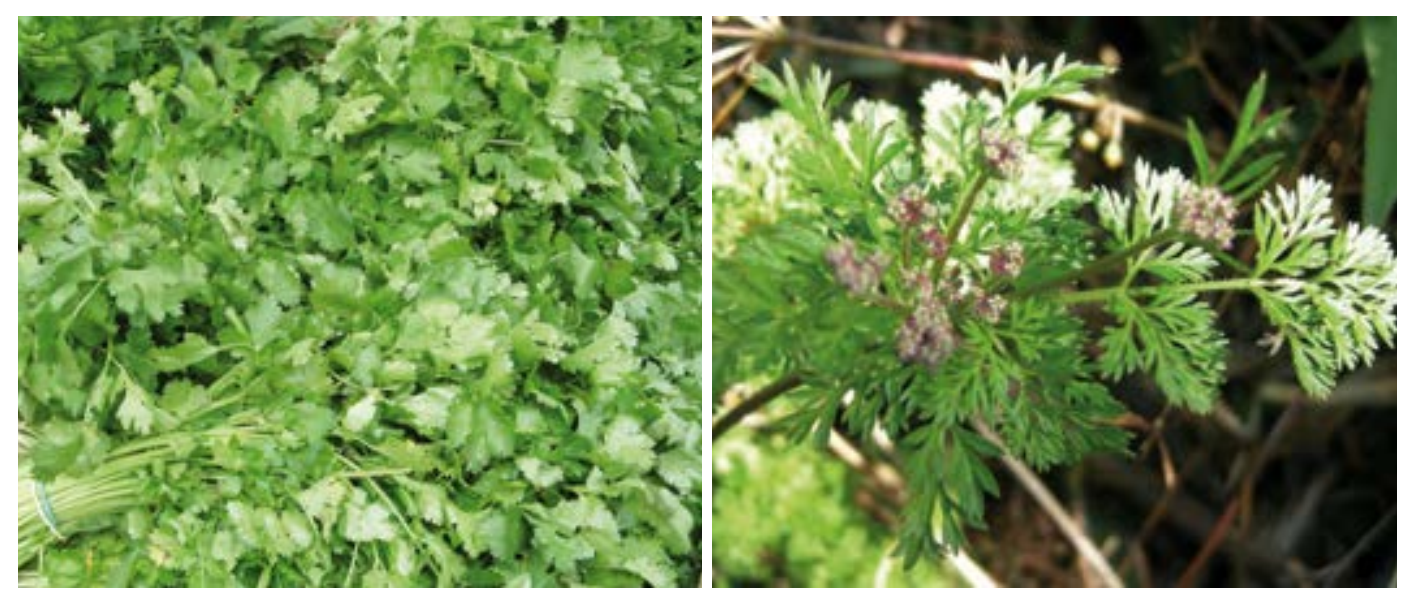

Coriandrum sativum

Daucus montanus machucado y mezclado con alcohol. Hervir 20-30 horas mezclado con Eucalipto, Ruda, Chamana, y Tilo. Tomar 1 taza, 4 veces por día por 2 meses o como se necesita. 3. Cáncer, Tuberculosis / Corteza y Latex, fresco / Oral / Añadir 20g de Corteza y resina (mas o menos $5 \mathrm{~cm}$ ) a 1 litro de agua. Hervir por 3 minutos. Tomar 1 taza, 4 veces por día por 2 meses o como se necesita. 4. Infección vaginal / Corteza y Latex, fresco / Tópico / Ańadir 20g de Corteza y resina (mas o menos $5 \mathrm{~cm}$ ) a 1 litro de agua. Hervir por 3 minutos. Usar 1 taza, 4 veces por día por 2 meses como bańo vaginal.

ANNONACEAE - Annona muricata $\mathrm{L}$

Guanábana, Graviola

Arbol, Amazonico, 0-500m, cultivado

Uso: Gastritis, Inflammación, Riñones, Cancer / Hojas, fresco / Oral/ Hervir 1/2 litro de agua con 10

Hojas de Guanábana, 10g de Amor Seco, Pineapple Peels y Achiote por 3-4 minutos. Tomar frío, 3-4 tazas por día por 1 mes.

APIACEAE - Ammi visnaga (L.) Lam.

Visnaga

Hierba, Costa, Andina, 0-3000m, introducido

Uso: Mal Aire, Dolor de Cabeza / Flores y Hojas, fresco / Tópico / 20g Hojas machucadas como emplasto, o $20 \mathrm{~g}$ por 5 litros de agua por 20 minutos como Bańo, 3 veces por semana.

APIACEAE - Apium graveolens $\mathrm{L}$

Apio Cimarrón, Apio

Hierba, Andino, Costal, 0-3000m, introducido

Uso: 1. Cólico, Bronquitis, Corazón, Nervios, Insomnia, Ansiedád, Gases, Gastritis, Cólico de Estómago / Planta entera, fresco / Oral/ Hervir 1 litro de agua, añadir 10g de Apio Cimarrón. Combinar con Manzanilla, Mejorana y Culantrillo. Tomar 4 tazas por día por 1 semana. 2. Susto en niños, Gastritis / Planta entera, fresco / Tópico / Hervir con Perejil. Mezclar con Agua del Susto, 3 Baños por mes.

APIACEAE - Arracacia xanthorrhiza Bancroft

Racacha, Racacha Cimarrona

Hierba, Andina, 3000-4000m, maleza

Uso: Susto / Hojas y Tallos, fresco / Tópico / Hervir 20g de material de planta con Flor de Chocho, Eucalipto, Chueguis y 2 litros de agua. Bañar el paciente en la mezcla caliente, frotando con las Hojas. Bańo 3 veces por semana por 1 mes con 1 taza de material.

APIACEAE - Coriandrum sativum $\mathrm{L}$

Culantro

Hierba, Amazonico, Andino, Costa, 0-3500m, maleza, introducido

Uso: Mal Aire que toma la vista / Hojas, fresco / Tópico / Poner Hojas frescas sobre los ojos. Applicar solo una vez. Dejar por 1 hora.

APIACEAE - Daucus montanus Humb. \& Bonpl. ex Spreng.

Zanahoria de Zorro, Zanahoria de Gentil, Zanahoria

Hierba, Andino, Costa, $0-4500 \mathrm{~m}$, maleza

Uso: 1. Mal Aire, Hechizería, Torceduras causadas por Hechizería, Torceduras, Contusiones causados por Hechizería, Susto de Huaca, Susto de las Cumbres / Hojas y Tallos, fresco / Tópico / Hojas con Vinagre y 7 Espíritus, 1 manojo en 3 litros de agua hervida con Ishpinguillo, Conchalay Blanco, Manzanilla de Cerro Lailambo y Timolina. As Baño, Limpia o Emplasto, $1-2$ veces por semana. 2. Vista, Manchas por sol / Raíz, fresco / Tópico / Machucar raíz, 3 gotas del jugo en cada ojo o piel afectada, 2 veces por día por 2-3 días. 3. Inflammación (generál) / Raíz, fresco / Oral/ 50g de tuberculo y 1/4 taza de agua, mezclar y filtrar. 1 vaso una vez por día por 15 días. Tomar frío durante desayuno, en ayuno. 


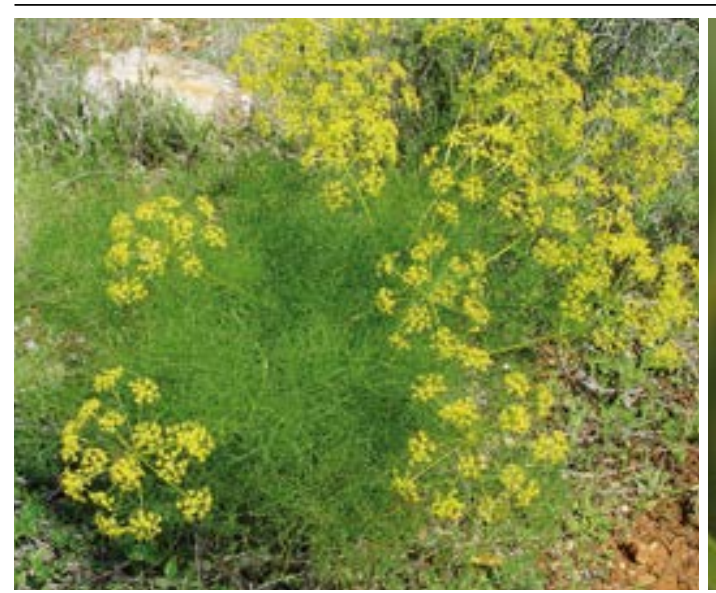

Foeniculum vulgare

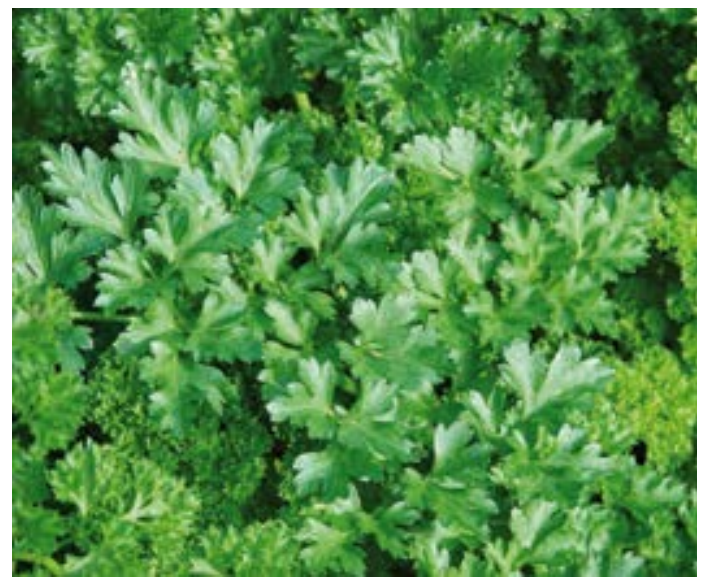

Petroselinum crispum

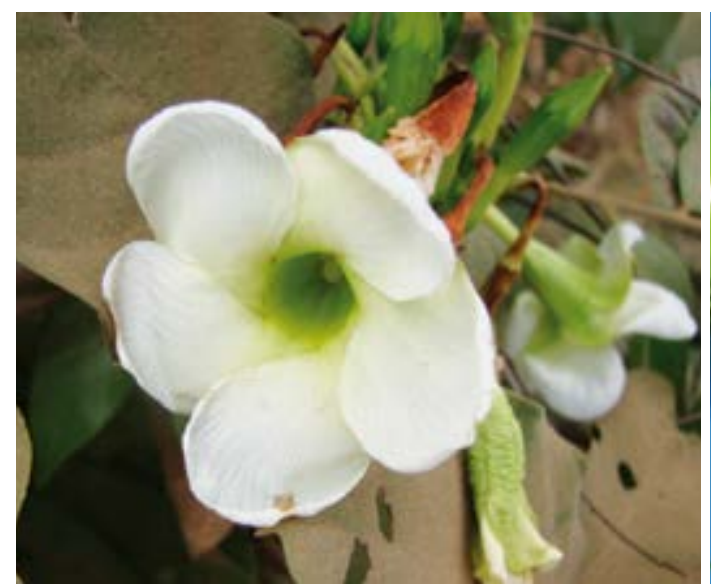

Mandevilla antennacea

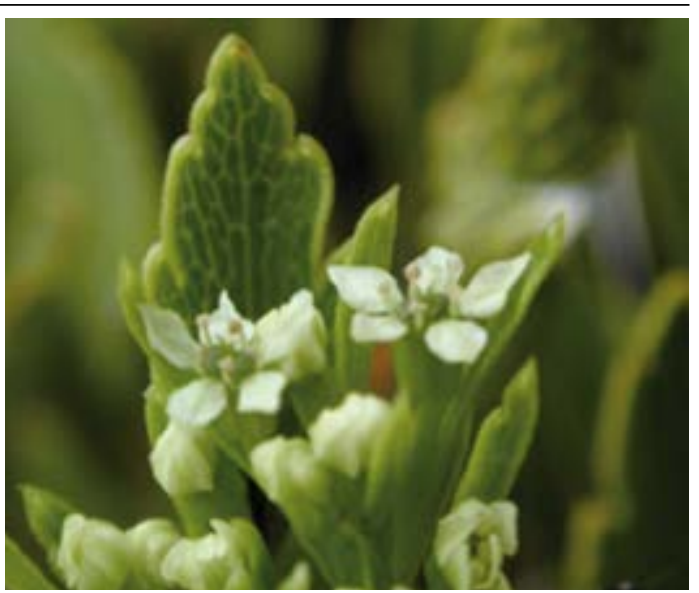

Niphogeton dissecta

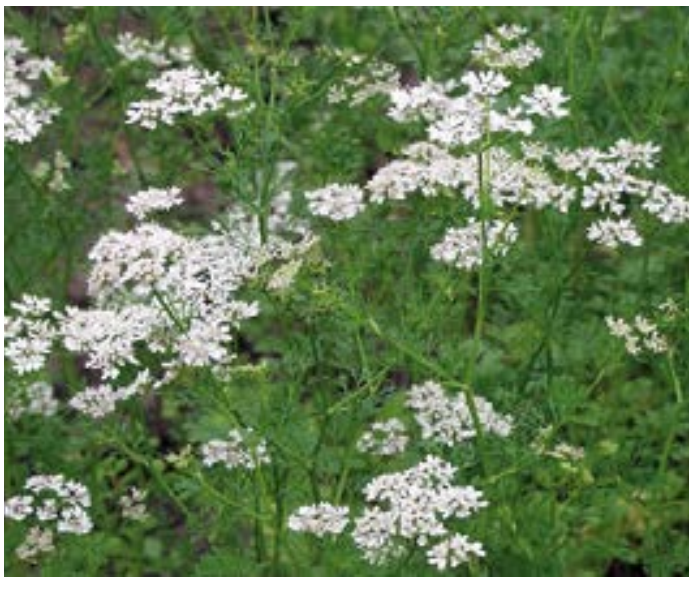

Pimpinella anisum

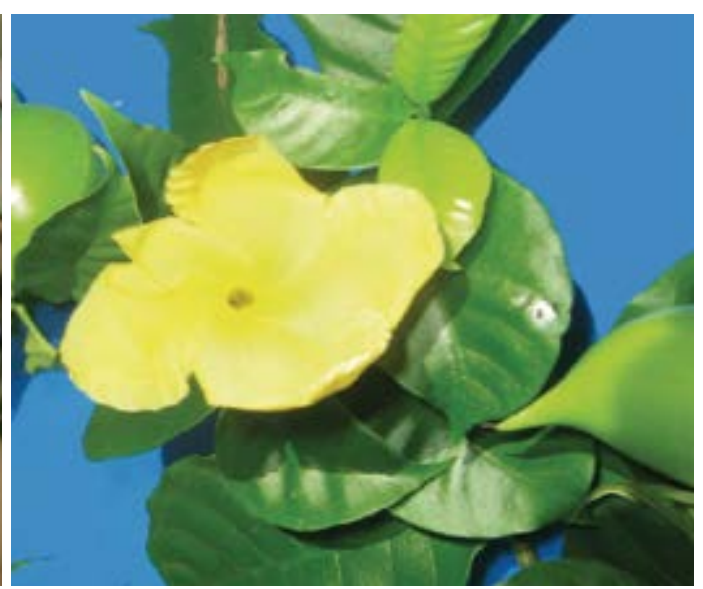

Mandevilla trianae
APIACEAE - Foeniculum vulgare P. Miller

Hinojo, Anís Criollo

Hierba, Andina, Costa, 0-2000m, maleza, introducido

Uso: 1. Cólico, Gases, Dolor de Estómago, Nervios. Después del parto, Diarrea / Planta entera, fresco / Oral/ Hervir $5 \mathrm{~g}$ en 1 litro de agua. Combinar con Manzanilla, Poleo, Toronjil, Pimpinela, Clavel y Borraja. Tomar 3 veces al día por 1 mes. 2. Cólico, Gases, Después del parto, Dolor de Estómago, Nervios, Diarrea / Semillas, fresco / Oral/ Ańadir 1 cucharilla de material de la planta a 1 taza de agua. Hervir mezcla por 2 minutos. Tomarcaliente. Se puede ańadir miel o azucar, dos veces por día por 2 días.

APIACEAE - Niphogeton dissecta (Benth.) J.F. Macbr.

Hórnamo Toro

Hierba, Andina, 4000-4500m

Uso: 1. Heridas (cancerogenas), Heridas de Hechizería / Hojas y Tallos, seco / Tópico / Hervir 20g por 5 litros de agua por 20 minutos y mezclar con other Hórnamos. Baño, 3 veces por semana. 2. Purgante / Planta entera, fresco / Oral/ Hervir 5g por 1/2 litro de agua y tomar 1 taza por día por 1 mes.

APIACEAE - Petroselinum crispum (Miller) A.W. Hill

Perejíl

Hierba, Andina, 3000-4500m, maleza, introducido

Uso: 1. Corazón, Sistema nervioso, Presión alta, Infecciones, Sangre de la nariz, Condimiento de comida, Olvidar Amor o trauma, Regulación de Menstruación / Planta entera, fresco / Oral/ 3-5o de Hierba en 1 litro de agua combinado con Toronjil, Pimpinela, Mejorana y Siempre Viva. Tomar 1 vaso 2 veces por día por 3 días antes periodo menstrual y tres días después. También se puede comer como ensalada. 2. Daño/Hechizería, Susto / Planta entera, fresco / Tópico / Manojo fresco Hojas y Tallos con Apio y quemar. 3. Infecciones, Sangre de la nariz, Condimiento de comida, Olvidar Amor o trauma / Planta entera, fresco / Tópico / Machucar Hierba y Hervir con carne y sal. Aplicar como emplasto, dos veces por mes como Limpia o Bańo.

\section{APIACEAE - Pimpinella anisum L.}

Anis Criollo, Anís

Hierba, Andina, Costa, 0-3000m, maleza, introducido

Uso: Gases, Dolor de Estómago, Cólico / Semillas, secas / Oral/ Té: 5-20g en 1 litro de agua con Menta y Manzanilla, 2-3 tazas por día por 3 días o como se necesita.

APOCYNACEAE - Mandevilla antennacea (A.DC.) Schum.

Bejuco Colambo Negro

Vine, Amazonico, Andino, 0-1500m

Uso: Proteger casa y chacra / Planta entera, fresco / Amuleta / Sembrar cerca de la casa.

APOCYNACEAE - Mandevilla trianae Woodson

Bejuco, Bejuco Negro (Grande), Bejuco Negro (Chico)

Vine, Amazonico, Andino, 0-1000m

Uso: Daño/Hechizería de Brebaje, Susto, Hechizería / Hojas, fresco o seco / Tópico / 1 manojo en 3 litros de agua hervida. Se puede combinar con Zanahoria de Gentil, Chilca, Añasquero Chico, Ishpinguillo, Conchalay, Hierba del Susto (when used por Susto) y 7 Espiritus. Baño una vez por semana y Limpia una vez al mes. 


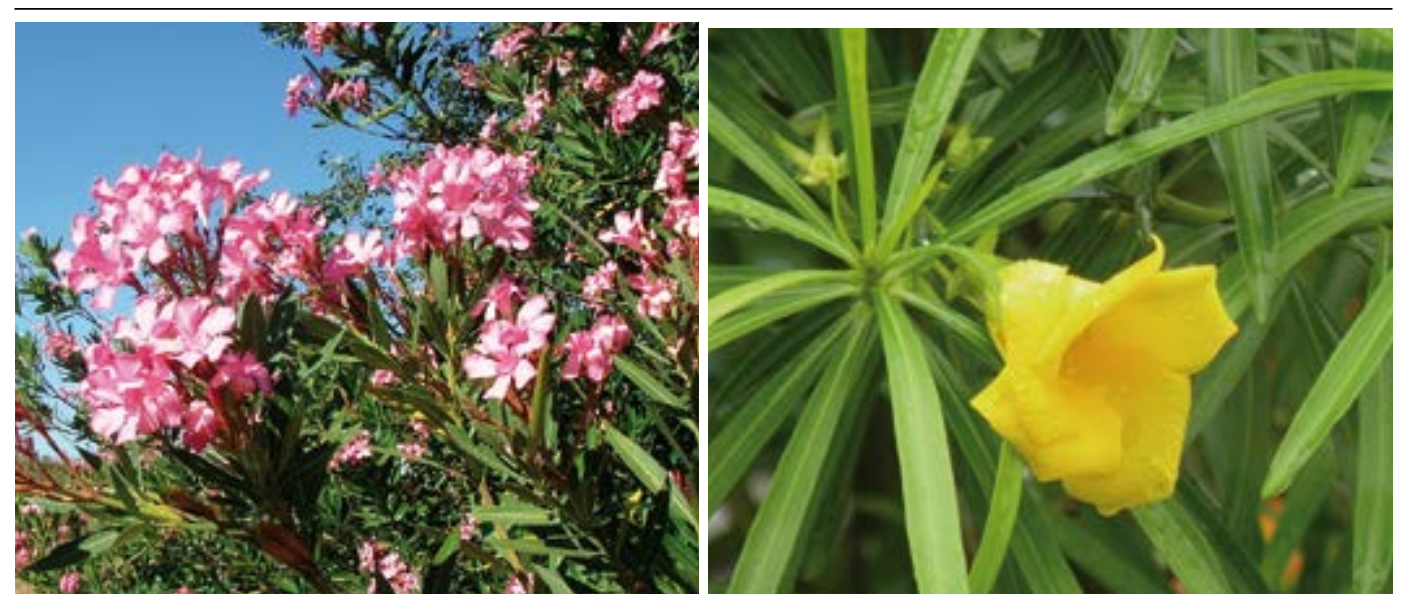

Nerium oleander

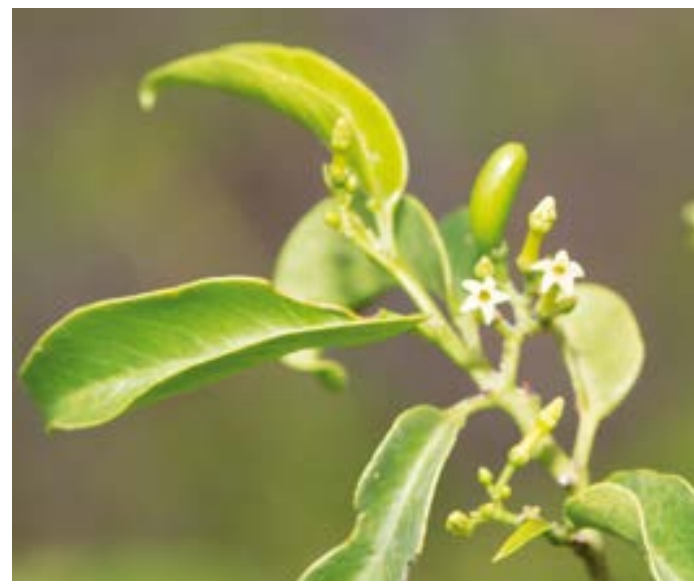

Vallesia glabra

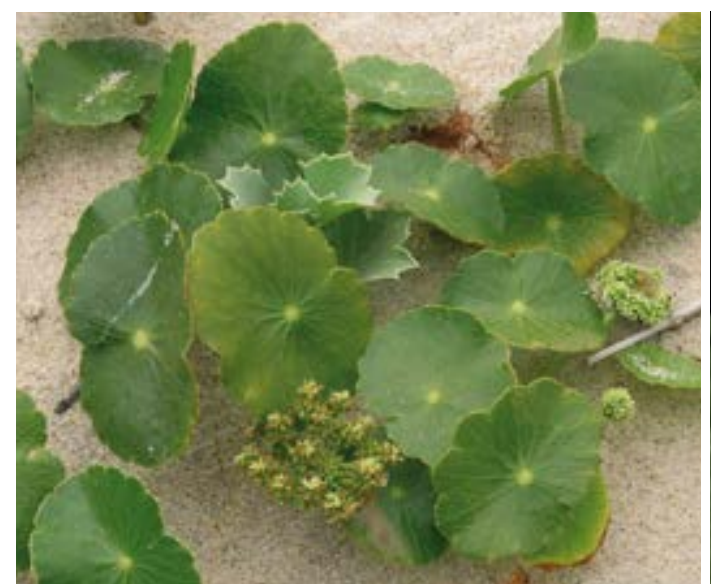

Hydrocotyle bonariensis
Thevetia peruviana

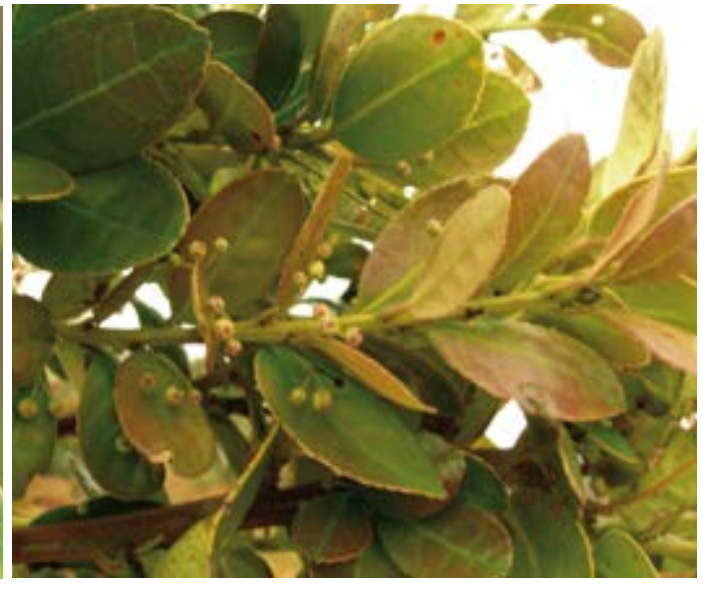

Ilex guayusa

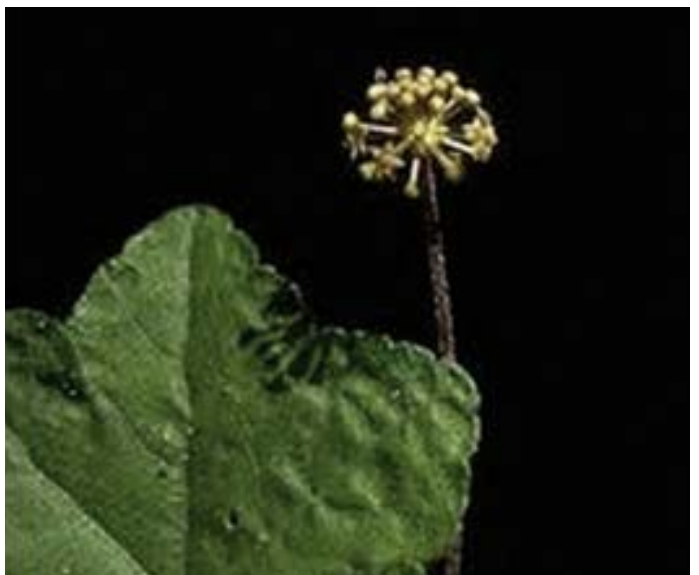

Hydrocotyle globiflora
APOCYNACEAE - Nerium oleander L.

Laurel, Laurel Rosa

Arbusto, Amazonico, Andino, Costa, 0-1500m, introducido, cultivado

Uso: Limpiar heridas, Escosez, Sarna, Irritaciones de la piel, Lesiones de la piel, Herpes / Flores, Hojas y Tallos, fresco / Tópico / Hervir 30g Laurel en 5 litros de agua por 5 minutos. Usar para bańo. Frotar Hojas en piel. No tocar ojos o boca durante el bńo porque hojas son venenosos. lavar cada otro día por 7 días o 3 veces: Martes, Viernes, Martes.

APOCYNACEAE - Thevetia peruviana (Pers.) Schum.

Mailchin, Maichil, Camalonga, Cabalonga

Arbusto, Amazonico, Andino, 0-2500m, maleza

Uso: 1. Bones, Reumatismo, Mal Aire, Artritis, Hechizo de mala suerte (Hechizería) / Tallos y Hojas, fresco / Tópico / Baño: añadir 10g de plant Hojas a 2 litros de agua y Hervir la mezcla por 3 minutos, o Hervir 20 minutos en 5 litros de agua. Aplicar la mezcla templado. Frotar el paciente con Flores y agua. del Después Baño, avisa el paciente de usar ropa abrigada, 2 Baños por semana (Martes y Viernes) o 3-4 veces por mes. No ingerir liquido! 2. Mal Aire, Epilepsia, Nervios, Ataque de Corazón / Semillas, secas / Oral/ Molido y cocido, macerado en Vino con poco alcohol. Debe ser Vino santo de la iglesia. Mezclado con Semillas de siete otras planta: Ashango, Pucho, Amala, Quina Quina, Nuez Mozcada y Ishpingo, una vez al mes o como se necesita. 3. Menopausia, Cancer, Mal Aire, Hechizería/Daño / Semillas, secas / Oral/ Poner 1Semilla de Cabalonga en 1 botella de Vino y deja por 8 días, tomar 1 pequeńo vaso de Vino una vez por día por 20 días o como se necesita.

APOCYNACEAE - Vallesia glabra (Cav.) Link.

Cuncuno, Cun Cun

Arbol, Costa, 0-1000m

Uso: 1. Mordedura de serpiente / Hojas, fresco / Oral/ Hervir 15 Hojas de Cuncuno con 10 Semillas de Fuque y $1 / 8$ litro aceite y 1 litro de agua por 20 minutos. Tomar frío, $1 / 2$ taza dos veces por día ( 6 de la mañana y 6 de la tarde) por 2 dias. No comer pescado o especies (no comer aji!) y mantenerse fuera del luz del sol durante tratamientot. 2. Diabetes / Hojas, fresco / Oral/ Mezclar 15 hojas para un extracto. Paciente debe tomar liquido frío. Tomar solo 6 de la mańana . No comer nada dulce durante el tratamiento, 1 pequeño vaso cada mańana por 30 días.

AQUIFOLIACEAE - Ilex guayusa Loes

Guayusa, Agracejo, Citrodora

Arbusto, Andino, 1000-1500m

Uso: Diabetes, Intoxicación de la sangre / Hojas, seco / Oral/ Té, 5-10g en 1 litro de agua, 1 taza 3 veces por dia como se necesita. Tomar caliente.

ARALIACEAE - Hydrocotyle bonariensis Commerson ex Lam.

Tutapure de Estrella

Hierba, Andino, Costa, 0-4500m, maleza

Uso: Hechizería / Hojas y Tallos, seco / Tópico / 1 manojo hervido en 3 litros de agua. Se puede combinar con Bejuco Amarillo y Palo Blanco, 1 Baño por mes.

ARALIACEAE - Hydrocotyle globiflora R. \& P.

Sombrerito

Hierba, Andina, 1000-2500m, maleza

Uso: Hígado, Inflammación de Riñones / Planta entera, fresco / Oral/ 4 pequeñas Hojas y 2 Flores en 1 litro de agua hervido por 3 minutos. Tomar 3 veces al día por 1 mes. 


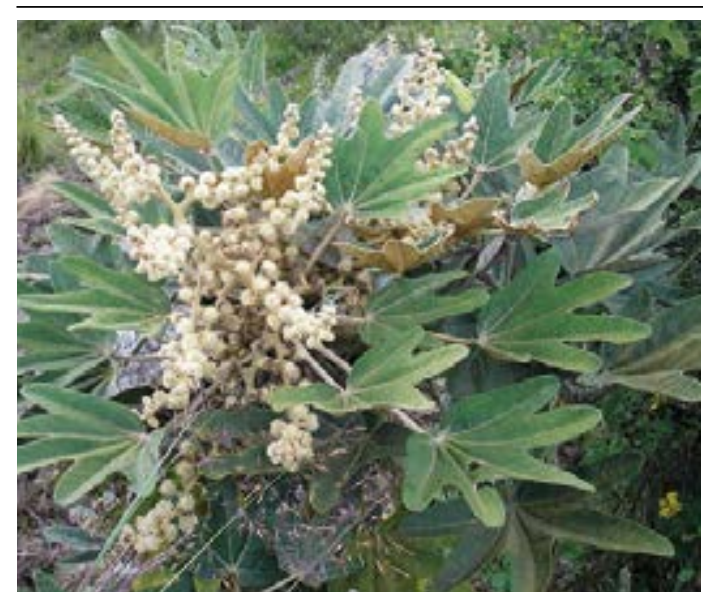

Oreopanax eriocephalus

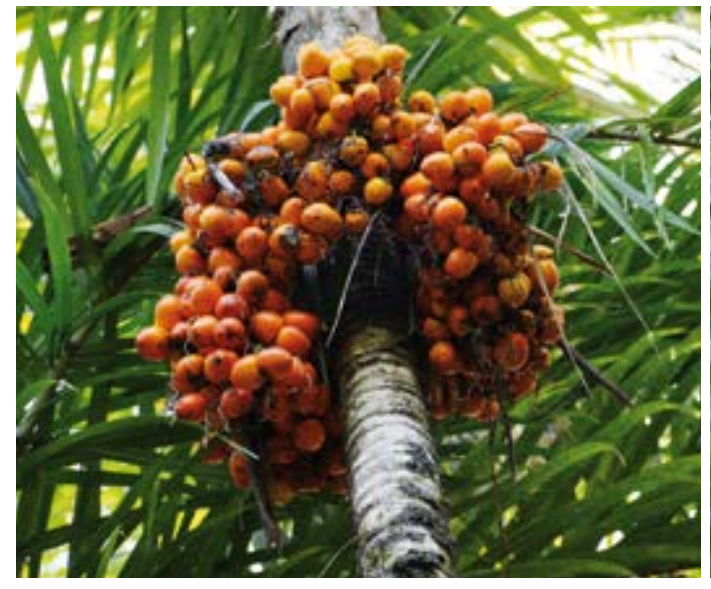

Bactris gasipaes

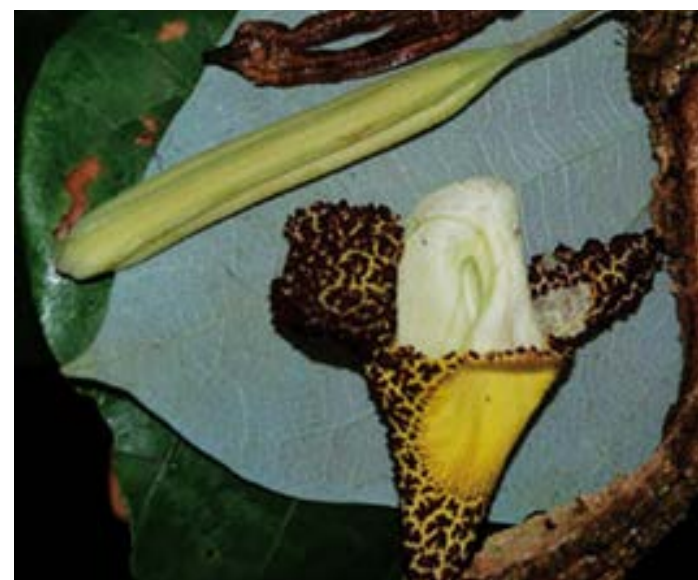

Aristolochia ruiziana

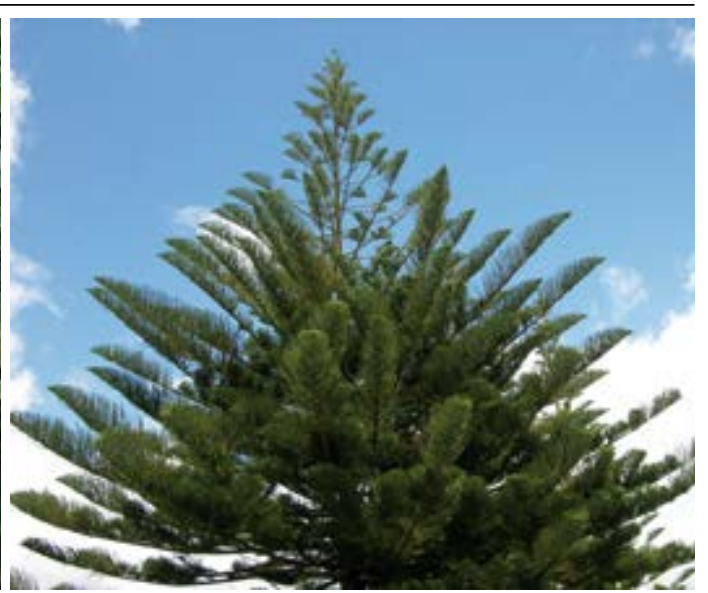

Araucaria heterophylla

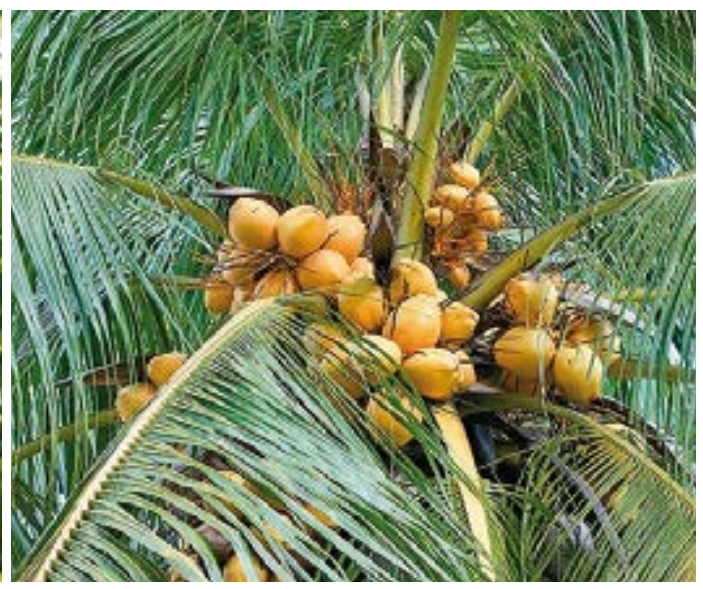

Cocos nucifera

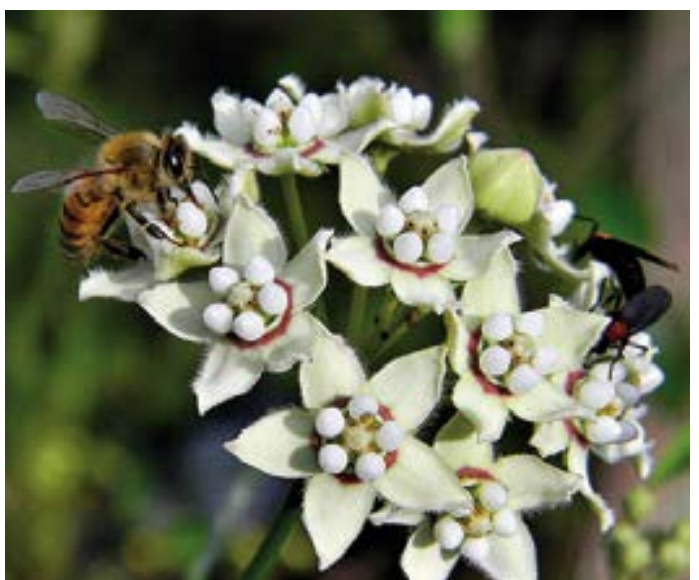

Sarcostemma clausum

\section{ARALIACEAE - Oreopanax eriocephalus Harms}

Maque Maque, Mano de León

Arbusto, Andino, 2500-3500m

Uso: 1. Corazón, Nervios, Inflammación, Fracturas, Sistema nervioso, Reumatismo, Protección del mal

/ Hojas y Flores, fresco / Oral/ Hervir 3-10g en 1 litro de agua. Tomar 3-4 veces por día por 1 mes. 2.

Corazón, Nervios, Inflammación, Fracturas, Sistema nervioso, Reumatismo, Protección del mal / Hojas y Flores, fresco / Tópico / Hervir 3-10g en 1 litro de agua. Tomar como Baño. 3. Susto / Hojas y Flores, fresco / Tópico / $5 \mathrm{~g}$ en 3 litros de agua hervida mezclado con Laurel, Rumilanche, Poleo de Gentil, 7

Espiritus, y Manzanilla Blanca, Romero Castillo y Nogal. Bańo 3 veces por mes.

ARAUCARIACEAE - Araucaria heterophylla (Salisb.) Franco

Pino

Arbol, Andino, Costa, introducido y cultivado

Uso: Dolor de muela, Extraer muelas / Resina, fresco o seco / Tópico / Calentar una pequeña cantidad de resin. Poner resina en diente afectado, 2 veces por dia como se necesita o hasta diente se sana.

\section{ARECACEAE - Bactris gasipaes Kunth}

Chonta

Arbol, Amazonico, $0-500 \mathrm{~m}$, cultivado

Uso: Protección / Madera / Amuleta / Pasar bastón sobre cuerpo rezando.

ARECACEAE - Cocos nucifera L.

Coco

Arbol, Amazonico, Costa, 0-500m, introducido y cultivado

Uso: Diarrea, Parásitos, Inflammación del Hígado, Inflammación (generál) / Cáscara del Fruto, seco / Oral/ Moler 10 Semillas de Coconut y Hervir en 1/4 litro de agua por 20 minutos combinado con 1-2 Hojas de Hierba Luisa, Culen, Hinojo y Poleo. Tomar 3 veces al día por 2-3 días. Tomar leche por Inflammacións.

ARISTOLOCHIACEAE - Aristolochia ruiziana (Klotsch) Duch.

Bejuco de Contra-Aire

Liana, Amazonica, 0-500m

Uso: Desenganchar un apersona que esta confusa o tiene problemas progresar en la vida / Tallos, seco / Oral / Hervir 20g de Bejuco en 1 taza de agua por 10 minutos. Paciente debe tomar liquido frío, solo una vez.

ASCLEPIADACEAE - Sarcostemma clausum (Jacquin) Schultes

Marrajudio

Vine, Amazonico, Andino, 0-2000m, maleza

Uso: 1. Susto, Irritación de la piel, Espinillas, Dolorillos de Resfrío, Marcas en la piel / Hojas, fresco / Tópico / a 2 litros de agua ańadir 10g de Flor de Retama, Quinual, Flor de Chuco y 20g de Eucalipto. Hervir por 3 minutos. Dejar resfriar. Tomar Bańo, 2-3 veces por semana o como se necesita. Alternativa: romper Tallo y colectar resina. Aplicar hasta área afectada, dos veces por día (AM y PM) como se necesita. 2. Promover lactancia después del partyo / Hojas, fresco / Oral/ Hervir 5 Hojas y 1 Tallo de la planta en $1 / 2$ litro de agua por 10 minutos. Tomar frío, 1 pequeńa taza 3 veces por semana, solo de la mańana . 

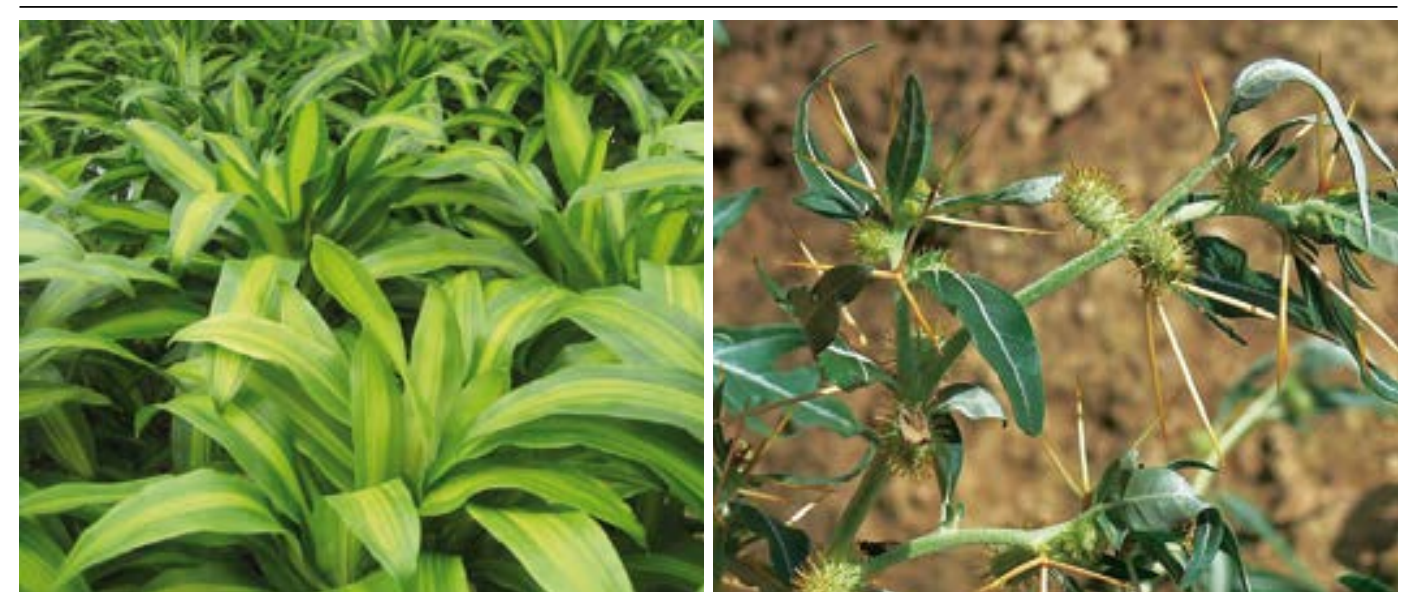

Dracaena fragrans

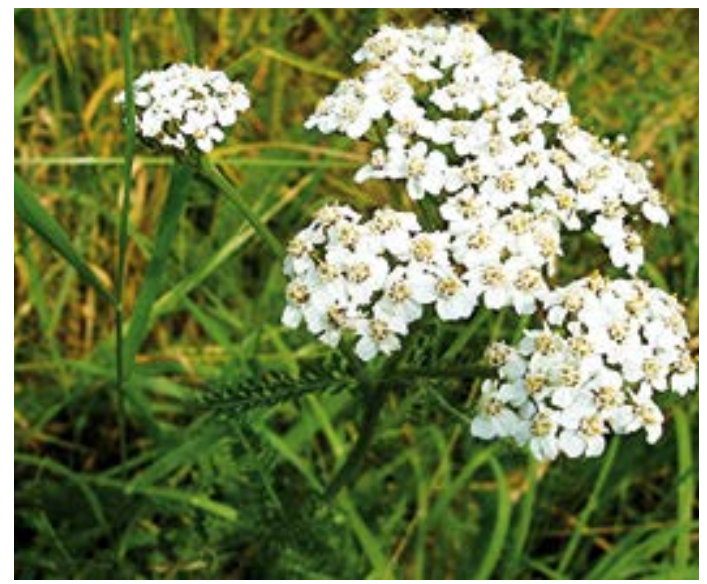

Acanthoxanthium spinosum

Achillea millefolium

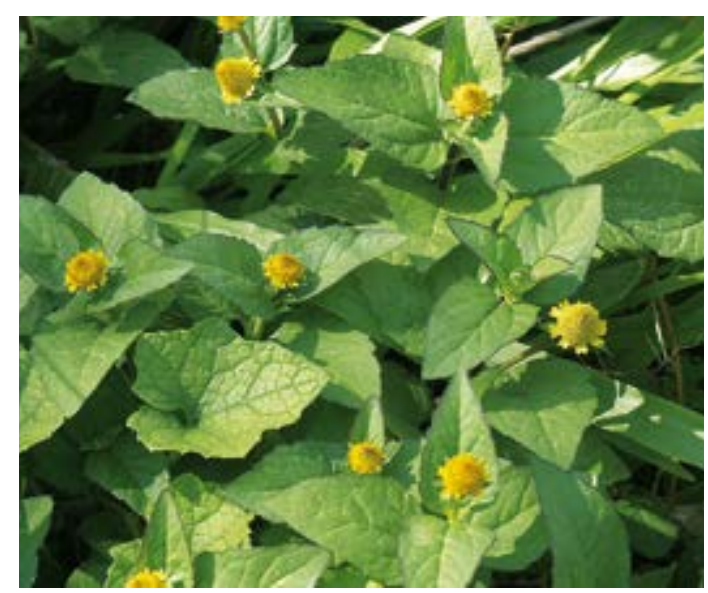

Acmella ciliata

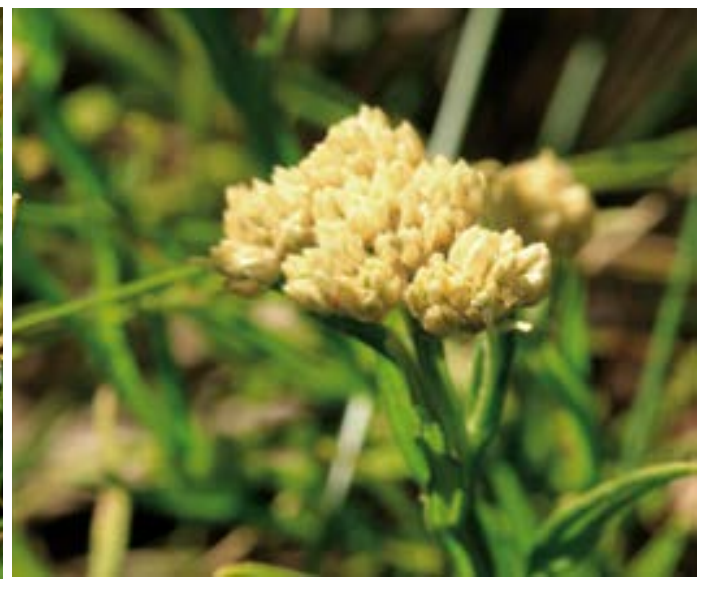

Achyrocline alata

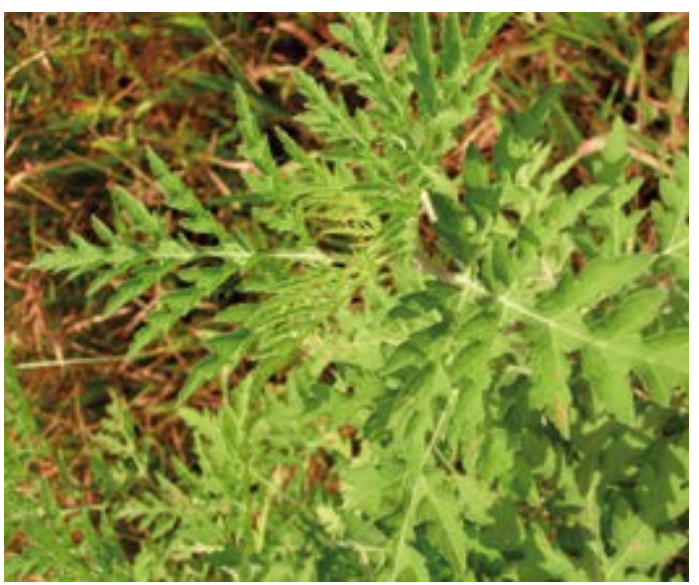

Ambrosia arborescens
ASPARAGACEAE - Dracaena fragrans Ker Gawl

Flor de Dracena

Arbol, Andino, Costa, 0-2000m, introducido

Uso: Tos, Bronquitis, Asma / Hojas y Tallos, fresco o seco / Oral/ Hervir 10g en 1 litro de agua, 3 tazas.

ASTERACEAE - Acanthoxanthium spinosum (L.) Fourreau

Juan Alonso, Espina de Perro, Corona de Cristo

Hierba, Andina, 2000-3500m, maleza

Uso: Detoxificacíon de alcohol y drogas, Inflammación, Bronquitis, Haemoragias / Planta entera, fresco

o seco / Oral/ Hervir 10g de material de planta con 1 litro de agua por 3-5 minutos. Ańadir semillas de Alcaparrilla y Guava. Tomar caliente, 1-2 litros por día, por 2-3 meses.

ASTERACEAE - Achillea millefolium L.

Milenrama, Chonchon

Hierba, Andina, 2500-3500m, introducido y cultivado

Uso: 1. Gastritis, Diabetes, Sangre, Cólesterol / Flores y Hojas, fresco / Oral/ Hervir 3-5g en 1 litro de agua y Tomar 3 veces al día por 1 semana. 2. Infección de la piel, Disipar Hechizos / Flores y Hojas, fresco / Tópico / 1 manojo en 5 litros de agua hervida, 3 Baños por mes en la noche.

ASTERACEAE - Achyrocline alata (Kunth) DC.

Ishpinguillo, Ishpingo, Flor de Ishpingo

Hierba, Andina, 2000-4500m, maleza

Uso: 1. Susto, Daño/Hechizería en niños, Artritis, Huesos / Tallos y Hojas, seco / Tópico / Bańo y Limpia: $5 \mathrm{~g}$ hervido en 3 litros de agua mezclado con Añasquero Grande, Ajenco y Tres Hojas, 2 veces por mes. Alternativo, $1 / 2 \mathrm{~g}$ hervido 10 minutos para Bańo. 2. Artritis, Huesos / Tallos y Hojas, seco / Tópico / Emplasto: Usar 1 manojo de fresco Hojas con 7 Espiritus y Vinagre por 6 horas, dos veces por mes o hasta enfermedad requiere.

ASTERACEAE - Acmella ciliata (Kunth) Cass.

Ufla

Hierba, Amazonica, Andino, Costa, 0-3000m, maleza

Uso: Hemorragia intrena, Hemorragia renal, Resfrío con mucho mucus / Raíz, seco / Oral/ Hervir 100g de Ufla y $100 \mathrm{~g}$ de Menta en 1 litro de agua por 10 minutos. Paciente debe tomarlo templado 2 veces por día por 3 dias.

ASTERACEAE - Ambrosia arborescens Mill.

Ambrosia

Hierba, Andina, Costa, 500-4500m, maleza

Uso: 1. Florecimiento / Planta entera, fresco / Tópico / Mezcla Alternativa para Florecimiento. Solo una vez. 2. Buenos Negocios, Protección, Buena Fortuna, Buena Salud / Planta entera, fresco / Seguro / Mezcla Estandar para Seguro. 


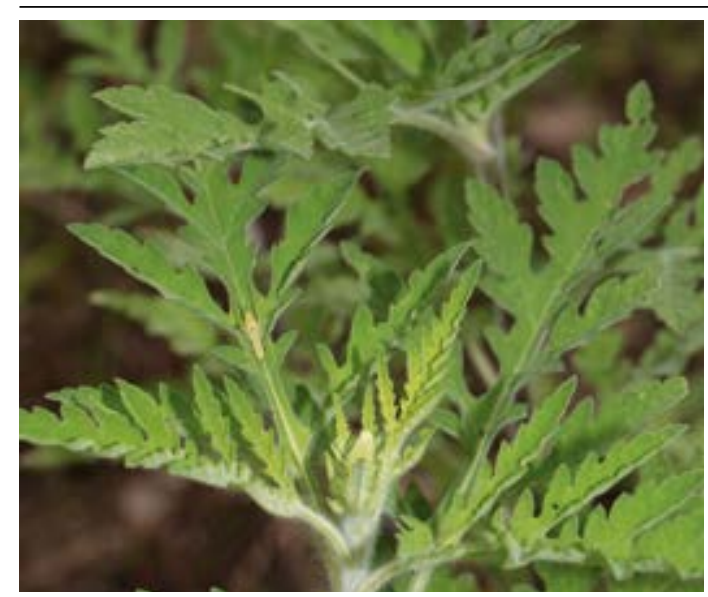

Ambrosia peruviana

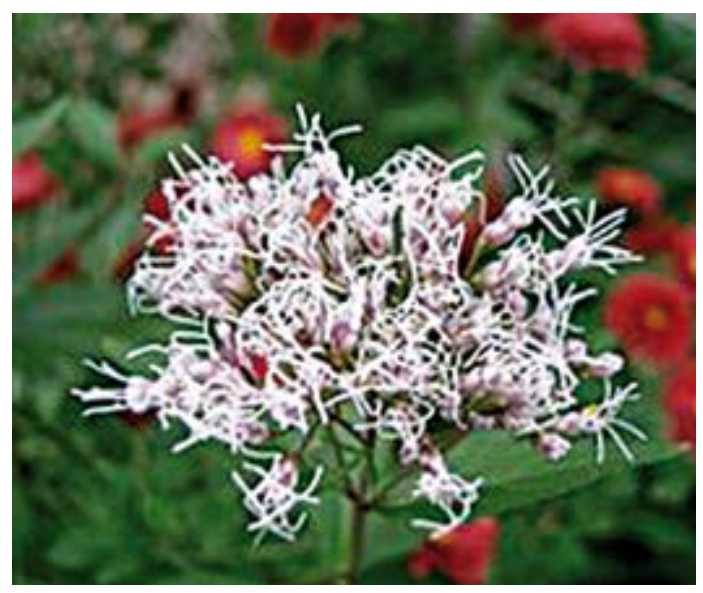

Aristeguietia gayana

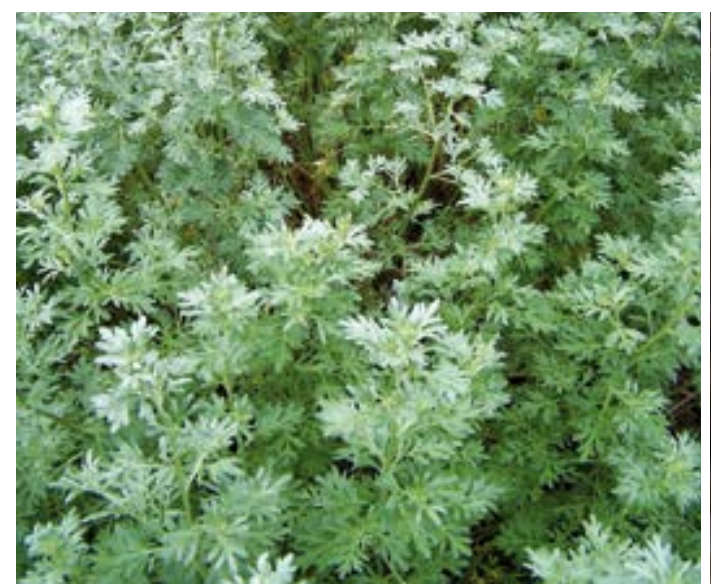

Artemisia absinthium

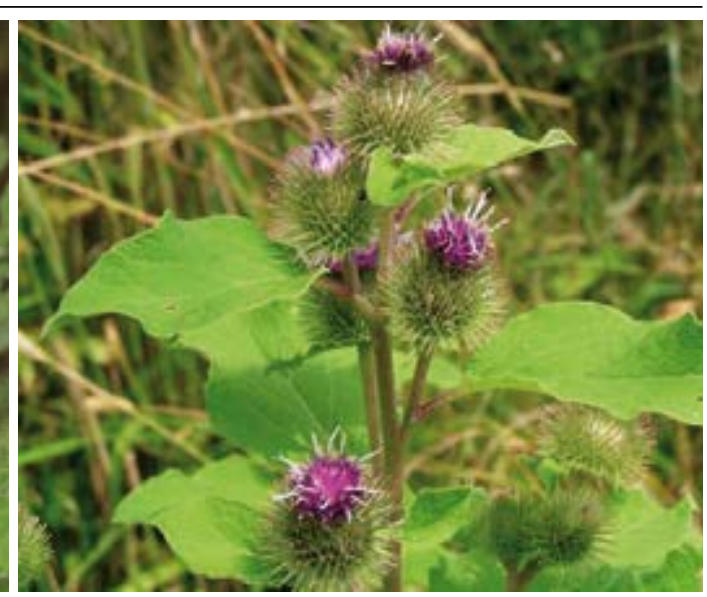

Arctium lappa

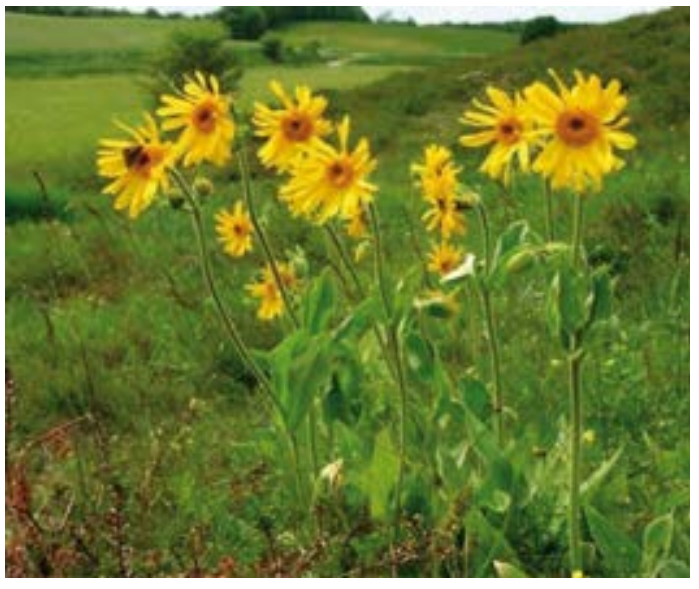

Arnica montana

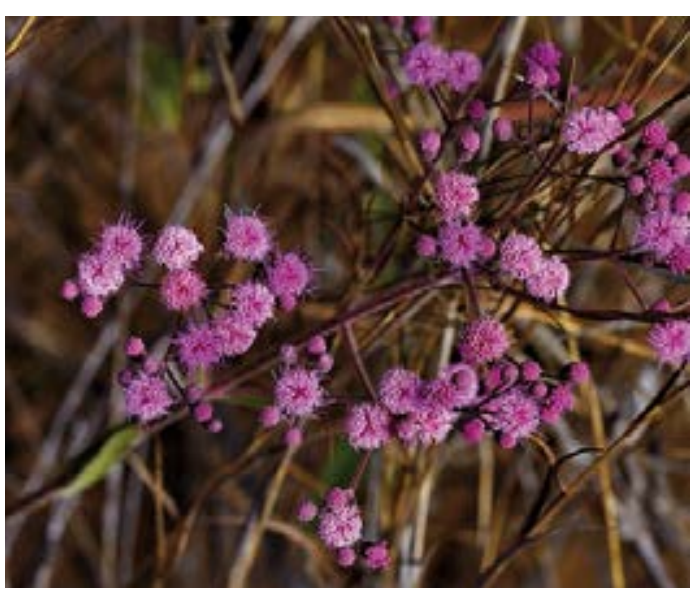

Ayapana amygdalina
ASTERACEAE - Ambrosia peruviana Willd.

Altamisa, Marco, Artamisa, Manzanilla del Muerto, Marcos, Alta Misa, Ajenco, Altamis, Llatama Negra Malera, Llatama Roja Malera

Hierba, Amazonica, Andina, Costa, 0-1500m, maleza

Uso: 1. Corazón, Nervios, Epilepsia, Hígado, Bronquitis, Resfríos, Mal Aire, Quemars / Hojas y Tallos, fresco / Oral / Hervir en 1 litro de agua por 2 minutos, despues mezclar agua con un total de $10 \mathrm{~g}$ de Manzanilla, Madre Selva, Hinojo, Borraja, Madre Selva, Toronjil, Manzanilla, Hinojo y Chancas de Comida por Nerve Disorders. Usar Boldo, Malva y Linaza por Hígado ailments. Usar Matico, Borraja, Eucalipto, Vira Vira y Brochamelia por Bronquitis. Cubrir y dejar por 2-3 minutos. Tomar templado, 3-4 tazas por día por un mes. Resfríos: Hervir $1 / 2$ litro de agua con $50 \mathrm{~g}$ de Altamiz y $10 \mathrm{~g}$ de Sauce, Chicoria, y Pájaro Bobo por 10 minutos. 2 cucharas cada 8 horas por 8 dís. 2 Honosos, Susto / Hojas y Tallos, y Pajaro Bobo por 10 minutos. 2 cucharas cada 8 horas por 8 dias. 2. Hongos, Susto / Hojas y Tallos, rresco / Topico / Hervir 200g en 3 litros de agua, 7 Espiritus y Agua de Susto. Usar un s Emplasto o Baño, 6 hrs por Baño, 2 veces por mes por 1 mes; por Susto 3 veces por semana: Martes, Viernes y el siguente Martes. 3. Después del parto para reducir calambres y inflamación en el utero / Hojas y Tallos, fresco / Tópico / Emplasto: Machucar 200g de Leaf y ańadir 5 gotas de Trementina (Turpentine). poner Emplasto en área afectada (abdomen de la mujer) y cubrir con tela. Dejar por 2 horas, 2 veces con pausa de 2 dias.

ASTERACEAE - Arctium lappa L.

Lampazo

Hierba, Andina, Costa, 0-3000m, introducido

Uso: Problemas Urinarias, Piel, Hígado, Vesicula, Intestinos, Tumores / Semillas, secas / Oral/ Hervir por 5 minutos $1 / 2$ litro de agua con $10 \mathrm{~g}$ de Cadillo, Amor Seco y Trińozo. Tomar templado, 1-2 tazas 3 veces por día por 20 días como se necesita.

ASTERACEAE - Aristeguietia gayana (Wedd.) R.M. King \& H. Rob.

Asma Chilca, Asma Chica

Arbusto, Andino, Costa, 2000-3000m

Uso: 1. Tos, Bronquitis, Asma / Hojas, fresco / Topcial / Emplasto: 200g con Balsamo de Buddha, 2 veces por mes. 2. Tos, Bronquitis, Asma / Hojas, fresco / Oral/ Hervir 5g en 1 litro de agua mezclado con Tilo, Huamanripa, Borraja y Nogal, 4 tazas por día por 10 dias.

\section{ASTERACEAE - Arnica montana L.}

Arnica

Hierba, solo disponible en extracto, introducido

Uso: Para despertar a una persona desmayada, para mantener espiritus malos lejos d ela casa / Tallo y Hojas / Amuleta / Poner cerca del paciente para inhalar. Chapotear todas las esquinas de la casa y el centro y hacer cruz en la puerta.

ASTERACEAE - Artemisia absinthium L.

Ajenco

Hierba, Andino, 2500-3500m, introducido y cultivado

Uso: 1. Susto en Niños, Hechizería / Hojas, fresco / Tópico / Natural, como Limpia, 1 manojo con Vinagre, Añasquero Grande, Añasquero Chico, Flores del Muerto, Hierba del Susto, 7 Espiritus y Agua del Susto, dos veces por semana (Martes y Viernes). 2. Susto en Nińos, Hechizería / Hojas, fresco / Tópico / Baño: con Añasquero Grande, Ruda Hembra, 7 Espiritus, y Agua del Susto (si se trata de Susto), dos veces por semana. 3. Hechizería / Hojas, fresco / Tópico / Baño: con Añasquero Grande, Ruda Hembra, 7 Espiritus, y Agua del Susto (si se trata de Susto), dos veces por semana. 4. Cólicos menstriales, Menstruación, regulación menstrual / Planta entera, especialmente Hojas y Tallos, fresco / Oral/ Té: 6-10 Hojas en 1 taza de agua hervida. 1 taza cada día por 3 días o ańadir $100 \mathrm{~g}$ de la planta a 1 taza de agua. Hervir la mezcla por 5 minutos, tomar $1 / 4$ taza, una vez por día, por 3 días.

ASTERACEAE - Ayapana amygdalina (Lam.) R.M. King \& H. Rob.

Chilco Hembra

Arbusto, Amazonico, Andino, Costa, 0-2000m

Uso: Irritación de piel / Hojas y Tallos, fresco / Tópico / Hervir 5 litros de agua con 20g de material de planta y Laurel por 5 minutos (como una Tisana). Baño 2 veces por día por 1 semana. 


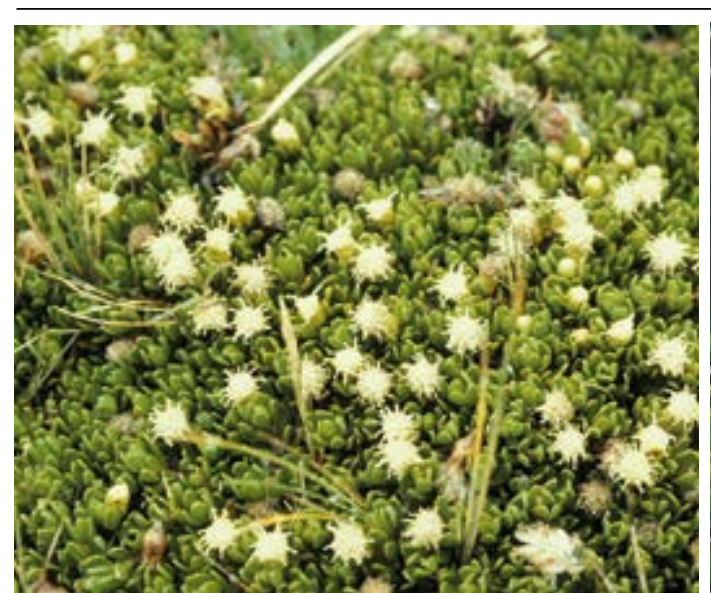

Baccharis caespitosa

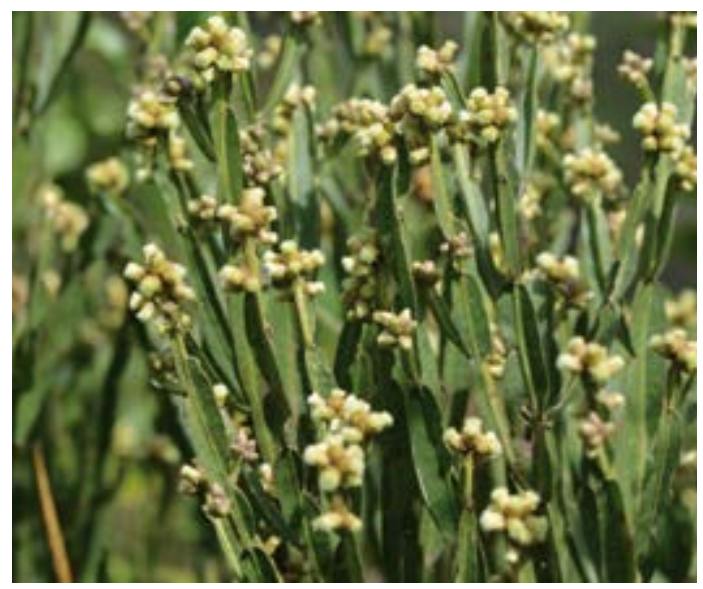

Baccharis genistelloides

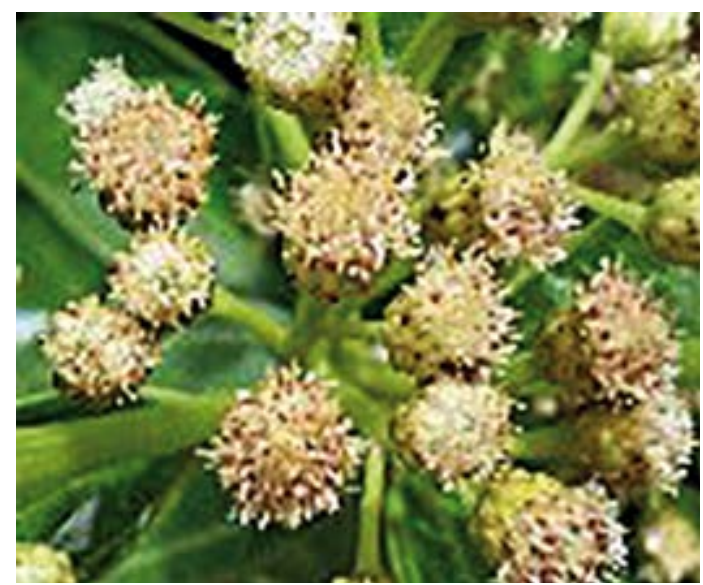

Baccharis pedunculata

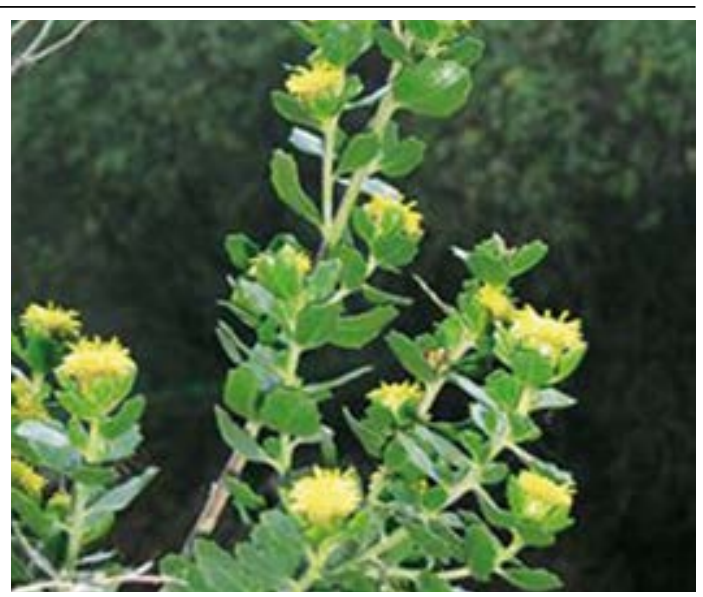

Baccharis chilco

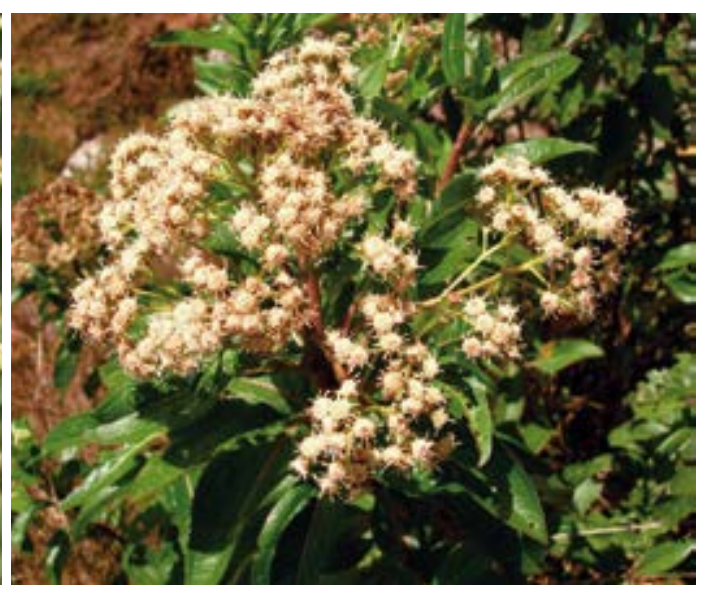

Baccharis latifolia

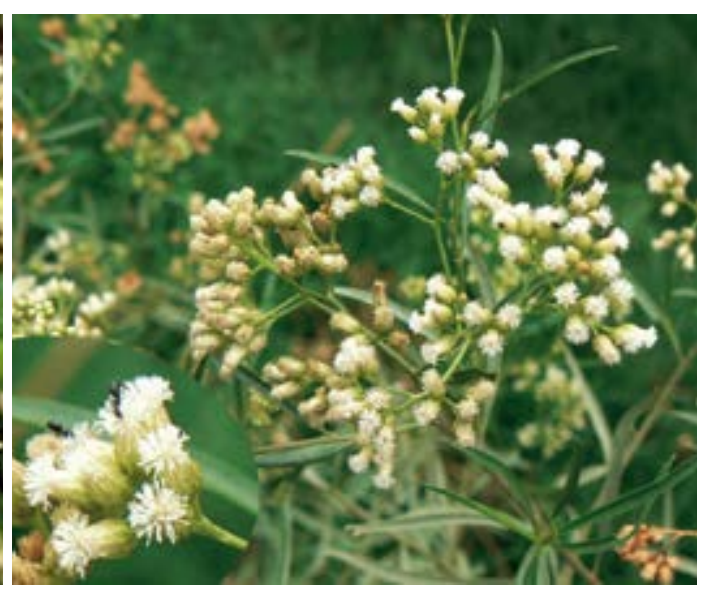

Baccharis salicifolia
ASTERACEAE - Baccharis caespitosa (Ruiz \& Pav.) Pers

Paja Amargoza

Arbusto, Andino, 3000-4000m

Uso: Hinchazónes / Flores y Hojas, fresco / Tópico / Moler 500g de material y aplicar como Emplasto , una vez por día por 8 días en área afectada.

ASTERACEAE - Baccharis chilco Kunth

Pata de Gallina

Hierba, Andina, 1000-3000m

Uso: Protección para trabajo y casa, Protección (generál) / Planta entera, fresco o seco / Seguro / Mezclar en una botella $10 \mathrm{~g}$ de Valeriana Estrella, Seńorita, Carpintero, Chupa Flor, Hierba de la Coqueta, Oro, Dolar. Añadir Agua Florida, Ramillete de Novia, Tabú y Agua Bendita. Poner en mesa cerca de la cama.

ASTERACEAE - Baccharis genistelloides (Lam.) Pers.

Simba Simba, Carceja, Karqueja, Cadillo

Hierba, Andina, 500-4500m

Uso: Diabetes, Sangre, Cólesterol, Riñones, Inflammación Interna, Hígado, Vesicula, Calvicie, Reducción de grasa / Planta entera, fresco / Oral/ Hervir 10g en 1 litro de agua por 2 minutos mezclado con Canchalagua, Verbena, Amor Seco, Cola de Caballo, Hierba del Toro, Camote. Tomar por deayuno y cena, 1 litro por día por 1 semana a 1 mes.

ASTERACEAE - Baccharis latifolia (Ruiz \& Pav.) Pers.

Chilca Chica, Chilca Grande

Arbusto, Andino, 1000-4500m

Uso: 1. Dolor de huesos, Reumatismo, Artritis / Hojas y Tallos, fresco o seco / Tópico / Baño: 5g en 3 litros de agua mezclado con Manzanilla Blanca, Hierba del Susto, Laurel y Agua del Susto, 2-3 Baños por 1 mes. Limpia: una vez por semana. 2. Dolor de huesos, Reumatismo, Artritis / Hojas, fresco / Tópico I Emplasto: 200g de fresco Hojas mezclado con 7 Espiritus. Aplicar 1 manojo de Hojas frescas por 6 horas, $2-3$ veces por mes.

ASTERACEAE - Baccharis pedunculata (Mill.) Cabr.

Pasto Miel

Arbusto, Andino, 500-2500m

Uso: Quistes, Heridas (coagulado), Abscessus / Planta entera, seco / Tópico / Hervir con Agua Florida. Poner Emplasto caliente en área afectada con tela. Dejar por 2 días y vaya absorber el quiste.

ASTERACEAE - Baccharis salicifolia (R. \& P.) Pers.

Hierba de la Plata, Chilco Hembra, Chilco Macho

Arbusto, Amazonico, Andino, Costa, 0-3500m, maleza

Uso: 1. Buenos Negocios, Protección, Buena Fortuna, Buena Salud / Planta entera, fresco / Tópico / tive mezcla por Florecimiento. Baño once. 2. Buenos Negocios, Protección, Buena Fortuna, Buena Salud / Planta entera, fresco / Seguro / Mezcla Estandar para Seguro. 3. Alergías, Irritación de la piel, Espinillas / Planta entera, fresco / Tópico / tive mezcla por Florecimiento. Bańo una vez. 4. Diabetes / Planta entera, fresco / Oral/ Hervir 1 litro de agua y 100g del material. Tomar mezcla 3 veces por día por 1 mes. 


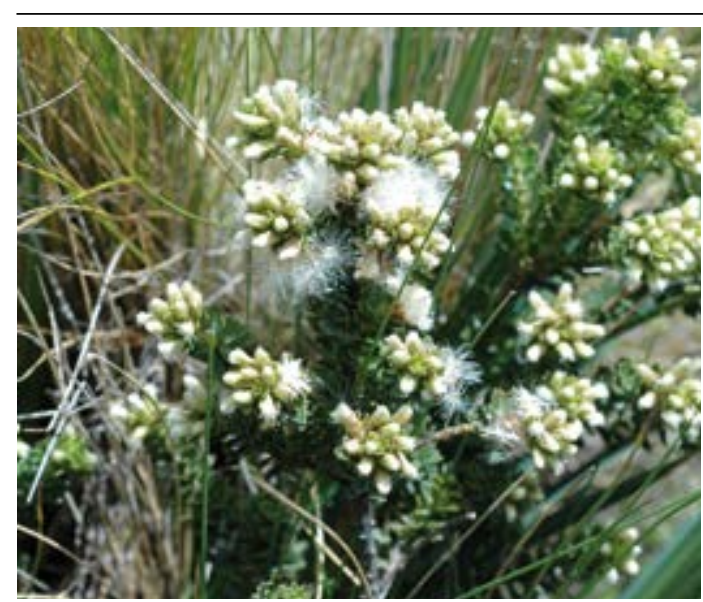

Baccharis tricuneata

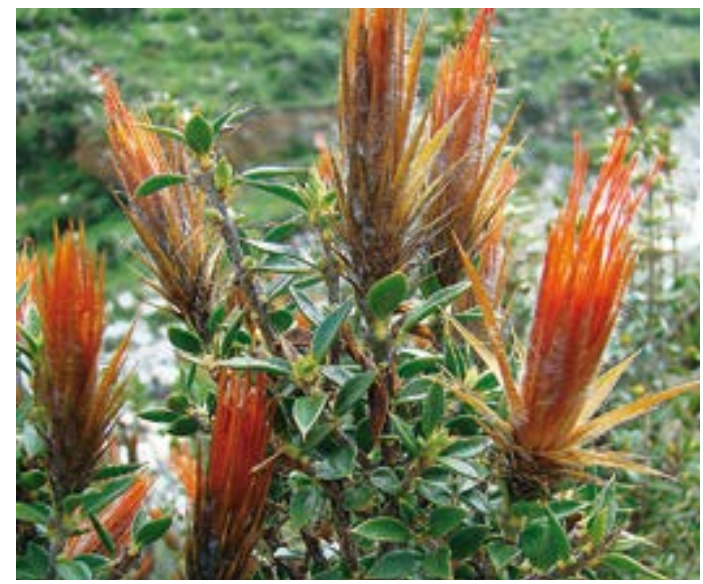

Chuquiragua spinosa

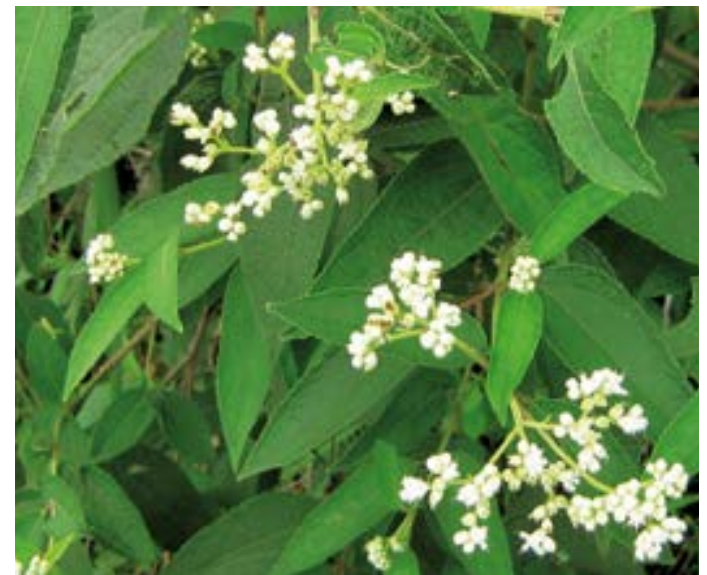

Clibadium sylvestre

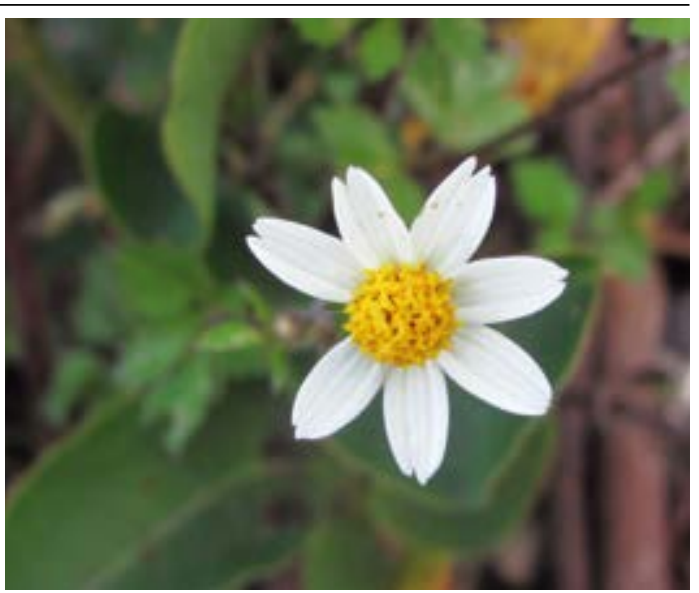

Bidens pilosa

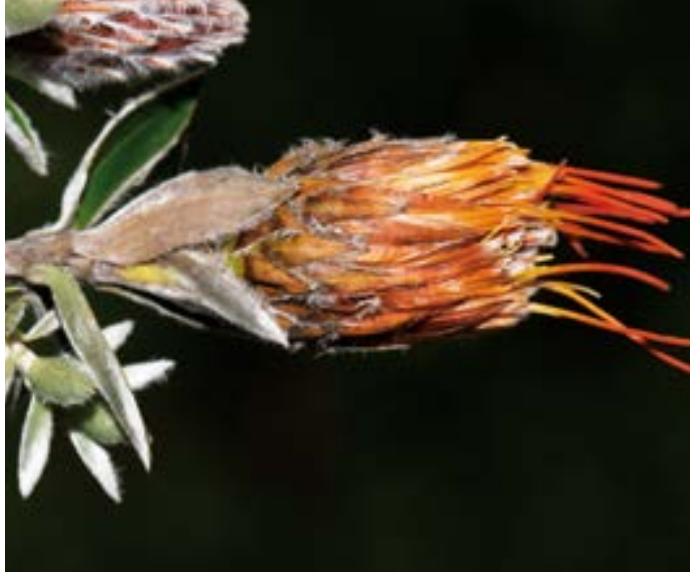

Chuquiragua weberbaueri

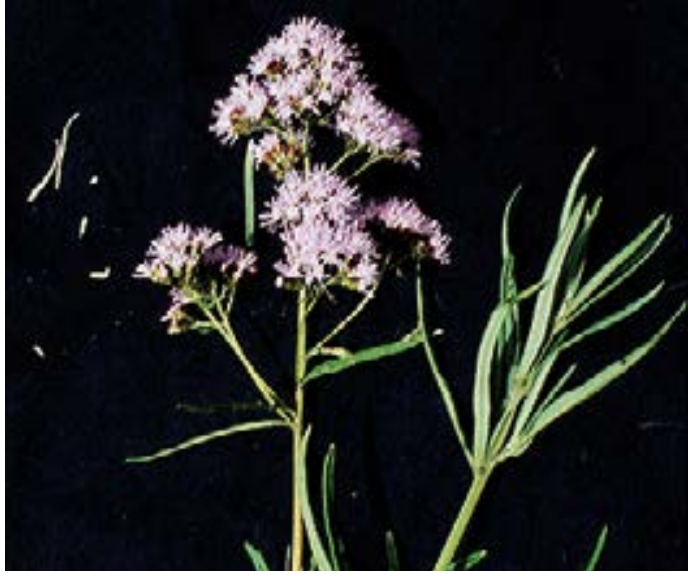

Cronquistianthus lavavandulaefolius
ASTERACEAE - Baccharis tricuneata (L.f.) Pers.

Sigueme Sigueme

Arbusto, Andino, 2000-4500m

Uso: 1. Buena Suerte, Florecimiento / Florecimiento / Flores y Hojas, fresco / Tópico / Mezcla Estandar para Seguro. Combinado con oración evocando nombre de paciente, dueño de Seguro. Soplar Martes y Soplar y masajar el paciente por buena suerte.

2. Buena Suerte, Florecimiento / Florecimiento / Flores y Hojas, fresco / Tópico / Baño en 50g de: Hierba del Lucero, Hierba del Este, Ambrocilla, Señorita, Caballero, Pega Pega, Siempre Viva, Carpintero, Waime Waime, Piri Piri (Hembra y Macho), Hierba del Buen Querer, Hierba del Oro, Hierba de la Plata, Hierba del Halago, Sigueme Sigueme y Hierba del Negocio. Hervir en 5-7 litros de agua por 20 minutos, añadir un poco de los perfumes siguentes: Carińo, Dios de la Huaringa, Dios de la Felicidad, San Antonio, Macumba Pusanga, Gran Jefe, Mil Flores, Llama Plata y Ekeko. Dejar enfriarse un poco antes de bañarse, 2 veces (Martes y Viernes solo) cada 3 meses.

ASTERACEAE - Bidens pilosa L.

Amor Seco, Cadillo, Tres Esquinas, Carqueja

Hierba, Amazonica, Andina, Costa, $0-4500 \mathrm{~m}$, maleza

Uso: 1. Vesicula, Inflammación de Riñones, Inflammación (generál), Rińones, Prostata, Perdida de Cabello, Diabetes, Hígado, Sangre, Corazón / Planta entera, fresco o seco / Oral/ $10 \mathrm{~g}$ en 1 litro de agua combinado con Chacur, Unquia, Flor de Arena, Espiga de Maiz, Cola de Caballo, Guanábana, Pimpinela y las Flores de Azares. Tomar 1 taza 4 veces por día por 1 mes. 2. Vesicula, Inflammación de Riñones, Inflammación (generál), Riñones, Prostata, Perdida de Cabello, Diabetes, Hígado, Sangre, Corazón / Planta entera, fresco o seco / Tópico / Mizma mezcla para Baño.

ASTERACEAE - Chuquiragua spinosa Lessing ssp. huamanpinta C. Ezcurra

Chuquiragua, Huamanpinta

Arbusto, Andino, 3000-4500m

Uso: Inflammación, Rińones, Prostata, Vejiga, Inflammación de Prostata, Impotencia sexual / Hojas, seco / Oral/ Hervir 5-10g en 1 litro de agua por 3-5 minutos, 1-4 tazas por día por 15 días o como se necesita. Para impotencia, macerar 6 plantas por 8 días en Vino en botella de 1 litro. Mezclar con Huevos del Angelote, Pollen, Catachi y Viril de Oso. Tomar como se necesita.

ASTERACEAE - Chuquiragua weberbaueri Tovar

Amaro Amaro

Arbusto, Andino, 3000-4500m

Uso: Tos, Bronquitis, Asma, Hígado, Mal Aire / Planta entera, fresco o seco / Oral/ Hervir 10g en 1 litro de agua por 3-4 minutos con Eucalipto, Matico, Mullaca, Muńa y Flor de Overo. Tomar una taza 3-4 veces por día por 1 mes.

ASTERACEAE - Clibadium sylvestre (Aubl.) Baill.

Flor de Novia

Hierba, Amazonica, Andina, 0-1500m

Uso: Resfrío, Antes de casarse / Flores, Hojas y Tallos, fresco o seco / Tópico / 1 manojo con 20 gotas de perfume en 3 litros de agua hervida, 3 Baños por mes.

ASTERACEAE - Cronquistianthus lavavandulaefolius (DC.) R.M. King \& H. Rob.

Clavelillo, Espino de Hoja, Pulmonária

Hierba o Arbusto, Amazonico, Andino, Costa, 500-4000m

Uso: Tos, Bronquitis, Dolor de Cabeza, Resfrío, Asma, Enfermedad pulmonar / Flores, Hojas y Tallos, fresco o seco / Oral/ Combinar 10g de material de planta con Matico, Zarzamora, Nogal, Salvia, Borraja, Llatama, Vira Vira y Hervir en 1 litro de agua. Hervir la mezcla por 3-4 minutos. Tomar 1 litro cada día por 3 meses. 


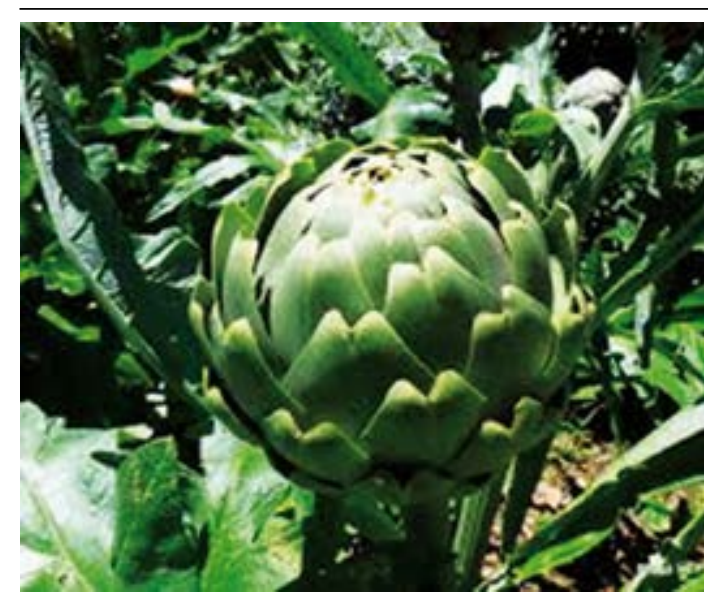

Cynara cardunculus

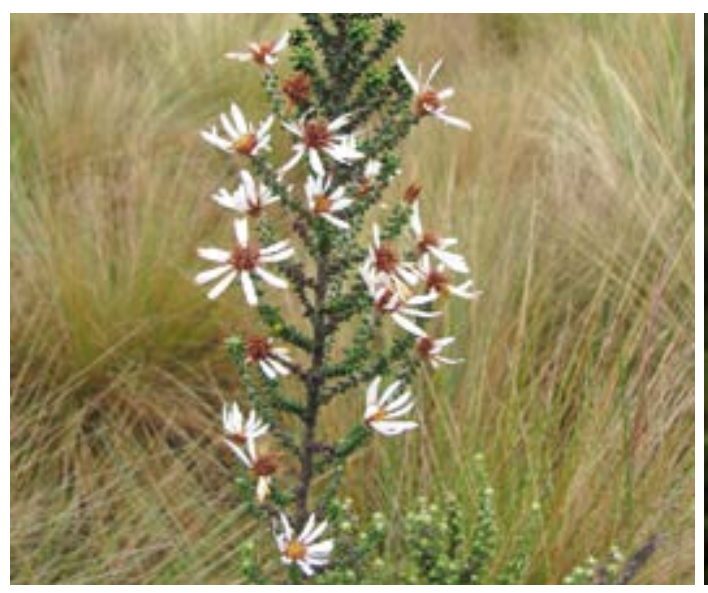

Diplostephium sagasteguii

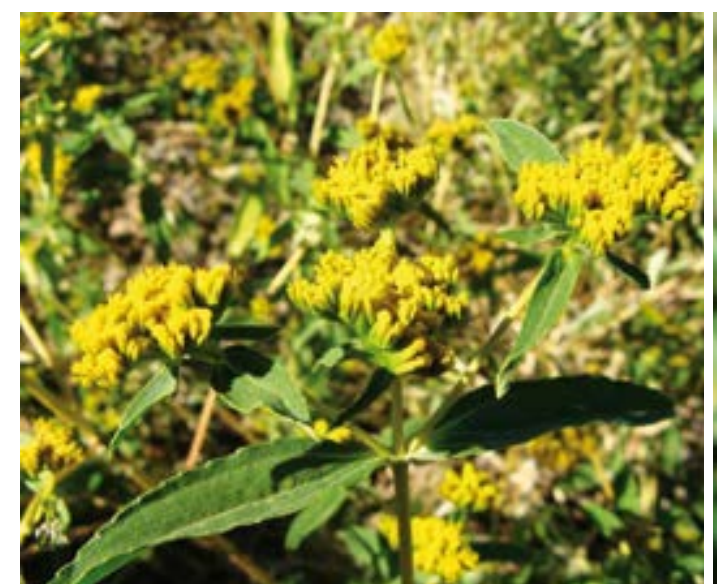

Flaveria bidentis

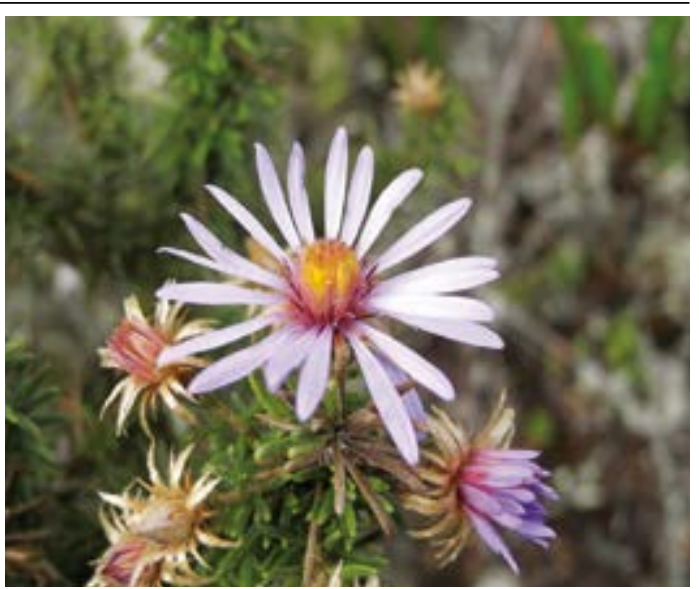

Diplostephium gynoxyoides

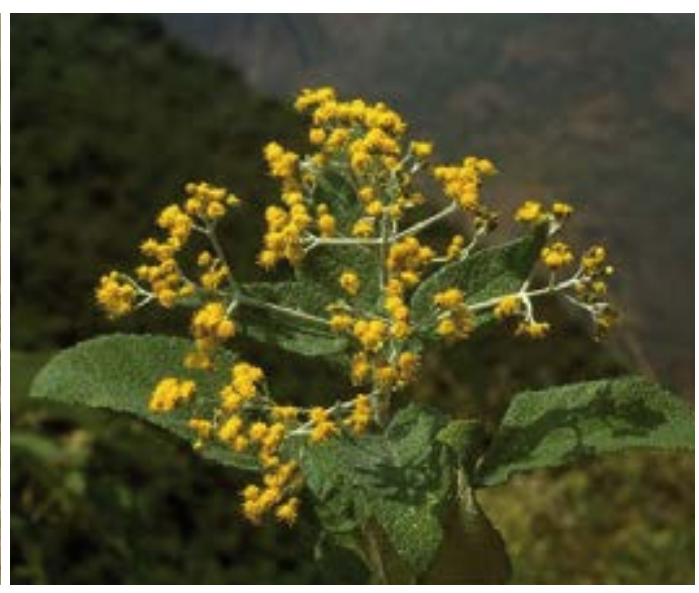

Ferreyranthus verbascifolius

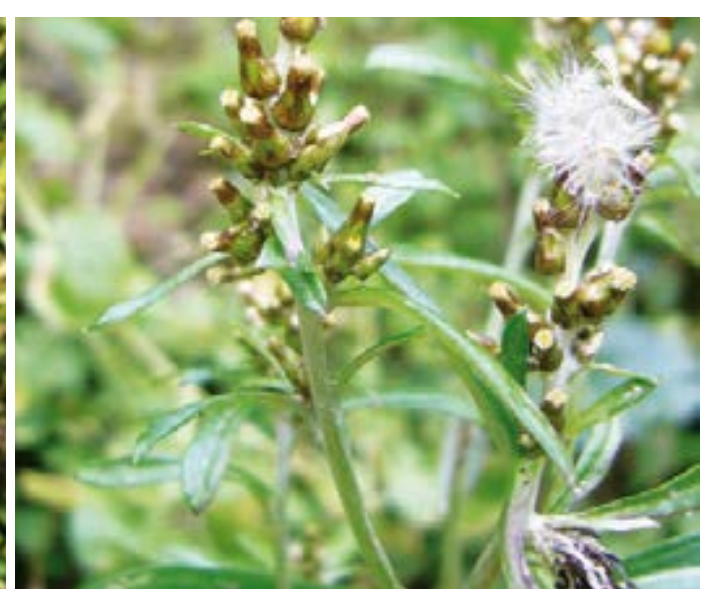

Gamochaeta americana
ASTERACEAE - Cynara cardunculus L.

Alcachofa

Hierba, Andina, Costa, 0-3500m, introducido y cultivado

Uso: 1. Diabetes, Perdidad de memoria, Cansancio fisico, Hígado, Purificación de la Sangre, Cansancio mental / Tallos y Hojas, fresco o seco / Oral/ Hervir 10g en 1 litro de agua por 5 min; 1 litro por día o 3-4 vasos por día. 2. Pérdida de Peso / Tallos y Hojas, fresco o seco / Oral/ Añadir 1 litro de agua a 1 Alcachofa y Hervir por 5 minutos. Tomar 1 taza 3 veces por día por 1 mes.

ASTERACEAE - Diplostephium gynoxyoides Cuatrec.

Parrano

Arbusto, Andino, $2500-3500 \mathrm{~m}$

Uso: 1. Resfrío, Inflammación de pulmones / Flores, fresco / Oral/ Hervir 10 Flores de Parrano y 4 Hojas de Chicoria en 1/2 taza de agua por 2 minutos. Paciente debe tomarlo caliente, 3 cucharas 3 veces por día por 5 días. 2. Mal Aire / Flores, fresco / Tópico / Machucar $2 \mathrm{~kg}$ de Hojas de Parrano con $200 \mathrm{~g}$ de Flor de Muerto, Frijol Chileno, Garlic y Agua Cananga. Ponersobre área afectada y cubrir con tela por 3 horas.

ASTERACEAE - Diplostephium sagasteguii Cuatrec

Hierba del Tigre

Arbusto, Andino, 3500-4500m

Uso: 1. Mal Aire, Fragancia, Buena Suerte en el trabajo, Hechizería/Daño (prevención), Deshacer malas cosas hecho al paciente, Fuerza, Maldad (curar), Mal Ojo / Hojas y Tallos, fresco o seco / Oral/ Hervir $10 \mathrm{~g}$ de Hierba del Tigre, $10 \mathrm{~g}$ de Hierba del Oso y $10 \mathrm{~g}$ de Semora Negra con 3 Hojas de Toro Cimuro y 3 Hojas de Misha Amarilla en 1/2 taza de agua por 5 minutos. Comouesto muy fuerte, ninca exidir dosis: 1/8 taza solo una vez. Tomar frío. Paciente debe quedarse dentro sin luz y ruido por 3 días. Debe obesrvar dieta especial (sin especies ni marisocs). 2. Protección del mal / Hojas y Tallos, fresco o seco / Tópico / Mezcla de Baño por Protección del Mal. Solo una vez. 3. Mal Aire, Fragancia, Buena Suerte en el trabajo, Hechizería/Daño (prevención), Undo bad things done hasta the victim, Strength, Evil/ Maldad (cure), Mal Ojo / Hojas y Tallos, fresco o seco / Seguro / 2 pequeñas ramas por Seguro.

ASTERACEAE - Ferreyranthus verbascifolius (Kunth) H. Rob. \& Brettell

Tutapure Amarillo, Tutapure Amarillo (Grande)

Arbusto, Andino, $1000-3000 \mathrm{~m}$

Uso: Susto, Diarrea en niños causado por Susto, Daño/Hechizería / Planta entera, fresco / Tópico / Mezclar con Timolina, 2 veces por semana como Limpia. mezclado con Tutapure Negro, Manzanilla Blanca, Añasquero Chico, Ruda Chingue, Conchalay, Ticra, Manzanilla y 7 Espiritus como Baño, 3 veces por semana. Se puede usar como Bańo una vez al mes.

ASTERACEAE - Flaveria bidentis (L.) Kuntze

Mata Gusano

Hierba, Andino, Costa, 0-2500m, maleza

Uso: Tos, Bronquitis / Flores, Hojas y Tallos, fresco o seco / Oral/ Hervir en 1 litro de agua, añadir 10g de Mata Gusano. Tomar 3-4 veces por día por 1-2 semanas, o como se necesita.

ASTERACEAE - Gamochaeta americana (Mill.) Wedd.

Lechuguilla

Hierba, Andina, Costa, 1000-4500m, maleza

Uso: Diabetes, Nervios / Planta entera, fresco o seco / Oral/ Hervir $1 / 2$ litro de agua con $10 \mathrm{~g}$ de Lechugilla. Paciente debe tomarlo templado, 1 vaso $2-3$ veces por día por 1 mes. 


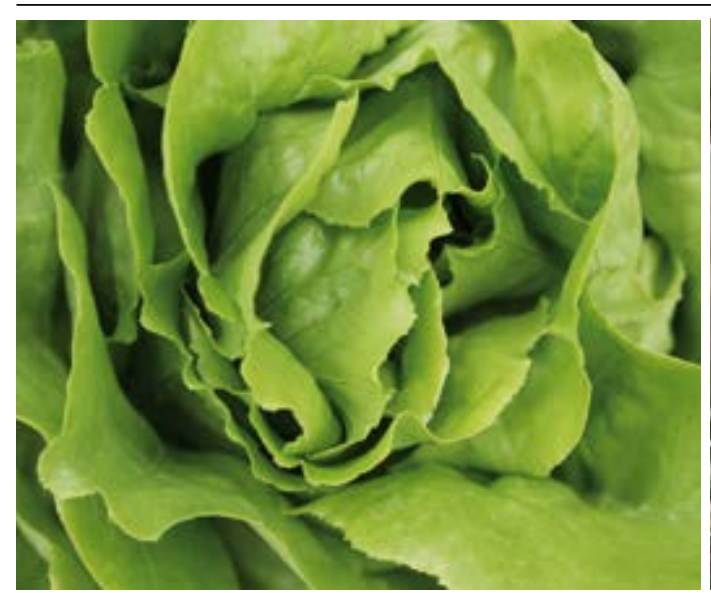

Lactuca sativa

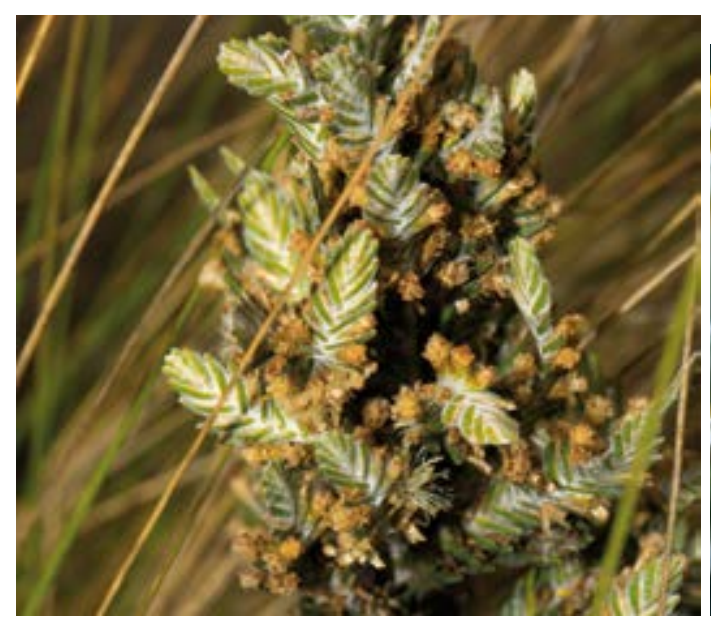

Loricaria thyrsoidea

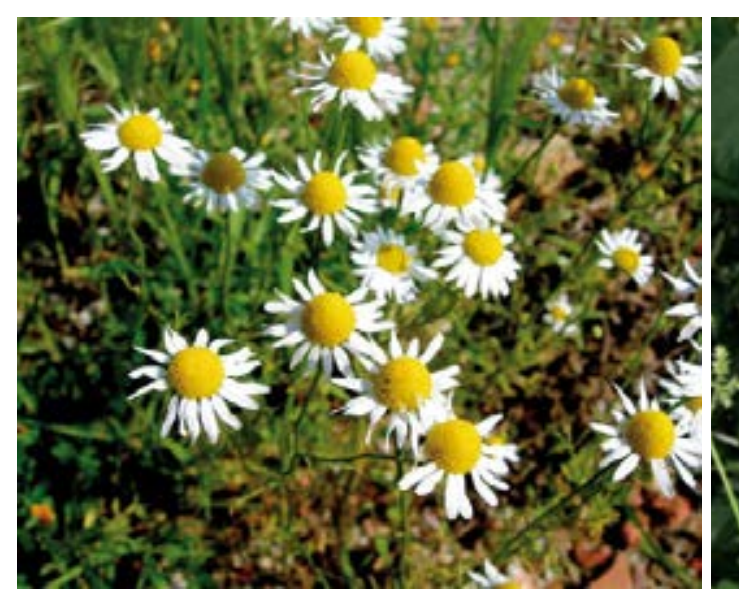

Matricaria recutita

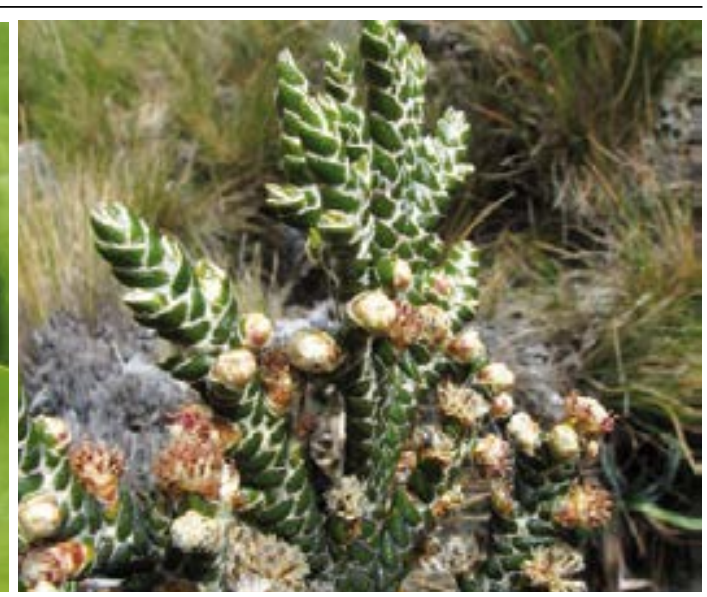

Loricaria ferruginea

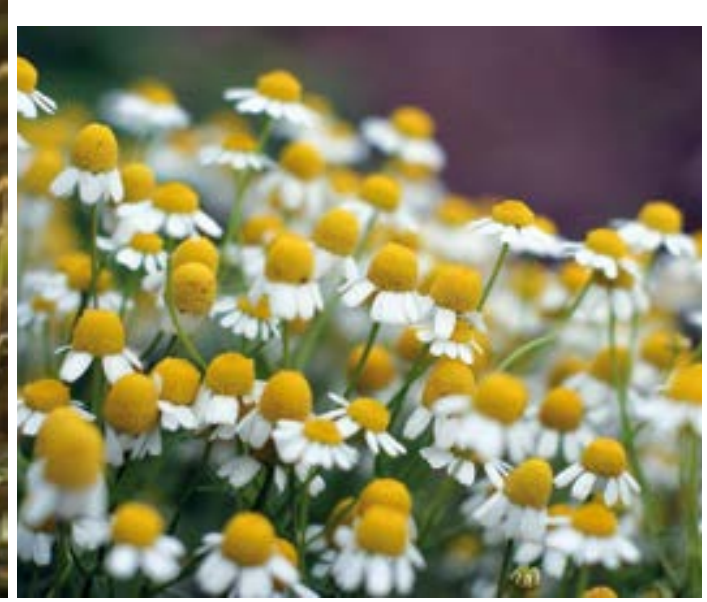

Matricaria chamomilla

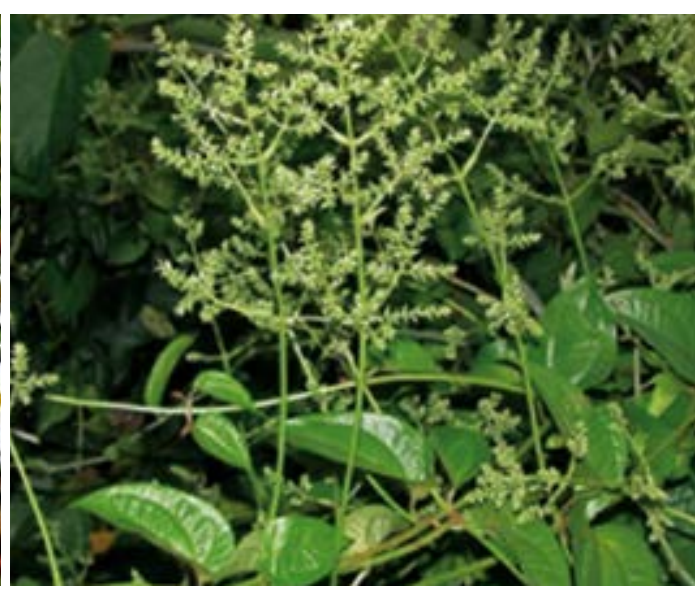

Mikania leiostachya
ASTERACEAE - Lactuca sativa L.

Lechuga

Hierba, Amazonica, Andina, Costa, 0-3500m, introducido y cultivado

Uso: Nervios, Purificación de la sangre, Cleans Toxins from blood / Raíz y Tallos, fresco / Oral/ Añadir $100 \mathrm{~g}$ de the material de la planta a $100 \mathrm{~g}$ de betarraga y $1 / 2$ litro de agua y calienta. Después deja enfriae Tomar 1 taza $2-3$ veces por día por 1 mes.

ASTERACEAE - Loricaria ferruginea (Ruiz \& Pav.) Wedd.

Palmerilla, Palmita, Pata de Gallina, Palmera, Trensilla, Palmilla, Patita de Gallo, Palmia Pina, Palmera Blanca, Destrensilla

Arbusto, Andino, 3000-4500m

Uso: 1. Florecimiento / Florecimiento, Retraso menstrual, Circulación de sangre / Hojas y Tallos, fresco / Tópico / Mezcla Alternativa para Florecimiento. Aplicar 3 veces por día por 1 semana; solo una vez por Florecimiento/Florecimiento. 2. Protección, Buena Salud, Buena Fortuna, Buenos Negocios, Fragancia, Éxito, Seguridad de viaje, Sociabilidad, Buenas relaciones con otros / Hojas y Tallos, fresco / Seguro / Mezcla Estandar para Seguro.

ASTERACEAE - Loricaria thyrsoidea (Cuatrec.) Dillon \& Sagástegui

Palmilla Ancha, Palmilla Verde, Palma Bendita

Shrub, Andean, $3500-4500 \mathrm{~m}$

Arbusto, Andino, $3500-4500 \mathrm{~m}$

Uso: 1. Negocios / Planta entera, fresco / Seguro / 7 pequeñas plantas por Seguro combinado con fuertes Hierbas magicas. 2. Para desechar espiritus malos / Planta entera, fresco / Tópico / Hervir 15-20 minutos, $10-20 \mathrm{~g}$ por 12 litros de agua. Baño: 2-3 veces por mes.

ASTERACEAE - Matricaria chamomilla L.

Manzanilla

Hierba, Andino, Costa, 0-4000m, introducido y cultivado

Uso: 1. Enfermnedad de amor, Nervios, Insomnia, Inflammación de heridas, Cólico, Dolor de Estómago, Bronquitis / Planta entera, fresco o seco / Oral/ Hervir agua first. Ańadir 10g de Manzanilla por taza, 3 tazas por día por 1 semana. 2. Inflammación, Cólico, Inflammación de Vagina Heridas (abiertas), Heridas (cerradas) / Planta entera, fresco o seco / Tópico / Hervir agua first. Añadir 10g Manzanilla por taza No (cezclar con otras Hies. Fo mezclar con otras Hierbas. Frotar solución sobre abdomen o area que necesita. Por Inflammación vaginal, sentarse sonor $2-3$ veces por dia, cada dia siguente. Alternativa: Hervir Manzanilla, poner sobre tela. Se puede hervir bolsa de te de Manzanilla. Poner tela Hierbas o bolsa de Té en área afectada por
minutos o hasta se enfrie. Calentar de nuevo y repetrir 3-4 veces por día pero no más que 2 dias.

ASTERACEAE - Matricaria recutita $\mathrm{L}$.

Manzanillón, Agua de la Banda, Manzanilla Blanca, Manzanilla Amarga, Manzanilla

Hierba, Andina, 2000-4500m, introducido y cultivado

Uso: 1. Segurio para viaje, Sociabilidad, Buenas relaciones con otros / Planta entera, fresca / Seguro / Tres Tallos por frasco. 2. Susto, Infeccion de heridas, Limpia Vaginal / Planta entera, fresco / Tópico / Hervir la planta por 3-5 minutos. Mezclar planta entera con Hierba del Susto y Ajenco después combinar 2 gotass de Vinagre. Hechar la mezcla en la tina y sentarse. Frotar 2-4 veces por mes. Hervir 1 manojo seco en 1 litro de agua por 5 min y lava heridas. 3. Purificación de la Sangre, Cólico Menstrual / Planta entera, fresco / Oral/ Hervir agua. Añadir 10g de Manzanillón a 1 taza de agua hervida. Manzanilla, Toronjil y Pimpinela se puede eñadir. Tomar 1 pequeña taza 3 veces por día por 1 mes. Tomar templado. 4. Infeccion d eheridas / Planta entera, fresco / Tópico / Cortar Hierba fresca hasta hacer un extracto y mezclar con Vaselina sin olor. Lavar con Llantén, despues aplicar como se necesita.

ASTERACEAE - Mikania leiostachya Benth.

Enredadera

Liana, Amazonica, Andino, 0-2000m

Uso: Daño/Hechizería, Daño de Brebaje, Hechizería / Hojass, seco / Tópico / 1 manojo en 3 litros de agua hervida combinado con $10 \mathrm{~g}$ cada uno de Huaminga, Chilca, Hierba del Susto y Agua del Susto. Tomar 2 Baños por semana. 


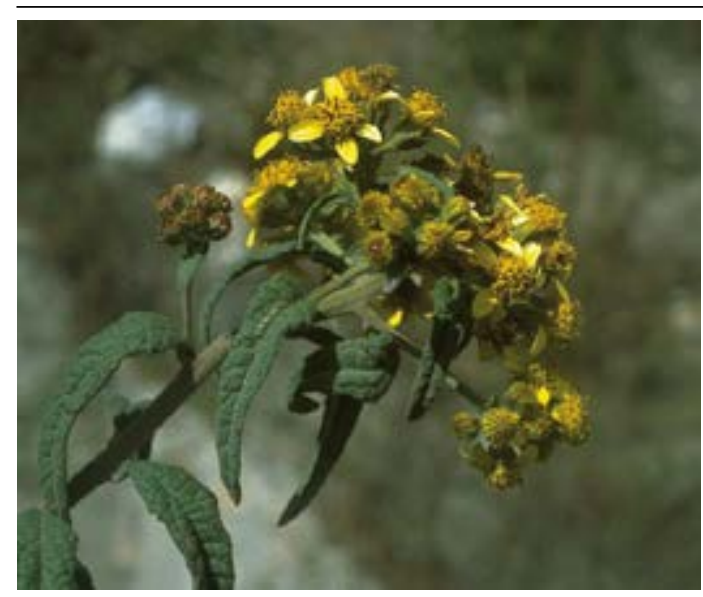

Monactis flaverioides

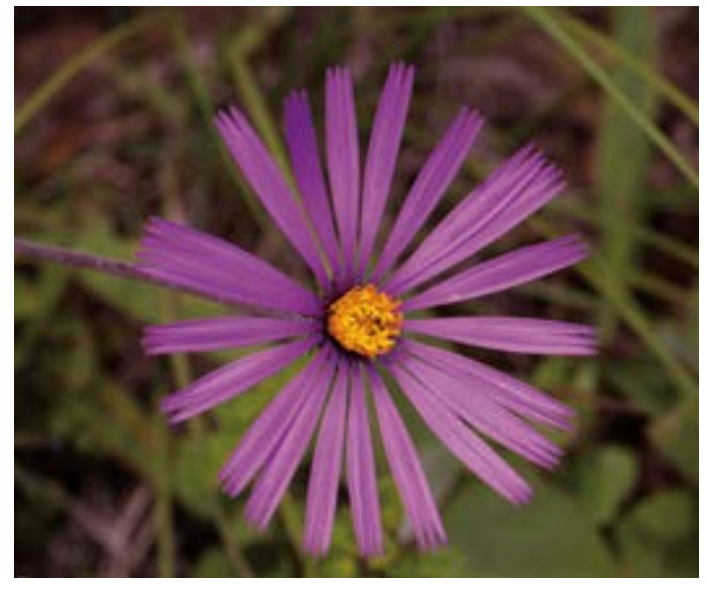

Onoseris odorata

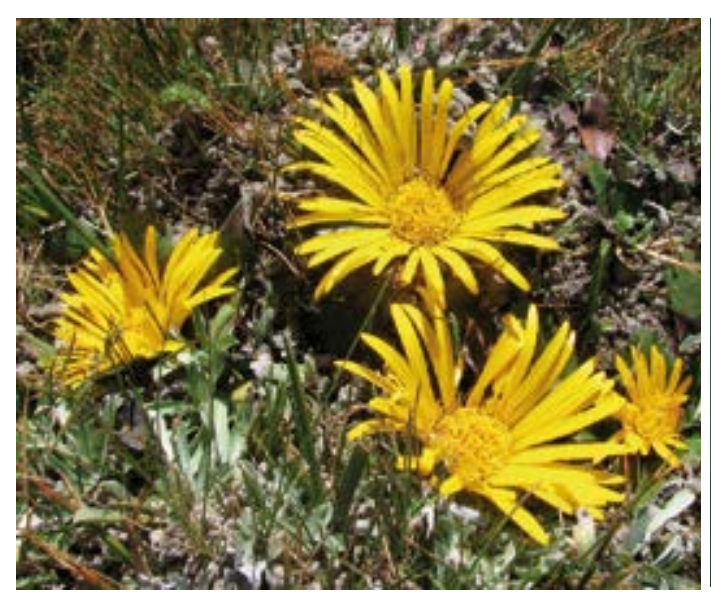

Paranephelius uniflorus

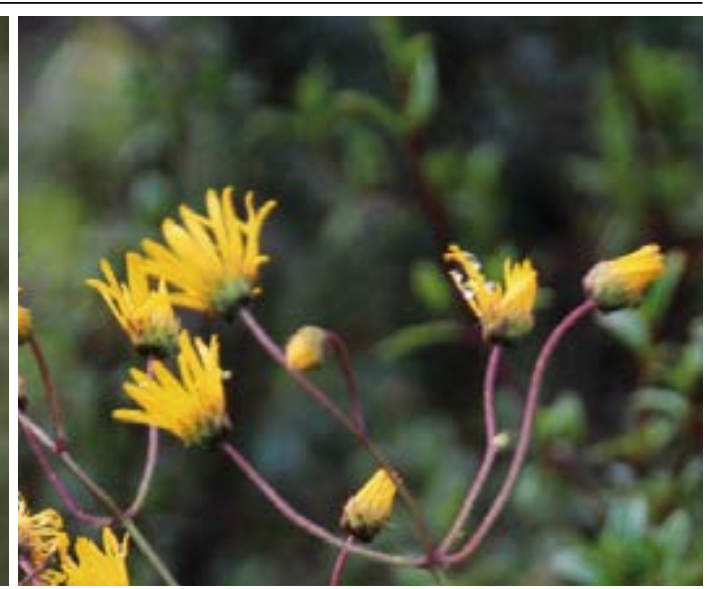

Munnozia lyrata

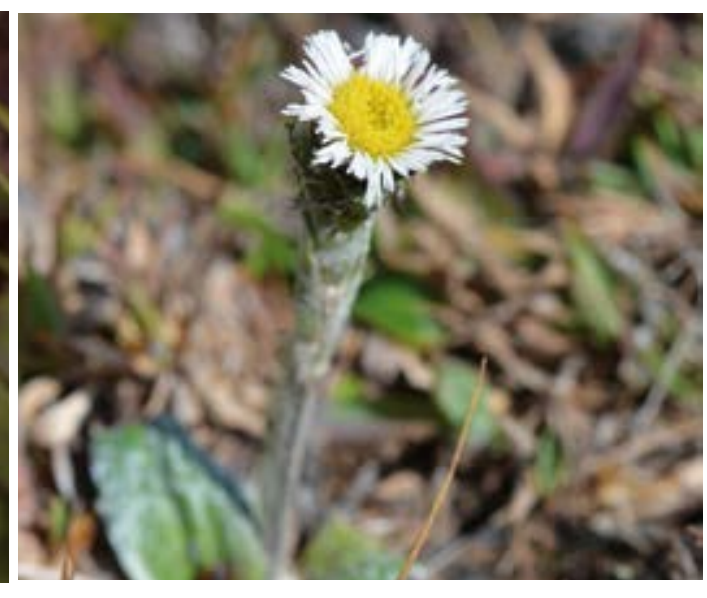

Oritrophium peruvianum

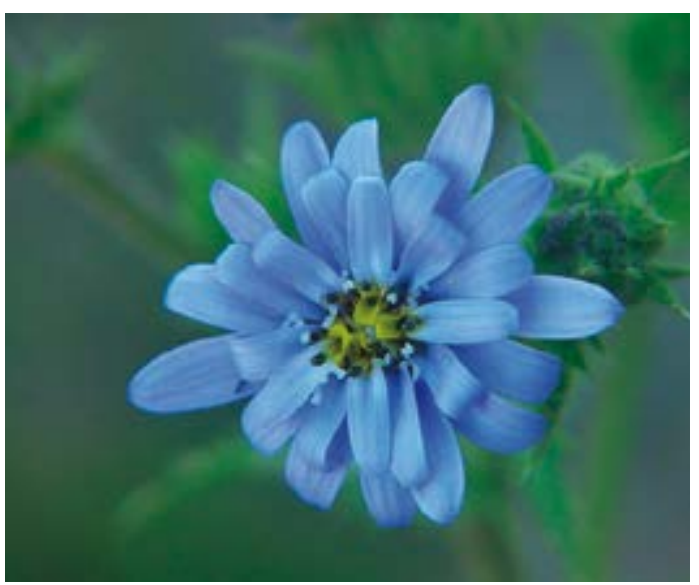

Perezia multiflora

\section{ASTERACEAE - Monactis flaverioides Kunth}

Hierba del Susto (Amarillo), Malva, Mocura, Hierba del Susto, Hierba Susto

Arbusto, Amazonico, Andino, Costa, 0-3000m

Uso: 1. Tallos y Hojas, fresco / Tópico / 7 Tallos con Hojas hervido en 3-5 litros de agua por 20 min y combinado con $10 \mathrm{~g}$ cada uno de Agua del Susto, Ajenco y Llatama. Baño: 2-3 veces por semana at 7, 9 y 11PM. / Mal Aire, Prostata, Susto (pérdida del alma), Limpia vaginal, Negocios, Mala Suerte (curar), Susto de Nińos. 2. Oral / Mezclar con Toronjil y Pimpinela y Hervir por 3-5 minutos, 1 litro cada día por 7 días. / Mal Aire, ProstataSusto (pérdida del alma), Limpia vaginal, Negocios, Bad Luck/Mala Suerte (cure), Fright en Children/Susto de Niños

ASTERACEAE - Munnozia lyrata (A. Gray.) H. Rob. \& Brettell

Canillahuanga

Hierba, Andino, 2000-4000m

Uso: Susto, Mal Aire / Planta entera, fresco o seco / Tópico / Baño: 20g total por 5 litros de agua, hervido por 20 minutos con Hierba del Susto, Ańasquero, Cutiquero, Hierba del Ave y Ishpingo, 3 veces por semana.

ASTERACEAE - Onoseris odorata (D. Don) Hooker \& Arnott

Hierba de la Reina

Hierba, Amazonica, Andina, Costa, 0-4000m

Uso: Corazón, Nervios / Planta entera, fresco o seco / Oral/ 10g en 1 litro de agua hervida, 3 tazas por dia.

ASTERACEAE - Oritrophium peruvianum (Lam.) Cuatrec.

Huamanripa, China Linda, Wiña Wiña, Vira Vira, Hórnamo, Hierba del Sol, Maguanmarica, Hierba del Lucero

Hierba, Andina, 3500-4500m

Uso: 1. Asma, Bronquitis, Neumonía / Planta entera, fresco o seco / Oral/ Añadir 10g de material de la planta a 1 litro de agua y Hervir por 3 minutos, 3 tazas por dia, como se necesita. Tomar templado. 2. Fragancia, Attract Amorrs, Florecimiento / Planta entera, fresco o seco / Tópico / Mezcla Estandar para Florecimiento. 3. Illuminar camino y destino, Buenos Negocios, Protección, Buena Fortuna, Buena Salud / Planta entera, fresco o seco / Seguro / Mezcla Estandar para Seguro.

ASTERACEAE - Paranephelius uniflorus Poepp. \& Endl.

Pacha Rosa, Carapa de Chancho

Hierba, Andina, 3000-4500m

Uso: Inflamación de Ovarios, Útero, Inflamación (órganos femeninos internos), Cálculos, Inflamación / Planta entera, fresco o seco / Oral / $5 \mathrm{~g}$ cada uno en 1 litro de agua hervida mezclado con Flor Blanca, Purenrosa, Flor de Arena, Manayupa, Sauco, Cola de Caballo y Pie de Perro. Se puede añadir otras plantas anti-inflamatorias, pero opcional. Tomar 3-4 veces por día por un mes.

ASTERACEAE - Perezia multiflora (Humb. \& Bonpl.) Lessing

Corzonera, Escorcionera, Escorzonera

Hierba, Andina, 3500-4500m

Uso: Nervios, Tos, Bronquitis, Asma, Dolor agudo en el cuerpo / Planta entera, fresco o seco / Oral / Hervir 1 litro de agua, añadir 10g cada uno de Escorcionera combinado con Matico, Eucalipto, Veronica, Vira Vira, Nogal, Huamanripa, Tilo y Zarzamora. Tomar 3 tazas por día por 15 días. Paciente debe tomar liquido frío. 


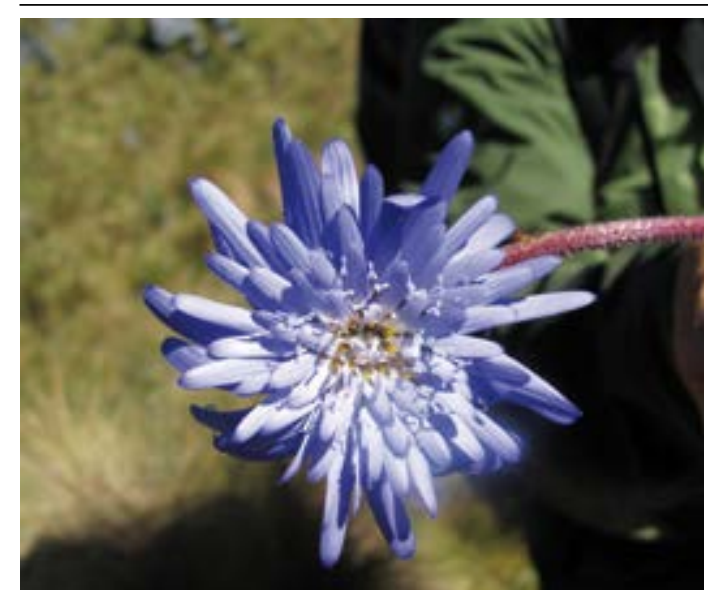

Perezia pungens

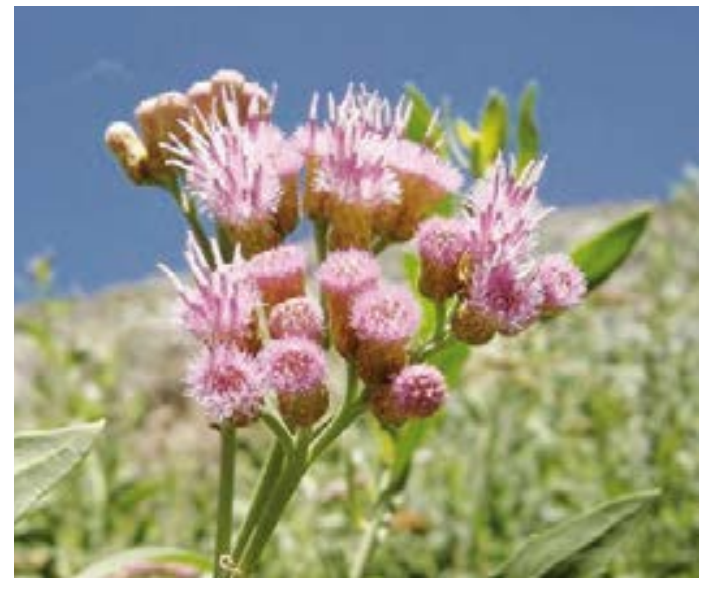

Pluchea absinthioides

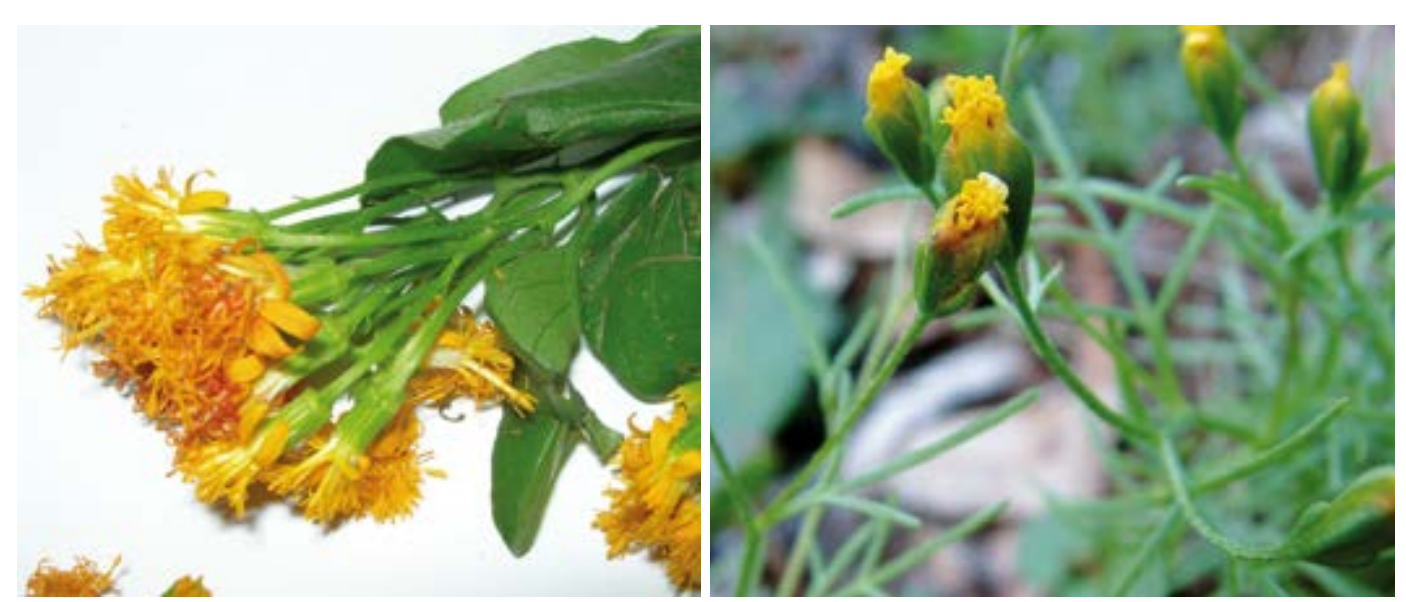

Pseudogynoxys cordifolia

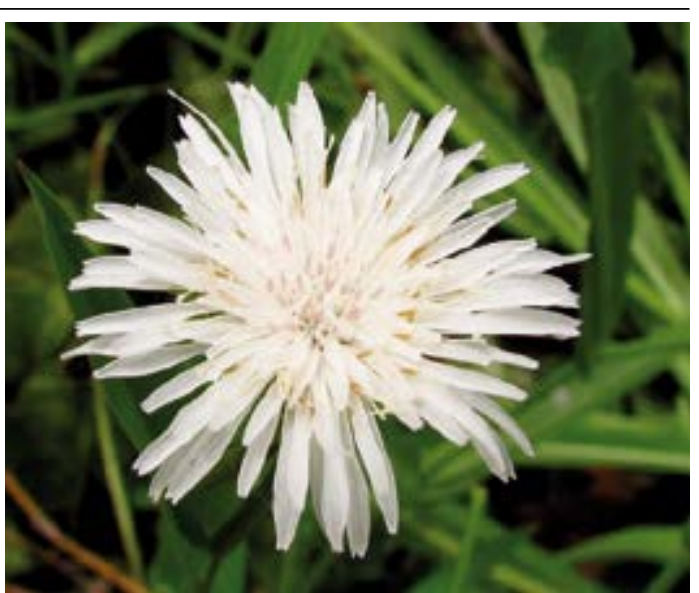

Picrosia longifolia

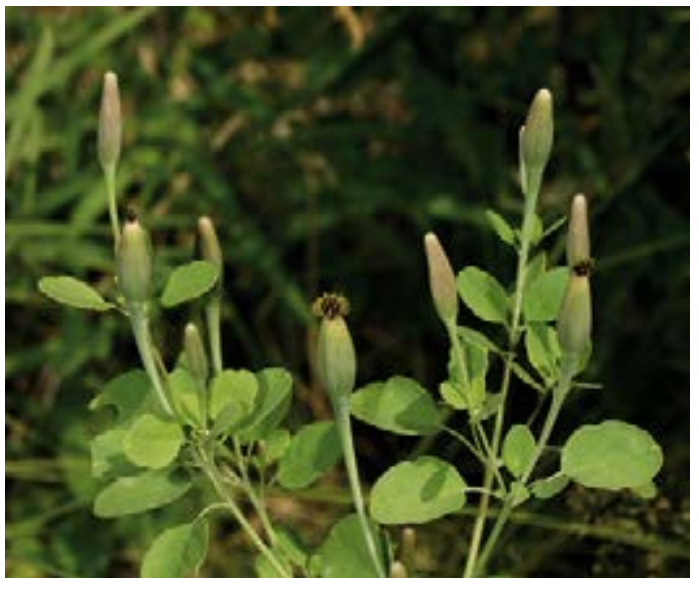

Porophyllum ruderale

Schkuhria pinnata

\section{ASTERACEAE - Perezia pungens (Kunth) Cass.}

Lengua de Vaca

Hierba, Andina, 3000-4500m

Uso: Infecciones de Heridas, Prevención de descamación de la piel después de quemaduras de sol,

Torceduras o Fracturas de Hechicería / Hojas, fresco / Tópico / 1 manojo de Hojas para crema. Aplicar 2 veces por semana.

ASTERACEAE - Picrosia longifolia D. Don

Achicoria, Chicoria

Hierba, Costa, 0-500m

Uso: Hígado, Sangre, Hepatitis, Vesícula, Purificación de Sangre, Bronquitis, Neumonía / Planta entera, fresco / Oral / Hervir 10-50g de Chicoria, Verbena, Canchalagua y Chochocon en 1 litro de agua. Tomar 1 litro cada día por 15-30 días. Como alternativa, cortar y extraer jugo de 200g de material fresco. Tomar 1 vaso por día, no mas que una semana. Sobredosis puede afectar visión.

ASTERACEAE - Pluchea absinthioides Hook. \& Arn.) H. Rob. \& Cuatr.

Pata de Gallina

Arbusto, Andino, 2000-2500m

Uso: Protección de Negocio y casa, Protección (general) / Planta entera, fresco o seco / Seguro / Mezclar en una botella $10 \mathrm{~g}$ de Valeriana Estrella, Señorita, Carpintero, Chupa Flor, Hierba la Coqueta, Oro, Dollar. Añadir Agua Florida, Ramillete de Novia, Tabú, Jugo de Lima, Agua Bendita y Azúcar. 1 botella para usar regularmente.

ASTERACEAE - Porophyllum ruderale (Jacq.) Cass.

Hierba Gallinazo, Hierba del Gallinazo

Arbusto, Amazónico, Andino, Costa, 0-2000m, maleza

Uso: 1. Limpiar la energía de la casa / Planta entera, seco / Incienso / Quemar con Llatama, Ajosquiro y Ańasquero Chico, $5 \mathrm{~g}$ de cada uno Hierba, 2 veces por mes. 2. Daño/Hechicería, Susto / Planta entera, seco / Tópico / Combinar 5g de Llantén, Ajosquiro, Hierba Gallinazo, Hierba del Romero, Flor del Muerto, Eucalipto, Floripondio Flores, Retama y Ańasquero Chico a 3 litros de agua. Baño 2 veces por mes, Martes y Viernes solo. Frotar cuerpo con Hierbas. Lavar con agua. Secar al aire, no usar toalla.

ASTERACEAE - Pseudogynoxys cordifolia (Cass.) Cabrera

San Juan

Vine, Amazónico, Andino, Costa, 0-2500m

Uso: Susto, Mal Aire / Planta entera, fresco o seco / Tópico / Añadir 10g de San Juan, Eucalipto, Chancas del Muerto y Romero a 2 litros de agua. Hervir la mezcla por 3 minutos. Lavar paciente con mezcla templada en la noche. Avisar de no salir de la casa después del bańo. Baño cada 2 días.

ASTERACEAE - Schkuhria pinnata (Lam.) Kuntze

Canchalagua, Canchalagua Chica

Hierba, Andino, $1000-3000 \mathrm{~m}$, maleza

Uso: Limpieza de corazón, Hígado, Vesícula, Mal aliento, Diabetes, Retraso menstrual, Alergias, Menstruación, Purificación de la Sangre, Inflamación de sistema urinaria. / Planta entera, fresco / Oral / Hervir 20g total en 1 litro de agua por 3-10 minutos mezclado con Ortiga, Lancetilla, Culantrillo, Panisara, Purenrosa, Boldo, Berro, Flor Blanca y Canchalagua. Tomar 3 veces por día (1 litro) por 1 mes. Purificación de la Sangre: Mezcla debe descansar por la noche antes de tomar. 


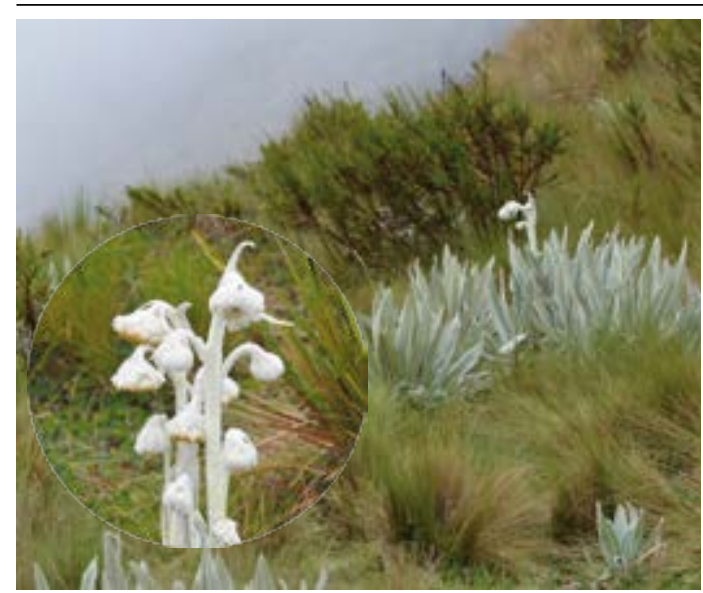

Senecio canescens

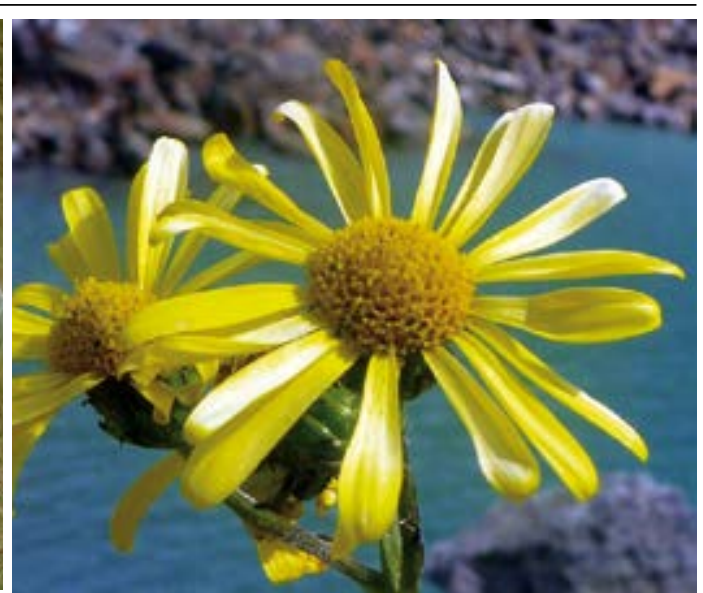

Senecio comosus
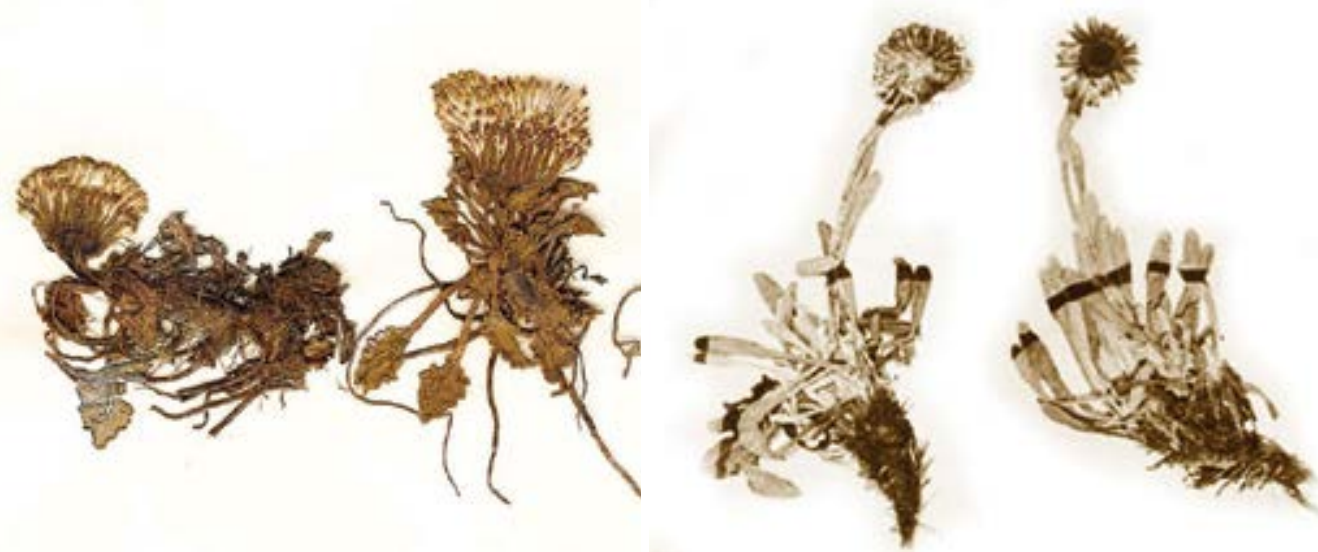

Senecio genisianus

Senecio hypsiandinus

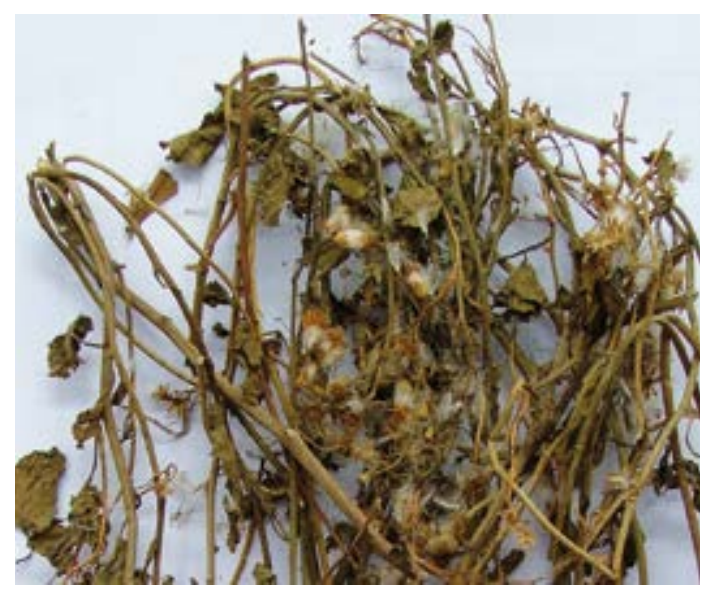

Senecio otuscensi
Senecio tephrosioides

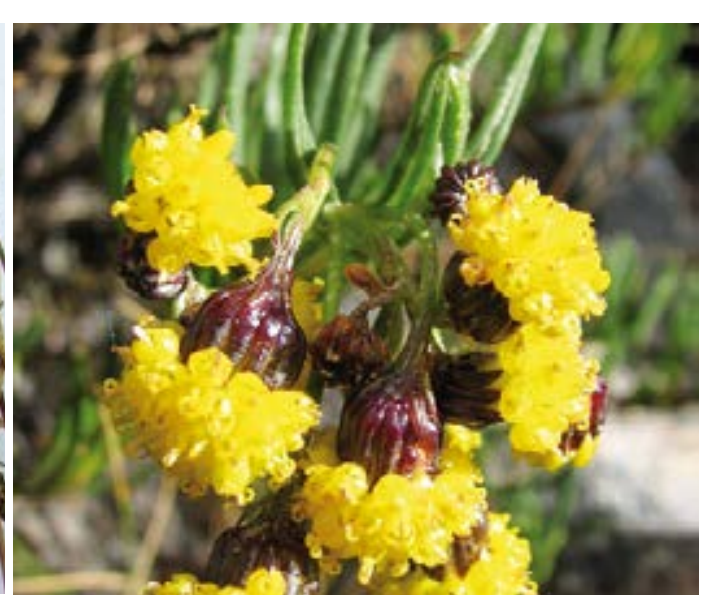

ASTERACEAE - Senecio canescens (H.B.K.) Cuatrecasas

Vira Vira, Oreja de Conejo

Hierba, Andina, 3500-4500m

Uso: 1. Bronquitis, Asma, Tos, Nervios / Planta entera, fresco / Oral / Hervir 10g cada uno de Hierba machucada en 1 litro de agua combinado con Borraja, Eucalipto, Escorcionera, Borraja, Cerraja, Polen de Hierbas, Manzanilla, Toronjil, Congona, Poleo, Claveles, Juan Alonso, Espina de Hoja y Camphora. Tomar 3 tazas por día por 1 mes. 2. Bronquitis, Asma, Tos, Nervios / Planta entera, fresco / Tópico / Usar la misma mezcla por Baños y inhalación.

ASTERACEAE - Senecio comosus Sch.-Bip.

Hórnamo Leon Amarillo

Hierba, Andina, 3500-4500m

Uso: 1. Mal Aire, Inflamación (general), Mejoramiento de visiones / Hojas y Tallos, fresco o seco / Oral / Hervir 3 tallos ( $15 \mathrm{~cm}$ cada uno) de Hórnamo León Amarillo y Hórnamo León Verde, 2 rodajas de San Pedro (6 costillas y 7 costillas) y 3 tallos ( $15 \mathrm{~cm}$ cada uno) de Condor Purga en 9 litros de agua por 1 hora a temperatura baja. Tomar frío, 1 pequeño vaso solo una vez. 2. Mal Aire, Inflamación (general), Mejoramiento de visiones / Hojas y Tallos, fresco o seco / Oral / Hervir 2 Hojas de Misha Morada, 1 Hoja de Misha Amarilla, 1 Hoja de Misha Blanca, 1 Hoja de Misha Rosada, 1g de Toromaique y $1 \mathrm{~g}$ de Toro Misha en 1/2 taza de agua por 5 minutos. Tomar frío, $1 / 8$ de un pequeño vaso. Paciente debe quedarse en un cuarto oscuro por 3 días con dieta sin especies y maricos. Paciente debe descansar 3 días después del tratamiento.

ASTERACEAE - Senecio genisianus Cuatr.

Tutapure Blanco

Hierba, Andina, 4000-5000m

Uso: Heridas (limpieza), Rabia, Mordeduras de animales / Hojas y Tallos, seco / Tópico / 1 manojo en 3 litros de agua hervida. Puede combinar ( 1 manojo cada uno) con Chuque, Huaminga, Chinque, Manzanilla de Cerro, Vinagre y 7 Espiritus. Un Bańo por semana, también para Limpias.

ASTERACEAE - Senecio hypsiandinus Cuatr.

Hórnamo Blanco

Hierba, Andina, 4000-5000m

Uso: Fragancia, Buena Suerte / Planta entera, fresco / Seguro / Unos Tallos por frasco.

ASTERACEAE - Senecio otuscensis Cabrera

Árnica

Arbusto, Andino, 2500-3000m

Uso: Inflamación, Reumatismo, Fiebre alto / Hojas y Tallos, fresco / Tópico / En 1/2 litro de agua Hervir $100 \mathrm{~g}$ de Árnica por 10 minutos. Poner una tela en mezcla caliente y aplicar por unos segundos. repetir hasta se baja la temperatura del cuerpo. Como alternativa machucar 200g y ańadir 8 gotas de alcohol y calentar en olla sobre fuego. Poner Emplasto en área afectada, cubrir con tela y un plástico. Aplicar 2 veces por semana como se necesita.

ASTERACEAE - Senecio tephrosioides Turcz.

Huamanripa, Genciana

Hierba, Andino, 3000-4500m

Uso: Bronquitis, Asma, Neumonía / Planta entera, fresco / Oral / Hervir 1 taza de agua, añadir 10g de Huamanripa combinado con Veronica, Vira Vira y Brochamelia. Tomar 3 tazas por día por 15 días. 


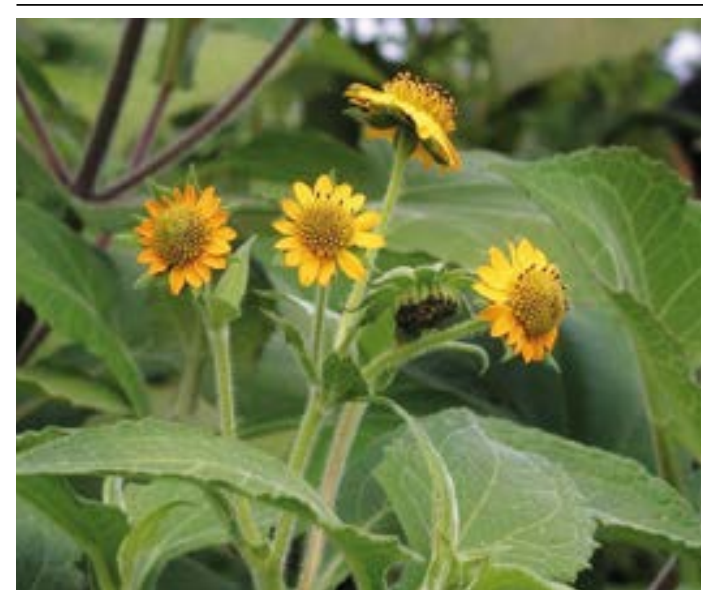

Smallanthus sonchifolius

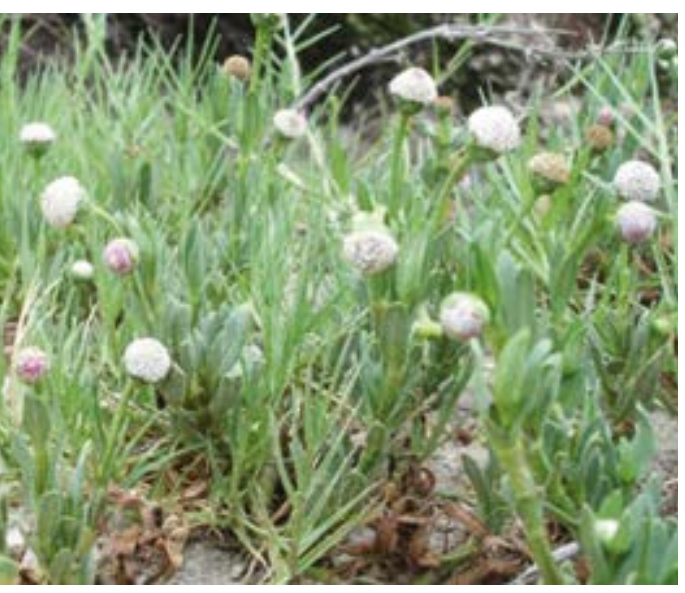

Spilanthes leiocarpa

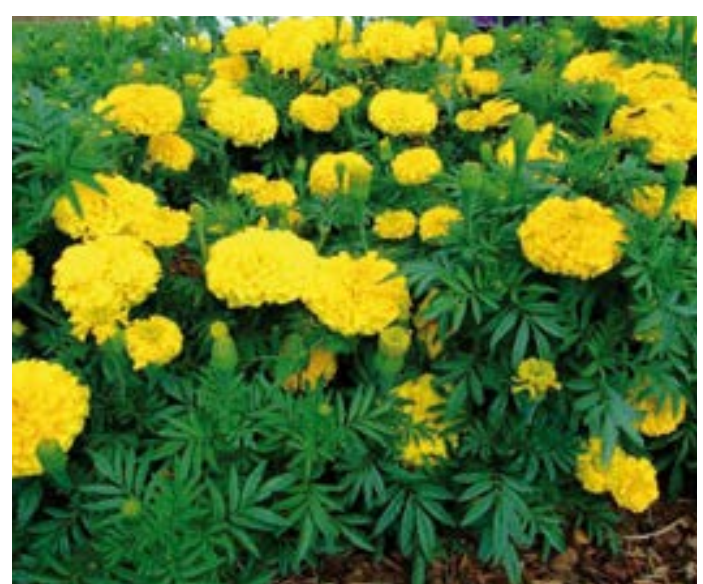

Tagetes erecta

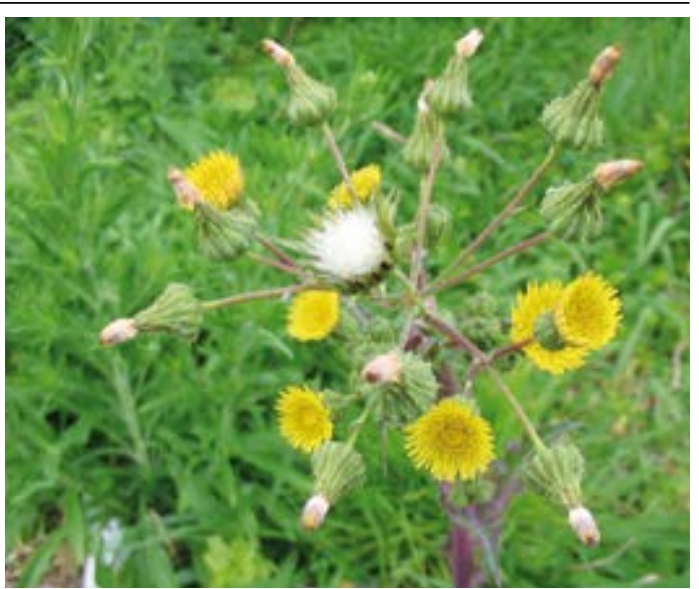

Sonchus oleraceus

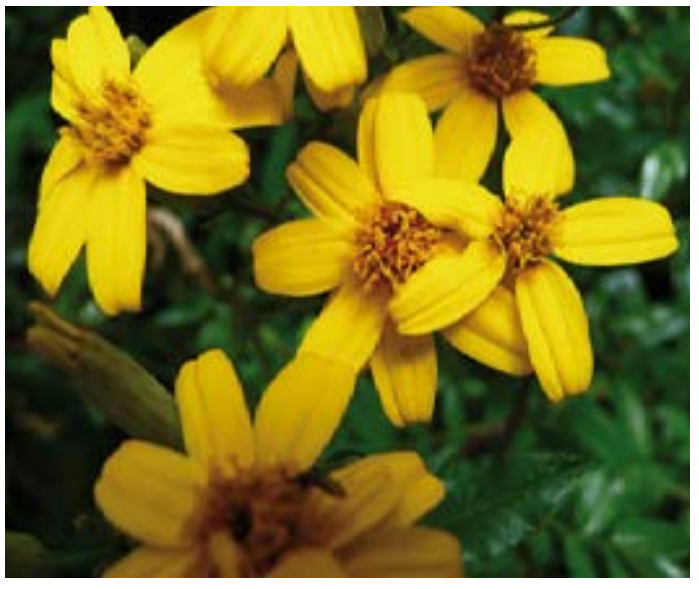

Tagetes elliptica

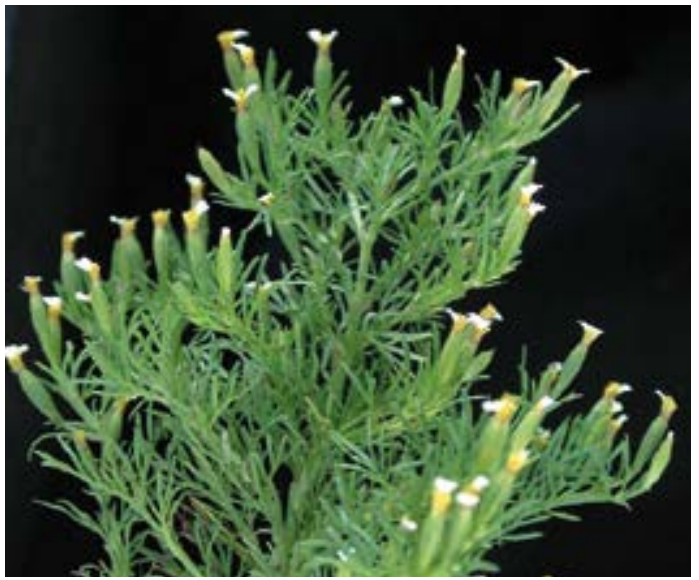

Tagetes filifolia
ASTERACEAE - Smallanthus sonchifolius (Poepp. \& Endl) H. Rob.

Hojas de Yacón, Llacón

Hierba, Andina, 2500-3500m, cultivado

Uso: Diabetes, Riñones, Inflamación de Próstata, Colesterol / Hojas, seco / Oral / Hervir 5g en 1 litro de agua. Tomar 3 veces por día, 1 litro en total.

ASTERACEAE - Sonchus oleraceus L.

Cerraja, Serraja, Zeraja

Arbusto, Amazónico, Andino, Costa, 0-4500m, maleza, introducido

Uso: 1. Enojo, Presión alta / Planta entera, fresco / Oral / Té: $5 \mathrm{~g}$ cada uno de Cerraja, Colores, Lancetilla, Contrahierba en 1 litro de agua hervida. Tomar 3 veces por día. 2. Vergüenza, Chuchaque, Energía negativa, Enojo / Planta entera, fresco / Oral / 1 taza con planta entera (especialmente Flores) cortado con tijeras con 3 gotas de lima, un poco de sal, y algo de pisco. Dejar mezcla por 3 minutos y tomar 1 taza 2 veces por día por 1 día hasta condición mejora. 3. Calmar carácter fuerte / Planta entera, fresco / Oral / 1 manojo de Hierba hervido con 1/2 litro de agua, 3 tazas por día antes de comer. 4 . Chuchaque / Planta entera, fresco / Oral / Tomar 1 planta entera, machucar y tomar extracto, solo una vez

ASTERACEAE - Spilanthes leiocarpa DC.

Turre

Hierba, Andina, Costa, 0-1000m, maleza

Uso: 1. Dolor de muela, Anestésico / Flores, fresco / Tópico / Emplasto: Machucar y moler la planta. Poner material de planta en área afectada. Aplicar 2 veces por día como se necesita. 2. Erupciones de la piel / Hojas y Tallos, fresco / Tópico / Paciente debe bañarse en la mezcla cuando esta fría. No lavar después. Paciente debe secar al aire. 2 veces por semana hasta erupción se va.

ASTERACEAE - Tagetes elliptica Sm.

Culantrillo Serrano

Hierba, Andina, 3000-4000m

Uso: Resfríos, Bronquitis, Congestión / Planta entera, fresco o seco / Oral / $5 \mathrm{~g}$ de la planta en 1 taza de agua hervido por 5 minutos. Tomar frío, 1/4 taza por día por 8 días.

\section{ASTERACEAE - Tagetes erecta L.}

Flor del Muerto, Clavel Chino, Flor de Muerto

Hierba, Amazónico, Andino, 0-3500m, maleza, cultivado

Uso: 1. Susto, Cólico del Estómago, Mal Aire / Flores, Tallos y Hojas, fresco o seco / Tópico / Macerado en perfume con 100g de Parrano, 100g de Frijol Chileno molido, 100g de Ajo molido, $5 \mathrm{~g}$ de polvo de Ají, $5 \mathrm{~g}$ de Pimienta Negra, $5 \mathrm{~g}$ de Orégano, $5 \mathrm{~g}$ de Flor de Chocho, $5 \mathrm{~g}$ de Retama, $5 \mathrm{~g}$ de Ruda (Hembra y Macho) y $5 \mathrm{~g}$ de Agua del Susto. Emplasto: Poner en pies y cubrir con tela. También se puede poner en Estómago. Alternativo, la mezcla se usa como Baño, 3 veces por semana, Martes, Viernes, Martes. 2. Tos, Nervios Inflamación (general) / Flores Tallos y Hojas, fresco o seco / Oral / Tomar 3-4 Flores y Hervir en 1 litro de agua con 10g mezcla de Toronjil, Pimpinela, Poleo y Manzanilla. Tomar 3-4 vasos por día por 1 mes. 3. Susto de la Muerte / Flores, Tallos y Hojas, fresco o seco / Tópico / Limpia: Hervir $5 \mathrm{~g}$ en 3 litros de agua mezclado con $5 \mathrm{~g}$ cada uno de Ajenco, Ruda Hembra, Hierba del Susto, Manzanilla Blanca y Timolina, 2 veces por mes.

ASTERACEAE - Tagetes filifolia Lag.

Anís, Anís Serrano

Hierba, Andino, 2500-3500m

Uso: Cólico severo, Estómago, Dolor de Estómago, Diarrea / Planta entera, fresco o seco / Oral / Hervir $10 \mathrm{~g}$ cada uno de Anís, Poleo, Manzanilla, Muña o Chancas de Comida y Hinojo en 1 litro de agua hervida. Tomar 3 tazas cada día por 1 semana a 1 mes. 


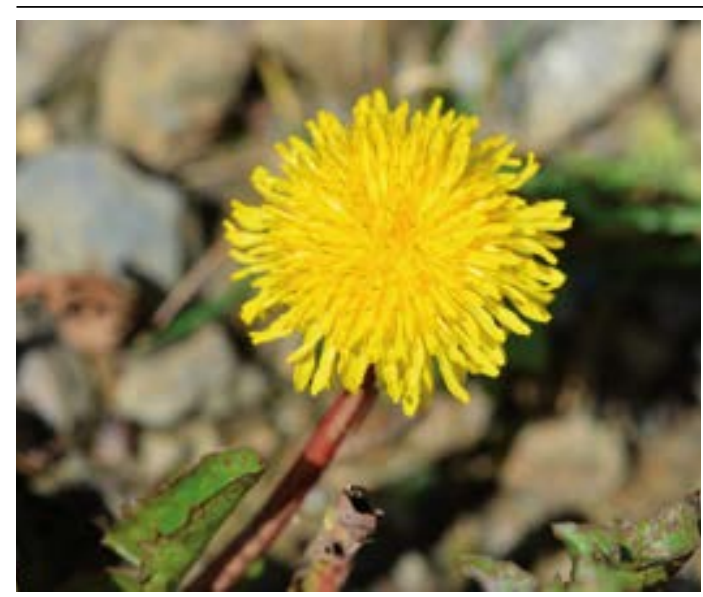

Taraxacum officinale

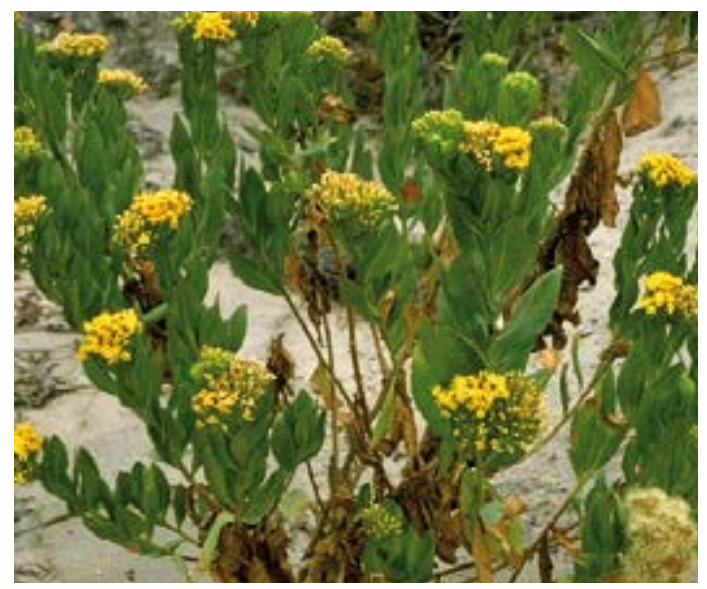

Trixis cacalioides

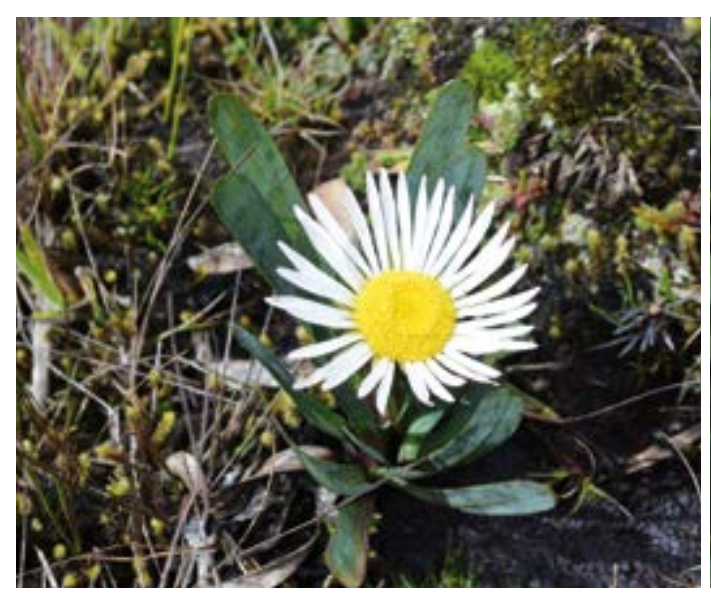

Werneria nubigena

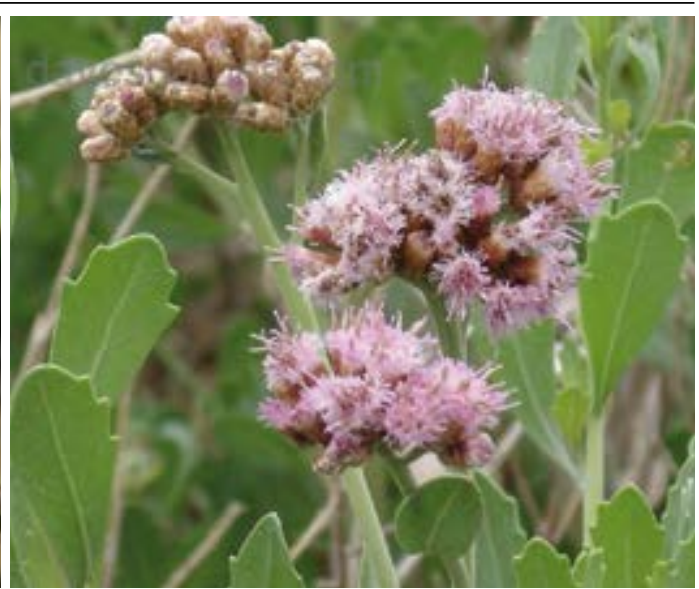

Tessaria integrifolia

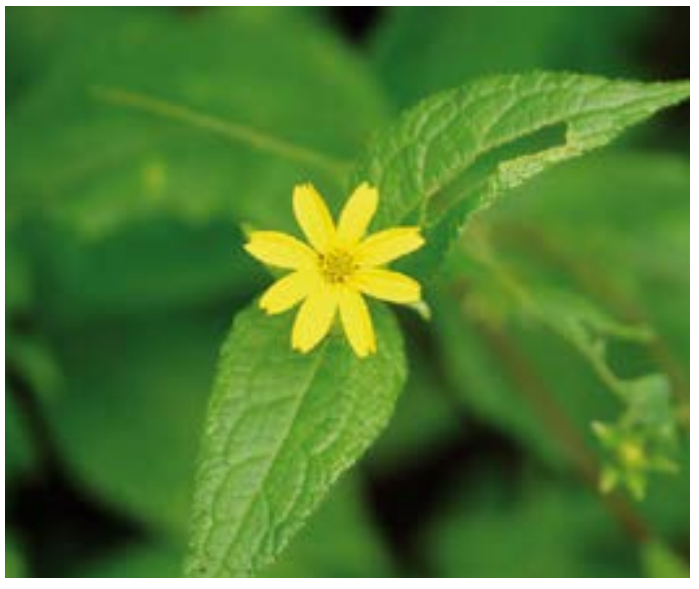

Weddelia latifolia

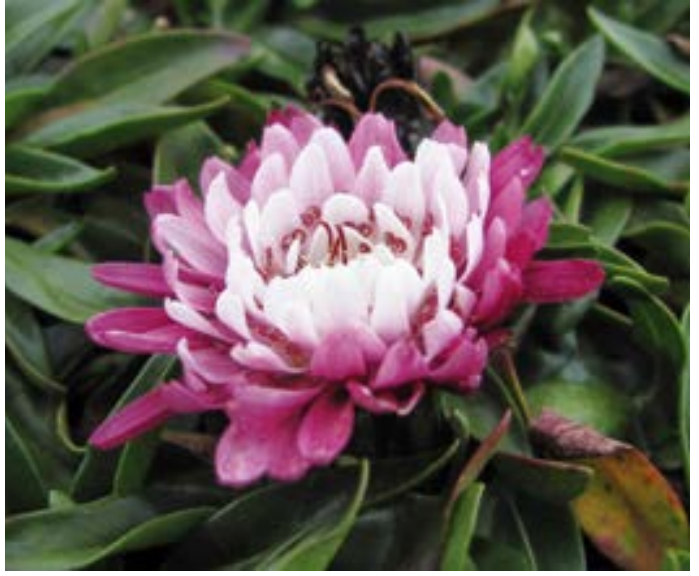

Werneria pygmaea
ASTERACEAE - Taraxacum officinale Wiggers

Diente de León, Amargón, Hierba del León

Herb, Amazonian, Andean, Coastal, 0-4500m, weed, introduced

Hierba, Amazónica, Andino, Costa, 0-4500m, maleza, introducido

Uso: 1. Hígado, Estómago, Inflamación (interno), Ovarios, Mal Aire, Protección contra el Mal / Planta entera, fresco / Tópico / Preparar 200g de Hojas en un frasco de 7 Espiritus. Emplasto: Aplicar 2 veces por mes. 2. Hígado, Estómago, Inflamación (interno), Ovarios, Mal Aire, Protección contra el Mal / Planta entera, fresco / Oral / Hervir 20g de Hojas en 2 litros de agua con $20 \mathrm{~g}$ total de Chacur, Pie de Perro, Cola de Caballo, Linaza, Malva y Amor Seco. Añadir un pedazo $(10 \mathrm{~cm})$ de Bejuco de Contra Aire y 2 Ramitas de Palmerilla. Hervir por 3 minutos. Tomar 1 taza 4 veces por día por 1 mes. 3. Protección del Mal / Planta entera, fresco / Tópico / Baño en mezcla por Protección del Mal. Solo una vez.

\section{ASTERACEAE - Tessaria integrifolia R. \& P.}

Pájaro Bobo

Arbusto, Amazónico, Andino, Costa, 0-2500m, maleza

Uso: Hígado, Riñones, Vesícula, Inflamación (general), Fiebre, Mal aliento / Flores y Hojas, fresco / Oral / Hervir 10g de Pájaro Bobo en 1 litro de agua combinado con Cola de Caballo, Verbena, Chacur, Paja Blanca y Espiga de Maíz. Tomar 3-4 veces por día por 15 días. Paciente debe tomarlo caliente por la mayoría de las enfermedades y solución fría por mal aliento.

\section{ASTERACEAE - Trixis cacalioides Kunth}

Añasquero Chico

Arbusto, Amazónico, Andino, Costa, 0-2500m

Uso: 1. Disipar energía negativa en la casa / Planta entera, fresco o seco / Incienso / Quemar 2 veces por mes. 2. Daño/Hechicería, Susto, Mal Aire / Planta entera, fresco o seco / Tópico / Mezclar con Añasquero Grande, Ruda Hembra, Ruda Macho, Ajenco, Timolin

\section{ASTERACEAE - Weddelia latifolia DC.}

Chulgan, Cuchalman

Arbusto, Amazónico, Andino, Costa, 0-2000m

Uso: 1. Fiebre / Planta entera, fresco / Oral / Hervir 10g de Chulgan con 1 litro de agua. Paciente debe tomarlo templado, solo una vez. 2. Fiebre / Planta entera, fresco / Oral / Hervir 1 pequeńo manojo de Chulgan con 2 litros de agua. No mezclar con otras Hierbas. Paciente debe tomarlo templado, solo una vez.

\section{ASTERACEAE - Werneria nubigena Kunth}

Hierba de la Señorita

Hierba, Andino, 2500-4000m

Uso: Inducir Amor en hombres y mujeres, Aclarar los sentimientos de hombres y mujeres / Flores, Hojas y Tallos, fresco / Seguro / 3 Flores o Tallos por frasco.

ASTERACEAE - Werneria pygmaea Gillies ex Hook. \& Arn

Hierba del Halago

Hierba, Andino, 3500-5000m

Uso: 1. Buenos Negocios, Protección, Buena Fortuna, Buena Salud / Fruta entera, fresco / Seguro / Mezcla Estándar para Seguro. 2. Florecimiento / Fruta entera, fresco / Tópico / Mezcla Estándar para Florecimiento. 


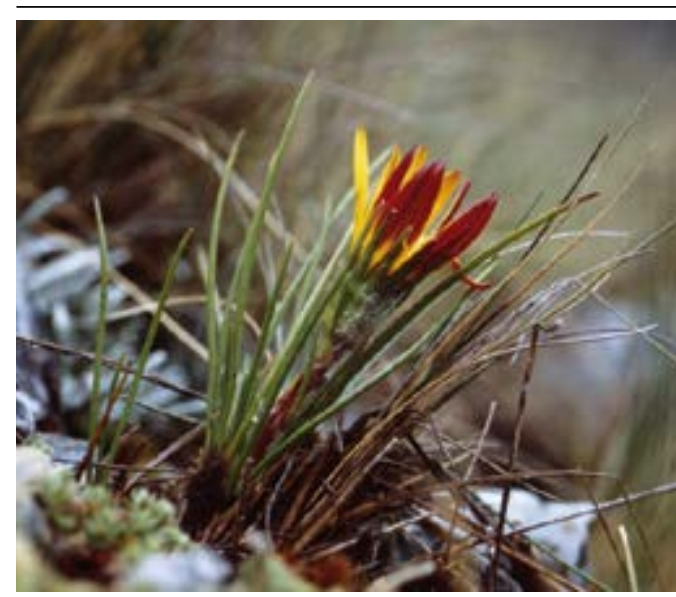

Werneria villosa

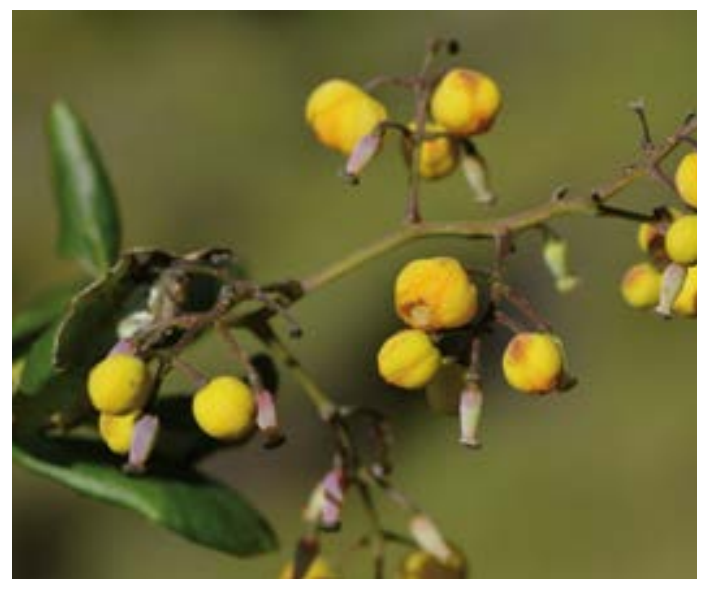

Berberis buceronis

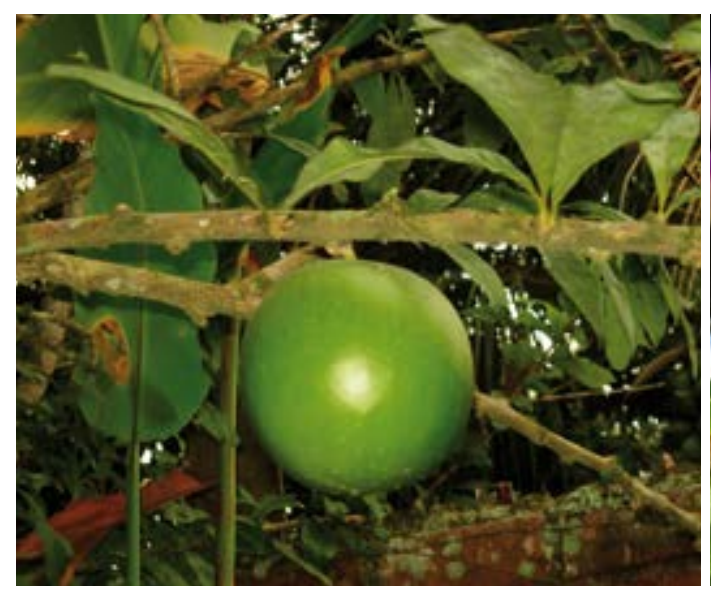

Crescentia cujete

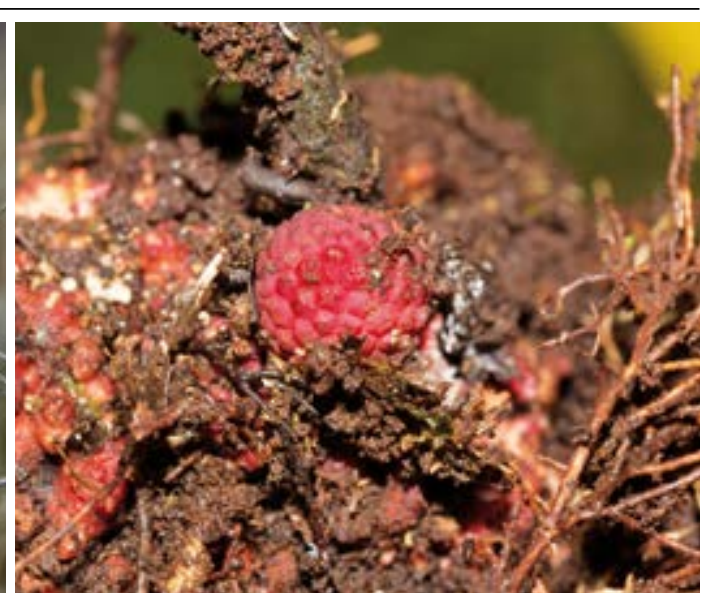

Corynaea crassa

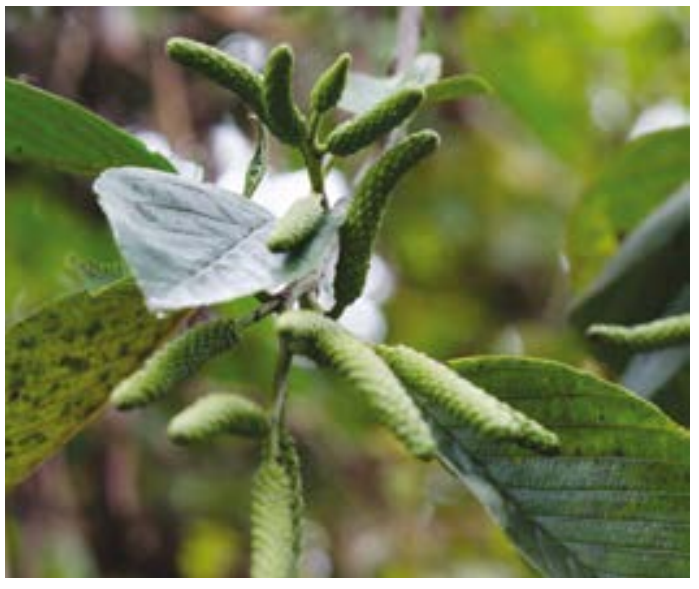

Alnus acuminata

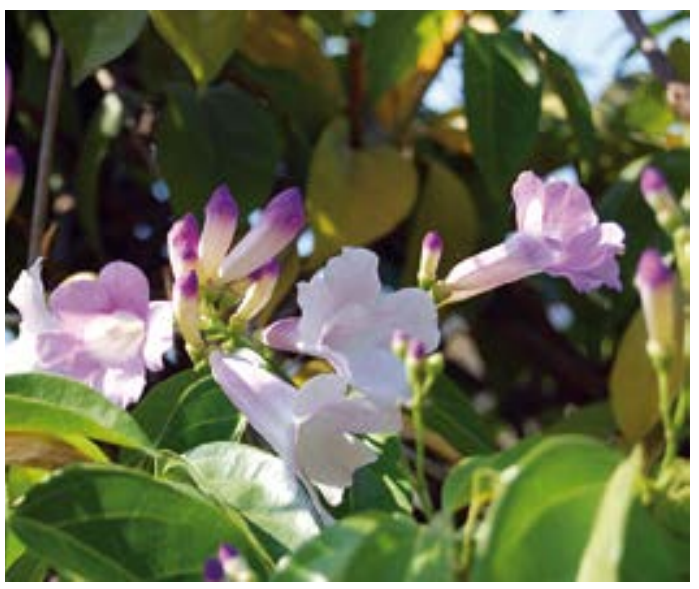

Cydista aequinoctialis

\section{ASTERACEAE - Werneria villosa A. Gray}

Hierba del Oro

Hierba, Andina, 3000-4000m

Uso: 1. Para que todo anda bien en vida y casa de una persona, Buena Suerte, Negocios grandes, Vida personal, Buenos Negocios, Protección, Buena Fortuna, Buena Salud / Hojas y Tallos, fresco / Seguro / Mezcla Estándar para Seguro. 2. Para que todo anda bien en vida y casa de una persona, Buena Suerte, Negocios grandes, Vida personal, Buenos Negocios, Protección, Buena Fortuna, Buena Salud / Hojas y Tallos, fresco / Tópico / Mezcla Alternativa para Florecimiento. Después de hervir, añadir una botella de perfume favorito. Frotar el cuerpo entero con las Hierbas, depuse lavar con agua y dejar secar. No usar jabón o toalla.

BALANOPHORACEAE - Corynaea crassa Hook. f

Huanarpo (Hembra and Macho)

Hierba parasita, Andina, $1500-2500 \mathrm{~m}$

Uso: Fertilidad, Potencia sexual, Impotencia masculina, Tensión / Raíz, fresco / Oral / a 1 botella de Vine añadir $10 \mathrm{~g}$ de Huanarpo. Después añadir $10 \mathrm{~g}$ cada uno de Huevo del Angelote, Polen de Abeja, Miel, Pacra, Palo Sangre, Palo Huaco, Chuchuhuasi, Cascarilla y Para-Para. Tomar 3 tazas por día por 3-6 meses. Tomar una pequeńa taza antes de hacer amor. Se puede llenar la botella de nuevo con Vino una vez con las mismas Hierbas y vaya ser mas fuerte. Por hombres usar Macho, por mujeres usar Hembra. Tomar 3 tazas por día por 3-6 meses.

BERBERIDACEAE - Berberis buceronis J.F. Macbride

Palo Amarillo

Arbusto, Andino, 2000-2500m

Uso: Hígado, Hepatitis / Madera y Corteza, seco / Oral / Hervir 2g de Corteza en 1 litro de agua por 3 minutos con un total de $10 \mathrm{~g}$ de Amor Seco y Cola de Caballo. Tomar templado con 3 gotas de Jugo de Lima, 3 tazas por día por 1 mes.

BETULACEAE - Alnus acuminata Kunth

Aliso Blanco (Liso), Aliso Colorado (Arrugado)

Árbol, Andino, Costa, $0-4000 \mathrm{~m}$, cultivado

Uso: 1. Sellar Heridas, Irritación de la piel, Artritis / Corteza, fresco / Tópico / Macerar 1kg de Aliso Colorado Corteza mezclada en 4 litros de alcohol. Aplicar en heridas. No ingerir! Aplicar hasta herida se cierra, 3 veces por día. 2. Artritis, Resfrío, Cólico del Estómago, Cólico del Intestinos / Corteza, fresco / Oral / Hervir por 10 minutos, 2 cucharas por taza hasta obtener extracto. Tomar $5 \mathrm{~g}$ cada 4 horas. 3. Dolor de Huesos, Artritis / Corteza, fresco / Tópico / Remojar Corteza en agua y usar como Baño o moler las Hojas y mezclar con Vaselina sin olor. Baño 3 veces por mes o masajear cada día en el paciente hasta síntomas mejoran.

BIGNONIACEAE - Crescentia cujete L.

Higuerón

Árbol, Amazónico, 0-500m, cultivado

Uso: Sanar el ombligo después del parto / Látex de Hoja, fresco / Tópico / con la leche de Higuerón formar una pelotita con el Látex. Aplicar con algodón blanco en el ombligo y apresurarlo con cinta. Dejar por 3 semanas.

BIGNONIACEAE - Cydista aequinoctialis (L.) Miers

Bejuco Amarillo

Liana, Amazónica, Andina, 0-1000m

Uso: Hechicería/Daño, Inflamación interna causado por Hechicería, Hematomas causados por Hechicería / Flores, Hojas y Tallos, fresco / Tópico / Hervir 1 manojo en 3 litros de agua por 5 minutos, 2 veces por mes. 


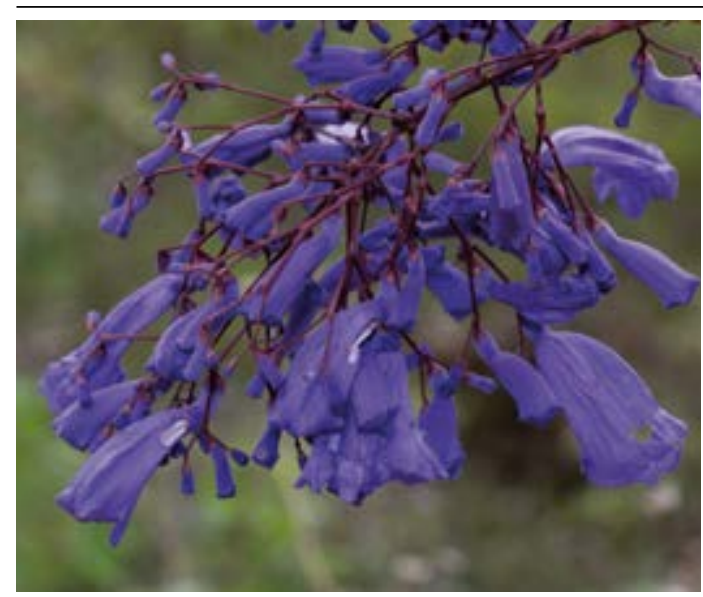

Jacaranda acutifolia

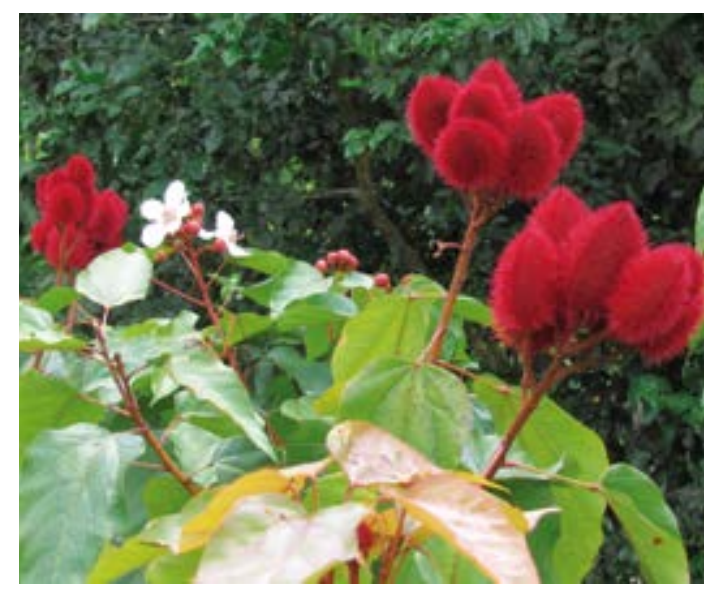

Bixa orellana

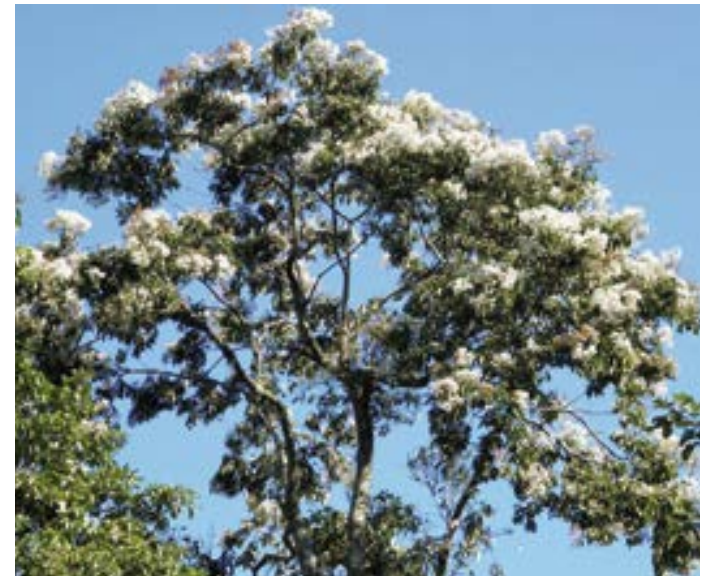

Cordia alliodora

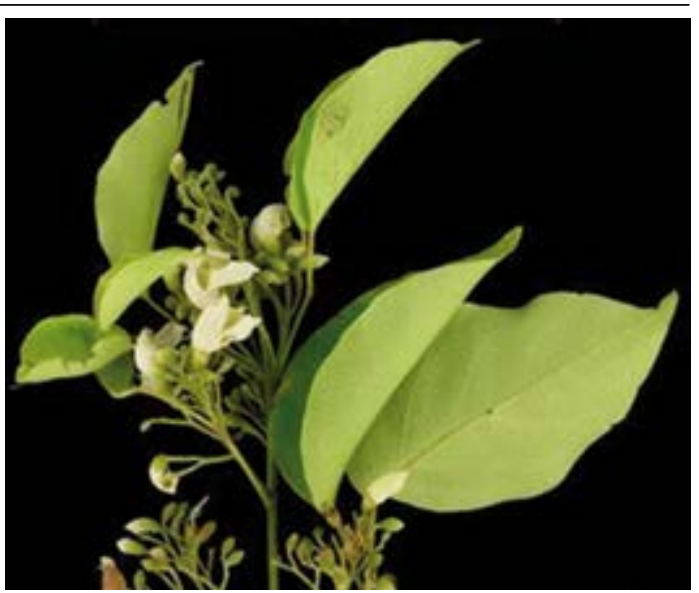

Tynanthus polyanthus

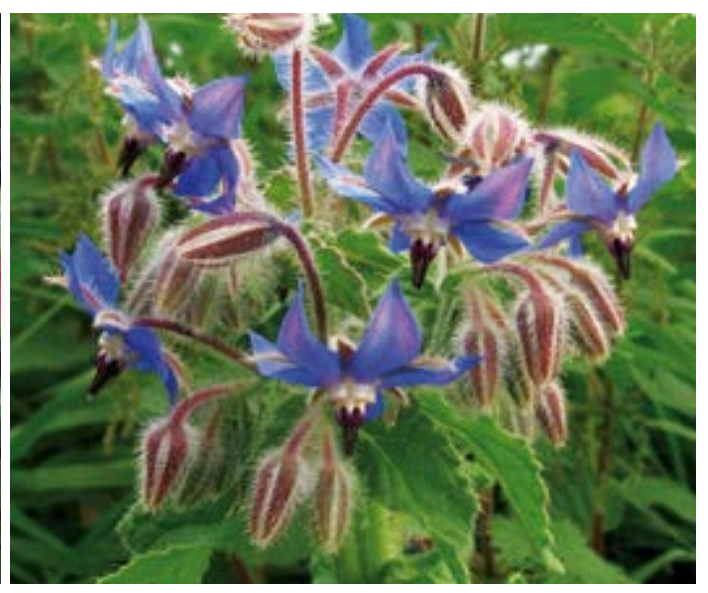

Borago officinalis

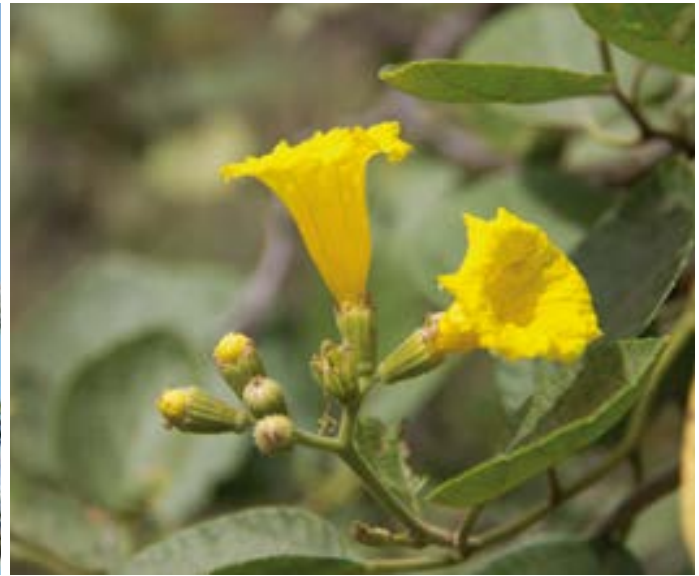

Cordia lutea

\section{BIGNONIACEAE - Jacaranda acutifolia Humb. \& Bonpl.}

Arabisca, Yarabisca

Árbol, Andino, 1000-2500m

Uso: Tos, Bronquitis, Asma, Mucus / Hojas y Tallos, fresco o seco / Oral / Hervir 10g en 1 litro de agua por 2-3 min. Tomar 3 tazas por día como se necesita.

BIGNONIACEAE - Tynanthus polyanthus (Bureau) Sandwith

\section{Clavo Huasca}

Liana, Amazonian, Andean, 0-1000m

Liana, Amazónico, Andino, 0-1000m

Uso: Mal Aire, Alucinógeno, Mejorar la visión del curandero / Hojas y Tallos, fresco / Oral / Mezclar $100 \mathrm{~g}$ de material de planta con $1 / 4$ vaso de agua y colar. Tomar frío. Usar durante ritual, $5 \mathrm{~g}$ por ritual.

\section{BIXACEAE - Bixa orellana L}

Achiote, Hoja de Achiote

Árbol, Amazónico, Andino, 0-1000m, maleza y cultivado

Uso: Inflamación de Riñones, Próstata, Color para comida, Bronquitis, Hemorragias, Sistema pulmonar, Infecciones Urinarias / Semillas y Hojas, fresco o seco / Oral / Machucar 3 Semillas y comer como se necesita. Como alternativa Hervir y añadir 10g de material de la planta a 10g de Uńa de Gato en 1 litro de agua. Hervir la mezcla por 3-4 minutos y mezclar con Chante porque la planta es fría. Tomar 1 litro por día por 1 semana. Paciente debe tomarlo caliente. Se es posible usar Hojas, como las Semillas tienen menos potencia.

BORAGINACEAE - Borago officinalis L.

Borraja

Hierba, Andino, Costa, 0-3500m, introducido y cultivado

Uso: Bronquitis, Pulmones, Sangre, Perder Peso, Ansiedad, Depresión, Corazón, Nervios, Insomnio, Tos, Resfrío, Hematomas / Planta entera, fresco o seco / Oral / Poner 10g total de la Hierba en 1 litro de agua hervida (hirviendo por 3-5 minutos) combinado con 10g Vira Vira. Tomar 3 veces al día o 1 litro por día por hasta cuando se necesita.

BORAGINACEAE - Cordia alliodora (R. \& P.) Oken

Ajosquiro, Ajos Quiro, Ajo Sacha

Árbol, Amazónico, Andino, 0-1500m

Uso: 1. Daño/Hechicería, Susto, Disipar energía negativa de la casa / Corteza y Tallos, seco / Tópico / Combinar 5g cada uno de Llatama, Ajosquiro, Añasquero Grande, Llatama, Hierba del Gallinazo, Añasquero Chico y Ruda Macho en 3 litros de agua por 2 Baños por mes. También se usa como Té. 2. Bronquitis / Corteza y Tallos, seco / Oral / Añadir 1 botella de Vino a 10g de material de planta y 20g total de Chuchuhasi, Cascarilla, Miel, Polen y Tutuma. Dejar mezcla por 1 semana. Tomar la mezcla. Paciente no debe salir de la casa durante tratamiento. Adultos toman 1 pequeńa taza. Nińos toman 1 cucharilla, pacientes toman 3-4 veces por día hasta que se acaba la botella

BORAGINACEAE - Cordia lutea Lam

Overo, Flor de Overo, Overal

Arbusto o Arbol, Andino, Costa, 0-1500m, maleza

Uso: Hígado, Vejiga, Hepatitis, Inflamación de Riñones, Inflamación de Próstata / Flores, fresco o seco / Oral / Poner $5 \mathrm{~g}$ en 1 litro de agua con Llantén y Boldo. Hervir por 5 minutos. Se debe cosechar las plantas en Enero y Febrero. Tomar 4 tazas por día por 1 mes, después de comidas. Después de tomar se debe comer un dulce de limón. Paciente debe limitar actividad física hasta descansar bien. Látex de la Fruta se puede usar como pegamento. 


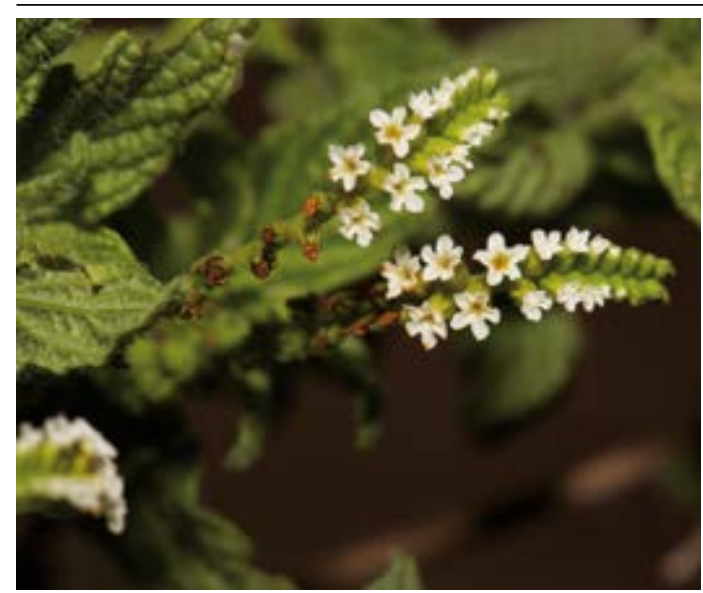

Heliotropium curassavicum

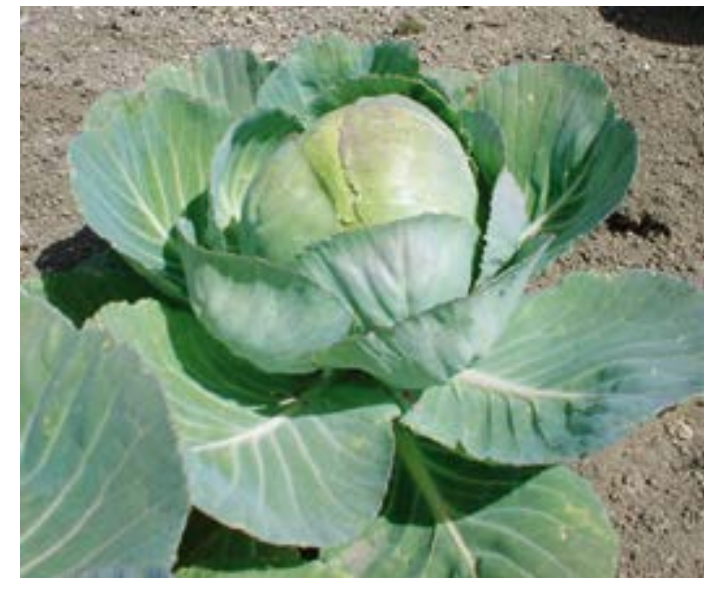

Brassica oleracea

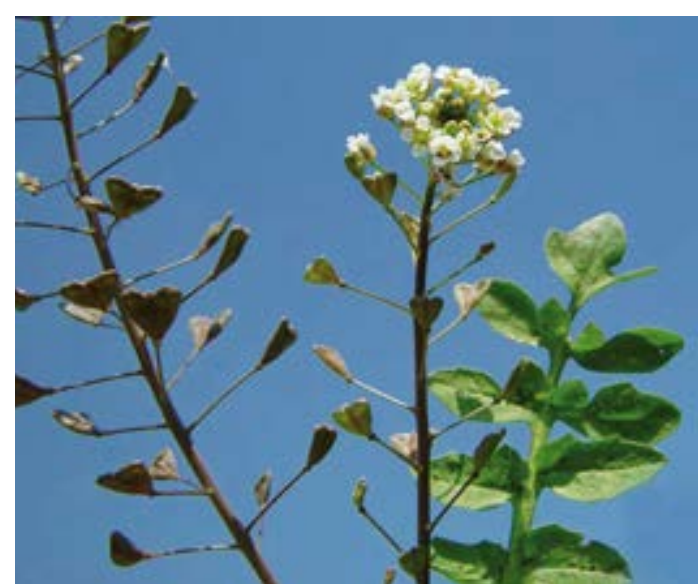

Capsella bursa-pastoris

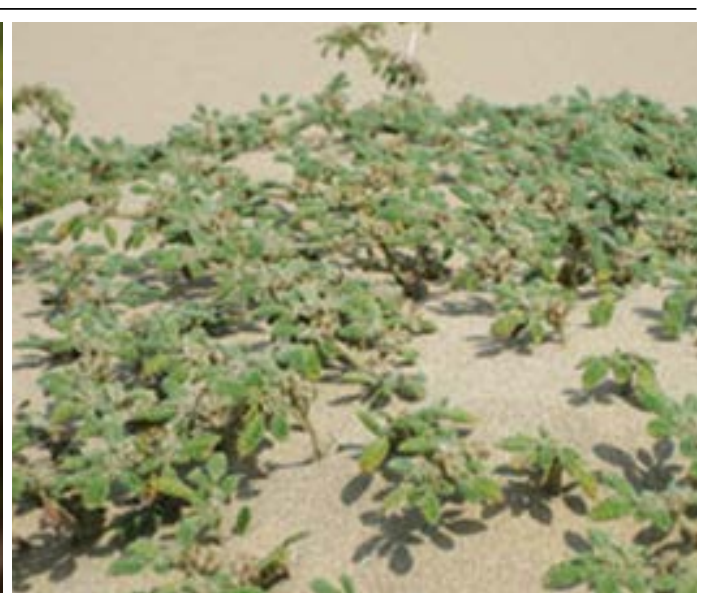

Tiquilia paronychioides

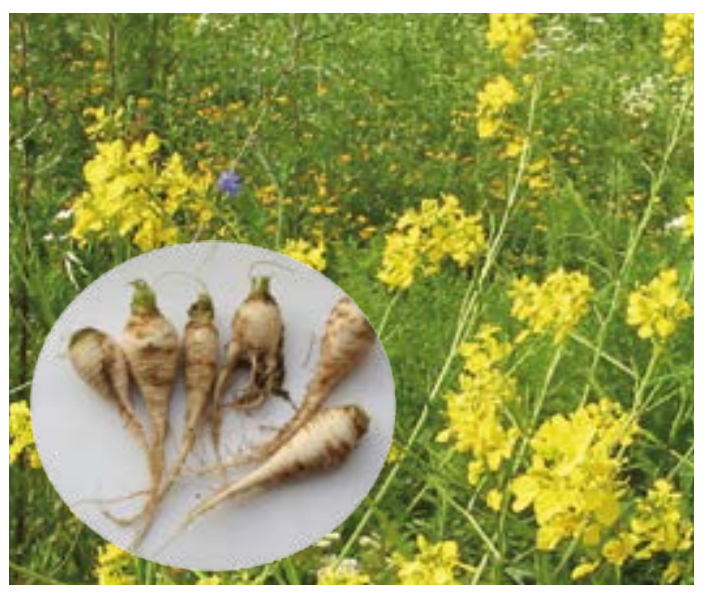

Brassica rapa

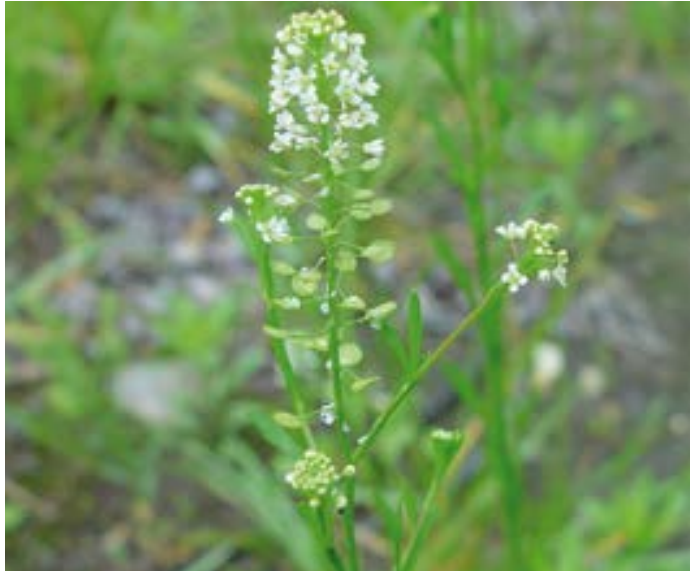

Lepidium virginicum
BORAGINACEAE - Heliotropium curassavicum L.

Alacrán, Alacrancillo

Hierba, Andina, Costa, $0-2500 \mathrm{~m}$, maleza

Uso: Florecimiento / Planta entera, fresco o seco / Tópico / Hervir 10g de Alacrán con 10g total de

Hierba de la Plata, Hierba de la Justicia, y Amarillo, Rojo y White Roses en 2-3 litros de agua. Baño 3 veces (Martes, Viernes y el Martes siguiente).

BORAGINACEAE - Tiquilia paronychioides (Phil.) Rich.

Flor de Arena, Paja de Lagartija, Mano de Ratón

Hierba, Andina, Costa, $0-1500 \mathrm{~m}$, maleza

Uso: Inflamación, Inflamación de Riñones, Inflamación de ovarios, Cálculos de Vesícula, Inflamación de Próstata, Vesícula, Infecciones Urinarias / Flores, fresco o seco / Oral / Combinar 10-100 de material de planta con 10g total de Malva, Espiga de Maíz, Cola de Caballo, Contrahierba, Flor Blanca, Cadillo, Berros, Chante, Achiote, Lancetilla y Pomanpara. Hervir 3-5 minutos en 1 litro de agua. Tomar 3-4 veces por día, 1 litro cada día por 2 semanas a 1 mes.

BRASSICACEAE - Brassica oleracea L.

Col, Repollo

Hierba, Andina, 2500-3500m, introducido y cultivado

Uso: Cálculos de Vesícula / Hojas, fresco / Oral / Combinar 3-4 Hojas de Col en 1 litro de agua con unas gotas de Aceite de oliva. Tomar templado, 1 taza 3 veces por día por 1 semana.

\section{BRASSICACEAE - Brassica rapa L.}

Nabo

Hierba, Andina, 2000-4000m, introducido y cultivado

Uso: 1. Infección y Inflamación de Garganta / Raíz, fresco / Tópico / Moler tubérculo y drenar liquido hasta extraer el jugo. Hacer gárgaras con el jugo 3 veces por día por 2-3 días. 2. Inflamación de Riñones, Ovarios / Raíz, fresco / Tópico / Moler 2 tubérculos grandes y Poner en el área afectada. Cubrir con un pedazo de tela por 5 minutos, 3-4 veces por día por 2 días.

BRASSICACEAE - Capsella bursa-pastoris (L.) Medic

Bolsita del Pastor, Hierba del Pastor, Bolsa de Pastor

Hierba, Andina, Costa, 0-4500m, maleza, introducido

Uso: Riñones, Próstata, Inflamación (general), Inflamación (interno), Hígado, Vesícula, Infección de Estómago, Sistema urinaria / Planta entera, fresco o seco / Oral / Combinar 10-30g total en 1 litro de agua mezclado con Chacur, Verbena, Espiga de Maíz, Flor Blanca, Cola de Caballo, Flor de Arena, Pasuchaca, Corpus Way, Cola de Caballo y Arenilla. Tomar 4 tazas por día por 1 mes como se necesita.

BRASSICACEAE - Lepidium virginicum $\mathrm{L}$.

Maipa

Hierba, Andina, Costa, 0-1500m, maleza, introducido

Uso: Cicatrices de viruela (Cara), Manchas de sol, Manchas de Malnutrición, Manchas de Piel (Cara), Heridas / Planta entera, fresco / Tópico / Hervir 1 taza de agua y mezclar con 2 pequeńas ramas, o 1 pequeña rama por cada mancha en la piel. Lavar la herida con agua en la mañana, tarde y noche. Lavar cara 3 veces por día. 


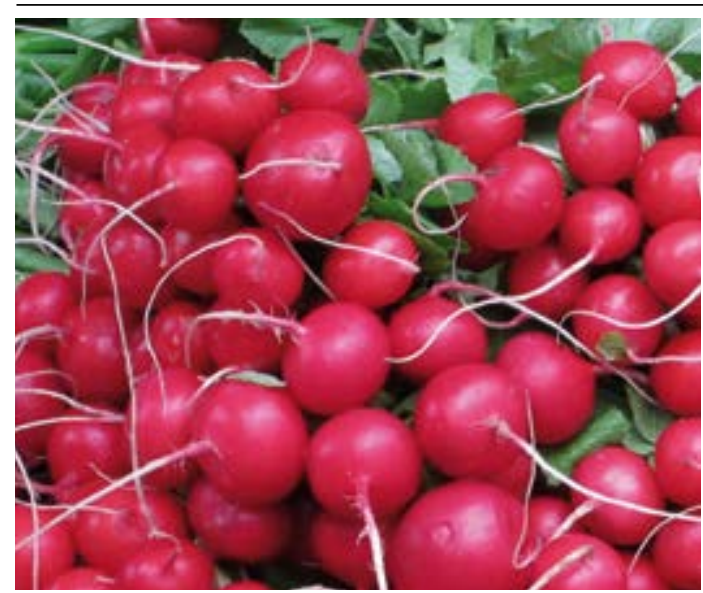

Raphanus sativus

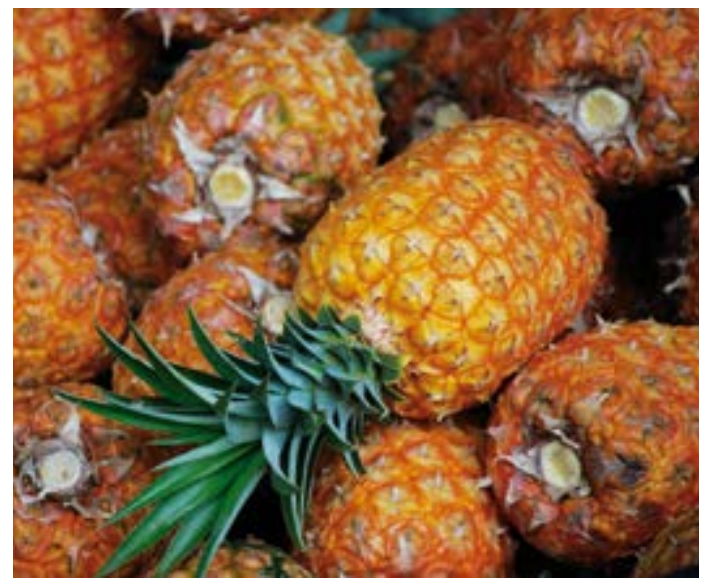

Ananas comosus

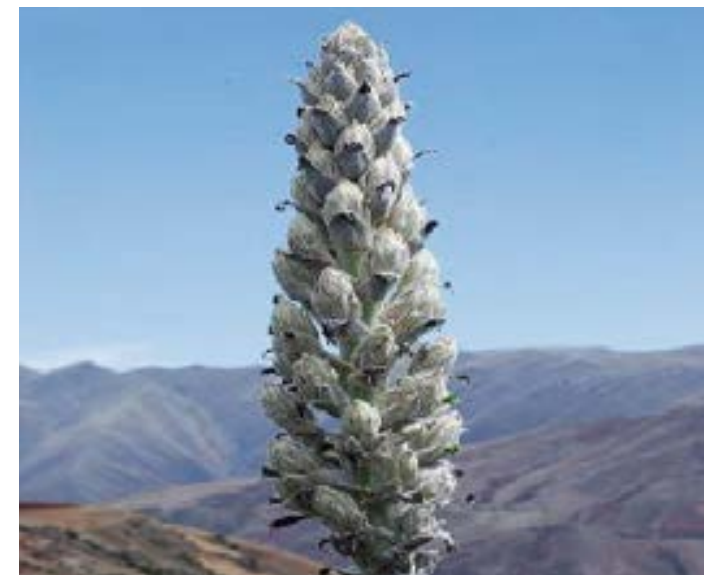

Puya weberbaueri

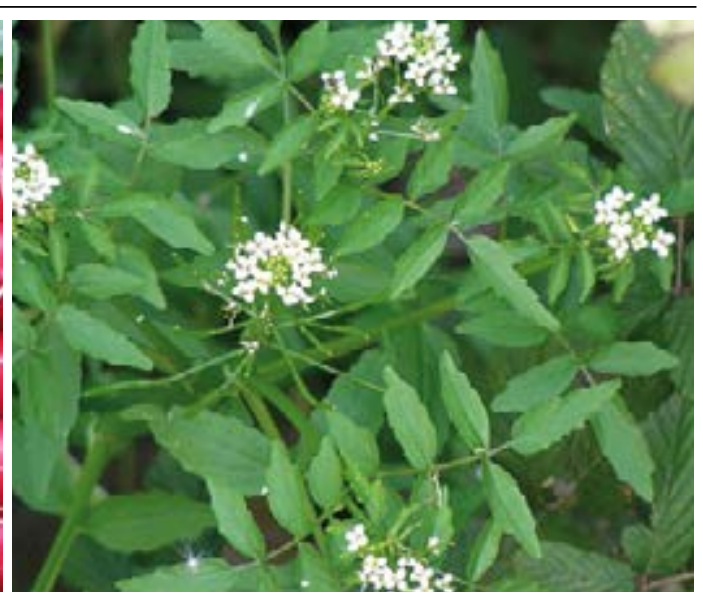

Rorippa nasturtium-aquaticum

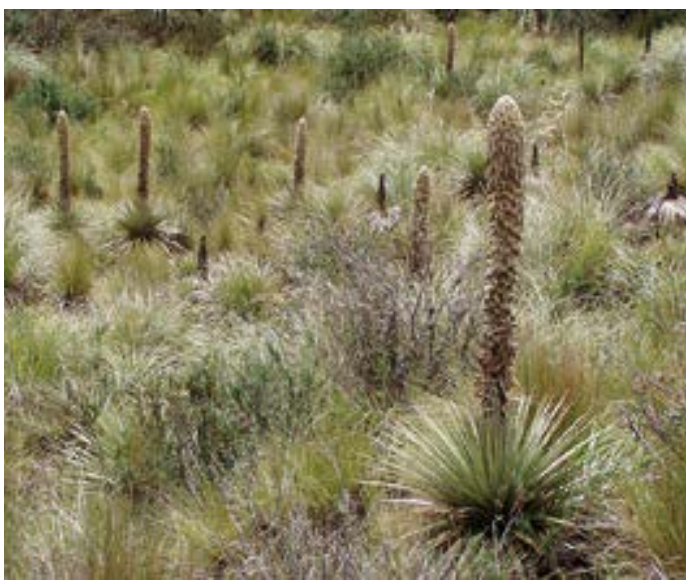

Puya hamata

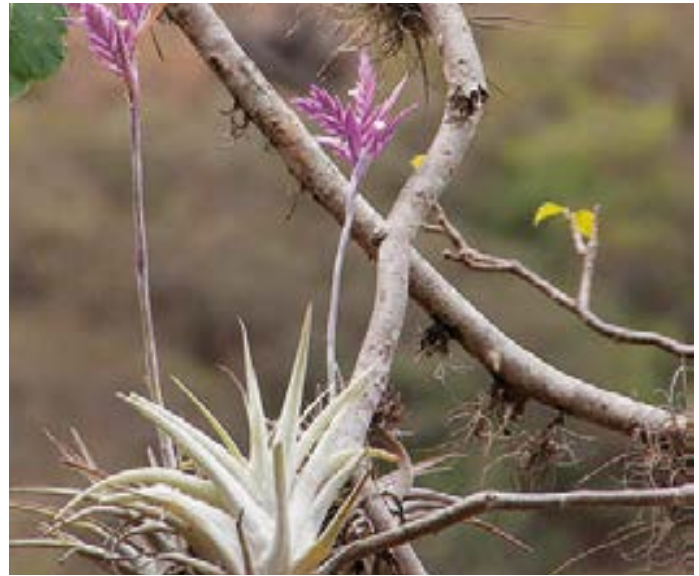

Tillandsia cacticola
BRASSICACEAE - Raphanus sativus $\mathrm{L}$.

Rabanito

Hierba, Andina, 2000-3500m, introducido y cultivado

Uso: 1. Bronquitis / Tubérculo, fresco / Oral / a $1 / 4 \mathrm{~kg}$ de azúcar añadir $1 / 2 \mathrm{~kg}$ de Rabanito cortado. Hervir con 1 Cebolla verde sin agua. El paciente toma el jarabe. Tomar $5 \mathrm{~g}$ cada 6 horas por 1 mes. 2. Decodificación de la sangre, Limpieza de Hígado, Lunares faciales / Tubérculo, fresco / Oral / Mezclar $50 \mathrm{~g}$ de Rabanito. Tomar frío en la mañana en ayuno, 1 vaso una vez por día por 15 días. Tomar en ayuno.

BRASSICACEAE - Rorippa nasturtium-aquaticum (L.) Hayek

Berros

Hierba, Andina, Costa, 0-3500m, maleza, introducido

Uso: Hígado, Retención de Orina, Bronquitis, Riñones, Inflamación del Hígado, Inflamación de Riñones, Anemia / Planta entera sin raíz, fresco o seco / Oral / Tomar fresco como se necesita o moler y tomar jugo con Alfalfa. hacer una sopa con nuca de una oveja y comer. Añadir papas y vegetables. Alternativa: Hervir 1 litro de agua con Berros con 10g total de Malva, Pie de Perro, Unquia, Amor Seco, Chacur, Paja Blanca, Flor de Arena y Purenrosa. Hervir por 3-4 minutos. Tomar 3-4 veces por día por 1 mes.

BROMELIACEAE - Ananas comosus (L.) Merrill

Piña

Hierba, Amazónica, Andino, 0-1500m, cultivado

Uso: Quemar grasa, Perder peso / Cáscara del fruto y Fruta, fresco / Oral / Poner cascara en 1 litro de agua hervido por 3-4 minutos. Tomar caliente, 1 taza 3 veces por día como se necesita. También tomar 1 vaso de jugo fresco por día.

BROMELIACEAE - Puya hamata L.B. Sm.

Hierba del Carnero, Hierba de Borrego

Hierba, Andina, 3000-4000m

Uso: 1. Hacer un hombre estúpido, Hacer hombres obedientes como ovejas, Limpiar, Controlar personas violentas, Dominar borrachos, Tumores, Infecciones / Parte peluda de Semillas, secas / Oral / Combinar 1 taza de agua y $5 \mathrm{~g}$ de la planta (lo mas importúnate esta la parte peluda de las semillas) y Hervir por 3 minutos. Tomar 1 taza dos veces por día 3-4 veces por semana. Se usa este Seguro hasta se puede controlar
el paciente, especialmente si esta violento o borracho. 2. Hacer un hombre estúpido, Hacer hombres el paciente, especialmente si esta violento o borracho. 2. Hacer un hombre estúpido, Hacer hombres
obedientes como ovejas, Limpiar, Controlar personas violentas, Dominar borrachos, Tumores, Infecciones / Parte peluda de Semillas, secas / Tópico / La misma mezcla puede ser aplicado como Emplasto.

BROMELIACEAE - Puya weberbaueri Mez.

\section{Ticta, Tifta}

Hierba, Andina, 2000-4000m

Uso: Mal Aire, Heridas, Cualquier enfermedad con Heridas / Planta entera, fresco o seco / Tópico / Hervir 15g de Ticta y 10g de Hierba Santa en 3 litros de agua. Hervir la mezcla por 3-4 minutos. Bañar el paciente en la mezcla. Paciente puede bañarse cualquier día. Baño una vez por semana por 1 mes.

BROMELIACEAE - Tillandsia cacticola L.B. Sm.

Palmera, Siempre Viva, Palma Bendita, Siempreviva

Hierba, Andina, Costa, 0-3000m

Uso: 1. Susto, Corazón, Gases, Nervios, Ansiedad, Aire Pesada, Buena Suerte, Susto de la muerte, Florecimiento, Buenos Negocios, Protección, Buena Suerte, Buena Salud / Hojas y Tallos, fresco / Tópico / Quemar 50g sobre carbón combinado con Romero, Palo Santo, Alucema, Incienso, Saumerio y Mirra. Para Baño: Mezcla Alternativa para Florecimiento. Tallo Baño como se necesita o Baño una vez por día por 15-30 días. 2. Susto, Corazón, Gases, Nervios, Ansiedad, Aire Pesada, Buena Suerte, Susto de la muerte, Florecimiento, Buenos Negocios, Protección, Buena Suerte, Buena Salud / Hojas y Tallos, fresco / Oral / 20g en 1 litro de agua hervido 2 minutos y combinado con $10 \mathrm{~g}$ cada uno de Pimpinela, Cedrón, Mejorana, Siempre Viva, Flores de Diamelas, Toronjil, Romero, Claveles y Orange Flores. Un litro por día o 3-4 tazas por día después de comidas. 3. Buenos Negocios, Protección, Buena Suerte, Buena Salud / Hojas y Tallos, fresco / Seguro / Mezcla Estándar para Seguro. 


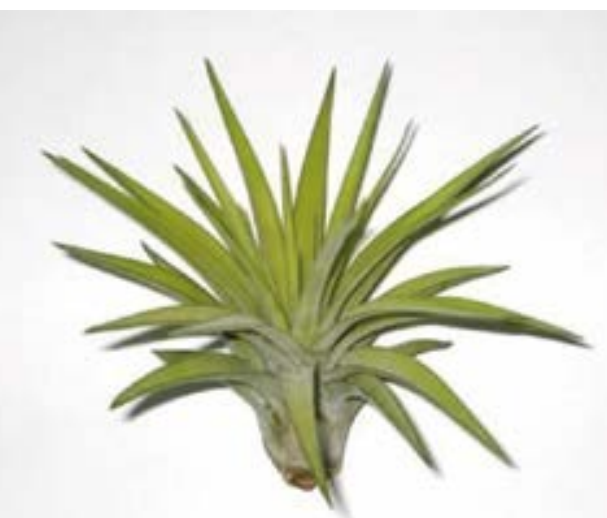

Tillandsia multiflora

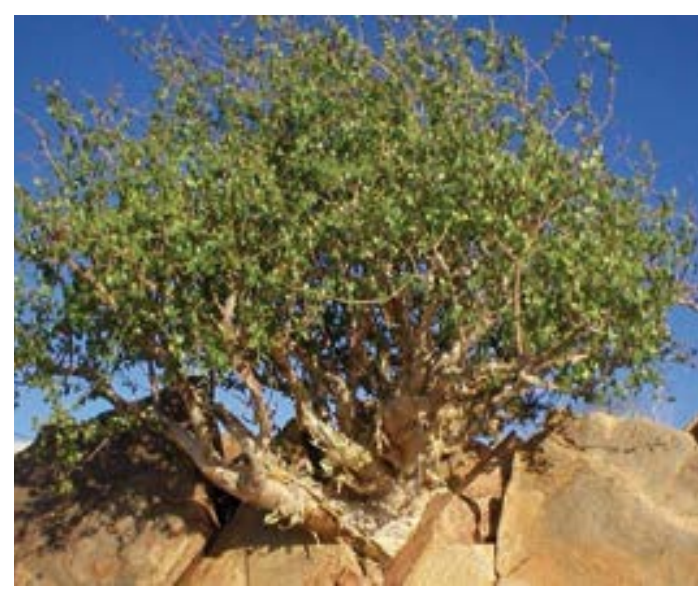

Commiphora myrrha

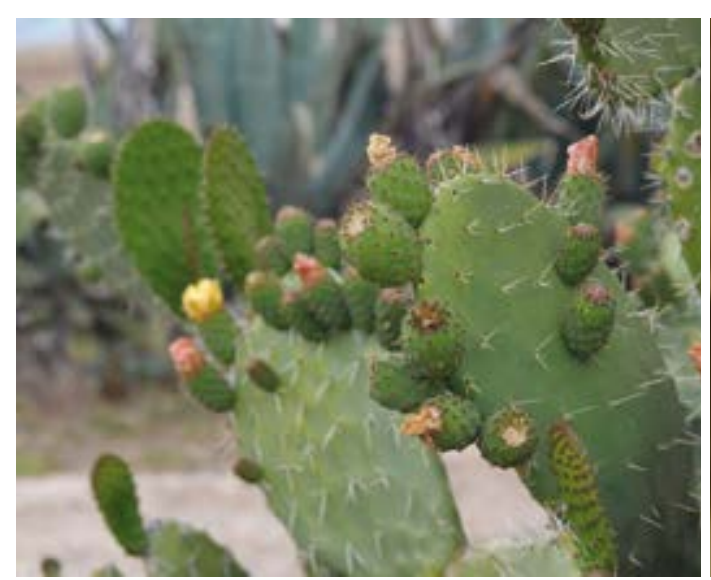

Opuntia ficus-indica

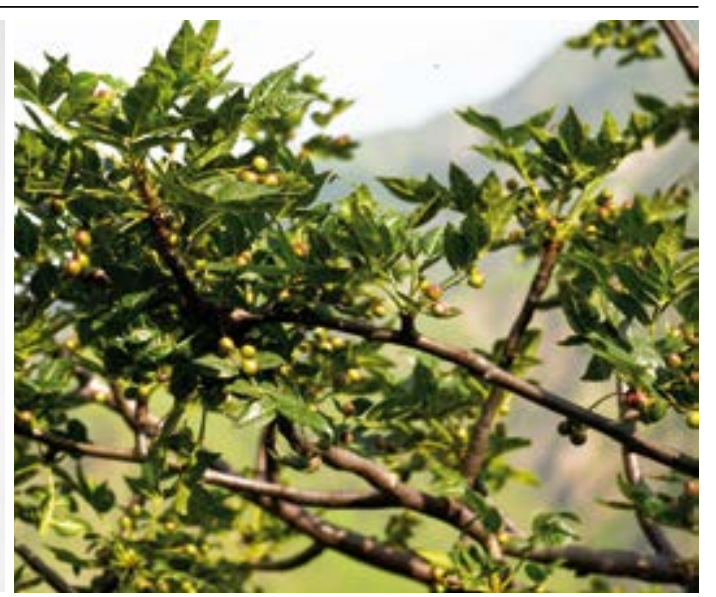

Bursera graveolens

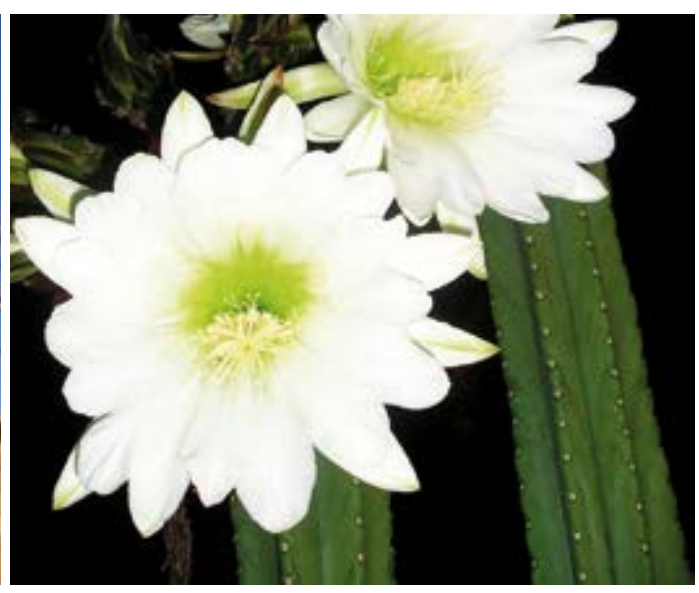

Echinopsis pachanoi

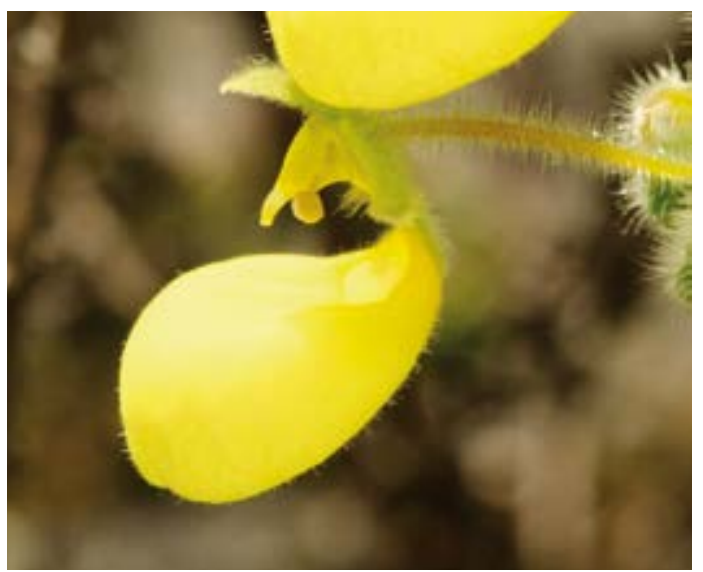

Calceolaria rugulosa
BROMELIACEAE - Tillandsia multiflora Bentham var. decipiens (Andre) Sm.

Siempre Viva, Siempre Viva Roja

Hierba, Andina, 1000-2500m

Uso: 1. Depresión, Corazón, Nervios / Flores, fresco / Oral / 10g en 1 litro de agua hervida combinado con $10 \mathrm{~g}$ cada uno Toronjil, Clavelin y Jugo de Lima. Tomar 3 veces por día por 1 mes. 2. Depresión, Corazón, Nervios / Planta entera, fresco / Tópico / 20g por 5 litros de agua hervido por 20 minutos. Baño 3 veces por semana.

BURSERACEAE - Bursera graveolens (Kunth) Triana \& Planchon

\section{Palo Santo}

Árbol, Andino, 1000-3500m

Uso: 1. Daño/Hechicería, Susto, Hechicería / Tallos Pequeños, Corteza, Madera, seco / Tópico / 3 cucharas por 3 litros de agua combinado con 10g cada uno Romero Blanco y Romero Castilla. Baño 2-4 veces por mes. 2. Tos, Gripe, Bronquitis, Resfrío / Small Tallos, Corteza, Madera, seco / Oral / Hervir 1 litro de agua, añadir 2 pedazos de $5-10 \mathrm{~g}$ de Palo Santo. Hervir por 5 minutos. Cubrir y dejar por 3 minutos. Tomar caliente, 1 vaso pequeño 3 veces por día por 2 días solo. 3. Disipar energía negativa de la casa, Sombras malas / Tallos Pequeños, Corteza, Madera, seco / Incienso / Casa grande: usas 250g de la Hierba. Casa pequeña: $20 \mathrm{~g}$ combinado con Romero Blanco, Romero de Castilla, Romero, Hierba de la Plata, Hierba de la Fortuna, Hierba de Oro, Incienso (Copal) y Mirra, cada Martes y Viernes como se necesita. Para gente: Paciente debe ser desnudo con una tela en su nuca. Poner olla con Palo de Santo fumando bajo pies de persona y deja el humo subir. También usado en establos de animales mezclado con Palo de Huaco para alejar insectos.

BURSERACEAE - Commiphora myrrha (T. Nees) Engl.

Mirra

Árbol, resina, introducido

Uso: Disipar energía negativa de la casa / Látex, seco / Incienso / Quemar sobre carbón mezcla con 10g de Mirra, Palo Santo, Saumerio y Romero. Quemar Incienso y dejar distribuir humo en toda la casa del paciente, 3 veces por semana: Martes, Viernes, Martes. Repetir como necesario.

CACTACEAE - Echinopsis pachanoi (Britton \& Rose) Friedrich \& G. Rowley

San Pedro, Huachuma

Hierba, Andina, Costa, 0-3000m, cultivado

Uso: 1. Úlceras, Alucinógeno, Mejorar visión durante rituales, Heridas causadas por Daño/Hechicería, Mal Aire, Inflamación (general), Acné / Planta entera, fresco / Oral, Tópico / Machucar San Pedro en rodajas y Hervir en de agua de 12 hasta 6 de la tarde. Hervir sobre fuego lento, añadir agua si se necesita, 1 vaso por paciente y 1 vaso por el curandero durante ritual. No se debe comer especies (ají), frejoles, pescado o mariscos por 24 horas después de tomar. Aplicar Tópico por Heridas y acné. Paciente debe mantenerse fuera del sol por 24 horas. 2. Lavar Cabello, Fortificar Cabello / Planta entera, fresco / Tópico / Frotar pulpa en cabello.

CACTACEAE - Opuntia ficus-indica (L.) Miller

Tuna

Hierba, Andina, Costa, 0-3500m, introducido y cultivado

Uso: 1. Diabetes / Frutas, fresco / Oral / Cascara y extracto de fruta. Tomar el extracto, 1 vaso por día como se necesita. 2. Perdida de Cabello / Hojas, fresco / Tópico / Cortar hoja en medio. Hervir cada medio en 3 litros de agua por 20 minutos. Lavar cabello con liquido y fricciona piel como con champú. Bañar una vez por día por 4 días.

CALCEOLARIACEAE - Calceolaria rugulosa Edwin

Potito

Hierba, Amazónica, Andino, Costa, 0-4000m, maleza

Uso: Inflamación / Planta entera, fresco / Oral / Añadir $10 \mathrm{~g}$ de material de la planta a $10 \mathrm{~g}$ cada uno de Verbena, Cola de Caballo, Pie de Perro, Amor Seco, Llantén y 1 litro de agua. Hervir la mezcla por 3 minutos. Tomar caliente. Tomar 1 taza, 3-4 veces por día por 1 mes. 


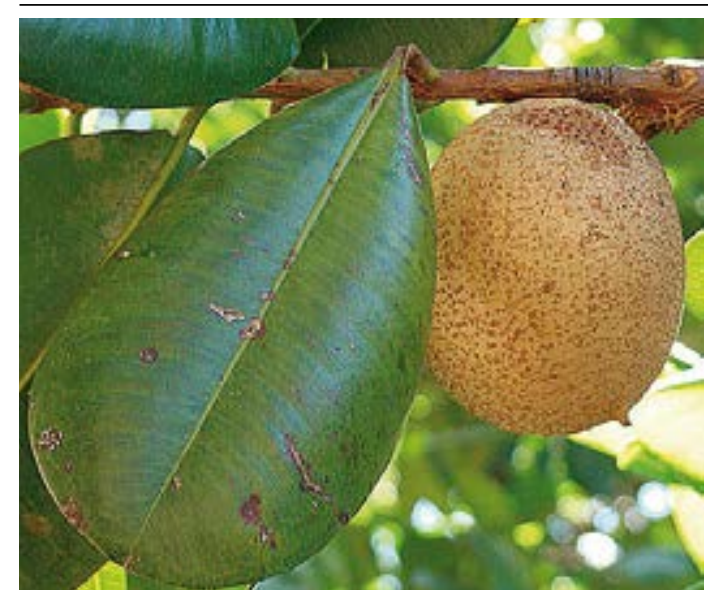

Mammea americana

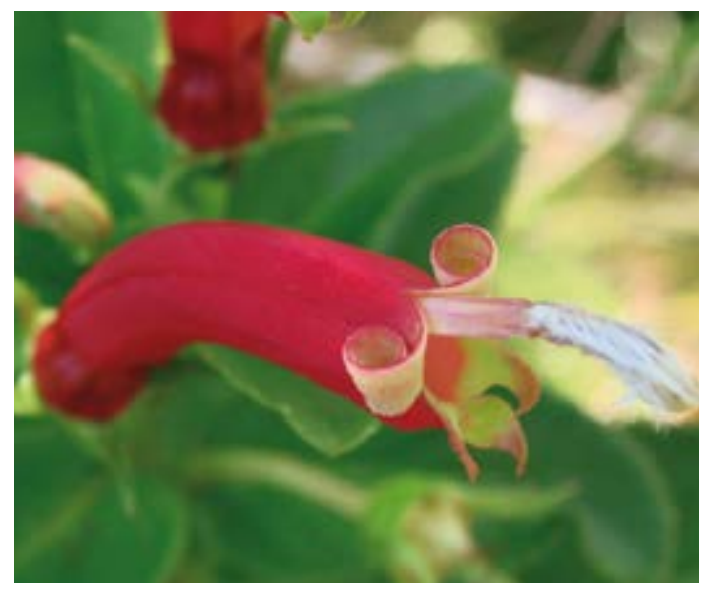

Centropogon cornutus

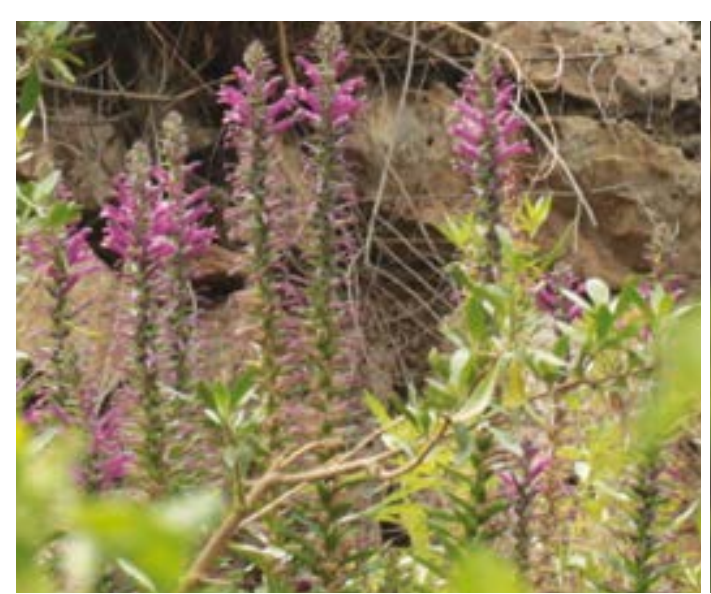

Lobelia decurrens

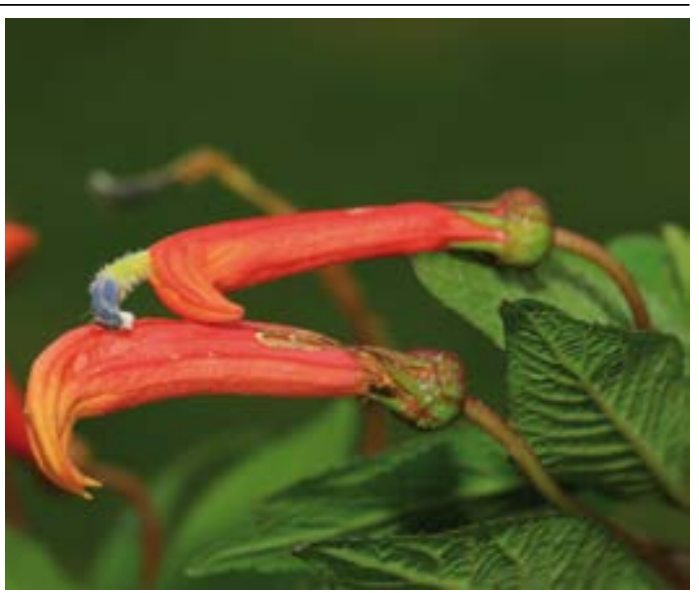

Centropogon argutus

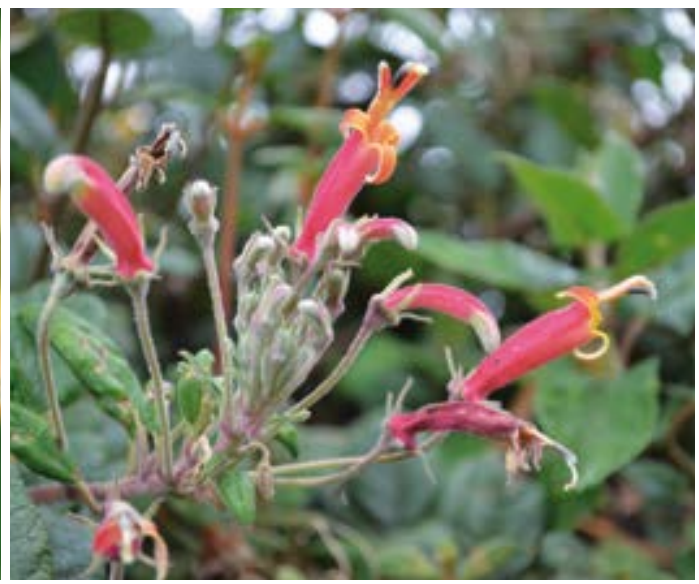

Centropogon rufus

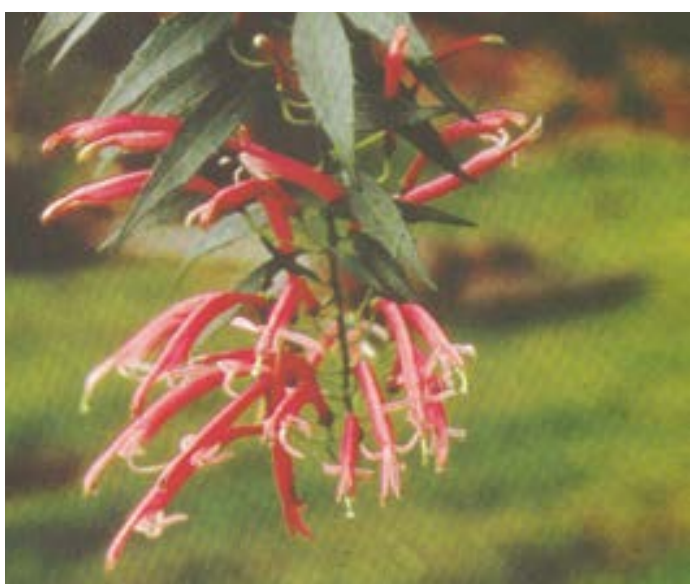

Siphocampylus angustiflorus
CALOPHYLLACEAE - Mammea americana L.

Mamey

Árbol, Amazónico, Andino, Costa, 0-1000m, cultivado

Uso: 1. Diarrea / Cáscara del fruto, fresco / Oral / Hervir 1 taza de agua, añadir 1/4 de Cáscara del Fruto de Mamey. Cubrir y dejar por 2-3 minutos. Paciente debe tomarlo caliente, 1 vaso 2-3 veces por día por 2 días. 2. Pérdida de Peso / Hojas, fresco / Oral / Hervir 1 litro de agua con 4 Hojas Mamey por 3-4 minutos. Tomar 1 vaso 3-4 veces por día por 1 mes.

CAMPANULACEAE - Centropogon argutus $\mathrm{E}$. Wimmer

Conchalay, Conchalalay

Arbusto, Andino, 2000-3000m

Uso: Susto, Aire / Tallos y Hojas, fresco o seco / Tópico / 20g por 5 litros de agua, hervido por 20 minutos. Baño: $1-3$ veces por mes.

CAMPANULACEAE - Centropogon cornutus (L.) Druce

Raínga

Hierba o Arbusto, Amazónico, Andino, 0-1500m

Uso: Mal Aire, Disolver/remover Tumores / Hojas y Tallos, seco / Oral / Hervir 100g de la planta en 1 taza de agua. Tomar frío, una vez por día. Hay que seguir tratamiento con otras Hierbas.

CAMPANULACEAE - Centropogon rufus Wimm

Trinoso

Hierba, Andino, 2000-3000m

Uso: Intestinos, Hígado, Vesícula, Tumores, Sistema Urinaria, Piel / Hojas y Tallos, fresco o seco / Oral / Combinar $10 \mathrm{~g}$ de cada uno de las hierbas siguientes: Cadillo, Amor Seco y Lampazo en $1 / 2$ litro de agua y Hervir por 5 minutos. Tomar templado, $1 / 2$ taza 3 veces por día por 20 días o como se necesita.

CAMPANULACEAE - Lobelia decurrens Cavaniles

\section{Contolla}

Hierba, Andino, 1000-3500m

Uso: Curar drogadictos. Causa vómitos y diarrea. / Planta entera, fresco / Oral / Hervir 1 litro de agua, ańadir $5 \mathrm{~g}$ de Contolla. Tomar 1 taza por semana por up a 1 mes. Como alternativa vaciar cigarrillo $75 \%$, llenar con $50 \%$ Contolla molida y rellenar los $25 \%$ remanentes con tabaco. Fumar.

CAMPANULACEAE - Siphocampylus angustiflorus Schlechtendal

Contoya, Hierba de Envidia, Contolla

Vine, Andino, 1500-3500m

Uso: 1. Purgante / Flores, Hojas y Tallos, fresco / Oral / Hervir $5 \mathrm{~g}$ en $1 / 2$ taza de agua. Tomar una vez al mes. 2. Daño/Hechicería, Descartar envidia / Flores, Hojas y Tallos, fresco / Tópico / Hervir 10g de Contolla en 10 litros de agua por 20 min mezclado con otras Hierbas como especifica el curandero por Buena Suerte. Baño 3 veces por semana. 


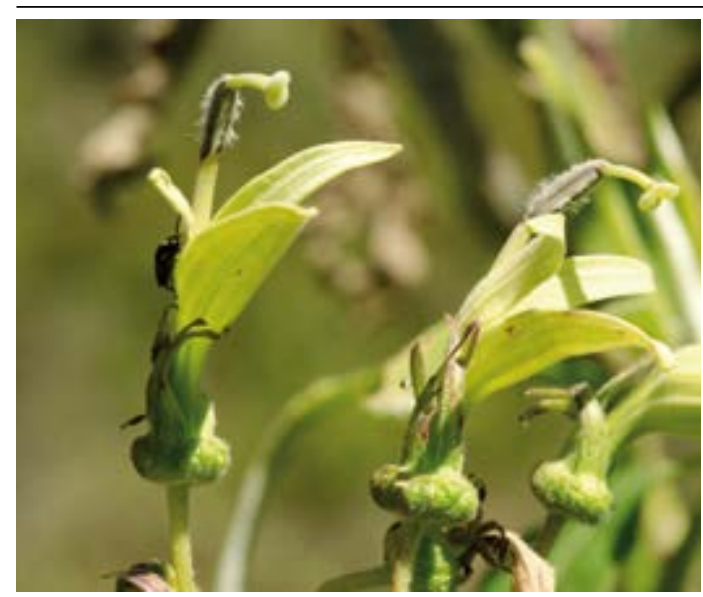

Siphocampylus cutervensis

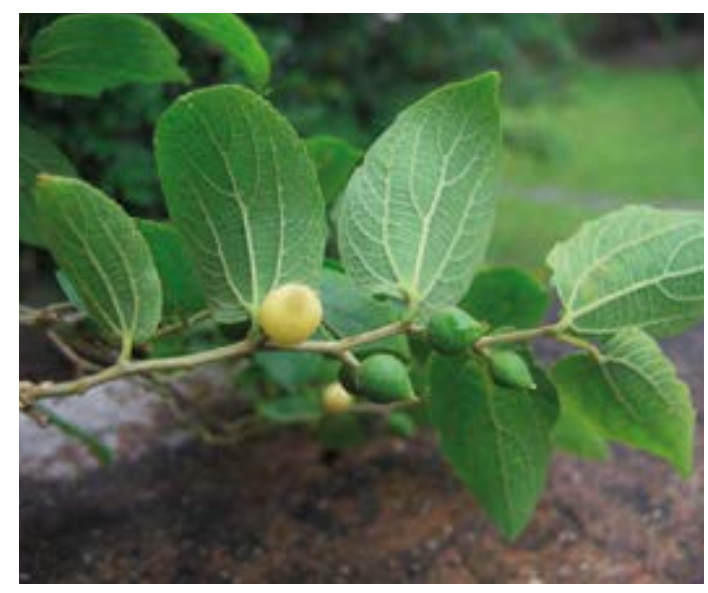

Celtis pubescens

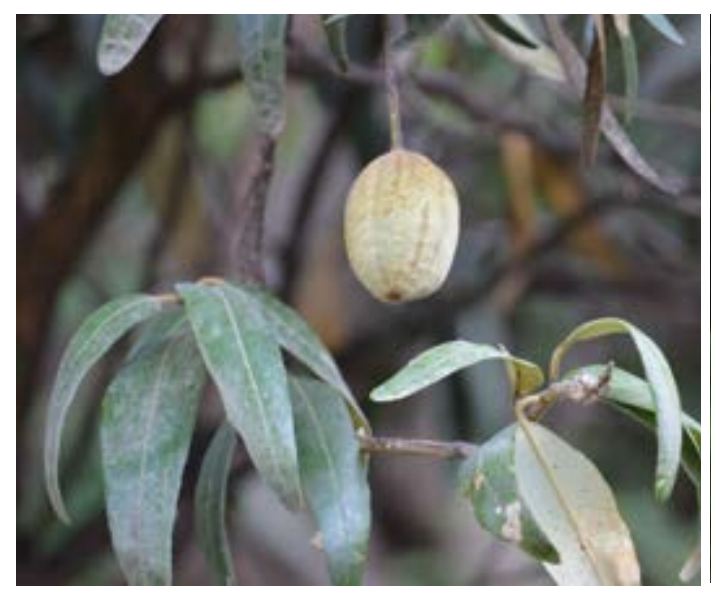

Capparis scabrida

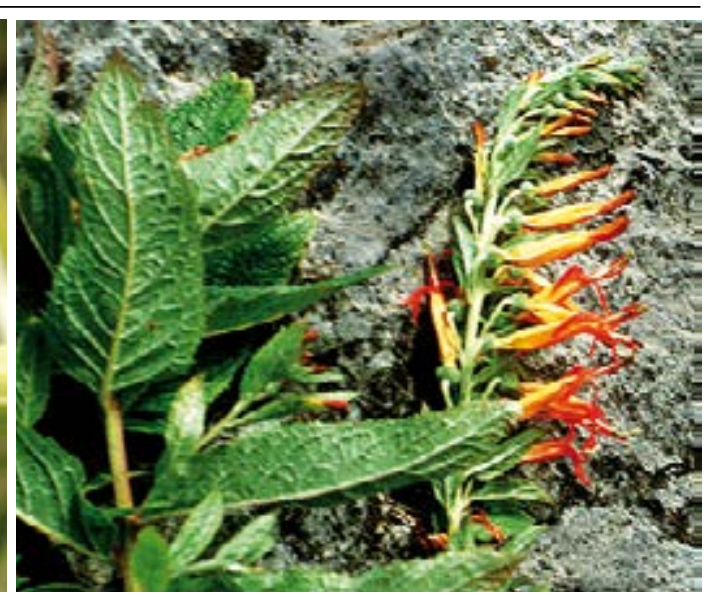

Siphocampylus tupaeiformis

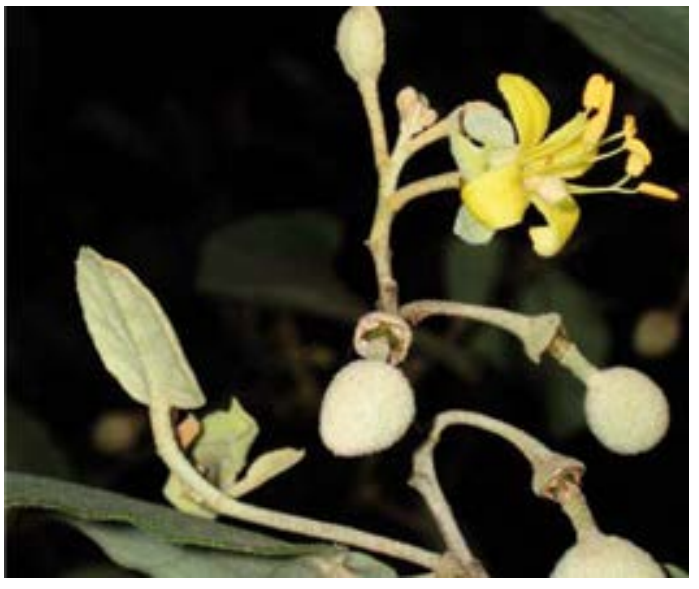

Capparis crotonoides

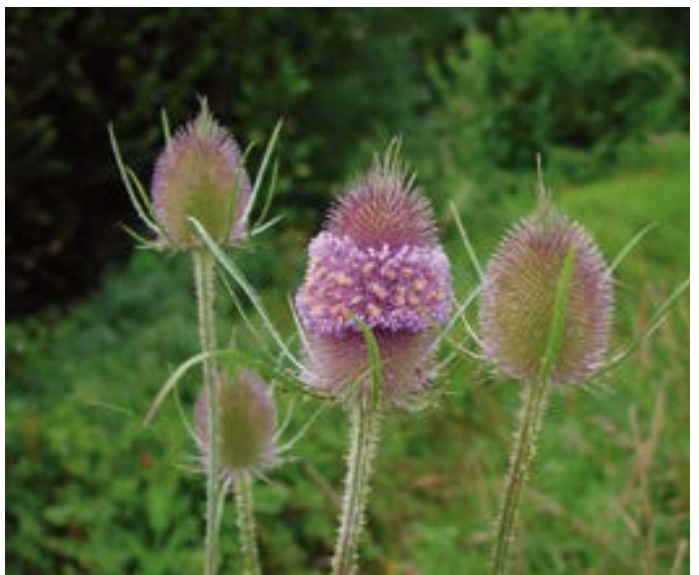

Dipsacus jallonum
CAMPANULACEAE - Siphocampylus cutervensis A. Zahlbr.

Conchalay Blanco, Conchalalay Blanco

Herb, Andean, 2000-3000m

Hierba, Andina, 2000-3000m

Uso: 1. Contusiones / Hojas, fresco / Tópico / Emplasto: una vez al mes. 2 Susto, Daño/Hechicería

/ Hojas, seco / Tópico / Un manojo en 3 litros de agua hervida combinado con Conchalay Colorado,

Huaminga, Vinagre y 7 Espiritus. Dos Bańos por semana en acuerdo que indica la Mesa. Limpia: 2 veces por mes.

CAMPANULACEAE - Siphocampylus tupaeiformis Zahlbr.

Cochaya

Hierba, Andina, 3000-4000m, maleza

Uso: Guardar casa y chacra / Fruta entera, fresco / Amuleto / Nunca cortar la planta. Usar en forma natural, sembrándolo cerca de la casa. Siempre sembrar Cochaya cerca a San Pedro. Se debe siempre tener algunos en la propiedad. Si viene un ladrón la palta hasta libera serpientes y amarrar la persona con cuerdas. Un ladrón se puede poner loco. La planta siempre detecta quien hace cosas malas y reconoce su propietario y la familia.

CANNABACEAE - Celtis pubescens (Humb. \& Bonpl.) Spreng.

Palo Huaco, Palo Blanco

Árbol, Amazónico, Andino, 500-1500m, maleza

Uso: Fertilidad, Potencia sexual, Artritis, Bronquitis, Dolor muscular, Circulación de sangre, Hemorragias (sanando) / Corteza, seco / Oral / Mezclar Palo Huaco, Palo Sangre, Chuchuhuasi, Huanaco, Huevo del Angelote, Pacra, Polen, Miel de Palo, Miel, Cascarilla y Huanarpo Macho en 1 botella de Vino o Tequila. Dejar mezcla por 1 semana. Tomar frío, 1 pequeñas Vino vaso 3 veces por día hasta se acaba la botella. Se puede repetir.

CAPPARIDACEAE - Capparis crotonoides (Kunth) Iltis \& Cornejo

Cimuro, Simuro, Bichayo

Árbol, Andino, Costa, $0-1000 \mathrm{~m}$

Uso: 1. Bronquitis / Flores, fresco / Oral / Hervir 10 botones florales en 1/2 taza de agua por 2 minutos. Paciente debe tomarlo caliente y quedarse en casa durante el tratamiento. Tomar 1 taza por día por 8 días. 2. Artritis, Reumatismo / Hojas, fresco / Tópico / Hervir 2kg de Bichayo Hojas en 5 litros de agua por 30 minutos. El paciente debe ser desnudo con toalla sobre la cabeza en un cuarto cerrado. Debe inhalar profundamente. Baño debe durar 1/2 hora. Baño cada 6 días, 2 veces solo. 3. Resfrío, Dolor General: muscular, huesos, etc. / Hojas, fresco / Tópico / Machucar 20 Hojas de Bichayo y Poner Hojas en área afectada. Masajear el área con Hojas. Paciente debe quedarse en casa durante tratamiento. 4. Mal Aire, Resfríos / Hojas, fresco / Tópico / Añadir 20g de material de la planta a 4-5 litros de agua. Hervir la mezcla por 5-6 minutos. No ingerir mezcla. Baño 2-3 veces como se necesita.

CAPPARIDACEAE - Capparis scabrida Kunth

Zapote

Árbol, Andino, Costa, 0-2500m

Uso: Inflamación (general), Palpitaciones del Corazón, Hígado, Reducción de Ansiedad, Incrementar producción de leche en vacas / Fruta, fresco / Oral / Machucar fruta y recoger extracto. Tomar sin calentar, 1 vaso por día por 4 días. Del tronco se puede extraer un pegamento.

CAPRIFOLIACEAE - Dipsacus jallonum L.

Cardo Santo

Hierba, Andina, Costa, 0-3000m, maleza, introducido

Uso: Diabetes, Hígado, Colesterol / Planta entera, fresco / Oral / 3-5g en 1 litro de agua hervida mezclado con Hierbas que se usa para la misma enfermedad. Tomar 3 veces por día. 


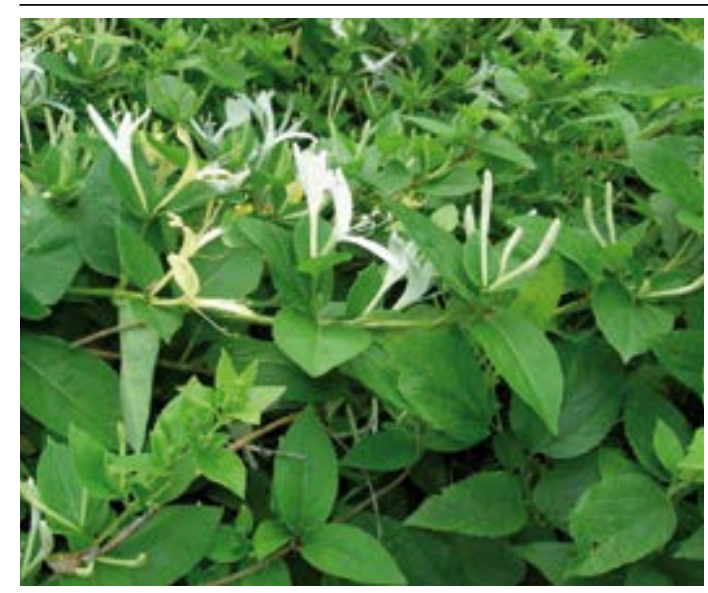

Lonicera japonica

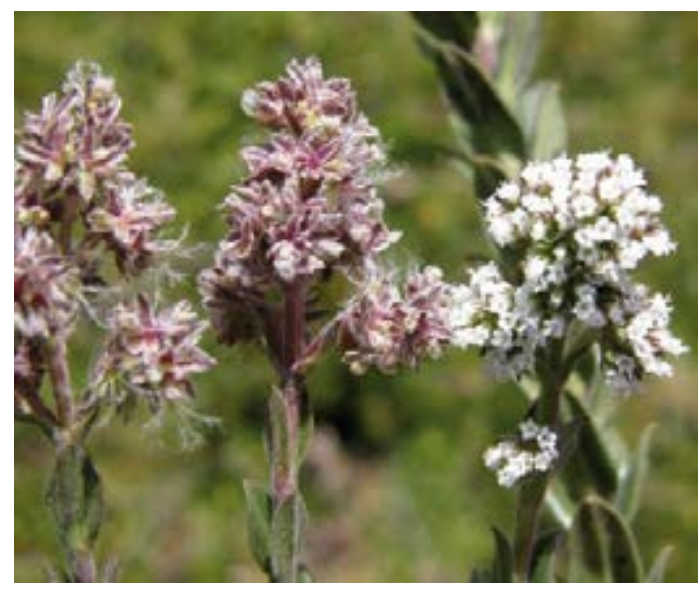

Valeriana microphylla

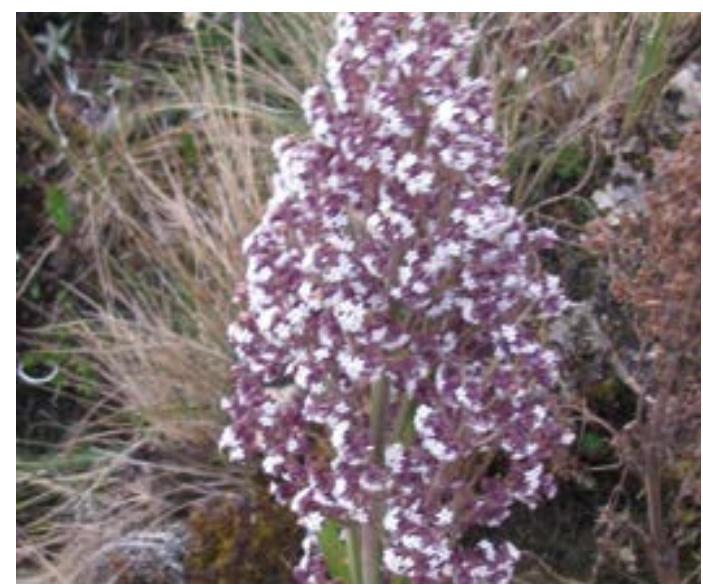

Valeriana plantaginea

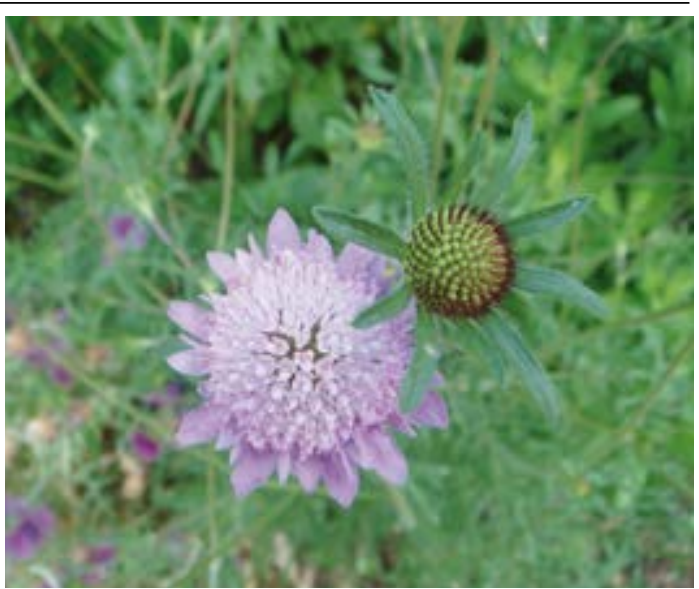

Scabiosa atropurpurea

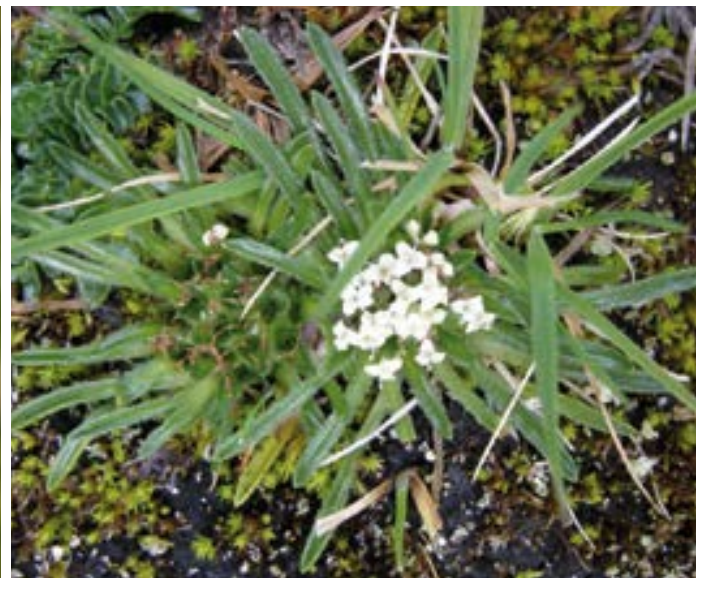

Valeriana niphobia

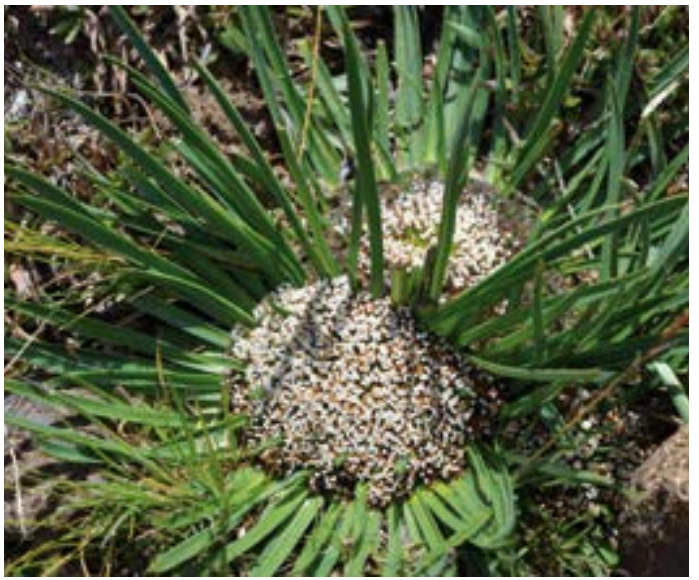

Valeriana rigida
CAPRIFOLIAEAE - Lonicera japonica Thunberg

Madre Selva

Arbusto, Andino, 2000-3000m, introducido

Uso: Depresión, Corazón, Mal de amor, Nervios, Epilepsia, Sufrimiento psicológico / Planta entera, fresco o seco / Oral / Hervir 1 litro de agua, ańadir 10g de Madre Selva. Tomar 3-4 tazas por día por 1-3 meses o como se necesita. Epilepsia se caracteriza por dolor de corazón, caerse al suelo y perdida de conocimiento.

CAPRIFOLIACEAE - Scabiosa atropurpurea L.

Ambarina, Ambarina Negra, Flor de Ambarina, Ambarindas

Hierba, Andina, Costa, $0-3000 \mathrm{~m}$, maleza, introducido

Uso: 1. Resfrío, Tos, Bronquitis, Limpiar la sangre, Tos ferina / Flores, fresco / Oral / Hervir 1 litro de agua con $20 \mathrm{~g}$ de material de planta y Veronica Hierba del Toro, Moradilla, Lancetilla y Hierba de la Rabia. Tomar caliente 3 veces por día hasta enfermedad persiste. 2. Regulación de menstruación / Flores, fresco / Inhalado / Machucar y mezclar con leche materna. Inhalar $5 \mathrm{~g}$ cada día por 8 días por la nariz y toma también por boca.

CAPRIFOLIACEAE - Valeriana microphylla Kunth

Hierba de la Fortuna

Hierba, Andina, 3000-400m

Hierba, Andina, 3000-400m
Uso: Fragancia, Buena Suerte / Planta entera, fresco o seco / Tópico / 10g en 1 litro de agua, 2 Bańos por mes en la noche.

\section{CAPRIFOLIACEAE - Valeriana niphobia Briquet}

Botón de Oro

Hierba, Andina, 3500-4500m

Uso: 1. Buena Suerte / Planta entera, fresco o seco / Tópico / Hervir 3 litros de agua con 10g de Botón de Oro y $10 \mathrm{~g}$ cada uno de Hierba de la Justicia, Hierba del Halago, Hierba de la Plata, Hierba de la Fortuna, Dollar y Sigueme Sigueme por 3 minutos. Añadir Agua Florida, Tabú, Azúcar Blanco y Jugo de Lima. Baño 3 veces por semana Martes, Viernes y Martes. 2. Buena Suerte / Planta entera, fresco o seco / Seguro / Preparar con perfumes y las hierbas típicas de Seguro. Rellenar con perfumes como se necesita. Mantiene su poder cuando esta lleno.

CAPRIFOLIACEAE - Valeriana plantaginea Kunth

Hórnamo Morado, Hórnamo Caballo

Hierba, Andina, 3500-4500m

Uso: 1. Mal Aire, Purgante, Laxante / Hojas y Tallos, fresco / Oral/ Hervir 10g de Hórnamo Morado con $1 / 2$ taza de agua por 2 minutos. Paciente debe tomar liquido frío, 1/2 taza una sola vez. 2. Protección / Hojas y Tallos, fresco / Tópico / Hervir 3 litros de agua por 10 minutos con 100g de Hórnamo Morado y $10 \mathrm{~g}$ de cada uno de: Misha Blanca, Misha Colambo, Misha Galga, Misha Morada, Misha Roja, Misha Rosada y Toro Maique. recitar una oración. Paciente debe frotarse cpn las hierbas. Después del bańo no se debe lavar o usar toalla, solo secar al aire.

CAPRIFOLIACEAE - Valeriana rigida Ruiz. \& Pav.

Hórnamo Estrella, Siete Sábios, Valeriana Estrella, Valeriana, Hierba de la Estrella

Hornamo Estrella, Siete Sabios,

Uso: 1. Fragancia, Buena Suerte / Tallos, fresco / Seguro / Mezclar con otras Hierbas de fuerza, Hierbas de uso: 1. Fragancia, Buena Suerte / Tallos, fresco / Seguro / Mezclar con otras Hierbas de fuerza, Hierbas de por 5 litros de agua por 20 minutos. otras Hierbas de fuerza, Hierbas de suerte Bańo 3 veces por semana. 3. Insomnio, Relajante, Nervios, Dolor de Cabeza, Menopausia / Tallos, fresco / Oral/ Hervir 1 litro de agua, añadir $10 \mathrm{~g}$ de Valeriana Estrella. Tomar 4 veces por dia como se necesita. Nińos no deben tomarlo de agua, añadir $10 \mathrm{~g}$ de Valeriana Estrella. Tomar 4 veces por dia como se necesita. Nińos no deben tomarlo de Tallos, fresco / Tópico / Combinar con Timolina, Vinagre, Agua Florida y Ârnica. poner en parte trasera de Tallos, fresco / Topico / Combinar con Timolina, Vinagre, Agua Florida y Arnica. poner en parte trasera de cabeza o área afectada. Dejar por la noche. 5. Florecimiento, Buena Suerte, Mal Aire, Exito / Tallos, fresco I Tópico / en una botella Poner 1g de cada uno de las hierbas siguentes: Hierba del Lucero, Hierba Estrella, Ambrocilla, Señorita, Caballero, Pega Pega, Siempre Viva, Carpintero, Waime Waime, Piri Piri (Hembra y Macho), Hierba del Buen Querer, Hierba del Oro, Hierba de la Plata, Hierba del Halago, Sigueme Sigueme y Hierba del Negocio. Añadir unas gotas de de los siguentes perfumes: Cariño, Dios de la Huaringa, Dios de la Felicidad, San Antonio, Macumba Pusanga, Gran Jefe, Mil Flores, Llama Plata y Ekeko. Recitar una 


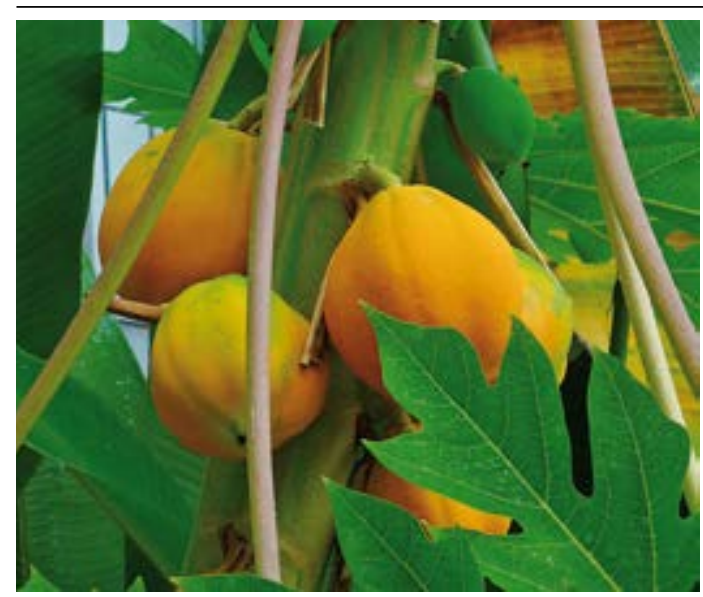

Carica papaya

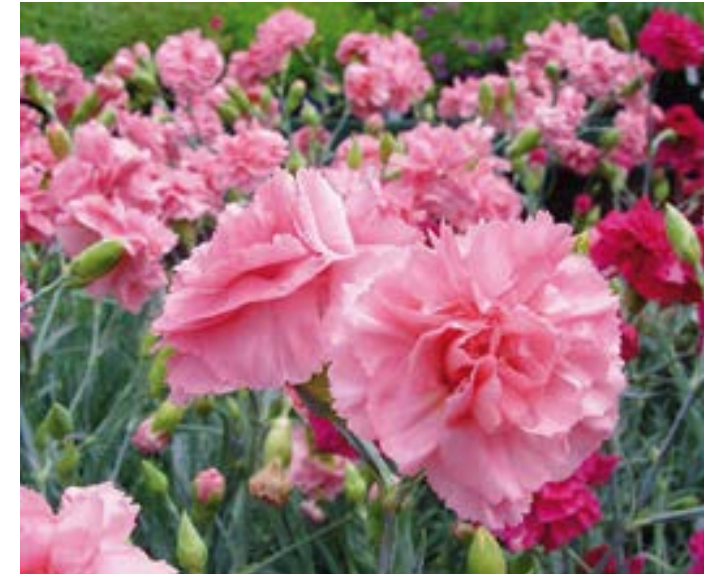

Dianthus caryophyllus

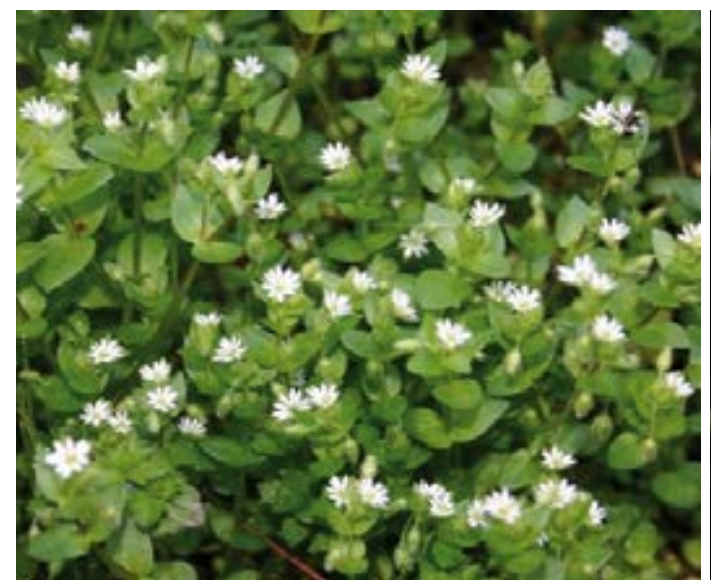

Stellaria media

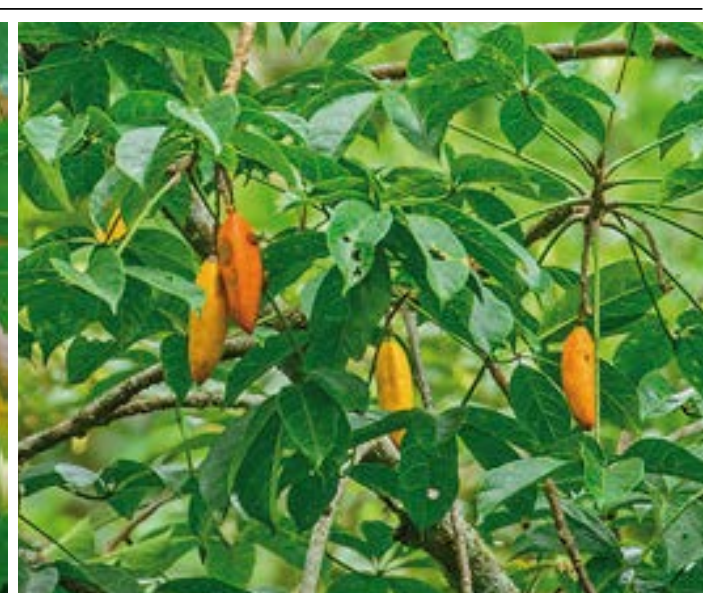

Jacartia digitata

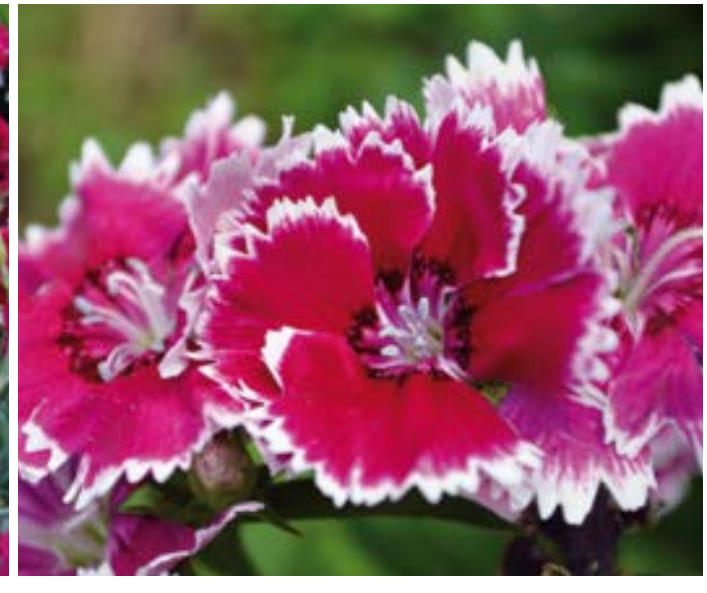

Dianthus caryophyllus

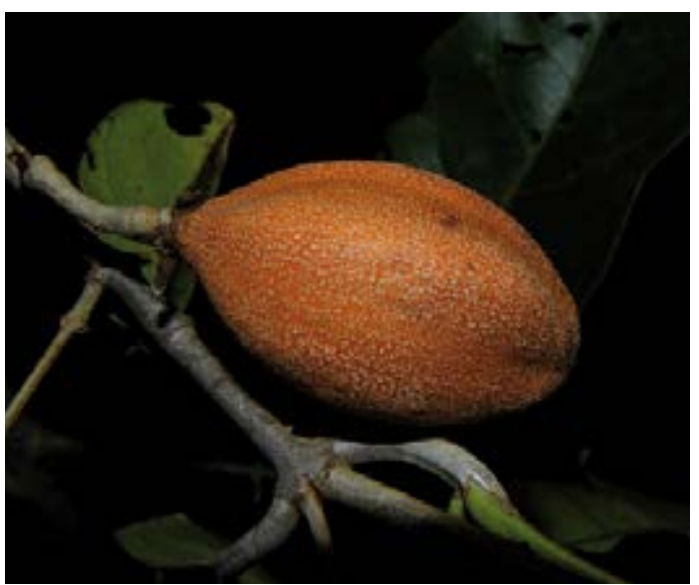

Salacia multiflora

oración invocando nombre del paciente, propietario del Seguro. Soplar y frotar el paciente con la mezcla por Buena Suerte, Martes y Viernes. 6. Florecimiento, Buena Suerte, Mal Aire, Éxito / Tallos, fresco / Tópico / Mezclar un total de $50 \mathrm{~g}$ de Hierba del Lucero, Hierba de la Estrella, Ambrocilla, Señorita, Caballero, Pega Pega, Siempre Viva, Carpintero, Waime Waime, Piri Piri (Hembra y Macho), Hierba del Buen Querer, Hierba del Oro, Hierba de la Plata, Hierba del Halago, Sigueme Sigueme y Hierba del Negocio. Hervir en 5-7 litros de agua por 20 minutos, ańadir un pcoc de de los siguentes perfumes: Cariño, Dios de la Huaringa, Dios de la Felicidad, San Antonio, Macumba Pusanga, Gran Jefe, Mil Flores, Llama Plata y Ekeko y dejarlo enfriar antes de bańarse. Bańo 2 veces (Martes y Viernes solo) cada 3 meses.

CARICACEAE - Carica papaya L.

Papaya

Arbol, Amazonico, Andino, 0-3000m, cultivado

Uso: 1. Estómago Parásitos, Laxante, Anti-venom, Reverse effects de Poison / Semillas y Cáscara del Fruto, fresco / Oral / Mezclar 10 litros de agua, 1 taza de Semillas y a whole peel de una pequeña Papaya. Tomar en ayuno, 1 vaso 3 veces por mes. Le vaya vomitar y defacar mucho. 2. Inflammación del Hígado / Fruit / Oral/ 1 recipiente pequeño cada dis por 1 semana en ayuno antes del desayuno.

CARICACEAE - Jacartia digitata (Poepp. \& Endl.) Solms-Lang.

Contra Hechizo

Arbol, Amazonico, Andino, 0-3000m

Uso: 1. Purgante (Dańo/Hechizería), Laxante para gente sufriendo de cólicos y gases / Raíz, fresco / Oral/ Hervir $25 \mathrm{~cm}$ de Raíz en 3 litros de agua por 20 minutos o machucar 200g de Contra Hechizo y añadir $50 \mathrm{~g}$ de azúcar. sacar jugo. Tomar 1 vaso por sesión de curación. 2. Acné / Raíz, fresco / Tópico / Machucar Tallos de Contra Hechizo y sacar jugo. Applicar en cara o área afectada como crema dos veces por día: de la mańana y antes de dormir por 6 días o hasta Acné disaparece.

CARYOPHYLLACEAE - Dianthus caryophyllus L.

Clavel, Clavelina, Clavel de la Costa

Hierba, Andina, 2000-4000m, introducido y cultivado

Uso: 1. Mal de amor, Sentimentalidád, Corazón, Nervios, Buena Suerte, Insomnia / Planta entera, fresco / Tópico / Hervir 7 plantass con Hierba de la Plata, Hierba de la Justicia, Ruda y Romero en 3 litros de agua por 5 minutos. Bańo como se necesita, en días especiales en dependencia a fase deluna1-3 veces por mes. 2. Mal de amor, Sentimentalidád, Corazón, Nervios, Buena Suerte, Insomnia / Planta entera, fresco / Oral / Tomar 50g de Claveles (blanco, rojo, amarillo, purpureo) con $5 \mathrm{~g}$ de azucar y $1 / 2$ taza de agua hervido por 2 minutos, 3-4 tazas por día por 1 mes.

\section{CARYOPHYLLACEAE - Dianthus caryophyllus L.}

Hierba, Andino, 2000-4000m, introducido y cultivado

Uso: Enfermedad cardiaca, Palpadós del Corazón / Planta entera, fresco / Oral/ Combinar 50g del material de la planta, 50g de Huamanripa y 1 taza de agua. Hervir la mezcla por 5 minutos. Tomar la mezcla fría. Tomar $1 / 4$ taza una vez por día por 30 dias.

CARYOPHYLLACEAE - Stellaria media (L.) Criollo

Tripa de Cuy

Hierba, Andino, Costa, 0-4000m, maleza

Uso: Inflammación de Riñones, Enfermedád renal / Planta entera, fresco / Oral/ Añadir 10g de material de la planta a 1 litro de agua, Malva, Amor Seco, Chacur y Unguia. Tomar 1 taza 3-4 veces por día por 1 mes.

CELASTRACEAE - Salacia multiflora (Lam.) DC.

Bejuco de Montaña

Liana, Amazonico, Andino, 0-1000m

Uso: Sistema nervioso / Semillas y Tallos, fresco o seco / Tópico / Hervir 200g por 3 litros de agua. Tomar 2 Banos por mes. 


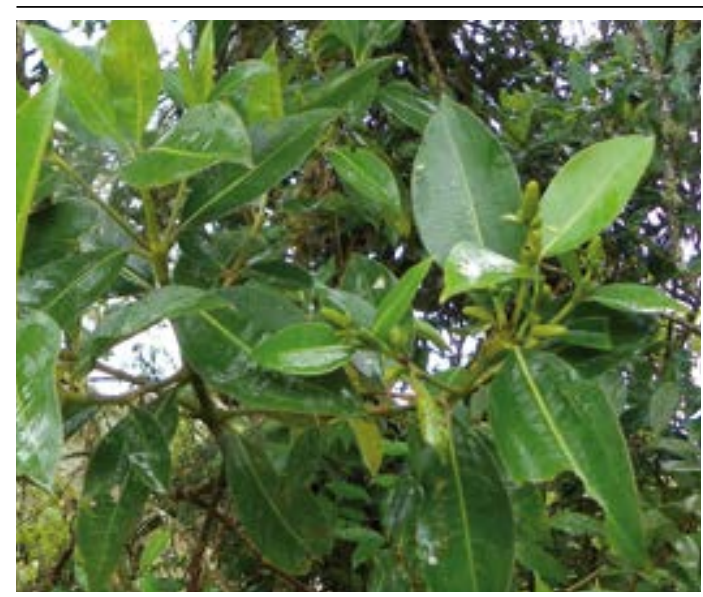

Hedyosmum racemosum

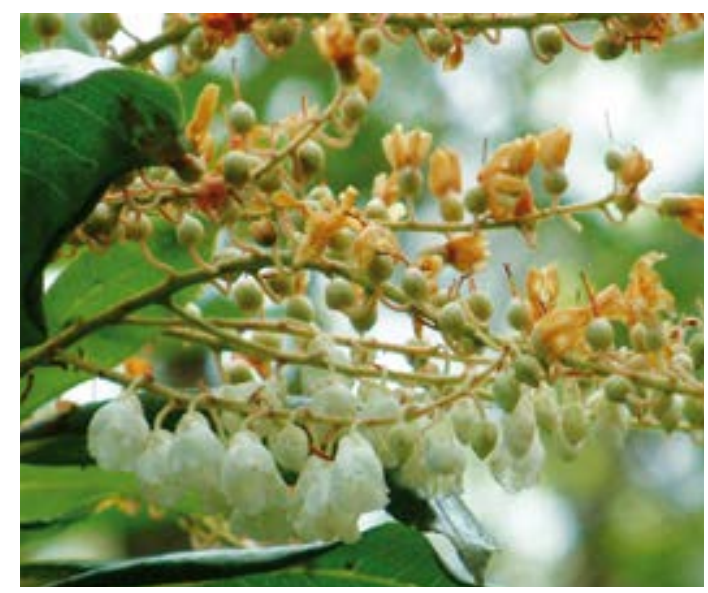

Clethra castaneifolia

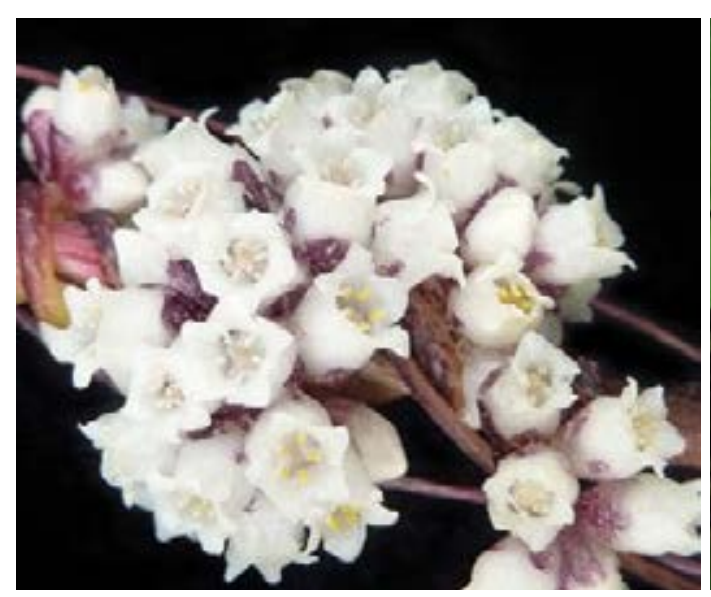

Cuscuta foetida

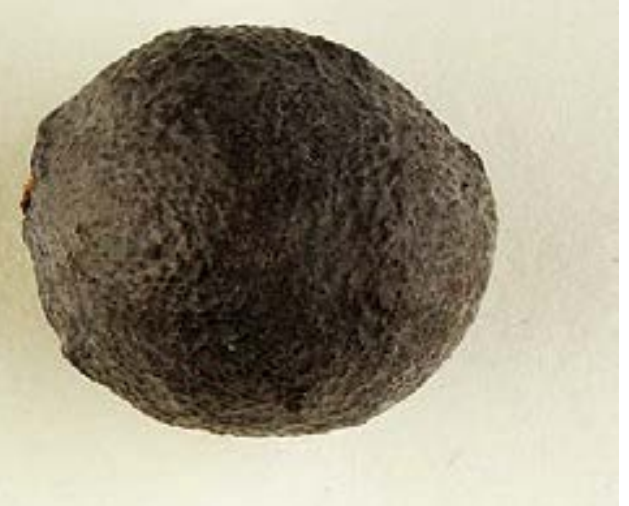

Couepia guianensis

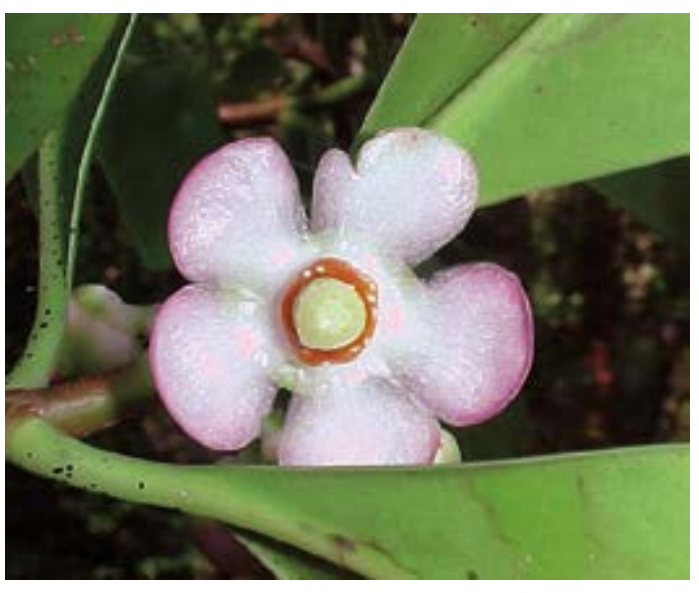

Clusia minor

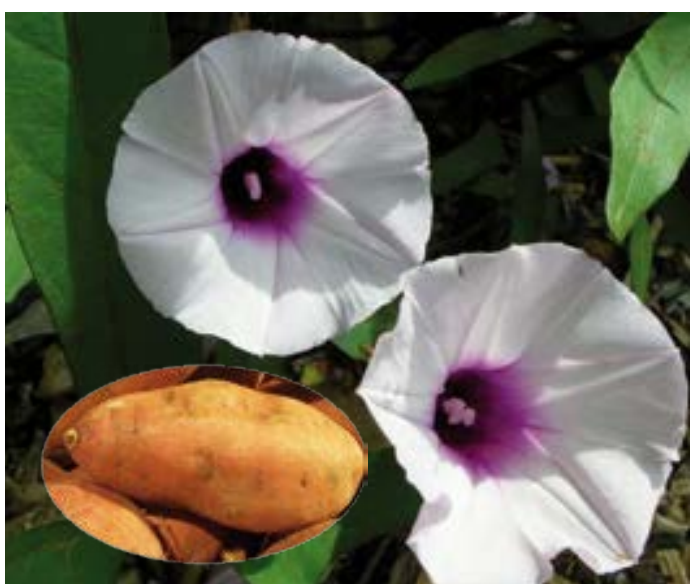

Ipomoea batatas
CHLORANTHACEAE - Hedyosmum racemosum (R. \& P.) G. Don.

Masamoche, Asancito, Asarcito, Asarquiro, Choleta

Arbol, Amazonico, Andino, 0-2500m

Uso: Bronquitis, Resfrío, Tos, Asma, Reumatismo, Dolor de Huesos, Sistema nervioso / Corteza, seco / Oral/ Usar parte externa de la Corteza 8-10g por 2 litros de agua hervido por 20 minutos. Tomar como se necesita. Alternativo, usar 30g por 2 botellas de alcohol mezclado con Chuchuhuasi, Cascarilla, 7 Raices y Huayacanes, permitir macerar por 8 días. Tomar como se necesita.

CHRYSOBALANACEAE - Couepia guianensis Aubl.

Acharachango, Charachango, Ashango

Arbol, Amazonico, 0-500m

Uso: 1. Susto, Mal Aire, Sistema nervioso, Encantamientos, Hechizería, Remover Daño/Hechizería, Epilepsia / Semillas, secas o fresco / Tópico / Baño: 20 Semillas por 5 litros de agua molido y hervido, 3 veces por semana o dos veces por mes, Martes y Viernes. 2. Susto, Mal Aire, Sistema nervioso, Enchantment, Hechizería, Remover Daño/Hechizería, Epilepsia / Semillas, secas o fresco / Oral/ Bebida: 7-15 Semillas en 1 litro de agua machucado y macerado por 8 días. Tomar 3-4 pequeńas tazas por día por 7 días. Semillas se puede macerar en alcohol por 5 días, tomar, $5 \mathrm{~g}, 3$ veces por día.

CLETHRACEAE - Clethra castaneifolia Meisn.

Hierba del Olvido

Arbol, Andino, 1000-2500m

Uso: Dominar juicios (ritual), Dominar problemas legales (ritual) / Hojas y Tallos, seco / Seguro / Juntar en una tela: $10 \mathrm{~g}$ de Hierba del Olvido, $10 \mathrm{~g}$ de Hierba del Demonio y $10 \mathrm{~g}$ de Hierba de la Justicia. Sellar y rezar. Paciente debe siempre levarlo y rezar.

CLUSIACEAE - Clusia minor L.

Chusgón

Arbol, Amazonico, 0-500m

Uso: Nervios, Enfermedad cardiaca / Fruta entera, fresco o seco / Oral/ Hervir 1 litro de agua, añadir $10 \mathrm{~g}$ de Chusgón, Pimpinela, Manzanilla, Toronjil, Barrojo, Romero y Chancas de Comida. Dejar 2-3 minutos. Paciente debe tomarlo caliente, 1 taza 4 veces por día como se necesita.

CONVOLVULACEAE - Cuscuta foetida H.B.K.

Yodo

Hierba parasitica, Andino, 2500-4000m

Uso: 1. Goiter / Planta entera, fresco / Oral/ 5g hervido en 1 taza agua. Tomar 1 taza por día. 2. Goitre / Planta entera, fresco / Tópico / 5g hervido en 1 taza agua. Aplicar como Emplasto.

CONVOLVULACEAE - Ipomoea batatas (L.) Lamarck

Camote (Sweet potato)

Hierba, Amazonica, Andino, 0-2500m, introducido y cultivado

Uso: Promover lactancia después del partyo / Planta entera, fresco / Oral/ Frotar paciente con planta primero, haciendo cruz sobre el pecho. Después lava planta y hiervela en 1 taza de agua. Tomar caliente 1 taza 2 veces por día por 2 días. 


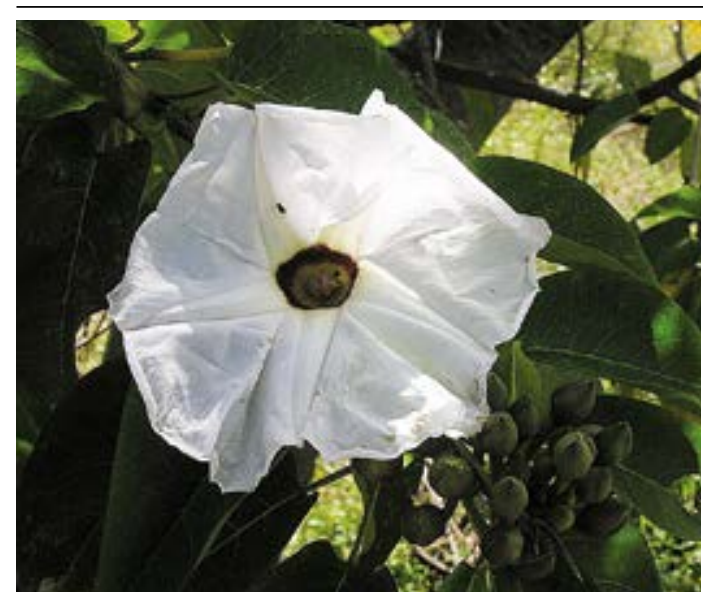

Ipomoea pauciflora

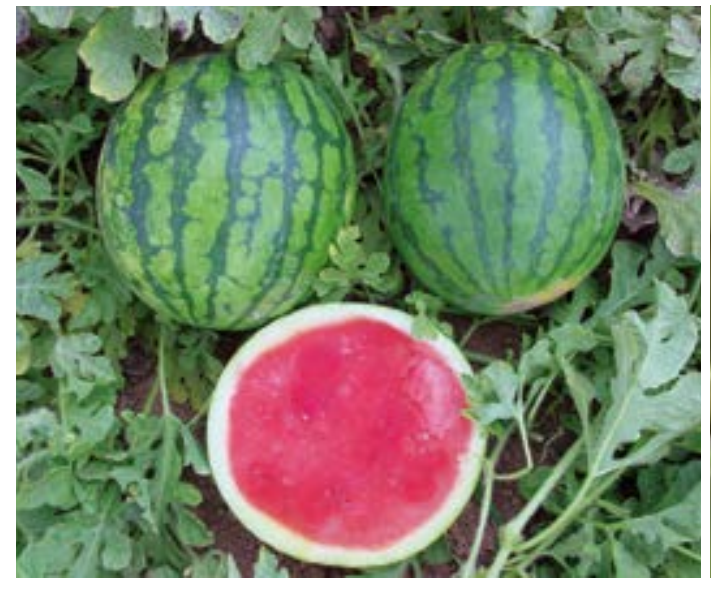

Citrullus lanatus

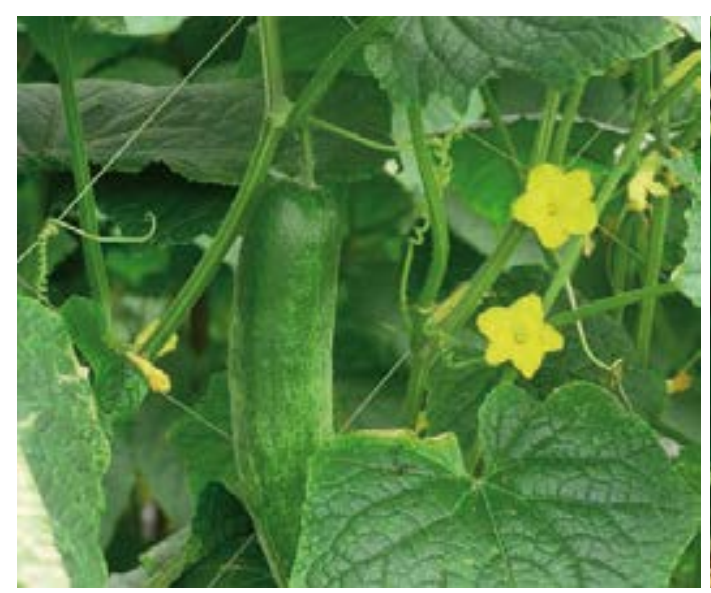

Cucumis sativus

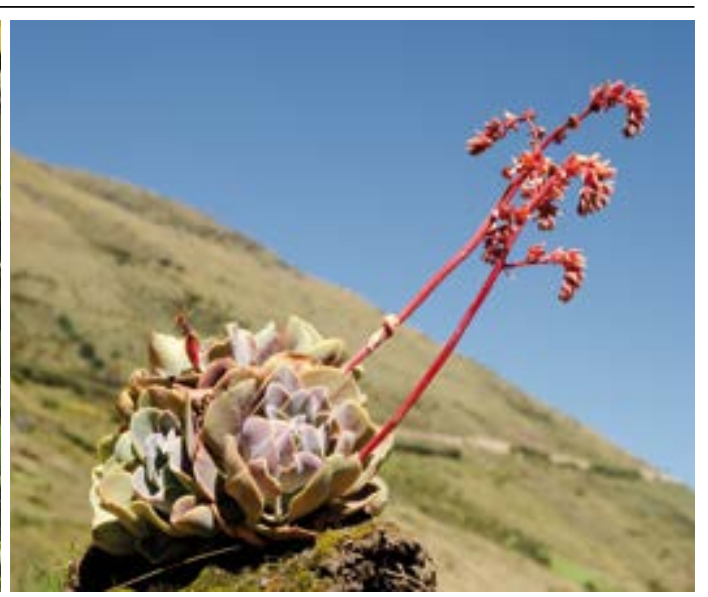

Echeveria peruviana

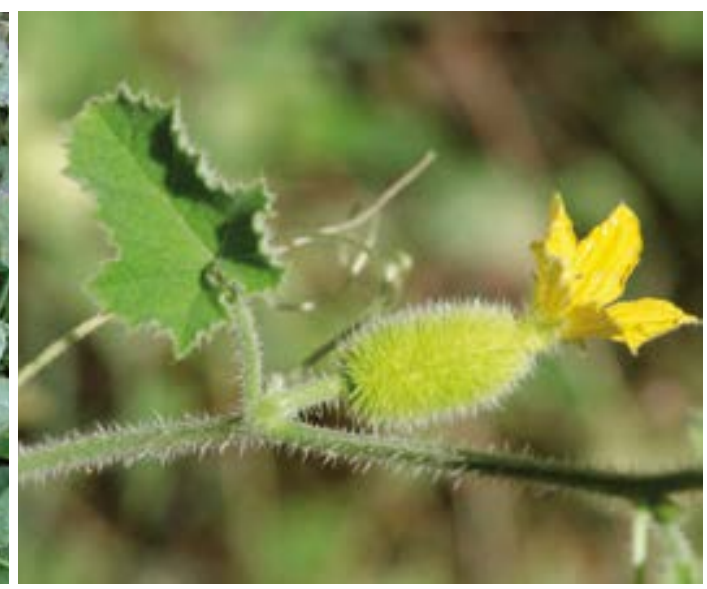

Cucumis dipsaceus

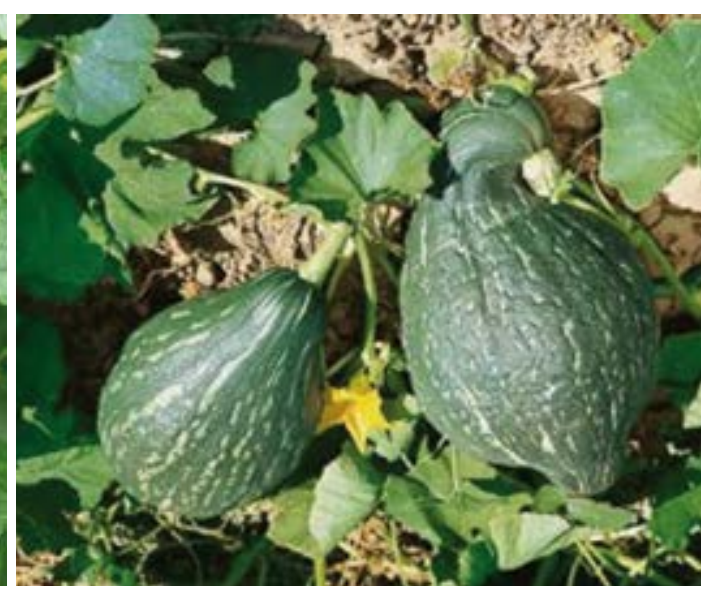

Cucurbita maxima
CONVOLVULACEAE - Ipomoea pauciflora M. Martens \& Galeotti

Huanarpo

Arbusto, Amazonico, Andino, 0-3000m

Uso: Escalofríos, Resfríos / Planta entera, fresco / Oral/ Poner en una botella de Cańazo o Yonque (Aguardiente) $20 \mathrm{~g}$ de material de planta con $20 \mathrm{~g}$ de Cascarilla, Diego Lope y Hualtaco. Deja por 8 días. Tomar frío 1 taza pequeña una vez al día o como se necesita (máximo 2 días).

CRASSULACEAE - Echeveria peruviana Meyen

Pinpin, Siempre Viva, Rosa Berta, Haya Rosa

Hierba, Andino, 2000-3500m

Uso: 1. Inflammación de Riñones, Nervios, Corazón, Inflamación del hígado / Hojas, fresco / Oral/ 2 Hojas por $1 / 2$ litro de agua hervido por 5 minutos. Tomar 1 litro por día. 2. Dolor de Oído / Hojas, fresco / Tópico / Calentar Hoja sobre fuego y exprimir jugo. Poner 10 gotas en oreja cada día o como se necesita.

CUCURBITACEAE - Citrullus lanatus (Thunberg) Matsumura \& Nakai Sandía

Vine, Amazonico, Andino, Costa, 0-3000m, introducido y cultivado

Uso: Circulación de sangre, Refresco Corazón / Corteza, seco / Oral/ Cascara de la fruta. Tomar la pulpa. Tomar frío, 1 vaso por día en ayuno por 20 días.

CUCURBITACEAE - Cucumis dipsaceus Ehrenb.

Vine, Amazonian, Andean, Coastal, 0-3000m, introduced and cultivated

Jaboncillo de Campo, Jaboncillo del Campo, Jaboncillo, Patito de Campo

Uso: Caspa, hacer el cabello briallante, Perdida de Cabello (prevención), parar bebé de mamear / Fruta, fresco / Tópico / Usar Fruta como shampú y jabon. Abrir fruta y frotar cabello con semillas. Baño: Usar la Fruta para frotar el cuerpo. Frotar 1/2 de la Fruta en el pecho de la mujer. Lavar 2-3 veces por semana como se necesita.

CUCURBITACEAE - Cucumis sativus $\mathrm{L}$.

Pepinillo

Vine, Amazonico, Andino, Costa, 0-3500m, maleza, cultivado

Uso: Quemar Grasa, Pérdida de Peso, Inflamación del hígado, Indigestión, Acidez, Acides intestinal / Fruta entera, fresco / Oral/ Remover cascara, Machucar la Fruta y añadir unas gotas de aceite de olivo y algo de sal. Extraer jugo o comer como ensalada. Tomar templado en ayuno, 1 vaso por día como se necesita o comer un poco. Oral: una vez por día por semana.

CUCURBITACEAE - Cucurbita maxima Duchesne

Zapallo

Vine, Amazonico, Andino, Costa, 0-3000m, cultivado

Uso: 1. Prevenir abortos involuntarios, Inflammación (generál), Ansiedád / Flores y unioned de Tallos, fresco o seco / Oral/ Hervir 10 Flores con Hojas y Tallos en $1 / 2$ litro de agua por 15 minutos. Tomar 1 taza 2 veces por día o la cantidad que se quiere por 2 días. 2. Enfermedád de Corazón / Semillas, secas / Oral / Solo en la mańana con un vaso de agua. Tomar 10 Semillas el primer día. Reducir monto por una semilla cada día hasta, el 10th día, se queda una solo. Pausar una semana y repetir. Proceso se puede demorar 2 semanas hasta un mes. 3. Verrugas, Lunares / Hojas, fresco / Tópico / Machucar 3-4 Hojas brandes. Poner Hojas en área afectada y cubrir con un pedazo de plastico, después una tela. Aplicar por 2 días, remover. 

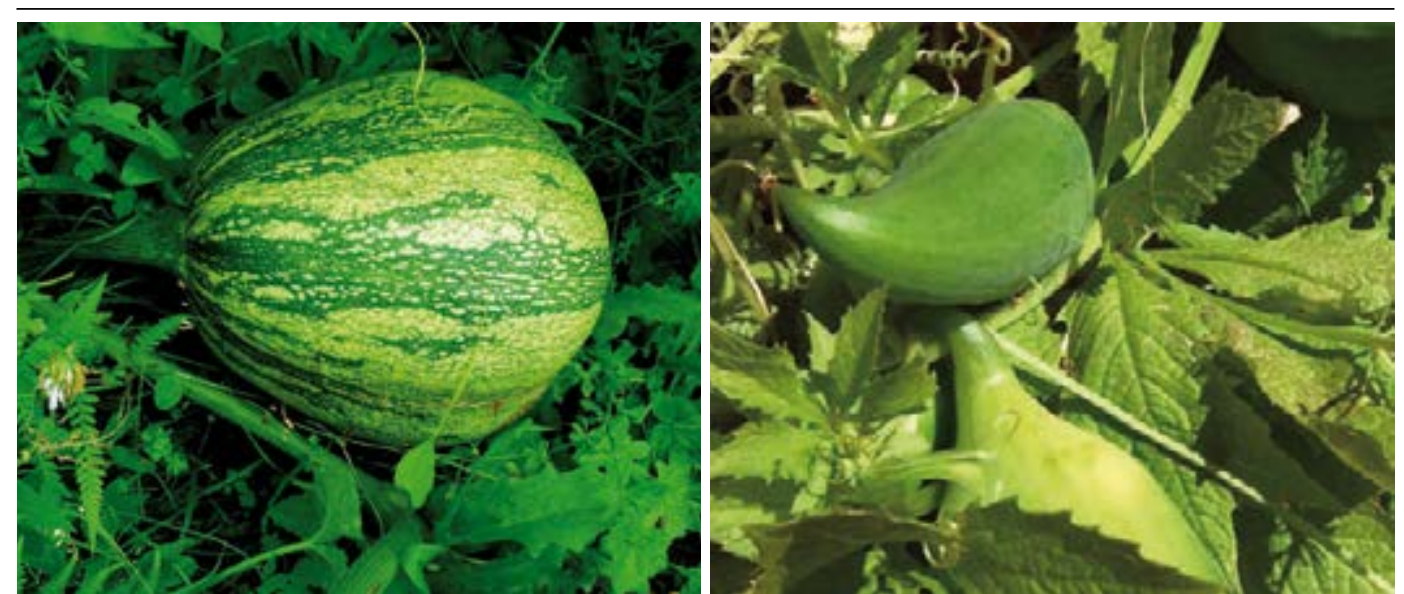

Cucurbita moschata

Cyclanthera pedata
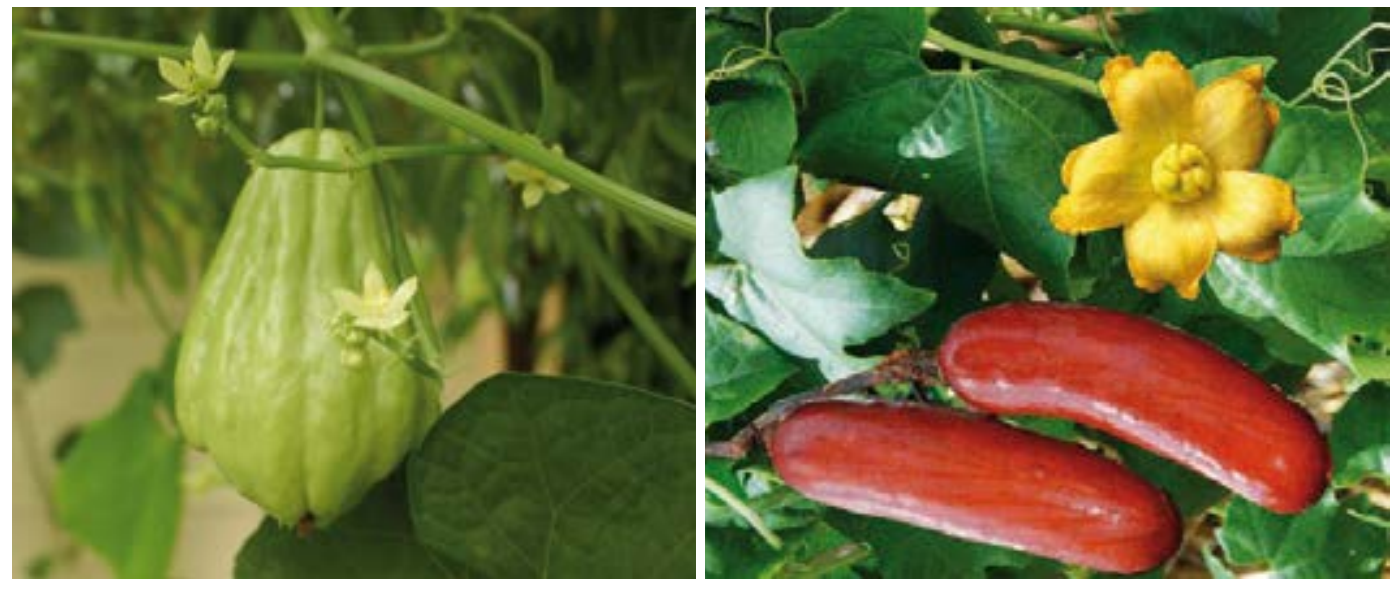

Sechium edule

Sicana odorifera

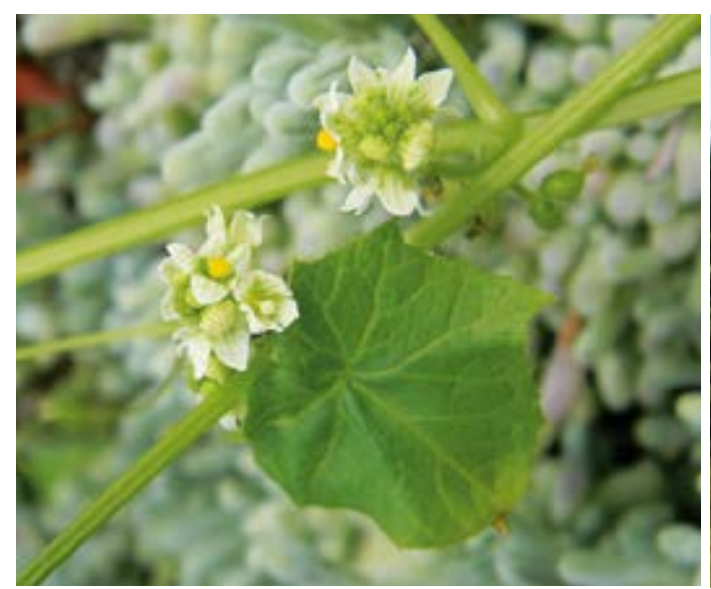

Sycos baderoa

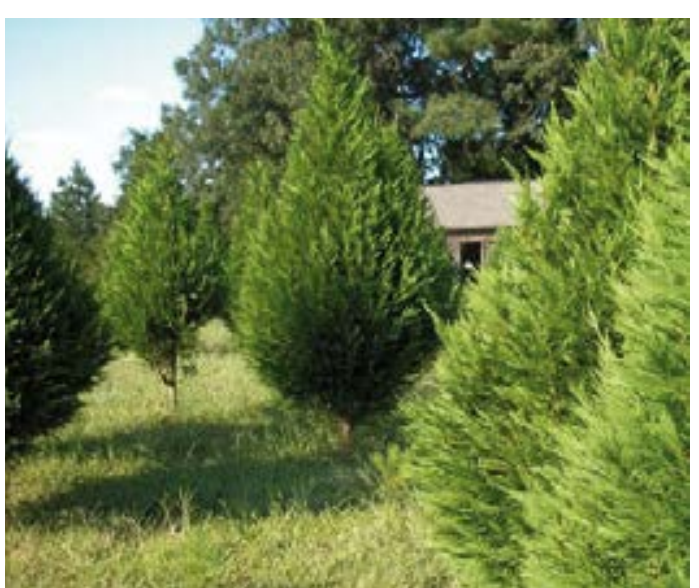

Cupressus lusitanica

\section{CUCURBITACEAE - Cucurbita moschata Duch}

Zapallo

Vine, Amazonico, Andino, Costa, 0-3000m, cultivado

Uso: 1. Prevenir abortos involuntarios, Inflammación (generál), Ansiedad / Flores y unioned de Tallos, fresco o seco / Oral / Hervir 10 Flores con Hojas y Tallos en $1 / 2$ litro de agua por 15 minutos. Tomar 1 taza 2 veces por día o la cantidad que se quiere por 2 dias. 2. Enfermedad de Corazón / Semillas, secas / Oral / Solo en la mańana con un vaso de agua. Tomar 10 Semillas el primer día. Reducir monto por una semilla cada día hasta, el 10th día, se queda una solo. Pausar una semana y repetir. Proceso se puede demorar 2 semanas hasta un mes. 3. Verrugas, Lunares / Hojas, fresco / Tópico / Machucar 3-4 Hojas brandes. Poner Hojas en área afectada y cubrir con un pedazo de plastico, después una tela. Aplicar por 2 dias, remover.

CUCURBITACEAE - Cyclanthera pedata (L.) Schrad.

Caihua

Vine, Amazonico, Andino, Costa, 0-3000m, cultivado

Uso: Tónico para el cerebro, Inflammación Renal, Enfermedad de cerebro, Dolor de Cabeza / Planta entera, fresco / Oral/ Licuar 3 Caihuas, 10g Rutabaga, 10g Zanahoria y 10g de Rabanito, 1 vaso de $250 \mathrm{ml}$ por día por 15 días en la mañana en ayuno. Tomar frío

CUCURBITACEAE - Sechium edule Swartz.

Caihua Chilena, Mochera, Caihua

Vine, Amazonico, Andino, Costa, 0-3000m, introducido y cultivado

Uso: Circulación de sangre, Venas varicosas (diluye coagulos de sangre) / Frutas, fresco / Oral/ 1/2 de la Fruta machucada con 10g de Moradilla. Hervir en 1 litro de agua por 3-5 minutos. Tomar 3-4 veces por día por 1 mes.

CUCURBITACEAE - Sicana odorifera (Vell.) Naud.

Secana

Vine, Amazonico, Andino, Costa, 0-3000m, introducido y cultivado

Uso: Celos / Planta entera, fresco / Amuleta / Dormir con material de planta y lavarlo cada mańana. No comer la planta. Al fin del tratamiento la Secana será arugada. Dejarlo en un lugar lejano. Usar 7 días y 7 noches.

CUCURBITACEAE - Sycos baderoa H. et A.

Fuque

Vine, Amazonico, Andino, 0-3000m, maleza

Uso: 1. Mordeduras de serpientes / Semillas, secas / Oral/ Moler 100g de Fuque y añadir 100g de Cuncuno y $5 \mathrm{~g}$ de aceite de cocina. Drenar liquido con un pcoc de agua. Tomar frío a 6 de la mañana en la mañana en ayuno, 1/2 un pequeño vaso por 4 dias. 2. Deshacer lunares de la piel / Hojas, fresco / Tópico / Hervir 100g de la Hoja con 1 litro de agua hasta todo el liquido evapora. Poner área afectada sobre la olla con liquido hirviendo. Despues poner Hojas en área afectada cuando caliente, una vez por día por 15 días. Usar el vapor para 20 min y deja la Hoja en el lunar por 3 horas.

CUPRESSACEAE - Cupressus lusitanica Miller

Cipre, Cipres

Arbol, Andino, 2500-4000m, introducido y cultivado

Uso: 1. Haemorragia vaginal, Haemorragia / Planta entera, fresco / Oral / Hervir 3 Ramas en 1 litro de agua por 20 minutos. Tomar 2 veces por día por 1 semana. 2. Acne, Perdida de Cabello / Planta entera, fresco / Tópico / Hervir 1/2 litro de agua con $10 \mathrm{~g}$ de Cipres por 3 minutos. Bańo y lavar cara con extracto caliente. No lavar con agua después de poner extracto a la cara. Aplicar 3 veces por día por 1 semana. Por Perdida de Cabello: Hervir 1 litro de agua con 10g total de Amor Seco, Romero, Cola de Caballo y Cipres por 3 minutos. Lavar cabello con mexcla fría una vez por día como se necesita. 


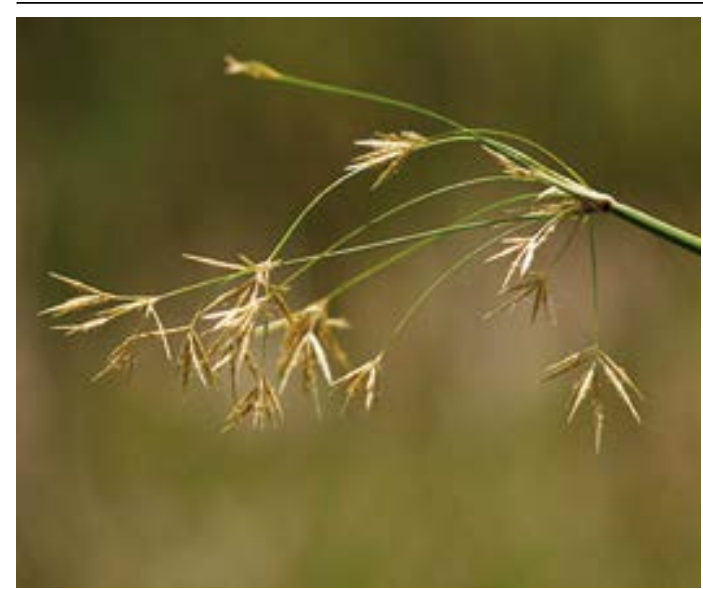

Cyperus articulatus

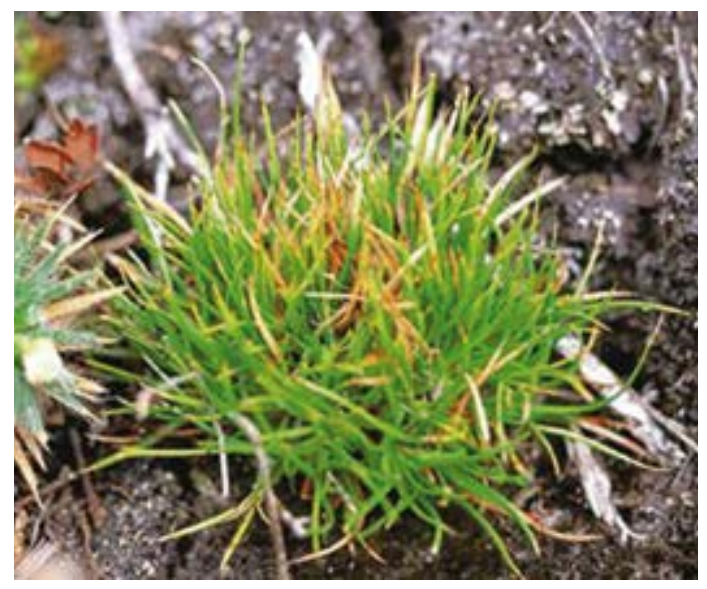

Oreobolos obtusangulus

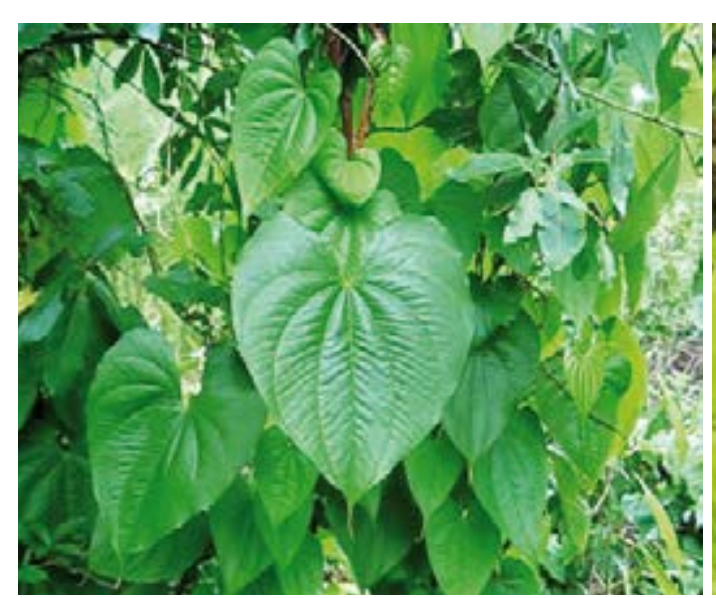

Dioscorea tambillensis

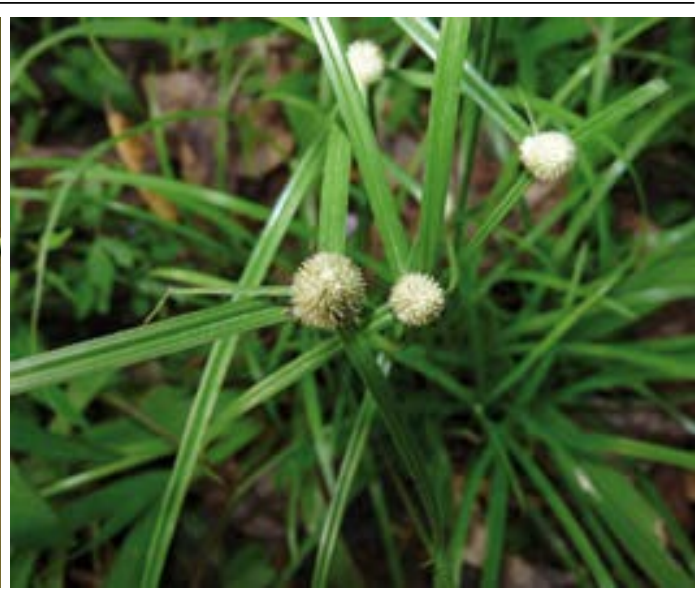

Kyllingia pumila

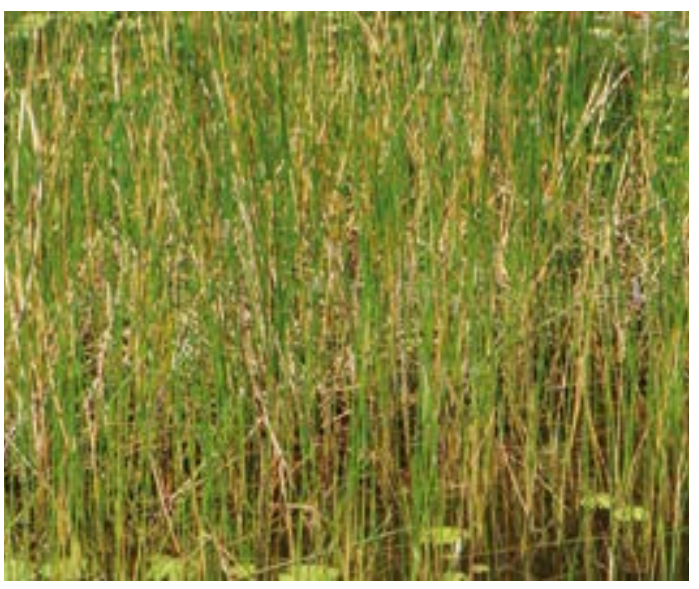

Scirpus californicus

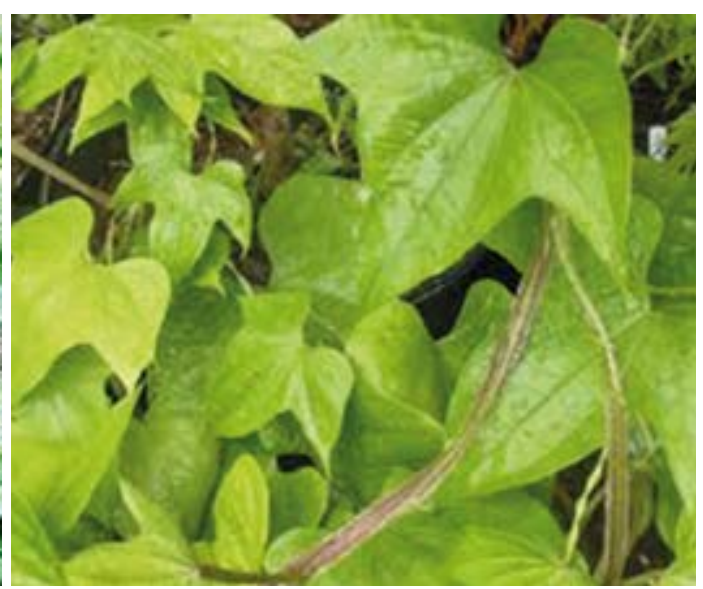

Dioscorea trifida
CYPERACEAE - Cyperus articulatus $\mathrm{L}$.

Bastón de San José, Varita de San José, Pura Pura

Hierba, Amazonica, Andino, Costa, 500-2500m

Uso: 1. Protección / Planta entera, fresco / Seguro / Añadir material de la planta a Hierba de la Plata, Hierba de la Justicia, El Dolar, Carpintero, Chupa Flor, Señorita, Hierba de Oro, Fortuna, Agua Florida, Ramillete de Novia, Jugo de Lima, Azúcar Blanco y Holy agua. Poner todos en una botella: Primero las Hierbas, después el resto de las materiales. Cubrir mezcla. Solo el paciente debe tocar Seguro. Mantener en la casa. 2. Florecimiento / Planta entera, fresco / Tópico / Hervir material de planta con Hierba de la Plat la casa. 2. Forecimiento / Planta enta fe la Plata, Hierba de la Justicia, Dollar, Carpintero, Chupa For, Sehoit (Hembra y Macho) y 3 litros de agua. Hervir la mezcla por 10 minutos hasta concentrar. Frotar el pacierte El Bańo debe hacerset antes de 12, a 3 de la tarde y medianoche. Pacientes deben bañarse por 3 cíclos.

CYPERACEAE - Kyllingia pumila Michx.

Hierba de la Golondrina

Hierba, Amazonica, Andina, 0-3000m, malez

Uso: Corazón, Nervios, Suerte, Daño/Hechizería contra mujeres / Planta entera, fresco / Tópico / Hervir 30g en 6 litros de agua por 20 minutos con otras Hierbas de Buena Suerte. Baño 3 veces por semana.

CYPERACEAE - Oreobolos obtusangulus T. Koyama

Hierba Chupaflor, Hierba de la Suerte, Hierba del Carpintero

Hierba, Andina, 3000-4000m

Uso: 1. Éxito, Mal Aire, Buena Suerte, Trabajo, Afrodisiaco, Buenos Negocios, Protección, Buena Fortuna, Buena Salud / Hojas, seco / Tópico / Hervir 20-50g en 3-5 litros de agua por 20 minutos. Mezclar con Buena Suerte Hierbas y Hierbas de Fuerza. Baño 3 veces por semana. Mezcla Alternativa para Florecimiento, vea abajo, solo una vez. 2. Éxito, Mal Aire, Buena Suerte, Trabajo, Afrodisiaco, Buenos Florecimiento, vea abajo, solo una vez. 2. Exito, Mal Aire, Buena Suerte, Trabajo, Afrodisiaco, Buenos
Negocios, Protección, Buena Fortuna, Buena Salud / Hojas, seco / Seguro / Mezcla Estandar para Seguro.

CYPERACEAE - Scirpus californicus (C.A. Meyer) Steudel subsp. tatora (Kunth) T. Koyama Balsa, Totor

Hierba, Andina, Costa, $0-3500 \mathrm{~m}$, cultivado

Uso: 1. Pie de atleta / Planta entera, seco / Tópico / Quemar entero para tener la ceniza. Aplicar ceniza en área infectada y frotar 3 veces por dia como se necesita. 2. Resaca, Mal Ojo / Corazón del Tallo, fresco / Amuleta / Hacer una escoba pequeña del corazón del tallo. Usar la escoba, hacer una cruz en el paciente después de frotar. Después de usarlo quemar la planta. Si se desintegra significa que el nińo tine Mal Ojo. Solo se usa en niños. 3. Fiebre, Resfríos / Planta entera, seco / Oral/ a 1/2 taza de agua ańadir 10g de Totora y Hervir por 3 minutos. Tomar frío, 1/2 taza por día por 8 días.

\section{DIOSCOREACEAE - Dioscorea tambillensis Kunth}

\section{Papa Semitona}

Hierba, Andina, 1500-2500m, cultivado

Uso: Inflammación de Riñones, Inflammación de los ovarios, Inflamación del hígado / Tubérculo, fresco / Oral/ Hervir 1 litro de agua y añadir 1 Papa Semitona (10g) con 20g total de Amor Seco, Chacur, Cola de Caballo, Pie de Perro, Verbena, Linaza y Cebada tostada. Hervir por 2-3 min. Tomar templado. Se puede ańadir Azúcar o Limas por sabor. Tomar 1 taza 3 veces por día por 1 mes.

\section{DIOSCOREACEAE - Dioscorea trifida L.f.}

Papa Madre, Papa Pacta

Hierba, Amazónica, Andina, 0-1000m

Uso: 1. Inflamación, Problemas de sistema urinaria, Quistes, Inflamación interna, Cáncer de útero, Inflamación de ovarios, Descargo vaginal, Inflamación de Riñones / Tubérculo, fresco / Oral / Hervir 1 litro de agua con $1 / 4$ de un tubérculo grande por 5 minutos con Flor Blanca, Purenrosa, Pacharosa y 10g de Berro. Tomar templado $3-4$ veces por día por 1 semana o on con se necesita, especialmente para niños de 3 meses -5 ańos. 2. Hongos, Lim ( 


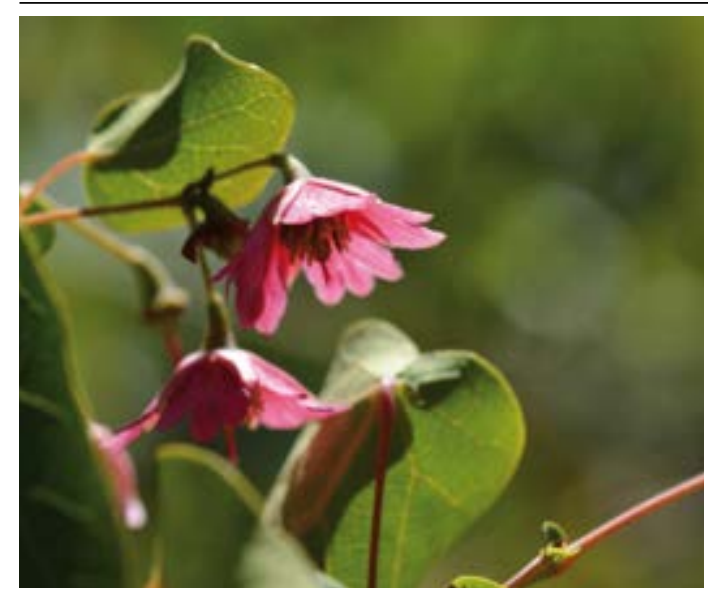

Vallea stipularis

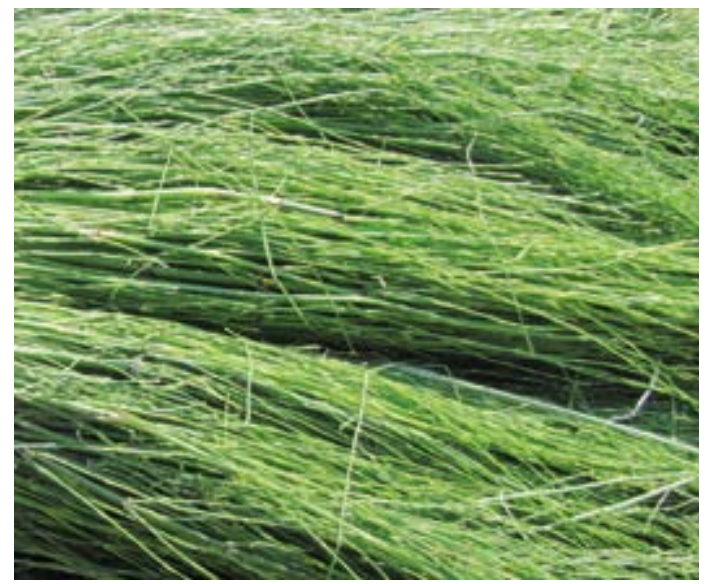

Equisetum bogotense

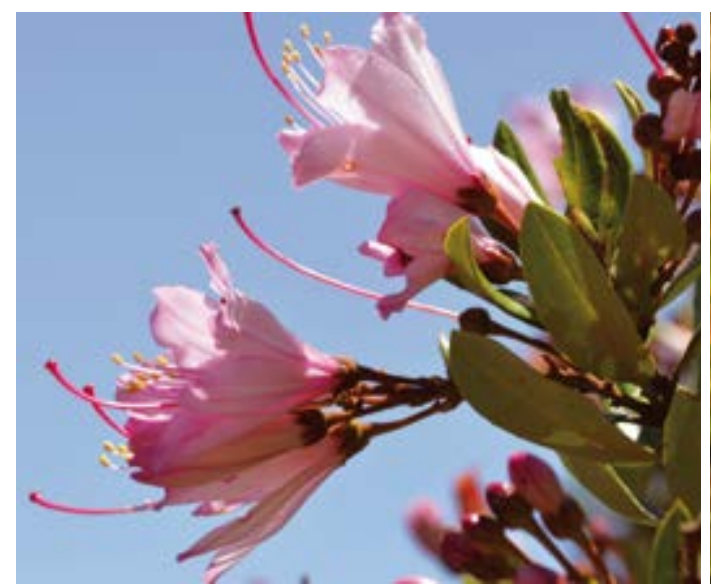

Bejaria aestuans

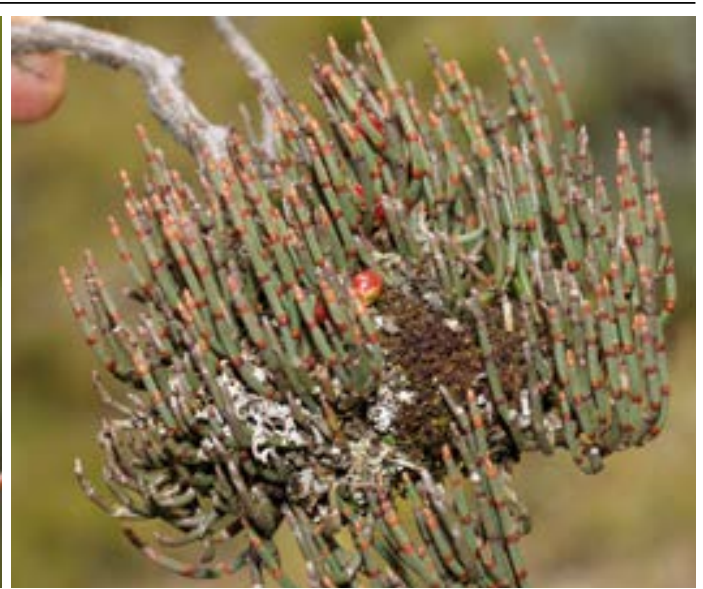

Ephedra americana

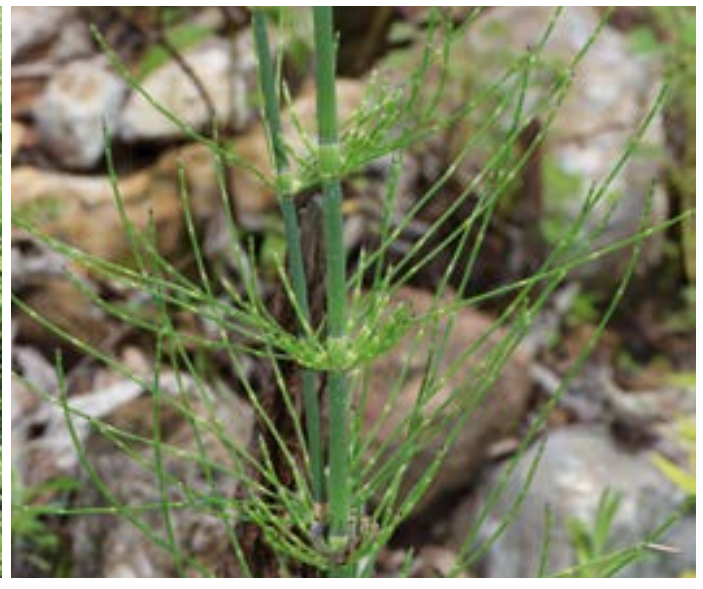

Equisetum giganteum

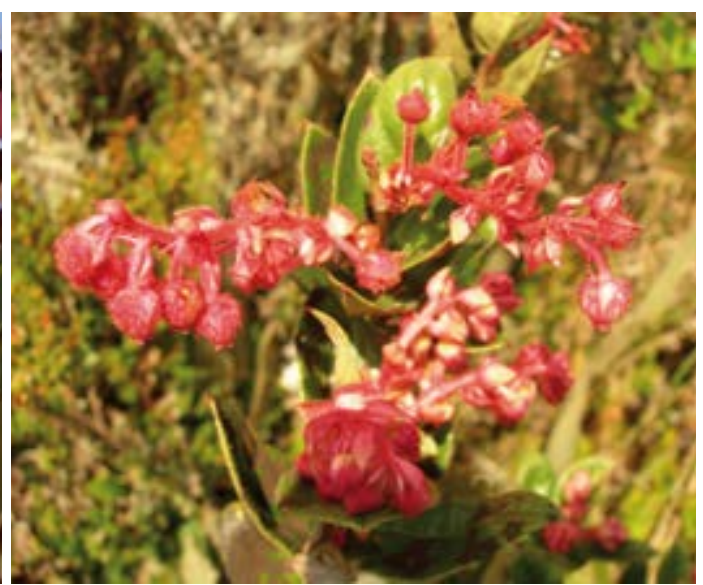

Gaultheria erecta

\section{ELAEOCARPACEAE - Vallea stipularis L.f.}

Chuingue

Árbol, Andino, 1500-4500m

Uso: Daño/Hechicería, Sordera, Problemas de Oído / Hojas, fresco o seco / Tópico / Usar 1 manojo en 3 litros de agua mezclado con Timolina por Limpia. Como alternativa mezclar leche materna con Hoja y poner en orejas.

EPHEDRACEAE - Ephedra americana Humb. \& Bonpl. ex Willd.

Diego Lopez, Suelda con Suelda

Arbusto, Andino, $500-4500 \mathrm{~m}$

Uso: 1. Hematomas, Fracturas, Lesiones externas / Planta entera, fresco o seco / Oral / 2. Hervir $5 \mathrm{~g}$ en 2 litros de agua por 5 minutos. Tomar 3 veces por día, 1-2 tazas por día por no más que 2 semanas. 2 . Hematomas, Fracturas, Lesiones externas / Planta entera, fresco o seco / Tópico / Moler planta y mezclar con grasa de un burro masculino y Poner alrededor de extremidad. Usar cada día hasta fractura se sana.

EQUISETACEAE - Equisetum bogotense H.B.K. (Kunth)

Cola de Caballo

Hierba, Amazónico, Andino, Costa, 0-4500m, maleza

Uso: 1. Inflamación de Rińones, Heridas (limpieza), Estómago, Sistema Urinaria, Riñones, Cálculos de riñones, Inflamación (general) / Tallos, seco / Oral / Hervir 5g en 1 litro de agua hervida mezclado con $10 \mathrm{~g}$ cada uno de Overo, Lancetilla, Chante, Achiote y Zarzaparrilla. Tomar 1 litro cada día por 1 mes. 2. Inflamación de Rińones, Heridas (limpieza), Estómago, Sistema Urinaria, Rińones, Cálculos de riñones, Inflamación de Rińones, Heridas (limpieza), Estómago, Sistema Urinaria, Rińones, Cálculos de rińones,
Inflamación (general) / Tallos, seco / Tópico / Lavar Heridas con 10g total de esta Hierba mezclado con Pie de Perro, Chacur y Untia hervido en 1 litro de agua.

EQUISETACEAE - Equisetum giganteum (Wedd.) Ulbrich

Limpia Plata, Cola de Caballo, Tembladera

Hierba, Andino, 500-2500m

Uso: 1. Artritis, Riñones, Hemorragias, Inflamación menstrual, Inflamación Interna y Externa, Próstata, Cálculos de riñones / Planta entera, fresco / Oral / Hervir 10-20g en 1 litro de agua combinado con Verbena, Manzanilla, Chacur, Unquia, Espiga de Maíz, Paja Blanca, Berro, Pata de Perro, Papa Madre, Pelo de Choclo y otras Hierbas buenas para los Riñones. Mezclar con Chante y Achote por Próstata. Hervir 2-5 minutos y tomar 4 tazas por día por 1 mes. 2. Heridas (limpieza) / Planta entera, fresco / Tópico / Hervir 10g de Limpia Plata con 1 litro de agua. Combinar con 10g cada uno de Chacur, Verbena, Hierba Santa, y Llantén. Limpiar herida con Hojas. Usar agua templada dos veces por semana hasta herida se sana. Planta solo se debe usar para lavar la herida, no como emplasto.

ERICACEAE - Bejaria aestuans Mutis ex L.

Cadillo, Payama, Hierba de la Postema, Purenrosa, Hierba de la Postema Rosada, Hierba del Buen Quere Arbusto o Árbol, Andino, 500-3000m

Uso: 1. Diabetes, Hígado, Próstata, Alergias, Regulación de menstruación, Enfermedades de sangre, Inflamación de Riñones, Inflamación de útero, Inflamación del hígado, Inflamación de Vejiga, Quistes, Inflamación de ovarios, Presión de Sangre, Dolor de Menstruación, Inflamación (general), Florecimiento / Flores, Hojas y Tallos, fresco o seco / Oral / Hervir 5 g en 1 litro de agua por 5 minutos con Flor Blanca, Papa Madre, Flor de Arena, Guayusa, Pasuchaca, Malva, Amor Seco, Verbena, Llantén, Cola de Caballo, Chumbiaura, Palo de China, Huaminga y Quinua Agrio. Tomar 3 tazas cada día o 1 litro por día por 1-3 meses. 2. Buena Suerte, Buenos Negocios, Protección, Buena Fortuna, Buena Salud / Flores, Hojas y Tallos, fresco o seco / Seguro / Mezcla Estándar para Seguro.

ERICACEAE - Gaultheria erecta Vent.

Mullaca Mistura, Mullaca, Mullaca Real

Arbusto, Andino, 500-4000m

Uso: Bronquitis, Asma / Planta entera, fresco o seco / Oral / Hervir 1 litro de agua y añadir 10g de Mullaca. Incluir $10 \mathrm{~g}$ de cada uno de las hierbas siguientes: Humanaripa, Escorcionera, Eucalipto, Matico y Veronica. Tomar 1 taza 3 veces por día por 1 mes. 


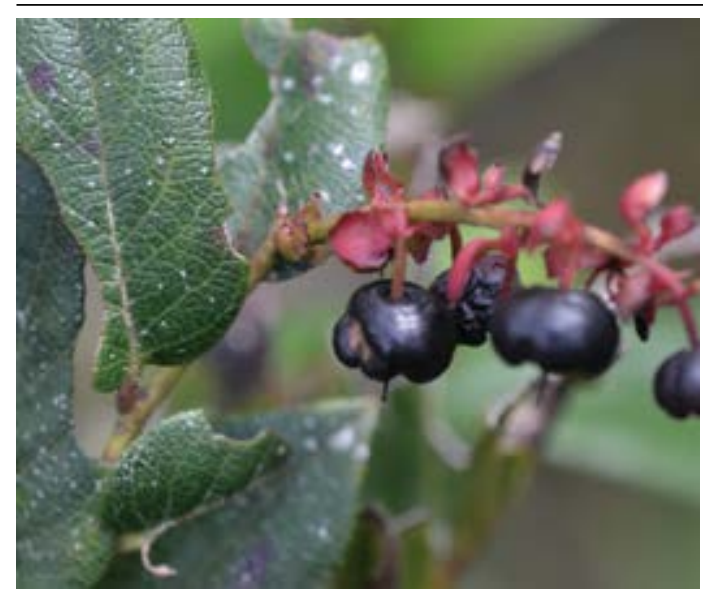

Gaultheria reticulata

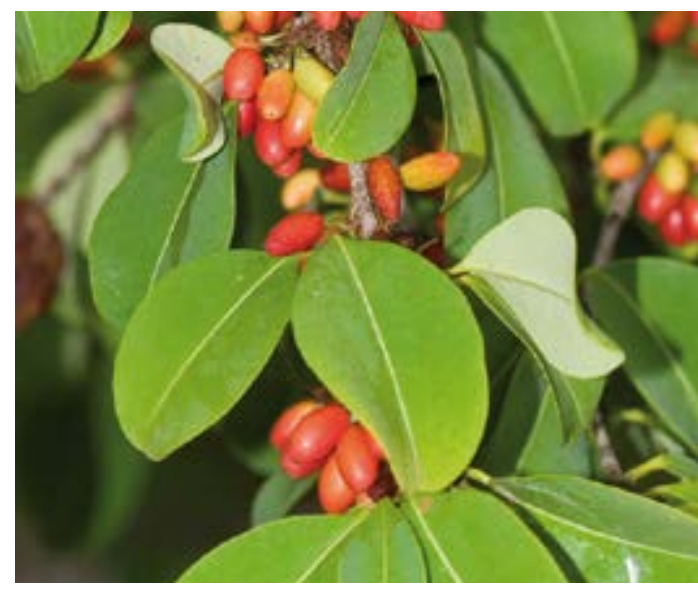

Erythroxylon coca

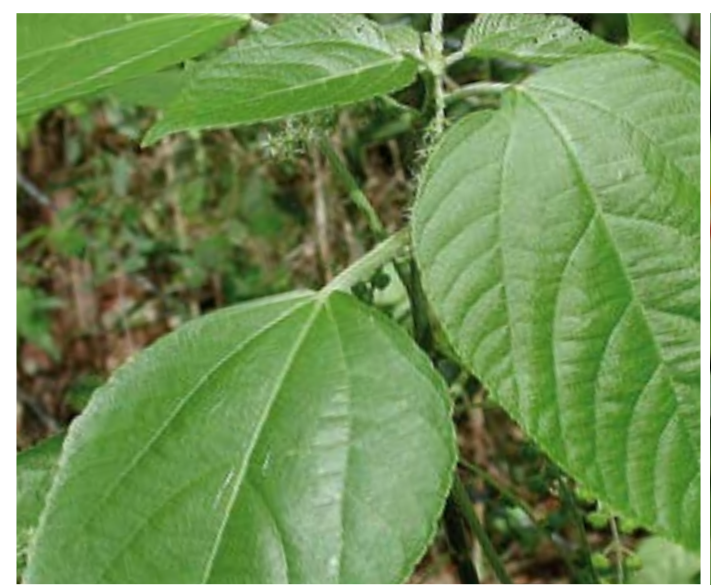

Acalypha villosa

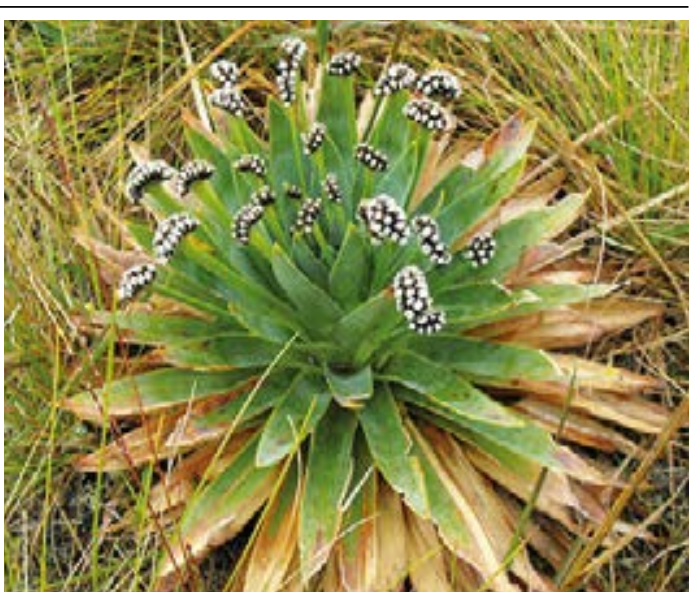

Paepalanthus ensifolius

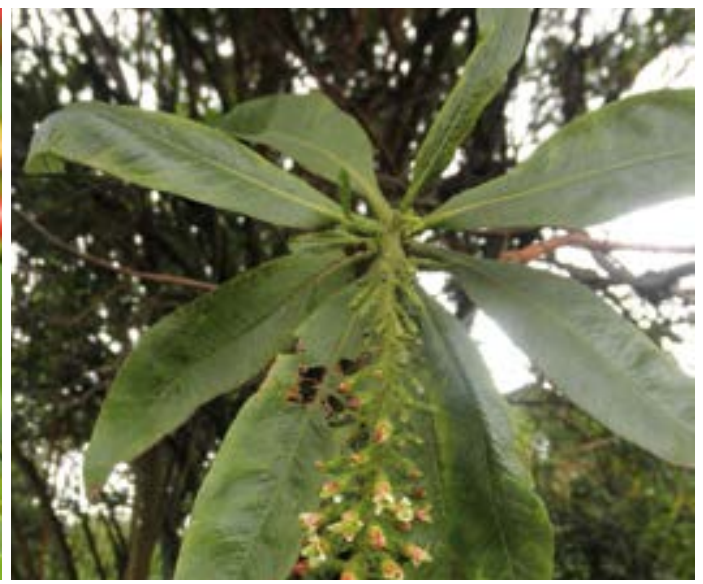

Escallonia pendula

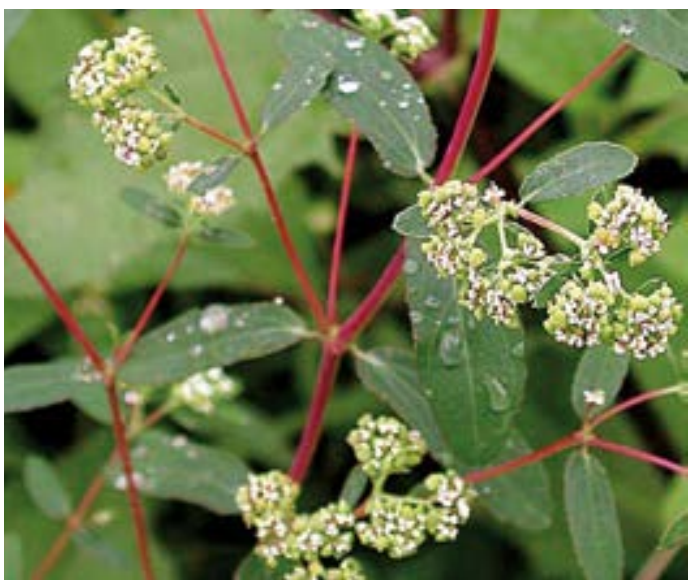

Chamaesyce hypericifolia
ERICACEAE - Gaultheria reticulata Kunth

Toromaique, Maique, Maique Candela, Toromaique Amarillo, Toromaique Verde, Gavilán Maique Amarillo, Gavilán Maique Verde

Arbusto, Andino, 1000-4500m

Uso: 1. Alucinógeno, Resfrío, Artritis, Bronquitis, Dolor reumático, Dolor de Huesos, Mal Aire, Heridas, Úlceras, Doloridos. / Planta entera, fresco / Tópico / Hervir 50g por 20-30 minutos en 7 litros de agua y mezclar con otros Maiques (7 variedades), $10 \mathrm{~g}$ de cada uno de: Misha Blanca, Misha Colambo, Misha Galga, Misha Morada, Misha Roja, Misha Rosada y Toromaique. Recite una oración. Bańo 3 veces por semana. Bañar el paciente en la mezcla masajeando con las Hierbas. Después lavar con agua y dejar el paciente secar al aire 2. Purgante / Hojas, seco / Oral / Hervir 3g de Hojas molidas en 1 taza de agua y tomar una vez al mes en la mañana antes de desayuno. 3. Proteger la casa, Proteger el paciente / Planta entera, fresco / Seguro / Añadir 10g de material de la planta a Hierba de la Plata, Hierba de la Fortuna, Hierba del Oro, Carpintero, Chupa Flor, Señorita, Condores, Trenzadilla, Agua Florida, Perfume Tabu, Jugo de Lima, Agua Bendita y Azúcar. Poner todos los ingredientes en una botella. 4. Proteger la casa, Proteger el paciente, Rituales / Planta entera, fresco / Incienso / Ahumar la casa de derecha a izquierda como se necesita. 5. Heridas, Quistes, Heridas causadas por Hechicería / Planta entera, fresco / Tópico / Hervir 50g de material de planta en $1 / 2$ taza de agua por 5 minutos. Aplicar hasta área afectada una vez por día hasta se sana.

ERIOCAULACEAE - Paepalanthus ensifolius (Kunth) Kunth

Madriguera

Hierba, Andino, 3000-4000m

Uso: Dar éxito a un negocio, controlar empleados / Planta entera, fresco / Seguro / 1/5 de planta por Seguro.

ERYTHROXYLACEAE - Erythroxylon coca Lam.

Coca

Arbusto, Amazónico, Andino, 0-1500m, cultivado

Uso: Resfrío, Tos, Inflamación de Garganta, Inducir parto, Fuerza por mujeres durante el parto, Apoyar el hígado de un bebé recién nacido, Alerta, Practica ritual / Hojas, seco / Oral / Añadir 5g de la Hoja a 1 taza de agua. Hervir la mezcla por 3-4 minutos, dejarlo enfriar. Hacer gárgaras 3 veces por día por 2 días. Tomar 1 taza antes de dormir por 2-3 días. Como alternativa lavar y masticar $5 \mathrm{~g}$ de Hojas.

ESCALLONIACEAE - Escallonia pendula (R. \& P.) Pers.

Chuque

Árbol, Andino, 2000-3000m

Uso: 1. Artritis, Dolor de Huesos, Hechicería/Daño, Reumatismo, Susto de Muerte / Hojas, seco / Tópico / Hervir 1 manojo en 3 litros de agua. Se puede combinar con Huaminga, Chingue, Ishpinguillo, Ajenco, y 7 Espiritus. Baño una vez por semana. 2. Artritis, Dolor de Huesos, Hechicería/Daño, Reumatismo, Susto de Muerte / Hojas, fresco / Tópico / Emplasto: No mezclar con otras plantas. Aplicar 3 veces por semana.

EUPHORBIACEAE - Acalypha villosa Jacq.

Chilca Dulce

Arbusto, Andino, 500-2000m, maleza

Uso: Inflamación del hígado, Decodificación de la sangre / Planta entera, fresco o seco / Oral / Poner $10 \mathrm{~g}$ de la planta en 1 litro de agua y Hervir por 3-5 minutos. Tomar 3 veces al día por 2 semanas.

EUPHORBIACEAE - Chamaesyce hypericifolia (L.) Millspaugh

Lecherita, Lechera

Hierba, Amazónico, 0-500m, maleza

Uso: 1. Cataratas, Problemas con la vista / Planta entera, fresco / Tópico / Quebrar los Tallos de la planta para extraer el jugo. Poner jugo lechoso en los ojos, 2 gotas 3 veces por día. 2. Inflamación (externo), Promover lactancia en mujeres después del parto / Planta entera fresco / Oral / Hervir 10g Lecherita con 1 litro de agua Combinar con $10 \mathrm{gcad}$ uno de Cola de Caballo, Amor Seco, Linaza, Chaur con 5Tallos 5 H Has de Marrajudio. Tomar 1 taza cada otro día por 4 días y/o lavar con solución 2 veces por día cuando se necesita. 


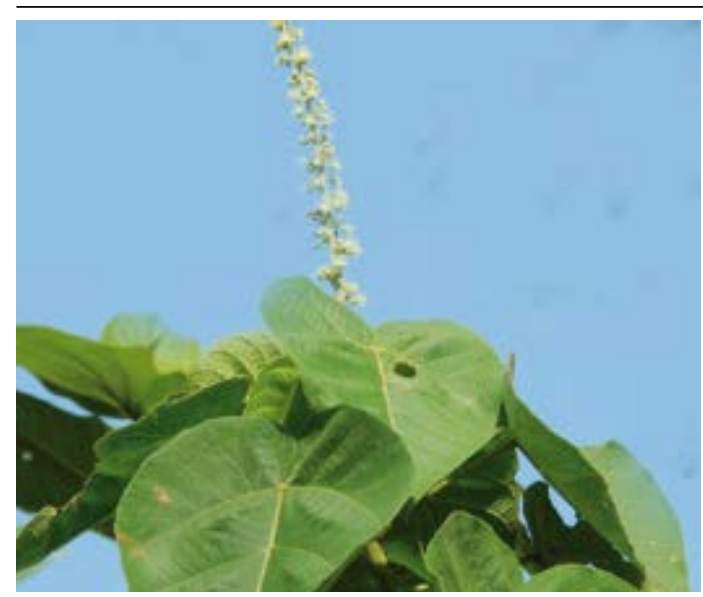

Croton draconoides

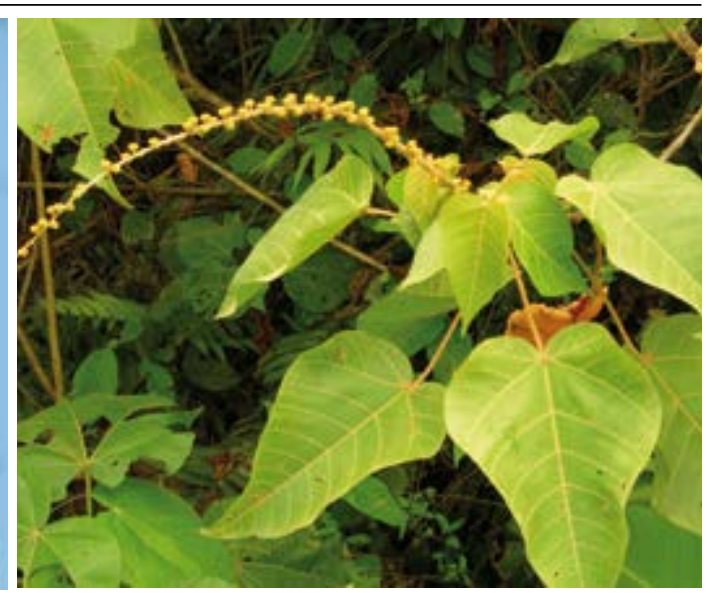

Croton lechleri

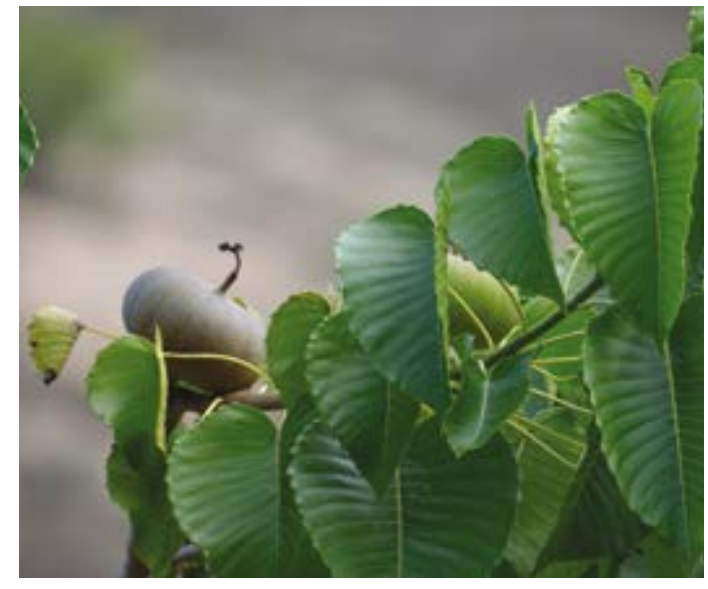

Hura crepitans

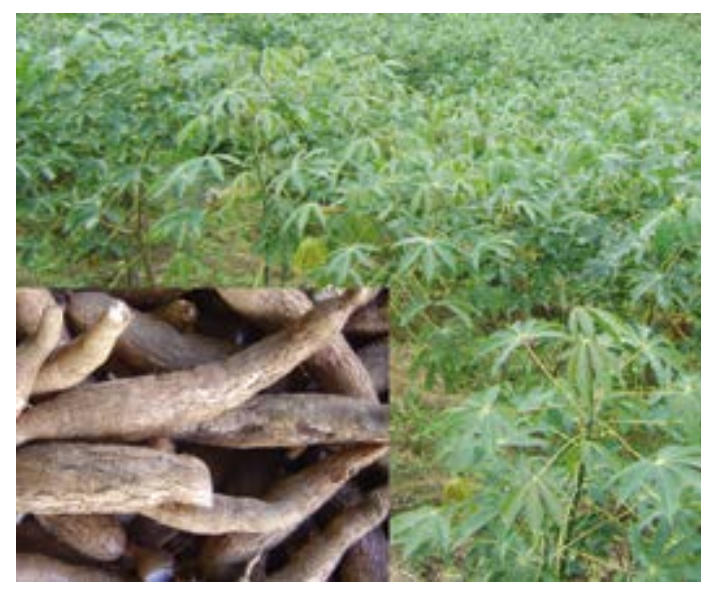

Manihot esculenta

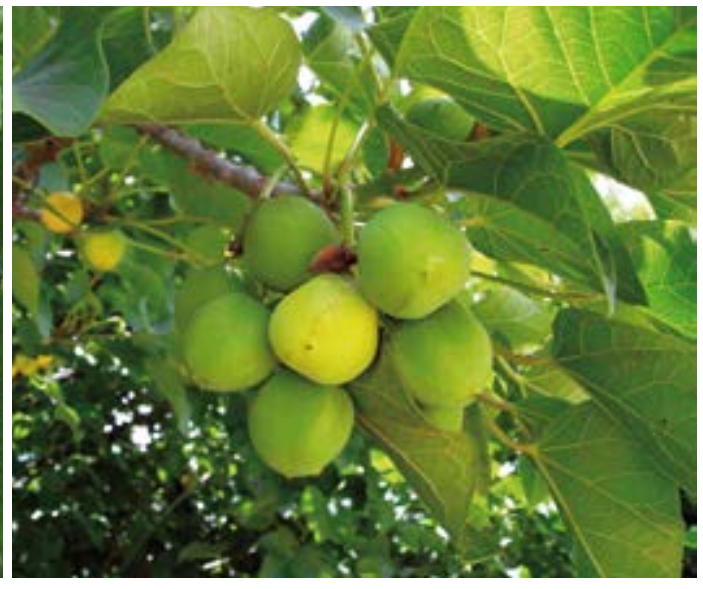

Jatropha curcas

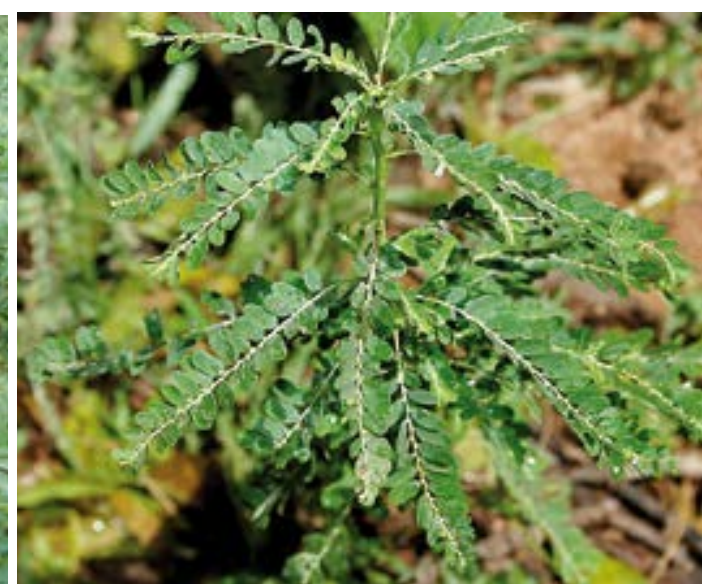

Phyllanthus niruri
EUPHORBIACEAE - Croton draconoides Müll.-Arg.

Sangre de Grado, Sangre de Drago

Arbusto, Amazónico, Andino, 0-2000m

Uso: 1. Úlceras, Sangradura (Interno), Gastritis, Circulación de sangre, Cicatrices de mordeduras de insectos, Después de operaciones internas / Látex, fresco o seco / Oral / Cortar solo durante la temporada húmeda. Cortar Corteza y permitir 5 gotas del liquido caer en medio vaso $(250 \mathrm{ml})$ de agua. Paciente húmeda. Cortar Corteza y permitir 5 gotas del liquido caer en medio vaso $(250 \mathrm{ml})$ de agua. Paciente
debe tomar solución templado, 3 veces por día hasta por 2 meses. Sana Cicatrices de dentro a fuera. 2. Heridas (externo), Cicatrices, Acné / Látex, fresco o seco / Tópico / Cortar la Corteza y extraer látex. Aplicar como emplasto. Usar 3 gotas para frotar área afectada, una vez por día como se necesita.

EUPHORBIACEAE - Croton lechleri Müll. Arg.

Sangre de Grado, Sangre de Drago

Árbol, Amazónico, Andino, 0-1000m

Uso: 1. Úlceras, Sangradura (Interno), Gastritis, Circulación de sangre, Cicatrices de mordeduras de insectos, Después de operaciones internas / Látex, fresco o seco / Oral / Cortar solo durante la temporada húmeda. Cortar Corteza y permitir 5 gotas del liquido caer en medio vaso $(250 \mathrm{ml})$ de agua. Paciente debe tomar solución templado, 3 veces por día hasta por 2 meses. Sana Cicatrices de dentro a fuera. 2. Heridas (externo), Cicatrices, Acné / Látex, fresco o seco / Tópico / Cortar la Corteza y extraer látex. Aplicar como emplasto. Usar 3 gotas para frotar área afectada, una vez por día como se necesita.

EUPHORBIACEAE - Hura crepitans L.

Habilla

Árbol, Amazónico, Andino, 0-1500m

Uso: Laxante, Sobrepasar flojera / Semillas, secas / Oral / Moler 3 Semillas y mezclar con 1 taza de avena. Hacer un cereal caliente y Tomar caliente, 1 taza solo una vez. Tomar frío. No exceder dosis, esta muy fuerte y puede matar paciente.

EUPHORBIACEAE - Jatropa curcas L., Jatropa gossypiifolia L., Jatropa weberbaueri Pax \& Hoffman Piñones

Arbusto, Amazónico, Andino, Costa, 0-1500m, maleza

Uso: Laxante, Sobrepasar flojera / Semillas, secas / Oral / Moler 7 Semillas y mezclar con 1 taza de avena. Comer caliente. Paciente reaccionara con diarrea y vómitos. Después de la purgación darle un te fuerte. Tomar 1 taza, solo una vez.

\section{EUPHORBIACEAE - Manihot esculenta Crantz}

Yuca (Manihot)

Hierba, Amazónica, Andina, Costa, 0-2500m, cultivado

Uso: 1. Infección vaginal, Descargo vaginal / Tubérculo, fresco / Oral / Hervir 1 taza de agua y añadir $50 \mathrm{~g}$ de Yuca y Hervir por 5 minutos. Tomar frío, 1/4 taza cada día por 15 días. 2. Alergias, Irritación de la piel / Tubérculo, fresco / Tópico / Machucar corteza de tubérculo y remover extracto con un pedacito de tela. Frotar área afectada con extracto y dejar por 3 horas. Después de que se seca, Baño , 2 veces por día por 20 días.

EUPHORBIACEAE - Phyllanthus niruri L., Phyllanthus stipulatus (Raf.) Webster, Phyllanthus urinaria L.

Chanca Piedra

Hierba, Amazónica Andina, 500-2500m

Uso: Inflamación del hígado, Decodificación de la sangre, Inflamación (Interno), Cálculos de vejiga, Hígado, Riñones, Vesícula Inflamación / Planta entera, fresco o seco / Oral / Hervir 10g de la planta, Cola de Caballo, Llantén, Boldo, Flor de Overo, Caña-Caña, Flor Blanca y Flor de Arena en 1 litro de agua por 3-5 minutos. Tomar 3 veces al día por 2 semanas. 


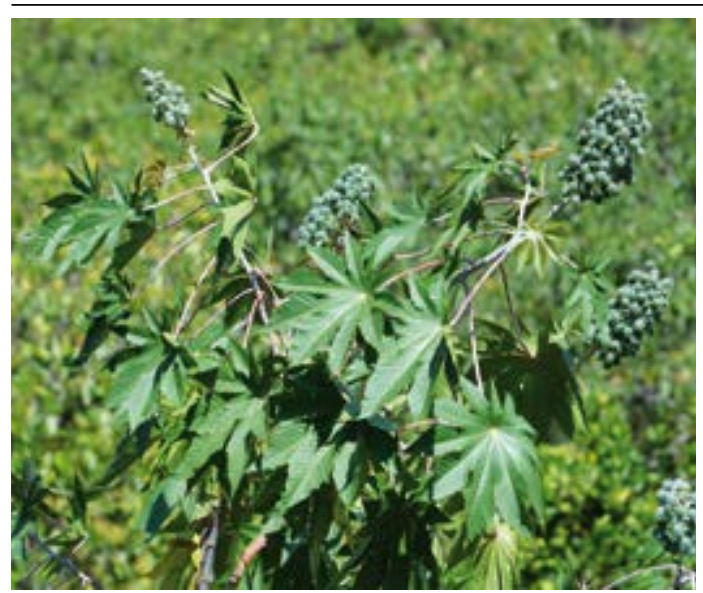

Ricinus communis

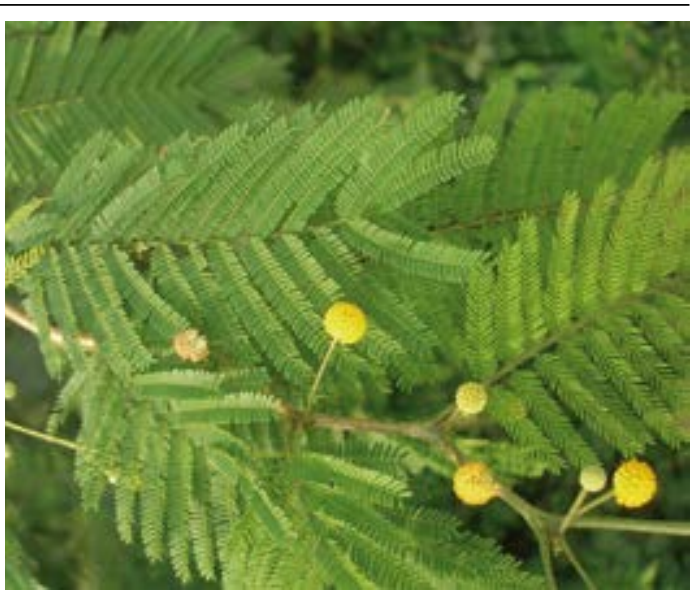

Acacia macracantha
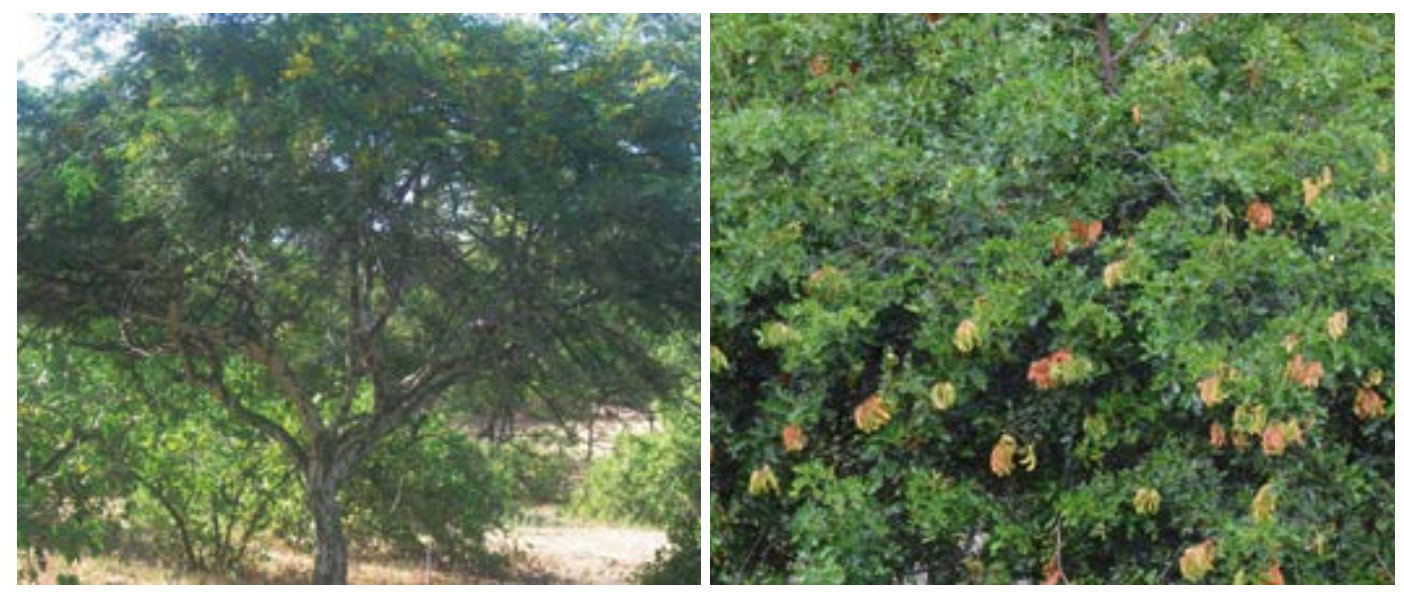

Caesalpinia paipai

Caesalpinia spinosa

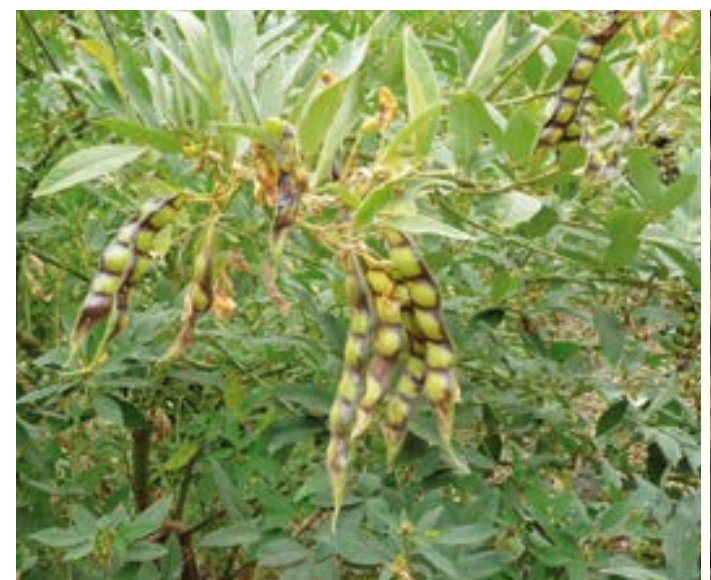

Cajanus cajan

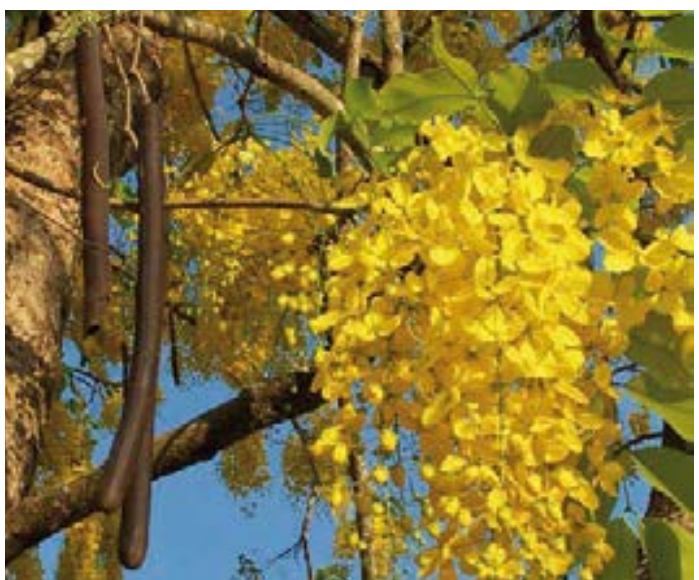

Cassia fistula
EUPHORBIACEAE - Ricinus communis L.

Higrillo, Higrilla, Piñon, Higuerilla, Llonque

Arbusto, Amazónico, Andino, Costa, 0-2000m, maleza, introducido

Uso: 1. Constipación / Hojas, fresco / Tópico / Poner aceite sobre la Hoja, después calentar sobre un fuego. Emplasto: Poner en el Estómago y envolver con plástico. Aplicar caliente o templado. No ingerir. Aplicar 2 veces por día. 2. Úlceras (Externo), Espinillas, Heridas / Semillas, fresco / Tópico / Moler 10g de Semillas con $1 / 2$ vaso de Cańazo (Aguardiente). Poner mezcla sobre área afectada. Dejar por 2 horas, solo una vez.

FABACEAE - Acacia macracantha Humb. \& Bonpl. ex Willd.

Faique, Espino, Huarango

Árbol, Amazónico, Andino, Costa, 0-3000m, maleza

Uso: 1. Heridas, Parar sangraduras / Corteza, seco / Tópico / Quemar Corteza, colectar cenizas, colar. Poner ceniza en área afectada. Cubrir herida entera, una vez por día hasta que la herida se sana. 2. Artritis, Reumatismo / Corteza, seco / Tópico / Extraer resina de 20g de Huarango. Disolver resina con grasa animal (serpiente, mula, pollo, cuy). Poner un pequeńo monto en el área afectada. Masajear como se necesita.

FABACEAE - Caesalpinia paipai Ruiz \& Pav

Pay Pay

Árbol, Amazónico, Andino, Costa, 0-2000m

Uso: Matar piojos, Heridas / Fruta, fresco o seco / Tópico / Hervir 10 Frutas en 1 litro de agua por 30 minutos. Lavar cabello con liquido frío cada día en la mañana por 3 días. Como alternativa aplicar una vez por día para sanar heridas. Monto depende en tamaño de la herida.

FABACEAE - Caesalpinia spinosa (Molina) Kuntze

Tara, Talla, Chanchalagua

Árbol, Andino, Costa, 0-3000m

Uso: 1. Laringitis, Garganta, Infección de la Piel, Mordeduras de animales, Antibiótico, Inflamación de Amígdalas / Vainas, fresco o seco / Oral / Hervir 3 frutas en 1 taza de agua y mezclar con Romero, Coca, Sangre de Grado y Vinagre. Hacer gárgaras 3 veces por día, mañana y noche, hacer gárgaras, escupir, tomar 1 vaso. Hacer gárgara y tomar 1 taza en la mañana, 1 en la noche por 6-7 meses. Semillas pulverizadas se aplica directamente sobre Heridas. 2. Hongos, Infección de piel, Angina Pectoris, Antibiótico, Heridas, hierves, Mordeduras de Animales, Infecciones con Amebas, Inflamación de ovarios, Inflamación de Útero, Inflamación Vaginal / Frutos, fresco o seco / Tópico / Hervir $5 \mathrm{~g}$ en 3 litros de agua por 20 minutos, mezclado con $10 \mathrm{~g}$ cada uno de Laurel, Hierba del Susto, Ajenco y Ishpingo. Baño: Una vez por semana, o lavar Heridas 3 veces por día por 1-3 meses. También como lavado vaginal, 2 veces por día por 2 días.

FABACEAE - Cajanus cajan (L.) Millsp.

Chivato

Arbusto, Amazónico, Andino, 0-1500m, maleza, introducido y cultivado

Uso: Mal Aire / Planta entera, fresco o seco / Tópico / Hervir 10g total de Eucalipto, Manzanilla, Ilambo, Cordón de Muerto y Chivato en 3 litros de agua por 5 minutos. Bañar paciente con agua y frotar con las plantas. 2 veces por semana o 4 veces por mes como se necesita, depende en la seriedad del Mal Aire.

FABACEAE - Cassia fistula L.

Caña Fistula

Árbol, Amazónico, Andino, 0-1000m, introducido y cultivado

Uso: Sistema nervioso, Epilepsia / Semillas, fresco o seco / Oral / Hervir 10g en 1 litro de agua. Tomar 1 taza cada día como se necesita (mas o menos 15-20 días). 

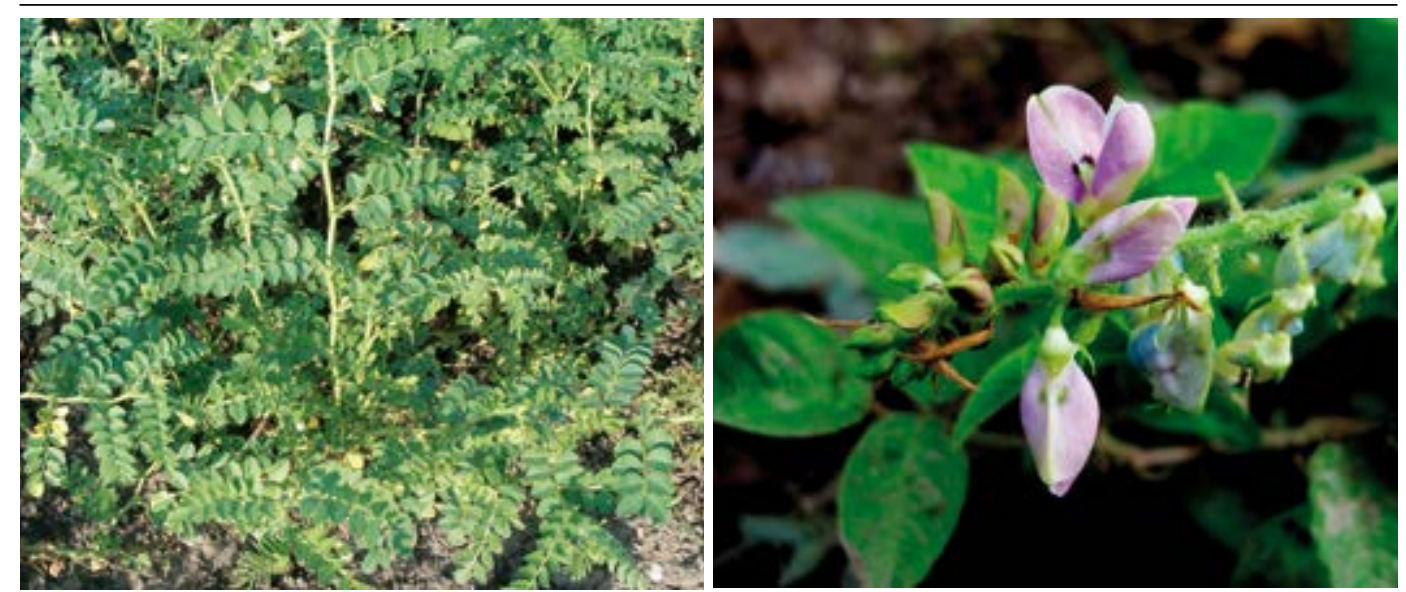

Cicer arietinum

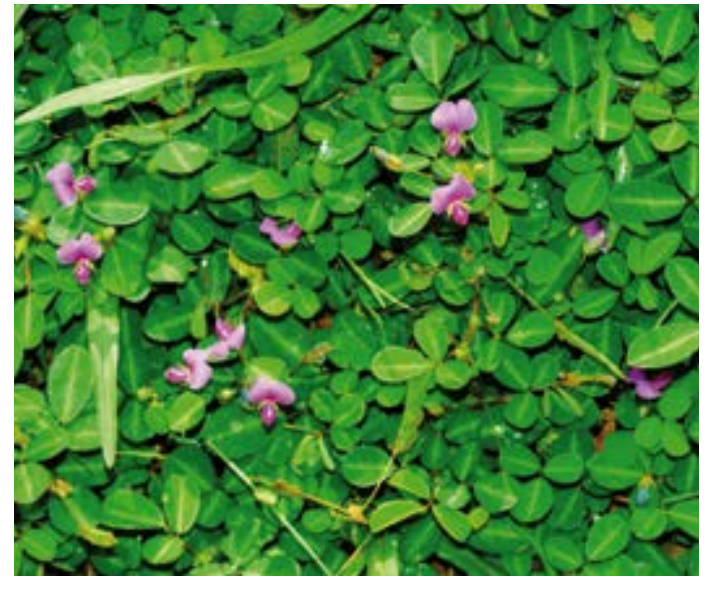

Desmodium triflorum

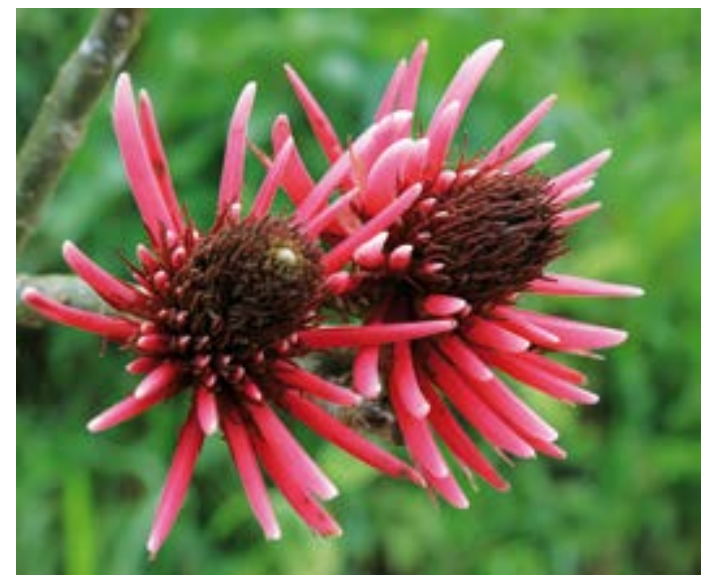

Erythrina amazonica
Desmodium molliculum

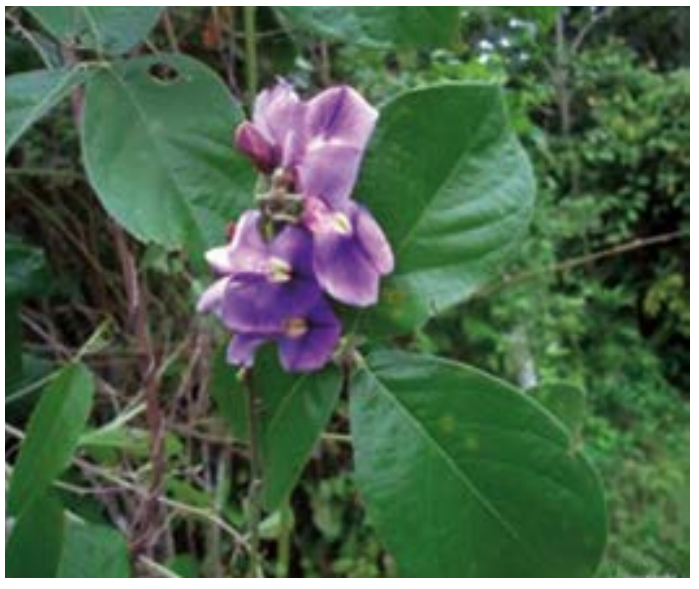

Dioclea virgata

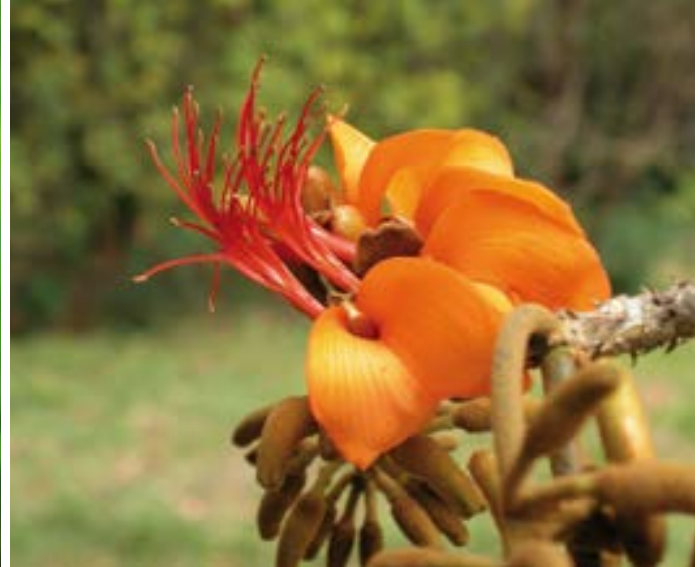

Erythrina velutina

\section{FABACEAE - Cicer arietinum $\mathrm{L}$}

Garbanzo

Hierba, Amazónica, Costa, 0-1000m, introducido y cultivado

Uso: Cáncer / Semillas, secas / Oral / Hervir $1 \mathrm{~kg}$ de Garbanzo en 1 litro de agua por 5 minutos. Tomar templado, 1 taza por día por 15 días.

FABACEAE - Desmodium molliculum (H.B.K.) DC

Pie de Perro, Pata de Perro, Chancas de Comida, Muña, Manayupa

Hierba, Andina, 1000-3500m, maleza

Uso: 1. Inflamación (Interno y Externo), Inflamación de Rińones, Diarrea, Dolor de Estómago, Inflamación de ovarios, Gastritis / Planta entera, fresco o seco / Oral / Hervir 10g de Pie de Perro en 1 litro de agua. Combinar con 10g cada uno de Chacur, Amalba, Amor Seco y Verbena. Tomar 4 veces por día por 1 mes. 2. Heridas (limpieza), Cicatrices / Planta entera, fresco o seco / Tópico / Hervir con Lllatén y Matico $20 \mathrm{~g}$ total en 1 litro de agua por $10 \mathrm{~min}$. Lavar una vez por día.

FABACEAE - Desmodium triflorum (L.) DC

Pega Pega

Hierba, Amazónico, Andino, Costa, 0-2500m, maleza, introducido

Uso: 1. Florecimiento / Planta entera, fresco / Seguro / Mezcla Estándar para Seguro. 2. Buenos Negocios, Protección, Buena Fortuna, Buena Salud / Planta entera, fresco / Tópico / Mezcla Estándar para Florecimiento.

FABACEAE - Dioclea virgata (Rich.) Amsh.

Yin Yin

Vine, Amazónico, Andino, 0-1500m, maleza

Uso: 1. Fertilidad de Cuyes / Planta entera, fresco / Oral / usar planta entera, 130g de planta cada día. 2. Promover habla en niños / Planta entera, fresco / Oral / Remover Semillas. Poner semillas en boca de niño. Enseguida decir el niño de cerrar la boca. Repetir 3 veces. Repetir 2 veces por día por 3 días.

FABACEAE - Erythrina amazonica Krukoff

Huayruro, Huairuro

Árbol, Amazónico, 0-500m

Uso: Protección del Mal / Semillas, secas / Amuleto / Hacer collar de Semillas y tener el curandero bendiciéndolo. Usarlo por vida.

FABACEAE - Erythrina velutina Willdenow

Porotillo

Árbol, Andino, Costa, 0-2500m

Uso: Limpia de intestinos / Flores, Hojas y Tallos, fresco o seco / Hervir 5g en 1 litro de agua. Adultos: Añadir 2 cucharas de aceite de glicerina. Niños: Añadir $5 \mathrm{~g}$ aceite de glicerina; 1 enema cada 3 meses o 1 cada 6 meses depende en la condición. 


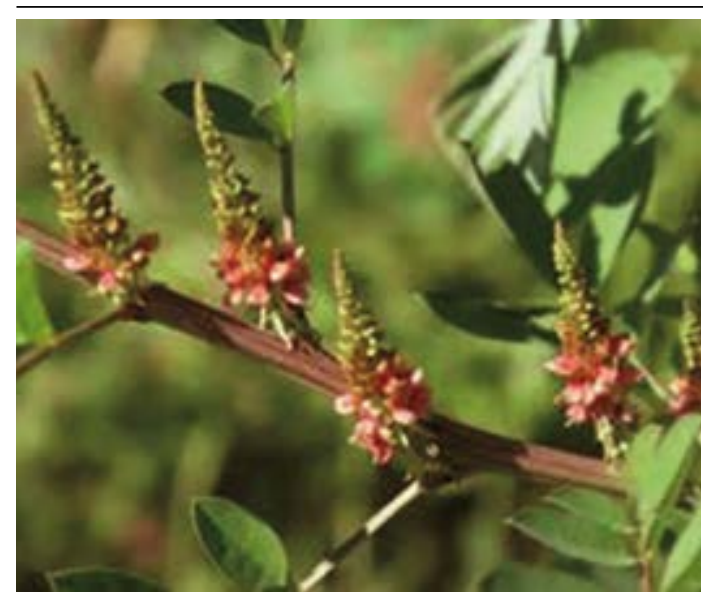

Indigofera suffruticosa

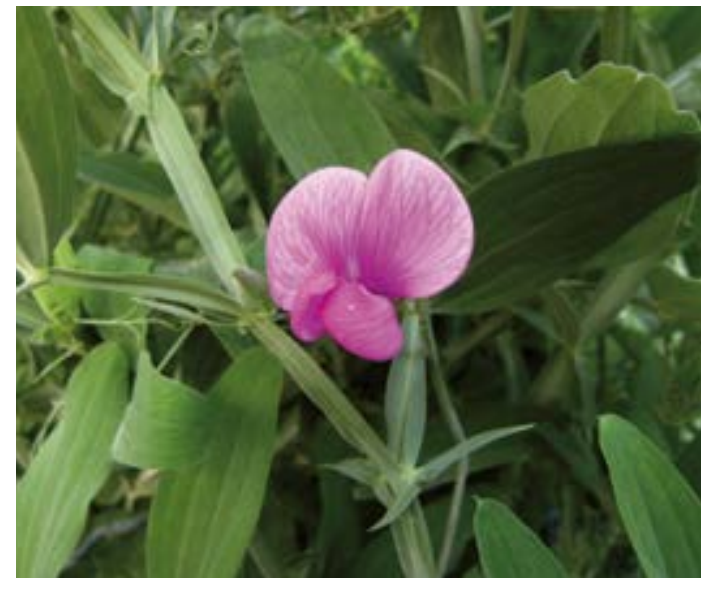

Lathyrus odoratus

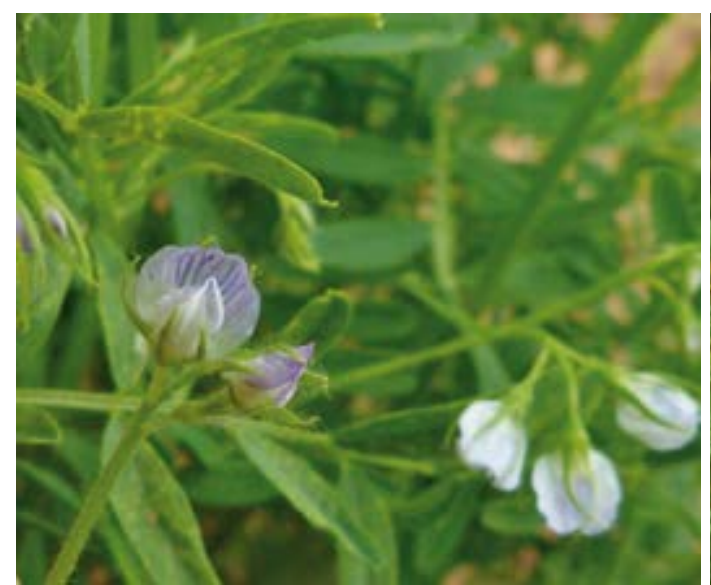

Lens culinaris

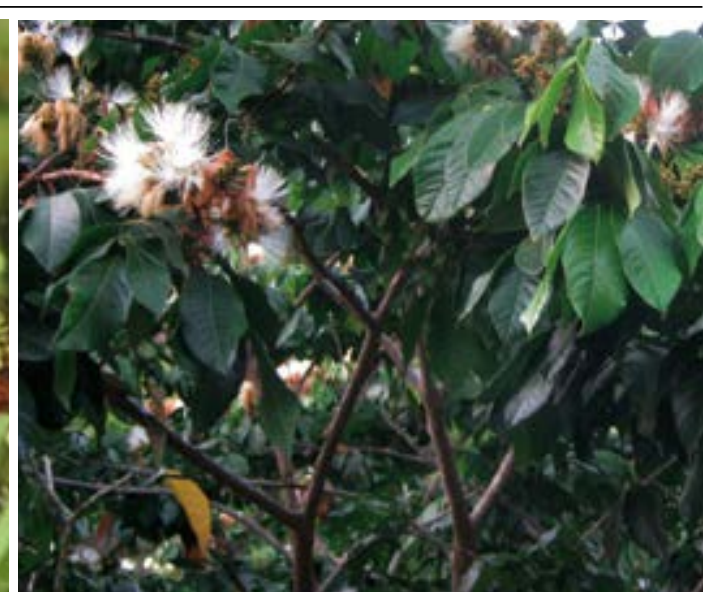

Inga edulis

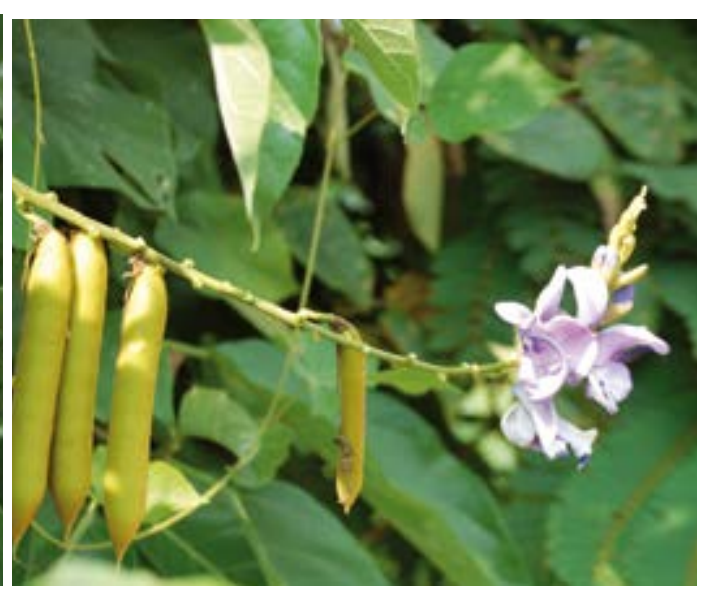

Lablab purpureus

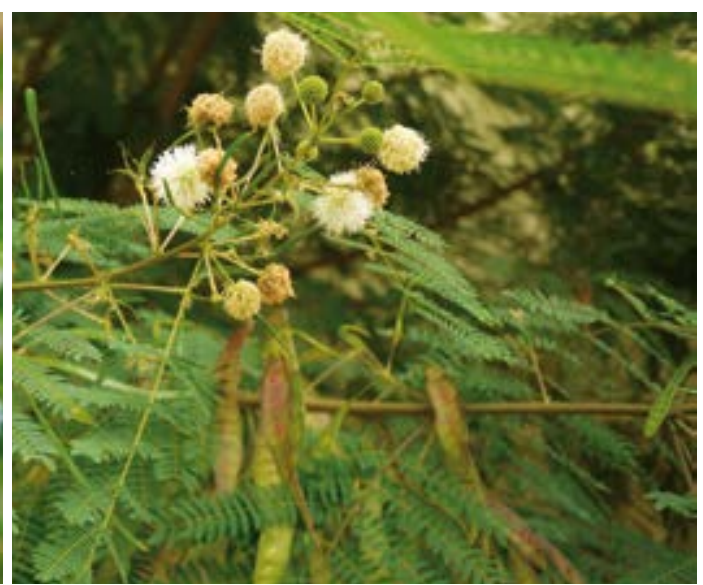

Leucaena leucocephala

\section{FABACEAE - Indigofera suffruticosa Miller}

Añil

Hierba o Arbusto, Amazónico, Andino, 0-1500m, maleza

Uso: Expulsar placenta después del parto / Tallos, fresco / Oral / Hervir 20g de Añil en 1 taza de agua por 5 minutos. Tomar templado, 1/2 taza solo una vez.

FABACEAE - Inga edulis C. Martius, Inga feuilleei DC

Guava, Huaba, Pacae, Pacai

Árbol, Amazónico, Andino, 0-1500m, cultivado

Uso: 1. Rehabilitación de adictos de droga o alcoholices, Laxante / Semillas, fresco o seco / Oral / Moler 10 Semillas y $10 \mathrm{~g}$ total de Juan Alonso y Alcaparilla. Hervir en 1/2 taza de agua por $2 \mathrm{~min}$. Mezclar con $1 / 2$ vaso de Orange Juice. Tomar 3 - 4 veces por día por 2 meses o como se necesita. 2. Añadir brillosa al cabello, Crecimiento de cabello / Flores, fresco / Tópico / Añadir 15g de Flores a 1 litro de agua. Hervir la mezcla por 3 minut

FABACEAE - Lathyrus odoratus L.

Tacón Blanco, Pensamiento Blanco

Hierba, Andino, 2500-4000m, introducido y cultivado

Uso: Corazón, Nervios, Ansiedad / Flores, Hojas y Tallos, fresco o seco / Oral / Hervir 5g en 1 litro de agua por 3 minutos combinado con $10 \mathrm{~g}$ cada uno de Toronjil, Pimpinela, Mejorana y Cedrón. Tomar 1 litro por día o 3-4 tazas por día por 1 mes.

FABACEAE - Lablab purpureus (L.) Sweet

Frijol Chileno

Arbusto, Costa, $0-1000 \mathrm{~m}$, maleza, introducido y cultivado

Uso: Fiebre, Inflamación de los intestinos, Protección del pulmón / Frutas, fresco / Oral / Hervir por 10 minutos $1 / 2 \mathrm{~kg}$ de material de planta en 1 litro de agua. Tomar templado, $1 / 2$ taza 2 veces por día por 8 días.

FABACEAE - Lens culinaris Medikus

Lenteja

Hierba, Amazónico, Andino, Costa, 0-3500m, introducido y cultivado

Uso: Protección de los huesos / Semillas, secas / Oral / Hervir 200g de Lenteja en 1 litro de agua por 5 minutos. Tomar frío, 2 veces por día por 20 días. Comer lentejas con arroz.

FABACEAE - Leucaena leucocephala (Lam.) De Wi

Arabisca, Huaba Bruja

Árbol, Amazónico, Andino, Costa, 0-1500m, introducido y cultivado

Uso: Antiséptico, Limpiar Heridas / Corteza, Flores y Tallos, fresco / Tópico / Hervir 1 litro de agua por 3-4 minutos con 10g total de Arabisca, Verbena, Hierba Santa, Llantén, Cola de Caballo y Chacur. Lavar Herida o irritación 2 veces por día o como se necesita hasta que se seca. 


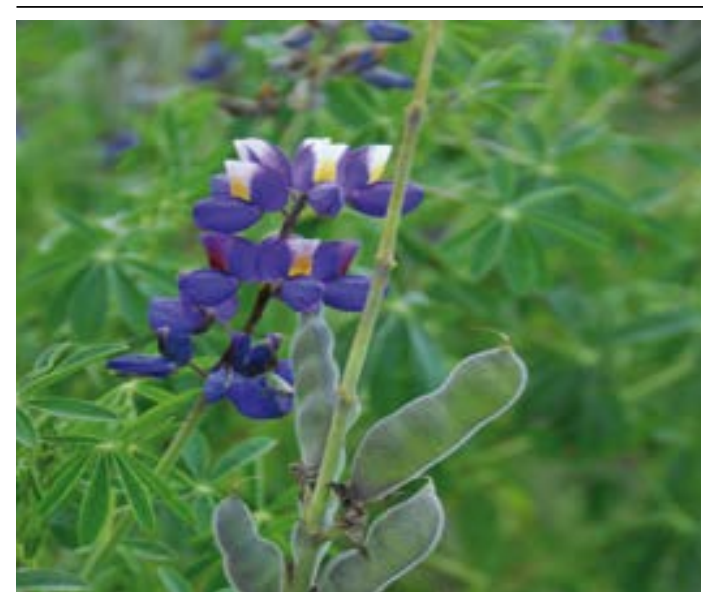

Lupinus mutabilis

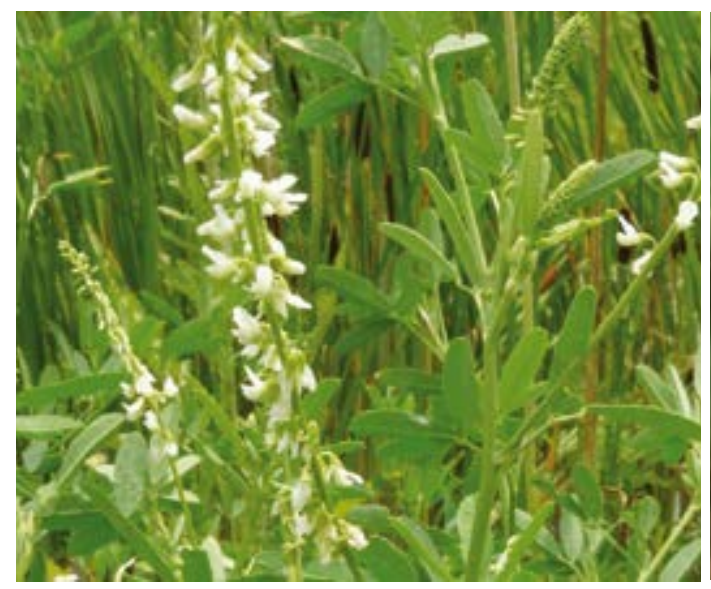

Melilotus alba

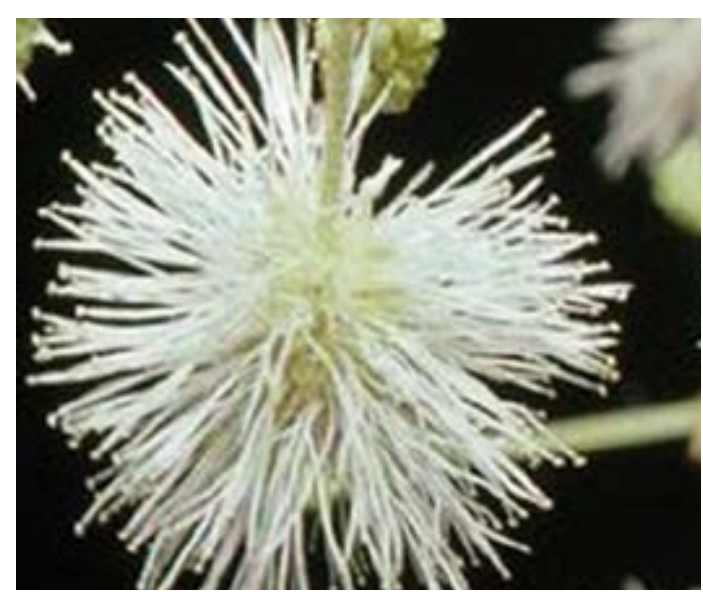

Mimosa nothacacia

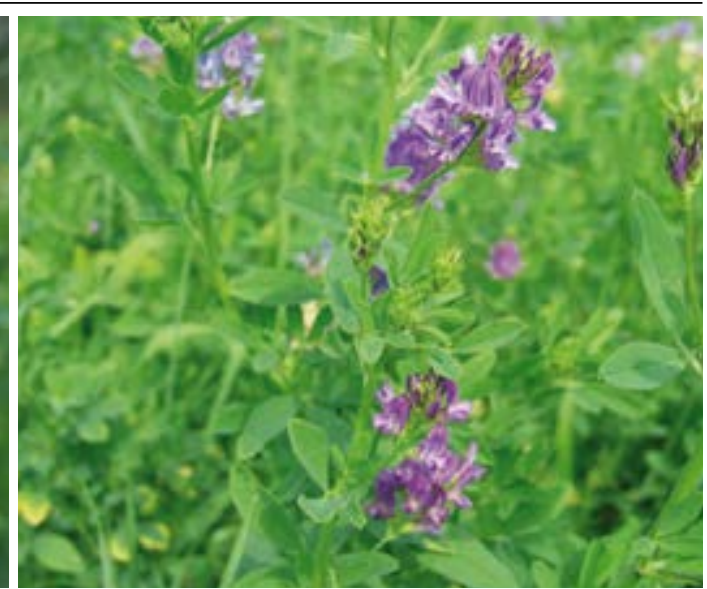

Medicago sativa

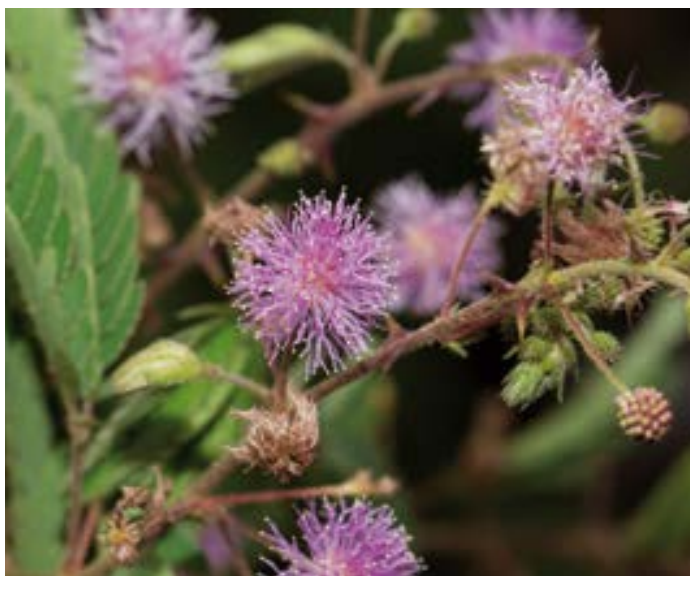

Mimosa albida

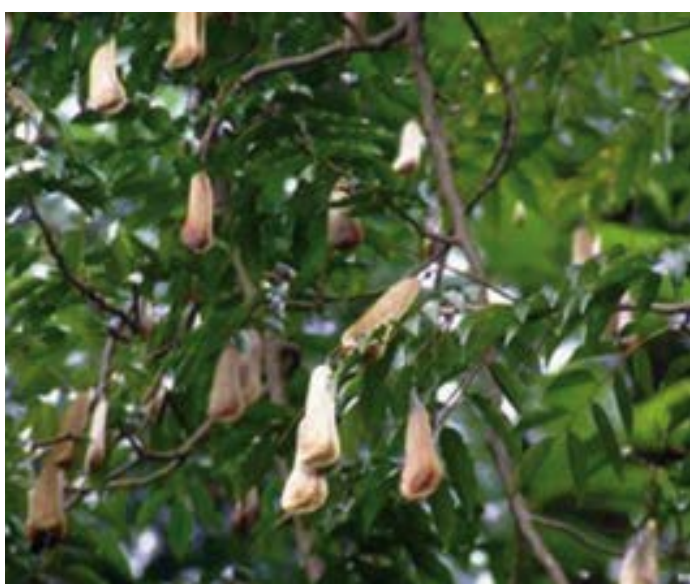

Myroxylon balsamum
FABACEAE - Lupinus mutabilis Sweet

Chocho, Tarhui

Hierba, Andino, 1500-4500m, cultivado

Uso: Malnutrición, Suplemento nutritivo / Semillas, secas / Oral / Remojar material de planta en agua por 1 semana. Triturar con cebolla o cocinar por 2 minutos, o servir como ensalada. Comer come ensalada o puré, 1 plato por día como se necesita.

\section{FABACEAE - Medicago sativa $\mathrm{L}$.}

Alfalfa

Hierba, Andino, Costa, 0-4500m, introducido y cultivado

Uso: 1. Bronquitis / Flores y Hojas, fresco / Oral / Mezclar Hojas y Flores con agua. Sacar extracto. Tomar extracto. Se puede añadir Miel. Tomar 1 vaso de extracto dos veces por día. 2. Amargues en la boca, Enfermedad renal / Flores, fresco / Oral / Mezclar 20 Flores en $1 / 4$ taza de agua. Tomar 1 No exceder dosis porque puede ponerse ciego. Planta muy caliente.

FABACEAE - Melilotus alba Medikus

Alfalfilla

Hierba, Andino, Costa, $0-4500 \mathrm{~m}$, introducido y cultivado

Uso: 1. ganar peso / Semillas, secas / Oral / Hervir 10g de Semillas molidas en 1/2 litro de agua por 10 min. Tomar templado, $1 / 4$ taza por día por 15 días. 2 . Fiebre, Tuberculosis, Resfríos, Infecciones respiratorias / Semillas, secas / Oral / Hervir 100g de material de planta en $1 / 2$ litro de agua por $10 \mathrm{~min}$. Tomar frío, $1 / 2$ a taza una vez por día por 8 días.

FABACEAE - Mimosa albida H. \& B.

Tapa Tapa

Hierba, Andino, Costa, 0-2000m

Uso: Hemorragia, especialmente después del aborto. Prevenir Hemorragias y sanar el útero después del parto. / Hojas, Tallos, Flores, fresco / Oral / Hervir 10g de Tapa Tapa con sal oscuro en 1/2 litro agua por 5 minutos. Tomar 1 taza dos veces por día por una semana.

\section{FABACEAE - Mimosa nothacacia Barneby}

Uńa de Gato de la Costa

Arbusto, Andino, 1000-1500m

Uso: 1. Cáncer, Inflamación de Riñones, Hepatitis, Hemorroides, Inflamación del hígado / Corteza, seco / Oral / Hervir 10g de Corteza en 1 litro de agua por 3-4 minutos. Tomar templado, 1 taza 3-4 veces por día como se necesita. 2. Quistes del ano, espinillas de la vagina, espinillas del ano / Corteza, seco / Tópico / Hervir 200g de Uńa de Gato de la Costa en 3 litros de agua por 10 minutos y llenar un a tina con la mezcla caliente. Sentarse en el baño por 5 minutos, 2 veces por semana hasta se cura el paciente.

FABACEAE - Myroxylon balsamum (L.) Harms.

Quina Quina, Kina Kina

Árbol, Amánico, 0-500m

Uso: 1. Sistema nervioso, Mal Aire, Epilepsia, Bronquitis / Semillas, secas / Oral / Moler 20 Semillas Uso: 1. Sistema nervioso, Mal Aire, Epilepsia, Bronquitis / Semillas, secas / Oral / Moler 20 Semillas
mezclado con 20 Semillas cada uno de 6 otras plantas: Ashango, Pucho, Amala, Ishpingo, Nuez Moscada y Camalonga. Poner en una botella de Vino y macerar por 8 días. Tomar 3 pequenas tazas por día. 2. Mal Aire, Bronquitis, Susto, Dolor de Cabeza / Semillas, secas / Tópico / Hervir 20 Semillas en 5 litros de agua por 20-30 minutos. Combinar con 20 Semillas cada uno de Ishpingo, Ashango, Pucho, Amala, Raucho, Tokio, Nuez Moscada y Pepa de Cedrón macerado en 1 litro de alcohol de 45\%. Añadir 2 pedazos de tabaco, 2 pedazos de Ajo Macho, 10g de Quina Quina, 2 Hojas de Pacra y 1 rama cada uno de Eucalipto y Maye. No dejar el Baño afuera. Tomar Baño cada día siguiente, 3 veces por semana. 3. Tos, Bronquitis, Asma / Semillas, secas / Oral / Tostar y aplastar 3 Semillas en 1 taza de agua. Tomar 1/2 taza por adultos, 1 cucharilla para nińos. 


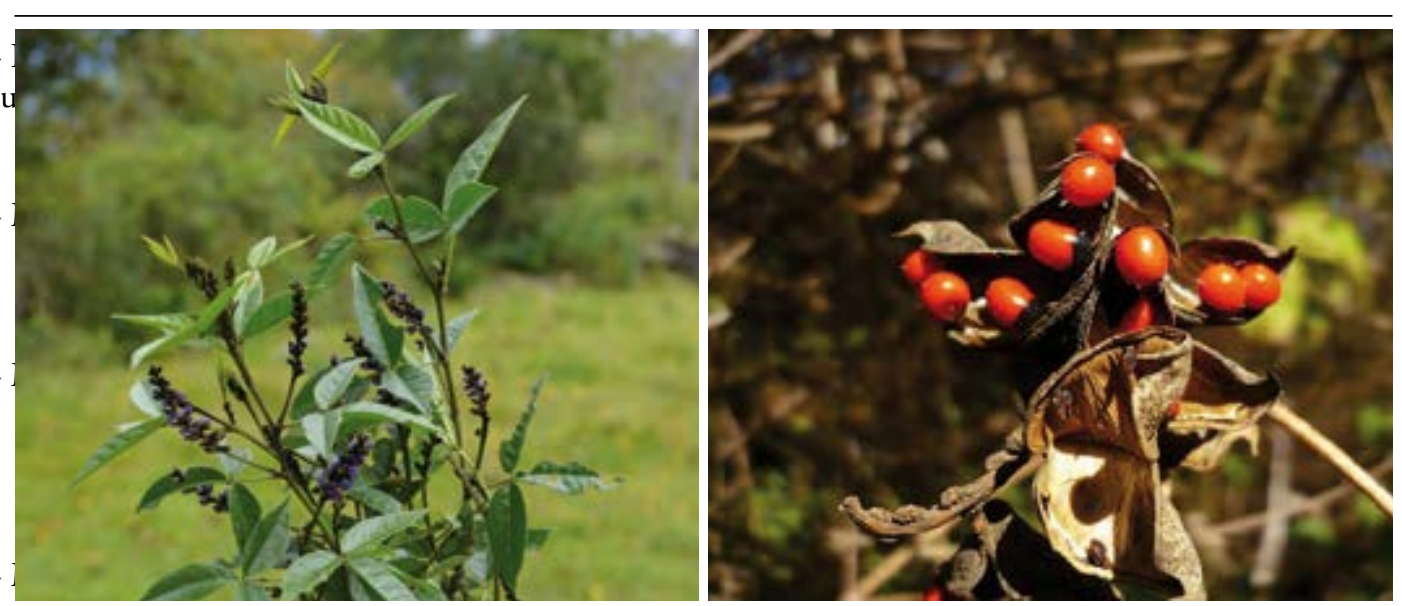

Otholobium mexicanum

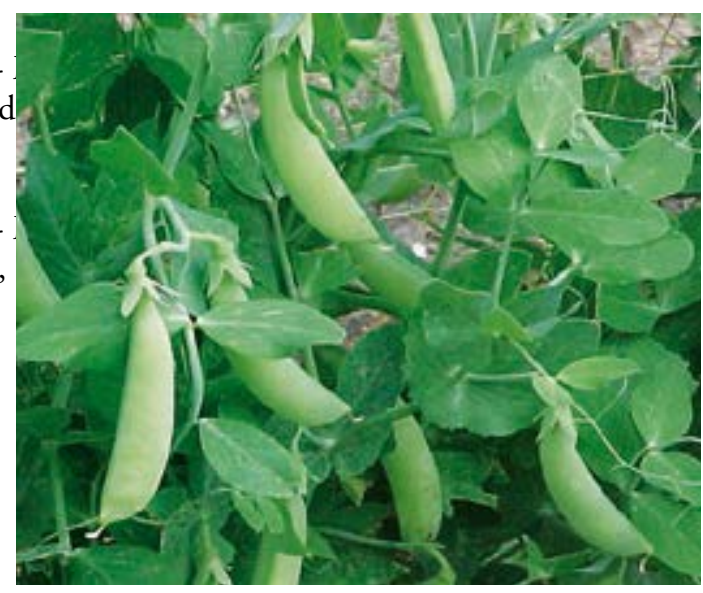

Pisum sativum

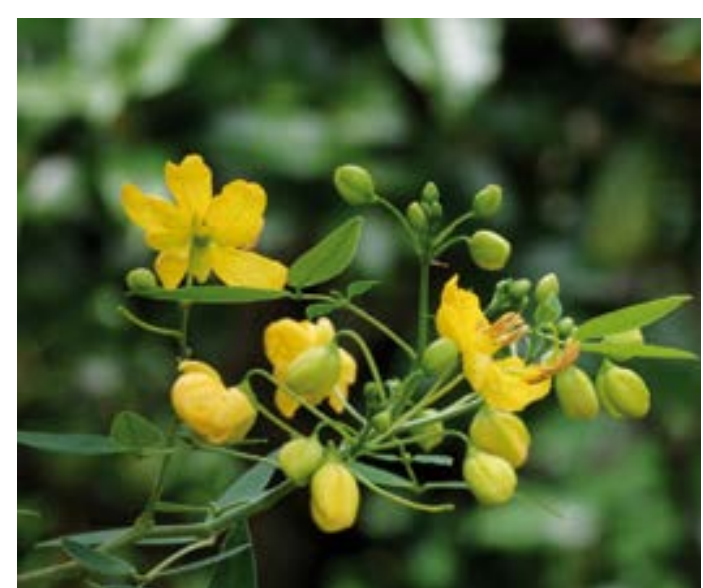

Senna alexandrina
Ormosia sp.

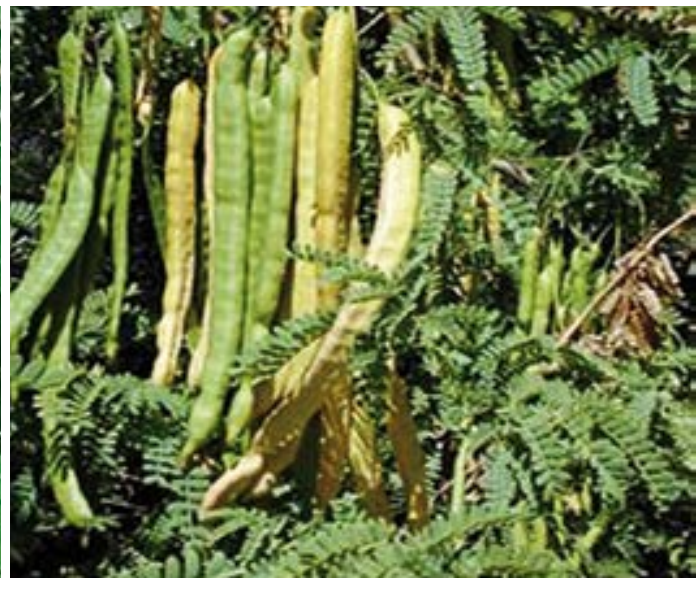

Prosopis pallida

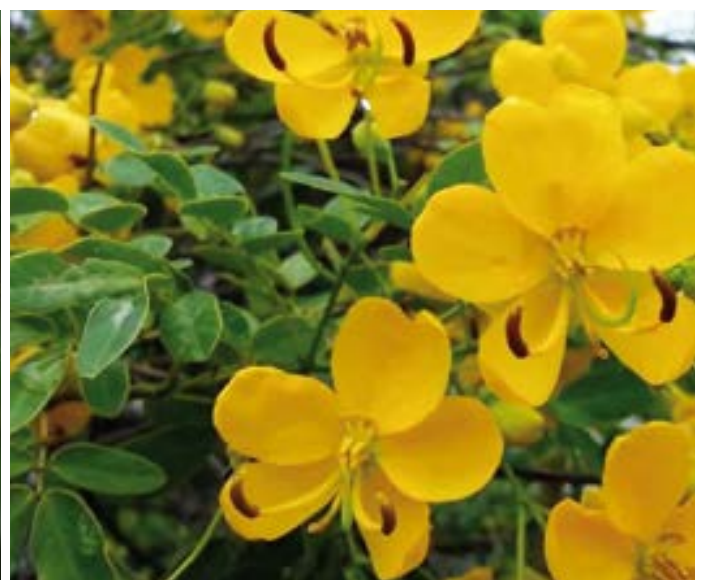

Senna bicapsularis
FABACEAE - Otholobium mexicanum (L.f.) Grimes

Culén

Arbusto, Andino, 1000-4000m

Uso: Diarrea, Resfrío en Estómago, Diabetes / Tallos, fresco o seco / Oral / Hervir 5g en 1 litro de agua.

Combinar con 10g cada uno de Manzanilla, Menta y Anís. Tomar 3 veces por día. Paciente debe tomarlo caliente.

\section{FABACEAE - Ormosia sp.}

Huayruro, Huairuro

Árbol, Amazónico, 0-500m

Uso: Mal Ojo / Semillas, secas / Amuleto / Hacer brazaletes. Usar siempre en mano izquierda.

FABACEAE - Pisum sativum $\mathrm{L}$.

Arbejas, Arvejas

Hierba, Andino, Costa, $0-4500 \mathrm{~m}$, introducido y cultivado

Uso: Viruela, Rubiola, Inflamación de los intestinos, Dejar energía negativa / Semillas, fresco / Oral / Hervir $100 \mathrm{~g}$ en 1 taza de agua. Tomar

FABACEAE - Prosopis pallida (H. \& B. ex Willd.) H.B.K.

Algarrobo

Árbol, Andino, Costa, 0-1500m

Uso: 1. Tos, Anemia, Fertilidad, Potencia sexual, Bronquitis, Suplemento Nutricional / Semillas, secas / Oral / Hervir 10kg de Algarrobo fruto y Semillas por 3 horas en calor mediano hasta alto hasta que se espese. Dejar enfriar. Drenar liquido y poner jarabe en botella. Tomar 2 cucharas en 1 pequeña taza, 3 veces por día por cuando quiere. 2. Dolor de Estómago, Chuchaque / Hojas y Tallos, fresco / Oral / Hervir $5 \mathrm{~g}$ de Algarrobo Corteza en 1/4 taza de agua por 3 minutos. Tomar. 3. Artritis, Reumatismo, Resfríos, Dolor de Huesos / Resina, fresco / Tópico / extraer Resina con navaja. Poner 5g de Resina en sartén para calentarlo. Frotar área afectada con Resina, una vez por semana por 3 semanas. 4. Dolor de muela, Extracción de muela / Resina, fresco / Tópico / Poner 2 gotas en diente afectado. La Resina de Algarrobo vaya polvorizar el diente. Cuidado - TODOS los dientes tocados por la resina se destruyeran. 5. Heridas Criticas / Resina, fresco / Tópico / Moler 100g de carbón de Algarrobo, 100g de azufre y 100g de ajo. Aplicar en área afectada, una vez por día hasta sanada.

\section{FABACEAE - Senna alexandrina Mill.}

Hojas de Sen

Hierba, Costa, 0-1500m, introducido y cultivado

Uso: Purgante, Constipación, Limpia de Estómago / Hojas, seco / Oral / Hervir 3g en 1 vaso de agua para nińos, $5 \mathrm{~g}$ por vaso de agua por adultos, una vez al mes.

FABACEAE - Senna bicapsularis (L.) Roxburgh

Alcaparrilla, Alpacaquilla

Hierba, Costa, $0-1000 \mathrm{~m}$, maleza

Uso: Decodificación de Alcohol y Drogas, Decodificación Hígado y Riñones / Planta entera, fresco / Tópico / Añadir 10g de Alcaparrilla a 1 litro de agua hervida. También añadir 30g total de Cola de Caballo, Juan Alonso y Verbena. Hervir la mezcla por 3-5 min. Tomar 1 taza, 3-4 veces por día por una mes o como se necesit 

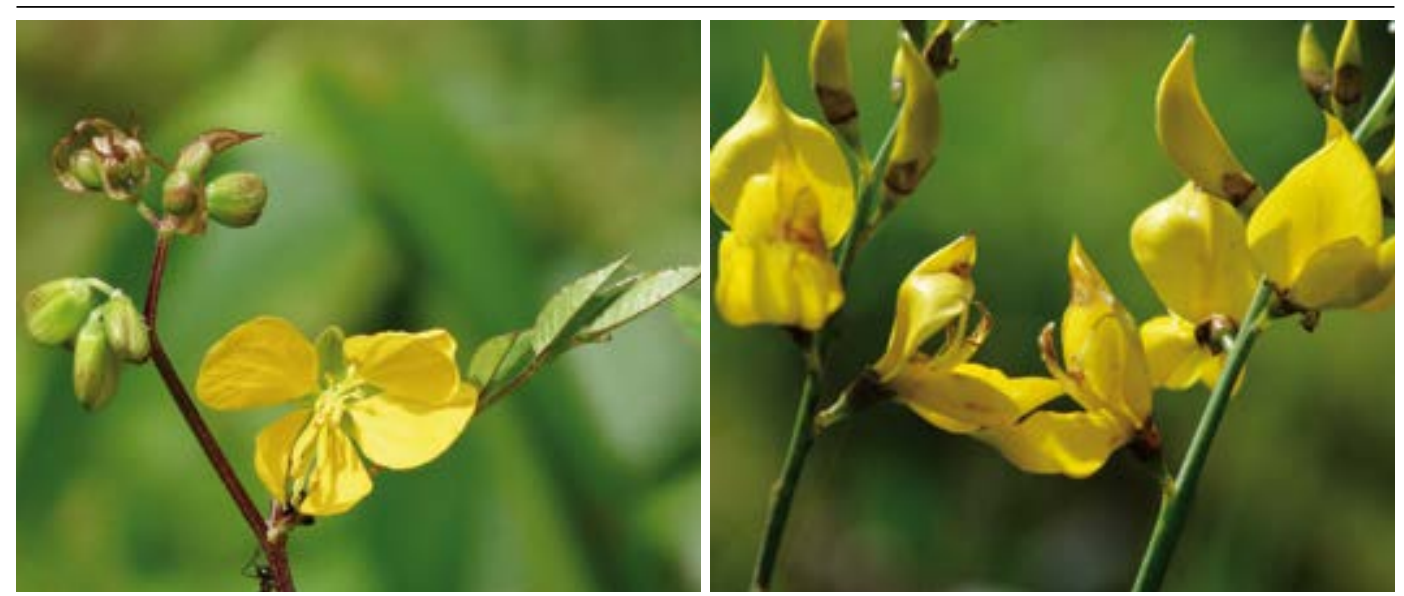

Senna occidentalis

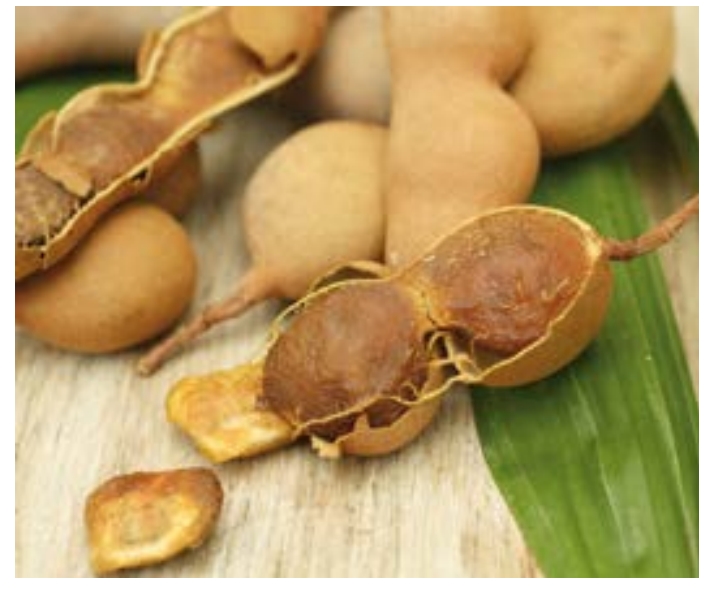

Tamarindus indica

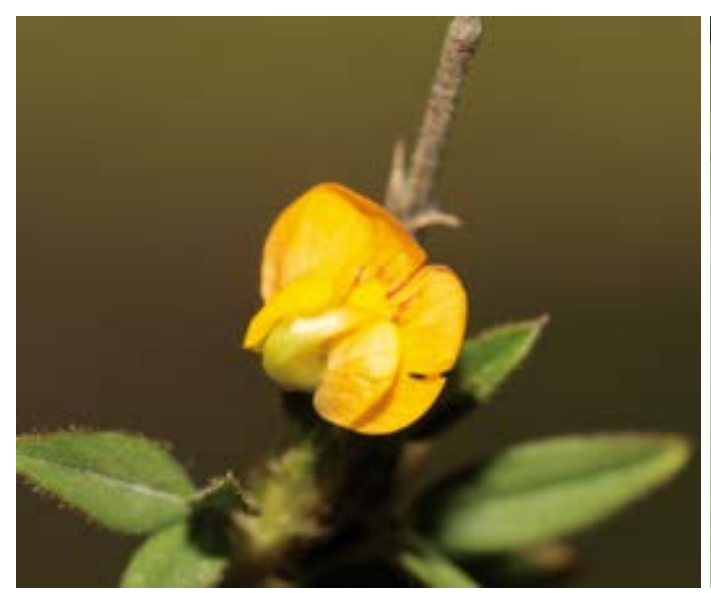

Zornia piurensis
Spartium junceum

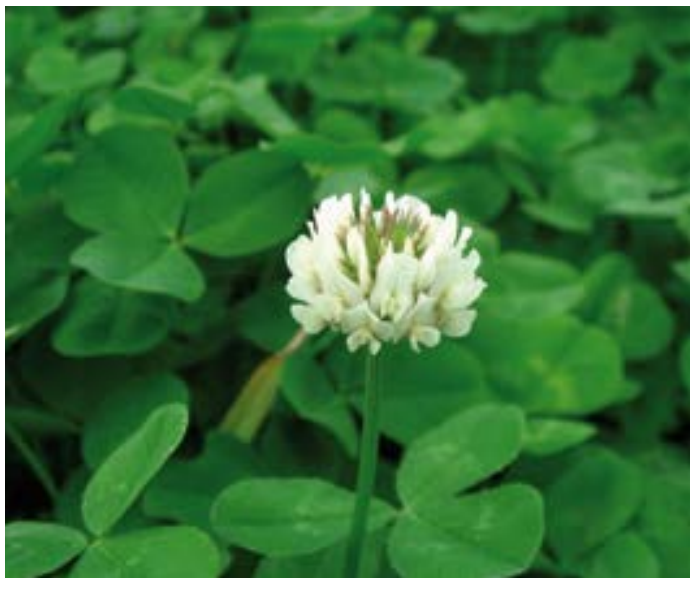

Trifolium repens

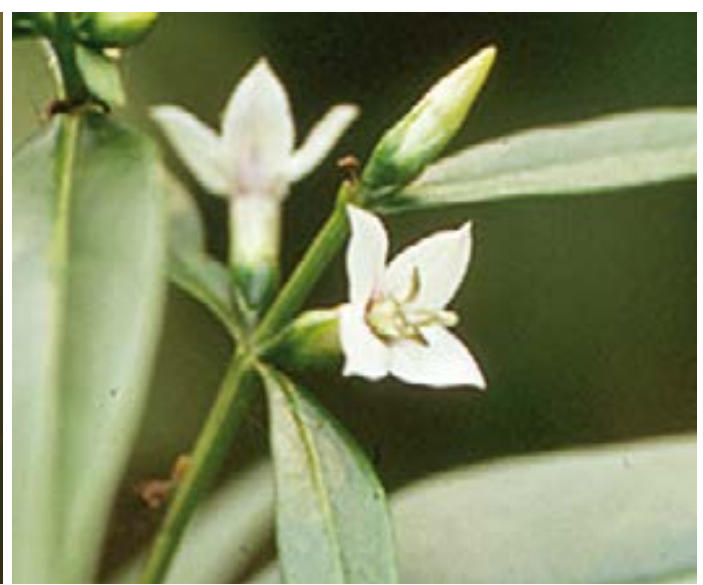

Coutoubea ramosa
FABACEAE - Senna occidentalis (L.) Link.

Retama, Retania

Hierba, Amazónica, Andina, 0-1000m, maleza

Uso: Inflamación (general) / Planta entera, fresco o seco / Oral / Hervir 10g total de Retama, Amor Seco, Cola de Caballo, Linaza, Chacur y Pie de Perro en 1 litro de agua. Tomar caliente, 1 taza 4 veces por día por 1 mes.

FABACEAE - Spartium junceum L.

Retama

Arbusto, Andino, Costa, 0-4000m, maleza, introducido

Uso: 1. Hepatitis, Hígado, Presión alta, Diabetes / Flores y Raíz, fresco / Oral / Hervir 3-5g en 1 litro de agua combinado con 3-5g de Flores de Overo. Tomar 3 veces por día. 2. Artritis, Buena Suerte, Dolor de Huesos, Sinusitis, Purificación de la Sangre / Planta entera, fresco / Tópico / Hervir por 20 min. y mezclar con Maique. Baño 3 veces por semana por una semana, $50 \mathrm{~g}$ total hervido 20-30 min. en 5 litros de agua con Hierbas de suerte y fuerza (Cóndor y Trensilla) o como Tallo Baño, 3 veces por semana.

FABACEAE - Tamarindus indica L.

Tamarindo

Arbol, Amazónico, Costa, 0-500m, maleza, introducido y cultivado

Uso: Laxante, Circulación de sangre, Epilepsia, Enfermedad de Corazón / Pulpa de fruta, fresco / Oral / Remover pulpa de $250 \mathrm{~g}$ de material. Añadir a 3 vasos de agua caliente. Mezclar. Tomar la mezcla fría en ayuno, 1 vaso en la mañana, una vez por día por 30 días. Repetir si necesario.

FABACEAE - Trifolium repens $\mathrm{L}$.

Trebol, Trebol de Agua

Hierba, Andina, Costa, 0-4500m, maleza, introducido

Uso: Inflamación, Inflamación de sistema urinaria, Estómago, Dolor de Estómago, Úlceras, Inflamación de Riñones / Mejorar la sangre / Flores, Hojas y Tallos, fresco o seco / Oral / Hervir $5 \mathrm{~g}$ en 3 litros de agua. Se puede combinar con Lancetilla y Colores, $5 \mathrm{~g}$ cada uno. También se puede combinar con Zarzaparrilla (1 cuchara). Tomar 1 litro cada día por 1-2 meses usar $5 \mathrm{~g}$ de la planta fresca machucada en la mañana cada día por 1 semana.

FABACEAE - Zornia piurensis Mohlenbrock

Hierba de la Víbora

Hierba, Costa, 0-1000m

Uso: Nerviosidad / Planta entera, seco / Oral / Hervir $5 \mathrm{~g}$ total en 1 litro de agua con Canchalagua, Nabo y Colores. Tomar 3 veces al día durante comidas.

GENTIANACEAE - Coutoubea ramosa Aubl.

\section{Genciana}

Hierba, Amazónica, 0-500m, maleza

Uso: Heridas, Cicatrices, Irritaciones de la piel, Ampollas de Resfrío / Frutas, fresco / Tópico / Extraer el jugo. Aplicar 2 gotas de jugo fresco en área afectada y dejarlo secar. Aplicar 2 gotas una vez por día como se necesita. 


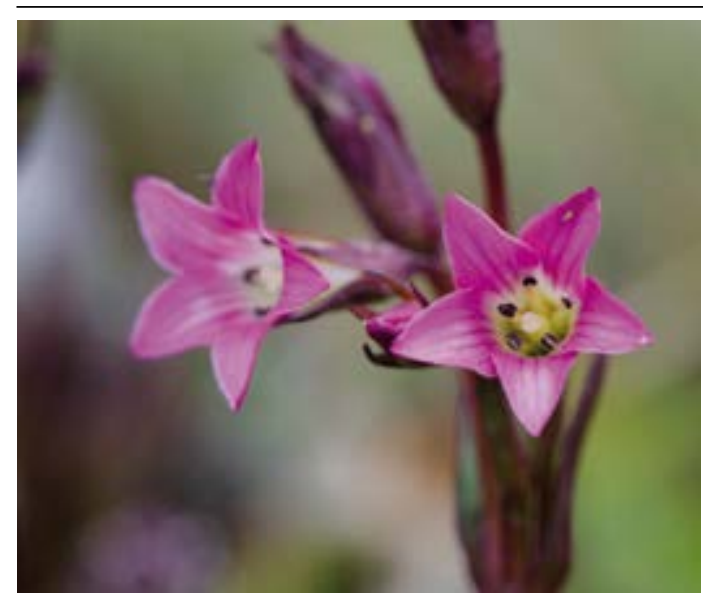

Gentianella bicolor

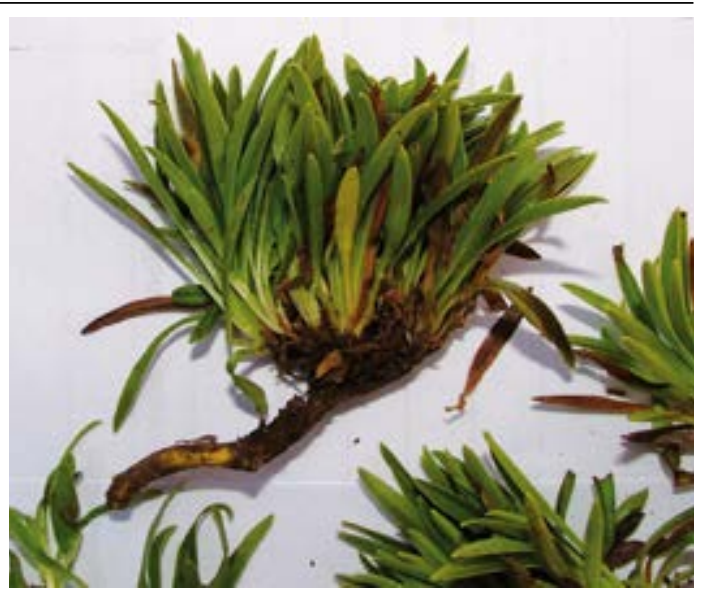

Gentianella brunneotincta

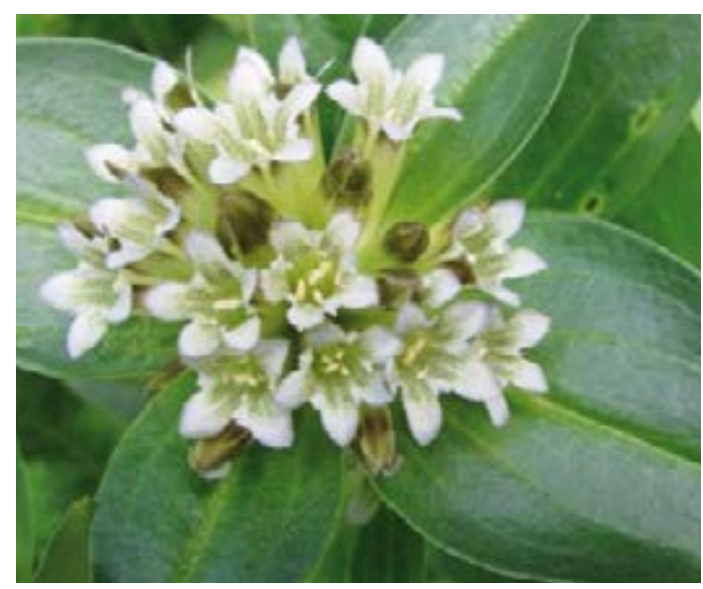

Gentianella crassicaulis

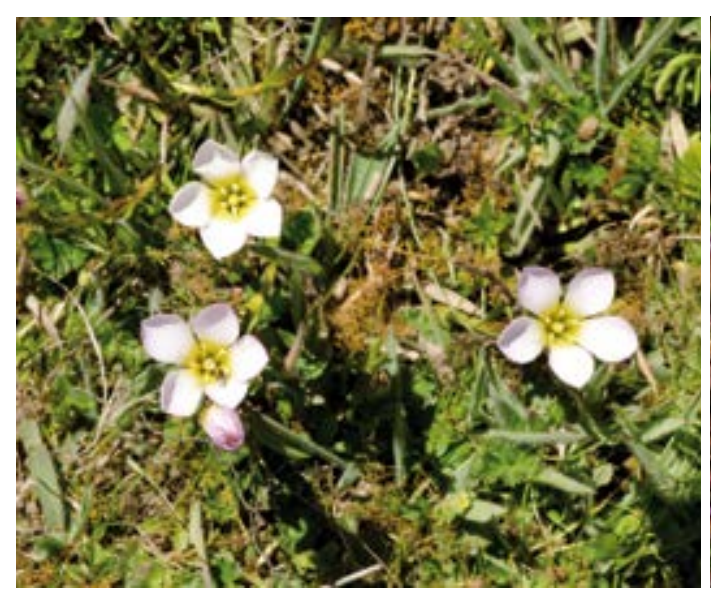

Gentianella graminea

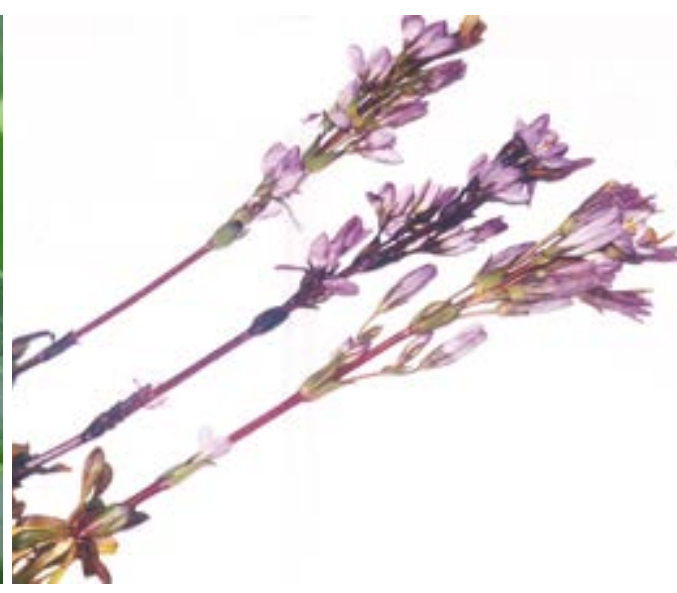

Gentianella dianthoides

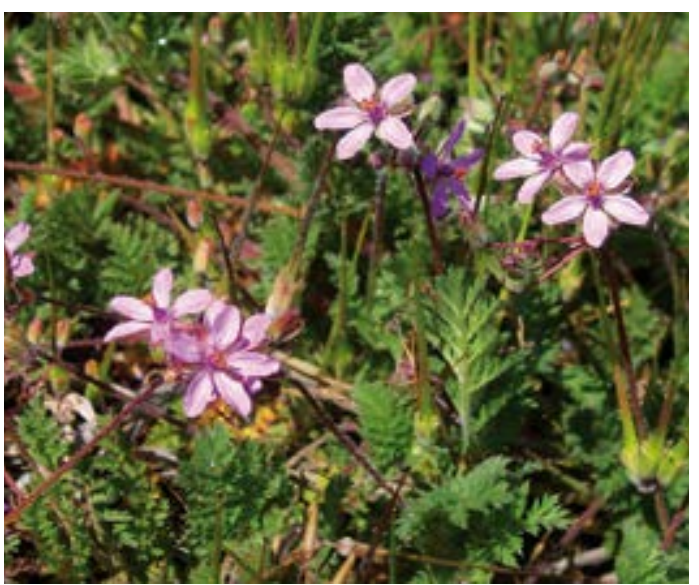

Erodium cicutarium
GENTIANACEAE - Gentianella bicolor (Wedd.) Fabris ex J.S.Pringle

Corpus Way, Hórnamo León

Hierba, Andina, 3000-4500m

Uso: 1. Artritis, Diabetes, Dolor de Huesos, Colesterol, Gastritis, Hígado, Sangre, Reumatismo / Planta entera, fresco o seco / Oral / Hervir 2-3 minutos en 1 litro de agua. Tomar cada día como se necesita. Té es muy amargo. 2. Buena Suerte, Buena Salud, Buenos Negocios, Protección / Planta entera, fresco o seco / Seguro / Mezclar material de planta con Hierba de la Plata, Hierba de la Fortuna, Hierba del Dólar, Hierba de la Justicia, Hierba del Oro, Carpintero, Seńorita y Sonrisa. Poner las Hierbas en 1 botella con Agua Florida y Jugo de Lima. Usar mezcla por rituales o como Seguro.

GENTIANACEAE - Gentianella brunneotincta (Gilg) J.S.Pringle

Anga Macha

Hierba, Andina, 3500-4500m

Uso: Infección uterina después del parto / Planta entera, fresco / Oral / Hervir $1 / 2$ litro de agua con $5 \mathrm{~g}$ de Valeriana Estrella y $5 \mathrm{~g}$ de Anga Macha por 3 min. Tomar caliente, 1 vaso 3 veces por día por 2-3 días.

GENTIANACEAE - Gentianella crassicaulis J.S.Pringle

Violeta Genciana

Hierba, Andina, $3000-4500 \mathrm{~m}$
Uso: Gastritis, Diabetes, Mareo / Planta entera, fresco o seco / Oral / Hervir 30g en 1 litro de agua por
3-5 minutos. Combinar con 10g cada uno de Pasuchaca, Amargón y Corpus Way. Tomar 3-4 vasos por

3-5 minutos. Combinar con 10g cada uno de Pasuchaca, Amargón y Corpus Way. Tomar 3-4 vasos por día por 15-30 días.

GENTIANACEAE - Gentianella dianthoides (H.B.K.) Fabris

Genciana, Egenciana, Amargón, Campanilla

Hierba, Andina, 3000-4500m

Uso: Hígado, Riñones, Sangre, Purgante, Diabetes, Limpia, Riego de la sangre, Problemas de sangre (general), Infección de Hígado / Planta entera, fresco / Oral / Hervir 10g de Genciana en 1 litro de agua por 2 minutos. Tomar una vez al día antes de comer en la noche, cada día siguiente por 1 semana. Sobredosis puede causar aborto en mujeres embarazadas. Planta contiene cortisona.

GENTIANACEAE - Gentianella graminea (H.B.K.) Fabris

Sumarán, Chinchimali, Corpushuay

Hierba, Andina, 2500-4500m

Uso: Diabetes, Hígado, Sangre, Quema Grasa, Fiebre Intestinal, Tos, Fiebre, Infección, Alergias en la sangre, Venas varicosas, Purificación de la Sangre, Inflamación del hígado, Decodificación de la sangre / Planta entera, fresco o seco / Oral / Hervir 20g en 1 litro de agua. Tomar 1 litro cada día por 1 semana. Mejor tomar con comida porque es muy amargo. Tomar templado en ayuno. Sobredosis puede causar ceguera.

GERANIACEAE - Erodium cicutarium (L.) L'Herit.

Agujilla Blanca, Auguilla.

Hierba, Andina, Costa, 500-4500m, maleza

Uso: Inflamación (General), Bronquitis, Presión alta, Presión baja de Sangre / Planta entera, fresco / Oral / Hervir $5 \mathrm{~g}$ de resina en 1 litro de agua mezclado con $5 \mathrm{~g}$ cada uno de Ambarindas, Hierba del Toro y Sanguinaria. Tomar 1 litro por día por 1-3 meses. 


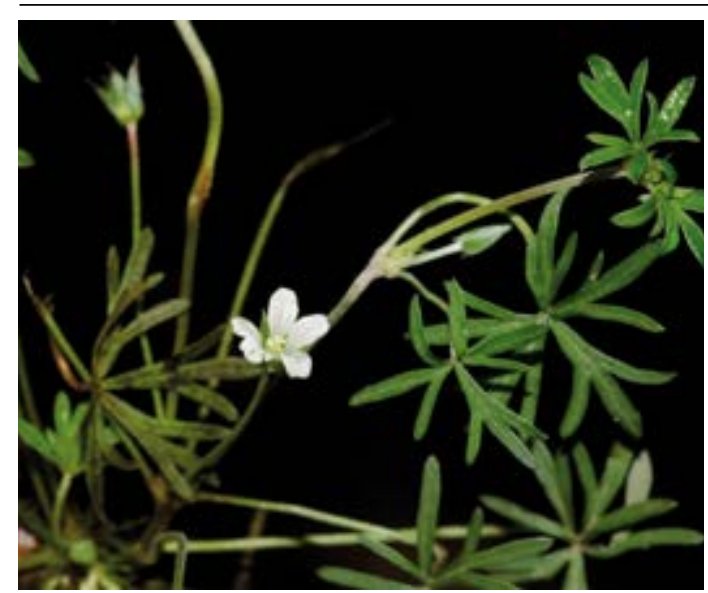

Geranium ayavacense

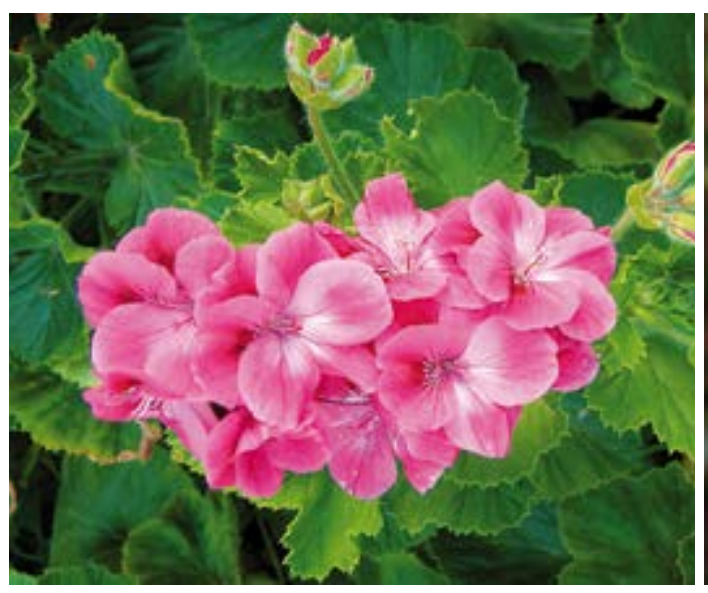

Pelargonium roseum

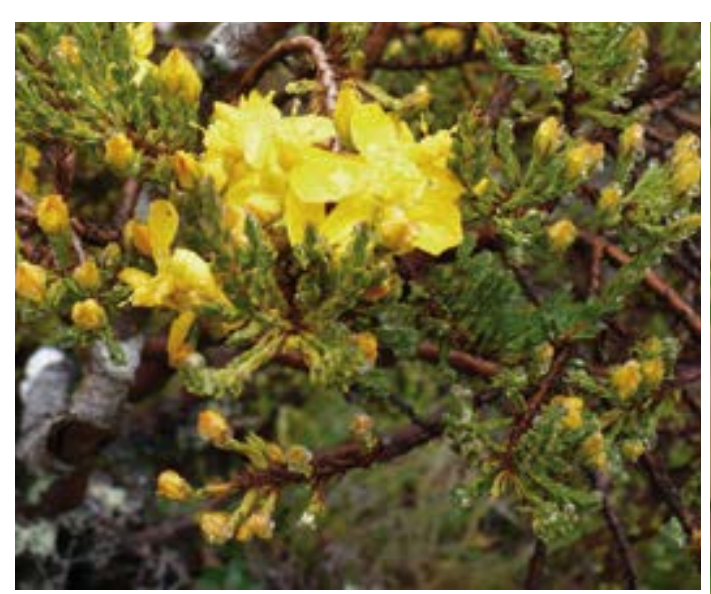

Hypericum laricifolium

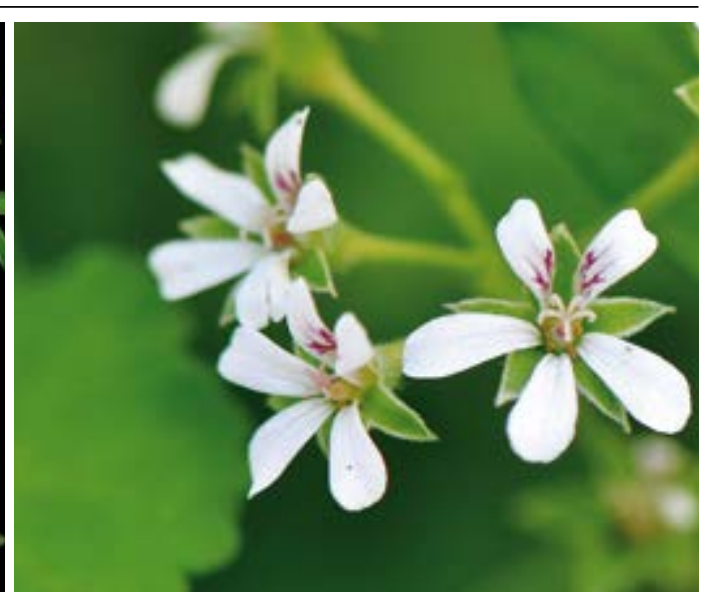

Pelargonium odoratissimum

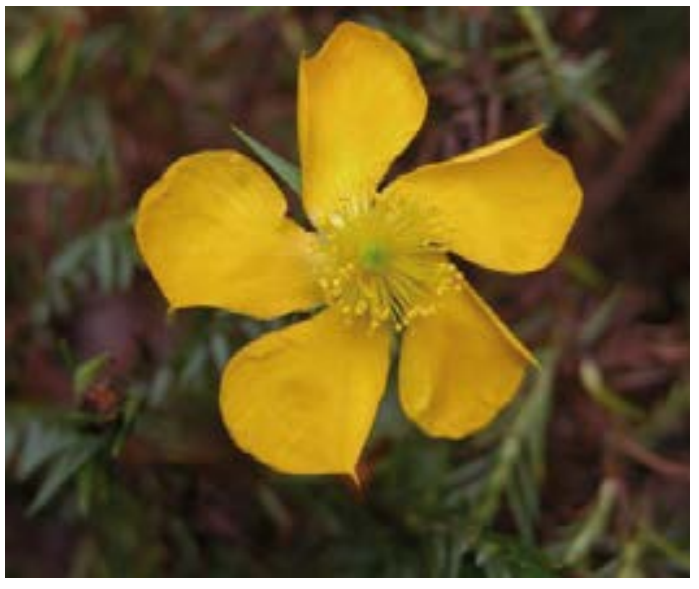

Hypericum aciculare

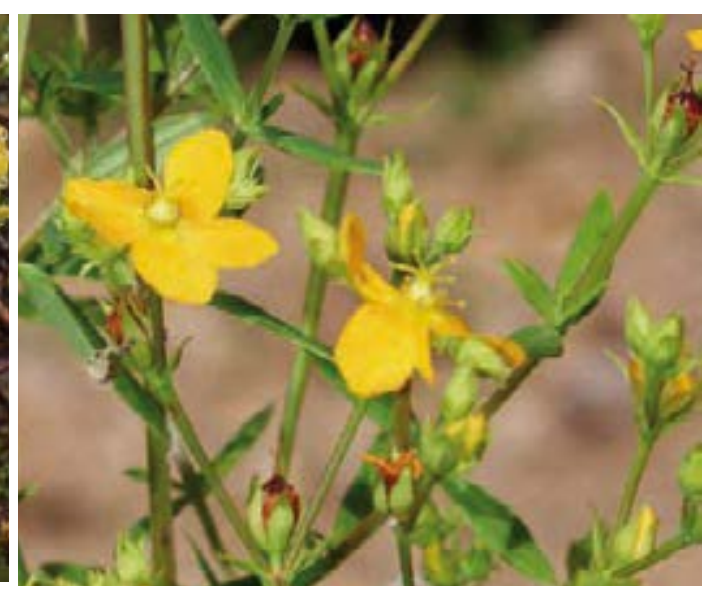

Hypericum silenoides
GERANIACEAE - Geranium ayavacense Willd ex H.B.K., Geranium sessiliflorum Cavanilles

Puli Punchi, Pasuchaca, Pachuchaca, Miscamisca

Hierba, Andina, 3000-4500m

Uso: 1. Diabetes / Planta entera, fresco o seco / Oral / Hervir 1 litro de agua por 3 minutos. Ańadir 10g de Pasuchaca y $1 / 2$ Hoja de Nogal. Combinar con $10 \mathrm{~g}$ cada uno de Culén y Citrodora. Tomar 4 tazas por día por vida. 2. Inflamación, Rińones, Hígado, Sistema Urinaria, Inflamación (General) / Planta por día por vida. 2. Inflamación, Rińones, Hígado, Sistema Urinaria, Inflamación (General) / Planta
entera, fresco o seco / Oral / Hervir 1 litro de agua con 10g de Pasuchaca por 3 minutos. Combinar con $10 \mathrm{~g}$ cada uno de Chacur, Cola de Caballo, Verbena, Unquia, Amor Seco y Grama Dulce. Tomar 4 tazas por día por 1 mes.

GERANIACEAE - Pelargonium odoratissimum (L.) L'Herit.

Malva de Oro, Malva Olorosa.

Hierba, Andina, 1500-3500m, introducido

Uso: 1. Artritis, Corazón, Nervios, Sangre, Susto, Inflamación de ovarios, Inflamación de útero / Planta entera, fresco o seco / Oral / Hervir $5 \mathrm{~g}$ en 1 litro de agua. Tomar 1 litro por día. 2. Susto / Planta entera, fresco o seco / Tópico / Hervir 2 litros de agua con $10 \mathrm{~g}$ cada uno de Ishpingo, Eucalipto, Cordón del Muerto, Flor de Chocho y Flor de Retama. Hervir por 3 minutos. Bańo 2-3 veces por mes.

\section{GERANIACEAE - Pelargonium roseum Willd.}

Geranio (Geranium)

Hierba, Andina, 1500-3500m, introducido

Uso: Hemorragias, Dolor de útero, Inflamación de útero, Amigdalitis, Infección de garganta / Flores y Hojas, fresco / Oral / Hervir 10g de Geranio en 1 litro de agua. Tomar 3 veces por día como se necesita.

Se puede usar para gárgaras, 3-4 veces cada día por 3-4 días.

HYPERICACEAE - Hypericum aciculare Kunth.

Hierba de las Cordilleras, Lechuguilla, Hierba del Imán

Arbusto, Andino, 2000-3500m

Uso: 1. Asegurar que alquilen quiere y tiene / Hojas y Tallos, fresco / Seguro / 1 pequeños tallos. 2. Daño/Hechicería, Dolor de Cabeza / Hojas y Tallos, fresco / Tópico / Mezclar con Aguardiente, 7 Espiritus y Hierba Santa. Limpa: 2 veces por semana. 3. Fiebre (General), Fiebre Intestinal / Hojas y Tallos, fresco / Oral / 3 Hojas machucadas y convertidos en extracto. No mezclar! $5 \mathrm{~g}$ por día por 8 días. 4. Daño/Hechicería, Dolor de Cabeza / Hojas y Tallos, fresco / Tópico / Natural, con 7 Espiritus. Aplicar como Emplasto por 4 horas.

HYPERICACEAE - Hypericum laricifolium Juss.

Hierba del Carińo, Hierba de la Fortuna, Solitario, Chinchango, Abrecaminos

Arbusto, Andino, 2500-4500m

Uso: 1. Fragancia, Suerte en amor y trabajo, Mal Aire, Protección, Buena Fortuna, Buena Salud / Planta entera, fresco / Tópico / Mezcla Alternativa para Florecimiento. Tomar 3 baños al mes. 2. Buenos Negocios, Protección, Buena Fortuna, Buena Salud / Planta entera, fresco / Seguro / Mezcla Estándar para Seguro.

HYPERICACEAE - Hypericum silenoides Juss.

Cintaura

Hierba, Andino, Costa, 500-3500m

Uso: Diarrea, Disentería / Planta entera, fresco / Oral / Combinar 3-5g de Cintaura en 1 litro de agua mezclado con $10 \mathrm{~g}$ cada uno de Culen y Hierba del Toro. Tomar 3 veces al día por 5 días o como se necesita. 


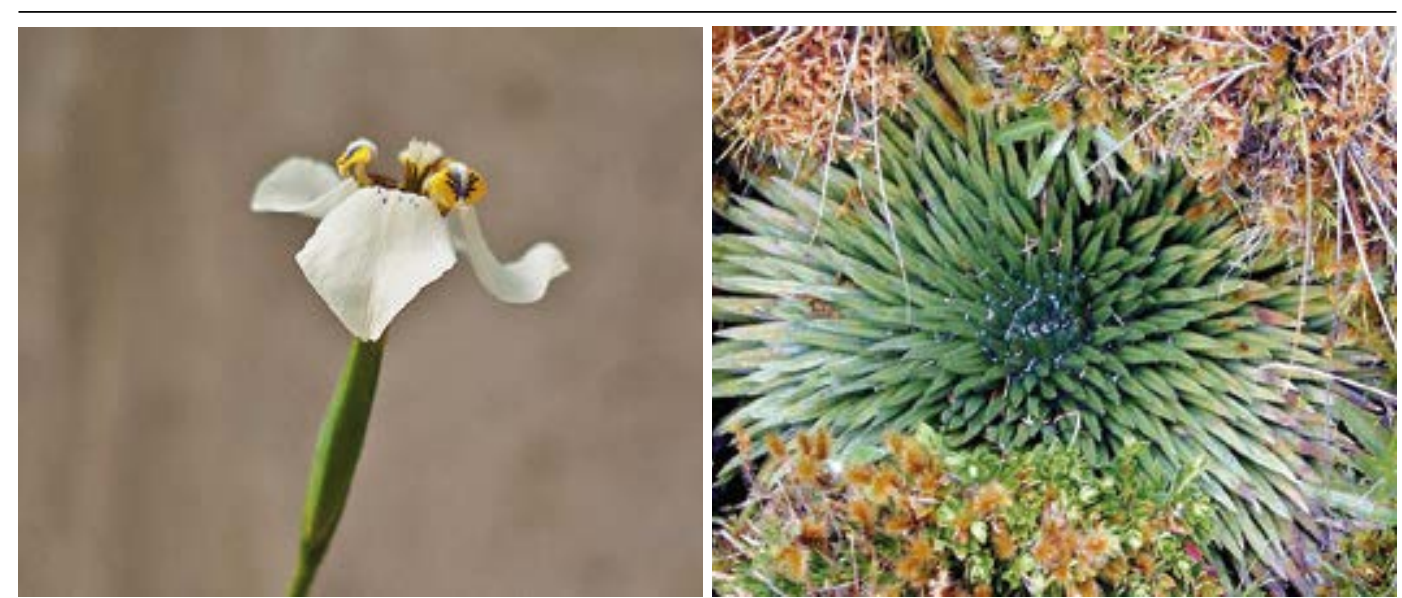

Hesperoxiphion niveum

Isoetes andina

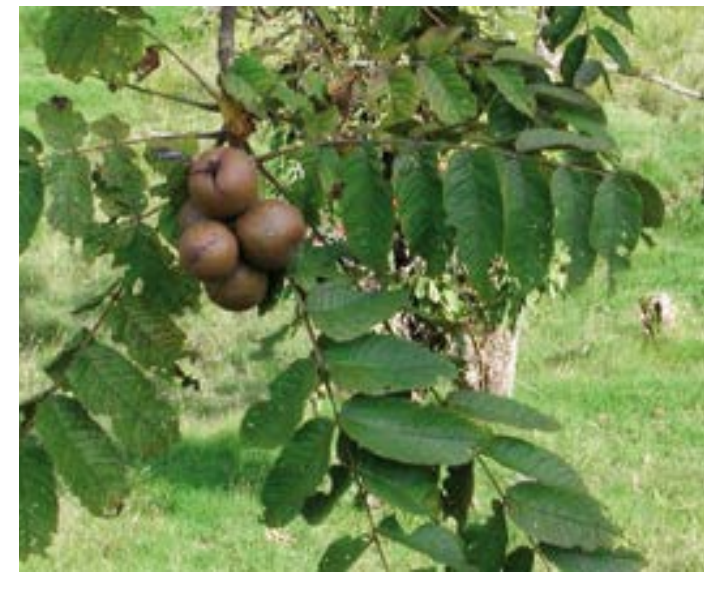

Juglans neotropica

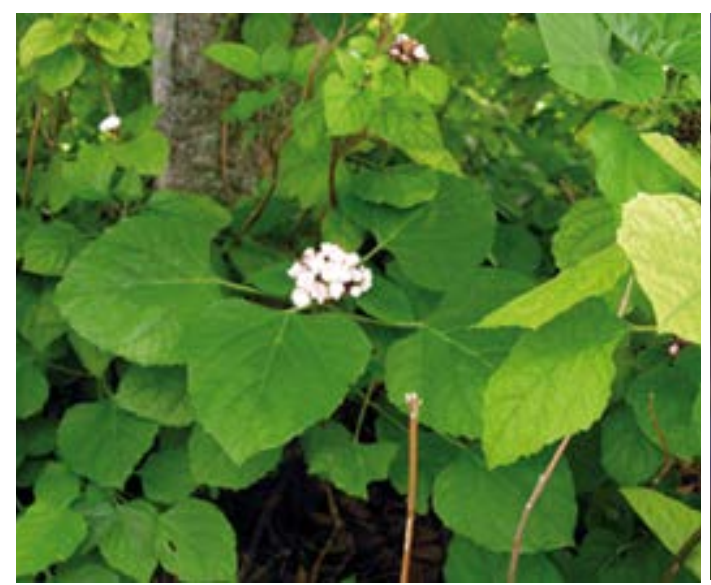

Clerodendrum philippinum

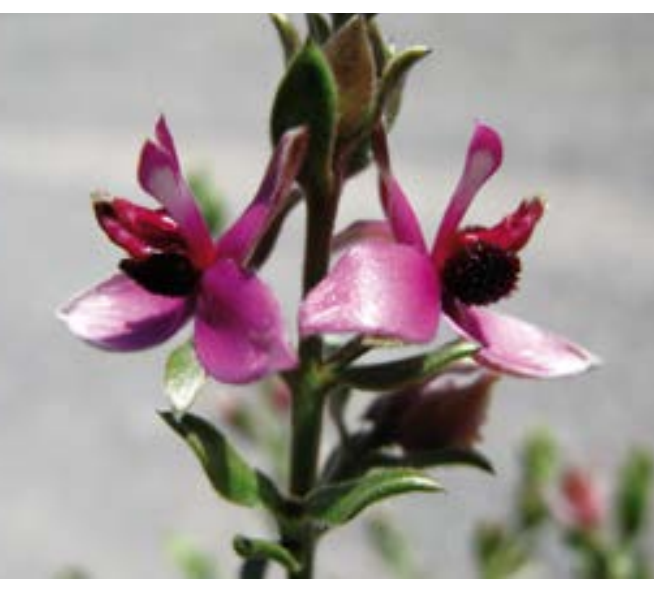

Krameria lappacea

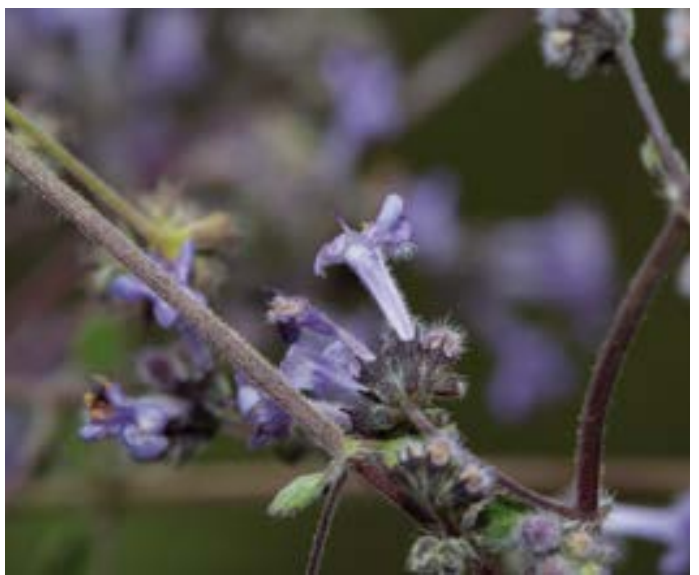

Hyptis sidifolia
IRIDACEAE - Hesperoxiphion niveum (Rav.) Rav.

Hierba de la Justicia, Piri Piri, Totorilla

Hierba, Andina, $1500-2500 \mathrm{~m}$

Uso: 1. Protección de casa, Protección de salud, Éxito profesional, Heridas, Fragancia, Buena Suerte, Amor, Dominación en asuntos de Justicia (ritual), Dominación asuntos legales (ritual) / Planta entera, fresco / Seguro / Poner en botella $10 \mathrm{~g}$ de Hierba de la Justicia y ańadir Hierba de la Plata, Dólar, Fortuna, Señorita, Valeriana Estrellada, Perfume Tabú, Agua Florida, Jugo de Lima, Azúcar y Agua Bendita. Mantener Seguro en dormitorio. Como alternativa juntar en una tela $10 \mathrm{~g}$ de Hierba de la Justicia, $10 \mathrm{~g}$ de Hierba del Dominio y $10 \mathrm{~g}$ de Hierba del Olvido. Sellar y rezar. Paciente debe cargar bolsita siempre y usarlo con oraciones. 2. Daño/Hechicería por boca, Daño/Hechicería (General), Purgante / Planta y usarlo con oraciones. 2. Daño/Hechicería por boca, Daño/Hechicería (General), Purgante / Planta entera, fresco / Oral / Paciente debe comer 3 plantas frescas. Debe quedarse en un ambiente oscuro
dentro de la casa por 1 semana. Causara vómito. Después de comer hay que seguir una dieta estricta sin dentro de la casa por 1 semana. Causara vómito. Después de comer hay que seguir una dieta estricta sin
especies por 1 semana 3. Florecimiento / Planta entera, fresco / Tópico / Hervir Hierba de la Justicia en algo de agua por 3-4 minutos. Baño 3-4 veces por mes.

ISOETACEAE - Isoetes andina Spruce ex Hook.

Piri Piri

Hierba, Andina, 3000-4500m

Uso: impotencia masculina / Tallos, fresco / Oral / Hervir 2 pequeñas ramas en 1 taza de agua. Tomar 1 taza por noche por 1 mes.

JUGLANDACEAE - Juglans neotropica Diels

Nogal

Árbol, Amazónico, Andino, 0-3000m

Uso: 1. Perdida de Cabello / Hojas, fresco / Tópico / Hervir 20g en 1 litro de agua por 20 minutos. Masajear cabeza por 3 minutos, 3 veces por semana. 2. Daño/Hechicería, Artritis, Heridas (limpieza), Susto / Hojas, fresco / Tópico / Hervir 3 litros de agua con a manojo de la Hierba, 3 veces por mes. 3. Tos, Bronquitis, Asma / Hojas, fresco / Oral / Hervir 10g en 1 litro de agua por 3-5 minutos. Por Bronquitis: Mezclar con Matico, Enredadera y Borraja, 10g cada uno. Tomar 3 vasos por día 1 litro por día 4. Diabetes/ $/$ cojas, fresco/Oral/5g con $5 \mathrm{~g}$ de Pasuchaca, 1 lito por dí. 5. Dajo/t Artritis, Heridas (limpieza), Susto / Hojas, fresco / Tópico / Limpia: Mezclar con Añasquero Grande, Rumilanche, Ishpinguillo y Sauco, 3 veces por mes.

KRAMERIACEAE - Krameria lappacea (Dombey) Burdet \& B.B. Simpson

Ratania

Arbusto, Andino, Costa, 500-4000m

Uso: Inflamación de Riñones, Inflamación de ovarios, Inflamación de los intestinos, Inflamación de la vejiga / Hojas y Raíz, fresco / Oral / Hervir 10g en 1 litro de agua por 3 minutos. Tomar como se necesita.

LAMIACEAE - Clerodendrum philippinum Schauer

Brochamelia

Arbusto, Amazónico, Andino, 0-1000m, introducido y cultivado

Uso: Bronquitis, Asma, Tos ferina, Laryngotracheitis (una condición cuando un bebé no puede respirar, se pone azul y suena como un gallo) / Flores, fresco o seco / Oral / Hervir 1 litro de agua y añadir 10g de Hierba. Hervir por 3 hasta 5 minutos más. Se puede mezclar con $10 \mathrm{~g}$ cada uno de Huamanripa y Veronica. Tomar 1 taza 3 veces por día por 2 semanas.

LAMIACEAE - Hyptis sidifolia (L’Her.) Briq.

Pedrorera, Hierba de la Ventosidad, Albaca Serrana

Hierba, Andina, Costa, $0-3500 \mathrm{~m}$, maleza

Uso: Gases, Cólico intestinal, Gastritis, calambres / Planta entera, fresco o seco / Oral / Hervir 5g en 1 litro de agua por 3-5 minutos. Tomar 1 taza, 3-4 veces por día por 2-3 días como se necesita. Cuando Estómago esta muy duro, esta planta lo relaja y los gases salen. 


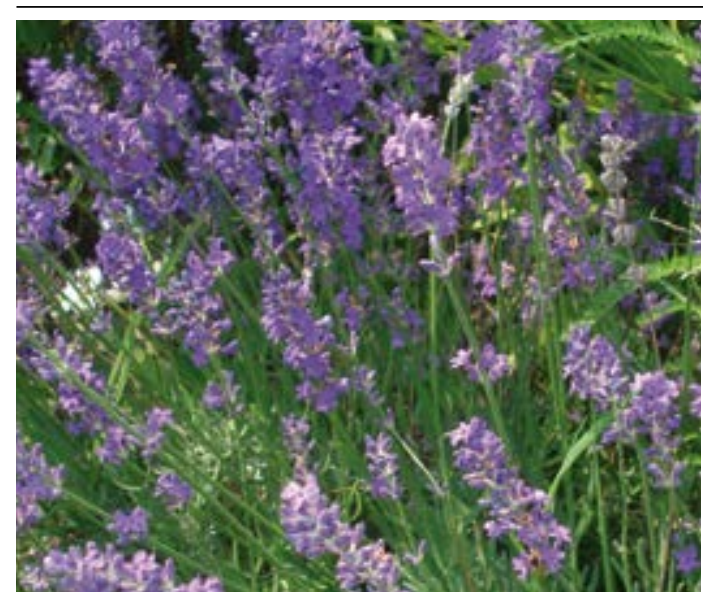

Lavandula angustifolia

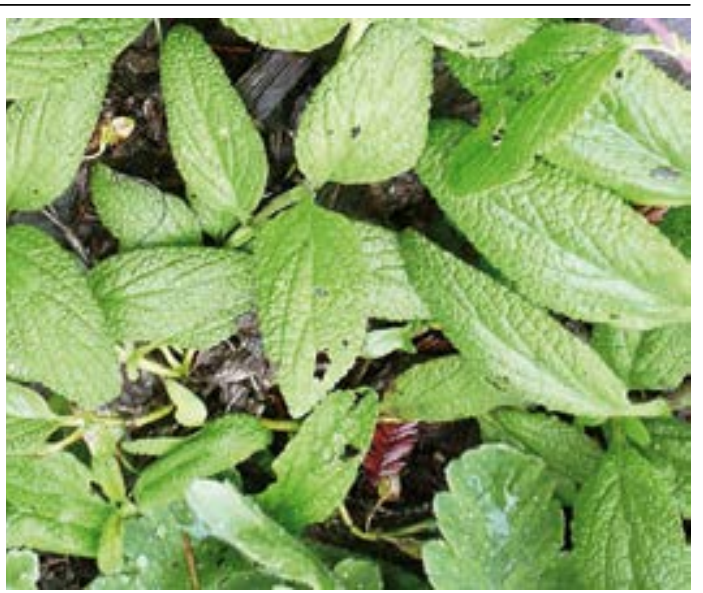

Lepechinia meyenii

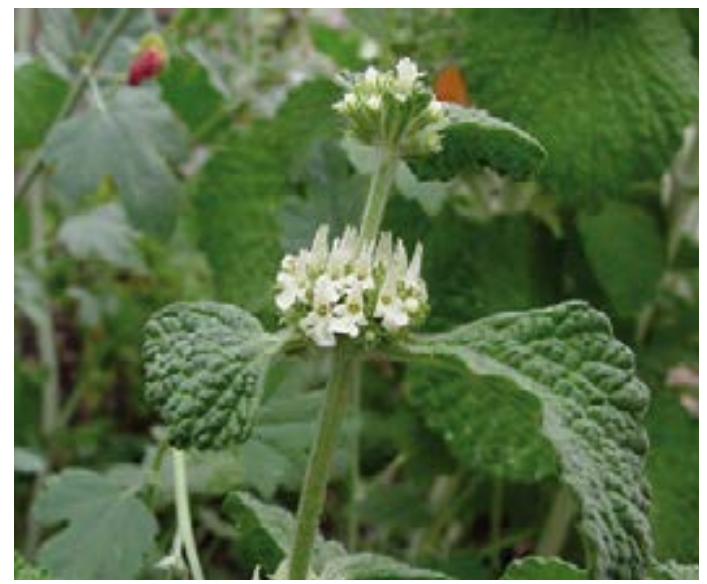

Marrubium vulgare

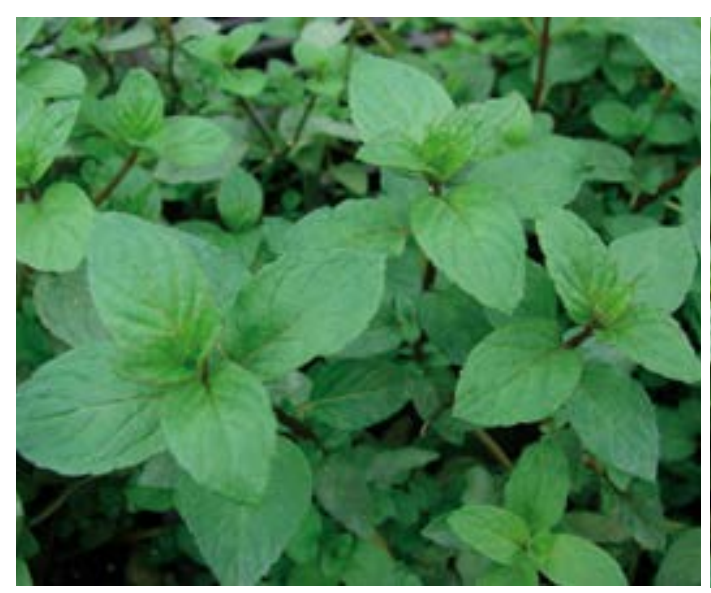

Mentha piperita

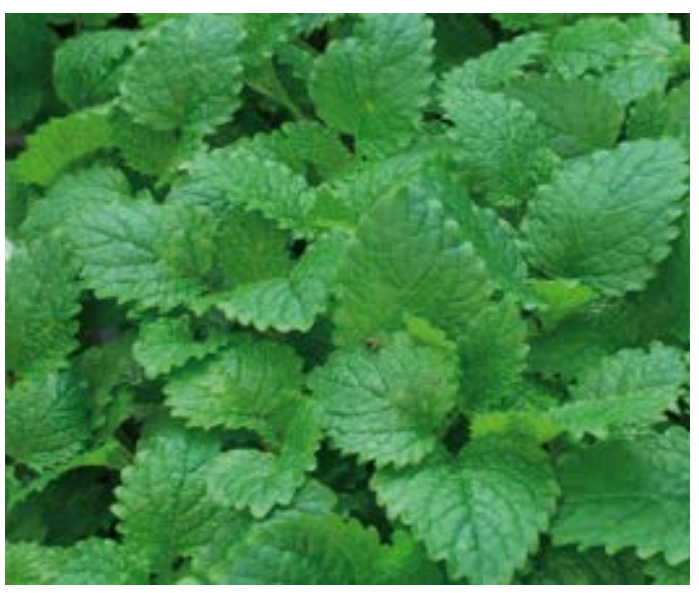

Melissa officinalis

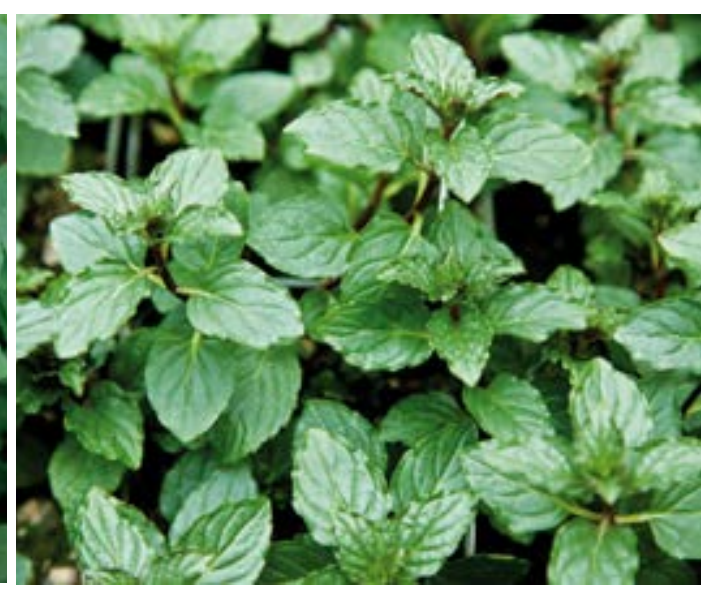

Mentha spicata

\section{LAMIACEAE - Lavandula angustifolia Miller}

Alucema, Labanda

Hierba, Andina, Costa, 0-1500m, introducido y cultivado

Uso: 1. Resfrío, Gases, Corazón, Nervios / Flores, Hojas, Tallos y Semillas, secas / Oral / No usar raíces. Hervir 1 litro de agua. Ańadir un total de 10g de Labanda, Romero, Claveles, Hinojo, Toronjil, Ajenco, Manzanilla y Pimpinela. Hervir por 2 min más. Paciente debe tomarlo templado, 1 taza 3-4 veces por día por 1 mes. 2. Relajante, Estrés / Flores, Hojas, Tallos y Semillas, secas / Tópico / Hervir 3 litros de agua con $20 \mathrm{~g}$ total de Labanda, Romero y Eucalipto por 3 minutos. Paciente debe lavarse con agua y masajear con Flores, 2 veces por semana o 4 veces por mes o como se necesita.

LAMIACEAE - Lepechinia meyenii (Walp.) Epling

Salvia, Salvia Real

Hierba, Andina, 2500-4500m, maleza

Uso: 1. Bronquitis, Corazón, Nervios, Memoria, Menstruación / Planta entera, fresco o seco / Oral / Hervir 30g en 1 litro de agua. Tomar con comidas, 3 veces por día. 2. Heridas, Perdida de cabello / Planta entera, fresco o seco / Tópico / Hervir 100g total en 8 litros de agua por 5 minutos combinado con Romero y Llantén. Bańo 3 veces por día por 1 mes. 3. Susto / Planta entera, fresco o seco / Tópico / Hervir $5 \mathrm{~g}$ en 3 litros de agua mezclado con Añasquero Chico, Ajenco, Nogal y Vinagre (5g cada uno). Baño 2 veces por mes.

LAMIACEAE - Marrubium vulgare L.

Cordón del Muerto, Chanca de Comida, Chancas del Muerto

Hierba, Andina, Costa, 500-4000m, introducido

Uso: Susto, Inflamación (Externo) / Planta entera, fresco o seco / Tópico / Hervir 20-30g total de Cordón del Muerto mezclado con Eucalipto, Ishpingo, Chivato y Quinual en 2-3 litros de agua por 5-8 minutos. Vaciar en un balde y dejar en un cuarto oscuro. Frotar en cuerpo de paciente con todas las plantas, 2 Bańos por semana por 4-5 meses si la condición del paciente permite. No dejar la mezcla tocar la boca.

\section{LAMIACEAE - Melissa officinalis L.}

Toronjil, Melissa

Hierba, Andina, Costa, $0-3500 \mathrm{~m}$, introducido

Uso: 1. Niños maleducados / Planta entera, fresco o seco / Tópico / Hervir 10g en 2 litros de agua por 10 minutos. Mezclar con $10 \mathrm{~g}$ cada uno de Toronjil y Churguis. Bańo dos veces por semana o como se necesita. 2. Mal de amor, Nervios, Insomnio, Corazón, Sistema nervioso, Tachycardia / Planta entera, fresco o seco / Oral / Hervir 20-30g en 1 litro de agua por 2 minutos con 10g cada uno de Pimpinela, Cedrón, Mejorana, Siempre Viva, Flores de Amelas, Romero, Claveles, Congona, Manzanilla, Mejorana y Orange Flores. Tomar 4 tazas por día por 1 mes.

LAMIACEAE - Mentha piperita L.

Poleo

Hierba, Andina, Costa, 0-3500m, introducido

Uso: Cólico, Dolor de Estómago / Planta entera, fresco o seco / Oral / Hervir en 1 litro de agua. Añadir $10 \mathrm{~g}$ de Poleo. Tomar cuando hay síntomas.

LAMIACEAE - Mentha spicata L.

Hierba Buena, Hierba Buena Silvestre, Menta (Mint)

Hierba, Andina, Costa, $0-3500 \mathrm{~m}$, introducido

Uso: 1. Parásitos, Cólico, Dolor de Estómago, Gastritis, Indigestión, Helminthes, Parásitos intestinales, Dolor de Cabeza, Afrodisiaco, Gases, Mal Aliento / Planta entera, fresco / Oral / Hervir 10g en 1 litro de agua. Puede usar mezclado con $10 \mathrm{~g}$ de Anís. Tomar 3 veces al día después de comidas por 1 mes. 2. Cólico, Dolor de Estómago / Planta entera, fresco / Tópico / Hervir por 20 minutos, 30g en 6 litros de agua con otras Hierbas de Buena Suerte (10g cada uno). Bańo 3 veces por semana. 


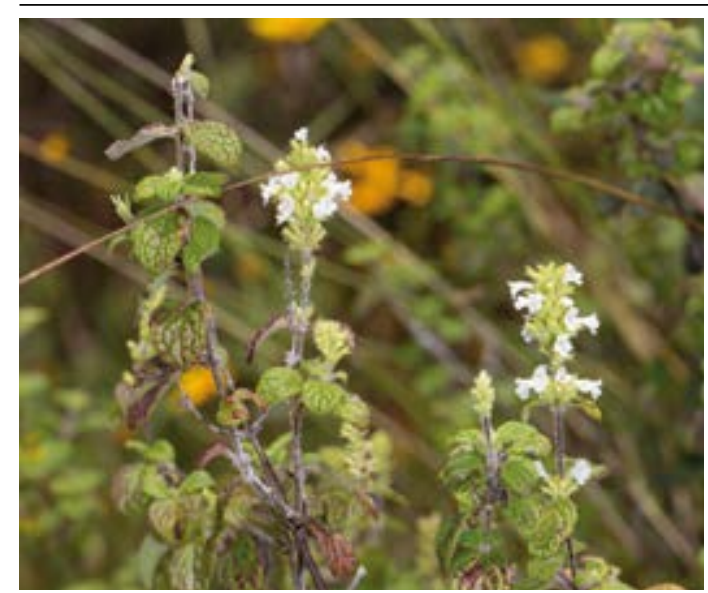

Minthostachys mollis

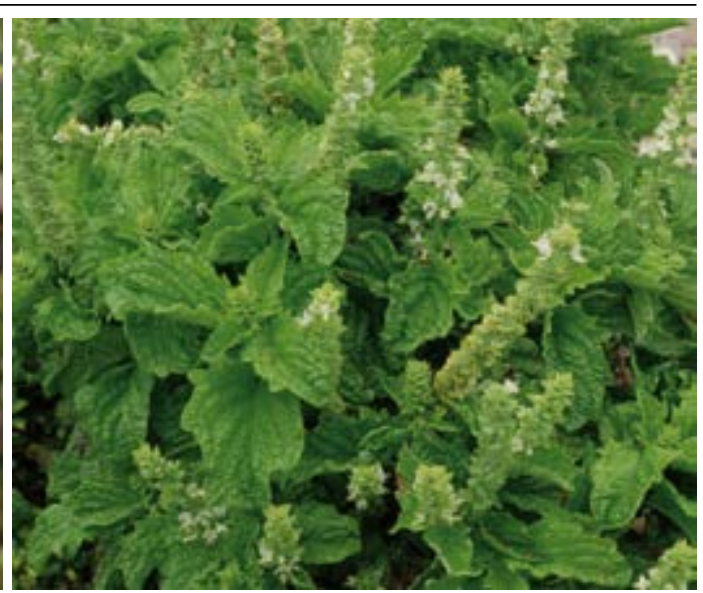

Ocimum basilicum

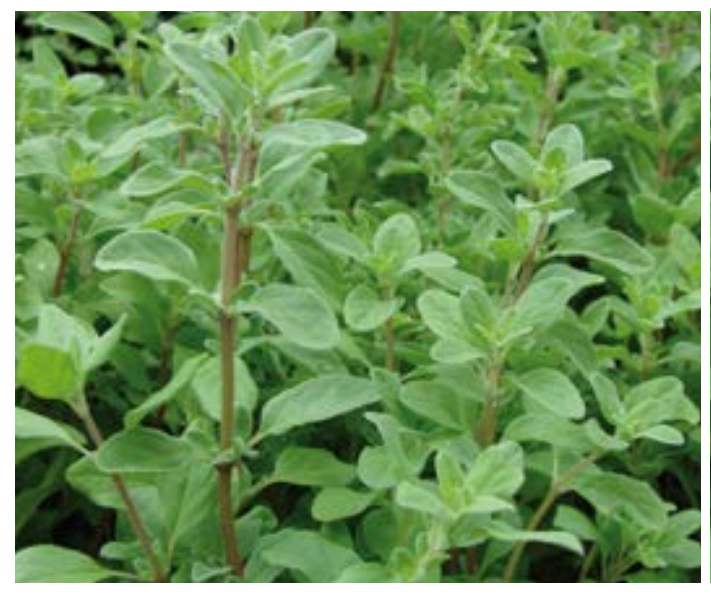

Origanum majorana

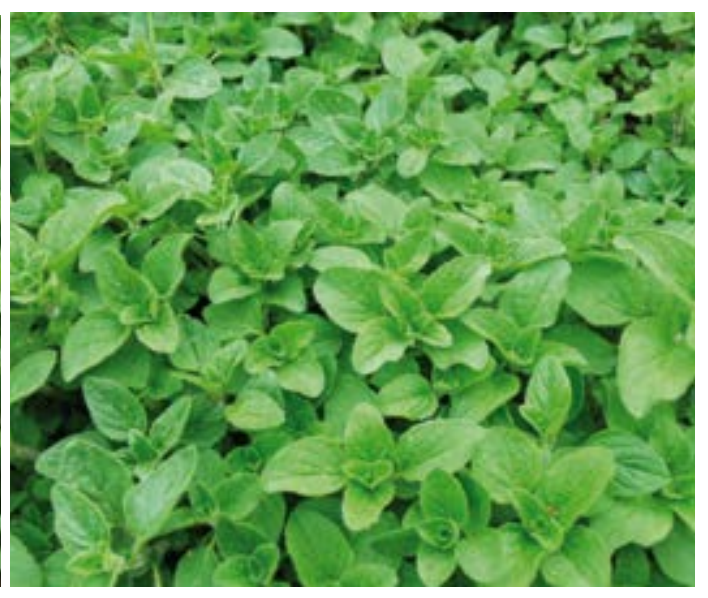

Origanum vulgare

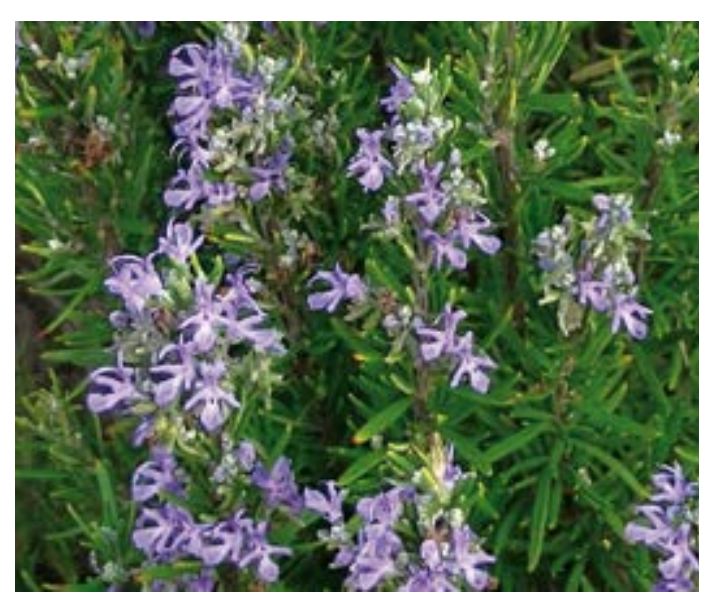

Rosmarinus officinalis

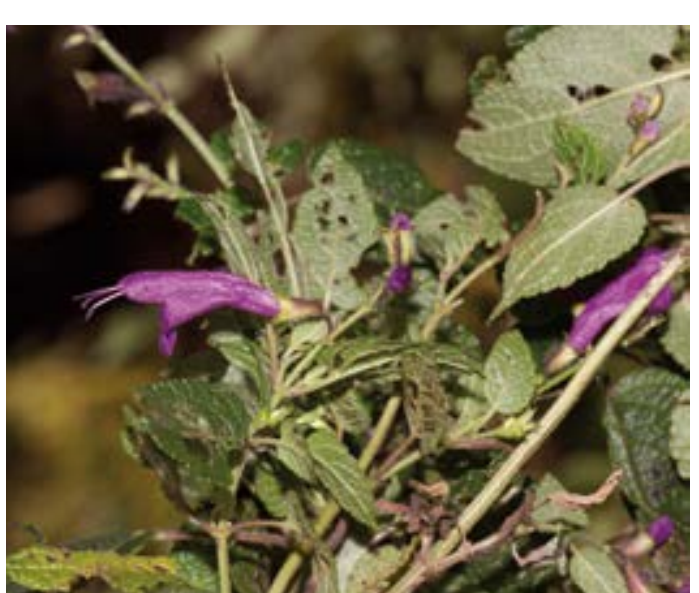

Salvia ayavacensis
LAMIACEAE - Minthostachys mollis (Benth.) Griseb.

Muña, Chancas de Comida

Hierba, AndinA, Costa, 500-3500m, maleza

Uso: Cólico, Gases, Estómago Parásitos, Dolor de Estómago, Corazón, Nervios, Diarrea / Hojas y Tallos, fresco / Oral / Hervir 2-10g en 1 litro de agua. Tomar 1 taza 3-4 veces por día por 3-4 semanas. Paciente debe tomarlo caliente. También se come como vegetal o sopa.

LAMIACEAE - Ocimum basilicum L.

Albaca, Albaca Mixtura, Albaca Negra, Albaca Morada (Basil)

Uso: 1. Daño/Hechicería, Susto, Mal Aire, Insomnio, Presión Baja de Sangre, Buena Suerte / Planta entera, fresco / Planta entera, fresco / Usar 20g de Hierba mezclado con Agua Florida, Eucalipto, Camphor, Molle, Aguardiente, Agua del Susto, Flor de Retama, Hierba del Gallinazo, Ruda (Hembra y Macho), Ajenco, 2 Ajíes (20g de cada uno). Limpia: Hacer Martes, Viernes y Martes. 2. Dilatación de Útero para apurar el parto, Prevención de Infecciones post-parto, Refrescar útero, Reducir Inflamaciones después del parto, Cólico, Gases / Planta entera, fresco / Oral / Hervir 10g en 1 taza de agua con un poco de sal. Tomar 1 taza, muy caliente. Tomar también inmediato después del parto. 3. Después del parto / Planta entera, fresco / Oral / Hervir $5 \mathrm{~g}$ en 1 litro de agua. Tomar 1 taza por día por 2 semanas. 4. Daño/Hechicería, Susto, Mal Aire, Insomnio, Presión Baja de Sangre, Buena Suerte / Planta entera, fresco / Oral / Hervir 20g en 1 litro de agua por 1-2 minutos combinado con Tilo, Toronjil, Mejorana y Cedrón. Tomar 3 tazas por día antes de la cena por 10 días. 5. Daño/Hechicería, Susto, Mal Aire, Insomnio, Presión Baja de Sangre, Buena Suerte / Planta entera, fresco / Planta entera, fresco / Hervir 10g en 1 litro de agua por 5-8 minutos combinado con Romero, Salvia Real, Yerba Santa y Malva Olorosa (10g cada uno). Baño 3 días por semana o cada 8 días por 2 meses. 6. Cataratas, Problemas de los ojos / Planta entera, fresco / Planta entera, fresco / Poner 1 Semilla directo en el ojo. Dejar por 3 horas o hasta el ojo lo bota. Aplicar una vez al mes por 2 meses.

LAMIACEAE - Origanum majorana L.

Mejorana

Hierba, Andina, Costa, $0-3500 \mathrm{~m}$, introducido y cultivado

Uso: Cólico, Corazón, Nervios, Menstruación, Ansiedad, Depresión, Dolor de Amor / Hojas y Tallos, fresco / Oral / Hervir 10g de Mejorana en 1 litro de agua combinado con Sanguinaria, Congona, Toronjil, Hinojo, Albahaca Serrana, Poleo y Manzanilla (10g cada uno). Paciente debe tomarlo caliente, 4 tazas por día por 1 mes. por Diabetes: 4 veces por día por vida.

LAMIACEAE - Origanum vulgare L.

Hierba, AndinA, Costa, $0-3500 \mathrm{~m}$, introducido y cultivado

Uso: Cólico, Calambres de Menstruación, Menstruación, Dolor de Estómago, Gases, Calambres de Estómago como parte de Sindroma Pre Menstrual / Hojas y Tallos, fresco o seco / Oral / Añadir 1 taza de agua a $3 \mathrm{~g}$ de Orégano. Hervir por 3-5 minutos. Tomar caliente por menstruación. Tomar templado por Cólico. Evitar tomar demasiado porque puede causar aborto. Tomar 2 tazas por 1 día solo.

LAMIACEAE - Rosmarinus officinalis $\mathrm{L}$.

Romero, Romero Castilla (Rosemary)

introducido y cultivado

Uso: 1. Perdida de Cabello / Hojas, fresco o seco / Tópico / Hervir $5 \mathrm{~g}$ cada uno de Romero, Nogal, Amor Seco y Cola de Caballo en 1 litro de agua por 5 min. Masajear cabello con liquido. Aplicar champú y lavar. 2. Gases, Corazón, Nervios, Bronquitis, Indigestión, Cólico, Dolor de Cabeza, Estomago, Mal de amor / Hojas, fresco o seco Tomar 2 tazas por dia por 2 dias, 4 tazas por dia por 1 mes. 3. Susto, Expulsar energia negativa de la casa $/$ Hojas, fresco o seco / Topico / Hervir 1 manojo de Romero con 3 litros de agua por 10 minutos. Combinar Flores, Cordón del Muerto, Verbena, Toronjil, Eucalipto y 7 Espiritus. Inhán o Bañar Martes, Vierces Flores, Cordón del Mueto, Verbena, Toronjil, Eucalipto y 7 Espiritus. Inhalar o Banar Martes, Viernes y Hojas, fresco o seco / Tópico / Quemar 1 majo de Rom, Abo Palo Santo sobre carbón. Inhalar. LAMIACEAE - Salvia ayavacensis Kunth

LAMIAC

Ticra Hierba, Andina, 2500-3500m

Uso: Hongos en la piel, Daño/Hechicería, Susto / Hojas, fresco o seco / Tópico / Poner 1 manojo en 1 Uso: Hongos en la piel, Daño/Hechicería, Susto / Hojas, fresco o seco / Conco / Ponar Amarillo, Conchalay
litro de agua hervida. Se puede combinar con Tutapure Blanco, Lailambo, Conchalay Blanco, Ticra, Zanahoria, Poleo de Gentil (5g cada uno) y 7 Espiritus. Bańo 1-2 veces por mes. No ingerir. 


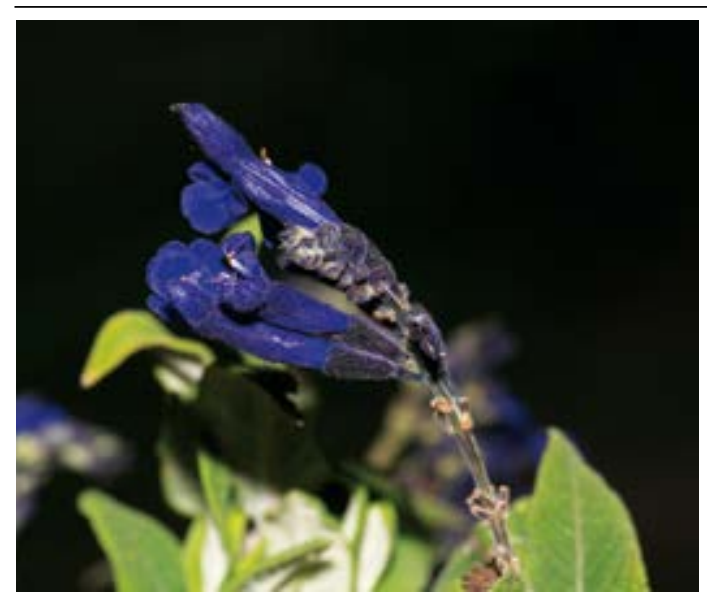

Salvia cuspidata

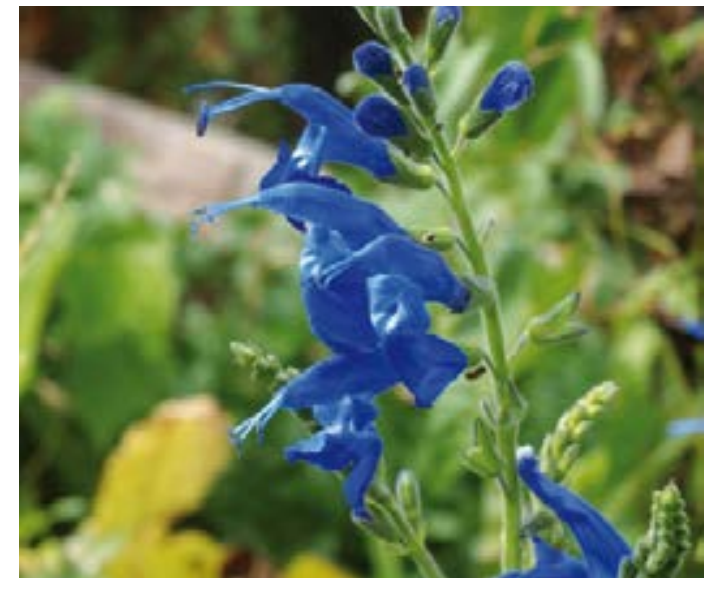

Salvia macrophylla

Salvia officinalis subsp. lavandulifolia

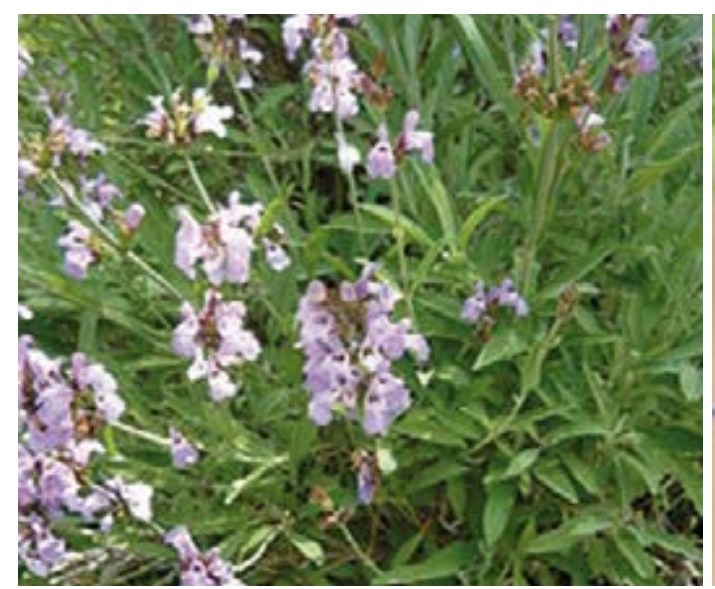

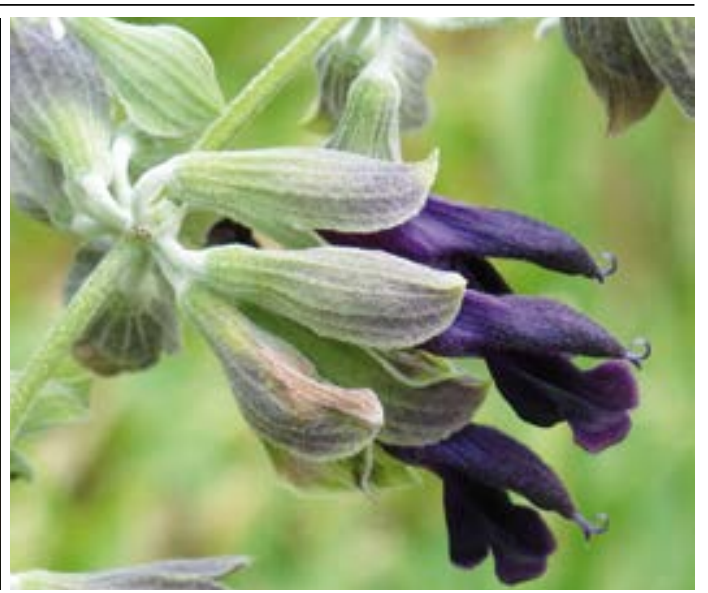

Salvia discolor

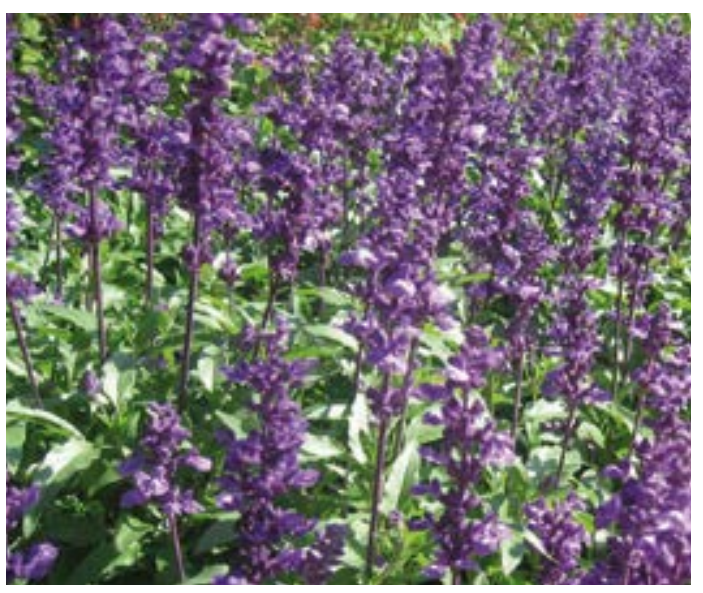

Salvia officinalis

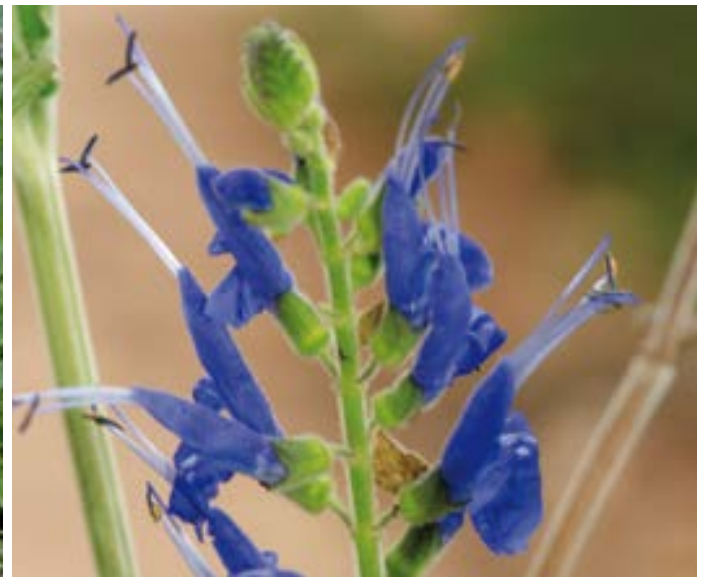

Salvia sagitatta
LAMIACEAE - Salvia cuspidata R. \& P.

Salvia Blanca

Hierba, Andina, 2000-3500m, maleza

Uso: Susto, Dańo/Hechicería / Planta entera, fresco o seco / Tópico / 1 manojo hervido por 5 minutos en 3 litros de agua. Bańo una vez por semana.

LAMIACEAE - Salvia discolor H.B.K.

Palmeras (Chica), Llatama, Yatama

Hierba, Andina, 1000-2500m, maleza

Uso: 1. Éxito / Tallos, fresco / Seguro / Poner 3 Tallos en 1 frasco. 2. Tos / Tallos, fresco / Oral / Hervir 3 Hojas en 1 taza de agua. No mezclar con otras Hierbas. Tomar 1 taza por día por 1 semana. 3. Limpiar energía de la casa, Prevención de Infecciones post-parto, Susto en niños / Tallos, fresco / Tópico / Se usa con Ishpinguillo, Hierba del Gallinazo, Ajosquiro y 7 Espiritus. Baño dos veces por mes por adultos y niños. 4. Prevención de Infecciones post-parto / Tallos, fresco / Oral / Hervir 5g en 1 taza de agua. Tomar 1 taza cada día por 1 mes.

LAMIACEAE - Salvia macrophylla Benth.

Cuchichara

Hierba, Andina, Costa, $0-3500 \mathrm{~m}$, maleza

Uso: Hechicería Heridas, Gangrena / Hojas, fresco o seco / Tópico / Tostar y machucar. Poner pulpa sobre herida.

\section{LAMIACEAE - Salvia officinalis L.}

Salvia

Hierba, Andina, Costa, 0-3500m, introducido y cultivado

Uso: Tos, Bronquitis, Regulación de ciclo menstrual / Planta entera, fresco o seco / Oral / Hervir 10g de la planta en 1 litro de agua por 3-5 minutos. Se puede usare mezclado con Matico, Nogal y Eucalipto (10 g cada uno). Tomar caliente, 1 taza 3-4 veces por día como se necesita, hasta una mes.

LAMIACEAE - Salvia officinalis subsp. lavandulifolia (Vahl) Gams

Romero del Campo, Romero Blanco, Romero Serrano

Hierba, Andina, Costa, 0-3500m, introducido y cultivado

Uso: 1. Inflamación, Mal Aire, Energía negativa, Limpia de Casa, Susto, Sinusitis / Planta entera, fresco / Tópico / Hervir 20g total en 1 litro de agua por 20 min con otros Romeros, Salvia y Mejorana. Administra templado y absorber el vapor, inhalar 2-3 veces por mes. 2. Inflamación, Mal Aire, Energía negativa, Limpia de Casa, Susto, Sinusitis / Planta entera, fresco / Tópico / Como alternativa quemar una manojo con carbón, Palo Santo, Incienso, Mirra y Eucalipto. Paciente deben rodearse con los vapores y el humo producido. 3. Inflamación, Mal Aire, Energía negativa, Limpia de Casa, Susto, Sinusitis / Planta entera, fresco / Tópico / Baño: Hervir 1 manojo cada uno en 3 litros de agua con Canchalagua y Cola de Caballo. En aplicación fresca, usar Hoja y Tallo, cuando se usa seco solo la Hoja. Aplicar solo una vez (Martes o Viernes).

LAMIACEAE - Salvia sagitatta Ruiz \& Pav.

Salvia Negra

Arbusto, Andino, 2500-3500m, maleza

Uso: Tos, Asma, Perdida de Cabello / Raíz y Tallos, fresco o seco / Oral / Hervir 10g en 1 litro de agua. Tomar 3 veces por día como se necesit 


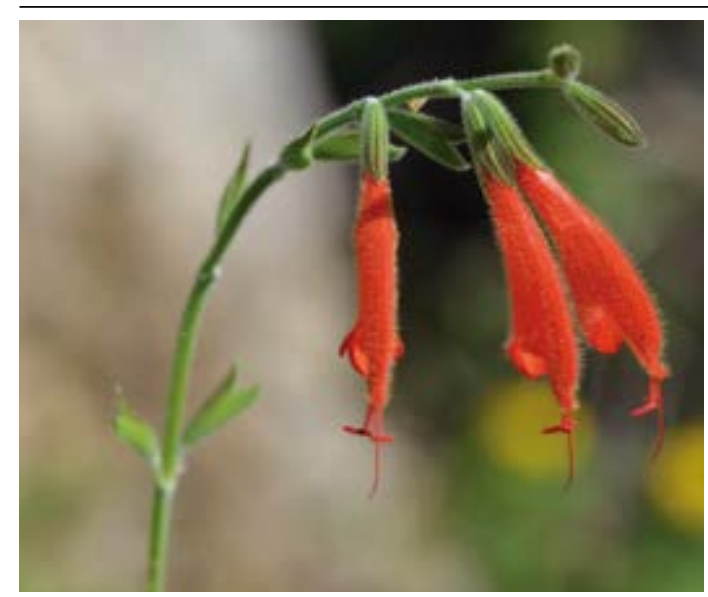

Salvia tubiflora

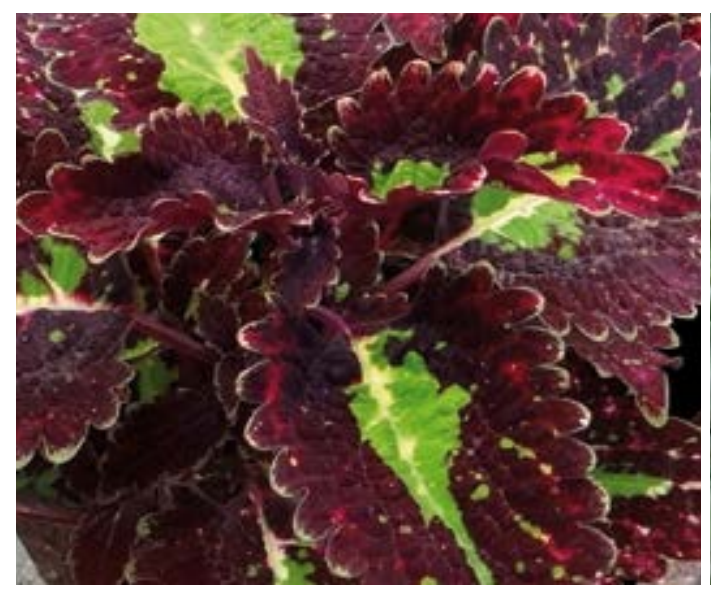

Scutellatia scutellarioides

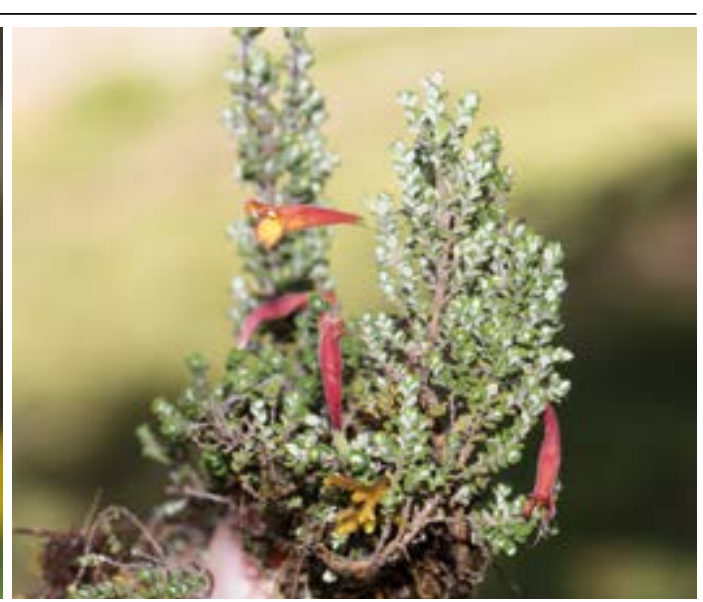

Satureja pulchella

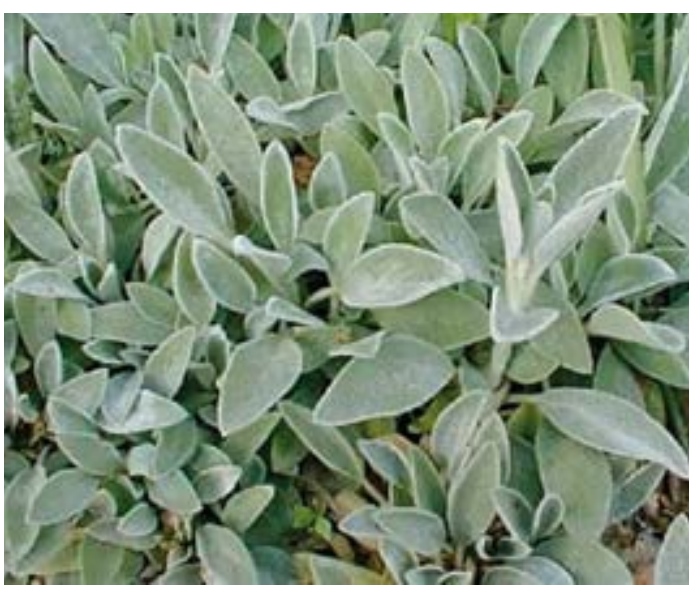

Stachys lanata

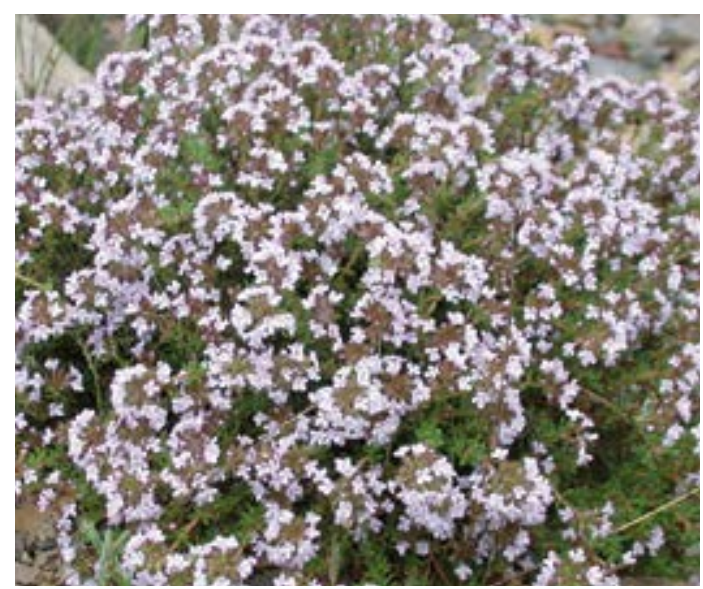

Thymus vulgaris

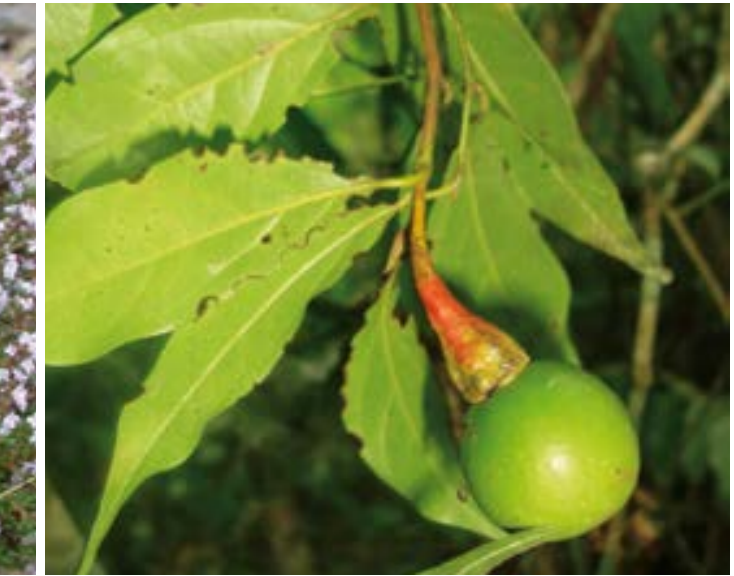

Aiouea dubia
LAMIACEAE - Salvia tubiflora R. \& P.

Hierba de la Recaida, Hierba del Aire, Cutiquero, Yuca del Aire, Paja del Aire

Hierba, Andina, Costa, $0-3500 \mathrm{~m}$, maleza

Uso: 1. Mal Aire, Dolor del Cuerpo / Planta entera, fresco o seco / Oral / Hervir 5g en 1 litro de agua. No mezclar. Tomar 1 taza 3 veces por día. 2. Mal Aire, Aneurisma, Parálisis, Dolor del Cuerpo / Planta entera, fresco o seco / Tópico / Hervir 50g en 1 litro de Aguardiente por 20 minutos. Añadir 1 botella de Agua Florida, 1 botella de Agua Cananga y finalmente llenar la botella con Aguardiente. Baño 3 veces por semana.

LAMIACEAE - Satureja pulchella (Kunth) Briquet

Panisara

Arbusto, Andino, 2500-3500m, maleza

Uso: Bronquitis, Asma, Enfermedad de Hígado, Infección (Interno), Nervios, Retraso menstrual, Vitamina / Hojas, fresco o seco / Oral / Hervir 50g total de Panisara, Culein, Manzanilla y Chancas de Comida en $1 / 2$ taza de agua por $3 \mathrm{~min}$. Tomar la mezcla fría. Tomar $1 / 8$ taza una vez por día por 3 días.

LAMIACEAE - Scutellatia scutellarioides (Kunth) R. Harley

Poleo de Gent

Hierba, Andina, 1000-3500m

Uso: Susto, Daño/Hechicería / Planta entera, fresco / Tópico / Hervir 1 manojo por 5 min en 3 litros de agua por 1 Baño.

\section{LAMIACEAE - Stachys lanata Jacq.}

Veronica (Macho)

Hierba, Andina, 2000-3500m, introducido

Uso: Bronquitis, Asma / Planta entera, seco / Oral / Hervir 10g de Veronica Macho con 1 litro de agua por 5 min. Combinar con Salvia, Matico y Muyaca (10g cada uno). Tomar después de las comidas, 3 tazas por día por 15 días.

LAMIACEAE - Thymus vulgaris $\mathrm{L}$.

Tomillo (Thyme)

Hierba, Andino, Costa, 0-3500m, introducido y cultivado

Uso: Tos, Cólico, Hígado, Gases, Indigestión, Vejiga / Hojas, Tallos y Flores, fresco o seco / Oral / Hervir $5 \mathrm{~g}$ en 1 litro de agua por $3 \mathrm{~min}$. Tomar 3 veces por día.

LAURACEAE - Aiouea dubia (Kunth) Mez

Ishpingo

Árbol, Andino, 500-2000m

Uso: 1. Susto, Mal Aire / Semillas, fresco o seco / Tópico / Machucar y Hervir 20 Semillas en 5 litros de agua por 20-30 min. Mezclar con Ishpingo, Ashango, Pucho, y Amala (20 Semillas cada uno). Baño 3 veces por semana. No dejar el baño fuera de la casa. 2. Mal Aire. Epilepsia / Semillas, fresco o seco / Oral / Machucar Semillas y mezclar con Semillas de 6 otras plantas: Ashango, Pucho, Amala, Quina Quina, Nuez Moscada y Cabalonga. Hervir en agua por 20-30 min. Tomar una vez al mes. 3. Reumatismo / Semillas, fresco o seco / Tópico / Hervir 5 Semillas en 1/2 litro de agua o Agua Florida. Frotar área afectadas una vez por día. 


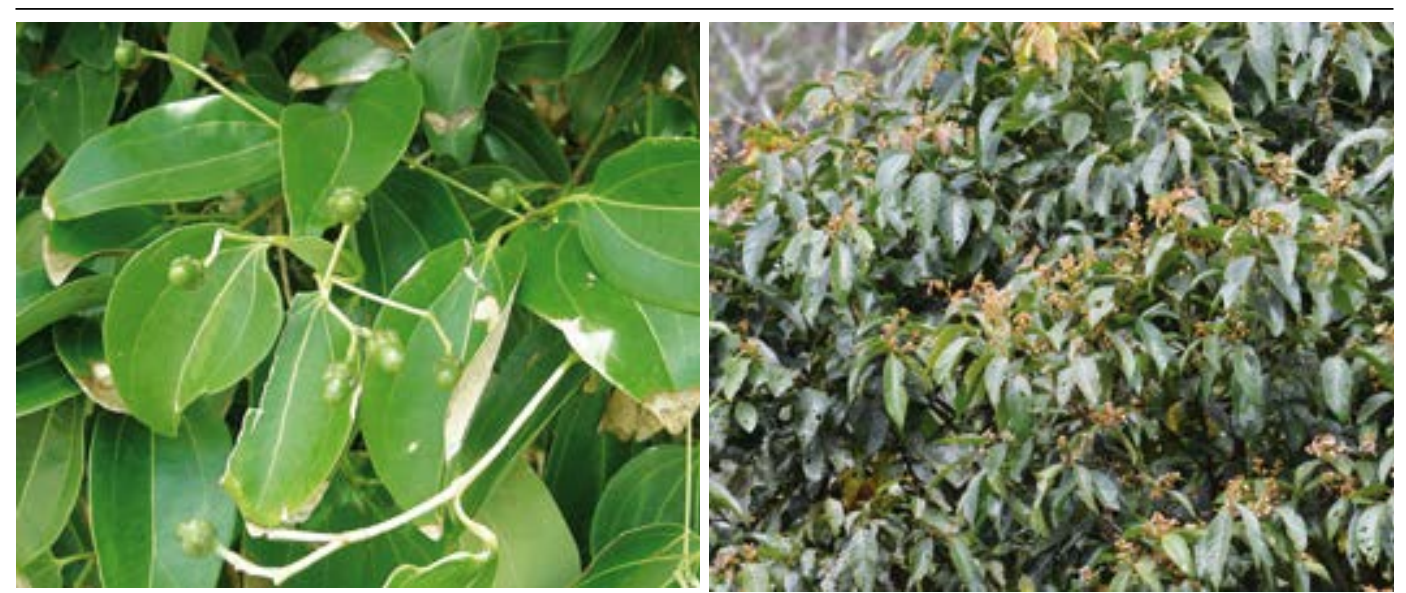

Cinnamonum verum

Nectandra reticulata

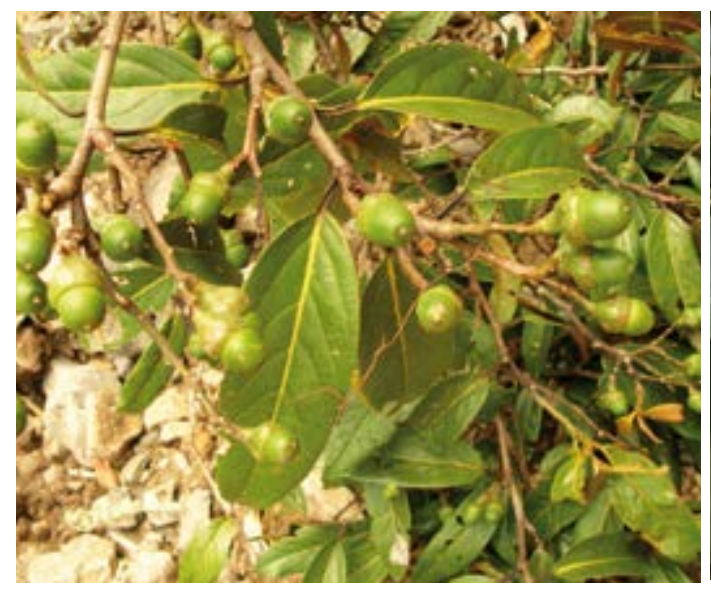

Nectandra sp.

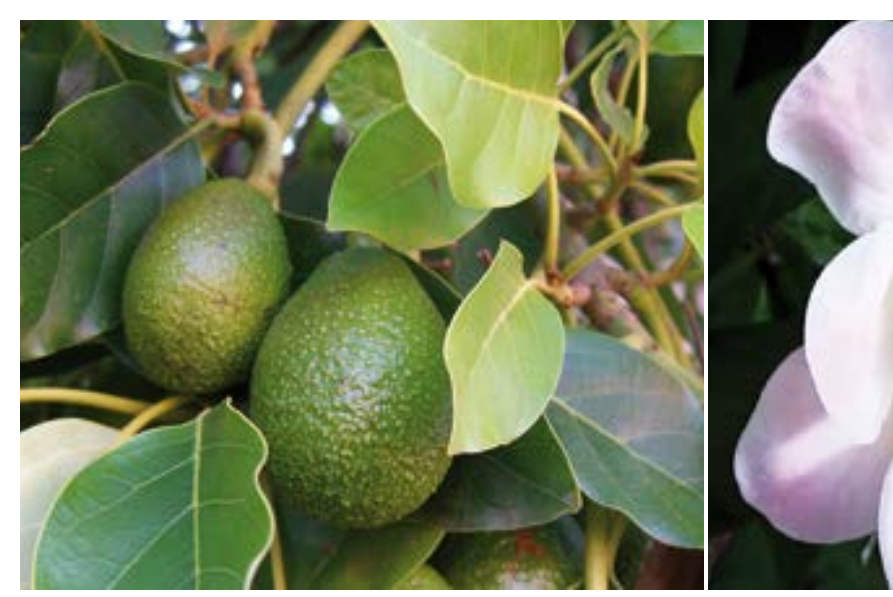

Persea americana

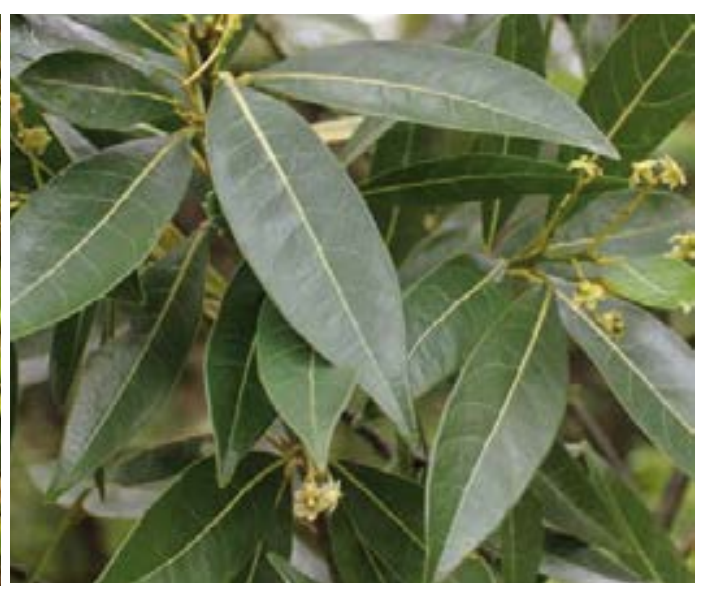

Ocotea floribunda

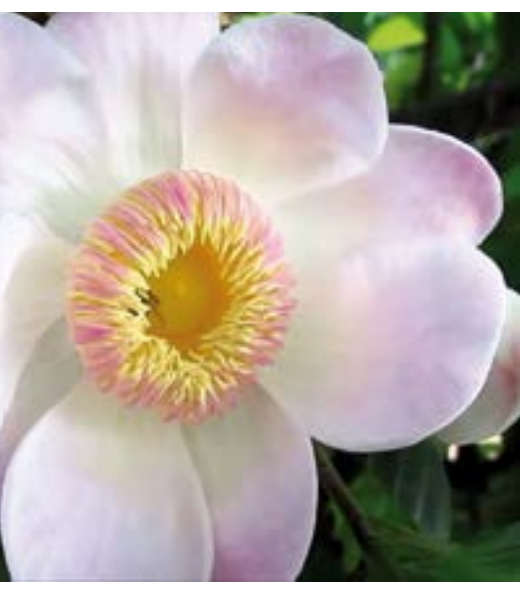

Gustavia augusta

\section{LAURACEAE - Cinnamonum verum J. Presl.}

Canela (Cinammon)

Árbol, Amazónico, 0-500m, introducido y cultivado

Uso: 1. Buena Suerte, Amor, Encantamiento / Corteza, seco / Tópico / Mezclar 1 litro de agua con 10g de Canela, Pétalos de Rosa (Rojo, Blanco, Amarillo), Ramillete de Novia, Agua Florida, Azúcar y Jugo de Lima de 1 Lime. Hervir por 2-5 minutos. Tomar a Baño con extracto 3-4 veces por mes. Como alternativa moler y pulverizar 100g. Frotar polvo sobre el cuerpo entero, rezando y desear por la persona alquilen anhela de, 4 veces por semana o como se necesita. 2. Bronquitis, Recuperar de rituales de toda la noche / Corteza, seco / Oral / Hervir 1 diente de ajo, 10g total de Matico, Veronica, Brochamelia y Vira Vira con $3 \mathrm{~g}$ de Canela en 1 litro de agua por 3-4 minutos. Tomar caliente, 3-4 veces por día como se necesita. Tomar frío después de un ritual en la mañana durante el desayuno.

LAURACEAE - Nectandra reticulata (Ruiz \& Pav.) Mez.

Ishpingo, Espingo-blanco, Espingo

Árbol, Amazónico, Andino, $0-2500 \mathrm{~m}$
Uso: 1. Sistema nervioso / Semillas, fresco o seco / Oral / Hervir 10g total de Ishpingo, Hierba de Chocho, Cordón del Muerto, Claveles y Eucalipto en 1 litro de agua por 3 min. Bańo y frotar cuerpo, 3 veces solo. 2. Susto / Planta entera, fresco o seco / Tópico / Moler 100g de Ashango y 100g total de Ishpingo, Cedrón Semillas, Samala y Quina Quina. Soplar polvo sobre cara de paciente, 2 veces por
semana por 4 meses.

\section{LAURACEAE - Nectandra sp.}

Samala, Asmala, Amal

Arbol, Amazónico, Andino, 0-2500m

Uso: 1. Susto, Mal Aire, Sistema nervioso, Encantamiento, Daño/Hechicería (Curar), Epilepsia / Semillas, secas o fresco / Tópico / Moler y Hervir 20 Semillas en 5 litros de agua por 10 minutos. Baño 2 veces por semana (Martes y Viernes) por 1 mes. 2. Susto, Mal Aire, Sistema nervioso, Encantamiento, Daño/ de agua por 8 días. Tomar 3-4 pequeñas tazas por día por 7 días. Se puede también macerar Semillas en de agua por 8 dias. Tomar $3-4$ pequenas tazas por día por 7 dias.
Aguardiente por 5 días y tomar, $5 \mathrm{~g} 3$ veces por día por 1 semana.

LAURACEAE - Ocotea floribunda (Sw.) Mez

Ishpino, Flor de Ishpingo, Hierba de Ishpingo

Uso: 1. Mal Aire, Epilepsia / Semillas y Corteza, fresco o seco / Oral / Mezclar con Semillas de 6 otras plantas: Ashango, Pucho, Amala, Quina Quina, Nuez Moscada, y Cabalonga. Hervir 5 Semillas de cada uno en $1 / 2$ litro de agua por 20 min. Tomar 1 litro una vez al mes por prevención; 7-15 días una vez por día por enfermedad. 2. Susto, Mal Aire, Nervios, Epilepsia, Encantamiento / Hojas y Flores, fresco o seco / Tópico / Limpia: Combinar 1 Hoja y 1 Flor de Ishpingo con Timolina y Vinagre. Aplicar 3 veces por semana. Bańo: 20g en 3-5 litros de agua hervido por 20-30 minutos y mezclado con Ajenco, Ruda, (1 Hoja y 1 Flor de cada uno), 3 veces por semana por enfermedad o una vez al mes por prevención.

LAURACEAE - Persea americana Mill.

Palta Árbol, Amazónico, Andino, 0-1500m, cultivado

Uso: 1. Pérdida de Peso / Hojas, fresco o seco / Oral / Hervir 1/2 litro de agua con 10 Hojas de Palta por 3 minutos. Paciente debe tomarlo caliente, 1 taza 2-3 veces por día por $1-2$ meses. 2. Diarrea, Cálculos de los Riñones, Contraceptivo, Esterilización (solo mujeres) / Semillas, fresco / Oral / Moler 1 Semilla de los Rinones, Contraceptivo, Esterilización (solo mujeres) / Semillas, fresco / Oral / Moler 1 Semilla templado, 1 taza 4 veces por día por a mes. Para una mujer tratando de esterilizarse, 3 veces seguidos vaya lograr la medida. 3. Tos / Flores, fresco / Oral / Hervir Flores de Palta en agua. Paciente debe tomarlo templado, $1 / 2$ a taza 3 veces por dia por semana.

LECYTIDACEAE - Gustavia augusta L.

Chope

Uso: Alergias, Irritación de la piel, Espinillas, Urticaria / Hojas, fresco / Tópico / Calentar 300g de Hojas de Chope con $20 \mathrm{~g}$ de caliza en un sarten por $3 \mathrm{~min}$. Poner cliente en área afectada y masajear dos veces por dia. 


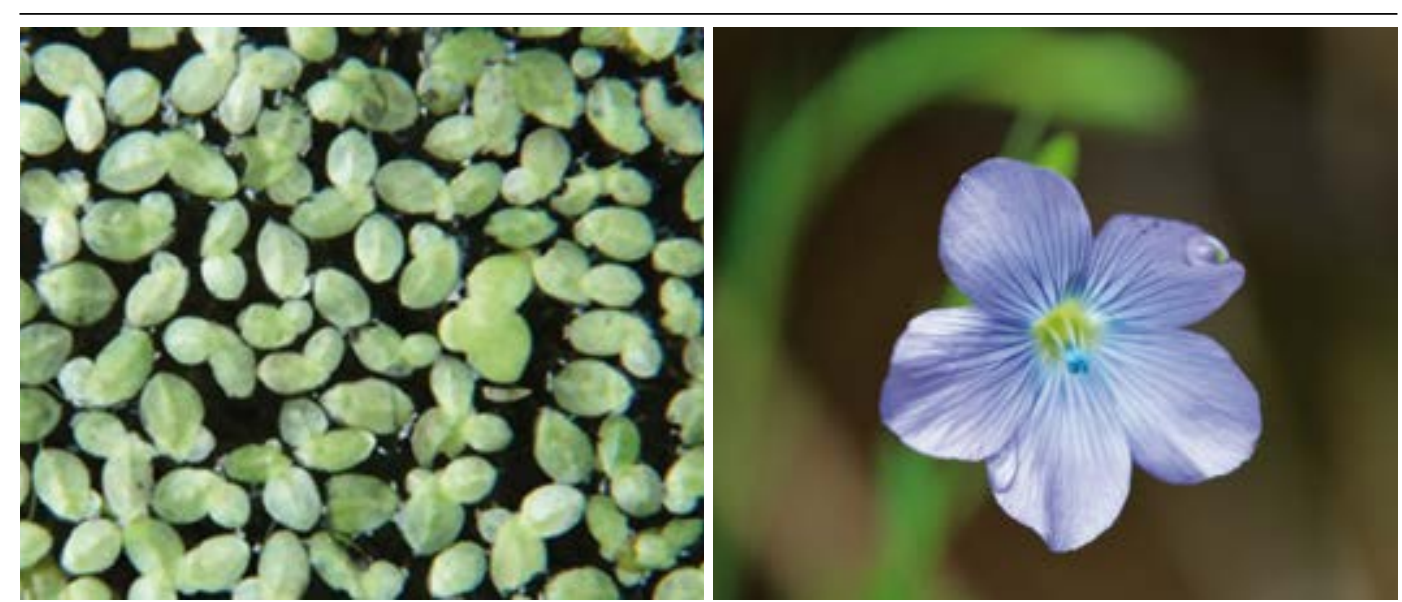

Lemna minuta

Linum sativum

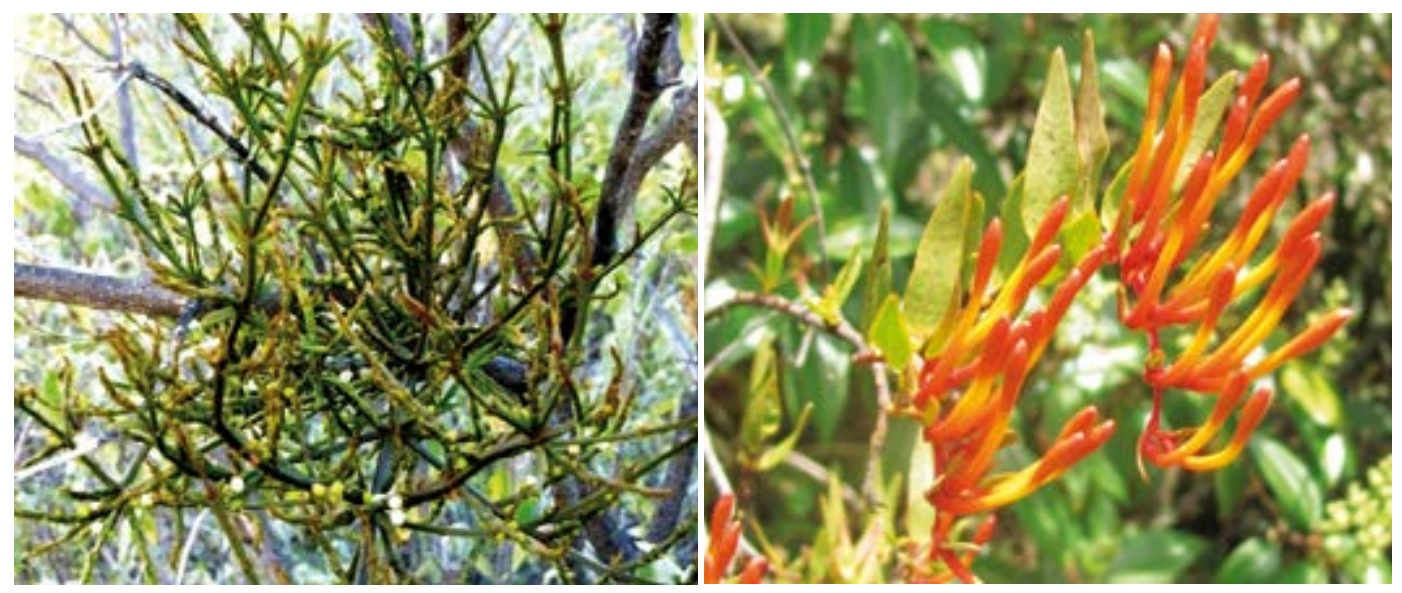

Psittacanthus chanduyensis

Tristerix longebracteatus

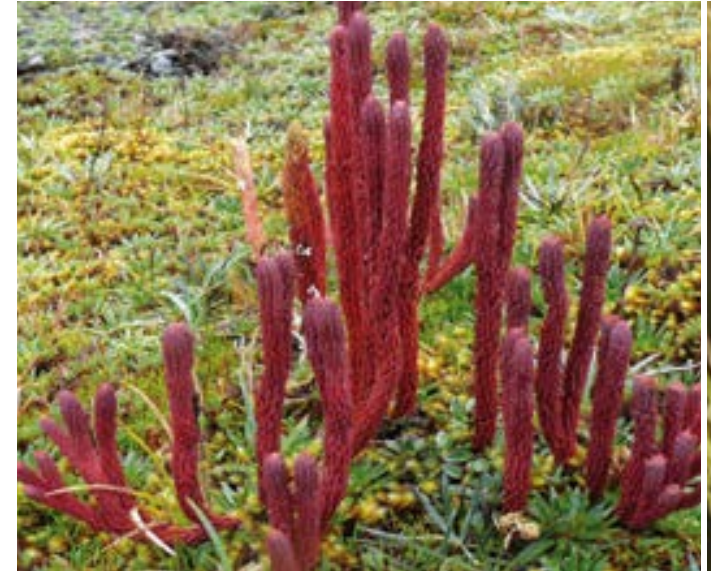

Huperzia crassa
LEMNACEAE - Lemna minuta Kunth

Flor de Agua

Hierba, Andina, 2000-3000m

Uso: Úlceras, Inflamación del Estómago. / Planta entera, fresco / Tópico / Hervir planta entera con agua hasta extraer 2 cuchara de liquido. Poner sobre Estómago con 2 claros de huevo. Usar por 4 horas como Emplasto.

LINACEAE - Linum sativum L., Linum usitatissimum L.

Linaza

Hierba, Andina, Costa, 0-3500m, cultivado

Uso: Inflamación de Riñones, Inflamación del hígado, Inflamación de próstata, Cálculos de Vejiga, Cálculos de riñones / Semillas, secas / Oral / Mezclar 5o de Linaza con 10g total de Cola de Caballo, Chanca Piedra, Caña Caña, Boldo y Overo. Hervir la mezcla por 5 minutos. Dejar mezcla resfriar. Tomar 1 taza, 3-4 veces por día por 2 semanas a 1 mes. Tomar templado.

LORANTHACEAE - Psittacanthus chanduyensis Eichler

Suelda con Suelda

Arbusto, Parásito, Costa, $0-1000 \mathrm{~m}$

Uso: Fracturas, Torceduras / Hojas y Tallos, fresco / Oral, Tópico / Hervir 5g en 1 litro de agua por 3 min. Té: 1 litro por día por 1 mes. Emplasto: 2 veces por mes.

LORANTHACEAE - Tristerix longebracteatus (Desr.) Barlow \& Wiens Suelda con Sueld

Arbusto, Parásito, Andino, 2000-4500m

Uso: Huesos (falta de calcio), Descargo vaginal, Huesos (Fracturas) / Planta entera, seco / Oral / Añadir $10 \mathrm{~g}$ de material de la planta a $5 \mathrm{~g}$ de Uńa de Gato, Diego Lope y 1 litro de agua. Hervir la mezcla por 4 minutos. Tomar la mezcla templado. Tomar 1 taza, 3 veces por día por 1 mes.

LYCOPODIACEAE - Huperzia crassa (H. \& B. ex Willd.) Rothm.

Condor, Condor Amarillo, Condorcillo, Condorcilla, Condor Rojo, Condor Verde

Licopodio, Andino, 3000-4500m

Uso: 1. Buena Suerte y Éxito en Viajes, Fragancia, Mal Aire / Hojas y Tallos, fresco / Seguro / Poner 3 pequeñas Ramas con Hojas en botella de Seguro. 2. Buena Suerte y Éxito en Viajes, Fragancia, Mal Aire / Hojas y Tallos, fresco / Tópico / Hervir 20g en 5 litros de agua por 20 minutos combinado con Hierbas de Fuerza y Suerte. Baño 2-3 veces por semana durante la noche.

LYCOPODIACEAE - Huperzia columnaris B. Øllg.

Hornamo Condor Purga

Lycopodium, Andino, 3000-4500m

Uso: Laxante / Hojas y Tallos, fresco / Oral / por 20 pacientes Hervir 2 San Pedros (1 de 7 costillas y 1 de 8 costillas) y 100g de Cóndor Purga en 4 litros de agua por 3 horas. Tomar frío, 1/2 taza solo una vez. 

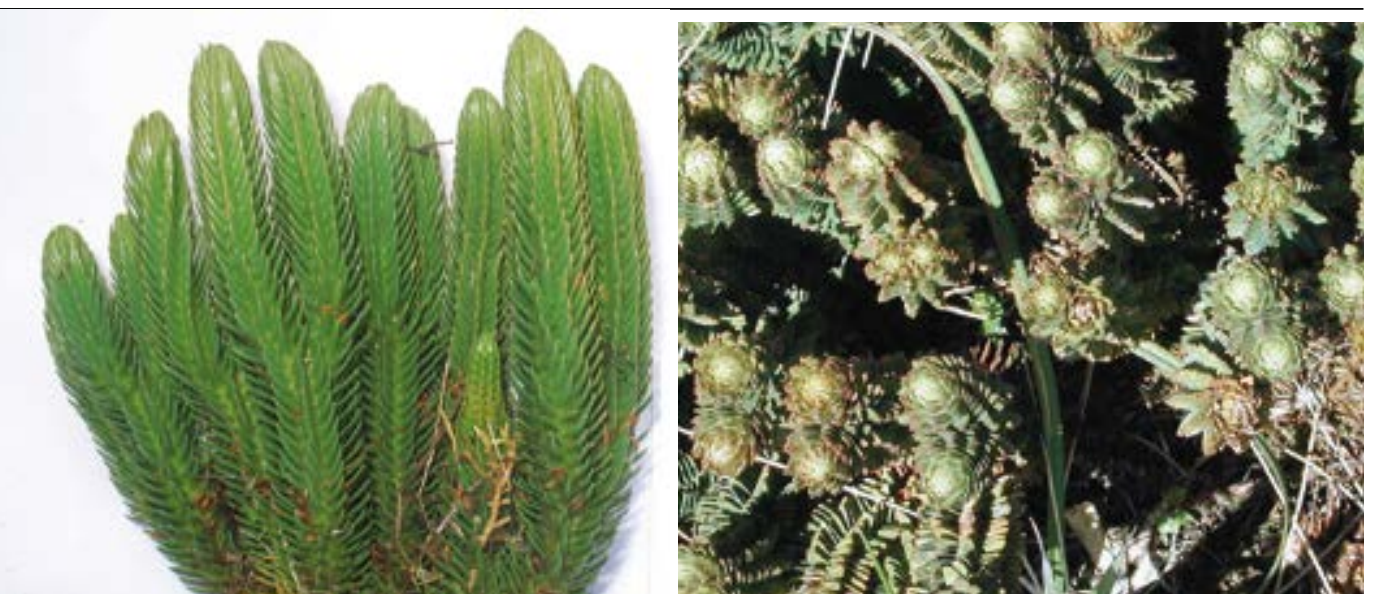

Huperzia hohenackeri

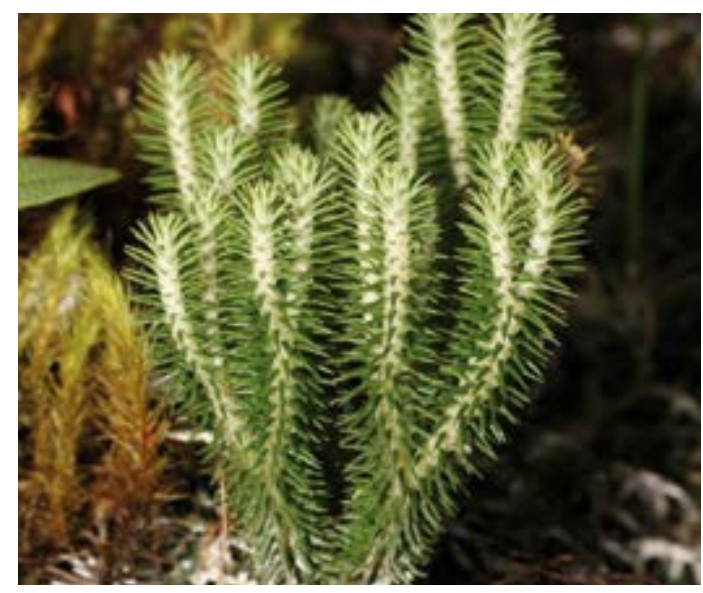

Huperzia reflexa

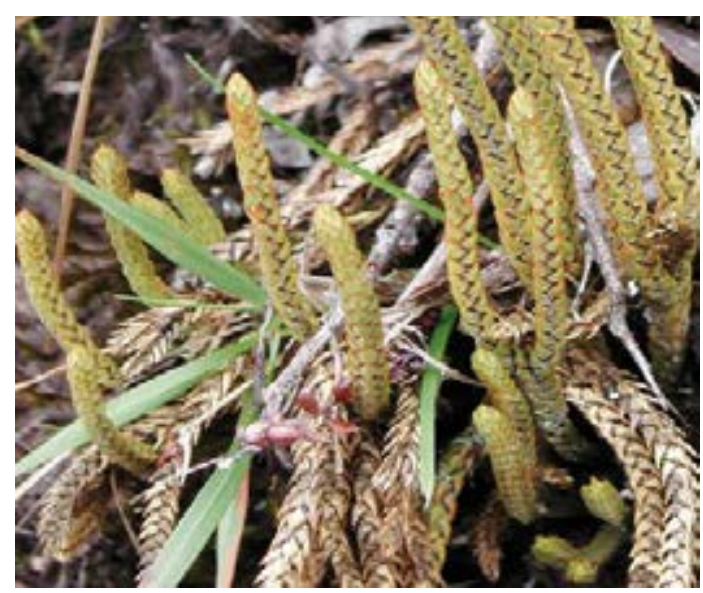

Huperzia tetragona
Huperzia kuesteri

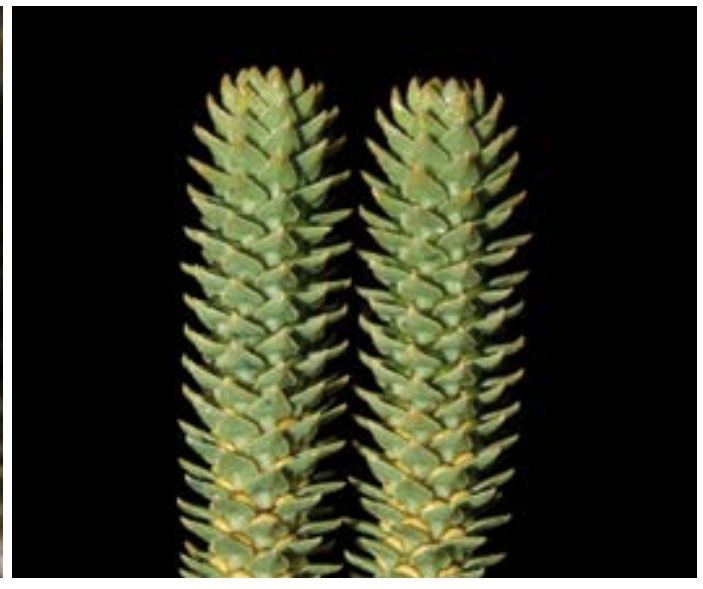

Huperzia sellifolia

Lycopodium clavatum

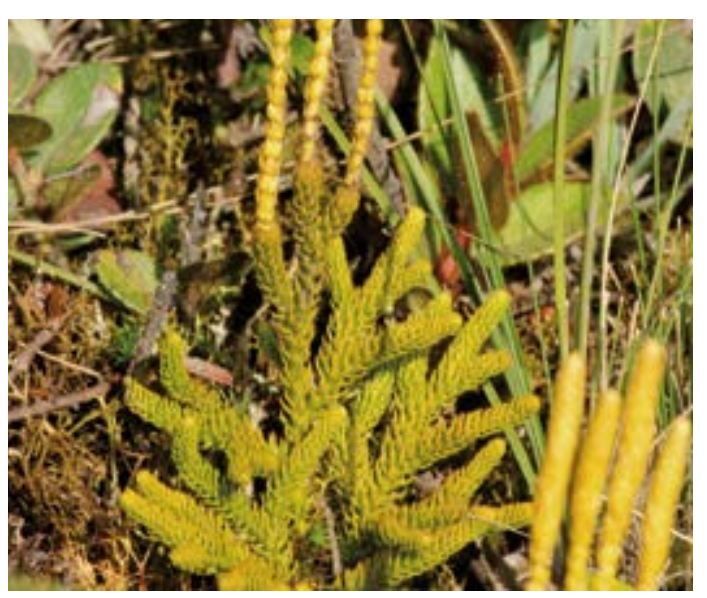

LYCOPODIACEAE - Huperzia hohenackeri (Herter) Holub

Guaminga, Huaminga

Licopodio, Andino, 3000-4500m

Uso: 1. Susto, Purgante, Mal Aire, Éxito en Trabajo, Éxito en Amor / Planta entera, fresco o seco / Oral

/ Hervir $5 \mathrm{~g}$ en 1 litro de agua. Tomar una vez por día. 2. Susto, Purgante, Mal Aire, Éxito en Trabajo,

Éxito en Amor / Planta entera, fresco o seco / Seguro / Seguro: Usar 7 pequeñas plantas por Seguro.

LYCOPODIACEAE - Huperzia kuesteri (Nessel) B. Øllg.

Condor Lasio, Trensa Hermosa, Condor Crespo, Condor Cimuro, Condor

Licopodio, Andino, 3000-4500m

Uso: 1. Suerte, Fragancia, Sobrepasar Hechicería, Éxito en Trabajo y Amor / Planta entera, fresco o seco

/ Tópico / Hervir en 1 taza de agua por 10 min 3 Hojas de las plantas siguientes: Cóndor Simuro, Misha

Galga y Cimora Curandera. Mezclar con $150 \mathrm{ml}$ de los siguientes perfumes: Jardín España y Tabú con una botella de $300 \mathrm{ml}$ de Agua Florida y una botella de $300 \mathrm{ml}$ de Cananga. Tomar frío. Paciente debe quedarse en un cuarto oscuro, aislado, con dieta sin especies por 3 días. 2. Suerte, Fragancia, Sobrepasar Hechicería, Éxito en Trabajo y Amor / Planta entera, fresco o seco / Seguro / Poner 7 pequeñas Ramas en la botella de Seguro.

LYCOPODIACEAE - Huperzia reflexa (Lam.) Trevis.

Condor Mulato, Enredader

Licopodio, Andino, 3000-4500m

Uso: Fragancia, Buena Suerte, Prevenir alquilen de salir, Hacer alquilen regresar / Hojas y Raíces, fresco / Tópico / Hervir 20g en 1 litro de agua por 30 minutos con Hierbas de Fuerza. Bańo 3 veces por semana.

LYCOPODIACEAE - Huperzia sellifolia B. Ollg.

Condor Crespo

Licopodio, Andino, 3000-4500m

Uso: Suerte, Fragancia / Planta entera, fresco o seco / Tópico / Hervir 10g en 1 litro de agua por $30 \mathrm{~min}$. Bańo dos veces por mes en la noche.

LYCOPODIACEAE - Huperzia tetragona (Hook. \& Grev.) Trevis. Trencilla Roja

Licopodio, Andino, 3000-4500m

Uso: Fracturas, Buena Suerte / Tallos, seco / Tópico / Hervir 20g en 5 litros de agua por 20 minutos y mezclar con Hierbas de Fuerza como Hórnamos y Maiques. Baño 3 veces por semana.

LYCOPODIACEAE - Lycopodium clavatum L.

Rastera

Licopodio, Andino, 1500-4500m

Uso: 1. Éxito en Trabajo / Planta entera, fresco o seco / Oral / Hervir 5g en 1 litro de agua. Tomar una vez por día. 2. Éxito en Trabajo / Planta entera, fresco o seco / Seguro / Seguro: Usar 7 pequeñas plantas por Seguro. 


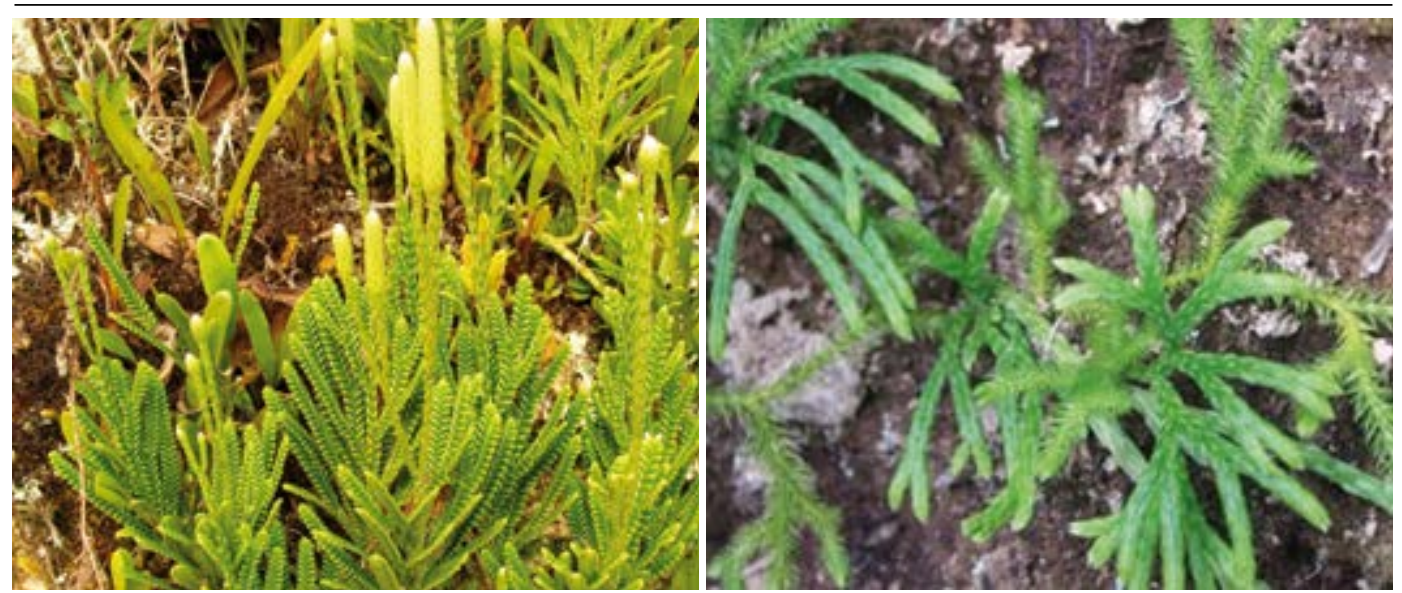

Lycopodium jussiaei

Lycopodium thyoides

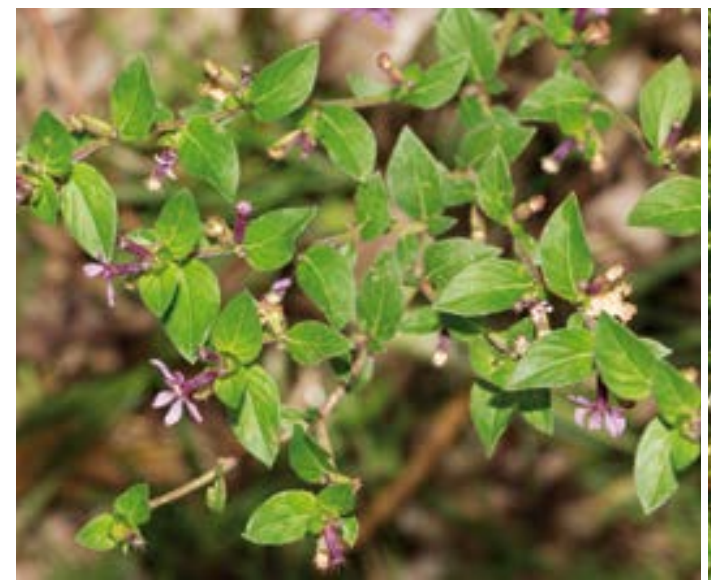

Cuphea strigulosa

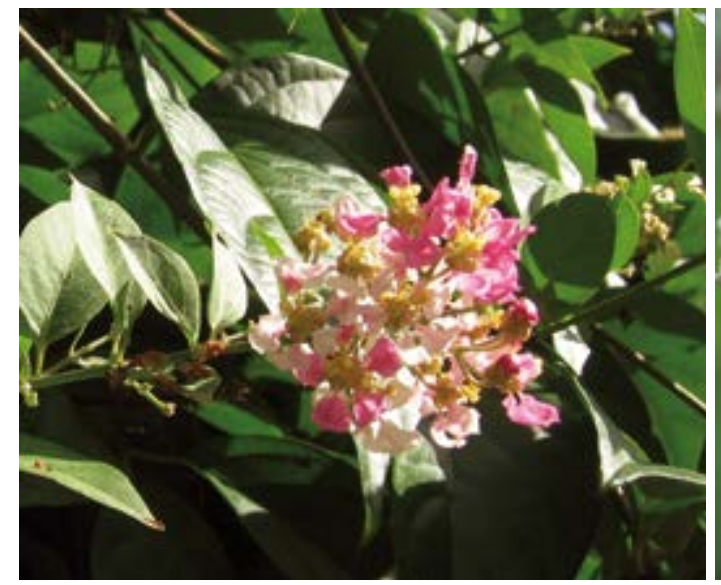

Banisteriopsis caapi

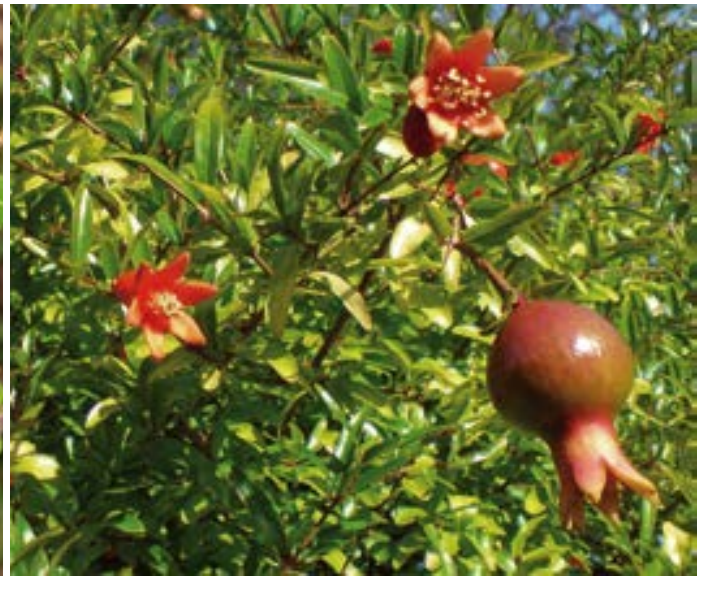

Punica granatum

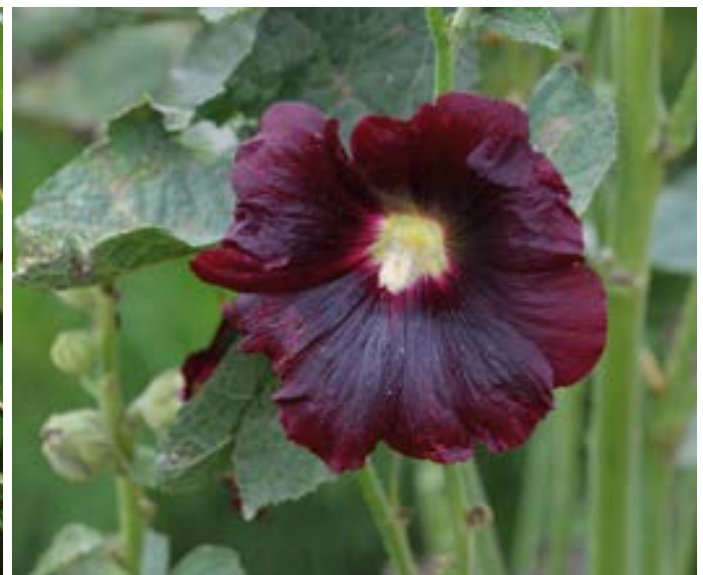

Alcea rosea
LYCOPODIACEAE - Lycopodium jussiaei Desv. ex Poir

Hierba del Hombre, Rastrera

Licopodio, Andino, 3000-4500m

Uso: 1. Éxito en Trabajo / Planta entera, fresco o seco / Oral / Hervir 5g en 1 litro de agua. Tomar una vez por día. 2. Éxito en Trabajo / Planta entera, fresco o seco / Seguro / Seguro: Usar 7 pequeñas plantas por Seguro.

LYCOPODIACEAE - Lycopodium thyoides H. \& B. ex Willd.

Trencilla Roja

Licopodio, Andino, 3000-4500m

Uso: Buena Suerte, Mal Aire, Éxito en Amor y Negocios / Tallos, seco / Tópico / Hervir 20g en 5 litros de agua por 20 minutos y mezclar con Hierbas de Fuerza como Hórnamos y Maiques. Baño 3 veces por seman

\section{LYTHRACEAE - Cuphea strigulosa H.B.K.}

Lancetilla, Sanguinaria, Hierba del Toro

Hierba, Amazónica, Andino, 0-1500m, maleza

Uso: 1. Florecimiento / Hojas y Tallos, fresco / Tópico / Mezcla Alternativa para Florecimiento. Baño una vez solo. 2. Buena Suerte / Hojas y Tallos, fresco / Seguro / Mezcla Estándar para Seguro. 3. Circulación de sangre, Fiebre, Purificación de la Sangre, Infecciones Intestinales, Corazón, Sistema nervioso, Hígado, Cólico, Gas, Diarrea, Inflamación del Estómago, Riñones, Inflamación interna, Fortalecer el cuerpo, Anemia, Mal Aire / Hojas y Tallos, fresco / Oral / Hervir 5-20g en 1 litro de agua por 3 minutos. Combinar con $5 \mathrm{~g}$ cada uno de Congona, Claveles, Madre Selva, Ortiga, Moradilla, Contrahierba, Colores, Agujilla, Pie de Perro, Cola de Caballo, Verbena, Pimpinela, Flor Blanca, Grama Dulce, Esencia de Rosa y Cadillo. Tomar 3 veces por día, 1 litro cada día por 1 semana a 3 meses. Tomar antes de comer.

LYTHRACEAE - Punica granatum L.

\section{Granoda}

Árbol, Amazónico, Andino, Costa, 0-2500m, introducido y cultivado

Uso: Diarrea / Cáscara del Fruto, fresco / Oral / en 1 litro de agua Hervir por 3-5 minutos 3/4 de la Cáscara de Fruta y mezclar con $10 \mathrm{~g}$ cada uno de Hinojo y Semilla molida der Palta. Tomar 1 vaso, templado 3-4 veces por día por 2 semanas.

MALPIGHIACEAE - Banisteriopsis caapi (Spruce ex Grieseb.) Morton

Ayahuasca, Ayahuasca Verde, Ayahuasca Amarilla

Liana, Amazónico, 0-500m

Uso: Mejorar visión durante rituales / Corteza, fresco o seco / Oral / Hervir 20g de Corteza en 1 litro de agua de 12 hasta 4 de la tarde sobre fuego lento, incrementando la temperatura hasta el fin. Tomar templado, 1 pequeńa taza durante el ritual. Se debe ayunar 24 horas antes de tomarlo. Paciente no puede tomar si esta menstruando.

MALVACEAE - Alcea rosea (L.) Cavanilles

Malva Blanca, Malva Morada

Hierba, Andino, 2500-3500m, introducido y cultivado

Uso: Inflamación, Tos, Hemorragias / Planta entera sin Tallos, fresco / Oral / Hervir 10g en 1 litro de agua 5 min. Tomar 3 veces por día como se necesita 

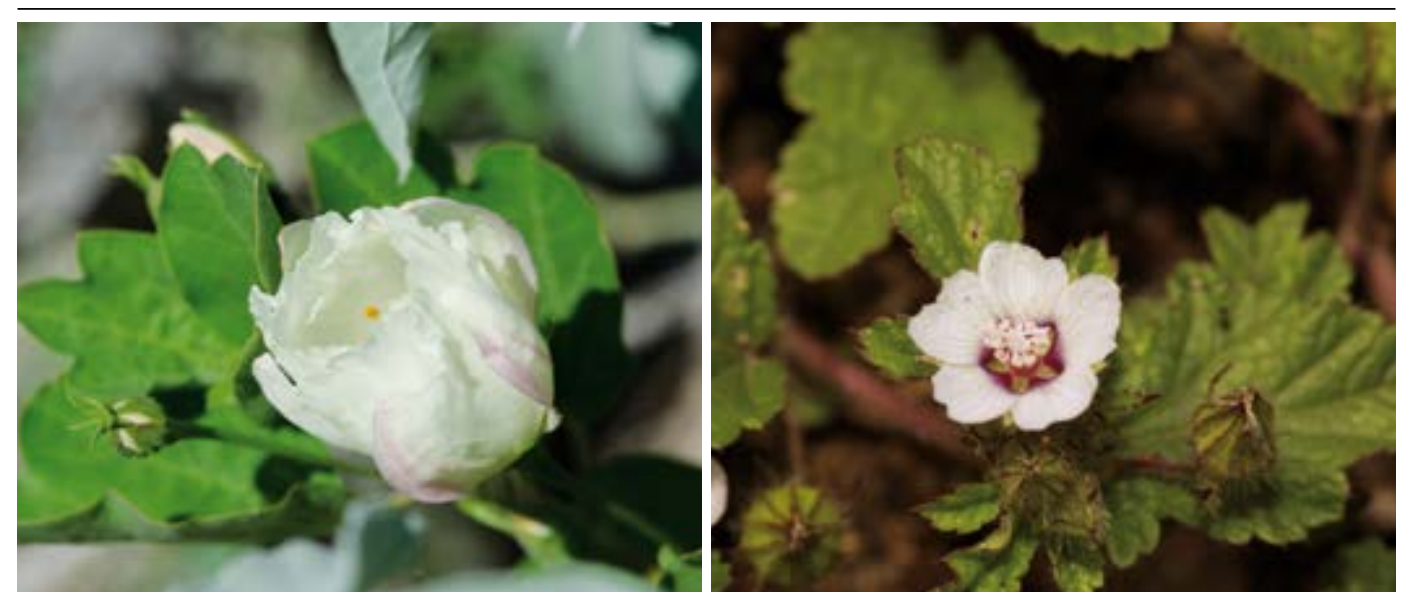

Gossypium barbadense

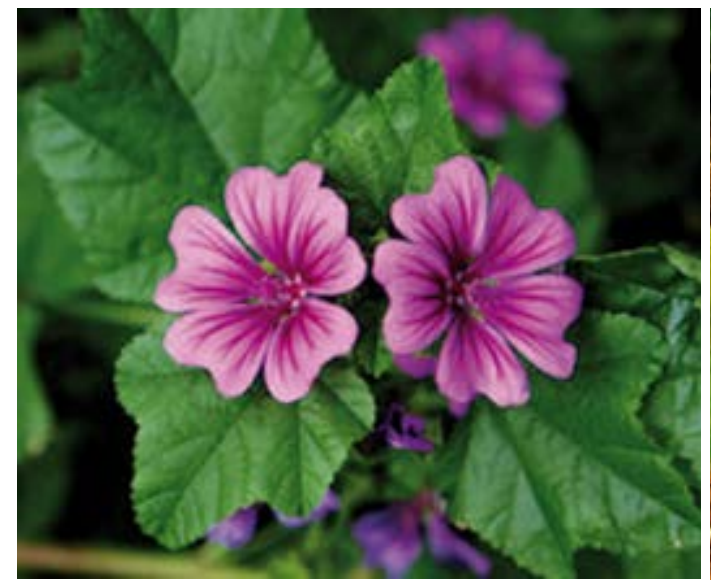

Malva sylvestris

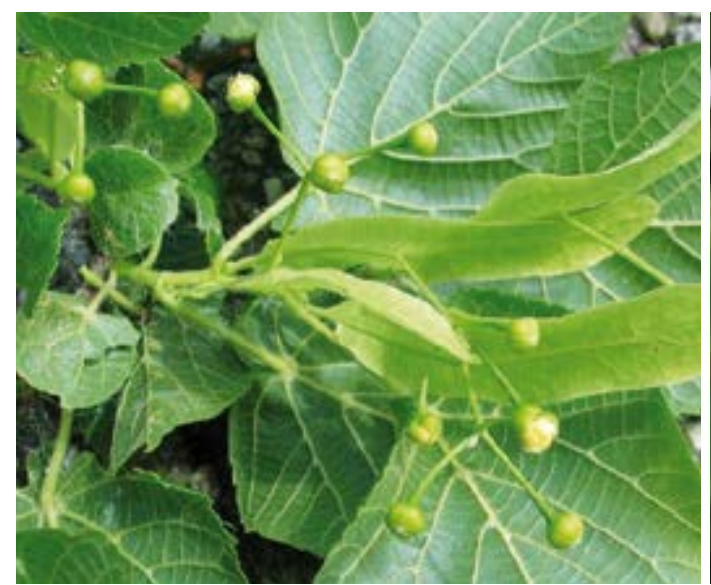

Tilia platyphyllos
Malva parviflora

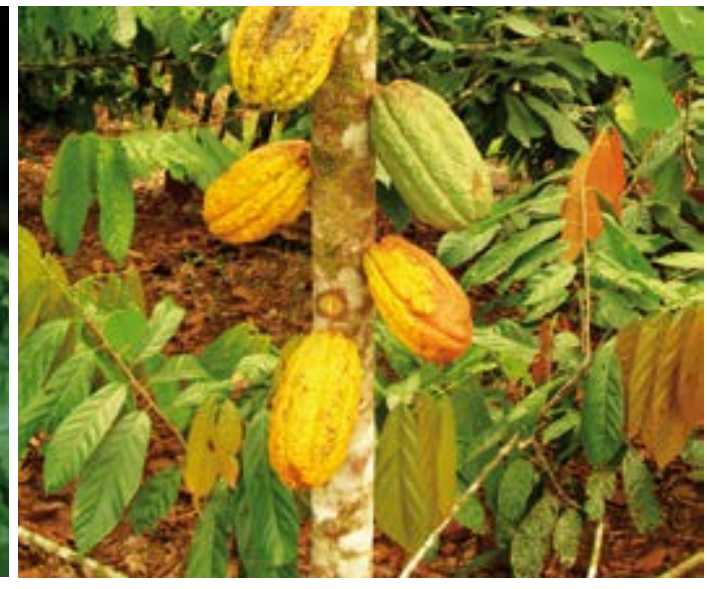

Theobroma cacao

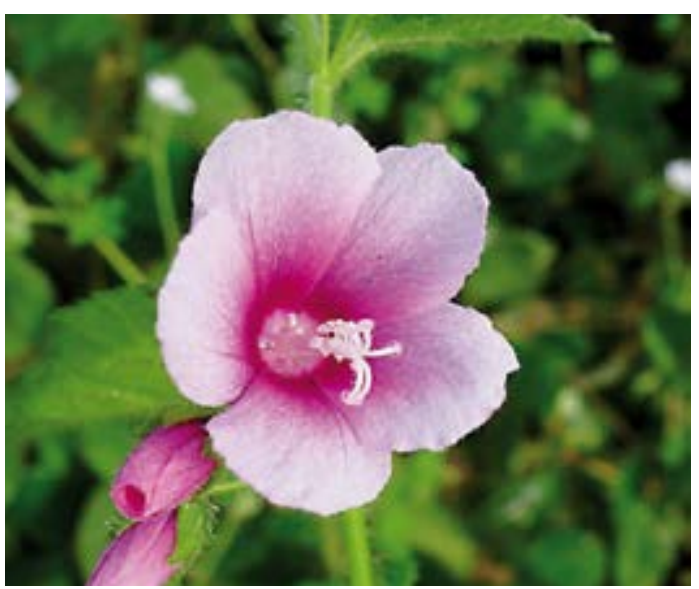

Urena lobata

\section{MALVACEAE - Gossypium barbadense L.}

Algodón Pardo, (Brown Cotton)

Hierba, Amazónica, Andina, Costa, 0-2500m, maleza, cultivado

Uso: 1. Mal Ojo (Niños) / Pelo de Semilla, seco / Tópico / Remover Semillas y Combinar con una mezcla de los corazones de 2 Totoras machucadas, 2 Ajíes y un huevo intacto. Frotar el paciente con el algodón y pasar por el cuerpo. Usar el algodón sin semillas para hacer una cruz sobre el paciente. Después Quemar el algodón en un lugar lejano. Si el algodón disuelve durante la frotación el paciente esta muy enfermo. Dejar el contenido del huevo caer en un vaso de agua y busca seńales de enfermedad en ello. 2. Heridas (Externo) / Semillas, fresco / Tópico / Moler 200g de Semillas y extraer aceite. Poner sobre área afectada una vez por día hasta se sana.

\section{MALVACEAE - Malva parviflora L.}

Malva Rosa, Malva Real

Hierba, Amazónica, Andina, Costa, 0-4000m, maleza

Uso: 1. Hígado, Inflamación (General), Tos, Bronquitis, Tozar sangre / Hojas, fresco / Oral / Combinar 1 litro de agua con $10 \mathrm{~g}$ cada uno de Pie de Perro, Chacuro, Verbena, Cola de Caballo, Amor Seco y Linaza. También ańadir 3-4 Hojas de Malva. Hervir la mezcla por 3 minutos. Paciente debe tomar templado. Tomar 1 taza 3-4 veces por día por 1 mes. 2. Hígado, Inflamación (General), Tos, Bronquitis, Tozar sangre / Hojas, fresco / Tópico / Aplicado como Emplasto.

MALVACEAE - Malva sylvestris L.

Malva (Chica), Malva Blanca

Hierba, Costa, 0-500m, maleza, introducido

Uso: 1. Susto, Mal Aire, Corazón, Nervios, Tachycardia, Epilepsia (Estado inicial) / Hojas y Tallos, fresco o seco / Oral / Hervir 20g en 1 litro de agua por 3 minutos. Mezclar con 10g cada uno de Toronjil, Pimpinela, Mejorana, Pensamiento y Cedrón. Tomar 1 litro por día por 15 días. 2. Heridas, Limpia vaginal / Hojas y Tallos, fresco o seco / Tópico / Baño: Hervir 20g en 2 litros de agua por 20 minutos. Lavar 3 veces por semana. 3. Limpia de intestinos / Hojas y Tallos, fresco o seco / Tópico / Hervir 10$15 \mathrm{~g}$ cada uno en 1 litro por 10 minutos combinado con Conchalagua, Amaro y Chicoria. Aplicar como Enema una vez al mes.

MALVACEAE - Theobroma cacao L.

Cacao

Árbol, Amazónico, Andino, Costa, 0-1500m, cultivado

Uso: Inflamación de Riñones / Cáscara del Fruto, seco / Oral / Hervir 1 litro de agua y añadir 10g de Cacao. Hervir 2-3 min. Tomar caliente, 1 taza 3 veces por día por 1 mes.

MALVACEAE - Tilia platyphyllos Scop.

Tilo

Árbol, Andino, Costa, 0-2500m, introducido y cultivado

Uso: Nervios, Tos, Resfrío, Fiebr e, Insomnio / Flores y Hojas, fresco / Oral / Hervir 1 litro de agua. Añadir $10 \mathrm{~g}$ cada uno de Sauco, Manzanilla, Hinojo, Coleo, Ajenco, Toronjil, Pimpinela y Claveles. Cubrir y dejar por 2-3 minutos. Paciente debe tomarlo caliente, 3-4 tazas por día por 1 mes.

MALVACEAE - Urena lobata L.

Buenas Horas

Hierba, Amazónica, Andina, Costa, 0-2000m, maleza

Uso: Enfermedad mental, Perdida de memoria, / Planta entera, fresco / Oral / Colectar planta en la tarde. Hervir $100 \mathrm{~g}$ de la planta en 1 taza de agua por 5 minutos. Tomar frío, $1 / 2$ taza antes de dormir una vez por día por 15 días o como se necesita. 


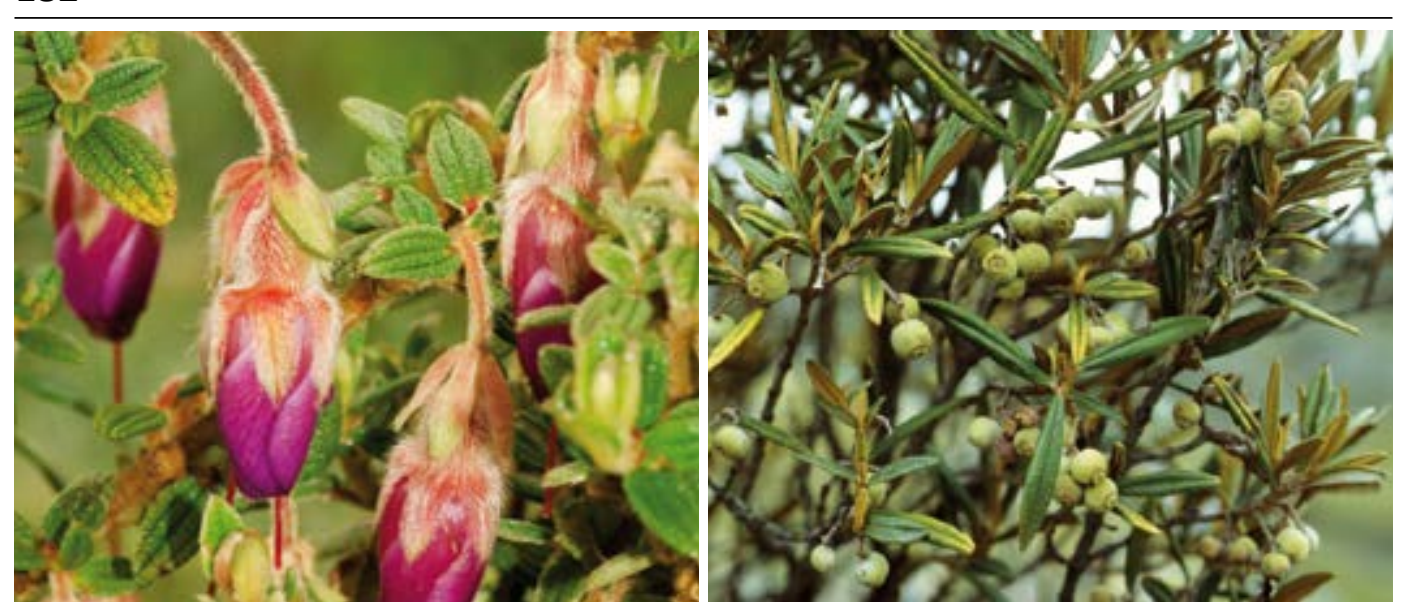

Brachyotum tyrianthinum

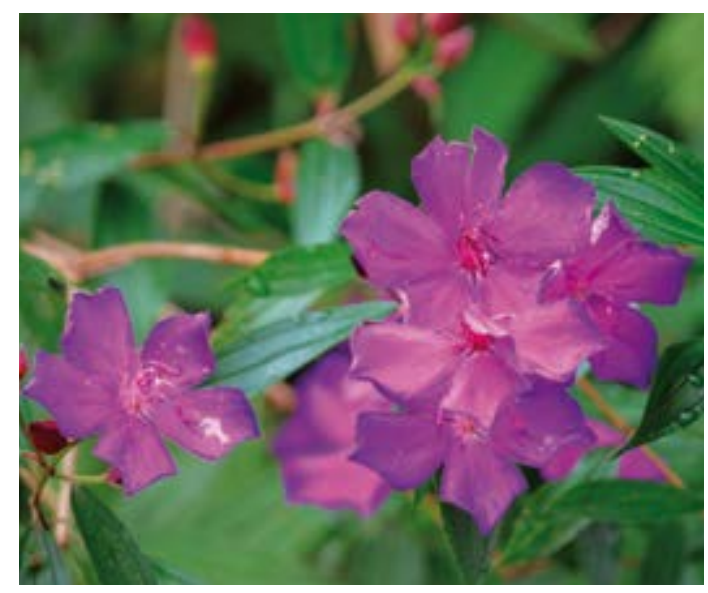

Tibouchina laxa

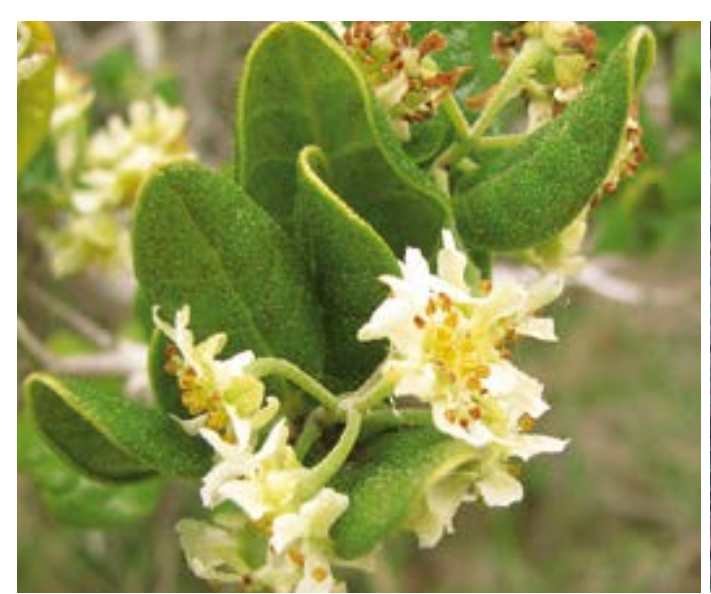

Peumus boldus
Miconia salicifolia

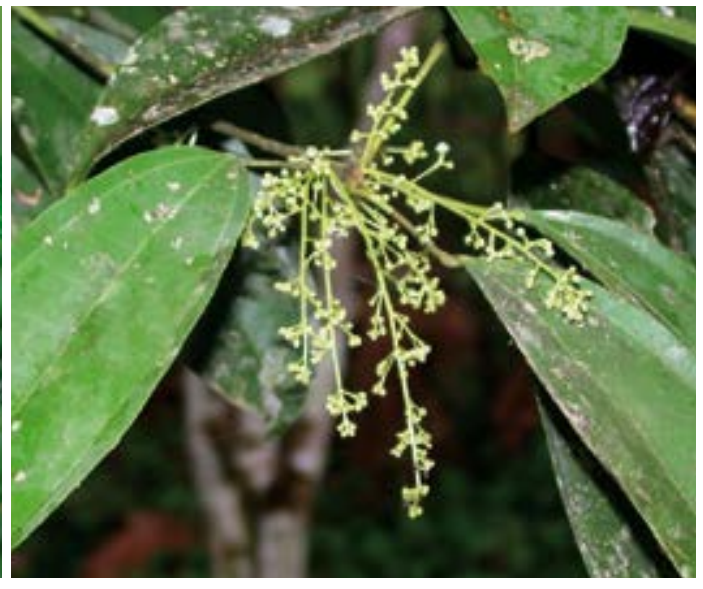

Abuta grandifolia

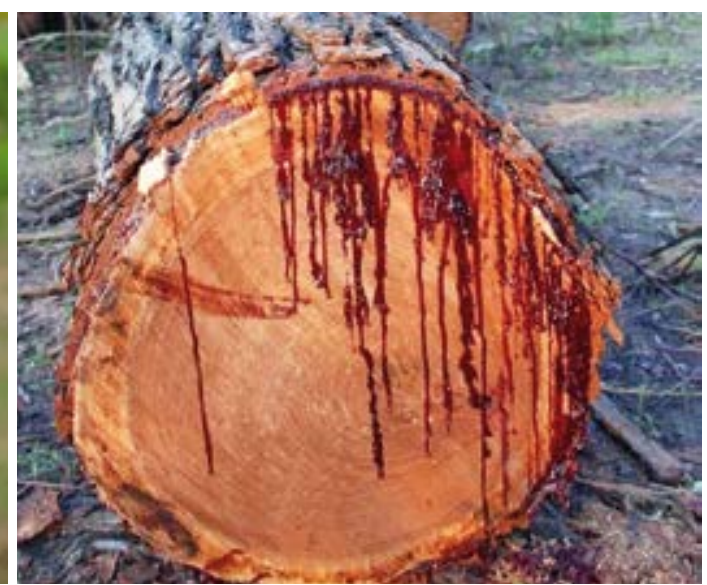

Brosimum rubescens
MELASTOMATACEAE - Brachyotum tyrianthinum J.F. Macbr.

Sarcilleja

Arbusto, Andino, 2500-3500m

Uso: Circulación de sangre / Tallos, fresco / Oral / Hervir 5g en 1 litro de agua por 3-5 minutos. Tomar 3 veces al día por 3 días.

MELASTOMATACEAE - Miconia salicifolia (Bonpl. Ex Naud.) Naud.

Llatama Roja

Arbusto, Andino, 2500-4500m

Uso: Mal Aire, Quemaduras / Hojas y Tallos, fresco o seco / Oral / Hervir 100g en 1 taza de agua por 5 minutos. Tomar frío, 1/4 taza solo una vez.

MELASTOMATACEAE - Tibouchina laxa (Des.) Cog.

Barbón

Arbusto, Andino, 1500-3500m, maleza

Uso: Cataratas / Flores, fresco / Tópico / Machucar y extraer jugo . Poner gotas en los ojos, 2 gotas por ojo dos veces por día.

MENISPERMACEAE - Abuta grandifolia (Mart.) Sandwith.

Abuta (Macho and Hembra)

Liana, Amazónico, $0-500 \mathrm{~m}$

Uso: Contraceptivo, Diabetes, Colesterol / Raíz y Tallos, fresco o seco / Oral / Hervir 20-100g en 1 litro de agua por 4-5 minutos. Tomar caliente, 1 taza 3 veces por día. Tomar 3 días antes y 3 días después de periodo menstrual.

MONIMIACEAE - Peumus boldus Molina

Boldo

Arbusto, Amazónico, Andino, 0-2500m

Uso: Inflamación del hígado, Inflamación de Riñones / Hojas, seco / Oral / Hervir 1 litro de agua y 10g cada uno de Boldo, Pie de Perro, Linaza, Berros, Pata de Perro, Papa Madre, Espiga de Maíz y Flor de Overo. Hervir por 2-3 minutos. Tomar caliente, 1 taza 3-4 veces por día por 1 mes.

MORACEAE - Brosimum rubescens (Aublet) Huber

Palo Sangre, Palo de Sangre, Ablita

Árbol, Amazónico, Andino, 0-1000m

Uso: 1. Fertilidad, Potencia sexual / Madera y Corteza, fresco o seco / Oral / a 1 botella de Vino tinto añadir $5 \mathrm{~g}$ cada uno de Palo de Sangre, Palo Huaco, Cascarilla, Chuchuhuasi, Pacra, Miel, Polen y Huevo del Angelote. Después ańadir $5 \mathrm{~g}$ de Huanarpo Macho si es por un hombre o $5 \mathrm{~g}$ de Huanarpo Hembra si es por una mujer. Tomar 1 taza 3 veces por día hasta botella se acaba. 2. Riego de la sangre, Coágulos, Hemorragias (Prevención y sanación), Diabetes / Madera y Corteza, fresco o seco / Oral / Machucar pequeñas ramas. Hervir $5 \mathrm{~g}$ de Ambarina en 1 litro de agua con $50 \mathrm{~g}$ de Palo Sangre y $50 \mathrm{~g}$ de Palo Huaco por 10 minutos. Tomar 1 litro cada día por 3 meses o más. 3. Artritis, Bronquitis, Dolor muscular / Madera y Corteza, fresco o seco / Oral / Añadir 7 Raíces o $50 \mathrm{~g}$ a 1 botella de Whisky o Tequila mezclado con $10 \mathrm{~g}$ de Chuchuhuasi y Cascarilla. Tomar durante comidas dos veces por día por 8-10 días. 


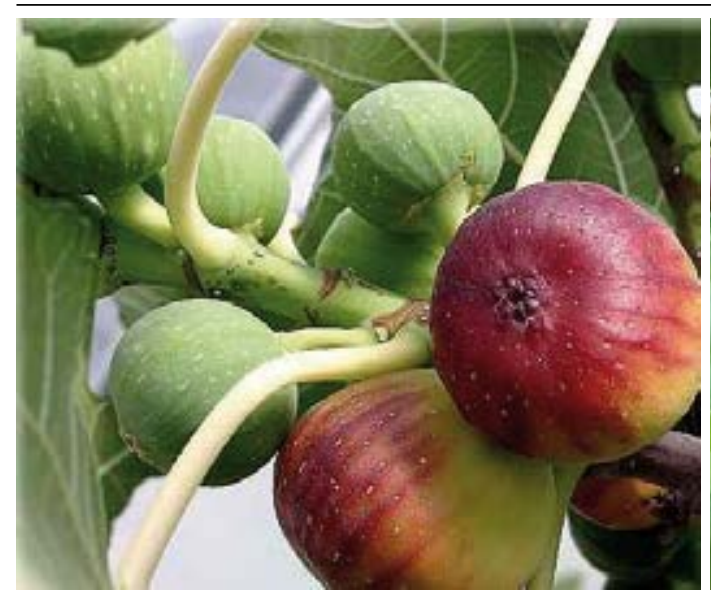

Ficus carica

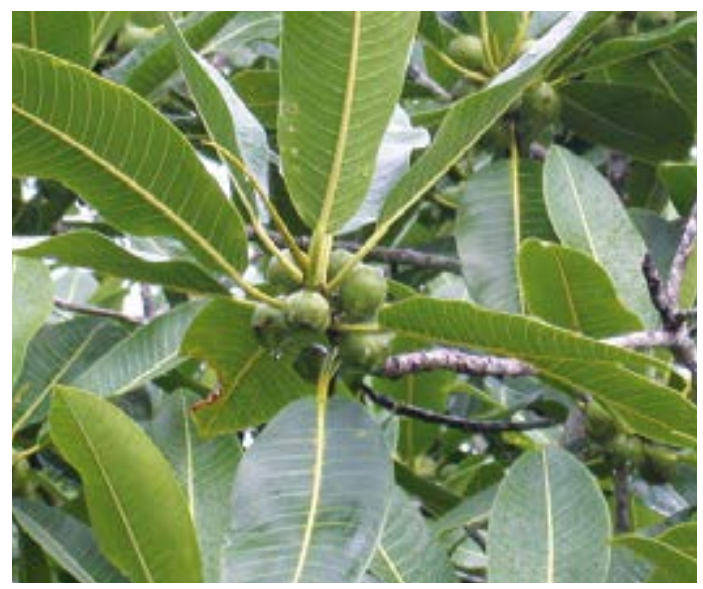

Morus alba

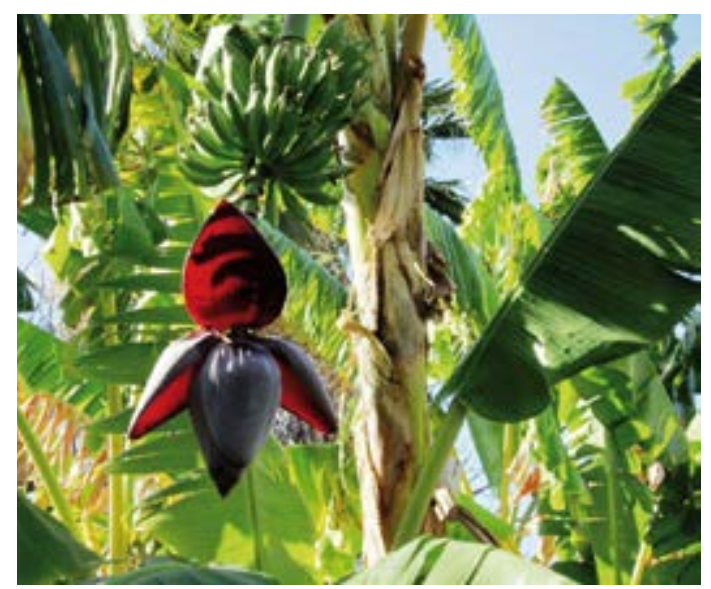

Musa x paradisiaca

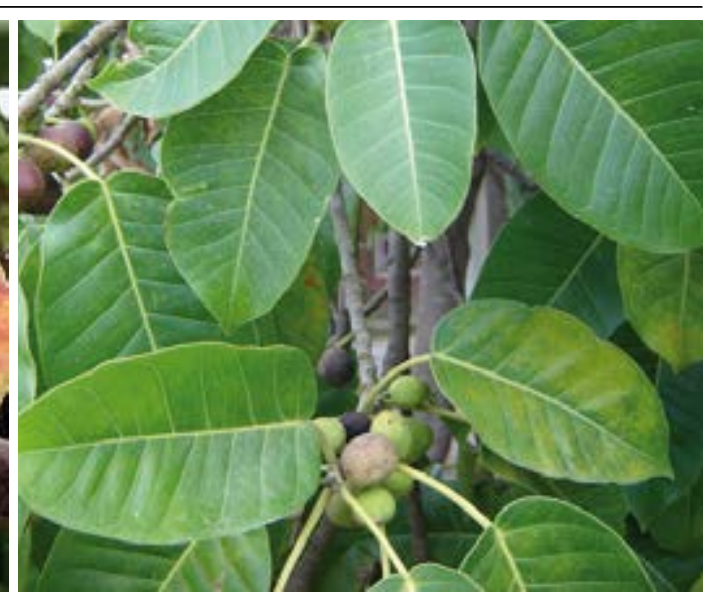

Ficus spp.

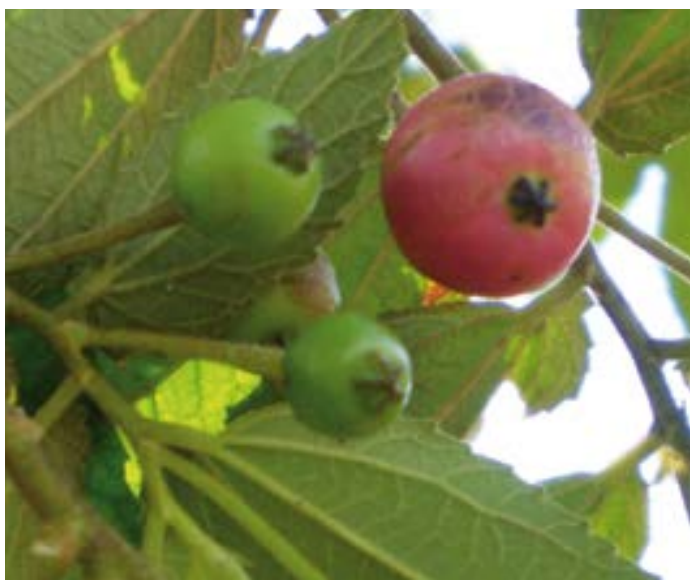

Muntingia calabura

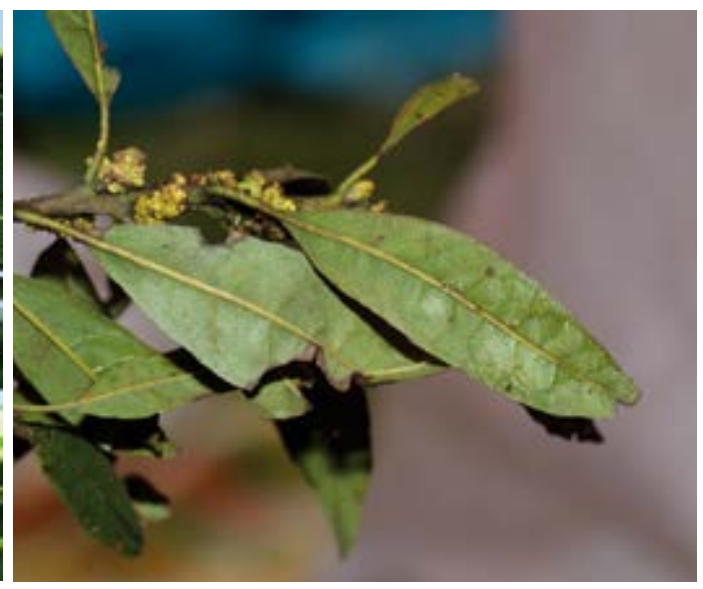

Myrica pubescens

\section{MORACEAE - Ficus carica L}

Higo

Árbol, Andino, Costa, 0-2000m, introducido, cultivado

Uso: Diabetes / Hojas y Tallos, fresco o seco / Oral / Hervir 4 Hojas en 1 litro de agua por 3 minutos. Tomar templado, 1 taza 3-4 veces por día como se necesita.

\section{MORACEAE - Ficus spp.}

Higuerón

Árbol, Amazónico, 0-500m

Uso: Huesos (Fracturado) / Corteza, fresco / Oral / Macerar en Aguardiente. Tomar 2 vasos por día.

MORACEAE - Morus alba L.

Morera (

Árbol, Costa, 0-1500m, introducido y cultivado

Uso: Diabetes / Hojas y Tallos, fresco o seco / Oral / Hervir 4 Hojas en 1 litro de agua por 3 minutos. Tomar templado, 1 taza 3-4 veces por día o como se necesita por vida.

\section{MUNTINGIACEAE - Muntingia calabura L.}

\section{Cerezo Cimarrón}

Árbol, Amazónico, Andino, Costa, 0-1500m, introducido y cultivado

Uso: Gastritis, Infecciones internas (General) / Fruta, fresco / Oral / Licuar 200g de la Fruta con 1/2 taza de agua. Tomar frío, 1 vaso una vez por día por 6 días.

MUSACEAE - Musa $\mathbf{x}$ paradisiaca L.

Plátan

Árbol, Amazónico, Andino, Costa, 0-2000m, Introducido y cultivado

Uso: 1. Diabetes / Flores, fresco / Oral / Hervir 1 litro de agua. Añadir 10g de Plátano. Cubrir y Hervir corto. Remover y dejar mezcla por 3 minutos. Tomar 1 taza, 3 veces por día como se necesita. 2. Asma, Enfermedad pulmonar, Paludismo, Dengue / Látex de los Tallos, fresco / Oral / Combinar 150ml de material de la planta, $150 \mathrm{ml}$ de Vino oporto, $50 \mathrm{ml}$ de Polen y 2 cucharas de Miel. Tomar el jarabe. Tomar $5 \mathrm{~g}$ cada 6 horas por 1 mes. 3. Heridas, Para Hemorragias / Látex de Tallos, fresco / Tópico I Cortar tallo de Plátano con a la machete. Extraer jugo y colectar en contenedor. Poner sobre área afectada. Aplicar una vez por día hasta que la herida se sana.

MYRICACEAE - Myrica pubescens H. \& B. ex Wild.

Árbol, Amazónico, Andino, 0-4000m

Uso: Susto, Hechicería/Daño / Hojas y Tallos, seco / Tópico / Baño: Hervir 5g cada uno de Laurel,

Sauco, Nogal y Hierba del Susto en 3 litros de agua por 10 min. Aplicar 2-4 veces por mes por lavar

Heridas en la mañana y tarde. 


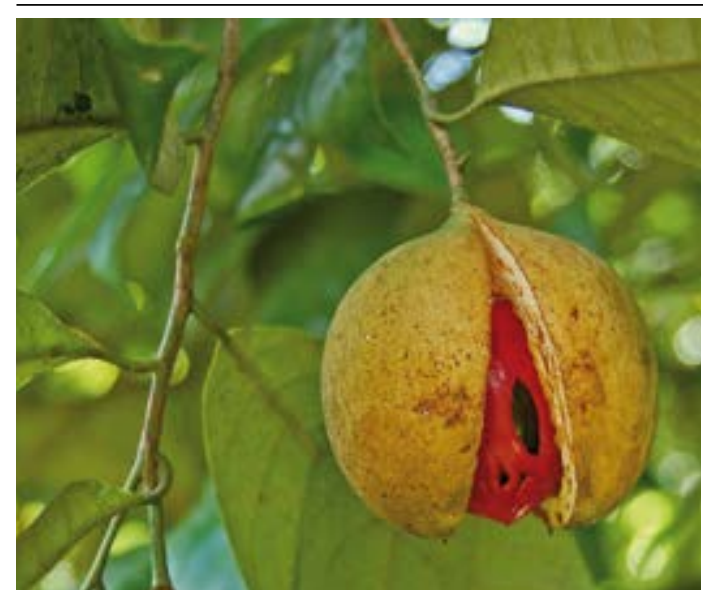

Myristica fragrans

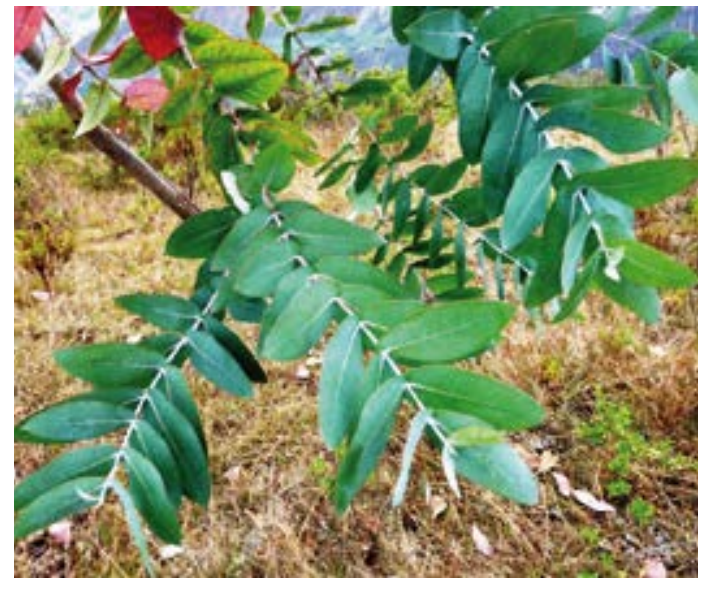

Eucalyptus globulus

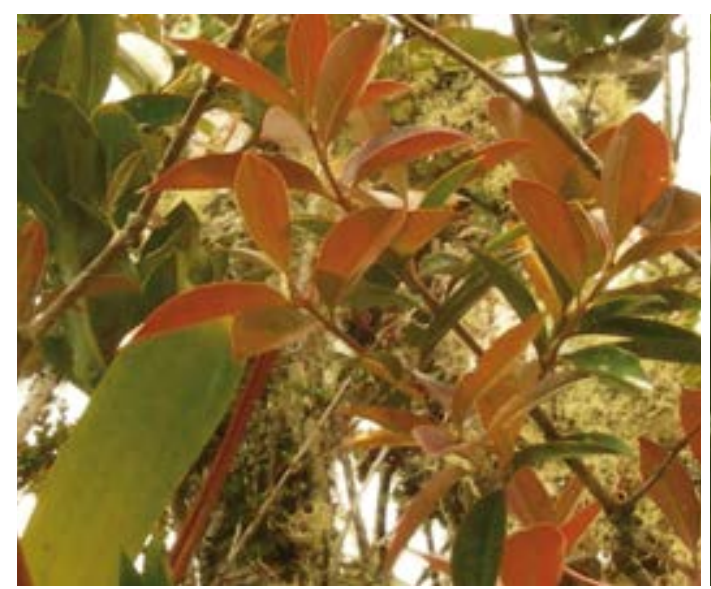

Myrcianthes discolor

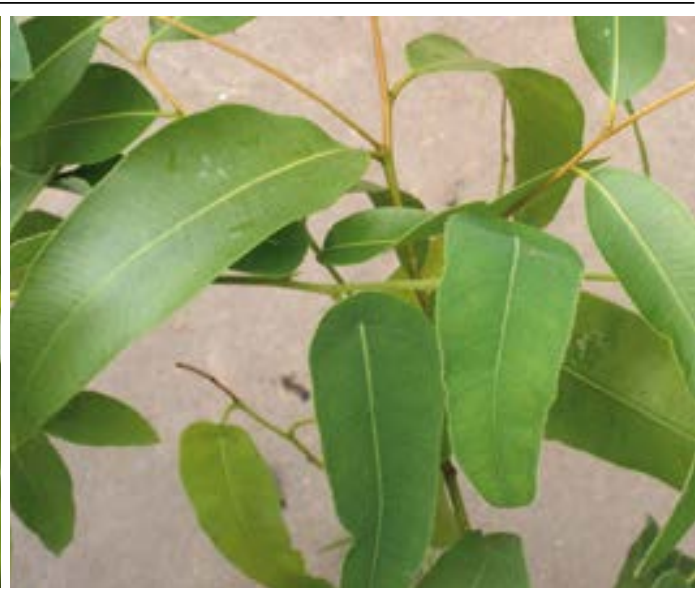

Eucalyptus citriodora

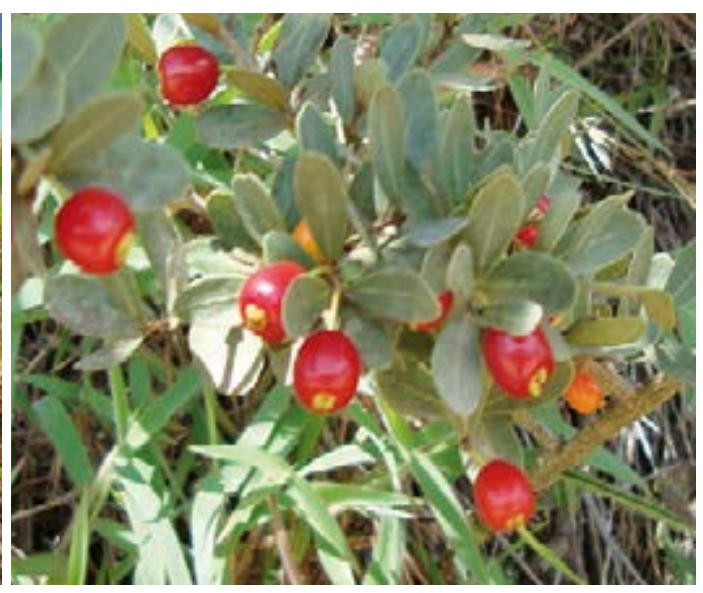

Eugenia punicifolia

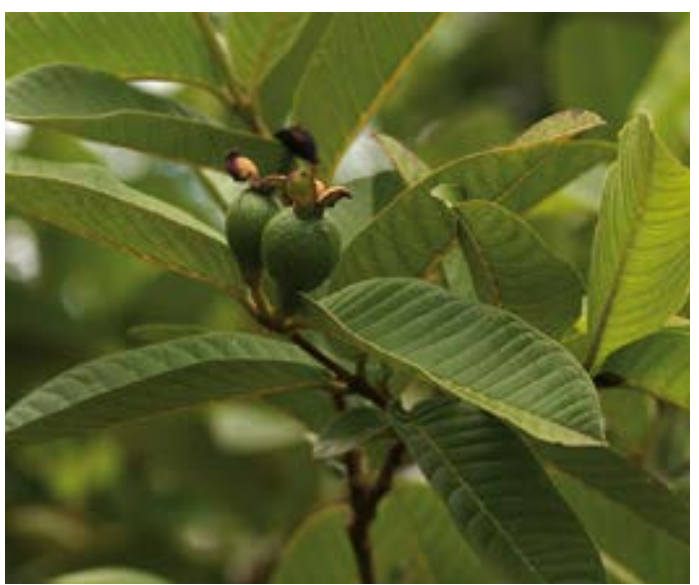

Psidium guajava
MYRISTICACEAE - Myristica fragrans L.

Nuez Moscada, Ajonjolí (Nutmeg)

Árbol, Amazónico, 0-500m, Introducido y cultivado

Uso: 1. Sistema nervioso, Tos, Cólico, Mal Aire, Asma, Gas, Vitaminas, Bronquitis, Fertilidad, Potencia sexual, Dolor de Huesos / Semillas, secas / Oral / Moler Semillas y Hervir en 1 litro de agua (1 Semilla rinde 4 vasos). Tomar 4 tazas por día por 7-15 días. Como alternativa Macerar Nuez Moscada con 10g de Ajonjoli en 1 botella de Vino tinto y $10 \mathrm{~g}$ cada uno de Palo Sangre, Palo Huaco, Miel, Pacra, Huanarpo Macho, Polen de Abeja, Huevo del Angelote y Para Para. Tomar 1 taza en la mańana, mediodía y en la noche hasta botella se acaba. 2. Mal Aire, Epilepsia / Semillas, secas / Oral / Moler Semillas y Hervir en 1 litro de agua con Semillas de 6 otras plantas: Ashango, Pucho, Amala, Quina Quina, Ishpingo y Cabalonga. Tomar una vez al mes.

MYRTACEAE - Eucalyptus citriodora Hooker

Citrodora

Árbol, Andino, 2500-4000m, Introducido y cultivado

Uso: Diabetes / Planta entera, fresco o seco / Oral / Hervir 10g en 1 litro de agua por 3 minutos. Tomar 3 veces al día por vida.

MYRTACEAE - Eucalyptus globulus Labill.

Alcanfor (Camphor), Eucalipto Serrano, Eucalipto (Eucalyptus)

Árbol, Andino, 2500-4000m, Introducido y cultivado

Uso: 1. Bronquitis, Respiración, Resfrío, Tos, Sinusitis, Asma, Reumatismo / Hojas, fresco o seco / Tópico / Hervir 10g cada uno de Eucalipto, Manzanilla, Matico, Nogal, Ajosquiro y Chilca en 1 litro de agua por $10 \mathrm{~min}$. Cubrir cabeza y inhalar por 15 min una vez por semana por 1 mes. 2. Bronquitis, Respiración, Resfrío, Tos, Sinusitis, Asma, Reumatismo / Hojas, fresco o seco / Tópico / Hervir 20g cada uno de Eucalipto, Cerraja, Borraja y Vira Vira en 10 litros de agua. Manzanillon, Romero, Lavanda y Ortiga ( $10 \mathrm{~g}$ cada uno) se puede añadir. Sentarse en el vapor una vez por semana por problemas moderadas, dos veces por semana por enfermedades severas. 3. Resfrío, Dolor de Huesos, Congestión, Quema Grasa / Hojas, fresco o seco / Tópico / Baño: 500g de Eucalipto hervido con Chilca Palo

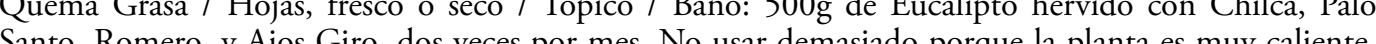
Santo, Romero, y Ajos Giro dos veces por mes. Paciente debe ser 20 minutos. Quedarse en casa por 24 has despues del Bano, una vez cadas 30 dias. 2 veces solo. 4. Bronquitis, Respiración, Resfrio, Tos, Sinusitis, Asma, Reumatismo / Hojas, fresco o seco / Oral / Hervir $10 \mathrm{~g}$ cada uno de Eucaliptus, Muñaca, Escorcionera, Veronica, Humanripa, Zarzamora y Matico en 1 litro de agua por $2 \mathrm{~min}$. Tomar caliente, 3 tazas por día, por 2 semanas.

MYRTACEAE - Eugenia punicifolia (Kunth) DC.

Unquia Real, Rumilanchi

Árbol, Andino, 500-1500m

Uso: Inflamación (General) / Hojas y Tallos, fresco o seco / Oral / Machucar up la planta y Poner en 1 litro de agua hervida por 2-3 minutos. Tomar 3 veces al día por up a 1 mes.

MYRTACEAE - Myrcianthes discolor (Kunth) Vaughn; Myrcianthes fragrans (Sw) McVaugh Lanche, Mirto

Árbol, Andino, 1500-3000m

Uso: Comida, Memoria, Cerebro, Vitamina (para cerebro y Resfríos), Inflamación, Dolor reumático, Estómago, Regulación Menstrual / Planta entera, fresco / Oral / Hervir 5g en 1 litro de agua por 10 min. hasta tener un jarabe o Té. Tomar 1 taza por desayuno, almuerzo y cena por 1 mes.

\section{MYRTACEAE - Psidium guajava L.}

Hoja de Guanabana, Graviola

Árbol, Costa, 0-2000m, introducido y cultivado

Uso: Cáncer, Hígado / Hojas y Tallos, fresco o seco / Oral / Hervir 5 Hojas en 1 litro de agua por 3 minutos. Tomar antes y después de comidas, 3 tazas por día por 1 mes. 


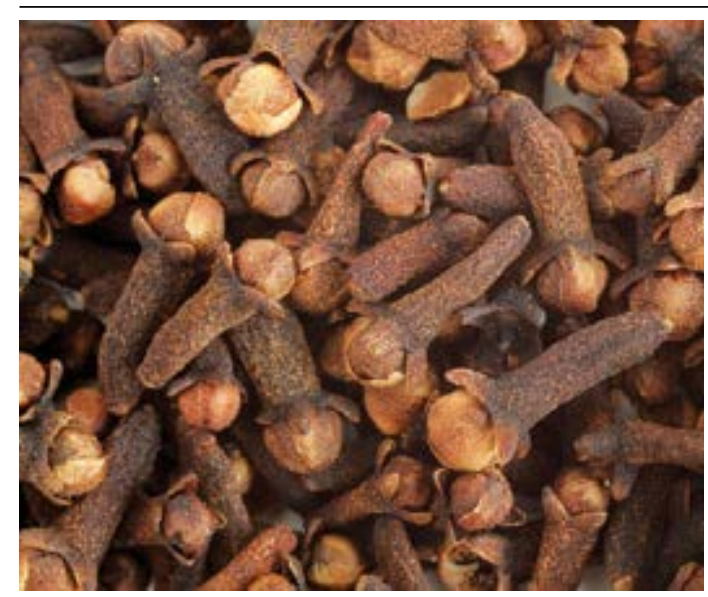

Syzygium aromaticum

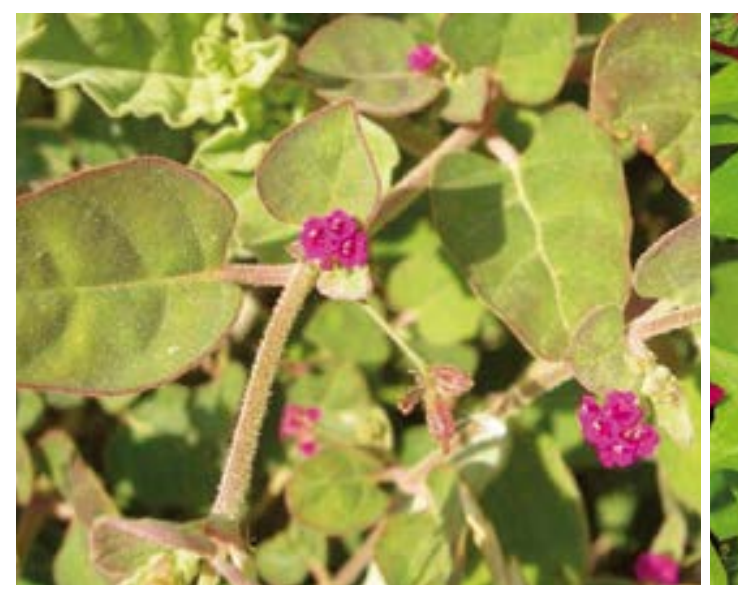

Boerhavia coccinea

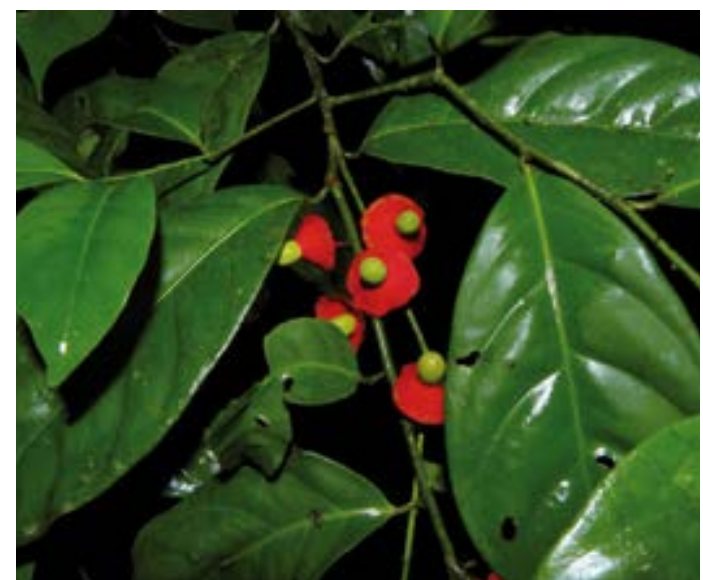

Heisteria acuminata

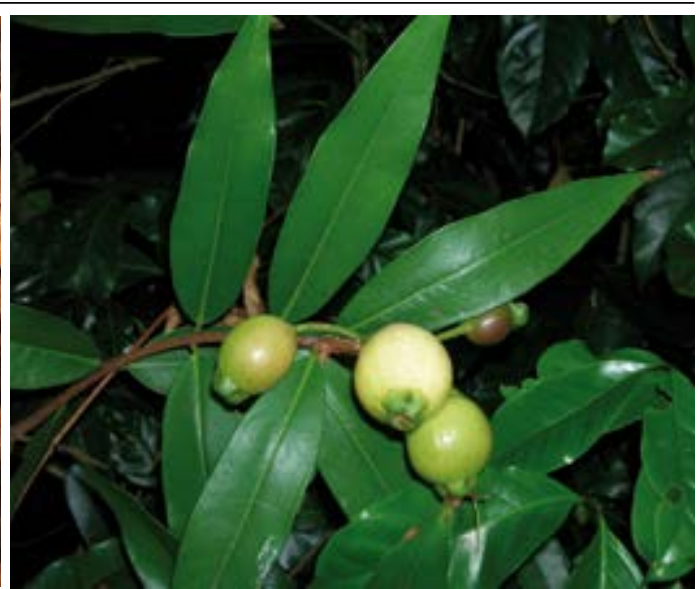

Syzygium jambos

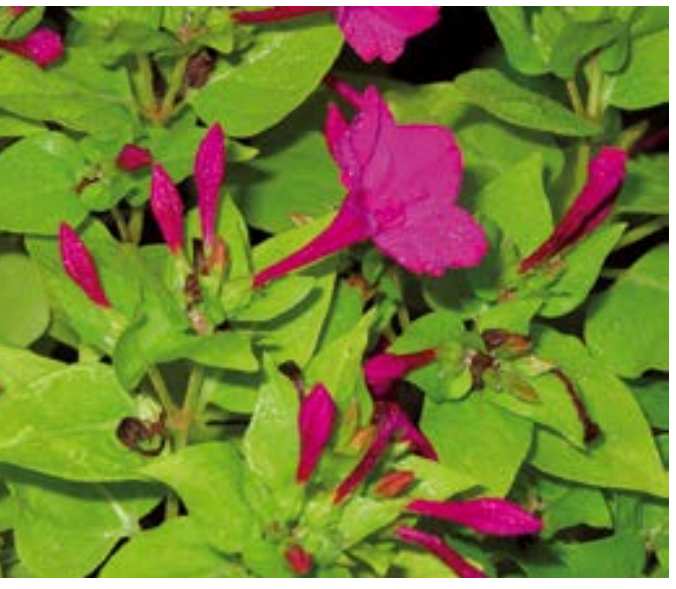

Mirabilis jalapa

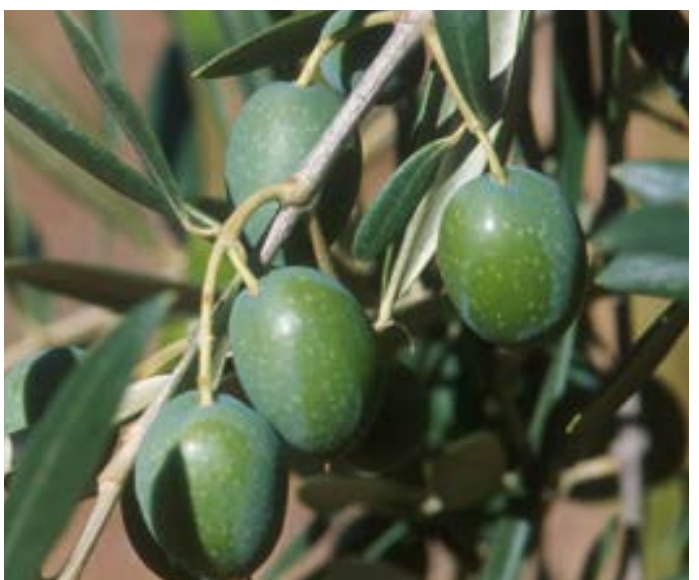

Olea europaea
MYRTACEAE - Syzygium aromaticum (L.) Merr. \& Perry

Clavo de Olor

Árbol, Amazónico, 0-500m, introducido y cultivado

Uso: 1. Dolor de muela / Botón floral, seco / Tópico / Poner cerca de diente afectado y masticar. Tomar 1-2 tubérculos por día como se necesita. 2. Dolor de Estómago / Botón floral), seco / Oral / Hervir 1/2 litro de agua. Añadir 10 tubérculos. Cubrir y dejar por 2-3 min. Tomar infusión. Sobrepasar dosis puede causar daño de rińones. Tomar mezcla 2 veces por día por 2-3 días.

MYRTACEAE - Syzygium jambos (L.) Alston

Poma Rosa

Árbol, Amazónico, 0-500m, introducido y cultivado

Uso: Diarrea / Frutas y Hojas, fresco / Oral / Hervir 1 taza de agua y 20g de la Hoja y Fruta por 5 min. Tomar frío, $1 / 4$ taza una vez por día por 8 días.

NYCTAGINACEAE - Boerhavia coccinea Mill.

Pega Pega

Hierba, Andina, Costa, 0-2000m, maleza

Uso: 1. Florecimiento / Planta entera, fresco / Tópico / Mezcla Alternativa para Florecimiento. Tomar 3 baños al mes en la noche. 2. Buenos Negocios, Protección, Buena Fortuna, Buena Salud / Planta entera, fresco / Seguro / Mezcla Estándar para Seguro.

NYCTAGINACEAE - Mirabilis jalapa L.

Buenas Tardes

Hierba, Amazónico, Andino, 0-1000m

Uso: 1. Hematomas, Venas Varicosas / Flores y Hojas, fresco / Tópico / Poner Hoja molida y Flores en área afectada y cubrir con tela dos veces por día como se necesita. 2. Enfermedad Renal, Inflamación (Interno), Próstata, Cálculos de rińones, Cáncer de Próstata / Raíz, fresco / Oral / Hervir 50g de cada uno de las hierbas siguientes: Buenas Tardes y Paja de Lagartija (Flor de Arena) en 1 taza de agua por 5 min. Ańadir Miel. Tomar templado, 1 taza 3-4 veces por día por 1 mes.

OLACACEAE - Heisteria acuminata (Humb. \& Bonpl.) Engler

\section{Chuchuhuasi}

Árbol, Amazónico, Andino, 0-2500m

Uso: 1. Resfrío, Tos, Huesos, Artritis / Corteza, fresco o seco / Oral / Moler Corteza y poner en 1 botella de Vino tinto para Macerar. Tomar 1 taza 3 veces por día por 15 días. Parar por 15 días. Empezar tratamiento de nuevo por 15 more días. 2. Fertilidad, Potencia sexual / Corteza, fresco o seco / Oral / Mezclar 10g de Corteza molida en 1 botella de Vino tinto. Ańadir Miel, y $10 \mathrm{~g}$ cada uno de Pacra, Huevo del Angelote, Cholitos y Huanarpo (Macho y Hembra). Tomar 1 pequeńa taza 3 veces por día como se necesita 3. Artritis, Dolor muscular, Dolor de Huesos, Esguinces, Resfríos, Quema Grasa, Colesterol (a) $30 \mathrm{~g}$ cada uno de Eucalipto, Molle y Bichayo en 5 litros de agua por 30 minutos. Paciente debe quedarse en un cuarto cerrado sin ropa con toalla sobre la cabeza. Inhalar el vapor de la mezcla y frotar el cuerpo con las Hierbas, solo una vez o, si se necesita, cada 3 meses.

OLEACEAE - Olea europaea L

Hojas de Olivo, Olivo

Árbol, Costa, 0-500m, introducido y cultivado

Uso: 1. Diabetes, Cólico / Hojas, fresco / Oral / Hervir 3g de Hoja de Olivo en 1 litro de agua mezclado con $3 \mathrm{~g}$ cada uno de Muña y Corpus Way. Tomar 3 veces al día por 8 días 2. Disipar energía negativa de la casa / Hojas, seco / Incienso / Poner a manojo de Olivo, Mirra, Palo Santo, Incienso (Copal) y Romero sobre carbón hasta generar humo para rituales. Pasar humo sobre cuerpo del paciente y en la casa. Repetir 2-3 veces por semana o como se necesita. 


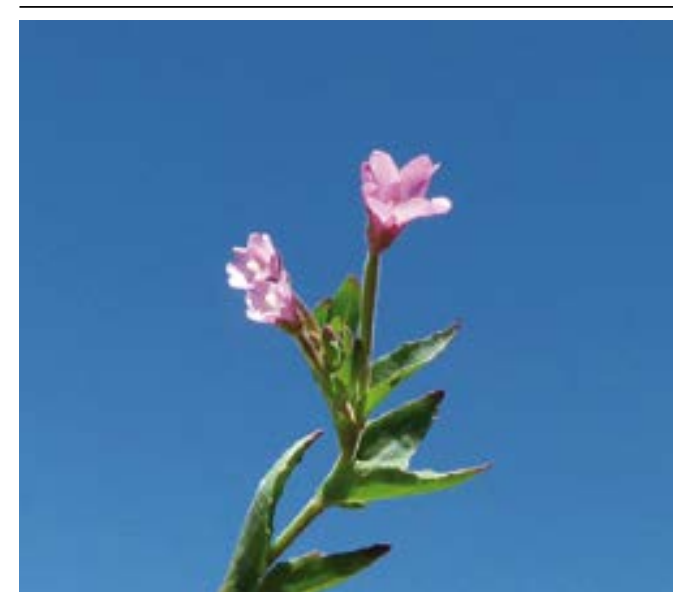

Epilobium denticulatum

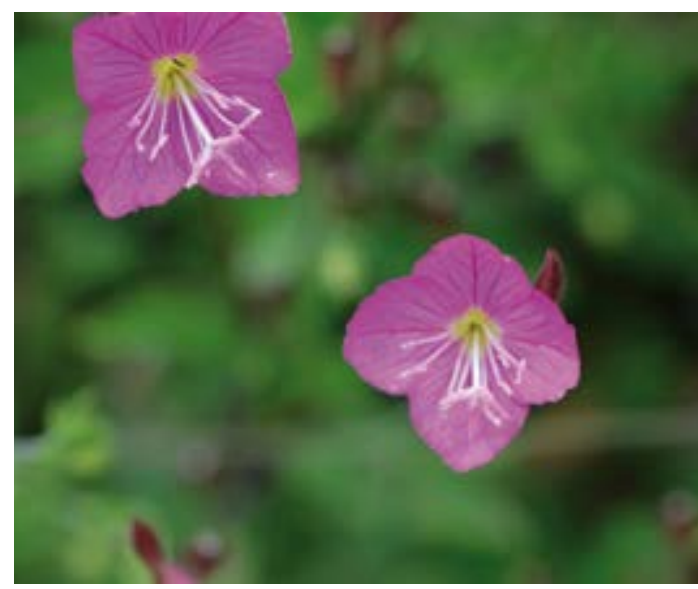

Oenothera rosea

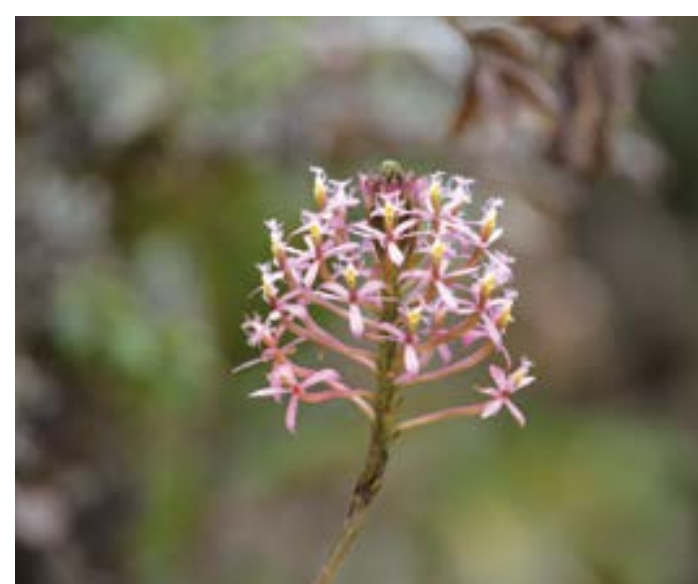

Epidendrum calanthum

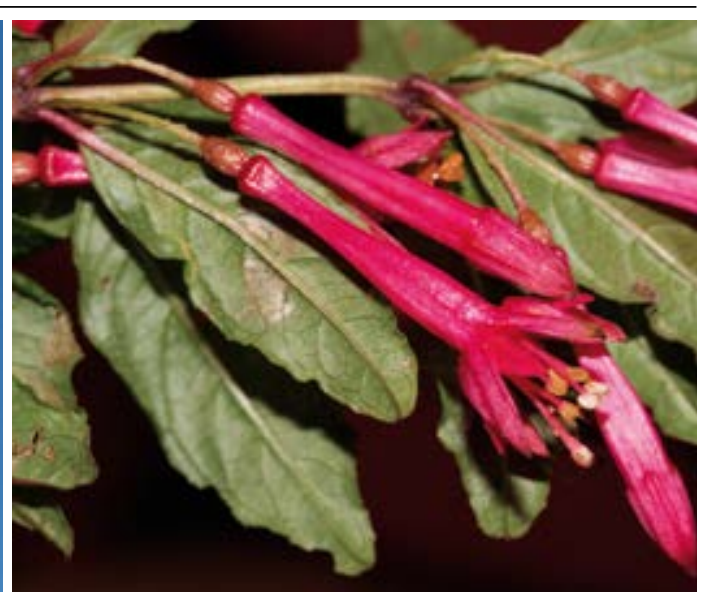

Fuchsia ayavacensis

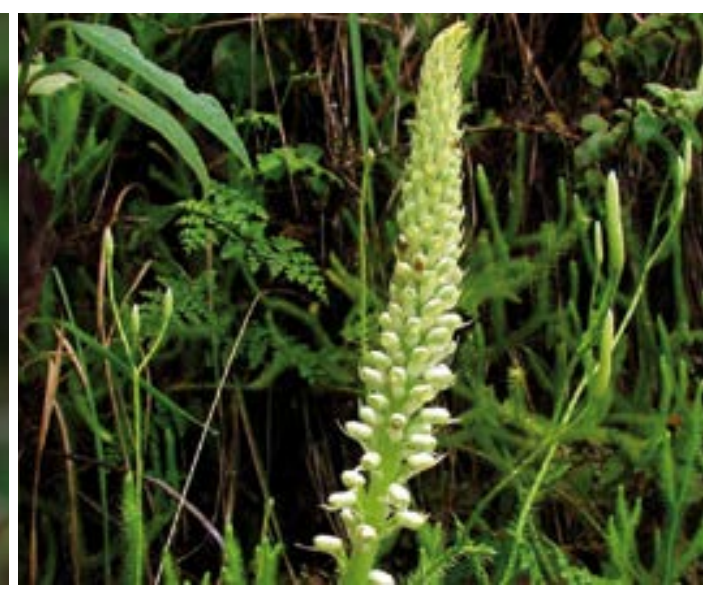

Aa paleacea

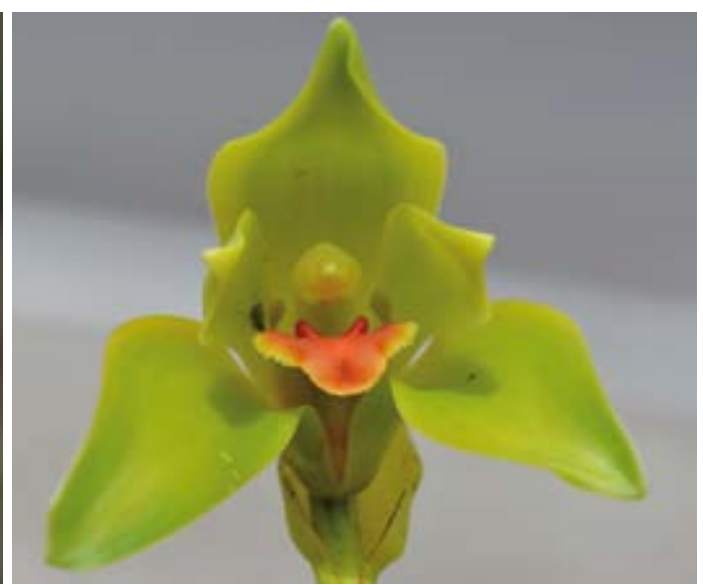

Lycaste gigantea
ONAGRACEAE - Epilobium denticulatum Ruiz \& Pav.

Hierba Rabia

Hierba, Andina, 2000-4000m

Uso: Mal humor, Intoxicación de la sangre, Enojo, Irritación de la piel de Intoxicación, Ingestión de medicina toxica / Planta entera, fresco / Oral / Hervir 5g en 1 litro de agua. Se puede combinar con $5 \mathrm{~g}$ cada uno de Pimpinela, Cadillo, Colores y Lancetilla. Tomar 1 litro cada día por 3 meses.

ONAGRACEAE - Fuchsia ayavacensis H.B.K.

Conchalay, Conchalay Colorado

Arbusto, Andino, 1500-3500m

Uso: 1. Resfrío, Daño/Hechicería, Susto / Hojas y Tallos, fresco o seco / Tópico / Hervir $5 \mathrm{~g}$ cada uno de Conchalay mezclado con Sauco, Nogal, Salvia, Añasquero Grande y 7 Espiritus en 3 litros de agua por 1 hora. dejar enfriar. Tomar 2 Baños templados por semana en acuerdo con que la Mesa indica, o dos veces por mes. 2. / Hinchazón, Artritis (Estado temprano) / Hojas y Tallos, fresco o seco / Tópico / Usar $5 \mathrm{~g}$ Hojas frescas, combinado con $5 \mathrm{~g}$ cada uno Conchalay Blanco, Guaminga, 7 Espiritus, Timolina y Vinagre. Usar como Emplasto dos veces por semana en acuerdo con que la Mesa indica.

\section{ONAGRACEAE - Oenothera rosea Aiton}

Hierba del Dominio

Hierba, Andina, $1500-4000 \mathrm{~m}$, maleza

Uso: Mejorar mal carácter / Planta entera, fresco o seco / Oral / Hervir 5g en 1 litro de agua por 10 min. Tomar 4 tazas por semana por 2 semanas.

ORCHIDACEAE - Aa paleacea (Kunth) Rchb.f.

Hierba de la Soledad, Hierba Sola

Hierba, Andina, 3000-4500m

Uso: 1. Depresión, Soledad / Hojas, fresco / Oral / Hervir 1 Hoja en 1 taza de agua. Tomar una vez al año. 2. Depresión, Soledad / Hojas, fresco / Seguro / 1 Hoja por Seguro. 3. Contraceptivo, Esterilización de mujeres / Hojas, fresco / Oral / Hervir 3-5g de Hierba de la Soledad, en 1 litro de agua mezclado con $5 \mathrm{~g}$ cada uno Tapa Tapa y Sicana en 1 litro de agua por 10 min. Tomar 1 litro cada día 1 semana cada uno mes.

ORCHIDACEAE - Epidendrum calanthum Rchb. f.

Címora Negra, Címora Curandera

Hierba, Amazónico, Andino, 0-2000m, maleza

Uso: Mal Aire, Susto / Hojas y Tallos, seco / Oral / Hervir 50g de material de planta en 1 taza de agua por 10 min. Tomar frío una vez por día.

ORCHIDACEAE - Lycaste gigantea Lindl.

ORCHIDAC

Hierba, Andino, 1500-2500m

Uso: Inflamación de Rińones / Tallos, fresco / Oral / Añadir 10g de material de planta y $10 \mathrm{~g}$ cada uno de Linaza, Berro, Pata de Perro, Papa Madre, Espiga de Maíz a 1/2 litro de agua. Hervir la mezcla por 5 minutos. Tomar frio, $1 / 2$ taza dos veces por dia por 8 días. 


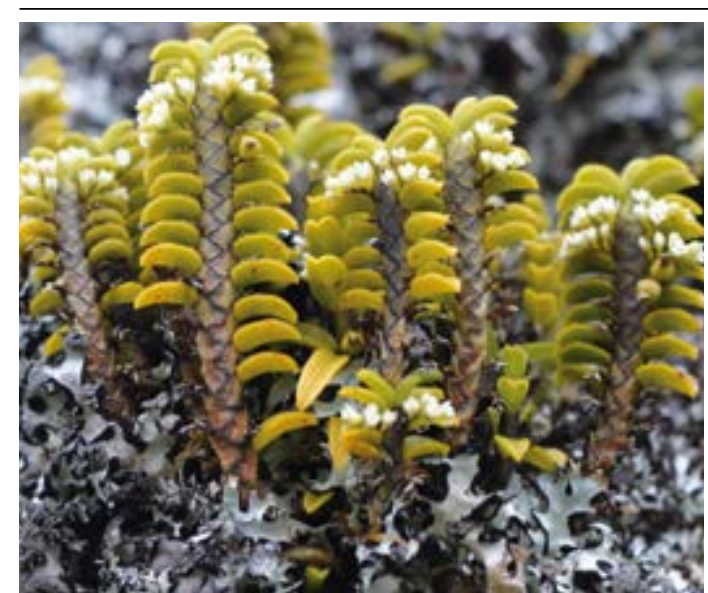

Pachyphyllum crystallinum

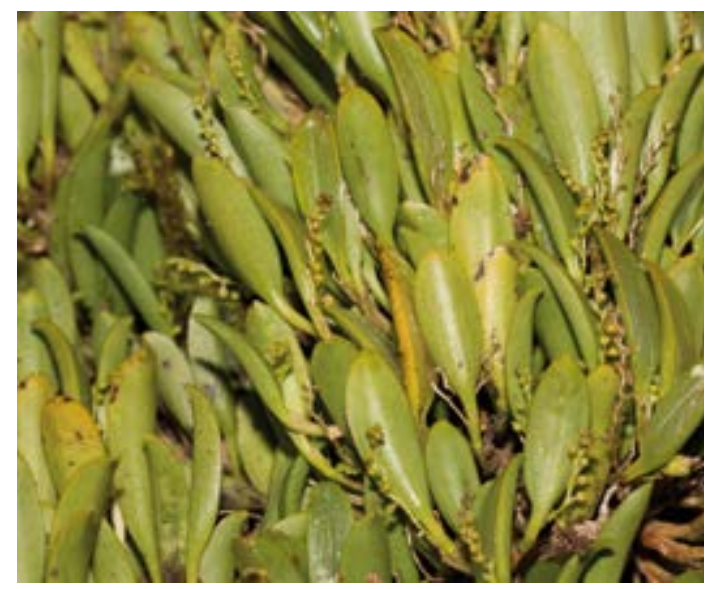

Stelis sp.

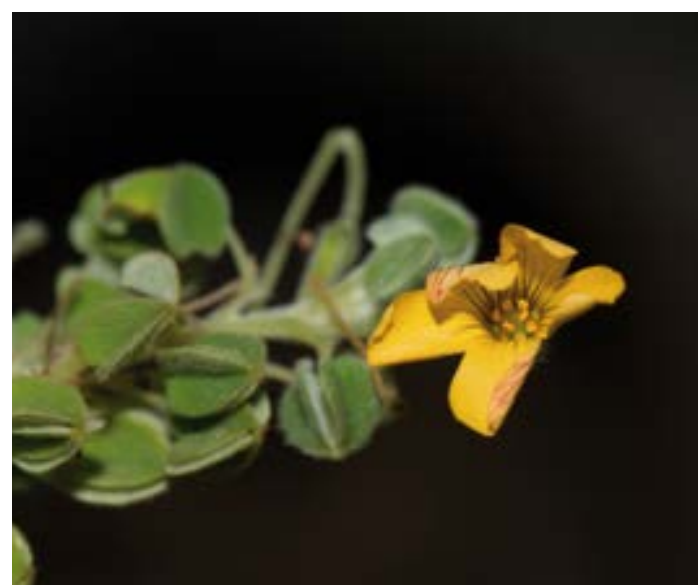

Oxalis bulbigera

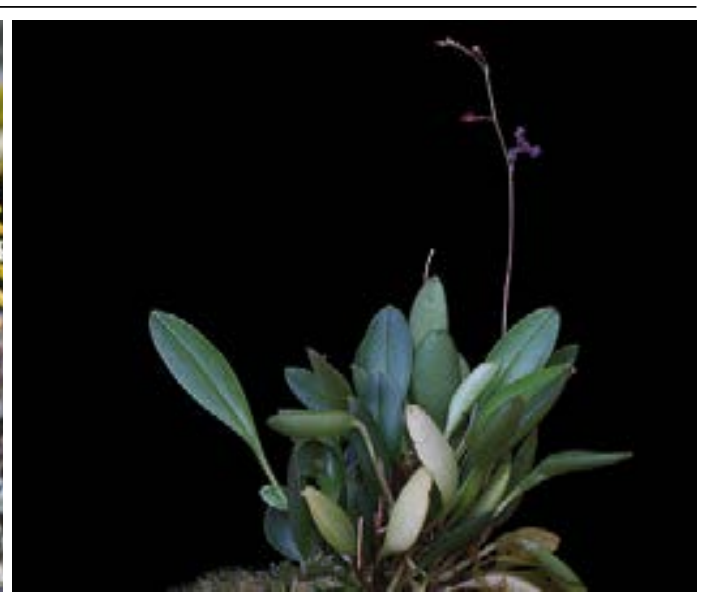

Stelis flexuosa

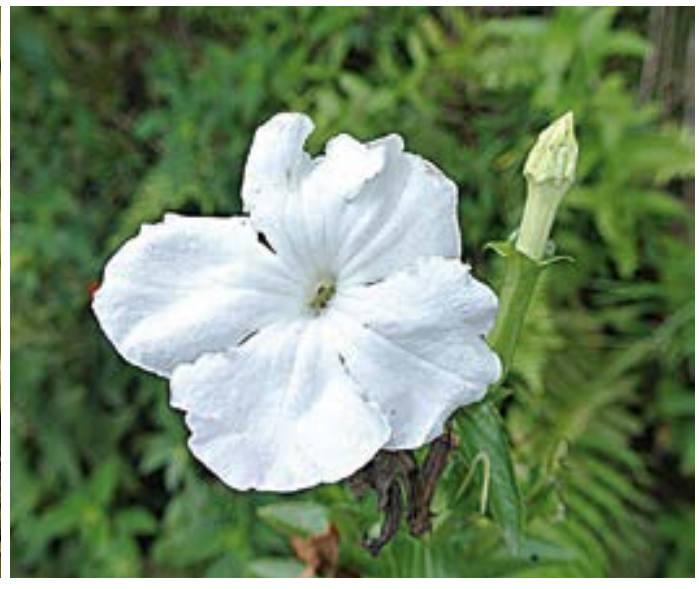

Escobedia grandiflora

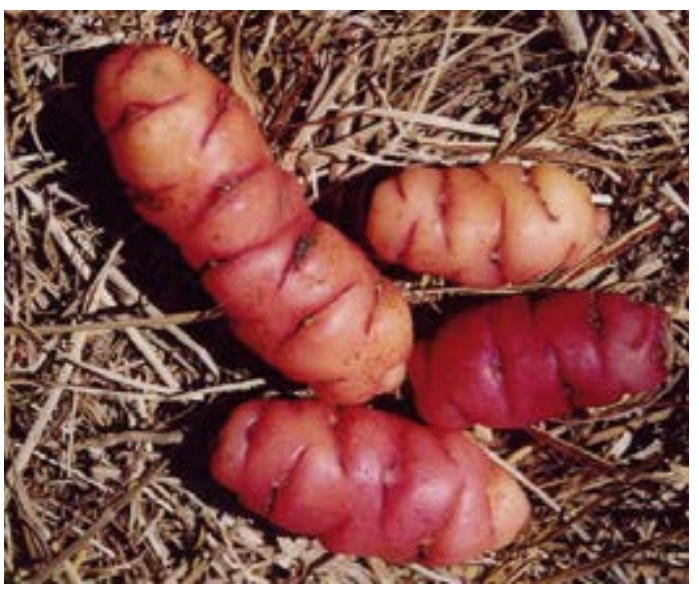

Oxalis tuberosa
ORCHIDACEAE - Pachyphyllum crystallinum Lindley

Guaimi Guaimi, Huaime Huaime

Hierba, Andina, 2500-4000m

Uso: 1. Autodefensa, Protección / Hojas, fresco / Tópico / Hervir 10g en 5 litros de agua por 10 min. con otras Hierbas fuertes. Aplicar 3 veces por semana. 2. Autodefensa. Protección / Tallos, fresco / Seguro / Añadir un pequeño Tallo al Seguro con Hierbas de Suerte.

ORCHIDACEAE - Stelis flexuosa Lindley

Hierba del Oro, Botón de Oro

Hierba, Andina, 2500-4000m

Uso: 1. Fragancia, Buena Suerte, Nervios, Suerte en Amor, Suerte en Negocios, Buena Suerte por Trabajo, Seguridad en Viajes / Planta entera, fresco / Seguro / Combinar 1 Tallo con Hierba de la Plata, Hierba de la Justicia, Hierba del Dominio, Encanto, Sígueme Sígueme y Hierbas de Fuerza y Suerte. 2. Fragancia, Buena Suerte, Nervios, Suerte en Amor, Suerte en Negocios, Buena Suerte por Trabajo, Seguridad en Viajes / Planta entera, fresco / Tópico / Bańo: Hervir 200g en 8 litros de agua por 20 min. Aplicar 3 veces por semana por 1-6 meses.

\section{ORCHIDACEAE - Stelis sp.}

Huaime-Huaime, Cucharilla

Hierba, Andina, 3000-4000m

Uso: 1. Mal Aire, Parálisis de cara causado por Mal Aire. / Planta entera, fresco / Tópico / Machucar la planta y calentar con Agua Florida. Usar 10g de planta aplastada y $25 \mathrm{ml}$ de Agua Florida. Poner Emplasto en lado opuesto de área afectada y cubrir con un pedazo de tela. Aplicar 2 veces por día por 2 días. 2. Inflamación de ovarios, Inflamación de útero / Raíz, seco / Tópico / Baño: Hervir 5g en 1 litro de agua por 3 Baños por mes. 3. Buenos Negocios, Protección, Buena Fortuna, Buena Salud / Hojas y Tatección, Buena Fortuna, Buena Salud / Hojas y Tallos, fresco / Seguro / Mezcla Estándar para Seguro.

OROBANCHACEAE - Escobedia grandiflora (L.f.) Kuntze

Azafrán

Hierba, 1500-3000m, maleza

Uso: Bronquitis, Neumonía, Escalofríos (General) / Flores, seco / Oral / Hervir 1/2 litro de agua por 3 minutos con $20 \mathrm{~g}$ de Azafrán. Tomar caliente, 1 taza en la mañana, 1 taza en la noche por semana.

OXALIDACEAE - Oxalis bulbigera Knuth.

Trébol

Hierba, Costa, 0-500m

Uso: Corazón, Nervios, Insomnio / Hojas y Tallos, fresco / Oral / Hervir agua. Ańadir 10g cada uno de Trébol, Toronjil, Poleo, Manzanilla, Hinojo y Romero. Dejar mezcla por 2-3 minutos. Tomar templado, 1 vaso 3 veces por día por 1 mes.

OXALIDACEAE - Oxalis tuberosa Molina Oca Rosada

Hierba, Andina, 2500-4500m, maleza, cultivado

Uso: Comida, Potencia Sexual / Tubérculo, fresco / Oral /Hervir 7-8 tubérculos en 1 litro por 2 minutos. Tomar 3 veces al día por 2 semanas hasta 1 mes. 


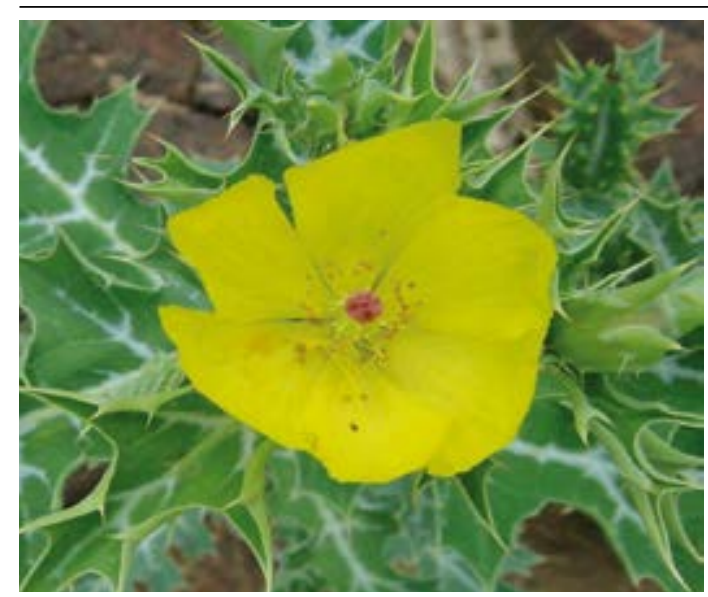

Argemone mexicana

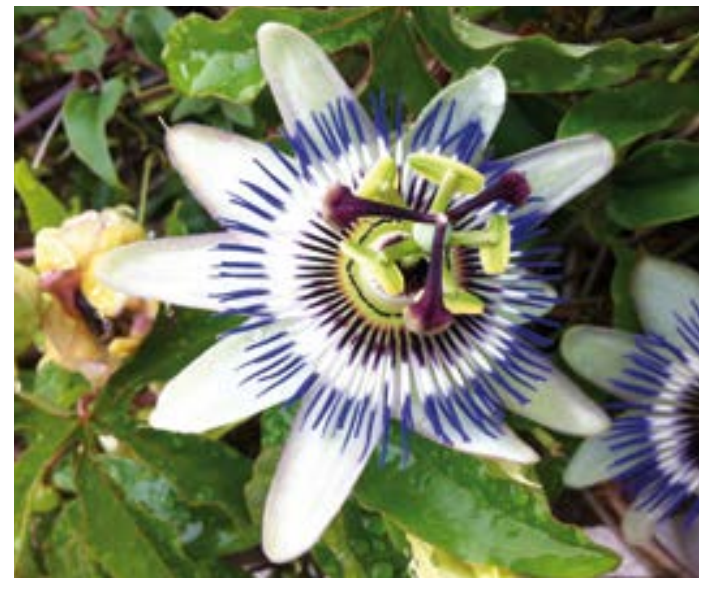

Passiflora caerulea

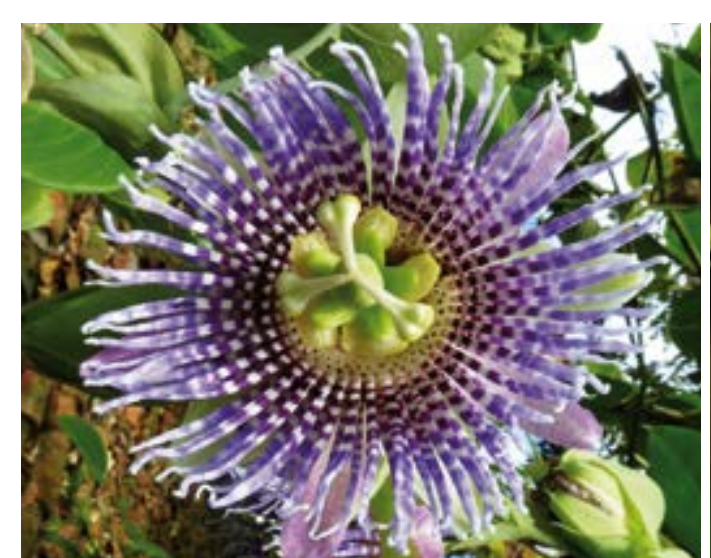

Passiflora ligularis

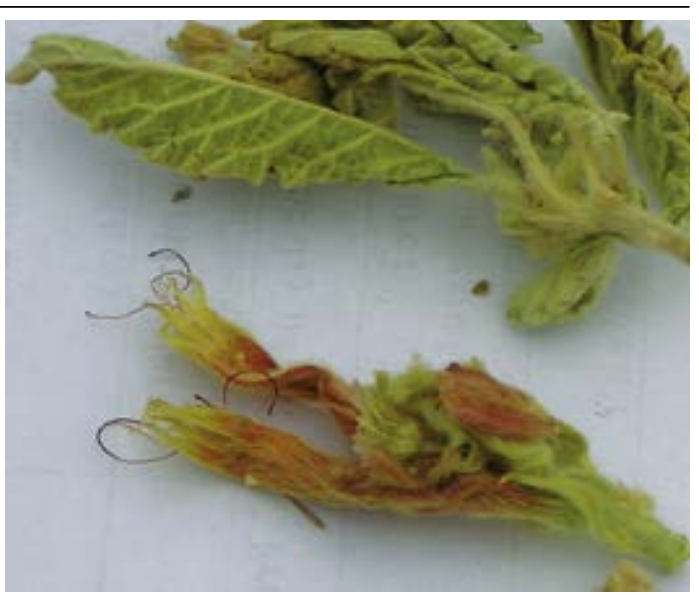

Malesherbia ardens

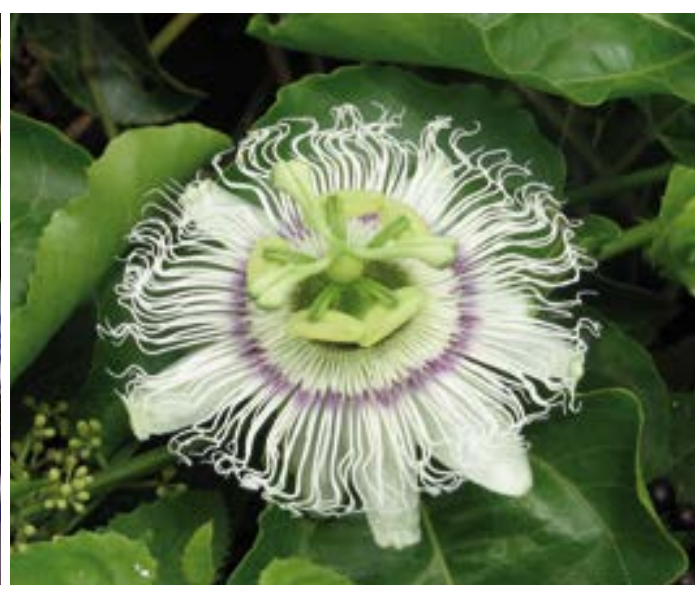

Passiflora edulis

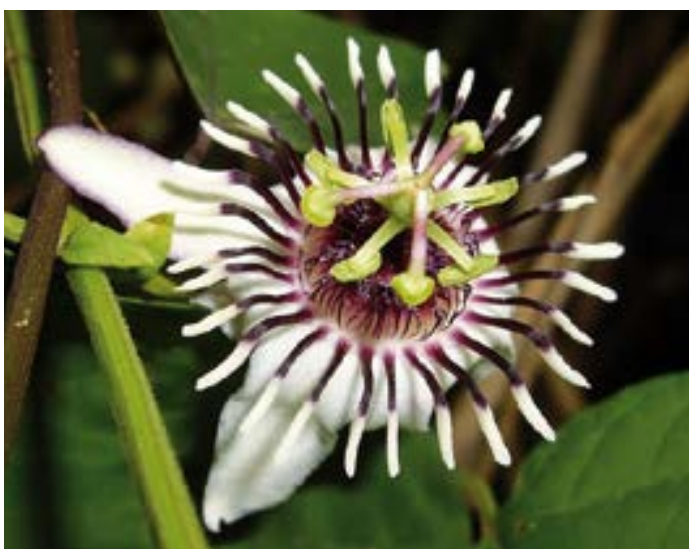

Passiflora punctata

\section{PAPAVERACEAE - Argemone mexicana L.}

Cardo Santo

Hierba, Costa, 0-1000m, maleza

Uso: 1. Dolor de Estómago, Inflamación (General) / Flores, Hojas y Tallos, fresco / Oral / Hervir 1 litro de agua y añadir $10 \mathrm{~g}$ de Cardo Santo mezclado con $10 \mathrm{~g}$ cada uno de Cola de Caballo, Malva, Llantén y Pie de Perro. Tomar 1 taza 2-4 veces por día por 1 mes. 2. Seguro de Casa, Seguro de Chacra / Flores, Hojas y Tallos, fresco / Amuleto / Sembrar Cardo Santo cerca de casa o chacra y recitar oración hasta se asegura que la planta guarda bien.

PASSIFLORACEAE - Malesherbia ardens J.F. Macbr.

Veronica

Arbusto, Andino, 1000-2500m

Uso: Resfrío, Tos, Bronquitis, Asma / Planta entera, fresco o seco / Oral / Hervir 5g en 1 litro de agua por 10 min. combinado con $5 \mathrm{~g}$ cada uno de Arabisca y Huamanripa ( $5 \mathrm{~g}$ cada uno). Tomar 3 veces por día, total 1 litro por día.

PASSIFLORACEAE - Passiflora caerulea L.

Pasionara

Vine, Costa, 0-500m, introducido y cultivado

Uso: Nervios, Insomnio, Ansiedad / Flores, Hojas y Tallos, fresco / Oral / Hervir 1 litro de agua. Añadir $10 \mathrm{~g}$ cada uno de Pasionaria, Toronjil, Pimpinela, Chancas de Comida, Romero y Cáscara de Membrillo. Dejar por 2-3 minutos. Tomar templado, 1 taza 3 veces por día por 1 mes.

PASSIFLORACEAE - Passiflora edulis Sims.

Maracuya

Vine, Amazónico, Andino, 0-1500m, introducido y cultivado

Uso: Presión alta / Flores y Fruta, fresco / Oral / Añadir agua a la Fruta. Consumir caliente o fría, 1 Fruta por día como se necesita.

PASSIFLORACEAE - Passiflora ligularis Juss.

Hoja de Granadilla, Granadilla

Vine, Andino, Costa, $0-2500 \mathrm{~m}$

Uso: 1. Hígado, Circulación de sangre, Inflamación (Externo), Inflamación de Rińones, Inflamación del hígado / Hojas y tallos jóvenes, fresco / Oral / Hervir 10g cada uno de Granadilla, Boldo, Cola de Caballo, Chacur y Amor Seco en 1 litro de agua por 3-5 minutos. Tomar 1 taza 3-5 veces por día por 1 mes. No usar si alquilen esta embarazada! 2. Diarrea / Cáscara del Fruto, fresco / Oral / Hervir 1 litro de agua. Añadir 3/4 de la Cáscara de Fruta con 10g cada uno de Culén, Hinojo y Chancas de Comida. Tomar caliente, 1 taza 3-4 veces por día por 3 días o como se necesita.

PASSIFLORACEAE - Passiflora punctata L.

Tumbillo

Vine, Andino, Costa, 0-1500m

Uso: Digestión / Fruta, fresco / Oral / Comer 50g 3 veces por día por 5 días. 

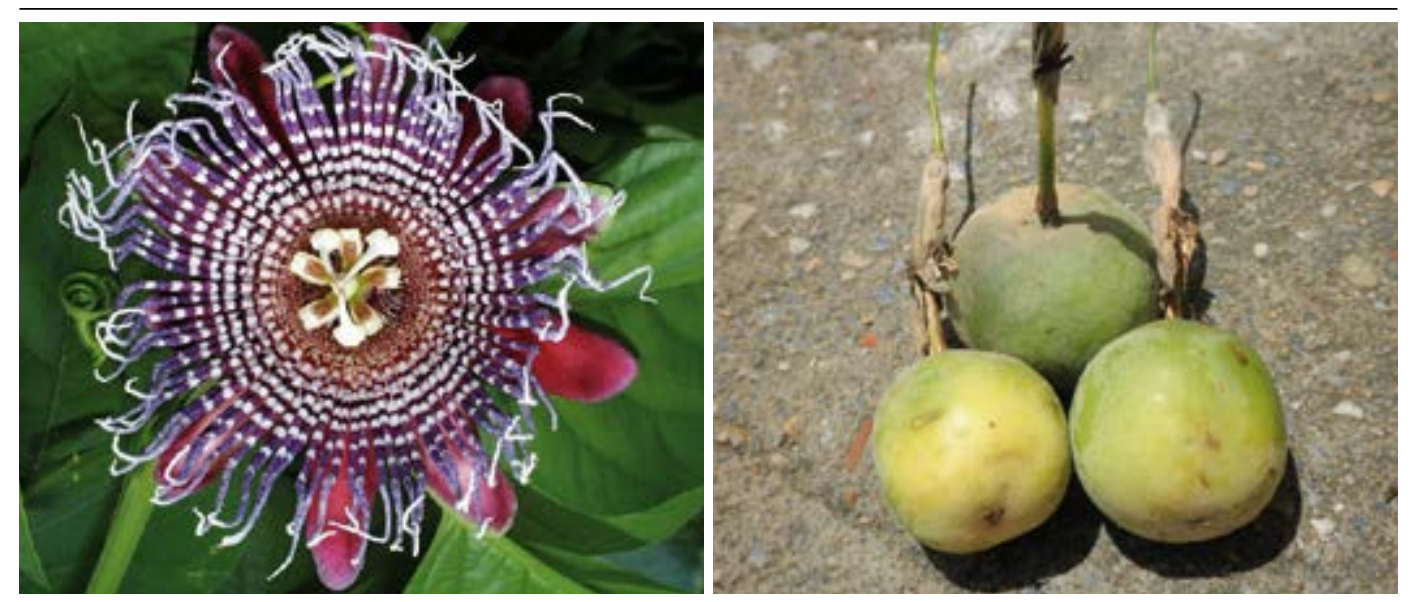

Passiflora quadrangularis

Passiflora sp.

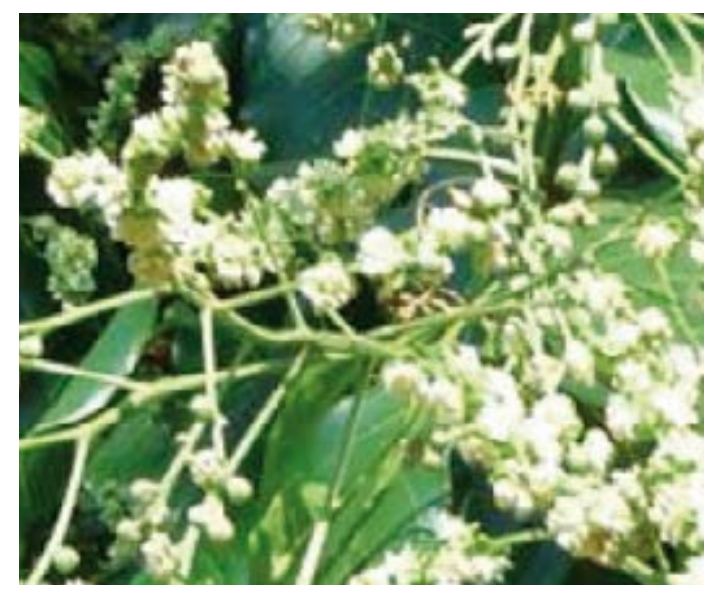

Gallesia integrifolia

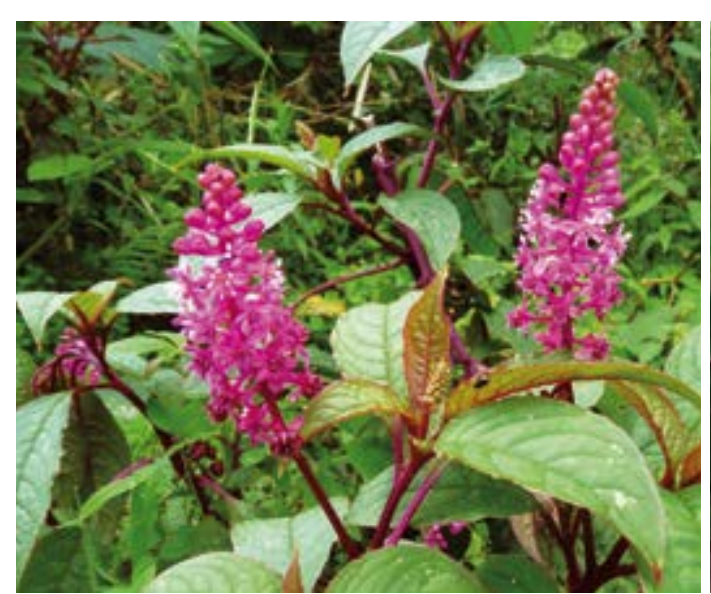

Phytolacca bogotensis

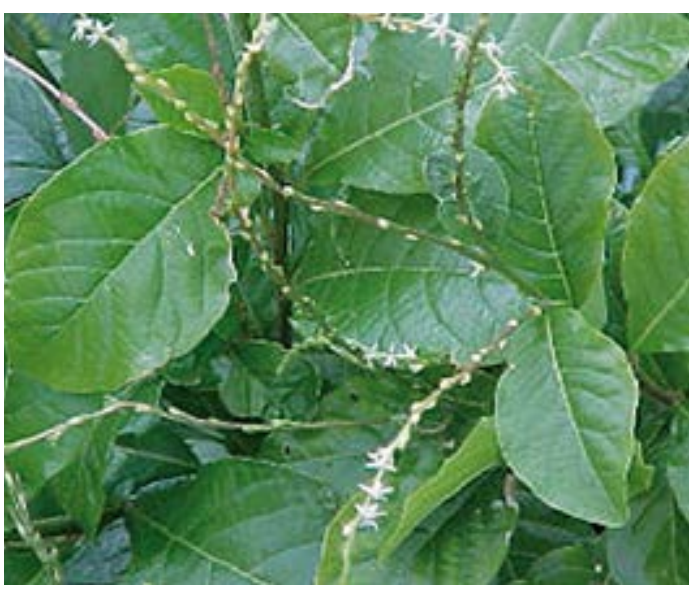

Petiveria alliacea

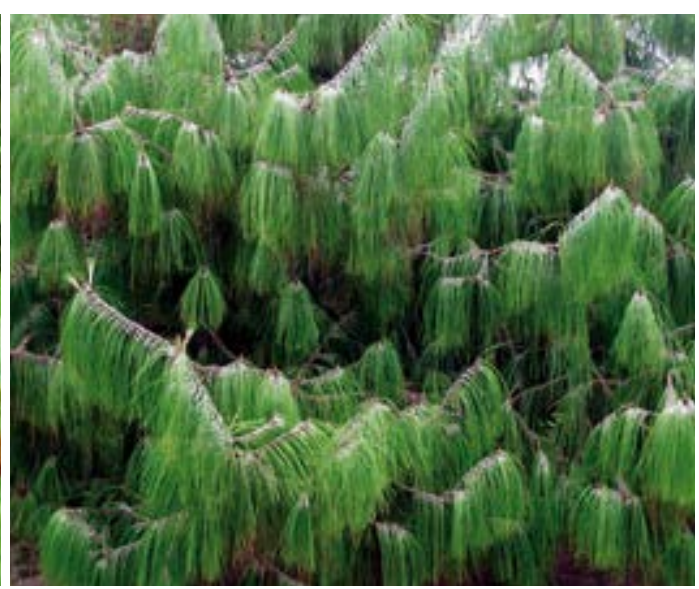

Pinus patula
PASSIFLORACEAE - Passiflora quadrangularis L

Hojas de Tumbo

Vine, Andino, Costa, 0-3000m

Uso: Hígado, Dolor de Menstruación, Dolor de Estómago / Hojas, fresco / Oral / Añadir 3 Hojas a 1 litro de agua hervida. Tomar 3 veces por día.

PASSIFLORACEAE - Passiflora sp.

Chulgán

Vine, Costa, $0-1500 \mathrm{~m}$

Uso: Promover dilatación vaginal en parto. / Hojas y Tallos, seco / Oral / Añadir 10g de material de la planta a 1 taza de agua. Hervir la mezcla por 3 minutos. Tomar caliente, 1 taza solo una vez.

PHYTOLACCACEAE - Gallesia integrifolia (Spreng.) Harms.

Palo de Ajo

Hierba, Andino, Costa, 0-1500m, maleza

Uso: Bronquitis, Asma / Tallos, seco / Oral / Hervir 20g de Palo de Ajo en 1/2 taza de agua por 2 minutos. Tomar frio, $1 / 8$ taza por dia por 8 dias.

PHYTOLACCACEAE - Petiveria alliacea L.

Mocura, Mucura

Hierba, Andina, Costa, 0-1500m, maleza

Uso: 1. Florecimiento / Planta entera, fresco / Tópico / A 5 litros de agua añadir 1 manojo de Mocura (10g) y Amarillo, Rojo y White Rose Pétalos. Hervir por a 2-3 minutos. Colar y dejar. Añadir 1 cucharilla de Azúcar, Agua Florida y Jugo de Lima. Bańo cuando templado. Rezar haciendo señal de cruz sobre cuerpo del paciente y lavar con las plantas. Bańo durante la energía positiva de Luna llena. Cantidad solo para una persona. No bañar hasta el siguiente día. Baño Martes, Viernes y Martes. 2. Protección / Planta entera, fresco / Seguro / Poner 1 Tallo en frasco con plantas típicas de Seguro y Hierbas (Hierba de la Plata, Hierba de la Fortuna, Hierba del Halago, etc.). Llevar el frasco siempre si esta pequeñas o mantenerlo en casa si esta grande. Solo el dueño lo debe tocar.

PHYTOLACCACEAE - Phytolacca bogotensis H.B.K.

Laylambo, Ilambo

Hierba, Andino, 2000-4000m, maleza

Uso: 1. Daño/Hechicería, Susto, Paludismo, Dengue, Fiebre Amarilla / Flores, Hojas y Tallos, fresco / Tópico / Aplicar Hojas frescas como Emplasto. Usar infrecuente porque es muy fría. 2. Daño/Hechicería, Susto, Paludismo, Dengue, Fiebre Amarilla / Flores, Hojas y Tallos, fresco / Tópico / Hervir 1 manojo de fresco Hojas en 3 litros de agua mezclado con 1 manojo cada uno de Ańasquero, Ajenco, Sauco, Tres Hojas y Agua de Susto. Baño 1-2 veces por semana mezcla caliente y frotar el paciente con las Hojas. Avisar al paciente de no enjuagarse después del Bańo. También se usa para Limpia.

PINACEAE - Pinus patula Schldl. \& Cham., Pinus radiata D. Don.

Pino

Árbol, Andino, 2500-4000m, introducido y cultivado

Uso: Artritis, Reumatismo, Dolor de Huesos / Hojas y Tallos, fresco / Oral / Hervir 100g de la planta por 5 minutos en 1 taza de agua. Tomar templado, 1/4 taza una vez por día por 15 días. 

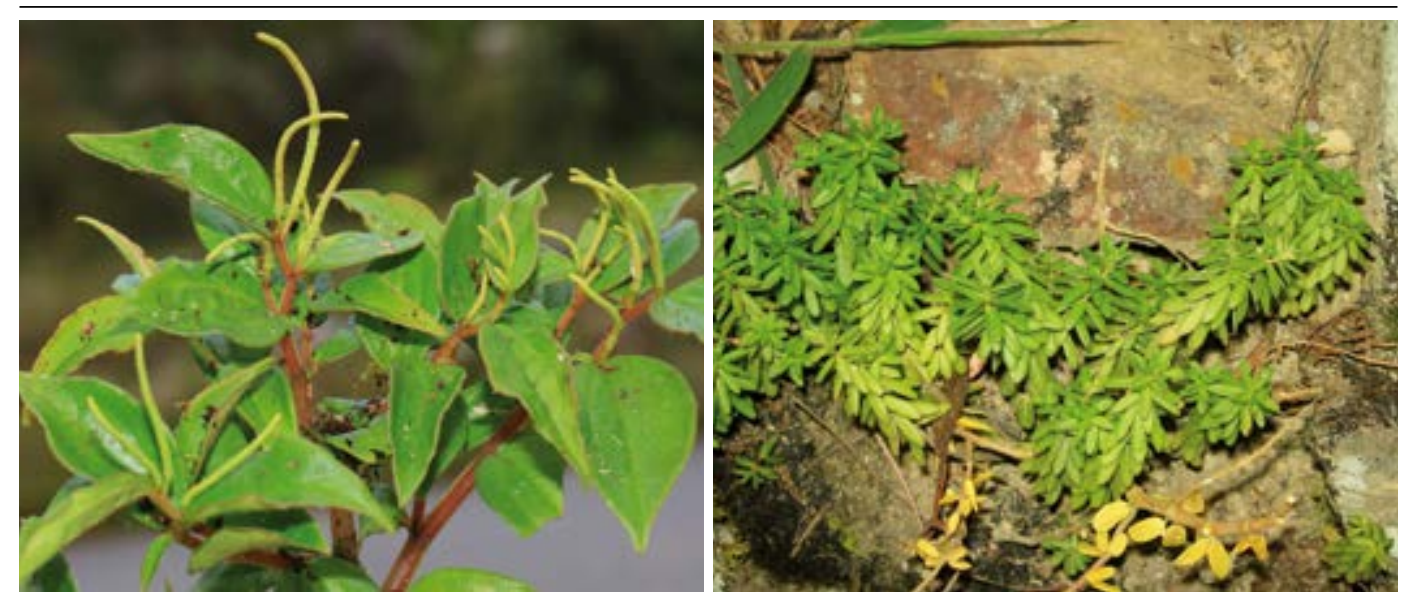

Peperomia fraseri

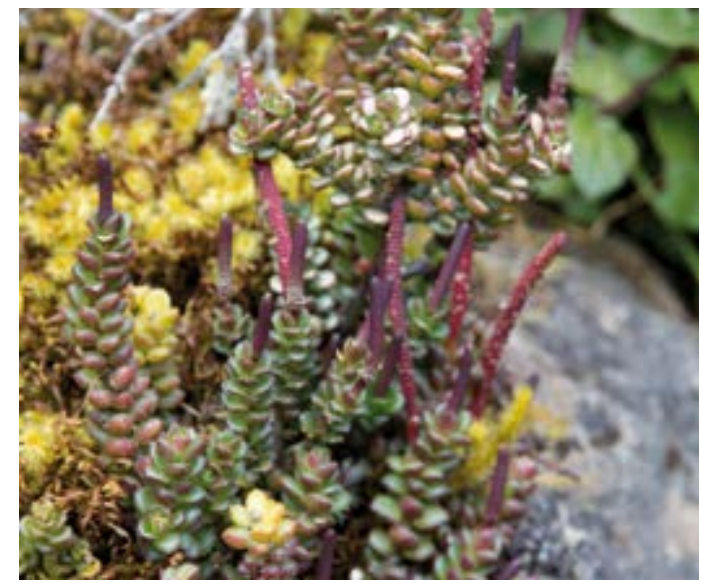

Peperomia hartwegiana

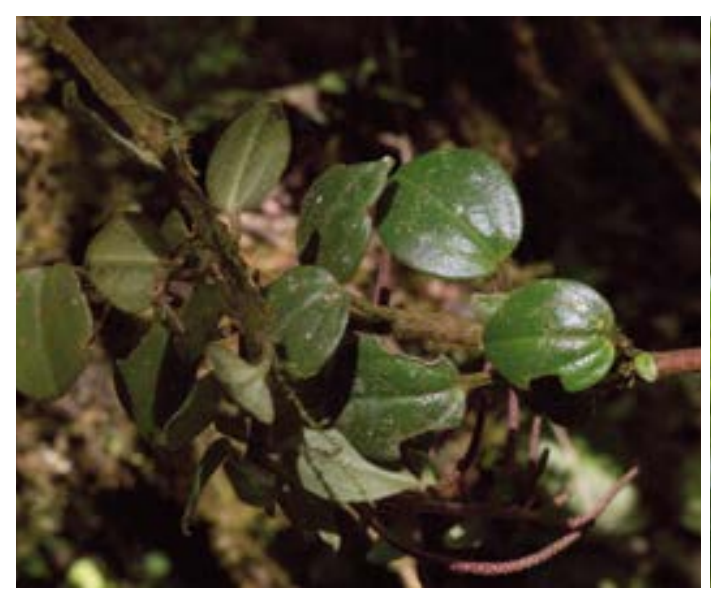

Peperomia quadrifolia
Peperomia galioides

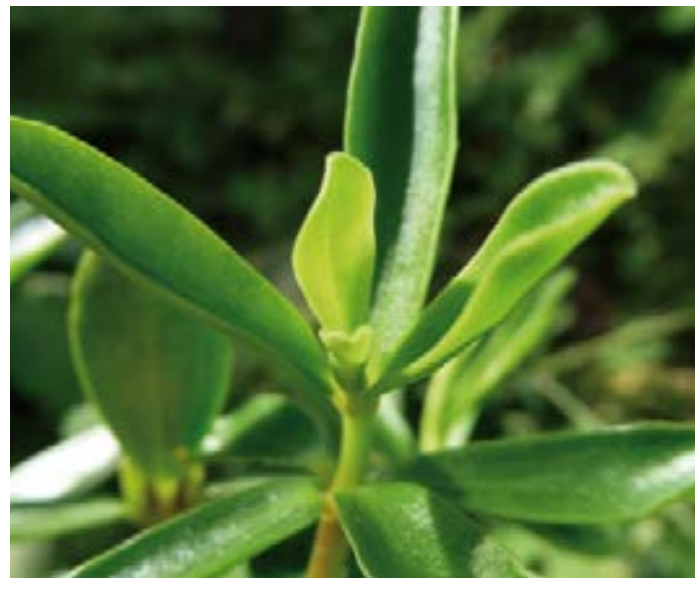

Peperomia inaequalifolia

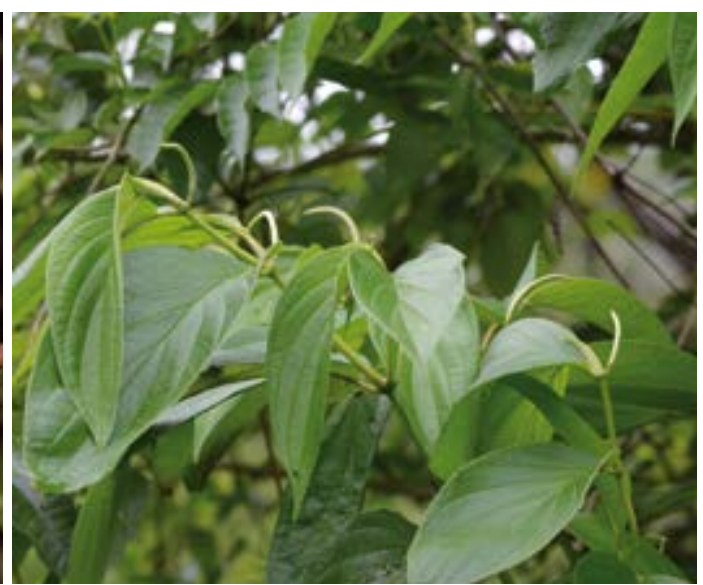

Piper aduncum
PIPERACEAE - Peperomia fraseri C. DC.

Hierba de la Plata, Dolar

Hierba, Andino, $500-1000 \mathrm{~m}$

Uso: 1. Fragancia, Buena Suerte, Amor, Afrodisiaco, Negocios, Seguridad en Viajes, Corazón, Nervios, Ansiedad / Flores y Hojas, fresco / Seguro / Poner 2 pequeñas Tallos en a Seguro. 2. Fragancia, Buena Suerte, Amor, Afrodisiaco, Negocios, Seguridad en Viajes, Corazón, Nervios, Ansiedad / Flores y Hojas, fresco / Tópico / Hervir 10-50g en 8 litros de agua por 30 minutos combinado con 10g cada uno de Condores, Hórnamos, Trenzas, Hierba del Oro, Hierba del Cariño y Hierba de la Estrella. Baño 3 veces por semana por 6 meses. 3. Corazón, Nervios, Ansiedad / Flores y Hojas, fresco / Oral / Hervir 10g en 1 litro de agua por 3 minutos combinado con $10 \mathrm{~g}$ cada uno de Siempre Viva, Toronjil, Pimpinela, Romero, Mejorana, y Pensamiento. Tomar 1 litro por día por 1-30 días.

PIPERACEAE - Peperomia galioides H.B.K.

Congonilla

Uso: Nervios, Amarrar Novio o marido, Depresión, Mal Aire, Corazón, Nerviosidad, Ansiedad de Nostalgia Trauma Emocional / Hojas y Tallos, fresco / Oral / Hervir 5g en 1 litro de agua por 1-2 minutos combinado con $5 \mathrm{~g}$ cada uno de Malva Olorosa, Siempre Viva, Contrahierba y Toronjil. "Cargarlo" en la Mesa y servir al paciente, 1 cucharilla, 3 veces durante la noche y 2 tazas cada día por 3-4 días.

PIPERACEAE - Peperomia hartwegiana Miq.

Hierba de la Plata, Hierba del Tesoro

Hierba, Andino, $3000-5000 \mathrm{~m}$

Uso: 1. Buenos Negocios, Protección, Buena Fortuna, Buena Salud / Flores y Hojas, fresco / Seguro / Mezcla Uso: 1. Buenos Negocios, Protección, Buena Fortuna, Buena Salud / Flores y Hojas, fresco / Seguro / Mezcla
Estándar para Seguro. 2. Florecimiento / Flores y Hojas, fresco / Tropical / Mezcla Estándar para Florecimiento. PIPERACEAE - Peperomia inaequalifolia R. \& P.

Congona

Hierba, Andino, $500-4000 \mathrm{~m}$

Uso: 1. Corazón, Dolor Emocional, Epilepsia, Olvidar Trauma, Olvidar Problemas, Olvidar Mal de amor, Olvidar relaciones malas, Ansiedad, Palpitaciones del Corazon / Planta entera, fresco / Oral / Hervir $5 \mathrm{~g}$ en 1 litro de agua con Congonilla, Toronjil, Pimpinela, Mejorana y Pensamiento. Tallos y Hojas especialmente. 2. Olvidar problemas, Olvidar Mal de Amor, Olvidar relaciones malas, Ansiedad, Palpitaciones del Corazon / Planta entera, fresco / Topico / Quemar Hojas y inhalar humo. 3. Corazon, Dolor emocional, Epilepsia, Olvidar Trauma, Olvidar Mal de Amor, Olvidar Problemas, Olvidar relaciones malas, Ansiedad, Palpitaciones del Corazón / Planta entera, fresco / Oral / Poner en comida hasta se mejore.

PIPERACEAE - Peperomia quadrifolia Trel.

Piri Piri (Macho y Hembra)

Uso: 1. Buena Suerte, Afrodisiaco, Buenos Negocios, Protección, Buena Fortuna, Buena Salud / Planta Uso. 1. Bun / Tópico / Hervir 20-50g de Tallo y Hojas de Piri Piri por 20 minutos en 3-5 litros de anta entera, fresco / Topico / Hervir 20-50g de Tallo y Hojas de Piri Piri por 20 minutos en 3-5 litros de agua con un poco de las hierbas siguientes: Hierba del Buen Querer, Palmerilla, Destrencilla, Lanzetilla, Hierba del Carpintero, Pega-Pega, Siempre Viva, Hierba de la Fortuna, Hierba del Tesoro, Hierba de la Plata, Después de hervir, añadir una botella de perfume favorito. Frotar el cuerpo entero con todas las Hierbas. Despues de hervir, anadir una botella de perfume favorito. Frotar el cuerpo entero con todas las Hierbas. Lavar con agua hervida y dejar secar al aire. No usar jabón o toalla. Baño 3 veces por semana. 2. Buena
Suerte, Afrodisiaco, Buenos Negocios, Protección, Buena Fortuna, Buena Salud / Planta entera, fresco / Tópico / Añadir 3 litros de agua a 15g de material de planta y $10 \mathrm{~g}$ cada uno de Hierba de la Fortuna, Dólar, Hierba de la Plata, Chupaflor, Hierba del Halago, Tabú y Pétalos de Rosas: Roja, Blanca y RojaAmarilla. También añadir Agua Florida, Azúcar Blanco y Jugo de Lima. Baño Martes, Viernes y el Martes siguiente. Paciente puede repetir cuando se necesita. 3. Buena Suerte, Afrodisiaco, Buenos Negocios, Protección, Buena Fortuna, Buena Salud / Planta entera, fresco / Seguro / Mezcla Estándar para Seguro. PIPERACEAE - Piper aduncum L.

Yerba del Soldado, Tilonga, Matico, Mogo-Mogo

Arbusto, Amazónico, Andino, 0-3000m

Uso: 1. Resfrío, Hongos, Tos, Heridas, Bronquitis, Escalofríos, Tuberculosis, Para Hemorragias / Hojas, fresco o seco / Oral / Hervir 5-10 Hojas en 1 litro de agua por 3-5 minutos mezclado con $5 \mathrm{~g}$ cada uno Se Salva Real, Escorcionar 


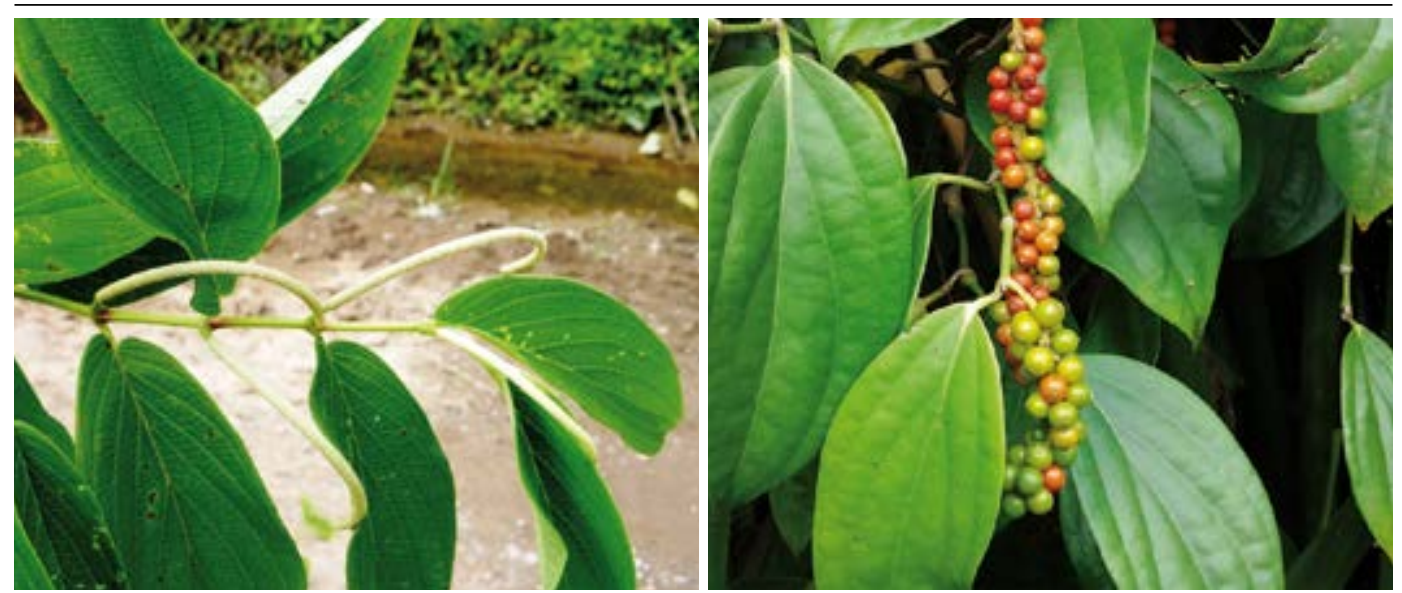

Piper aequale

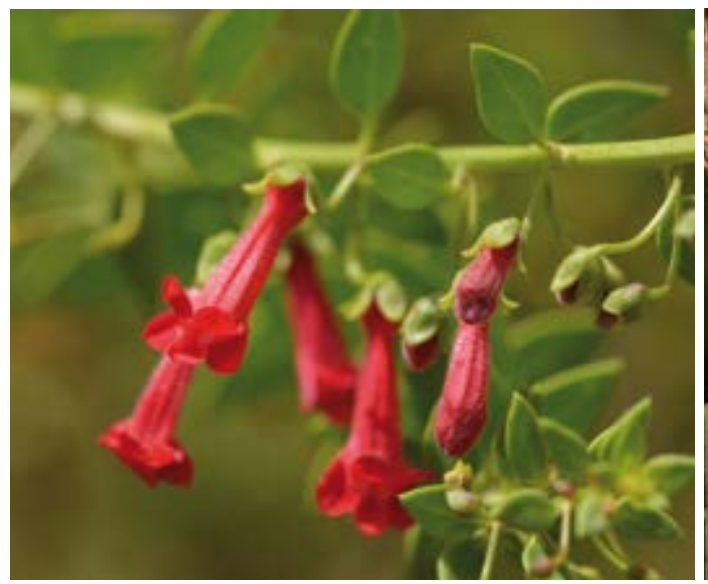

Galvesia fruticosa

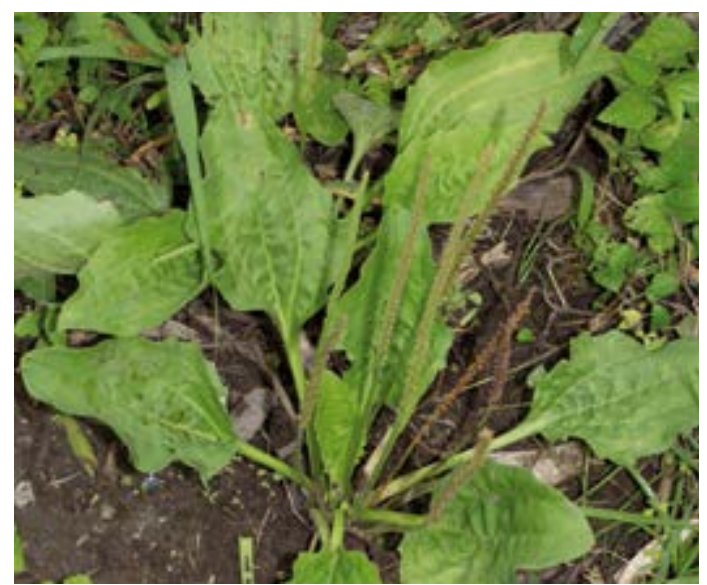

Plantago major
Piper nigrum

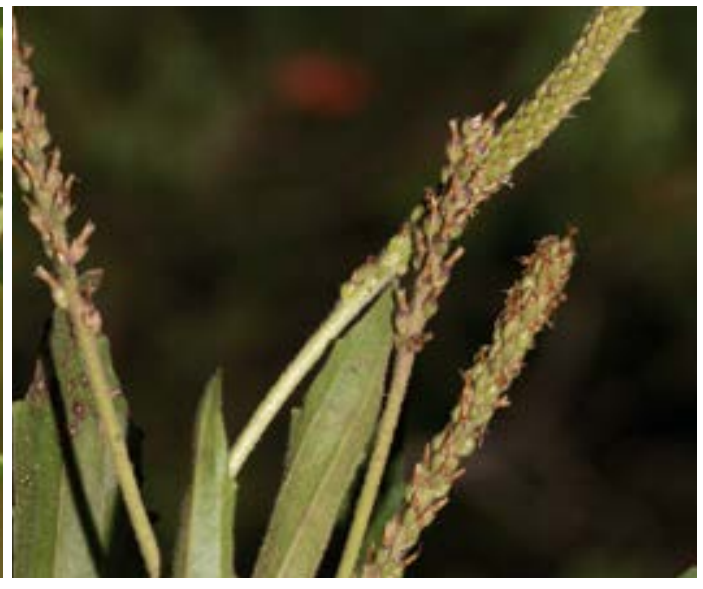

Plantago linearis

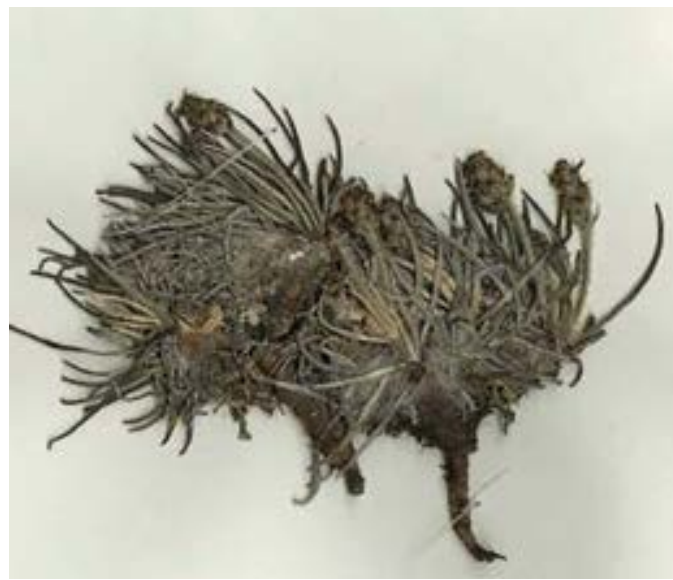

Plantago sericea de agua por 10 minutos combinado con $10 \mathrm{~g}$ cada uno de Eucalipto, Laurel, Verbena y Altamisa. Baño dos veces por semana. Como alternativa moler y polvorizar $200 \mathrm{~g}$ del material de la planta. Aplicar el polvo en área afectadas, una vez por día hasta que la herida se sana.

PIPERACEAE - Piper aequale Vahl.

Modoquero, Mogoquero

Arbusto, Amazónico, Andino, 0-2500m

Uso: Hígado, Hepatitis, Infecciones internas / Hojas y Tallos, fresco o seco / Oral / Hervir $5 \mathrm{~g}$ en 1 litro de agua mezclado con $5 \mathrm{~g}$ cada uno de Flor de Overo y Boldo. Tomar 3 veces al día por 1 semana.

\section{PIPERACEAE - Piper nigrum L.}

Pimienta Negra (

Arbusto, Amazónico, 0-500m, introducido y cultivado

Uso: Bronquitis / Semillas, secas / Oral / Añadir 10g cada uno de Asma Chilca, Borraja, Escorcionera, Mullaca, Vira Vira, Veronica, Canela y a Tubérculo de Ajo. Hervir por 5 minutos. Tomar caliente. Tomar 1 taza 2 veces por día por 2 semanas.

PLANTAGINACEAE - Galvesia fruticosa J. Gmelin

Curil, Machacha

Hierba, Andino, Costa, $0-1500 \mathrm{~m}$, maleza

Uso: 1. Artritis, Reumatismo, Dolor de Nervios / Flores, Hojas y Tallos, fresco / Tópico / Hervir 50g en 1/2 litro de Aguardiente. Frotar 1 taza cada día en área afectada por 1-6 meses. 2. Resfrío, Bronquitis, Asma / Flores, Hojas y Tallos, fresco / Oral / Hervir 10g cada uno de las Flores y Tallos de Curil, Zarzamora, Matico y Nogal en 1 litro de agua por 10 min. Tomar 3-4 veces por día por 2 semanas.

PLANTAGINACEAE - Plantago linearis Kunth

Llantén, Llantén de la Costa, Llantén Serrano

Hierba, Andino, 1500-4000m

Uso: 1. Inflamación de Heridas, Limpia de Heridas / Planta entera, fresco / Tópico / Hervir 1 planta entera con $10 \mathrm{~g}$ de Matico en $1 / 2$ litro de agua. Dejarlo enfriar un poco hasta templado, remover la pláones, Heridas, Vejiga / Planta entera, fresco / Oral / Hervir 10 rramos en 1 litro de agua por 10 min Rine 4 veces por dra 1 mes. Pude 4 veces por dia por 1 mes. Puede danar vista, no usar más que 1 mes. 3. Tos, Bronquitis / Raiz, fresco / Oral / Hervir 2 raíces en 1 litro de agua por 3 minutos y combinar con $10 \mathrm{~g}$ cada uno de Matico, Nogal,
Vira Vira, Eucalipto. Tomar 4 veces por día como se necesita.

PLANTAGINACEAE - Plantago major $\mathrm{L}$.

Llantén

Hierba, Amazónico, Andino, Costa 0-2500m, maleza, introducido

Uso: 1. Hemorroides, Tumores de la Piel (Benignos), Limpia vaginal, Heridas. / Hojas, fresco / Tópico / Hervir 6 Hojas en 1 litro de agua por 5 minutos y mezclar con $10 \mathrm{~g}$ cada uno de Matico, Artemisa, Salvia Real, Retania y Piedra Azul. Lavar una vez por día por 8 días. 2. Purificación de la Sangre, Inflamación, Hígado, Rińones, Mal aliento por contaminación de un órgano / Hojas, fresco / Oral / Hervir 20-30g en 1 litro de aguar3-5 minutos y mezclar con $10 \mathrm{~g}$ cada uno de Ortiga, Berros, Lancetilla, Chanca Piedra y Flor Blanca. Tomar una vez al día por 3-8 días. Tomar demasiado puede dañar vista. 3. Artritis, Dolor, Esguinces, Contusiones, Infecciones / Hojas, fresco / Tópico / Emplasto: Aplicar 5 Hojas con o sin agua, 1-2 veces por día por 2-8 días. Aplicar caliente. 4. Bronquitis, Tos, Cólico, Golpes infectados / Semillas, fresco o seco / Oral / Hervir 10g o $5 \mathrm{~g}$ en 1 litro de agua. Tomar 1 taza en la mañana, mediodía, y en la noche antes de comer.

PLANTAGINACEAE - Plantago sericea Ruiz \& Pav. var. sericea

Rabo de Paloma, Hierba del Susto (de Cerro)

Rabo de Paloma, Hierba del Su

Uso: Susto / Hojas, fresco / Oral / Hervir 2-3g en 1 litro de agua por 3-5 minutos. Mezclar con Toronjil y Mejorana (3g cada uno). Tomar 3 veces por día. 


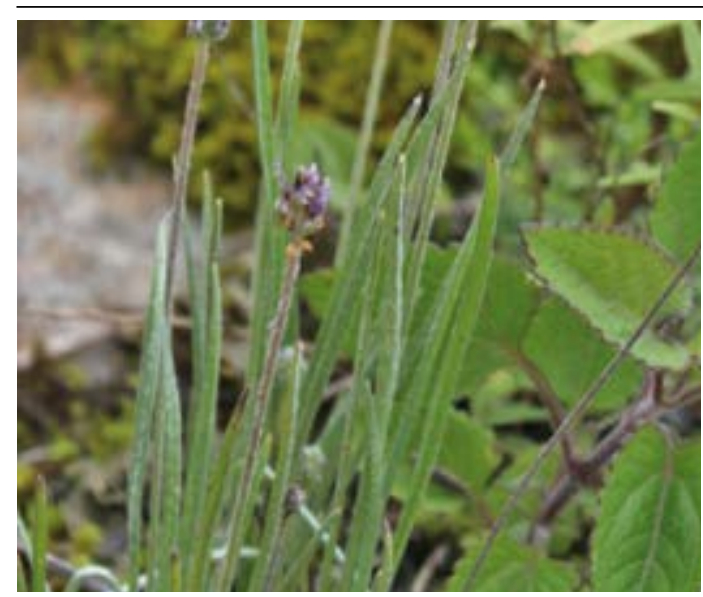

Plantago sericea var. lanuginosa

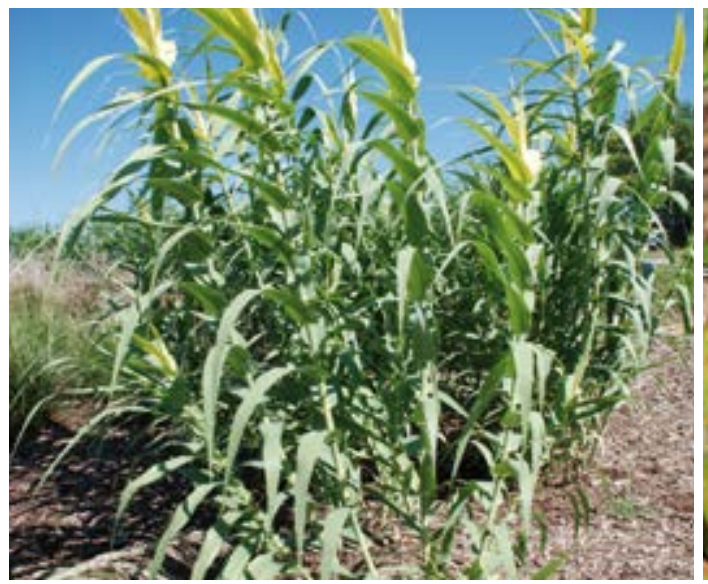

Arundo donax

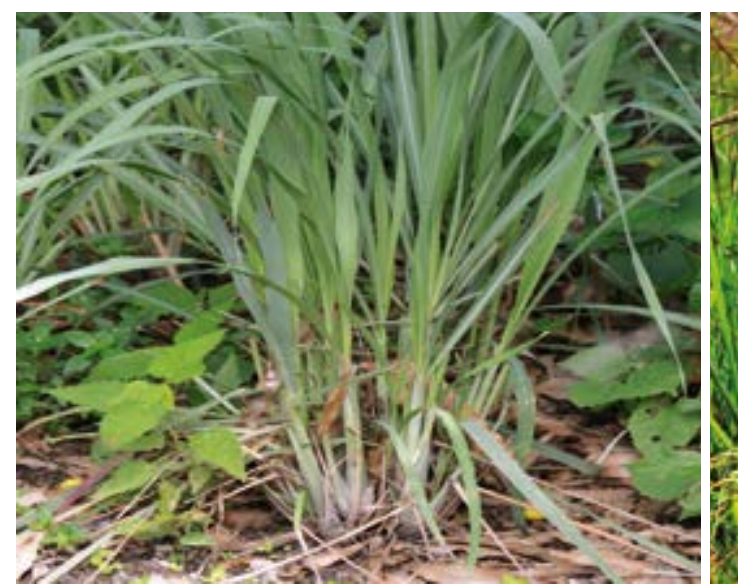

Cymbopogon citratus

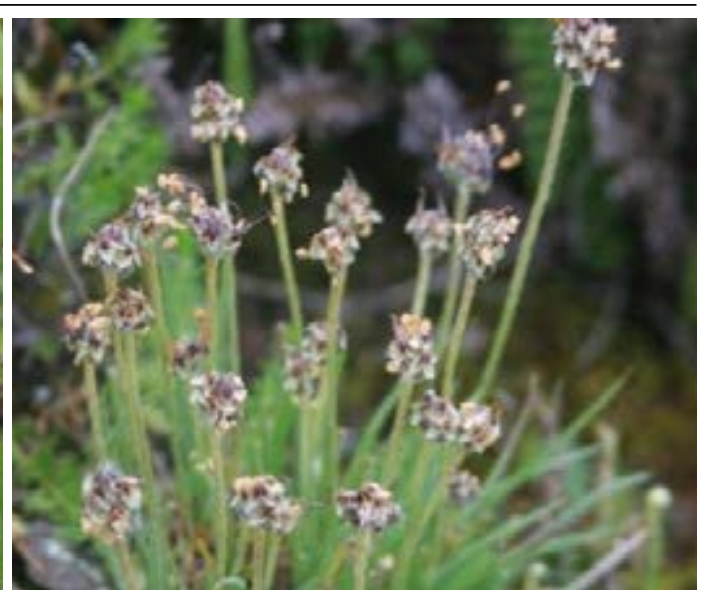

Plantago sericea subsp. sericans

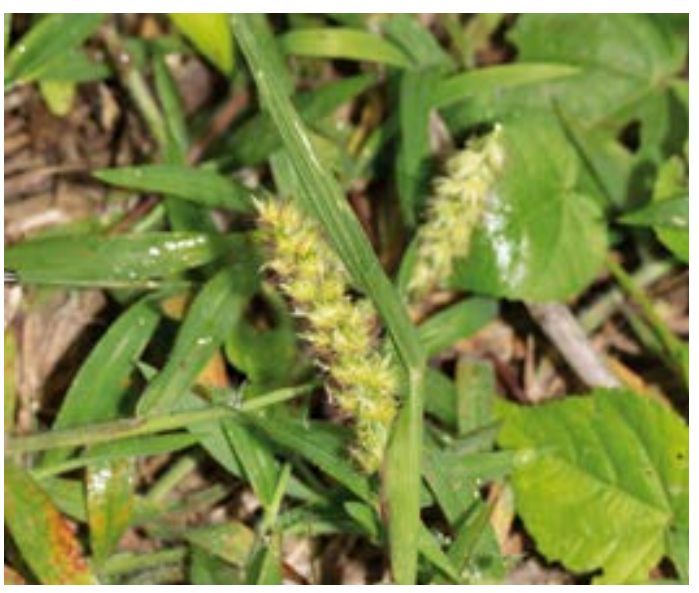

Cenchrus echinatus

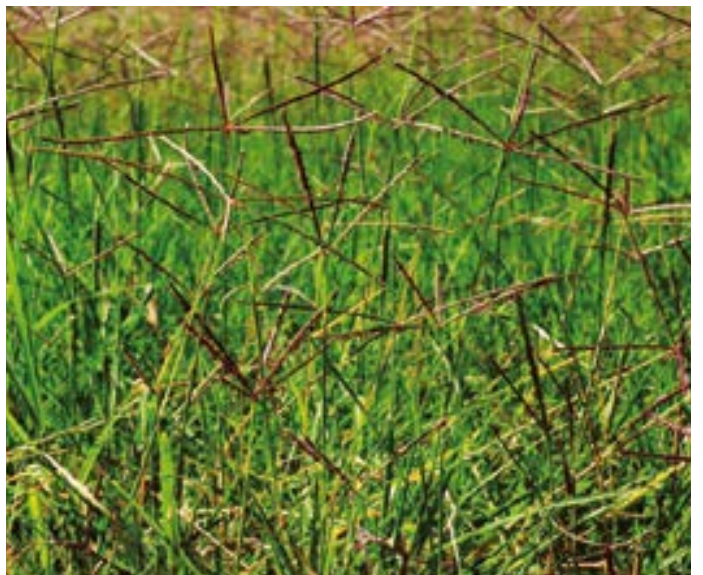

Cynodon dactylon
PLANTAGINACEAE - Plantago sericea R. \& P. var. lanuginosa Grieseb.

Pajilla Blanca

Hierba, Andina, $1500-4500 \mathrm{~m}$

Uso: Descargo vaginal / Planta entera, fresco o seco / Oral / Hervir 10g cada uno de Pajilla Blanca y Anga Macha en 1 litro de agua por 3-4 minutos. Tomar caliente, 1 taza 2-3 veces por día por 1 mes.

PLANTAGINACEAE - Plantago sericea subsp. sericans (Pilg.) Rahn

Paja Blanca

Hierba, Andina, 1500-4500m

Uso: Dolor de ovarios, Inflamación de ovarios, Inflamación de útero / Tallos, fresco o seco / Oral /

Hervir $3 g$ en 1 litro de agua por 3-4 min. Tomar 3 veces por día.

POACEAE - Arundo donax L.

Carrizo, Caña Hueca

Hierba, Andina, 1500-3000m

Uso: 1. Hemorroides / Planta entera, fresco / Tópico / Cortar planta fresca donde crece. Sentarse cerca de riachuelo y tener otra persona machucar punta de planta parra recoger jugo. Poner en el área afectada cada mańana por 1 semana. 2. Rasgaduras en los ojos, Opacidad de ojos / Planta entera, fresco / Tópico / Macerar 5 Tallos durante la noche en 1 vaso de agua. Poner 1-5 gotas en ojo afectado una vez por día por 3 días o como se necesita.

POACEAE - Cenchrus echinatus L

Cadillo, Abrojo

Hierba, Andina, Costa, 0-3000m

Uso: Dolo agudo en cualquier parte del cuerpo, Inflamación (General), Piel, Intestinos, Enfermedad de Hígado, Enfermedad de Vejiga, Tumores, Enfermedades Urinarias / Planta entera, fresco / Oral / Hervir $100 \mathrm{~g}$ total de Cadillo, Amor Seco, Lampazo y Trinozo en 1/2 taza de agua por 3 minutos. Tomar 1/4 taza una vez por día por 3 días.

POACEAE - Cymbopogon citratus (DC.) Stapf.

Hierba Luisa, Cedrón, Maria Luisa

Hierba, Amazónica, Andina, Costa, 0-2500m, introducida y cultivado

Uso: Resfrío, Tos, Nervios, Gripe, Venas varicosas, Dolor de Estómago, Circulación de sangre, Cáncer / Hojas, Raíces y Tallos, fresco o seco / Oral / Hervir 1 litro de agua. Añadir 5g de Hierba Luisa. Dejar por 2-3 minutos. Ańadir un poco de Tequila. Tallos son lo mas fuerte. Tomar caliente con comida (mejor para desayuno).

POACEAE - Cynodon dactylon (L.) Persoon

Grama Dulce

Hierba, Costa, 0-1500m, maleza, introducida

Uso: Quistes de ovario, Quistes de útero, Inflamación de Riñones, Inflamación (General), Útero, Fibroides, Prolapso de útero / Tallos, seco / Oral / Hervir 10g en 1 litro de agua mezclado con 10g cada uno de Cola de Caballo, Verbena, Amor Seco, Malva, Flor Blanca, Hierba de Apostema, Zarzaparrilla y Hierba del Toro. Tomar 1 litro cada día por 6-12 meses. 

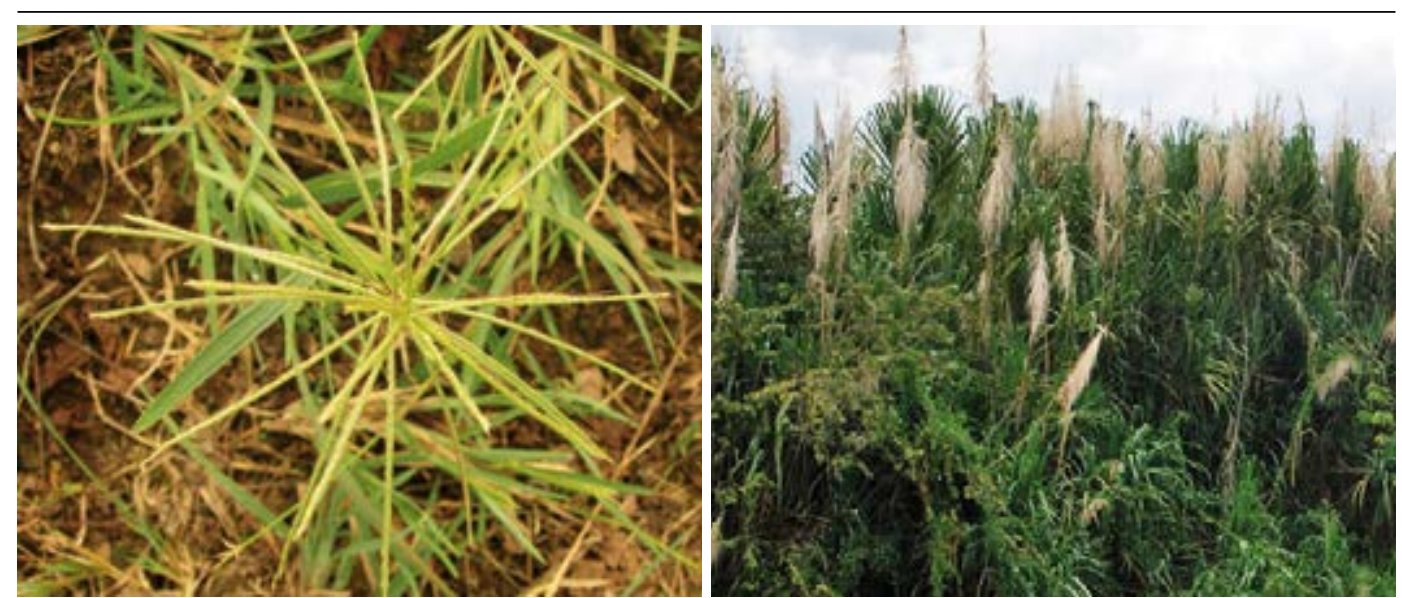

Digitaria ciliaris

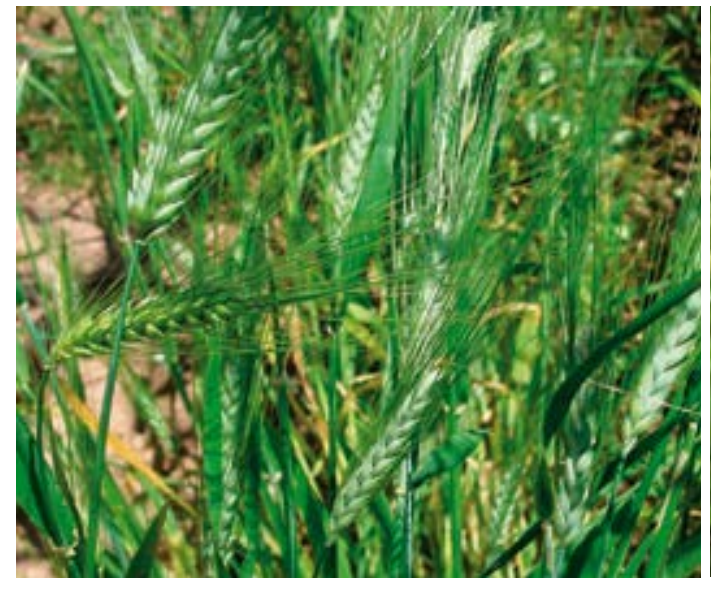

Hordeum vulgare

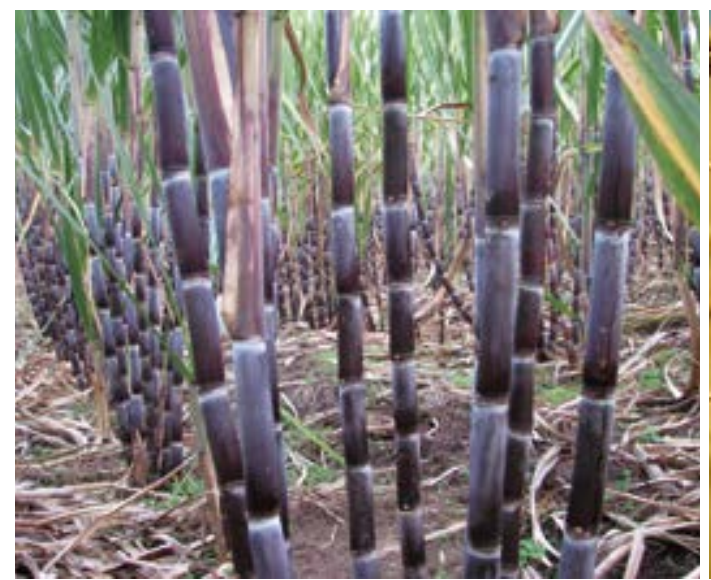

Saccharum officinarum
Gynerium sagittatum

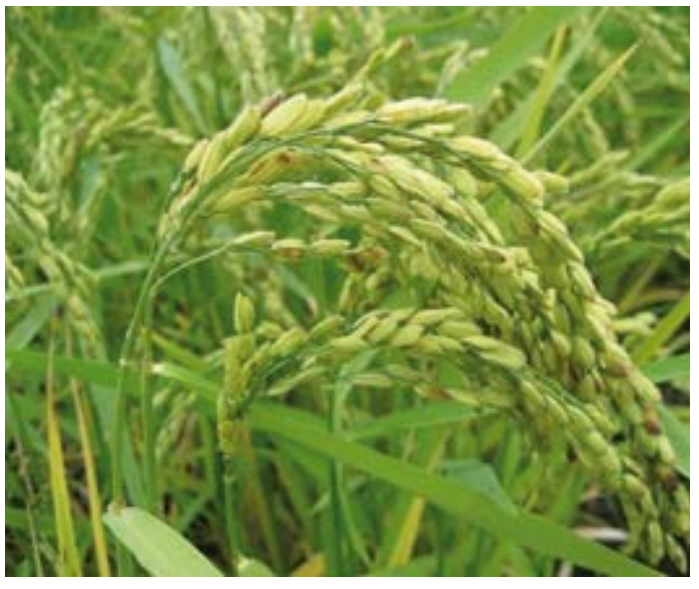

Oryza sativa

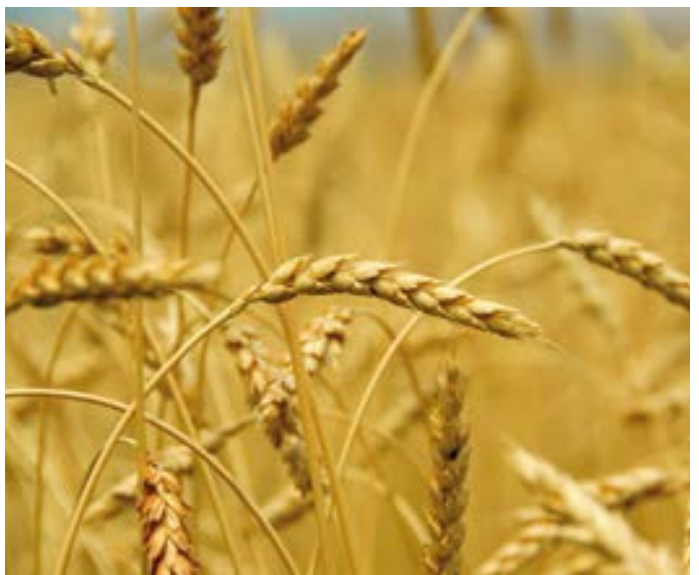

Triticum aestivum
POACEAE - Digitaria ciliaris (Retz.) Koehler.

Hierba de los Siete Vientos

Hierba, Amazónica, Andina, 0-2500m, maleza

Uso: Mal Aire / Hojas y Tallos, fresco o seco / Tópico / a 1/2 botella de Aguardiente añadir 200g de Hierba de los Siete Vientos, 1 botella de Agua Florida, 1 botella de Agua Cananga y unos Tallos de Hierba del Aire, Ishpingo, Samala, y Hierba del Dominio. Dejar 15 días. Soplar sobre el paciente dos veces por semana por 1 mes.

POACEAE - Gynerium sagittatum (Aublet.) P. Beauvois

Cańa Brava

Hierba, Amazónica, 0-500m

Uso: 1. Hemorroides / Planta entera, fresco / Tópico / Cortar planta fresca donde crece. Sentarse cerca de riachuelo y tener otra persona machucar punta de planta parra recoger jugo. Poner en el área afectada cada mańana por 1 semana. 2. Rasgaduras en los ojos, Opacidad de ojos / Planta entera, fresco / Tópico / Macerar 5 Tallos durante la noche en 1 vaso de agua. Poner 1-5 gotas en ojo afectado una vez por día por 3 días o como se necesita.

POACEAE - Hordeum vulgare L.

Cebada

Hierba, Andina, 1500-3000m, introducido y cultivado

Uso: Inflamación de Riñones, Inflamación (General) / Semillas, secas / Oral / Hervir 2 litros de agua con 250g de Semillas tostadas de Cebada, $50 \mathrm{~g}$ de Linaza y $10 \mathrm{~g}$ cada uno de Cola de Caballo, Amor Seco y Malva. Tomar 1 taza 3-4 veces por día por 1 mes.

\section{POACEAE - Oryza sativa L.}

Arroz

Hierba, Amazónica, Andina, 0-1000m, introducida y cultivad

Uso: Diarrea, Cólico / Semillas, secas / Oral / Tostar 10g de arroz hasta Amarillo. Poner en 1/2 litro de agua con 1 pedazo de Canela y 1 cucharilla de Azúcar. Hervir 3-4 minutos. Tomar caliente, 2-3 veces por día por 2 días.

POACEAE - Saccharum officinarum L.

Caña de Azucar, Caña Dulce

Hierba, Amazónica, Andina, Costa, 0-2000m, introducida y cultivada

Uso: 1. Depresión, Dolor (psicológico), Bronquitis, Afrodisiaco / Azúcar Fresco / Tópico / Azúcar se pone en una papa para fermentar. El jugo se pone en los ojos. 2. Huesos (Fracturado) / Tallos, fresco / Oral / Extraer jugo de la caña. Tomar frío 1 vaso por día por 2-2 1/2 meses. 3. Inflamación de Rińones, Inflamación de Próstata / Tallos, fresco / Oral / Hervir 20g de cada uno de las hierbas siguientes: Caña Dulce (con cáscara), Cola de Caballo, Linaza, Chanca Piedra, Boldo y Pata de Perro en 1/2 litro de agua por 5 minutos. Tomar frío 1 taza por día por 20 días.

POACEAE - Triticum aestivum $\mathrm{L}$.

Trigo

Hierba, Andino, 2500-4000m, introducido y cultivado

Uso: Infección vaginal, Descenso vaginal / Semillas, secas / Tópico / Añadir 100g de la planta a 1/2 litro de agua. Hervir la mezcla por 5 minutos. Aplicar como ducha vaginal templado. No exigir dosis. Aplicar 3 veces por día por 15 días. 

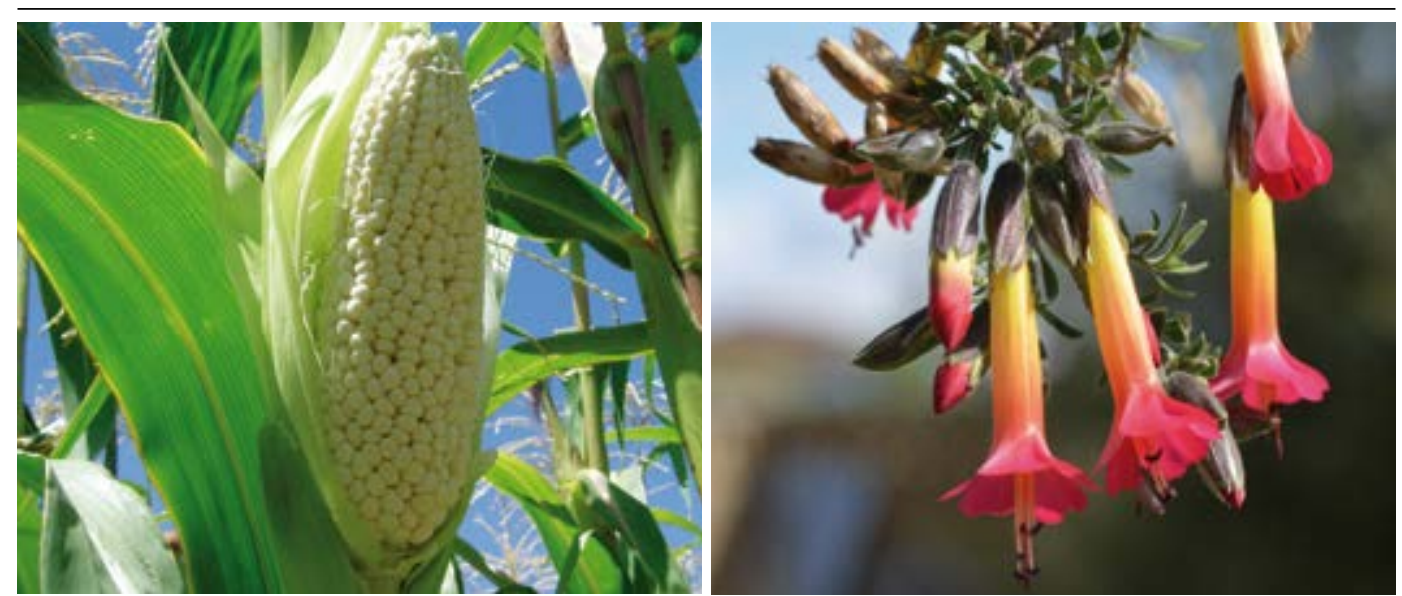

Zea mays

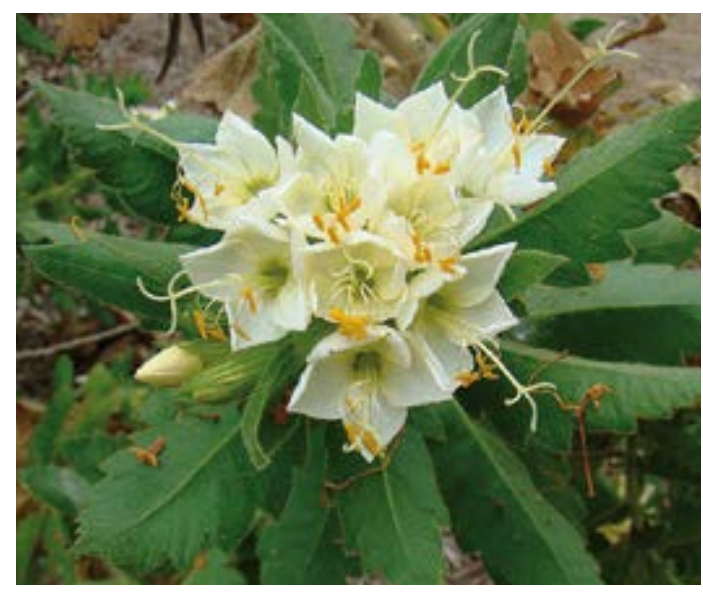

Cantua quercifolia

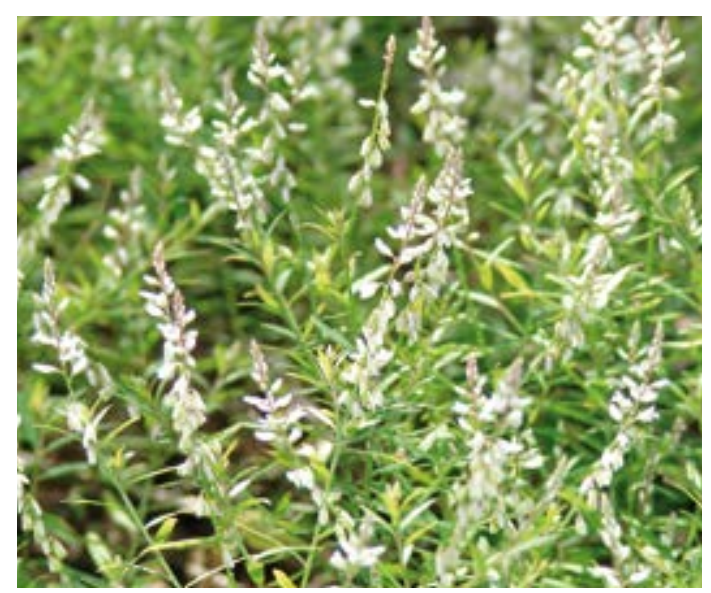

Polygala paniculata
Cantua buxifolia

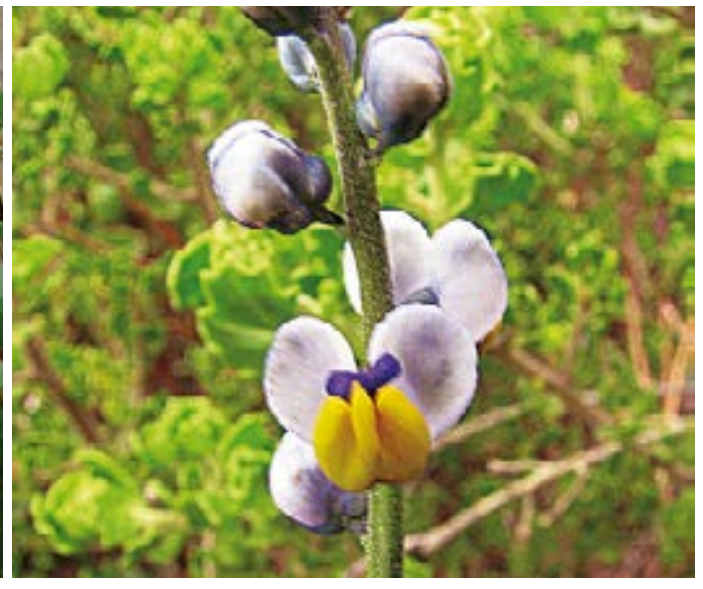

Monnina pterocarpa

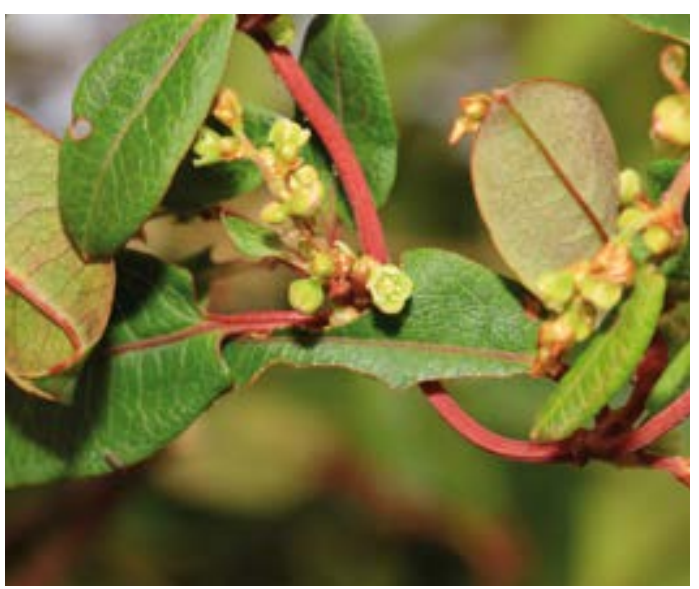

Muehlenbeckia tamnifolia
POACEAE - Zea mays L.

Espiga de Maíz, Chuño de Maíz, Maíz (Corn)

Hierba, Amazónica, Andina, Costa, 0-4000m, introducido y cultivado

Uso: 1. Riñones, Inflamación (Interno) / Flores, fresco / Oral / Hervir 10g de Espiga de Maíz en 1 litro de agua por 3 minutos. Tomar 4 veces por día o como se necesita. 2. Escalofríos, Dolor de pulmones, Inflamación de Riñones / Semillas, secas / Oral / Hervir $1 / 2$ litro de agua, $1 / 2 \mathrm{~kg}$ de maíz y $10 \mathrm{~g}$ cada uno de dulce de Caña por 5-10 minutos hasta Maíz esta cocido. Servir caliente. Calentar si no esta fresco. Después de comer quedarse en la casa Comer dos veces por día por 2 días. 3. Inflamación (General), Reducción de Enojo / Semillas, secas / Tópico / Moler 1/2kg de maíz en 5 litros de agua. Dejar por la noche y Bańarse a las 6 de la mañana sin jabón una vez al mes. 4. Indigestión, Acidez, Acido de Estómago / Hojas, fresco / Oral / Machucar 100g de Hojas y Tallos y filtrar el jugo con un pedazo de tela. Tomar frío en ayuno. Tomar durante desayuno, 1 vaso pequeño una vez por día por 10 días.

POLEMONIACEAE - Cantua buxifolia Jus. ex Lam.

Candu

Hierba, Andina, 2500-4000m

Uso: Susto, Impedimento de Habla / Planta entera, fresco o seco / Tópico / Hervir 10g de la planta en 1 litro de agua y ańadir mezcla de $10 \mathrm{~g}$ cada uno de Eucalipto, Chancas de Muerto y Flor de Chochos. Baño 3 veces por semana (Martes, Viernes, Martes) en la tarde. Con cuidado golpear niños en la boca para inducir que hablen.

POLEMONIACEAE - Cantua quercifolia Jus.

Dormidera, Hierba Adormecedora, Tutapure Morado (Chico)

Hierba, Andina, Costa, 0-2500m

Uso: 1. Insomnio, Sedante, Buena Suerte, Nervios / Hojas y Tallos, fresco / Oral / Hervir 3-5g en 1 litro de agua por 3 min. Tomar 1 taza por día en la noche. 2. Daño/Hechicería, Alergias de la piel / Hojas y Tallos, fresco / Tópico / Hervir Hierba en 3 litros de agua y absorber vapores sobre la mitad del cuerpo. Se puede combinar con Chingue, Huaminga y Chuque. Bańo una vez al mes.

POLYGALACEAE - Monnina pterocarpa Ruiz \& Pav

Clarín

Hierba, Andina, Costa, 0-2500m

Uso: 1. Infección de Garganta / Flores y Hojas, fresco / Oral / Apretar 10-15 Flores y Hojas para remover el jugo. Tomar frío, 1/4 vaso pequeño una vez por día por 8 días. 2. Infección de oído / Flores y Hojas, fresco / Tópico / Usar la misma mezcla para gotas; 5 gotas en cada oreja 2 veces por día (6 de la mañana y 6 de la tarde) por 3 días.

POLYGALACEAE - Polygala paniculata L.

Canchalagua

Hierba, Andina, Amazónica, 0-3000m, maleza

Uso: Circulación de sangre / Planta entera, fresco o seco / Oral / Hervir 3-5g en 1 litro de agua por 3 min. Tomar 3 veces al día por 1 semana.

POLYGONACEAE - Mueblenbeckia tamnifolia (Kunth) Meisner

Chumbiauri, Chumbiauria

Hierba, Andina, 1500-4000m

Uso: 1. Artritis, Huesos, Reumatismo, Apoyo a dormir, Cáncer / Raíz, fresco / Oral / Hervir 4 kg Chumbiauri con $10 \mathrm{~g}$ cada uno de Hierba de la Postema y Hierba China en 16 litros de agua por 8 horas hasta se quedan 2 litros. Tomar 1 pequeña taza de Té mezclado con 1 taza de Miel en la noche por 1 mes. 2. Fiebre / Hojas, fresco / Tópico / Machucar y mezclar con Aguardiente. Hacer una Limpia dos veces en 1 día, solo un día. 


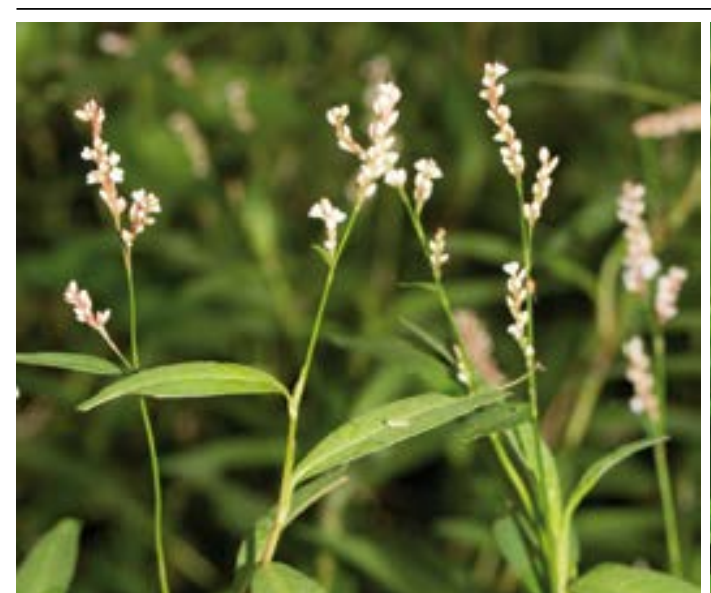

Polygonum hydropiperoides

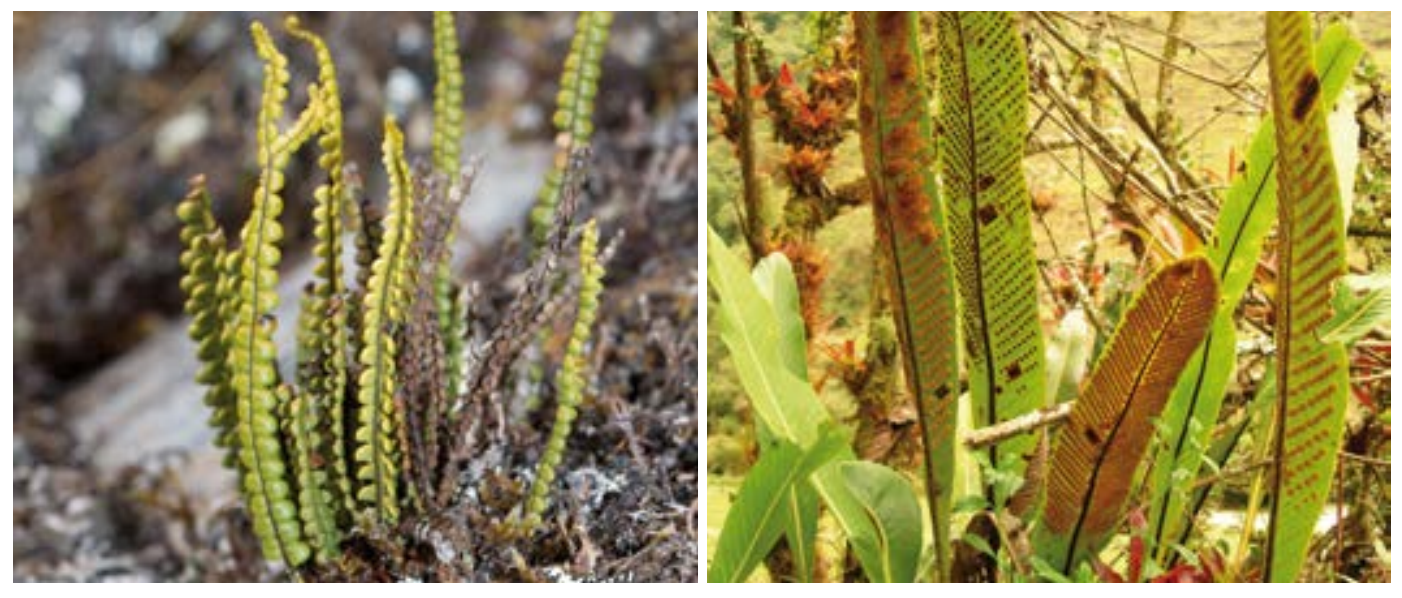

Grammitis moniliformis

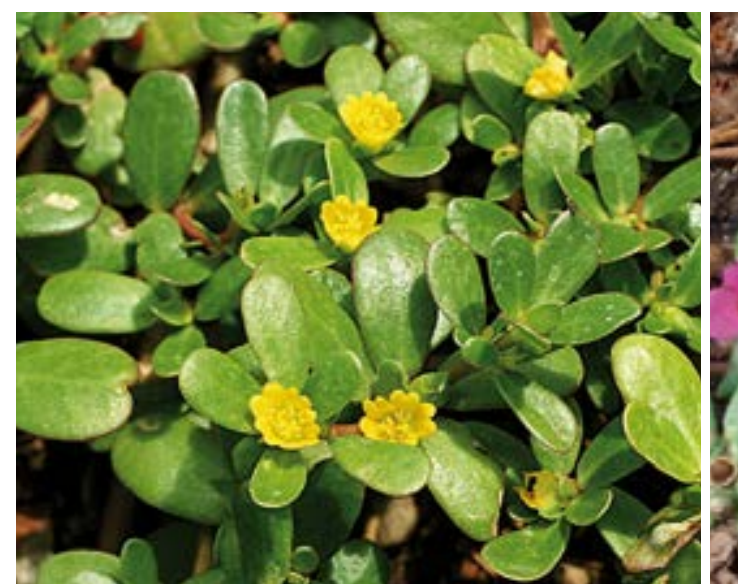

Portulaca oleracea

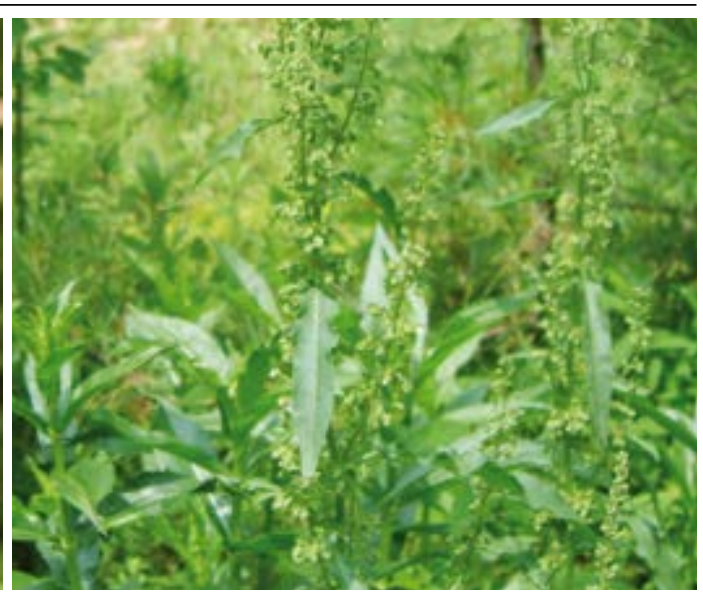

Rumex crispus

Polypodium crassifolium

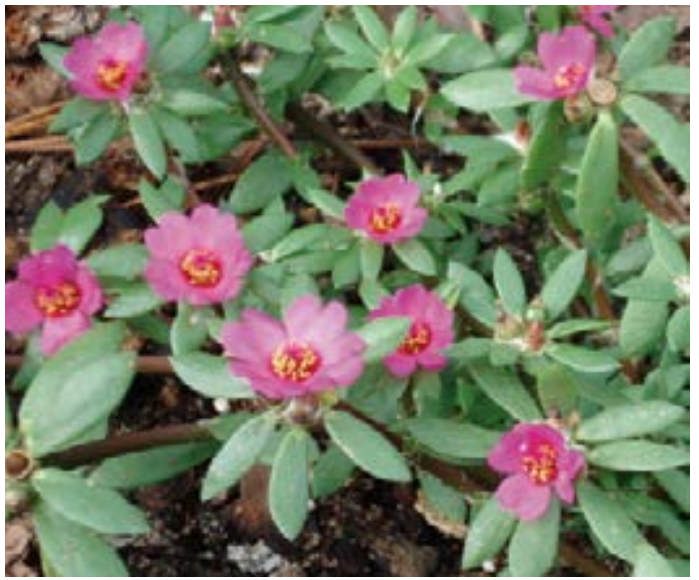

Portulaca pilosa
POLYGONACEAE - Polygonum hydropiperoides Michaux

Pica Pica

Hierba, Andina, Amazónica, 0-4000m, maleza

Uso: 1. Infección de útero, Inflamación de Rińones / Planta entera, fresco / Oral / Hervir 20g de Acelga en 1 litro de agua por 10 minutos. Tomar 3 veces al día por 1-1/2 meses. 2. Inflamación (Órganos femeninas internas), Inflamación Vaginal / Planta entera, fresco / Tópico / Hervir planta entera en 1/2 litro de agua por 10 minutos. No mezclar con otras plantas. Elevar piernas en posición de "V". Verter liquido en Vagina y dejar por 10 minutos. Ir al baño y contraer músculos de la vagina hasta expulsar liquido. Repetir una vez mas de inmediato.

POLYGONACEAE - Rumex crispus L.

Acelga, Lengua de Vaca, Hojas de Mala Hierba

Hierba, Andina, 1000-4000m, maleza

Uso: 1. Infección de útero, Inflamación de Riñones / Planta entera, fresco / Oral / Hervir 20g de Acelga en 1 litro de agua por 10 minutos. Tomar 3 veces al día por 1-1/2 meses. 2. Inflamación (Órganos femeninas internas), Inflamación Vaginal / Planta entera, fresco / Tópico / Hervir planta entera en 1/2 litro de agua por 10 minutos. No mezclar con otras plantas. Elevar piernas en posición de "V". Verter liquido en Vagina y dejar por 10 minutos. Ir al baño y contraer músculos de la vagina hasta expulsar liquido. Repetir una vez mas de inmediato.

POLYPODIACEAE - Grammitis moniliformis (Lag. ex Sw.) Proctor

Trencilla Pequeña

Helecho, Andina, 3000-4500m

Uso: Garantía por Éxito permanente, Prevención de mala suerte / Planta entera, fresco / Seguro / Poner 4-5 pequeñas Ramas en una botella.

POLYPODIACEAE - Polypodium crassifolium L.

Lengua de Ciervo, Lengua de Siervo, Calaguala

Helecho, Andino, 3000-3500m

Uso: Inflamación de Rińones, Próstata, Vejiga, Inflamación (Interno), Inflamación (General), Hígado, Rińones, Úlceras / Tallos, fresco / Oral / Hervir 10g en 1 litro agua por 10 minutos. con 10g total de Pie de Perro, Amor Seco, Cola de Caballo y Cáscara de piña. Tomar 1 litro cada día por 1 mes. Tomar templado.

PORTULACACEAE - Portulaca oleracea L. subsp. tuberculata Danin \& H.G. Baker Verdolaga

Hierba, Amazónica, Andina, 0-1000m, maleza

Uso: Hígado, Rińones, Hepatitis, Inflamación del hígado, Limpia de Hígado / Planta entera, fresco / Oral / Hervir Boldo, Flor de Arena y Cola de Caballo en 1 litro de agua por 3 minutos. La cantidad total debe ser de 10g. Tomar 1 taza 3-4 veces por día por 1 mes. Se puede también comer como ensalada con aceite de olivo, limón y sal una vez por semana.

PORTULACACEAE - Portulaca pilosa L.

Verdolaga

Hierba, Amazónica, Andina, 0-4500m, maleza

Uso: Perdida de cabello, Higiene / Raíz y Tallos, fresco / Tópico / Machucar Tallos y raíz y drenar liquido para usar como champú en ducha o baño. 


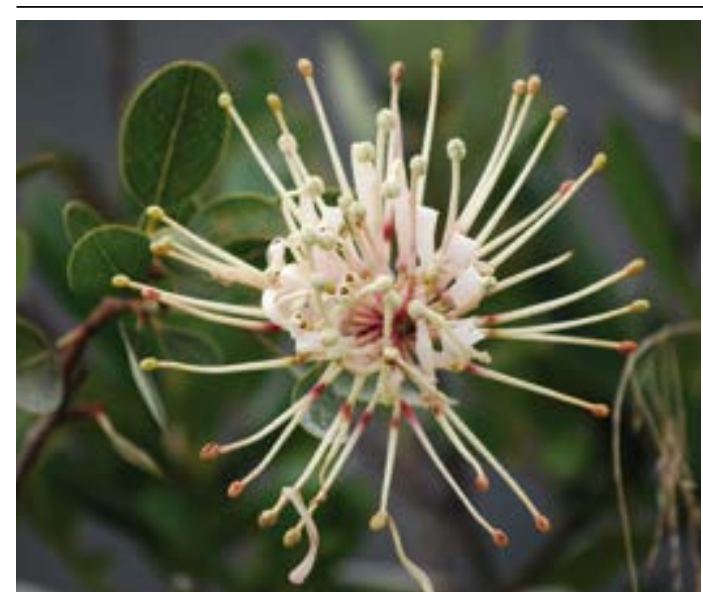

Oreocallis grandiflora

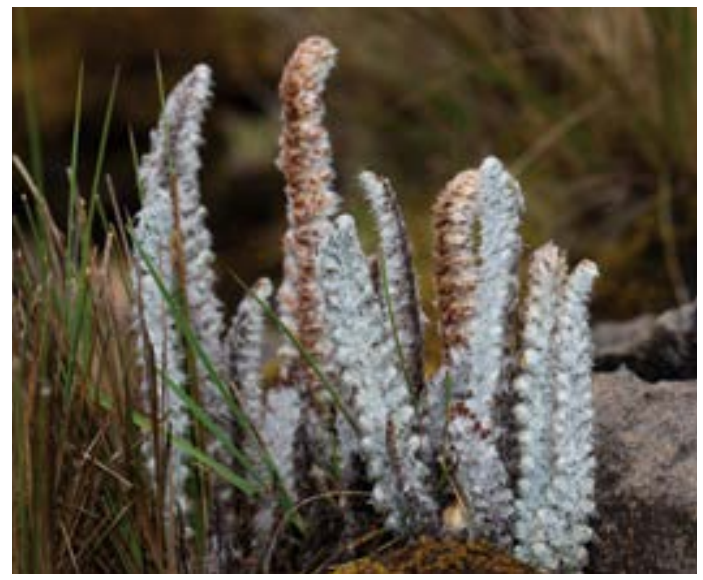

Cheilanthes myriophylla

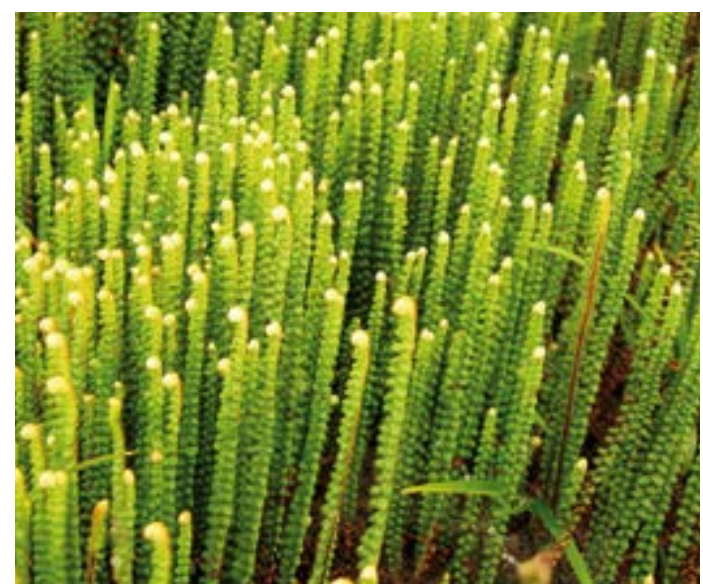

Jamesonia rotundifolia

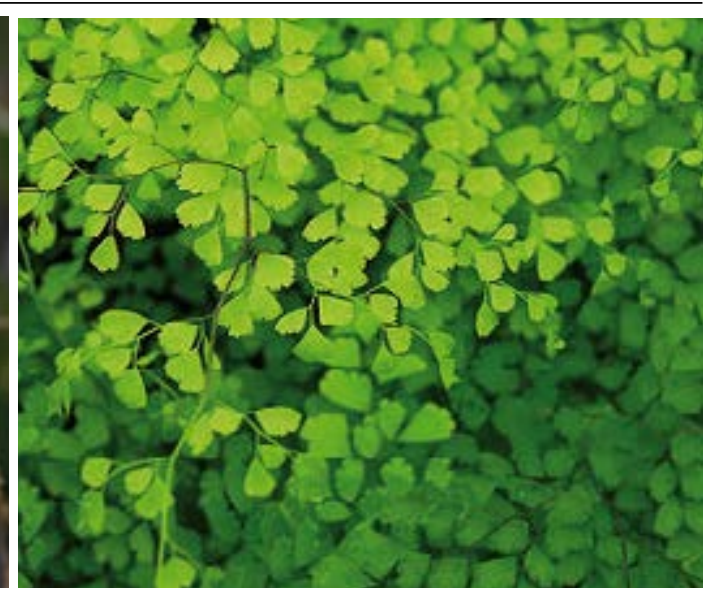

Adiantum concinnum

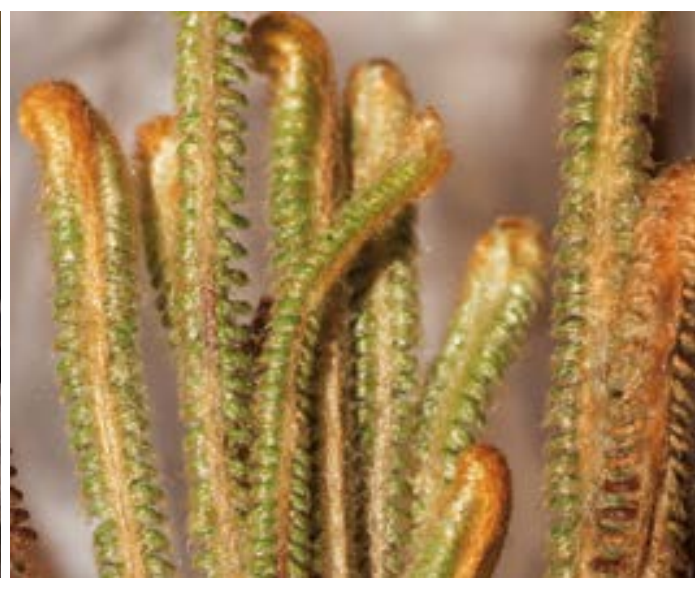

Jamesonia goudotii

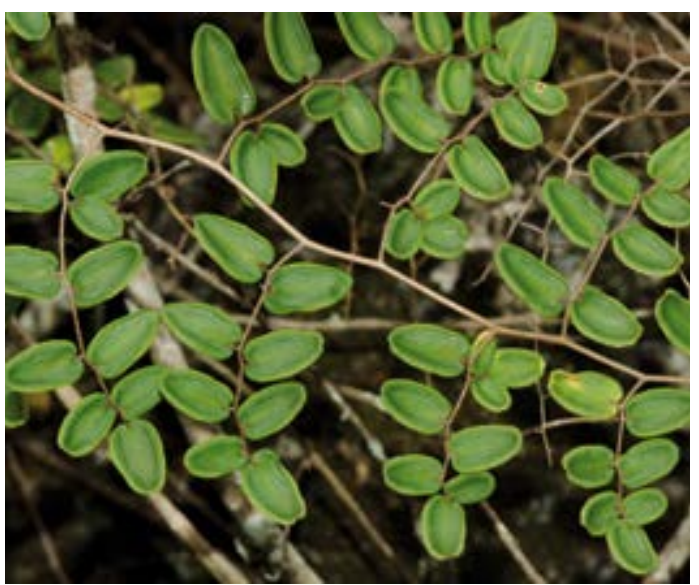

Pellaea ternifolia
PROTEACEAE - Oreocallis grandiflora (Lam.) R.Br

Rumilanche, Huaminga

Arbusto, Andino, $1500-4000 \mathrm{~m}$, maleza

Uso: 1. Inflamación de ovarios, Inflamación de útero, Inflamación de Riñones, Inflamación del hígado, Artritis, Sangre / Hojas y Tallos, fresco o seco / Oral / Hervir 5o en 1 litro de agua por 10 minutos. mezclado con $5 \mathrm{~g}$ cada uno de Flor Blanca y Flor de Arena. Tomar 4 tazas por día por 1 mes. 2. Daño por Brebaje, Susto / Hojas y Tallos, fresco o seco / Tópico / Poner 1 manojo en 3 litros de agua. Se puede combinar con Chingue, Poleo, Zanahoria Gentil, Conchalay Blanco, Apostema y Trebol. Hervir por 10 minutos. Bańo una vez por semana por 1 mes.

PTERIDACEAE - Adiantum concinnum Humb. \& Bonpl. ex Willd.

Culantrillo del Pozo, Culantrillo

Helecho, Amazónico, Andino, Costa, 500-3000m

Uso: Purificación de la sangre, Perdida de cabello, Regulación de menstruación / Hojas y Tallos, fresco o seco / Oral / 20g en 1 litro de agua por 5 minutos combinado con Purenrosa, Lancetilla, Moradilla, Orégano. Tomar 3 vasos por día por 3 días.

PTERIDACEAE - Cheilanthes myriophylla Desv.

Hierba del Dominio

Helecho, Andino, 3000-4500m

Uso: 1. Dominar una persona difícil, Dominar una persona fuera de control, Controlar enojo y mal humor / Hojas y Tallos, fresco o seco / Seguro / Poner en una botella 10g de Hierba del Dominio, 10g de Hierba de la Justicia y $10 \mathrm{~g}$ de Hierba del Olvido. Sellar. El paciente debe llevar la botella siempre y usar oraciones. 2. Dominar una personas difícil, Dominar una persona fuera de control, Controlar enojo y mal humor / Hojas y Tallos, fresco o seco / Oral / Hervir 3-5g en 1 litro de agua por 10 minutos. Tomar 3 veces al día por 1 semana.

PTERIDACEAE - Jamesonia goudotii (Hieron) C. Chr.

Hierba del Carpintero

Helecho, Andino, 3000-4500m

Uso: Éxito, Abrir una puerta y mantenerla abierta / Tallos, fresco / Seguro / 3 Tallos por Seguro.

PTERIDACEAE - Jamesonia rotundifolia Fée

Botón de Oro, Trencilla Amarilla, Hierba del Oso, Bonito de Oro, Bastón del Inca

Helecho, Andino, 3000-4500m

Uso: 1. Buena Suerte, Fragancia, Fuerza, Adorno / Planta entera, seco Planta entera, seco / Seguro / Tres pequeños Tallos por 1 Seguro. 2. Adorno, Fragancia, Fuerza / Hojas, fresco / Tópico / Bańo: Hervir 200g en 15 litros de agua.

PTERIDACEAE - Pellaea ternifolia (Cav.) Link.

Cuti Cuti, Cuti Cuti Amarillo

Helecho, Andino, 3000-4500m

Uso: Diabetes, Hígado / Planta entera, fresco / Oral / 5g en 1 litro de agua, Tomar 3 veces al día por 1 seman 


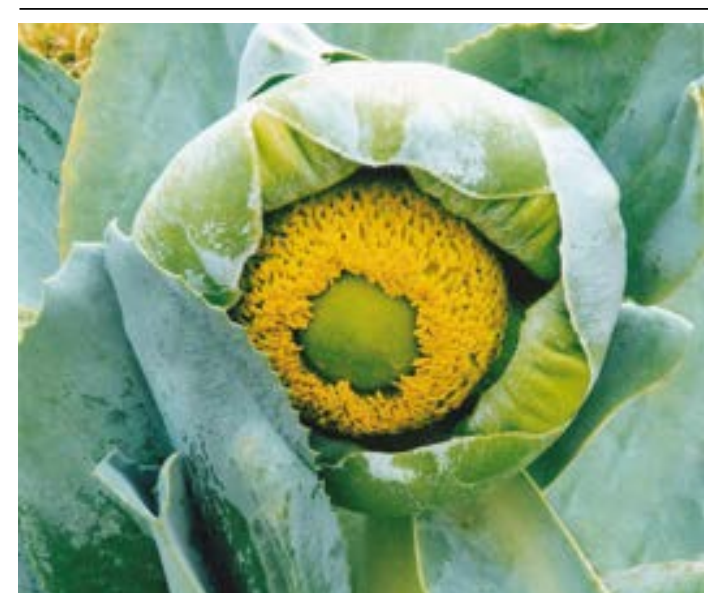

Laccopetalum giganteum

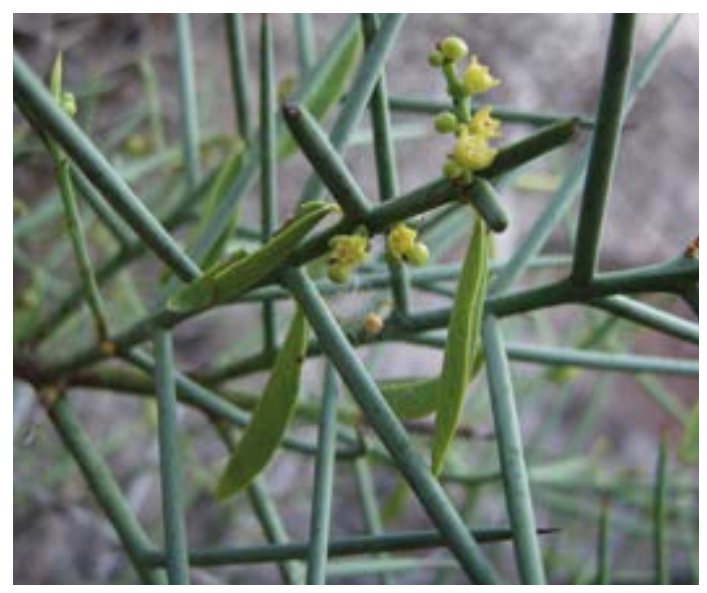

Scutia spicata

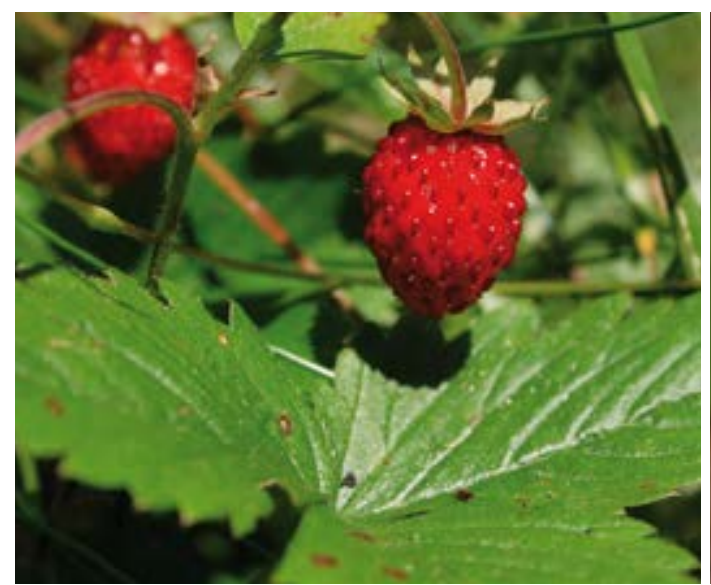

Fragaria vesca

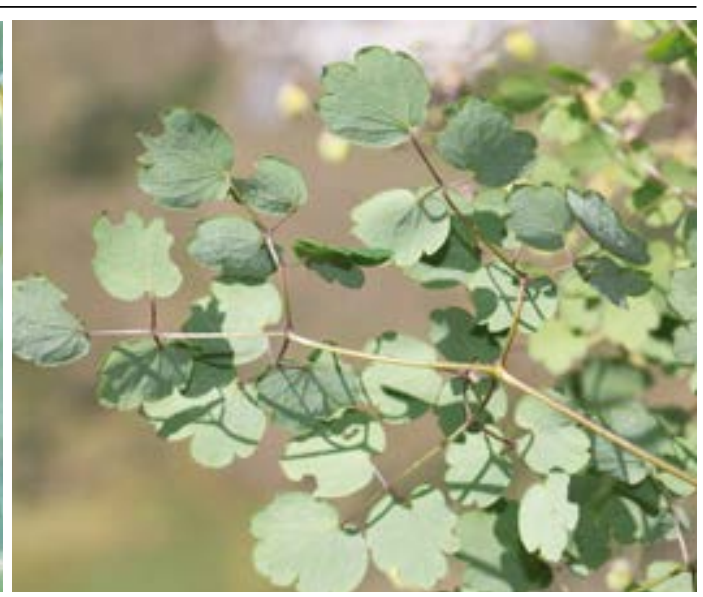

Thalictrum decipiens

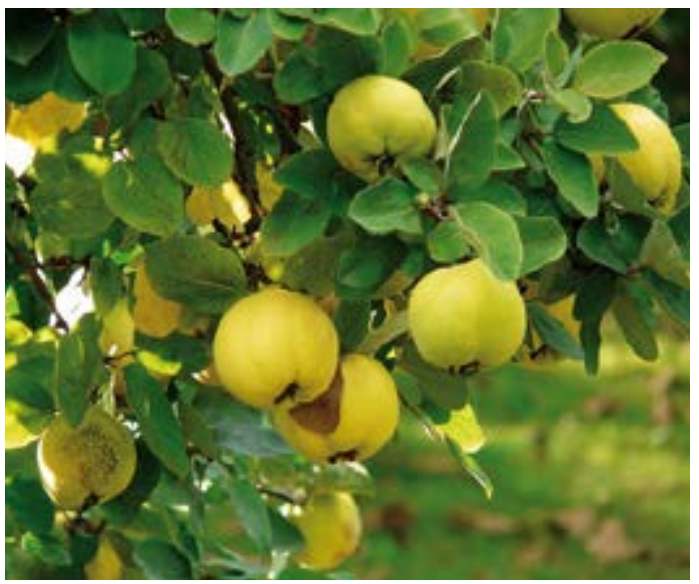

Cydonia oblonga

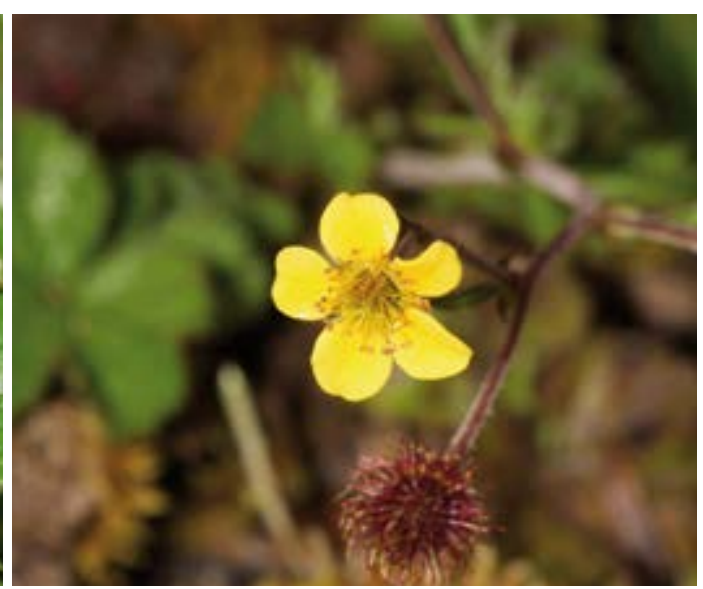

Geum peruvianum
RANUNCULACEAE - Laccopetalum giganteum (Wedd.) Ulbrich

Huamanripa, Pacra, Flor de Guarmayra

Hierba, Andina, 4000-4750m

Uso: 1. Tos, Bronquitis, Asma, Gripe, Resfrío / Hojas, fresco o seco / Oral / Poner 2 pequeńas Hojas en $1 / 2$ litro agua hirviendo por 10 minutos. Tomar 1 litro por día por 3 meses. 2. Fertilización (mujeres) / Hojas, fresco o seco / Oral / a 1 botella de Vino añadir 5-6 Hojas de Pacra, 1 Ajo, 1 Huevo del Angelote, 3-4 cucharas de Miel y Polen (Abeja), 2 Cholitos (1 Hembra y 1 Macho), 1 Huanarpo (Hembra), 1 pedazo de Palo Sangre y 1 cráneo de Pejesapo. Dejar por 1 semana. Tomar 3 veces al día hasta se acaba la botella. 3. Reumatismo / Planta entera, fresco / Tópico / Macerar 1 Huamanripa entera en alcohol con 10g de Ajo Sacha, 3-4 Ajos (Machos), 10g cada uno de Eucalipto y Molle. Dejar mezcla por semana. Frotar en área afectada como se necesita. 4. Epilepsia, Enfermedad del Corazón, Palpitaciones / Planta entera, fresco / Oral / Hervir $10 \mathrm{~g}$ de Huamanripa y $10 \mathrm{~g}$ de Congona en $1 / 2$ taza de agua por 10 minutos. Tomar solución fría, 1/2 taza una vez por día en la mañana en ayuno por 25 días.

RANUNCULACEAE - Thalictrum decipiens B. Boivin

Chontilla (Chica)

Hierba, Andina, $1500-4500 \mathrm{~m}$

Uso: Fiebre, Paperas (Niños) / Planta entera, seco / Tópico / Combinar 10g con 10g cada uno de Ajenco, Salvia Real, Lailambo, 7 Espiritus y Agua del Susto. Hervir 1 litro de agua por 5 minutos. y dejar enfriar. Aplicar dos veces por mes o como enfermedad requiere.

RHAMNACEAE - Scutia spicata (H. \& B. ex Schultes) Weberb. var. spicata Pial, Pus

Árbol, Andino, Costa, 0-3000m

Uso: mantener espíritus malos lejos de la casa / Tallos, fresco o seco / Amuleto / Poner los Tallos en forma de cruz y amarrar con cinta roja. Poner cruz tras la casa.

ROSACEAE - Cydonia oblonga Miller

Membrillo

Arbusto, Andino, 1500-2500m, introducido y cultivado

Uso: 1. Depresión, Nervios, Insomnio, Problemas del Corazón / Cáscara del fruto, fresco / Oral / Hervir 1 litro agua. Añadir cascara del fruto de 1 Membrillo, 10g cada uno de Manzanilla, Toronjil, Hinojo, Madre Selva y Romero. Tomar extracto caliente, 1 taza 3-4 veces por día por 1 mes. 2. Vomitar, Nausea / Pulpa de fruta, fresco / Oral / Machucar la Pulpa del fruto y Poner en 2 tazas de agua. Hervir por 3-5 minutos. Paciente debe tomarlo lentamente con cucharilla, 1 taza cada 6 horas. Usar por nińos y mujeres embarazadas. 3. Depresión, Nervios, Insomnio, Problemas del Corazón / Hojas, fresco / Oral / Hervir 1 litro de agua. Añadir 10g de Hoja de Membrillo, Manzanilla, Toronjil, Pimpinela, Borraja, Pensamiento, Mejorana y Romero. Dejar mezcla por 2-3 minutos. Tomar 1 taza 3-4 veces por día por 1 mes.

ROSACEAE - Fragaria vesca $\mathrm{L}$.

Fres

Hierba, Andino, 2000-4000m, cultivado

Uso: Nervios, Insomnio, Enfermedad de Corazón / Hojas, fresco / Oral / Hervir 1 litro de agua. Añadir $10 \mathrm{~g}$ de Fresa. Mezclar con $10 \mathrm{~g}$ total de Hinojo, Manzanilla y Pimpinela. Dejar por 2-3 minutos. Tomar caliente, 1 taza 2-3 veces por día por 1 mes.

ROSACEAE - Geum peruvianum Focke

Valeriana

Hierba, Andino, 2500-4500m, maleza

Uso: Nervios, Insomnio / Tallos y Frutas, seco / Oral / Hervir 1 taza de agua y 10g de Valeriana por 3 minutos. Tomar frío, 1/2 taza una vez por día antes de dormir por 15 días o como se necesita. 


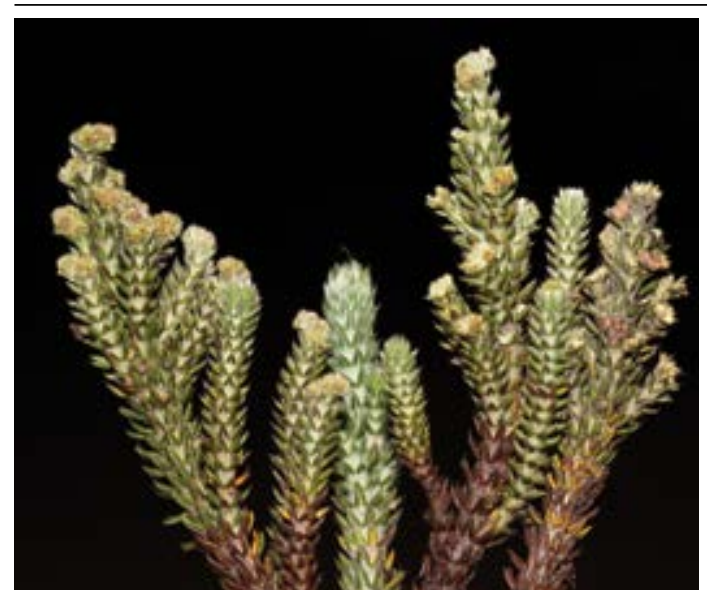

Lachemilla nivalis

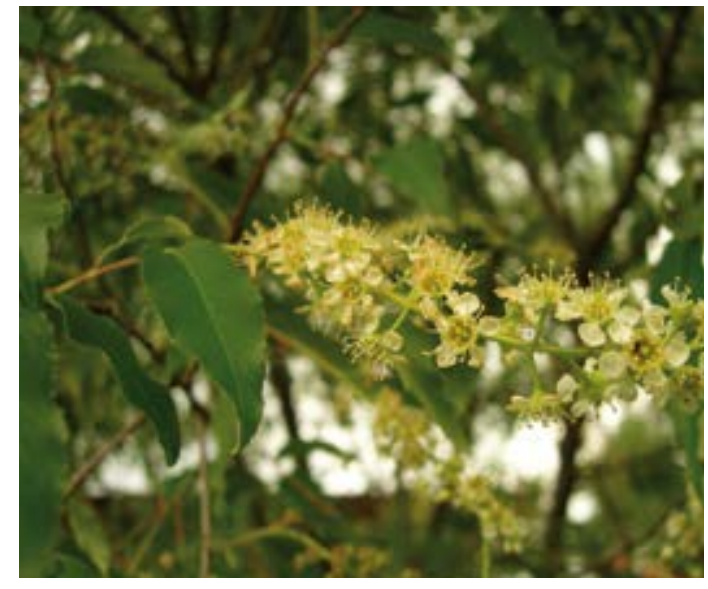

Prunus serotina

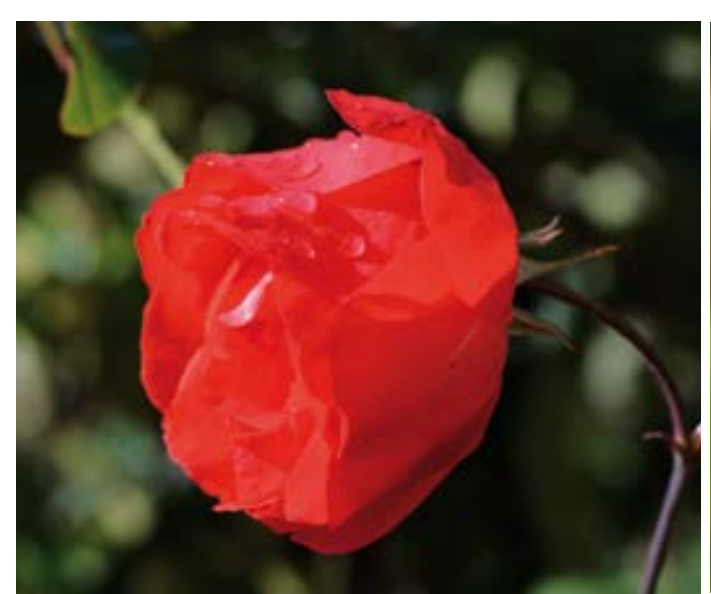

Rosa centifolia

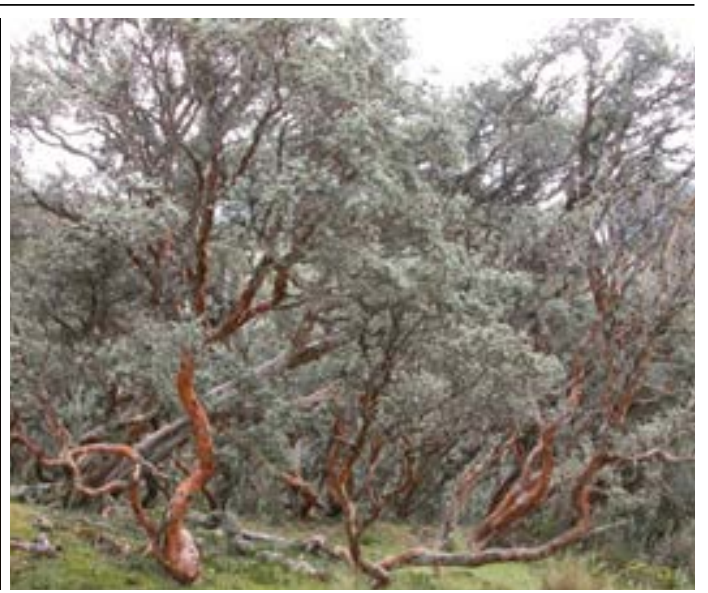

Polylepis racemosa

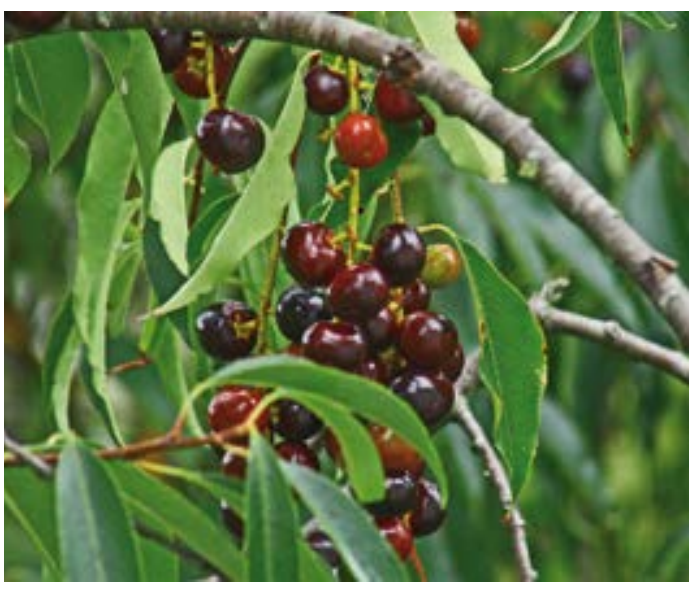

Prunus serotina

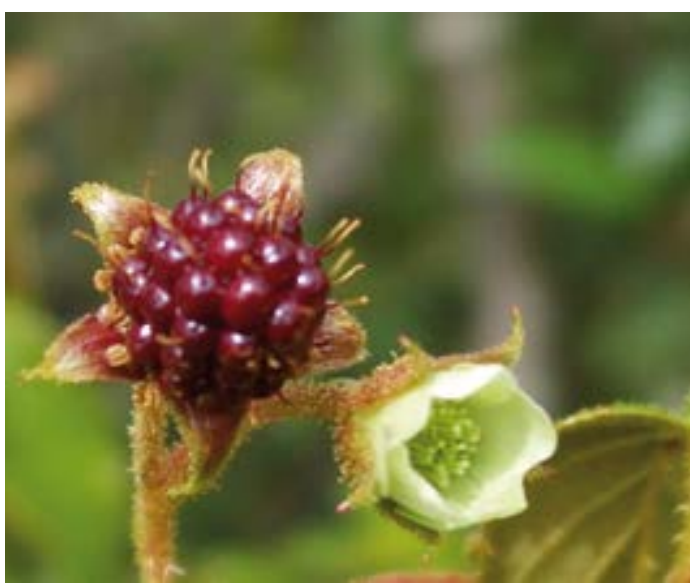

Rubus robustus
ROSACEAE - Lachemilla nivalis Kunth

Hierba del Oso

Hierba, Andina, 3000-4000m

Uso: Fuerza y Poder Espiritual / Hojas y Tallos, fresco / Seguro / 3 Tallos por frasco.

ROSACEAE - Polylepis racemosa R. \& P.

Quinual

Ârbol, Andino, 2500-4500m

Uso: 1. Hinchazón, Decodificación después del parto / Hojas, fresco o seco / Oral / Hervir agua, añadir $5 \mathrm{~g}$ de Quinual a 2 tazas de agua hervida. No mezclar con otras plantas. La madree debe tomar no más que 2 tazas. 2. Mal Aire / Hojas, fresco o seco / Tópico / Hervir 1 manojo de Quinual con 4-5 litros de agua. No mezclar con otras plantas. Paciente debe bañarse en mezcla templada, 2 o 3 veces como se necesita.

ROSACEAE - Prunus serotina Ehrh.

Helialiso

Árbol, Andino, 2000-4000m, introducido y cultivado

Uso: 1. Artritis, Fracturas, Dolor de Huesos, Esguinces / Hojas, fresco o seco / Tópico / Mezclar 10g con $10 \mathrm{~g}$ cada uno de Altamisa, Ajenco, Ruda y Romero y Hervir por 20 minutos. Bańo 3 veces por semana. 2. Artritis, Fracturas, Dolor de Huesos, Esguinces / Hojas, fresco o seco / Tópico / Machucar 300g y Macerar en alcohol. Poner en tela mojada u usar como Emplasto por 1 semana.

ROSACEAE - Prunus serotina Ehrhart subsp. capuli (Cav.) McVough

Capuli

Árbol, Amazónico, Andino, Costa, 0-4000m, introducido y cultivado

Uso: Lesiones de Piel / Planta entera, fresco / Tópico / Hervir 1 litro de agua con 20g de Capuli por 3 minutos o $10 \mathrm{~g}$ de Capuli en $1 / 2$ litro mezclado con $10 \mathrm{~g}$ cada uno de Verbena y Cola de Caballo. No ingerir! Lavar solo con agua, no con las Hierbas, $2-3$ veces por día como se necesita.

\section{ROSACEAE - Rosa centifolia L.}

Rosa de Castilla, Rosa

Arbusto, Andino, $2500-4000 \mathrm{~m}$, introducido y cultivado

Uso: 1. Laxante / Flores, fresco o seco / Oral / Añadir $10 \mathrm{~g}$ de material de planta y 1 Hoja de Sen a $1 / 2$ litro de agua y Hervir la mezcla por 1-2 minutos. Tomar caliente, 1 taza solo una vez. 2. Mejorar la Salud, Amor, Finanzas / Flores, fresco o seco / Tópico / Colectar planta en la tarde. Macerar en 3 litros de agua $100 \mathrm{~g}$ de Roses de cada color y 100g de Margaritas. Dejar por la noche y ańadir 1 botella de Agua Florida $(300 \mathrm{ml})$ y 1 botella de Perfume $(300 \mathrm{ml})$. Frotar cuerpo con Flores y Hojas. Enjuagar y secar al aire, dos veces por semana por 7 días.

ROSACEAE - Rubus robustus C. Presl.

Zarzamora, Moyaca, Zarza, Zarza Parrilla, Mora, Cushai (Blackberry)

Arbusto, Andino, 2000-4000m

Uso: 1. Susto, Dolor del Cuerpo / Flores y Hojas, fresco o seco / Tópico / Hervir 10g en 5 litros de agua por 30 minutos. Baño 3 veces por semana. 2. Diabetes, Tos, Colesterol (High), Bronquitis / Flores y Hojas, fresco o seco / Oral / Hervir 3 Botones de flores en 1 taza de agua mezclado con 10g de Llatama. Tomar 1 litro por día por 1 mes. También se puede inhalar. 3. Garganta (Seca), Laringitis / Flores y Hojas, fresco o seco / Oral / Masticar como chicle una mezcla de Moradilla, Sanguinaria y Hierba de la Postema. Mezclar con Chante y Chote. Se puede usar con casi todas las otras hierbas. Tomar 1 litro cada día por 2-3 meses. 4 Cálculos de los Rifínes, Inflamación de Rifínes, Inflamación de átero, Artritis día por 2-3 meses. 4. Cálculos de los Rinones, Inflamación de Rinones, Inflamación de útero, Artritis litro cada día por 2-3 meses.
litral / Hervir 10g de Hojas en 1 litro de agua por 5 minutos. Tomar 1 


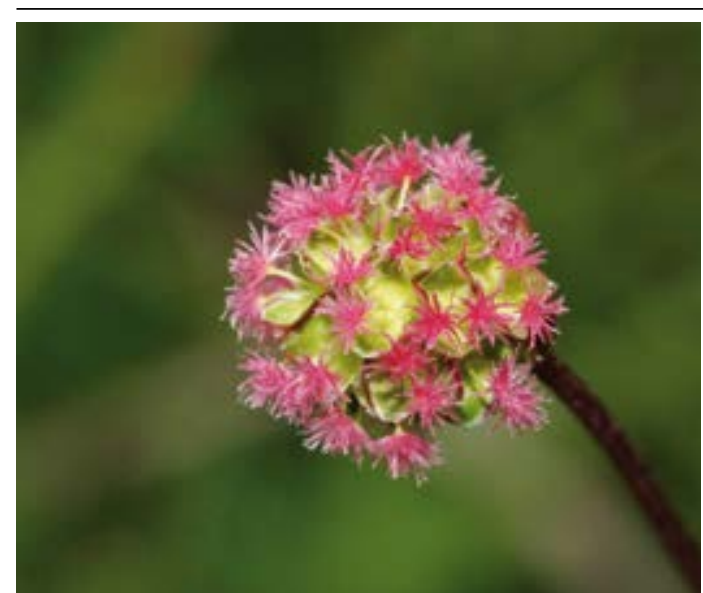

Sanguisorba minor

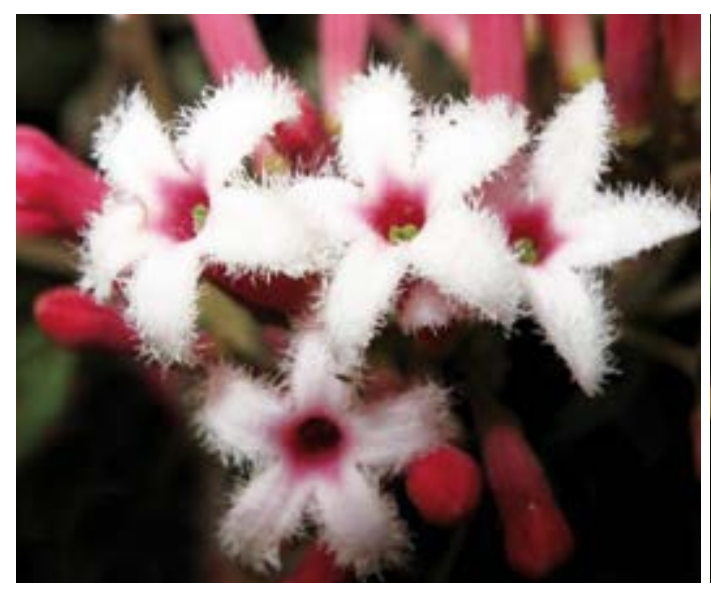

Cinchona officinalis

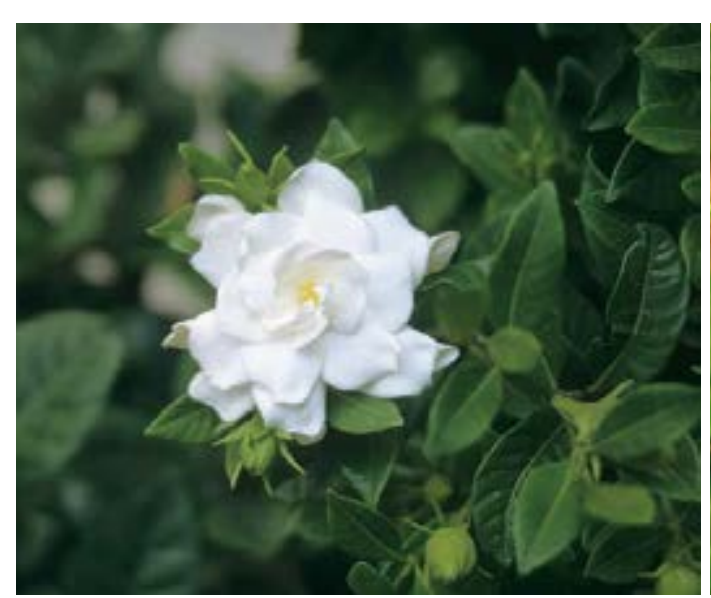

Gardenia augusta

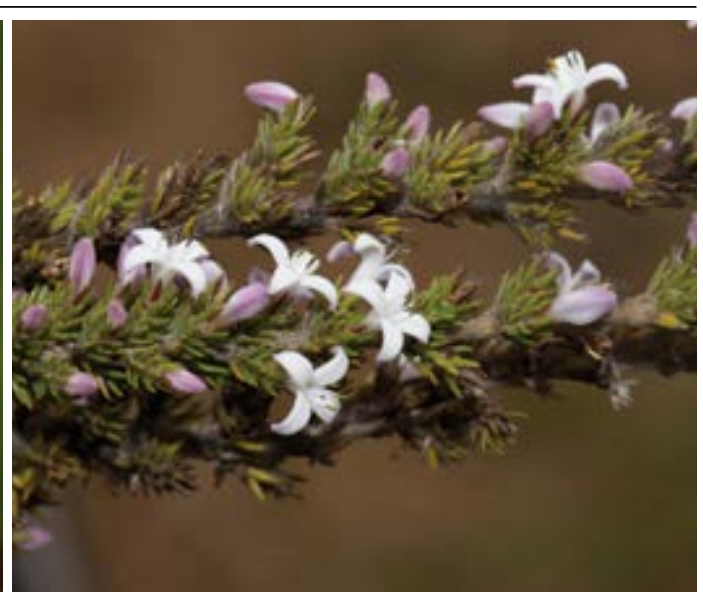

Arcytophyllum filiforme

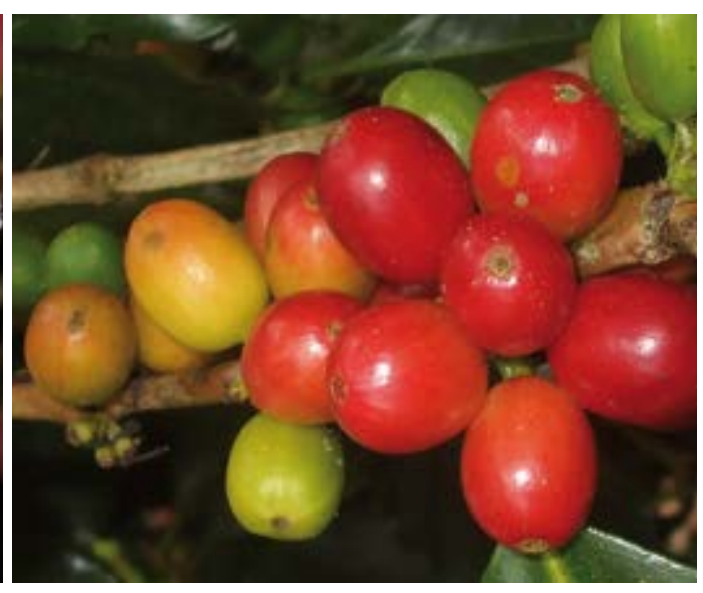

Coffea arabica

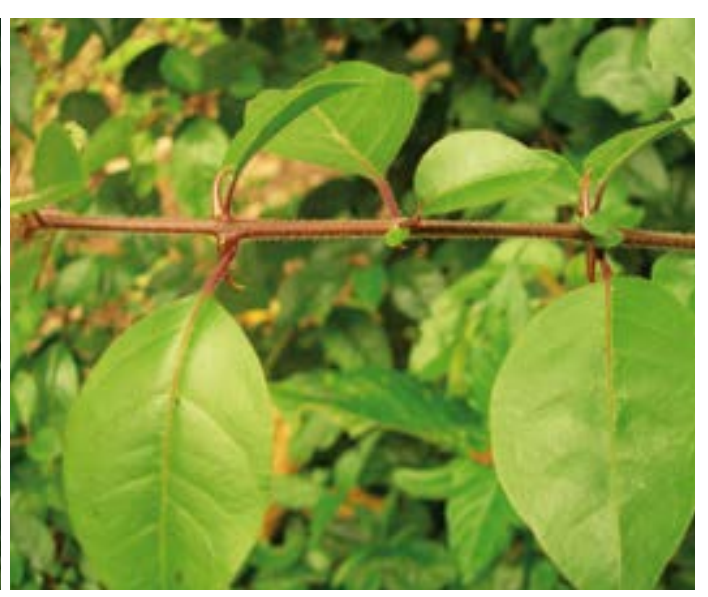

Uncaria guianensis
ROSACEAE - Sanguisorba minor Scop.

Pimpinela, Flor de Overa

Hierba, Andina, 2500-4500m, maleza, introducido

Uso: 1. Corazón, Sistema nervioso, Nervios, Insomnio, Depresión, Dolor del Corazón, Mal de amor, Ansiedad, Regulación de menstruación, Artritis, Sangre, Susto / Planta entera, fresco / Oral / Hervir $5 \mathrm{~g}$ en 1 litro de agua mezclado con $10 \mathrm{~g}$ cada uno de Cadillo, Hierba de la Apostema, Esencia de Rosa, Lancetilla, Toronjil, Congona, Clavel, Manzanilla y Azares. Tomar 3 veces al día por 6-12 meses. 2. Florecimiento, Buena Suerte / Planta entera, fresco / Tópico / Mezcla Estándar para Seguro. Soplar la mezcla y frotar el cuerpo del paciente con el liquido por Buena Suerte. Soplar la mezcla cada Martes y Jueves como se necesita. 3. Forecimiento, Buena Suerte / Planta entera, fresco / Seguro / Mezcla Estándar para Seguro. Soplar la mezcla y frotar el cuerpo del paciente con el liquido por Buena Suerte. Soplar la mezcla cada Martes y Jueves como se necesita. 4. Florecimiento, Buena Suerte / Planta entera, fresco / Tópico / Mezclar 50g total de: Hierba del Lucero, Hierba del Este, Ambrocilla, Señorita, Caballero, Pega Pega, Siempre Viva, Carpintero, Waime Waime, Piri Piri (Hembra y Macho), Hierba del Buen Querer, Hierba del Oro, Hierba de la Plata, Hierba del Halago, Sigueme Sigueme y Hierba del Negocio. Hervir en 5-7 litros de agua por 20 minutos. Después ańadir un poco de los siguientes perfumes: Carińo, Dios de la Huaringa, Dios de la Felicidad, San Antonio, Macumba Pusanga, Gran Jefe, Mil Clores, Lla Plata y Ekeko dejarlo enfriar antes de bañarse. Baño dos veces (Martes y Viernes solo) cada 3 meses. RUBIACEAE - Arcytophyllum filiforme (Ruiz \& Pav.) Standl.

Hierba de la Madriguera

Hierba, Andino, 2500-4500m, maleza

Uso: Para prevenir gastos exagerados / Planta entera, fresco / Seguro / Seguro, 1/5 de la planta por frasco. RUBIACEAE - Cinchona officinalis L.

Quinua, Cascarilla

Arbol, Andino, 500-3500m, maleza

Uso: 1 . Tos / Flores y Hojas, seco / Oral / Hervir $5 \mathrm{~g}$ en 1 litro de agua mezclado con $10 \mathrm{~g}$ cada uno de Flor Blanca, Grama Dulce y Esencia de Rosa. Tomar 1 litro cada día por 2 meses o más. 2. Fertilidad, Potencia sexual / Corteza, seco / Oral / Añadir a una botella de Vino o Aguardiente (Aguardiente) $10 \mathrm{~g}$ de Cascarilla con $10 \mathrm{~g}$ cada uno de Palo de Sangre, Palo Huaco, Pacra, Piri Piri y Huanarpo. Añadir Miel. Tomar 1 taza 3 veces por día hasta botella se acaba. 3. Cáncer / Raíz, fresco / Oral / Hervir 1 Raíz en 3 tazas de agua. Esperar hasta agua evapora dejando 1 taza. Se puede combinar con Chumbiauria, Zarzaparrilla, Hierba de la Postema y Poleo de la China. Tomar $5 g$ por dia por 14 dias. 4. Resfríos, Reumatismo / Corteza, seco / Oral / Hervir 50g de Quinua en 1 taza de agua por 10 minutos. Tomar templado, 1/4 taza una vez por día por 15 días.

RUBIACEAE - Coffea arabica L.

Café

Arrol, Amazónico, Andino, 0-1500m, introducido y cultivado

Uso: Dolor, Alerta / Semillas, secas / Oral / Hervir 1/2 litro de agua y filtrar 50-100ml de Café en el agua. Tomar cuando se necesita.

RUBIACEAE - Gardenia augusta (L.) Merr.

Jasmín, Margarita

Uso: 1. Nervios, Inflamación de Garganta, Limpiar la voz / Hojas, Tallos y Flores, fresco / Oral / Hervir 1 litro de agua y $10 \mathrm{~g}$ de Flores por 3-5 minutos. Dejar por 2-3 minutos. Tomar y hacer gárgaras con la solución, 2-3 veces por día por 2-3 días. 2. Mejoramiento de salud, Amor, Finanzas / Hojas, Tallos y macerar un día y añadir 1 botella de Agua Florida y 1 botella de Perfume favorito. Frotar cuerpo con Flores, lavar con Agua Florida y secar. No usar jabón ni toalla. Hacer dos veces por semana por 7 días. Se puede usar Jazmín comercial.

RUBIACEAE - Uncaria guianensis (Aublet) Gmelin

Liana, Amazónico, Andino, $0-1000 \mathrm{~m}$, maleza

Liana, Amazónico, Andino, $0-1000 \mathrm{~m}$, maleza
Uso: Bronquitis, Riñones, Asma, SIDA, Alergias, Infecciones Reumáticas, Cáncer, Contraceptivo, Úlceras, Próstata, Vejiga, Artritis, Huesos, Circulación de sangre, Hemorragias (Internas), Heridas
ún (Internas), Inflamación de Rińones / Hojas y Tallos, fresco o seco / Oral, Tópico / Moler material Mejor seco. Hervir 10g en 1 litro de a ua por 10 minutos combinaco seco. Hervir $10 \mathrm{~g}$ en $1 \mathrm{l}$. templado. También se puede usar como a Emplasto. Lavar herida, aplicar hojas maceradas. 


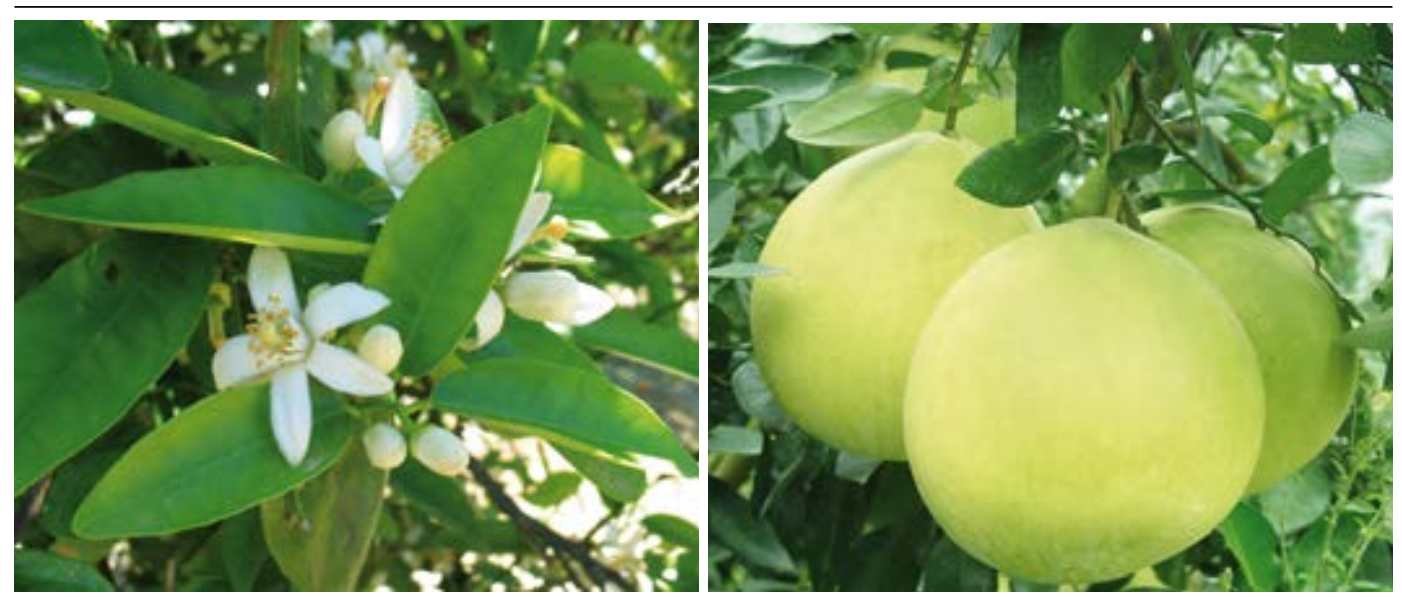

Citrus aurantium

Citrus grandis

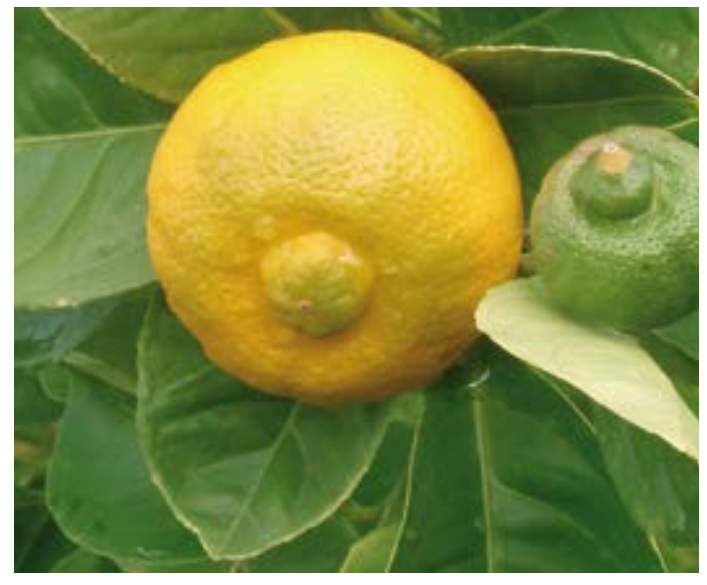

Citrus limetta

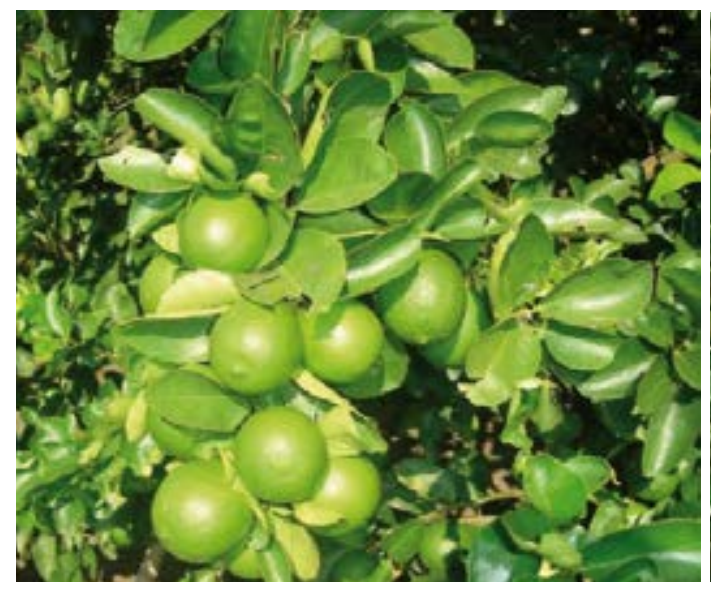

Citrus limon

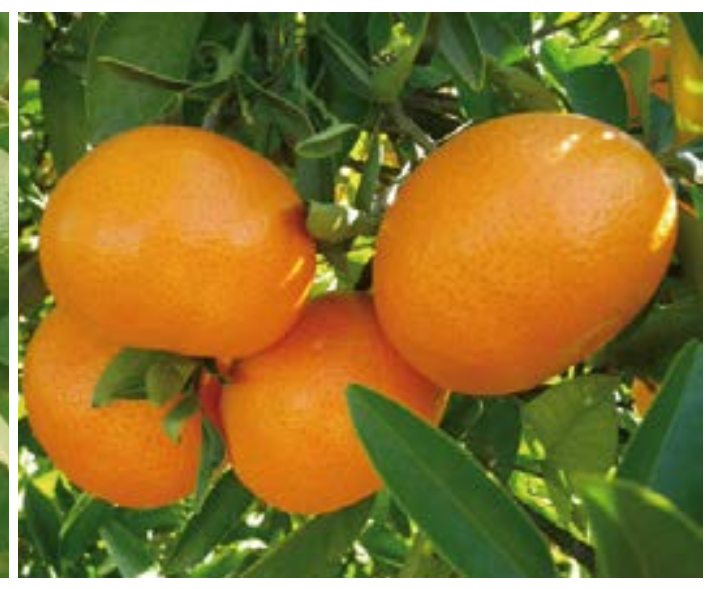

Citrus reticulata

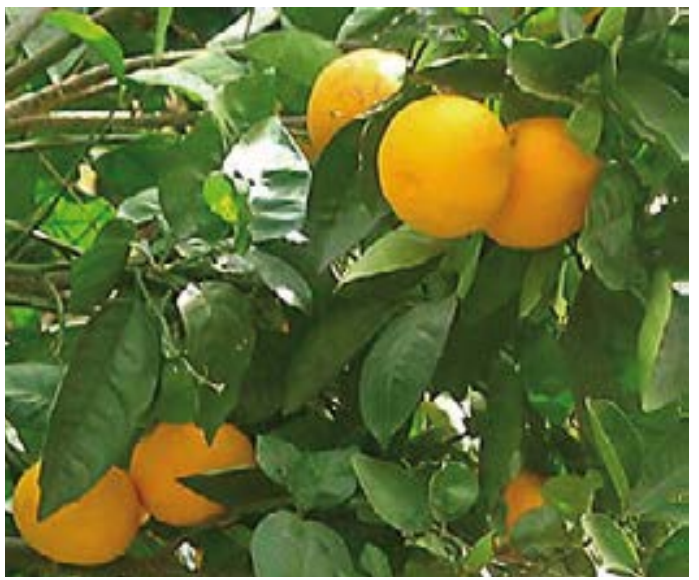

Citrus sinensis
RUTACEAE - Citrus aurantium (Christmann) Swingle

Hojas de Naranja

Árbol, Amazónico, Andino, 0-1200m, introducido y cultivado

Uso: Nervios, Estómago / Hojas y Tallos pequeños, seco / Oral / Hervir $5 \mathrm{~g}$ en 1 litro de agua mezclado con $5 \mathrm{~g}$ cada uno de Bolsilla de Menta y Anís. Tomar 3 veces al día por 1 semana.

RUTACEAE - Citrus grandis (L.) Osbeck

Toronja

Árbol, Amazónico, Andino, 0-1200m, introducido y cultivado

Uso: Colesterol, Pérdida de Peso, Quema Grasa / Fruta, fresco / Oral / Extraer Jugo. Tomar 1 vaso en la mañana y 1 vaso en la noche si se necesita.

RUTACEAE - Citrus limetta Riso

Lima

Árbol, Amazónico, Andino, 0-1200m, introducido y cultivado

Uso: 1. Nervios / Flores, fresco / Oral / Hervir 1 litro de agua. Añadir 10g cada uno de Flores de Lima, Manzanilla, Hinojo, Toronjil, Romero, Borraja, Madre Selva y Violeta. Tomar 1 vaso 3-4 veces por día por 1 mes. 2. Inflamación del Estómago, Gastritis, Enfermedad del Corazón, Acidez, Refrescar el 2 días. 3. Florecimiento Remover dolor, Refrescar Paciente, Extraer Tomar 1 vaso 2 veces por día por 2 días. 3. Florecimiento, Remover dolor, Refrescar Paciente, Extraer amargues / Fruta, fresco / Tópico / Después de cortar la Lima el curandero chupa el jugo y lo sopla por el paciente.

RUTACEAE - Citrus reticulata Blanco

Mandarina

Árbol, Amazónico, Andino, 0-1200m, introducido y cultivado

Uso: Nervios / Flores y Cáscara del fruto, fresco / Oral / Hervir 1 litro de agua por 2-3 minutos. Añadir Mandarina Flores y Cascara y $10 \mathrm{~g}$ cada uno de Mejorana, Toronjil, Pimpinela, Poraja y Manzanilla. Tomar 1 taza 3 veces por día por 1 mes.

RUTACEAE - Citrus limon (L.) Burm. $\mathrm{f}$.

Limón

Árbol, Amazónico, Andino, 0-1200m, introducido y cultivado

Uso: 1. Nervios, Úlceras / Flores, fresco / Hervir 1 litro de agua. Añadir $5 \mathrm{~g}$ de Flores de Limón, Manzanilla, Toronjil, Pimpinela, Violeta y Claveles. Dejar la mezcla por 2-3 minutos. Tomar 1 vaso, 3-4 veces por día por 1 mes o como se necesita. 2. Inflamación (General), Inflamación de Riñones, Inflamación de ovarios, Inflamación del Estómago, Inflamación de Garganta, Perdida de cabello, Caspa / Fruta sin Semillas, fresco / Preparar Jugo de Limón removiendo cáscara y Semillas de 3 Limones y ponerlo en una lata con algo de sal. Calentar sobre el fuego por un par de segundos hasta Limones están dulces. Exprimir Jugo de Limón sobre área afectada (Estómago, Riñones o Ovarios) y cubrir con un pedano con umación de Riñones, Inflamación de ovarios, Inflamación del Estóma. Inflamación de Gargantal Perdida de cabello Caspa / Fruto y Cáscara del Fruto, fresco / Hervir 1 litro de agua con 1 Limón por Perdida de cabello, Caspa / Fruto y Cascara del Fruto, fresco / Hervir 1 litro de agua con 1 Limon por 2-3 minutos combinado con $10 \mathrm{~g}$ cada uno de Cola de Caballo, Pie de Perro, Chacur, Amor Seco y 4 . Buena Suerte / Fruto y Cáscara del Fruto, fresco / Poner 7 Limones verdes en una olla con 4 litros 4. Buena Suerte / Fruto y Cascara del Fruto, fresco / Poner 7 Limones verdes en una olla con 4 litros Añadir $5 \mathrm{~g}$ de Azúcar a agua templada. Aplicar mezcla como Baño de Florecimiento y con masaje. Tomar 2 Limones sumergidas en el agua rezando frotar Limones sobre cuerpo del paciente. Repetir hasta se queda 1 Limón. Con este reza: "Fuera la negatividad, entra lo positivo para el Hogar, Trabajo, Amor, Estudios". Finalizar frotando el ultimo Limón sobre el cuerpo del paciente. Botar todos los Limones. Después del Baño, enjuagar con agua de canela.

RUTACEAE - Citrus sinensis (L.) Osbeck

Naranja

Árbol, Amazónico, Andino, 0-1200m, introducido y cultivado

Uso:1. Depresión, Nervios, Insomnio, Ansiedad / Flores, fresco / Oral / Hervir 1 litro de agua con $5 \mathrm{~g}$ de Flores de Naranja. Dejar cubierto por 3 minutos. Mezclar con Toronjil, Claveles, Manzanilla, Mejorana, Chancas de Comida y Romero. Tomar templado, 3 tazas por dia por 1 mes. Tomar en ayuno. 2. Laxante, especialmente para niños / Fruta, fresco / Oral / Hervir cáscara entera de una naranja en 1 litro de agua por 3-4 minutos. Tomar / Thplado, 1 taza 3 veces por día por 1 semana 3. Dolor de Estómago / Cascara del fruto, fresco / Oral / Hervir cáscara entera de una naranja en 1 litro agua por 3-4 minutos. Tomar
templado, 1 taza 3 veces por día por 1 semana 


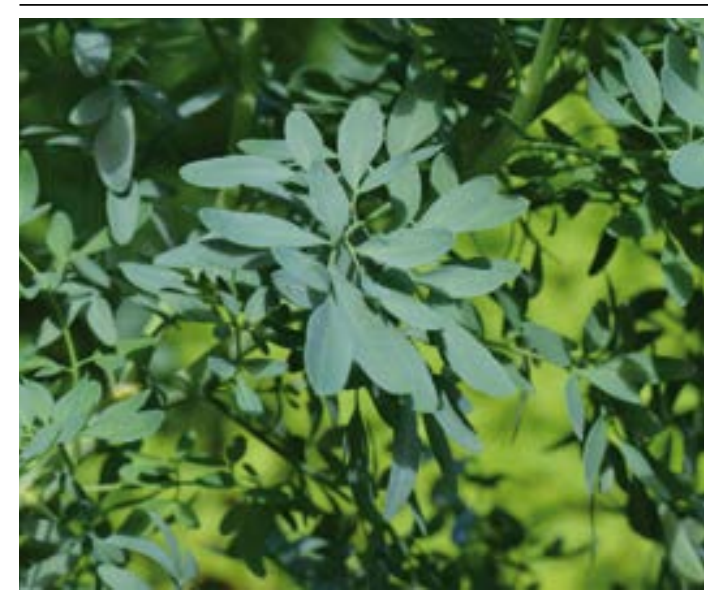

Ruta graveolens

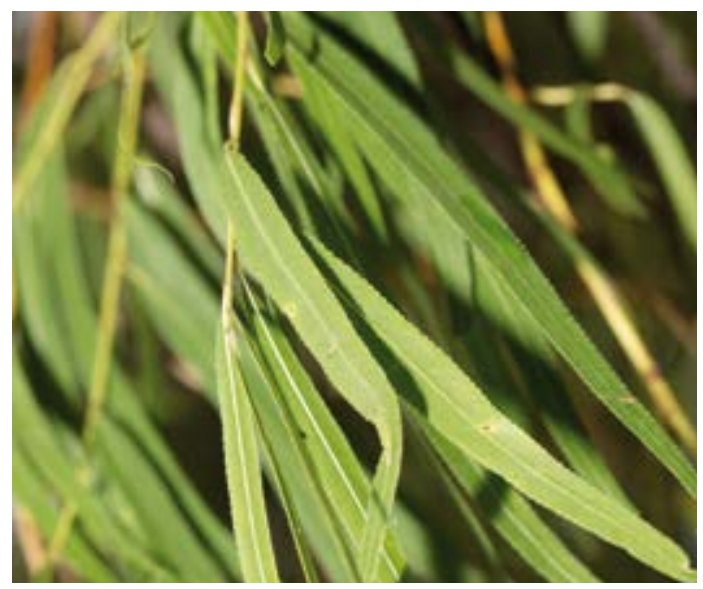

Salix chilensis

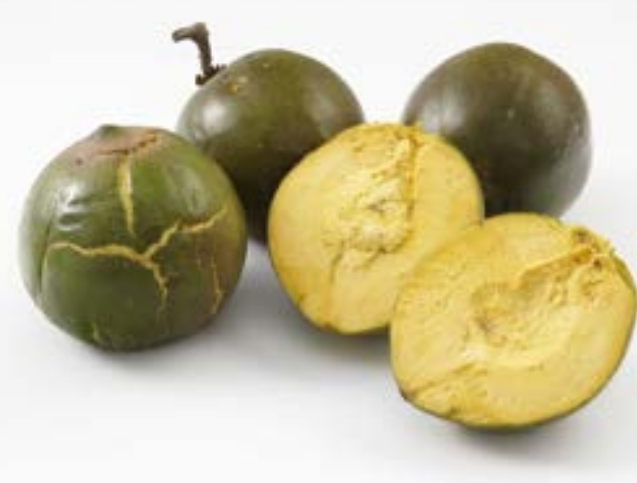

Pouteria lucuma

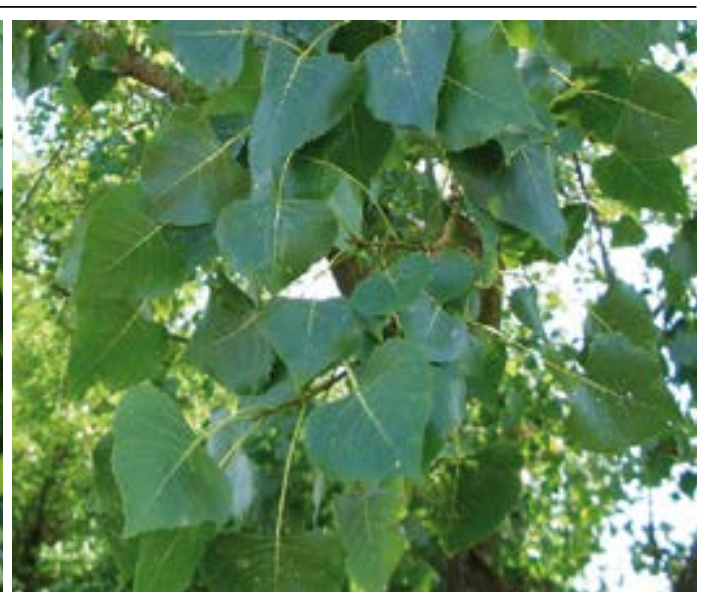

Populus deltoides

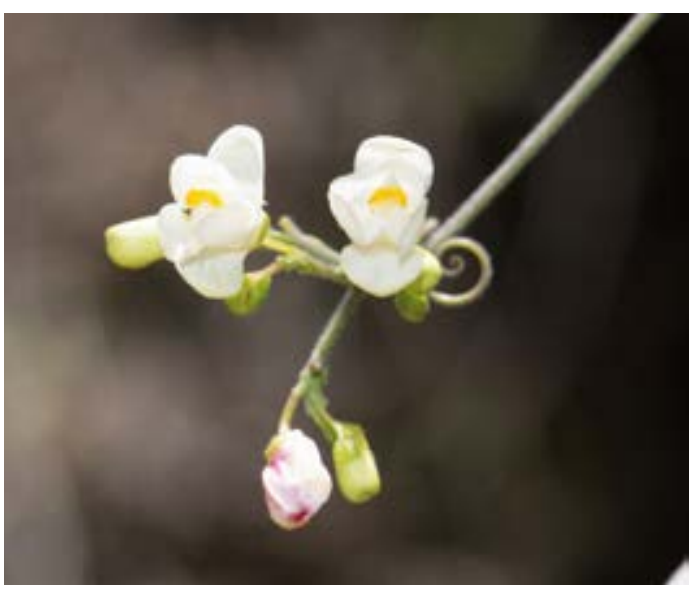

Serjania brachyptera

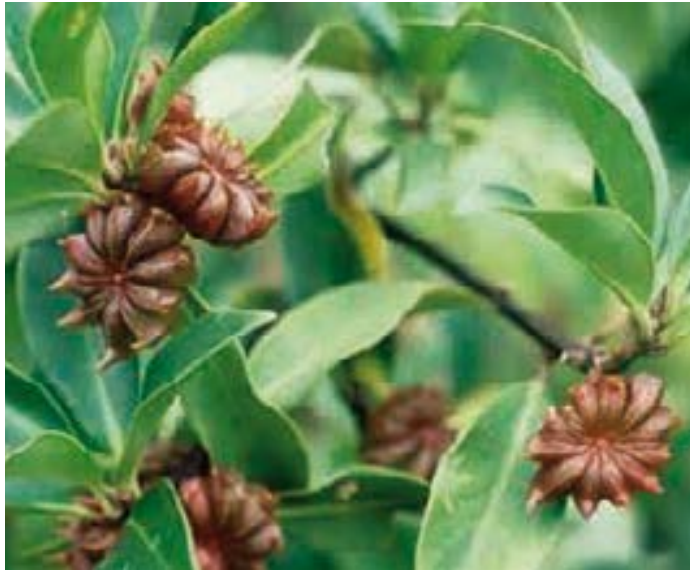

Illicium verum
RUTACEAE - Ruta graveolens $\mathrm{L}$

Ruda, Ruda (Macho y Hembra), Hierba del Quinde

Hierba, Andino, 1500-3000m, introducido y cultivado

Uso: 1. Aborto, Cólicos fuertes, Buena Suerte, Susto, Corazón, Regulación de menstruación, Depresión, Mal Aire, Reumatismo, Nervios, Vómito, Nausea / Planta entera, fresco / Oral / Hervir 1 litro de agua con 1 Ruda Hembra entera y Agenciana Corpus Way Salvia, Orégano, Molle, Eucalipto, Altamisa, Ajenco y Culantrillo Permitir Hervir hasta se Por 2 días. Cuidado ingerirlo porque la Sobrepasar envidia, Exito en Negocios, Vida mejor / Planta entera, fresco / Topico / Un Manojo de la Hierba con Gallinazo, Flor de Retama, Flor de Chochos, Clavel Blanco, Manzanillon, Romero, Agua del Susto, Rosas Blancas, Rosas Amarillas, Rosas Rojas, Azúcar Blanco, Hierba de la Justicia, Hierba de la Plata, Hierba de la Fortuna, Hierba del Oro, Jugo de 3 Limas, Perfume Tabú, Agua Florida y Roca cristalina. Frotar paciente 3 veces por mes Martes, Viernes y el Martes siguiente. 3. Para todo anda bien, Para abrir una puerta y mantenerla abierta, Para tener Éxito / Planta entera, fresco / Seguro / Poner planta entera en Seguro. 4. Por bebés que lloran demasiado y no se callan / Planta entera, fresco / Oral / Machucar 20 Hojas y drenar liquido. Tomar extracto templado o mix con un vaso de agua, 3-4 gotas solo una vez.

SALICACEAE - Populus deltoides Bartram

Alamo

Árbol, Costa, 0-500m, introducido y cultivado

Uso: Corazón, Nervios, Ansiedad / Hojas, fresco o seco / Oral / Hervir 1 litro de agua con 10g de material por 5 minutos. Añadir 10g cada uno de Manzanilla, Toronjil, Pimpinela, Hinojo, Chancas de Comida y Cascara de Membrillo. Dejar mezcla por 2-3 minutos. Tomar caliente, 1 taza 3-4 veces por día por 1 mes.

SALICACEAE - Salix chilensis Molina

Sauce

Árbol, Amazónico, Andino, Costa, 0-4000m, maleza

Uso: 1. Fiebre de Chuchaque, Fiebre, Paludismo, Resfríos / Hojas, fresco / Tópico / Machucar Hojas por jugo y aplicar como enema una sola vez. No ingerir. Solo usar si el paciente esta muy enfermo. 2. Fiebre de Chuchaque, Fiebre, Paludismo, Resfríos / Hojas, fresco / Oral / Hervir 10g de Sauce y 10 Frutas de Capulí en 1 litro de agua por 30 minutos. Tomar caliente, 1/2 pequeńa taza cada vez que el paciente tiene escalofríos.

SAPINDACEAE - Serjania brachyptera Radlk. Huarate

Liana, Amazónico, Andino, Costa, 500-1500m

Uso: Diabetes, Nervios / Tallos, seco / Oral / Hervir 1 litro de agua Añadir 10g total de Manzanilla, Toronjil, Pimpinela, Hinojo y Huarate Tallos. Dejar mezcla por 2 minutos. Paciente debe tomarlo templado, 1 taza 3-4 veces por día por 1 mes. También usado por hechiceros por Hechicería/Daño y para quemar cualquier cosa que les puede rastrar.

SAPOTACEAE - Pouteria lucuma (R. \& P.) Kuntze.

\section{SAPOTAC}

Árbol, Amazónico, Andino, 0-3000m, cultivado

Uso: Promover lactancia después del parto / Fruta, fresco / Oral / Cortar 2 Frutas y Hervir en 2 tazas de agua. Hervir por 4-5 minutos. Tomar caliente, 1 taza dos veces por día por 3 días.

SCHISANDRACEAE - Illicium verum Hook. f. Anis Estrella

Árbol, Amazónico, 0-500m, introducido y cultivado

Uso: Expulsar heces de los Estómagos de niños recién nacidos / Semillas, secas / Oral / Hervir 10-15g de material de planta en 1 litro de agua por 2-3 minutos. Tomar caliente. poner en la botella del bebé, 3-4 veces por día por 1-2 semanas. 


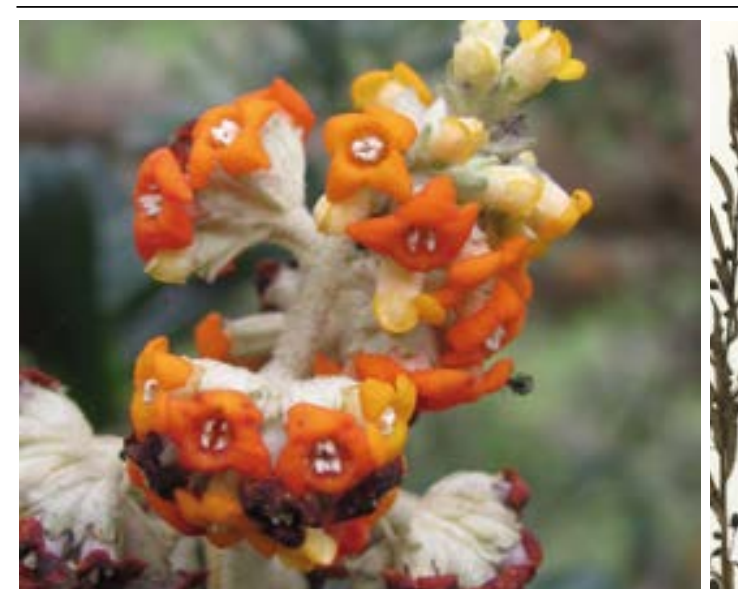

Buddleja coriacea

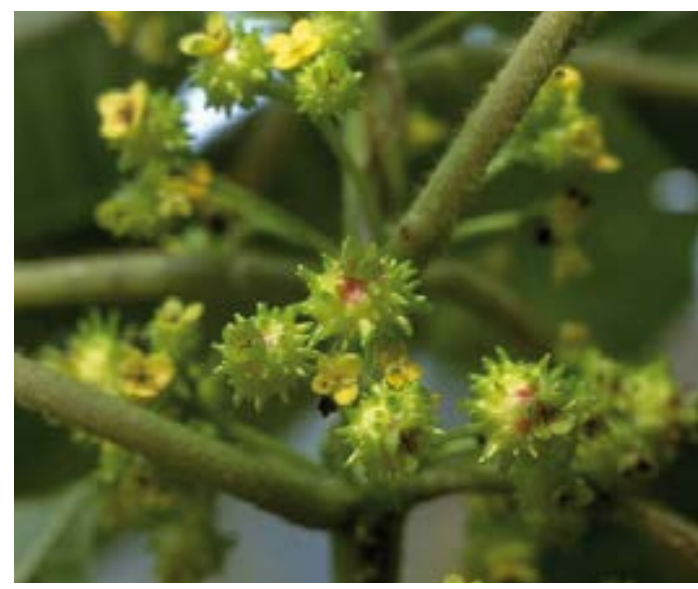

Siparuna muricata

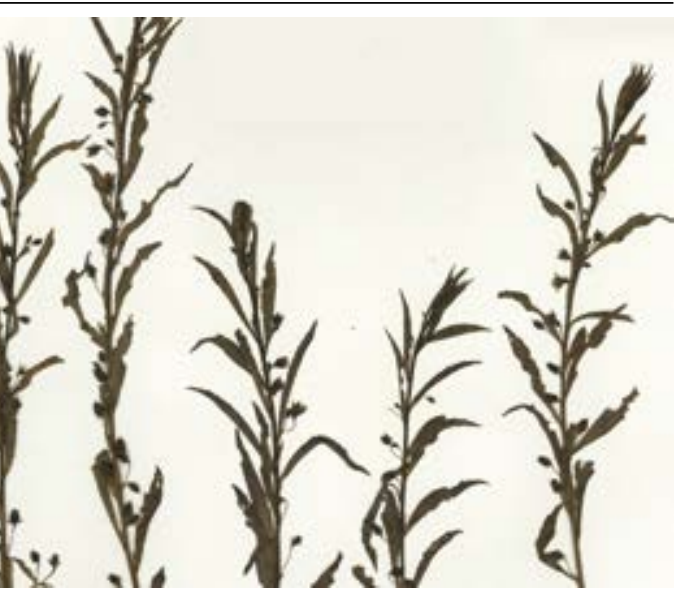

Capraria peruviana

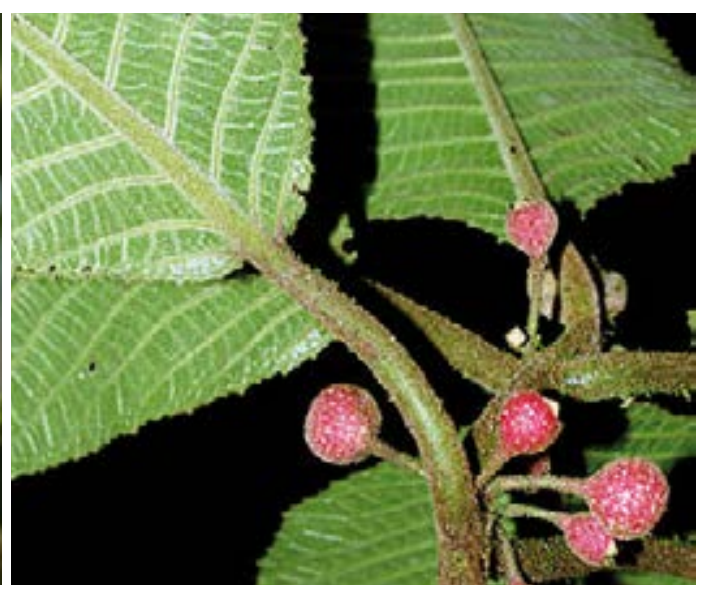

Siparuna tomentosa

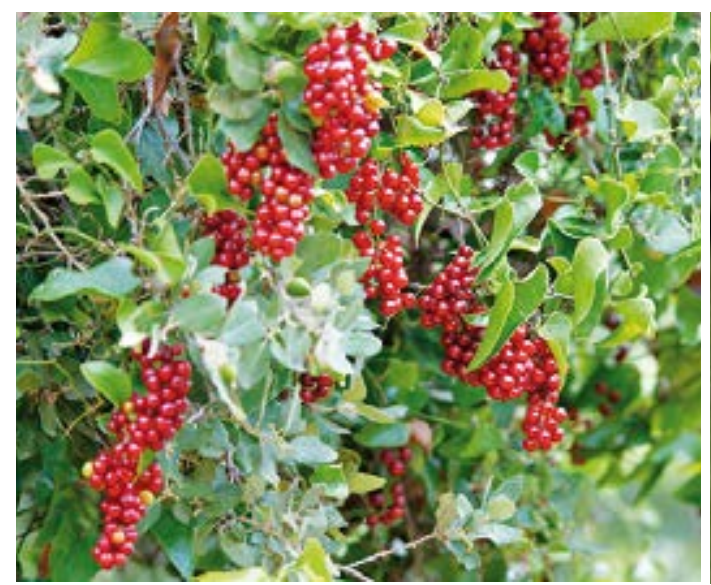

Smilax febrifuga

\section{SCROPHULARIACEAE - Buddleja coriacea Remy}

Flor Blanca

Árbol, Andino, 3000-4500m

Uso: Menstruación, Quistes de los ovarios, Inflamación de Útero, Inflamación (General) / Flores, fresco o seco / Oral / Hervir $5 \mathrm{~g}$ en 1 litro de agua por 3-5 minutos. Mezclar con 10g cada uno de Grama Dulce y Hierba de la Postema. Tomar 1 litro cada día por 3-8 meses.

SCROPHULARIACEAE - Capraria peruviana Bentham

Flor de Arenilla, Té de Indio

Hierba, Amazónico, Andino, Costa, 0-2000m, maleza

Uso: Retención de Orina, Inflamación de sistema urinaria, Cólico, Riñones, Disolver Ácidos / Planta entera, fresco o seco / Oral / Hervir $5 \mathrm{~g}$ en 1 litro de agua por 10 minutos. Tomar 3 veces por día.

SIPARUNACEAE - Siparuna muricata (R. \& P.) A. DC

Ańasquero, Hojas de Añasquero, Ańasquero (Grande)

Árbol, Andino, 2500-3500m

Uso: Susto, Artritis, Reumatismo, Dolor de Huesos, Dolor muscular, Dolor de Estómago, Daño/ Hechicería, Gas, Cólico / Hojas y Tallos, seco / Tópico / Hervir 5 litros de agua con una madera de cada uno de: Añasquero, Hierba del Susto, Ishpingo, Romero, Ruda Hembra, Ishpinguillo, Chuque, Palo Santo y 7 Espiritus por 10 minutos. Frotar cuerpo con Hierbas y limpia con agua. No secar con toalla. También usado como Emplasto, 3 veces por semana por 1 mes.

SIPARUNACEAE - Siparuna tomentosa (Ruiz \& Pav.) A. DC.

Rinchinchin, Chinchin

Árbol, Andino, 500-3500m

Uso: Causar problemas para una persona, Causar rompes en la familia / Hojas y Tallos, seco / Tópico / Moler $100 \mathrm{~g}$ de material de planta hasta esta pulverizado. Soplar el polvo en la cara de la persona para la cual quiere causar problemas, diciendo su nombre completo, una vez por ritual por 3 rituales.

SMILACACEAE - Smilax febrifuga Kunth

Palo de la China (Blanco)

Vine, Amazónico, Andino, 0-2000m

Uso: Cáncer (todos los tipos) / Corteza, Raíz y Tallos, fresco / Oral / Hervir 50g en 2 litro de agua. Esperar hasta se queda $1 / 2$ litro. Se puede combinar con $10 \mathrm{~g}$ cada uno de Quinuagiro y Miel. Mezclar también con 10g de Hierba de la Postema. Tomar 5g por día en la noche.

SMILACACEAE - Smilax kunthii Killip \& Morton

Zarzaparilla, Zarza Parilla

Vine, Andino, $1500-3000 \mathrm{~m}$

Uso: Mal Aire, Corazón, Inflamación de Rińones, Inflamación (General) / Tallos, seco / Oral / en 1 taza de agua Hervir 20g de Zarzaparrilla con $5 \mathrm{~g}$ cada uno de Congona, Chacur, Matico y Cola de Caballo por 5 minutos. Tomar 1 taza en la mañana antes del desayuno por 1 mes. Repetir si se necesita. 

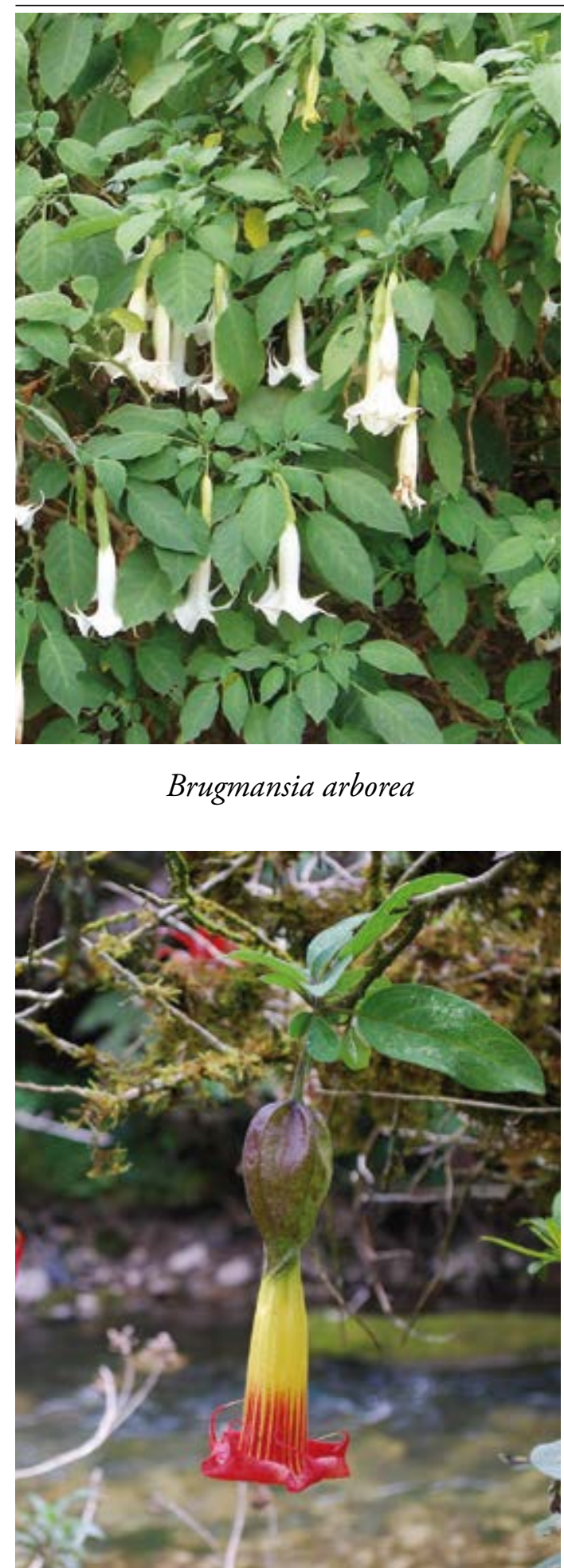

Brugmansia sanguinea
Brugmansia arborea

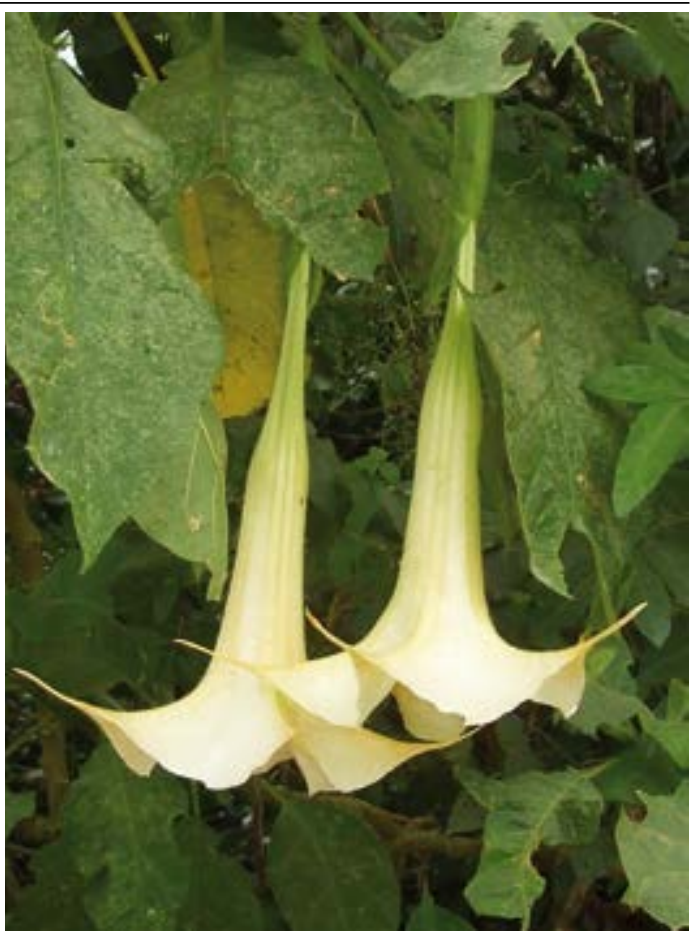

Brugmansia candida

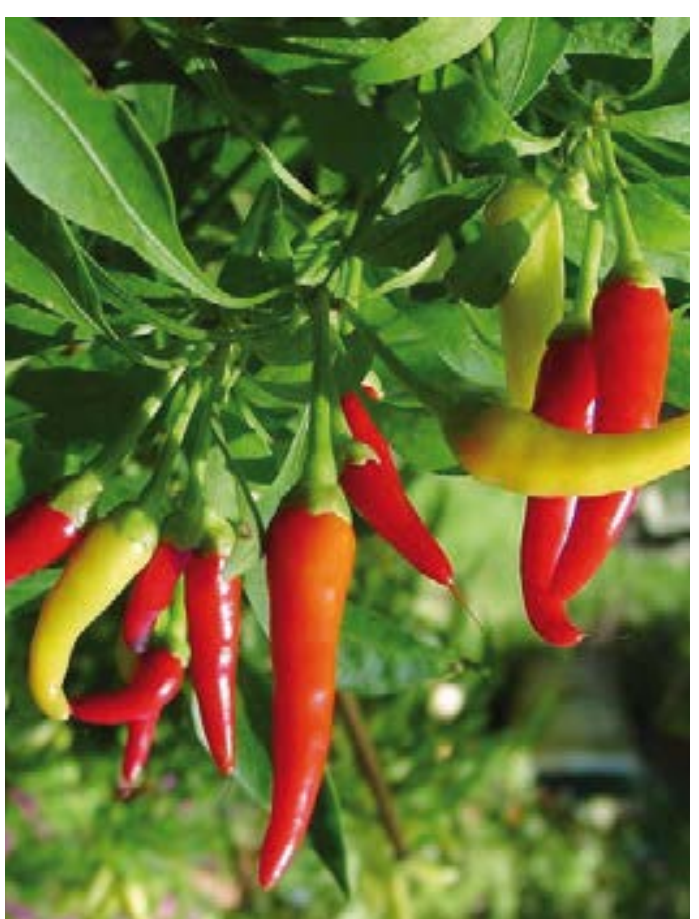

SOLANACEAE - Brugmansia arborea (L.) Lagerheim

Floripondio, Misha Blanca, Misha Rastrera, Misha Colambo, Datura

Árbol, Amazónico, Andino, Costa, 0-3000m, cultivado

Uso: 1. Remover Hechicería, Sanar efectos del Mal / Hojas, seco / Oral / Hervir 3 Hojas de Misha Blanca y 10 Hojas de Toromaique en 1 taza de agua hasta se reduce a 1/2 taza. Tomar frío. Paciente debe quedarse en un cuarto oscuro y tranquilo en dieta sin especies y mariscos por 3 días. Después puede salir pero debe descansar adentro 3 dís más. Tomar 1 taza pequena una vez al d́a por 3 días. 2 . Protección pero debe descan a d a del Mal / Planta enr a fia Martes, Vienes, Martes. 3 . Alucinggeno en 8 litros de agua por 1/2 hora. Efecto como Misha Roja y Misha Amarilla, pero visiones mas débiles. Usar con San Pedro y Hórnamo, 1 taza por día. Como alternativa, masticar 1/4 de una hoja. Sobredosis es letal! 4. Mal Aire / Hojas, fresco / Oral / Colectar planta antes de 6 de la mañana . Añadir 2 Hojas del material de la planta, 1 Hoja de Misha Amarilla, 1 Hoja de Misha Roja, 1g de Toromaique y $1 \mathrm{~g}$ de Toromisha a 1/2 taza de agua. Hervir la mezcla por 5 minutos. Tomar frío. Paciente debe descansar en un cuarto oscuro por 3 días, con dieta sin especies y mariscos. Sobredosis es letal! 5. Úlceras, Quistes, Úlceras por Hechicería/Daño / Hojas, seco / Tópico / Moler Hojas y poner polvo en área afectada como se necesita. 6. Insomnio / Flores, fresco / Tópico / Poner 4 Flores bajo la almohada en forma de cruz.

\section{SOLANACEAE - Brugmansia candida Persoon}

Misha Amarilla, Misha Galga

Árbol, Andino, Costa, 0-3000m, cultivado

Uso: 1. Mal Aire, Diarrea, Alucinógena o para mejorar visones / Hojas, fresco / Oral / Añadir 2 Hojas de la planta, 1 Hoja de Misha Blanca, 1 Hoja de Misha Roja y $1 \mathrm{~g}$ de Toromaique a 1/2 taza de agua. Hervir la mezcla por 5 minutos. Tomar la mezcla fría, 1/8 de un vaso pequeño. Paciente debe descansar en un cuarto oscuro por 3 días, con dieta sin especies y mariscos. Sobredosis es letal! 2. Úlceras, Quistes, Heridas por Daño/Hechicería / Hojas, seco / Tópico / Moler y polvorizar Hojas. Poner polvo en área afectada hasta que se sana. 3. Protección del Mal / Planta entera, fresco / Tópico / Baño en la mezcla por Protección del Mal. Baño una vez.

SOLANACEAE - Brugmansia sanguinea (R. \& P.) D. Don.

Misha Roja, Misha Morada, Misha Guargan, Guar Guar Rojo,

Árbol, Amazónico, Andino, Costa, 0-3000m, cultivado

Uso: 1. Mal Aire, Protección de Daño/Hechicería, Tensión de Nervios, Susto de Espíritus, Espiritus Negativos / Hojas y Tallos, fresco / Oral / Hervir 1/2 taza de agua y 50g de Misha Roja por 3 minutos. Tomar frío, solo una vez. 2. Mal Aire, Protección de Daño/Hechicería, Tensión de Nervios, Susto de Espíritus, Espiritus Negativos / Hojas y Tallos, fresco / Tópico / Hervir 6 litros de agua con 10g de cada uno de: Misha Roja, Misha Blanca, Misha Amarilla, Agua de Susto, Hierba del Gallinazo, Flor de Choclo y Toromaique por 5 minutos. Recitar una oración. Bañar el paciente en la mezcla frotando con las Hierbas. después lavar con agua y permitir que se seca al aire. Hacer 3 veces por día: Martes, Viernes y Martes siguiente. 3. Para ver el otro mundo / Flores y Hojas, fresco / Tópico / Hervir 6 litros de agua con 10g de cada uno de: Misha Roja Misha Blanca, Misha Am, rilla / Agur dusto, Hierba del Gallinan $10 \mathrm{~g}$ de Cada uno de: Misha Roja, Misha Blanca, Misha Am, Flor de Choclo y Toromaique por 5 minutos. recitar oración. Banar el paciente en la mezcla frotando con las Hierbas. después lavar con agua y permitir que se cese al aire. Hacer 3 veces por día: Martes, Viernes y Martes siguiente.

SOLANACEAE - Capsicum annuum $\mathrm{L}$

Aji Panca

Hierba, Amazónico, Andino, Costa, 0-3000m, cultivado

Uso: Mal Aire / Fruta, fresco / Incienso / Mezclar $1 \mathrm{~kg}$ de Aji Panca y 1/2kg azufre y poner sobre carbón caliente para producir humo. Hacer oraciones espirituales. Humo debe extenderse en toda la casa, cuarto por cuarto. Nadie debe ser en la casa excepto el curandero haciendo las oraciones espirituales. 


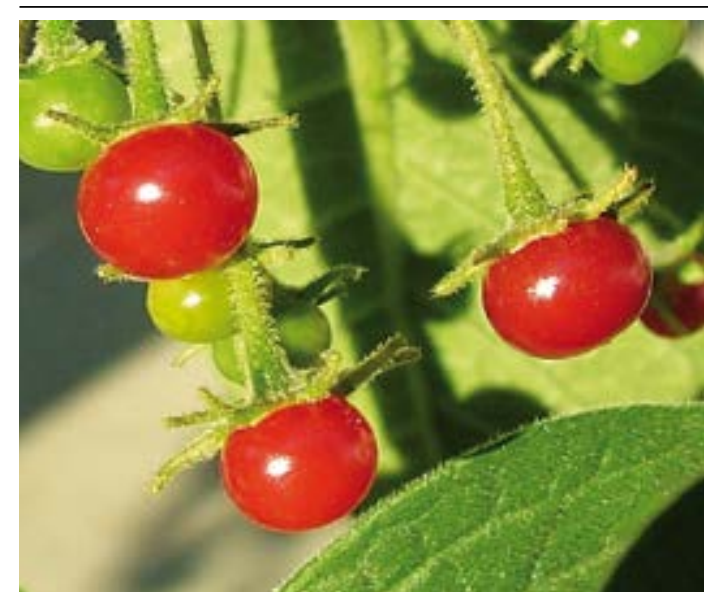

Capsicum rhomboideum

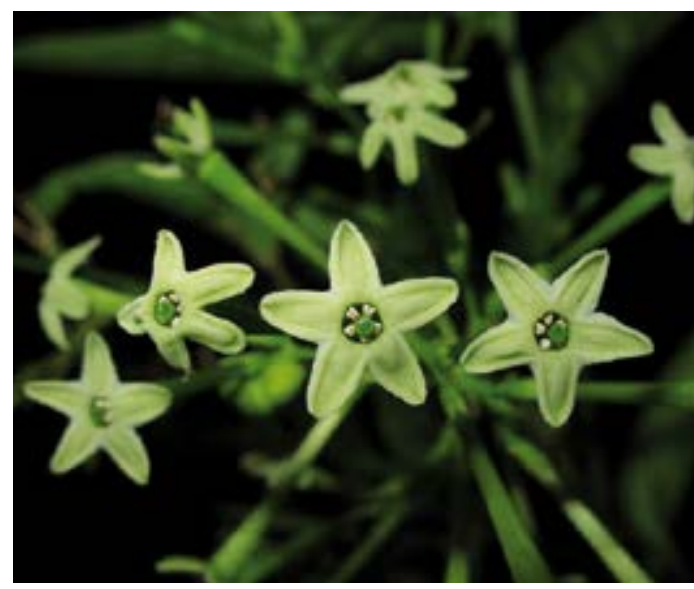

Cestrum nocturnum

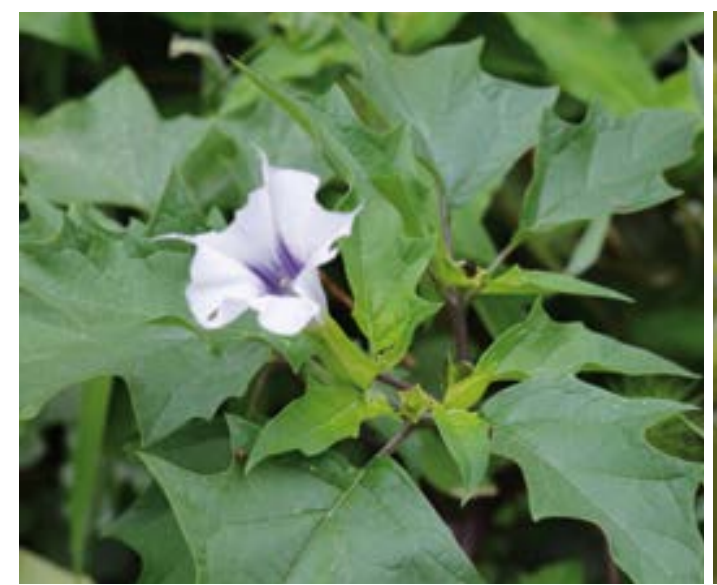

Datura inoxia

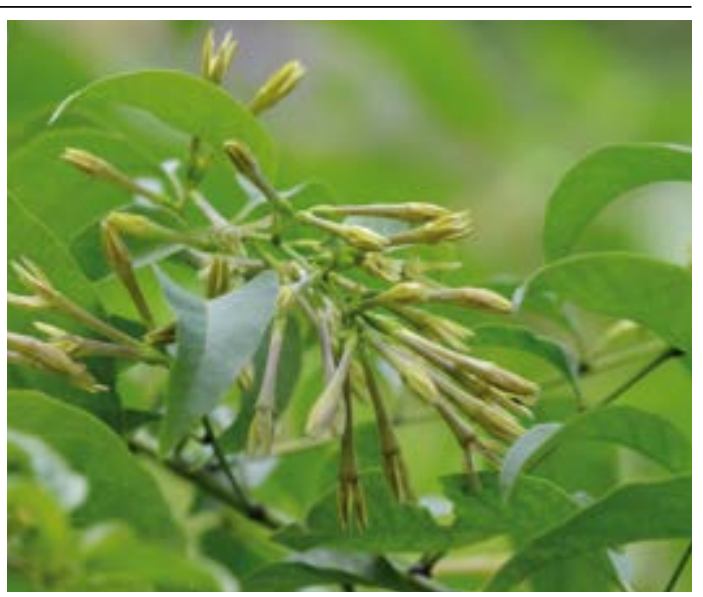

Cestrum auriculatum

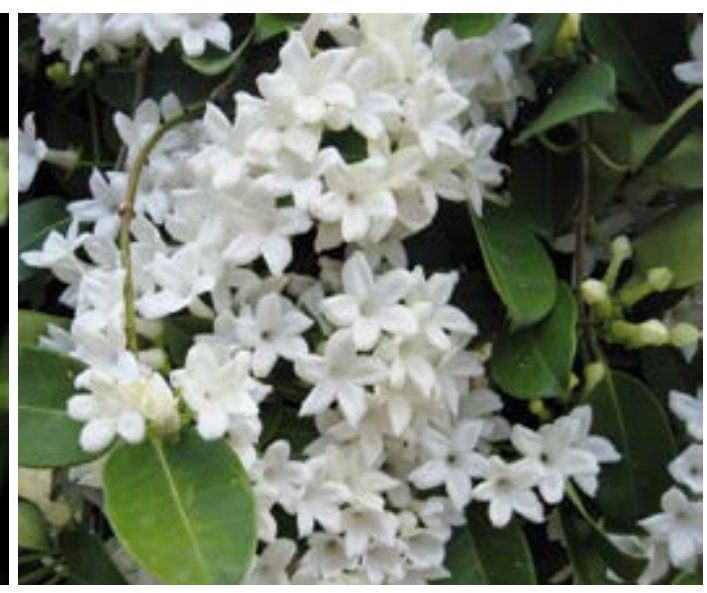

Cestrum strigilatum

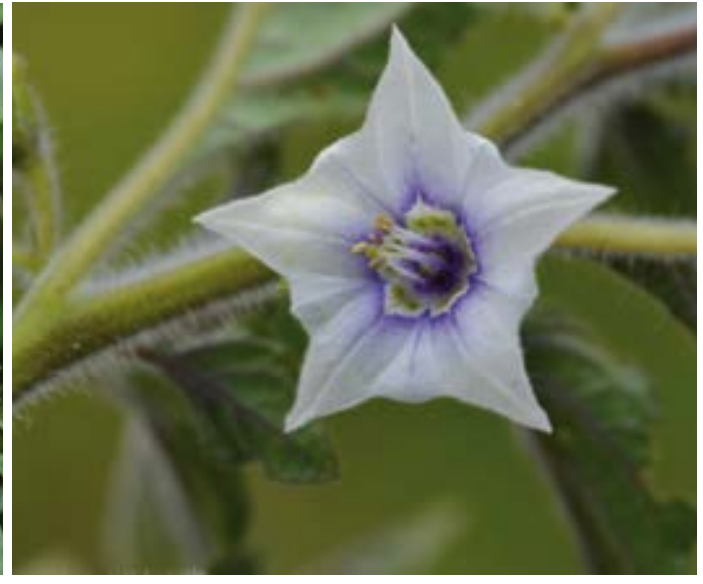

Jaltomata sp.
SOLANACEAE - Capsicum rhomboideum (Dunal) Kunze.

Aji Colorado

Hierba, Amazónica, Andina, 0-2000m, cultivado

Uso: 1. Mal Ojo, Protección de envidia/ Fruta entera, fresco / Amuleto / Amarrar 3 pimientas (verde, amarillo, rojo) con cinta roja y Ruda (macho y hembra) para protección contra envidia. Poner manojo tras la puerta de la casa. Si no se necesita mas botar en océano o rio. Si el manojo se pudre hay energía negativa en la casa. 2. Mal Ojo, Protección de envidia / Fruta entera, fresco / Tópico / Envolver un Aji y un huevo en Algodón Pardo. Frotar cuerpo con agua y Hierbas. Usar el manojo para frotar el paciente en todo el cuerpo. Después lleva lejos de la casa y quema todo. Romper el huevo y dejar contenido en un vaso de agua para diagnosis.

SOLANACEAE - Cestrum auriculatum L'Herit

Hierba Santa, Agrasejo

Arbusto, Andina, Costa, $0-2500 \mathrm{~m}$, maleza

Uso: 1. Heridas (Limpia) / Hojas, fresco o seco / Tópico / Hervir 10g de Hierba Santa en 1 litro de agua por 3 minutos. Combinar con 10g de Cola de Caballo. lavar con Hierbas y agua. Usar las plantas para limpiar herida 3 veces por día hasta que herida se sana. 2. Fiebre, bajar Presión sanguinea / Hojas, fresco o seco / Tópico / Niños: Hervir 5g en 1/2 litro de agua por 2 minutos. Adultos: Hervir 10g en 1 litro de agua por 2 minutos. Ańadir 7 Espiritus y Aguardiente. No mezclar con otras plantas. Bañarse o aplicar como enema, 3-4 veces por mes. Limpia: Para incrementar Presión Sanguinea. 3. Relajante, Susto, Dolor del Cuerpo, Presión alta, Tifoidea, Espasmos después del parto/ Hojas, fresco o seco / Tópico / Hervir 1 manojo (20g) de Hierba Santa en 3 litros de agua. Combinar con $10 \mathrm{~g}$ cada uno de Quinual, Eucalipto y Romero de Campo. Lavar paciente con Hierbas y agua o usar por Limpia, 3 veces por mes como se necesita. 4. Tos, Susto, Bronquitis, Cólico, Presión alta (bajar), Tifoidea, Diabetes, Hígado, Colesterol / Hojas, fresco o seco / Oral / Hervir $5 \mathrm{~g}$ en 1 litro de agua con $10 \mathrm{~g}$ cada uno de Corpus Way, Carqueja y Flor de Overo. Tomar 1 litro por día por 7 días. 5. Mal Aire, Resfríos, Espantar Sombras Malas / Hojas, fresco o seco / Incienso / Poner 200g de la Hierba sobre carbón caliente. Inhalar humo, una vez o como se necesita.

SOLANACEAE - Cestrum nocturnum L.

Flor de Azares

Arbusto, Costa, 0-1000m, introducido y cultivado

Uso: Corazón / Flores, fresco / Oral / Hervir 5g en 1 litro de agua. Mezclar con 5g cada uno de Pimpinela y Cadillo. Tomar 1 litro por día por 1 mes.

SOLANACEAE - Cestrum strigilatum R. \& P., Cestrum undulatum R. \& P.

Santa María

Uso: Regular Menstruación / Flores, Hojas y Tallos, fresco o seco / Oral / Hervir 1 litro de agua. Ańadir $10 \mathrm{~g}$ de Santa María, Ruda y Orégano. Dejar por 2-3 minutos. Paciente debe tomarlo caliente, 1 taza 2 veces por día por 2 días.

SOLANACEAE - Datura inoxia Miller

Chamico

Hierba, Costa, $0-500 \mathrm{~m}$, introducido

Uso: Hechizar hombres, bajar el moral / Hojas, seco / Oral / Comparar después de 6 de la tarde por rituales de noche para que sea fresco. Seco, 2 Hojas. Moler en polvo. Añadir 1 taza de agua hervida. Dejar por 3 minutos. Tomar caliente hasta templado como se necesita. Demasiado puede matar. Mezclar con Té, chocolate o café si se desea.

SOLANACEAE - Jaltomata sp

Hierba del Tigre

Hierba, Andino, 2000-3000m

Uso: 1. Mal Aire, Fragancia, Buena Suerte (Trabajo), Daño/Hechicería (Prevención), Remover Daño hecho al paciente, Fuerza, Mal (Cura), Mal Ojo / Hojas y Tallos, fresco o seco / Oral / Hervir 10g de Hierba del Tigre, $10 \mathrm{~g}$ de Hierba del Oso, $10 \mathrm{~g}$ de Cimora Negra, 3 Hojas de Toro Cimuro, y 3 Hojas de Misha Amarilla en 1/2 taza de agua por 5 minutos. Compuesto muy fuerte. No exceder la dosis! 1/8 taza solo una vez. Tomar frío. Paciente debe quedarse en casa sin luz o ruido por 3 días. Debe observar dieta (sin especies, frijoles, mariscos). 2. Protección del Mal / Hojas y Tallos, fresco o seco / Tópico / Baño por Protección del Mal. Solo una vez. 3. Mal Aire, Fragancia, Buena Suerte (Trabajo), Daño/Hechicería (Prevención), Remover Daño hecho al paciente, Fuerza, Mal (Cura), Mal Ojo / Hojas y Tallos, fresco o seco / Seguro / Poner 2 ramas pequeñas en el Seguro. 


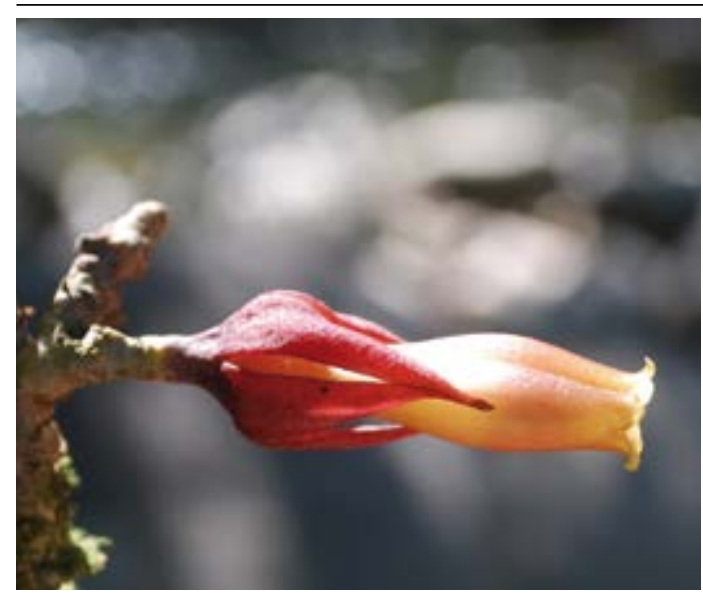

Juanulloa ochracea

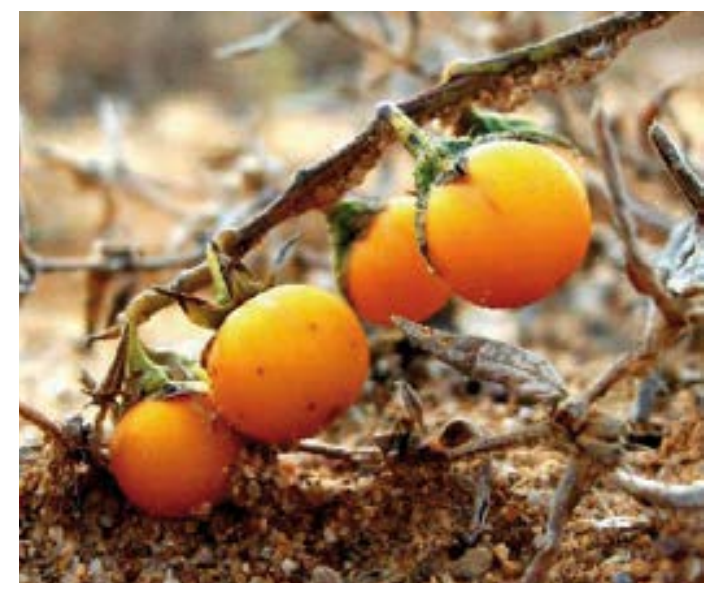

Lycopersicon hirsutum

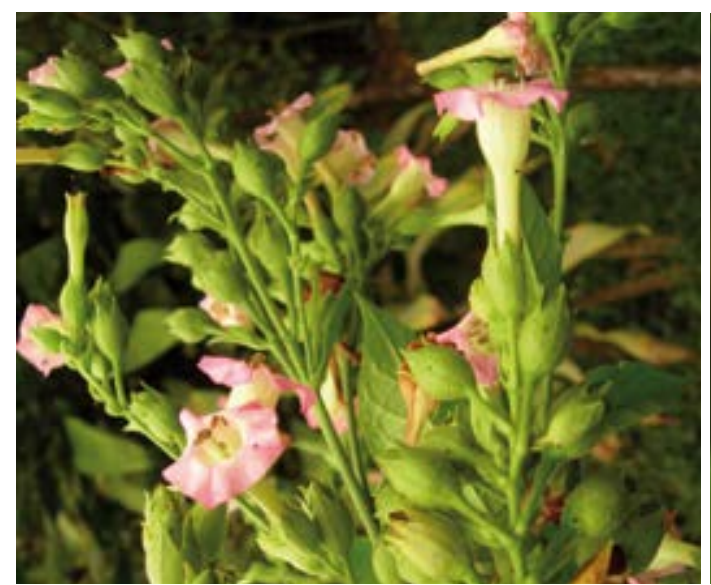

Nicotiana tabacum

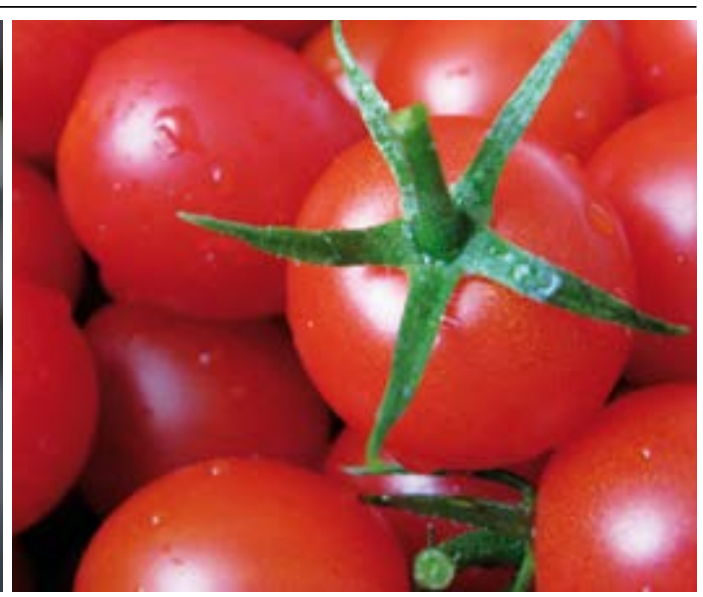

Lycopersicon esculentum

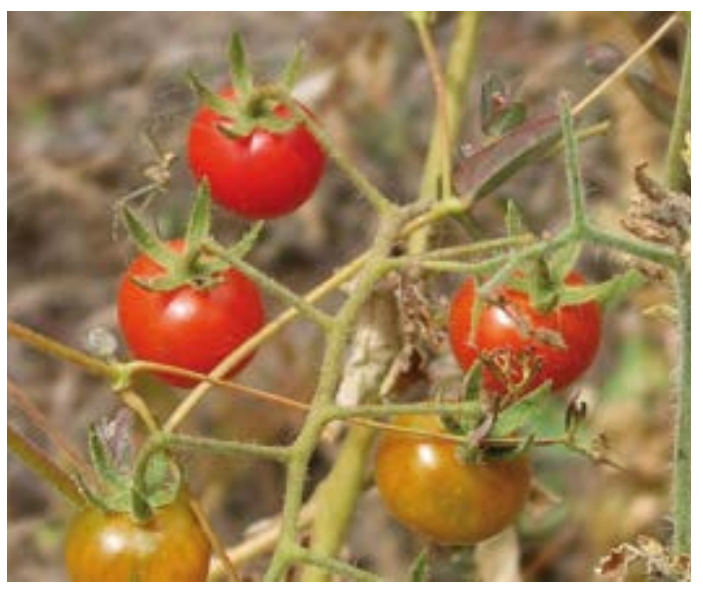

Lycopersicon peruvianum

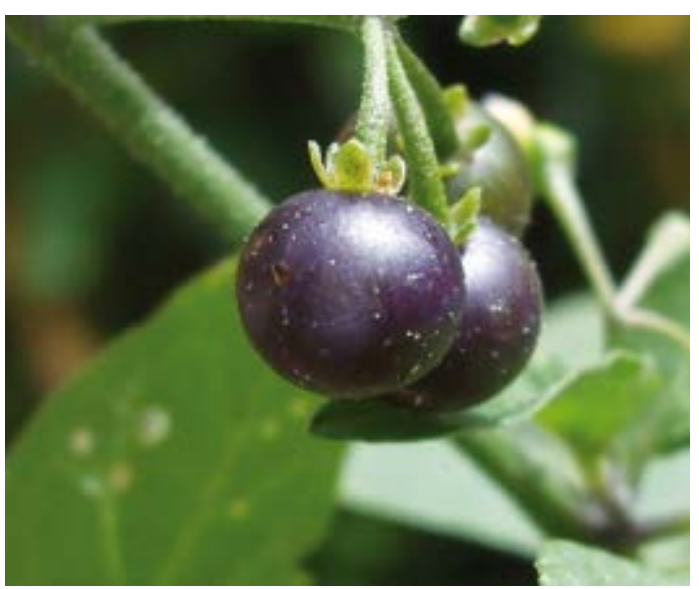

Solanum americanum

\section{SOLANACEAE - Juanulloa ochracea Cuatrecasas}

Cuya Cuya

Arbusto, Amazónico, Andino, 0-2000m

Uso: Mal Aire, Dolor del Cuerpo/ Semillas, secas / Tópico / Moler 1Semillay mezclar con Agua Florida,

Timolina y Aguardiente. Frotar como se necesita.

SOLANACEAE - Lycopersicon esculentum Mill.

Tomate

Hierba, Andina, Costa, $0-2000 \mathrm{~m}$, cultivado

Uso: Prevención de deformación de articulaciones por Artritis / Fruta, fresco / Oral / Extraer jugo. Tomar fresco, 1 vaso por día por 1 mes.

SOLANACEAE - Lycopersicon hirsutum Duna

Ambulluco del Muerto

Hierba, Andina, 1000-4000m, maleza

Uso: Susto de la Muerte / Planta entera, fresco o seco / Tópico / Mezclar con $10 \mathrm{~g}$ cada uno de Flores del Muerto, Zanahoria, Poleo Gentil, Vinagre, 7 Espiritus, Agua del Susto. Hacer Limpia dos veces por semana.

SOLANACEAE - Lycopersicum peruvianum $\mathrm{L}$.

Tomate de Monte

Hierba, Andina, Costa, 0-3000m, maleza

Uso: Inflamación (Interno), Infecciones Urinarias / Planta entera, fresco / Oral / Hervir 100g de material de planta en 1 litro de agua por 5 minutos. Tomar frío, 1/2 taza en ayuno por 5 días.

SOLANACEAE - Nicotiana tabacum L.

Tabaco

Hierba, Amazónica, Andina, Costa, 0-3000m, cultivado

Uso: 1. Mejorar visiones y percepción durante rituales, Incrementar energía del paciente (Ritualmente y Físicamente) / Hojas, seco / Oral / Mezclar 1g de Tabaco con Agua Florida, Jugo de Lima Ramillete de Novia, Azúcar Blanco, Agua Bendita, Aguardiente, Agua Florida y Agua Cananga. Dejar mezcla por 2 horas. Ambos curandero y paciente deben inhalar la mezcla por la nariz. 2. Fracturas / Hojas, seco / Tópico / Macerar Hojas en Aguardiente y calentar. Mezclar con un poco de Trementina. Poner sobre fractura. Poner Emplasto en área afectada y cubrir con tela, solo una vez por 3 días.

SOLANACEAE - Solanum americanum Mill.

Hierba Mora, Hierba del Susto, Baja del Espanto

Hierba, Amazónica, Andina, Costa, 0-3000m, maleza

Uso: 1. Sinusitis, Gripe, Resfrío, Orinar involuntariamente / Frutas frescas / Tópico / Machucar 20 Frutas para extraer jugo, 2 gotas por lado de nariz 2. Fiebre / Planta entera, fresco / Tópico / Adultos: Hervir $10 \mathrm{~g}$ en 1 litro de agua por 10 minutos. Nińos: Hervir $1 / 2$ litro de agua por $10 \mathrm{~g} 3$ veces por día hasta que sale todo el mucus. 3. Ampollas de Resfrío, Ampollas en la Boca, Herpes / Frutas frescas / Tópico / Extraer jugo de la fruta. Aplicar jugo en área afectada, una vez por día hasta sanado. 4. Susto / Planta entera, fresco / Oral / Hervir 1/2 taza de agua con 100g de material de planta por 5 minutos. Mezclar con $10 \mathrm{~g}$ cada uno de Toronjil y Mejorana. Tomar $1 / 4$ taza, solo una vez. 5. Susto / Planta entera, fresco / Tópico / Baño: Hervir 5 litros de agua con 100g de: Hierba del Susto, Hierba del Gallinazo, Romero, Paja del Aire, Ashango, Ishpingo, Samala, Flor del Muerto y Ruda. Hervir por 10 minutos. Primero frotar el cuerpo con Hojas. Después lava con agua. No usar jabón! Baño solo una vez Martes o Viernes. 


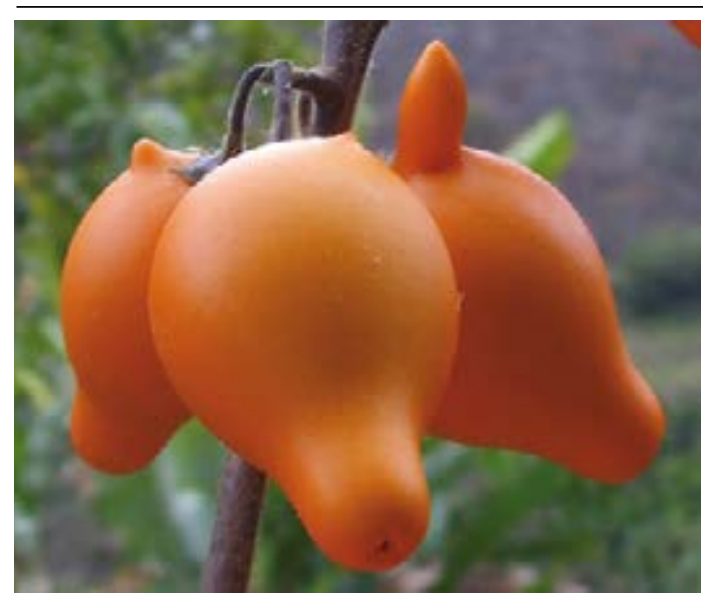

Solanum mammosum

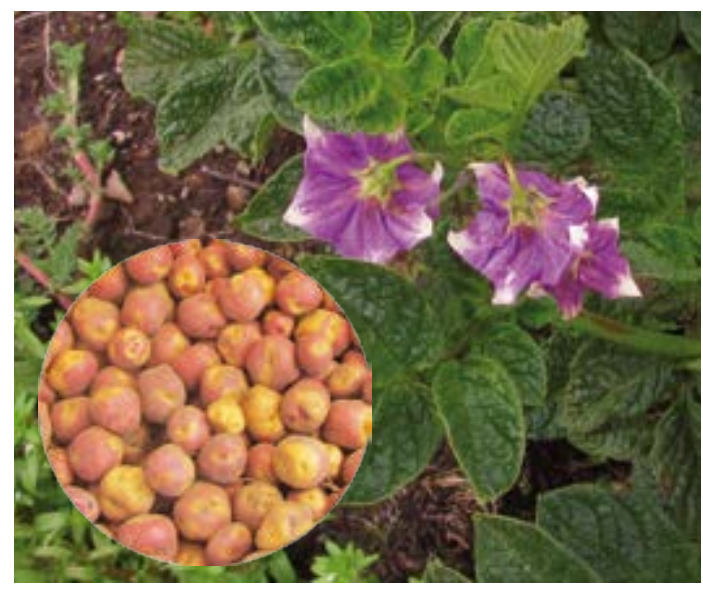

Solanum tuberosum

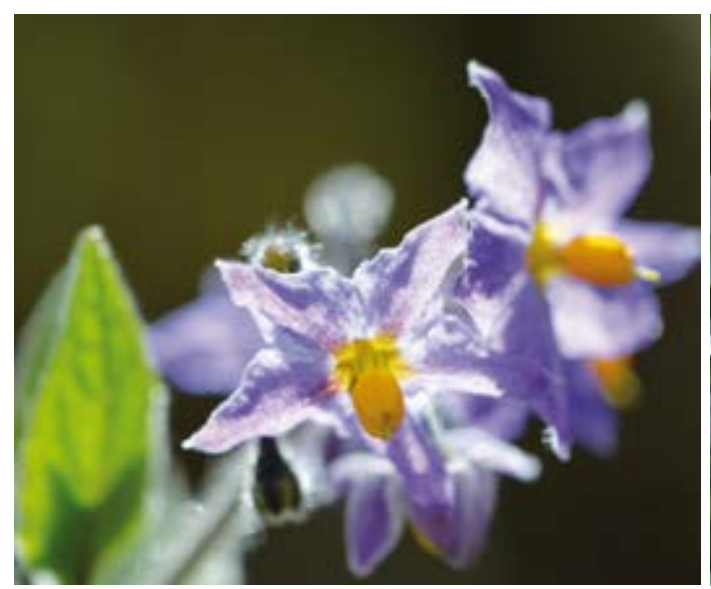

Solanum sp.

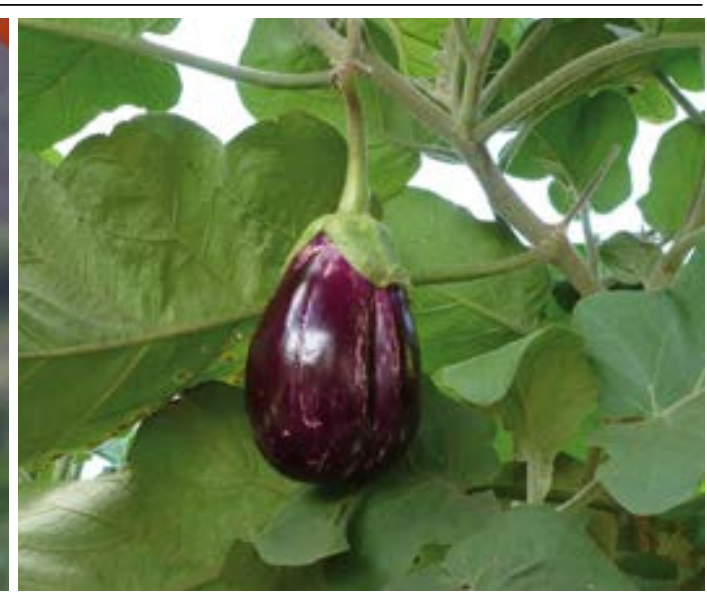

Solanum melongena

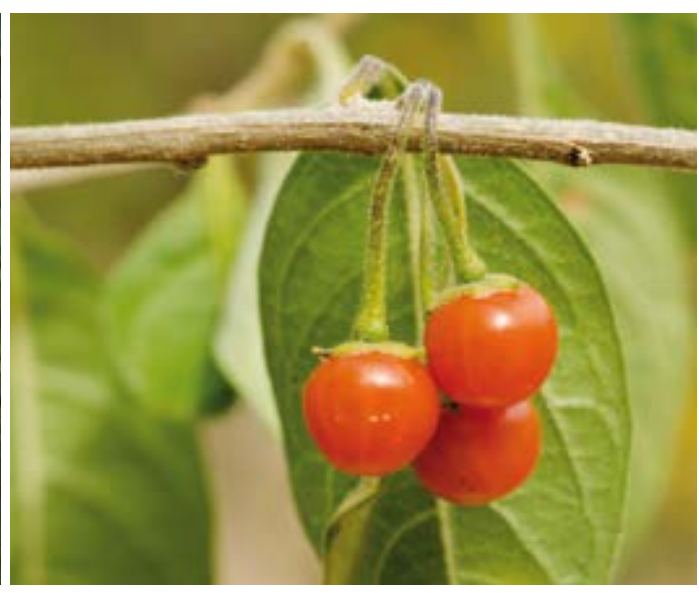

Solanum sp.

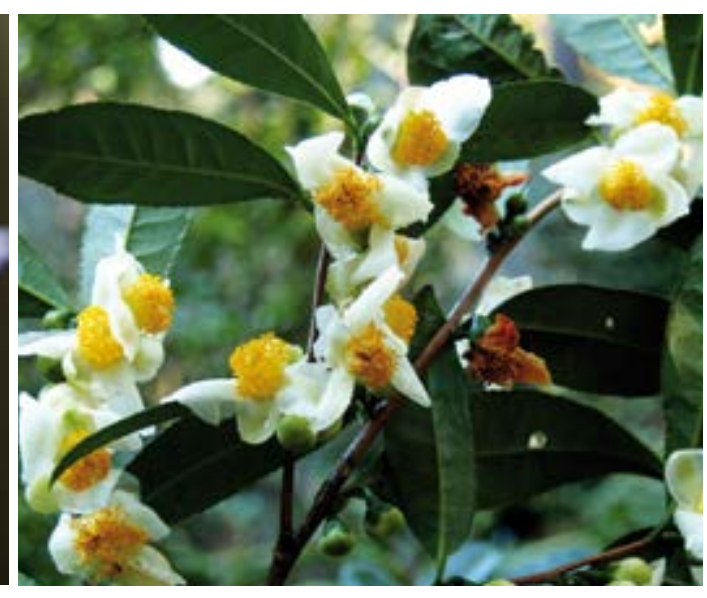

Camellia sinensis
SOLANACEAE - Solanum mammosum L.

Toro Misha Amarillo, Toro Misha, Toro Cimuro, Macumamuna

Hierba, Amazónica, Andina, Costa, 0-2000m, cultivado

Uso: 1. Buena Suerte, Para ganar Peso, Baño de ganado / Fruta, fresco / Tópico / Hervir ,Fruta entera con Agua Florida por 20 minutos. Bańo una vez por semana por 1 mes. Planta muy tóxica. 2. Mal Aire

/ Hojas, fresco Planta entera, fresco / Oral / Hervir 100g de Toro Misha Amarillo en 1 taza de agua por 10 minutos. Tomar 1 taza fría. 3. Protección del Mal / Tópico / Mezcla de Bańo por Protección del Mal.

SOLANACEAE - Solanum melongena L.

Berenjena

Hierba, Amazónica, Andina, Costa, 0-2500m, cultivado

Uso: Quema Grasa, Perder Peso / Fruta entera, fresco / Oral / Mezclar 2 Berenjenas con 1/4 piña. Tomar 1 vaso por día ayunando, como se necesita.

\section{SOLANACEAE - Solanum tuberosum L.}

Chuńo de Papa

Hierba, Amazónico, Andino, Costa, 0-3000m, cultivado

Uso: Complicaciones en el parto, Bronquitis, Problemas Respiratorias / Tubérculo, seco / Oral / Hervir $1 / 2 \mathrm{~kg}$ de Chuño de Papa en 1/2 litro de agua. Añadir Chancaca, Angamacha y Valeriana Estrella y Hervir por 10-15 minutos o mas hasta que sale el almidón. Remover del fuego. Servir caliente 3 veces por día por 2 días durante 10 días después del parto del bebé. La preparación rinde un tipo de dulce. Comer caliente y fresco. Tomar la ultima dosis en la cama para no salir mas al frío.

\section{SOLANACEAE - Solanum sp.}

Tutapure Chico

Hierba, Andina, 1000-3000m

Uso: Susto de Muerte, Espiritus / Hojas y Tallos, fresco / Tópico / Hervir 1 mano en 3 litros de agua por 10 minutos. Mezclar con Agua del Susto y 7 Espiritus. Puede combinar con Tutapure Grande, Tutapure Blanco y Zanahoria, $5 \mathrm{~g}$ cada uno. Baño dos veces por mes o 1-2 veces por semana depende en la severidad. Mas usado por niños.

\section{SOLANACEAE - Solanum sp.}

Hórnamo Cimuro

Hierba, Andina, 1000-3000m

Uso: Protección del Mal / Planta entera, fresco o seco / Tópico / Mezcla de Baño por Protección del Mal. Una sola vez.

THEACEAE - Camellia sinensis (L.) Kuntze

Arbusto, Andino, 1500-2500m, introducido y cultivado

Uso: Cólico, Diarrea, Dolor de Estómago / Hojas y Tallos, seco / Oral / Tostar 20g de Arroz. Moler y mezclar con $20 \mathrm{~g}$ de Té. Hervir 1 taza de agua por 5 minutos y añadir la mezcla molida y el jugo de 3 Limas después de hervir. Tomar frío, $1 / 2$ taza 2 veces por día hasta se va el dolor. 


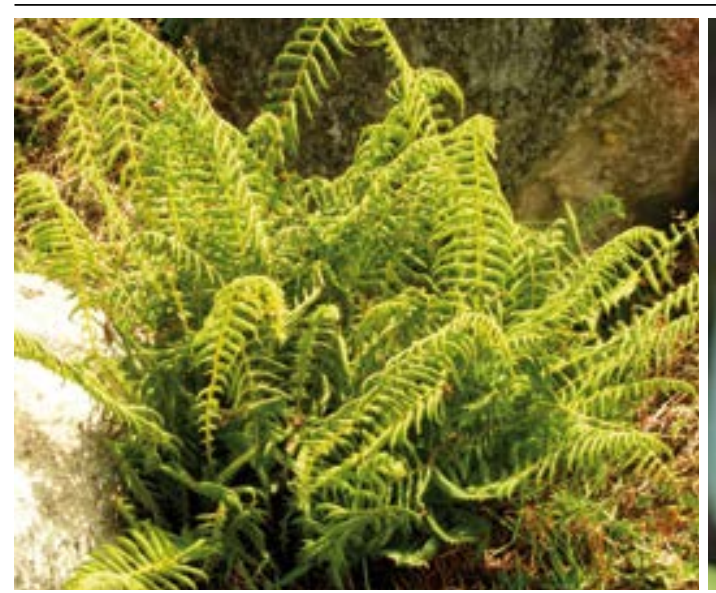

Thelypteris scalaris

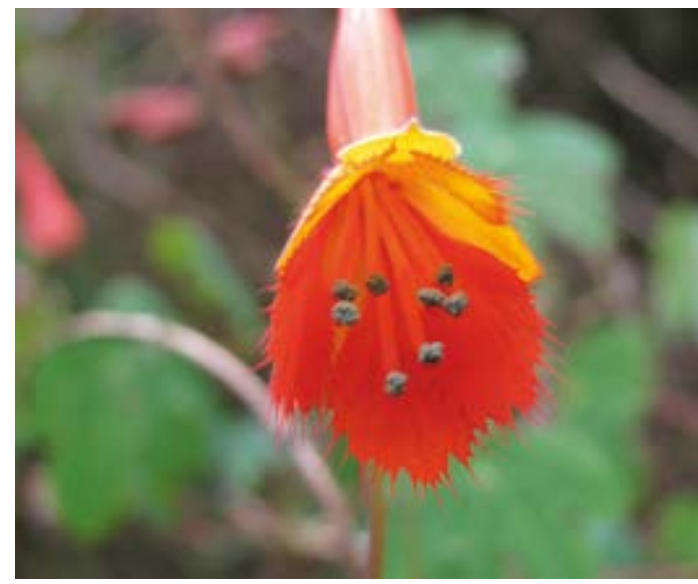

Tropaeolum minus

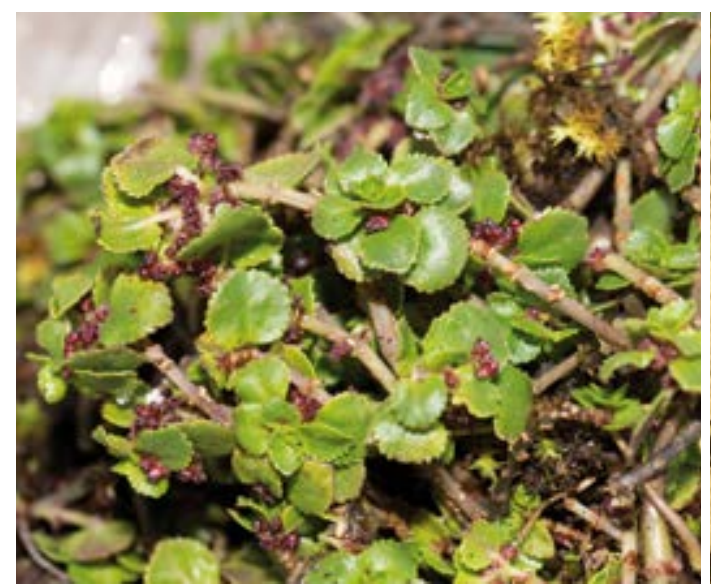

Pilea microphylla

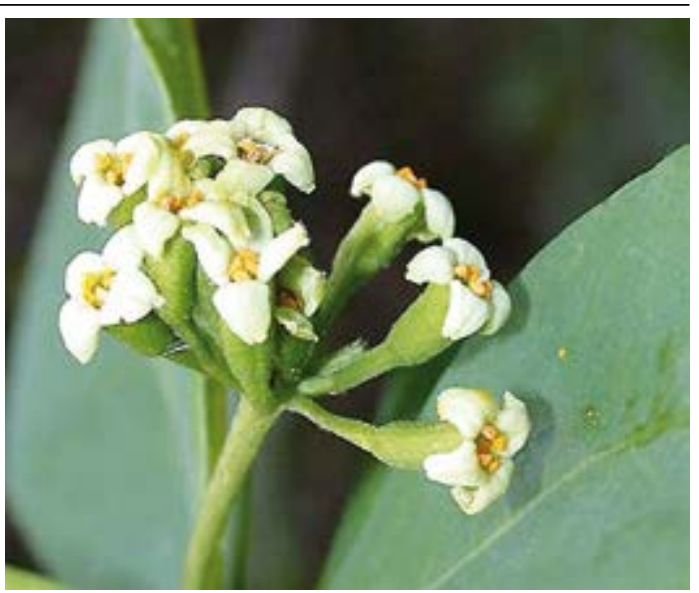

Daphnopsis weberbaueri

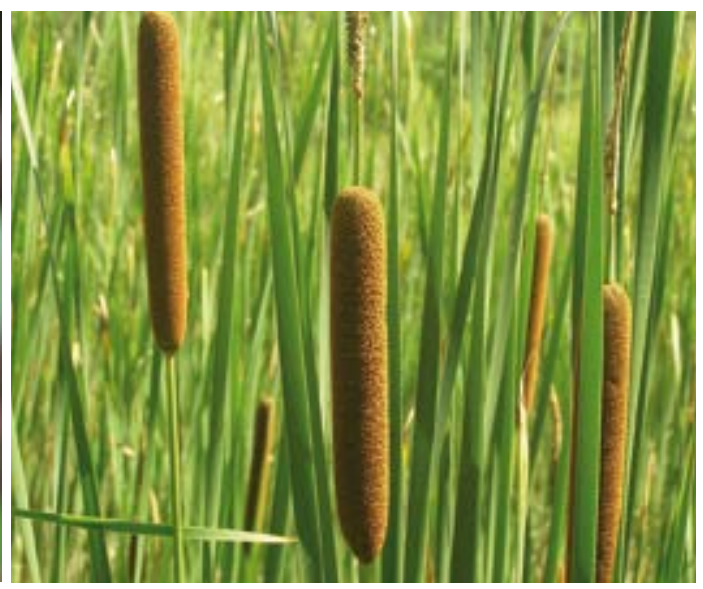

Typha angustifolia

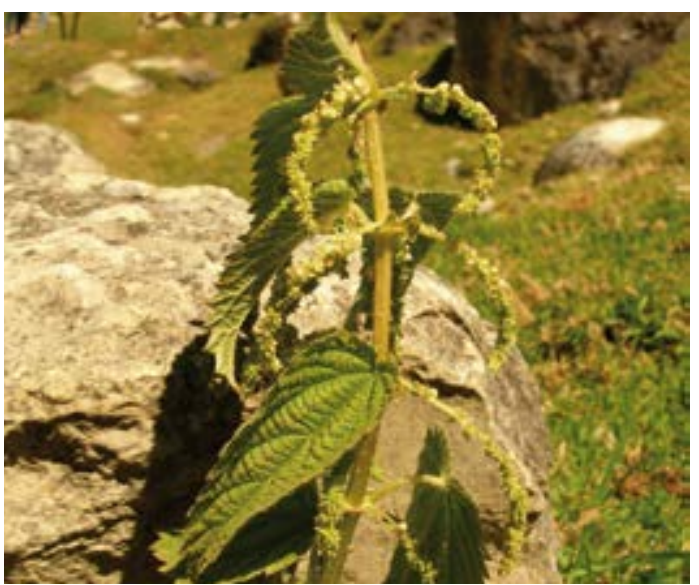

THELYPTERIDACEAE - Thelypteris scalaris (Christ.) Alton

Helecho Macho

Helecho, Andino, 1500-2500m

Uso: Contraceptivo / Planta entera, fresco o seco / Oral / Hervir 10g de Helecho Macho con 10g de Pata de Gallina y $10 \mathrm{~g}$ de Perejil en 1 litro de agua por 10 minutos. Tomar durante los días en que la mujer se puede embarazar.

THYMELEACEAE - Daphnopsis weberbaueri Domke

Cholitos (Macho and Hembra)

Arbusto, Andino, 3000-3500m

Uso: Infertilidad / Semillas, secas / Oral / Por 1 botella de Vino añadir 1 Semilla Hembra y 1 Semilla Macho de Cholitos, Pacra, Huanarpo (Hembra y Macho), Miel, Polen de Abeja, Huevo de Angelote, Chuchuhuasi, Palo Sangre, Palo Huanco y Cascarilla (10g de cada uno). Dejar por 1 semana. Tomar 1-2 tazas pequeńas por día por 1 semana. Tomar at a temperatura de ambiente en la mañana antes del desayuno y en la noche antes de dormir.

TROPAEOLACEAE - Tropaeolum minus L.

Mastuerzo

Hierba, Amazónico, Andino, Costa, 0-3500m, maleza

Uso: 1. Manchas por el sol / Flores, fresco / Tópico / Frotar Flores en área afectada (normalmente cara) Flores no deben ser mojados. Hacer 3 veces por día como se necesita. 2. Inflamación del Estómago/ Planta entera, fresco / Oral / Hervir 10g de Mastuerzo en 1 litro de agua. Combinar con 10g cada uno de Amor Seco, Chacur, Cola de Caballo, Verbena y Espiga de Maíz. Tomar 3 tazas por día por 1 mes.

TYPHACEAE - Typha angustifolia L.

Chante

Hierba, Costa, $0-1500 \mathrm{~m}$, introducido

Uso: Próstata / Tallos, seco / Oral / Hervir 5g en 1 litro de agua por 10 minutos. Se puede combinar con Agujilla y Achiote. Tomar 1 litro por día.

URTICACEAE - Pilea microphylla (L.) Lieberman

Contra Hierba

Hierba, Amazónica, Andina, 0-3500m, maleza

Uso: Cálculos de Vejiga, Inflamación de Rińones, Próstata, Quistes / Planta entera, fresco / Oral / Hervir $5 \mathrm{~g}$ de la planta por 3-5 minutos en 1 litro de agua mezclado con $10 \mathrm{~g}$ cada uno de Cola de Caballo, Hoja de Achiote y Chanca Piedra. Tomar 1 litro por día por 15 días.

URTICACEAE - Urtica magellanica A. Jussieu ex Poiret

Ortiga, Ortiga (Chica), Ortiga de Oveja, Ortiga Negra.

Hierba, Andino, 1000-4500m, maleza

Uso: 1. Purificación de la Sangre, Felicidad, Fiebre, Reumatismo, Artritis, Circulación de sangre, Hemorragias, Perdida de Cabello, Asma, Hemorroides, Inflamación (General) / Planta entera, fresco o seco / Oral / Hervir 10g de Ortiga Negra en 1 litro de agua por 10 minutos. Combinar con 10g cada uno de Huamanripa, Veronica, Corpus Way, Carqueja, Nogal, Ocalito, Molle, Ruda y Matico. Tomar 4 tazas por día por 15 días. 2. Purificación de la Sangre, Felicidad, Fiebre, Reumatismo, Artritis, Circulación de sangre, Hemorragias, Perdida de Cabello, Asma, Hemorroides, Inflamación (General) / Planta entera, fresco o seco / Tópico / Usar la misma mezcla por Baño y frota Hojas en partes afectadas por Reumatismo 3 veces por semana. 


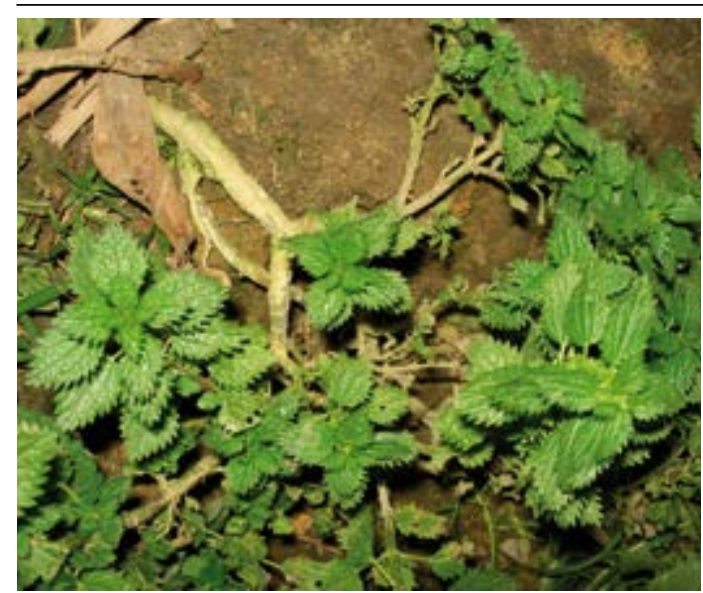

Urtica urens

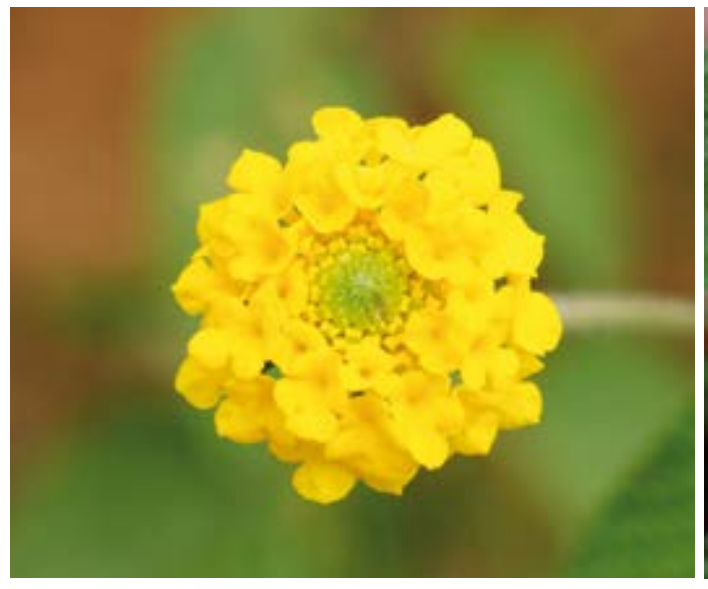

Lantana scabiosaeflora

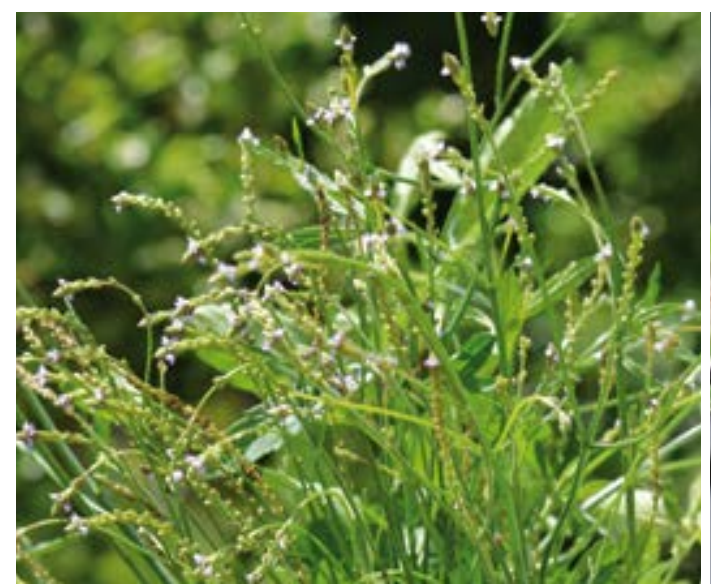

Verbena litoralis

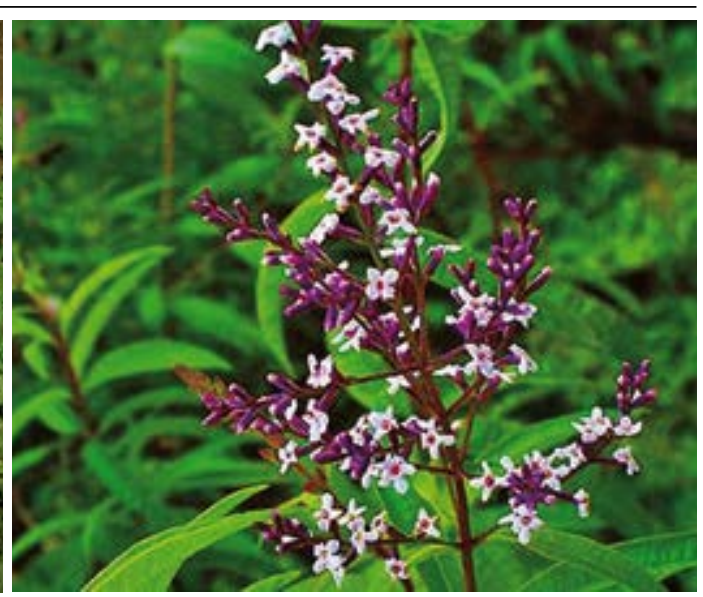

Aloysia triphylla

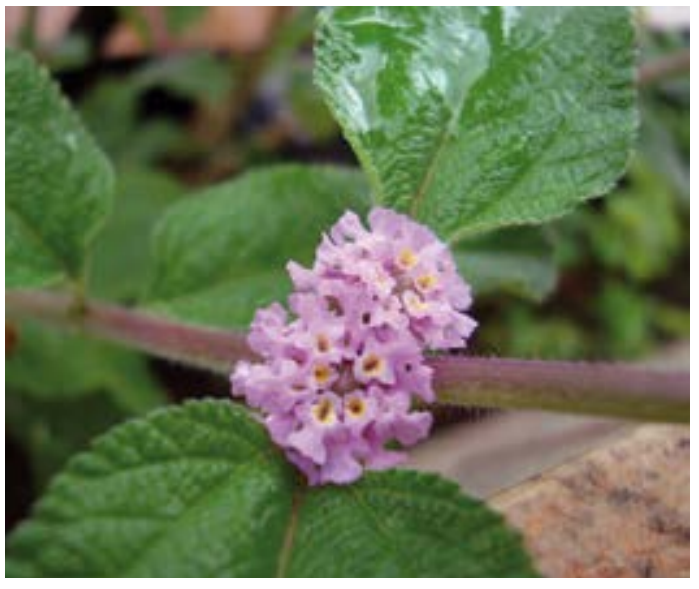

Lippia alba

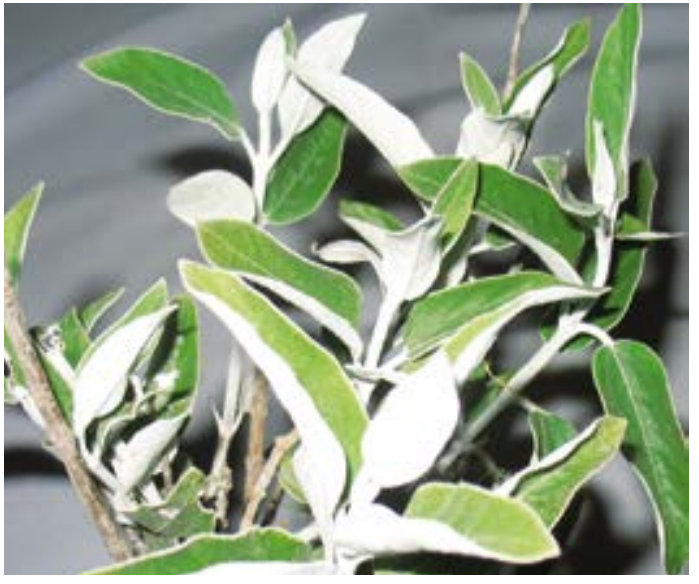

VERBENACEAE
URTICACEAE - Urtica urens L.

Ortiga

Hierba, Amazónico, Andino, Costa, 0-4500m, maleza, introducido

Uso: Mal Aire, Próstata, Susto, Limpia vaginal, Negocios, Sobrepasar mala suerte, Susto en Niños /

Tallos y Hojas, fresco / Tópico / Hervir 7 Tallos con Hojas en 3-5 litros de agua combinado con 10g cada uno de Agua del Susto, Ajenco y Llatama por 20 minutos. Bańo 2-3 veces por semana at 7, 9 y 11 PM.

VERBENACEAE - Aloysia triphylla (L'Her.) Britt.

Cedrón, Pepas de Cedrón,

Árbol, Andino, 2000-4000m, maleza

Uso: 1. Depresión, Nervios, Insomnio, Estómago / Planta entera, fresco / Oral / Hervir 1 litro de agua. Añadir Cedrón y mezclar con Chancas de Comida, Toronjil, Hinojo, Madre Selva, Claveles y Pensamiento. Usar un total de 10g del material. Dejar mezcla por 2-3 minutos. Paciente puede tomar en cada temperatura, pero se recomiende templado. Tomar 1 taza, 3-4 veces por día por 1 mes. 2. Mal Aire / Semillas, fresco o seco / Tópico / Moler 4-5 Semillas y Hervir en 5 litros de agua por 10 minutos. Baño. 3. Mal Aire / Semillas, fresco o seco / Oral / Hervir 1 Semilla en 1 litro de agua por 10 minutos. Tomar 4 tazas por día por 7 días. 4. Dolor agudo del Cuerpo/ Semillas, fresco o seco / Oral / Mezclar 10g de Semillas molidas, $1 / 4$ de una pequeńa taza de Pisco, $1 \mathrm{~g}$ de Alucema, $1 \mathrm{~g}$ de Orégano y $1 \mathrm{~g}$ de Pimienta. Calentar. Tomar 1 cuchara por día por 6 días.

VERBENACEAE - Lantana scabiosaeflora Kunth

Mastrando, Mastrante

Árbol, Andino, Costa, 0-4000m

Uso: Resfrío, Ovarios, Menstruación, Mujeres después del parto para evitar resfrió / Hojas y Tallos, fresco o seco / Oral / Hervir 20-100g en 1 litro de agua por 3 minutos. Mezclar 10g cada uno de Canchalagua, Culantrillo, Purenrosa, Panisara y Salvia Real. Tomar templado 1 litro por día por 3 días. Este tratamiento solo es para mujeres.

VERBENACEAE - Lippia alba (Miller) N.E. Brown

Poleo del Inca

Arbusto, Amazónico, 0-500m, maleza, cultivado

Uso: Resfrío, Cólico, Inflamación de Rińones, Bronquitis, Reumatismo, Gases / Hojas y Tallos, fresco / Oral / Hervir 5g en 1 litro de agua por 10 minutos. Tomar 1 litro cada día por 1 mes.

\section{VERBENACEAE - Verbena litoralis Kunth}

\section{Verbena}

Hierba, Amazónico, Andino, Costa, 0-4000m, maleza

Uso: 1. Fiebre, Hongos / Planta entera, fresco o seco / Tópico / Adultos: Hervir 10g de Verbena en 1 litro de agua. Nińos: Hervir $10 \mathrm{~g}$ de Verbena en $1 / 2$ litro de agua. Aplicar como enema una vez cuando agua esta templada. Como alternativa, Hervir 10g por 2 litros de agua por 30 minutos combinado con Matico, Malva, Llantén, y Para Para, 3 veces por día por 8 días. 2. Hiperactividad, ADHD, Tranquilidad / Planta entera, fresco o seco / Tópico / Hervir por 20 minutos 5-10g de la Hierba en 1 litro de agua mezclado con $10 \mathrm{~g}$ cada uno de Matico, Malva y Manzanilla. Bańo 3 veces por semana. 3. Inflamación, Heridas (limpieza), Purificación de la Sangre, Cholera, Modificar Carácter fuerte, Cólicos, Resfríos / Planta entera, fresco o seco / Oral / Hervir 30g en 1 litro de agua por 3 minutos. Mezclar con 10g cada uno de Cerraja, Moradilla y Verdolaga. Tomar 2 vasos por día por 4 días en la mañana y noche.

\section{VERBENACEAE}

Uso: Ampollas en los pies / Hojas y Tallos, seco / Oral / Hervir 100g de material de planta en 1 taza de agua por 10 minutos. Tomar frío, $1 / 4$ taza dos veces por semana. 

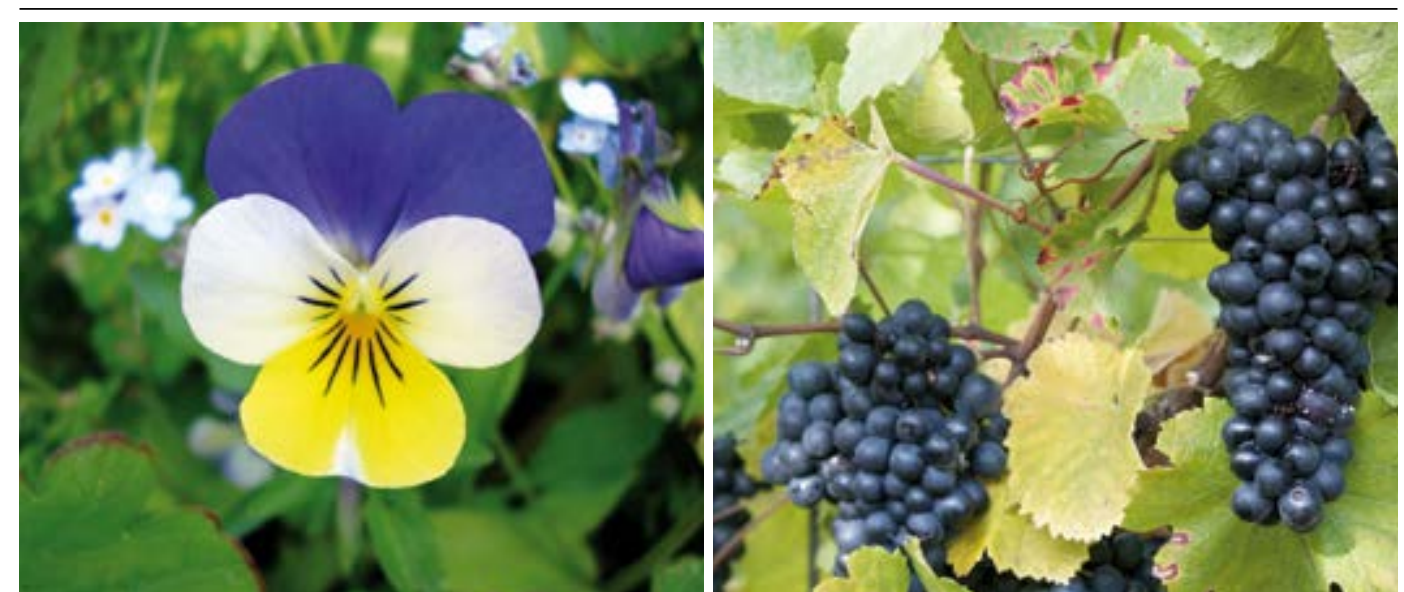

Viola tricolor

Vitis vinifera

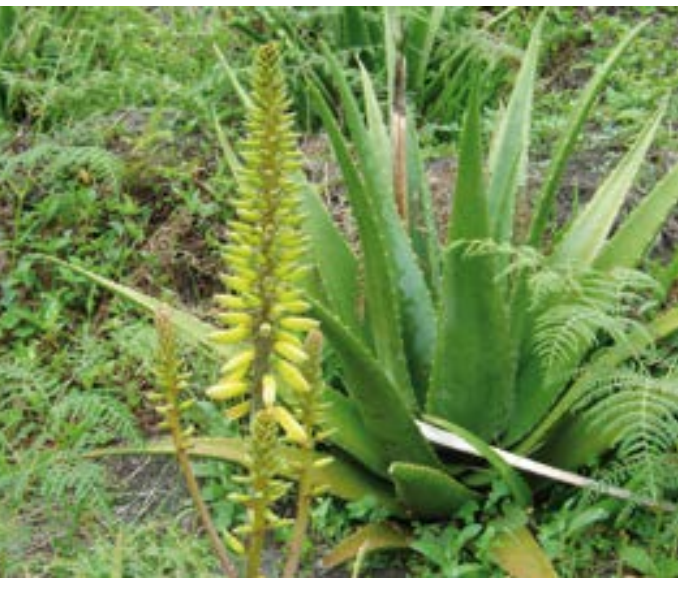

Aloe vera

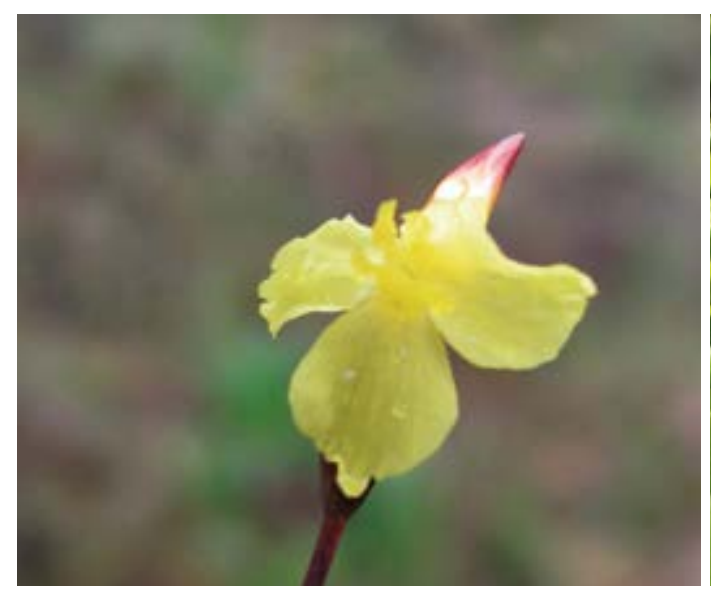

Xyris subulata

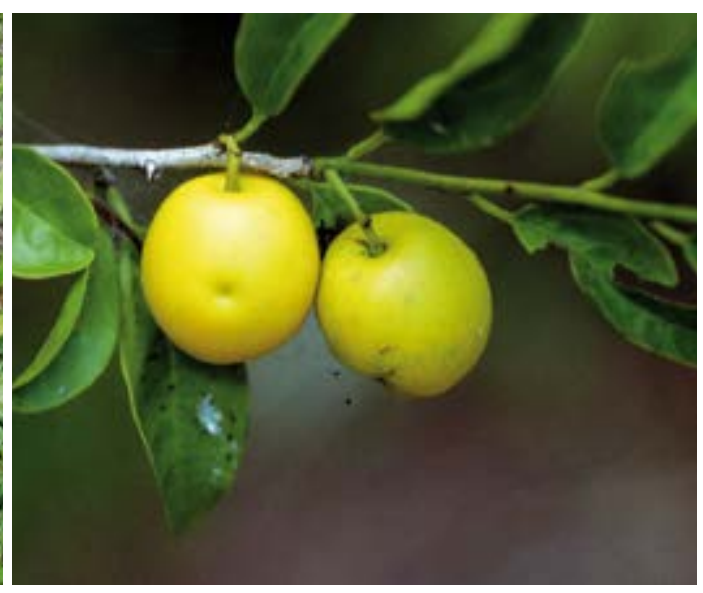

Ximenia americana

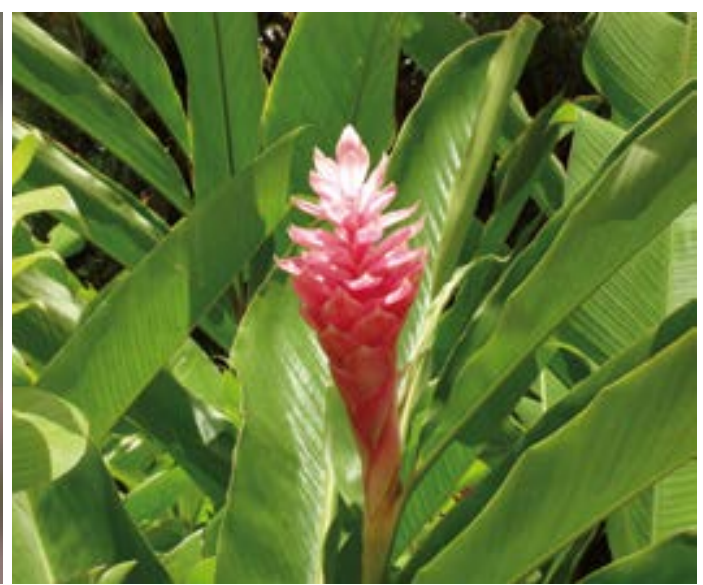

Zingiber officinale
VIOLACEAE - Viola tricolor L

Pensamiento Amarillo, Hierba del Pensamiento, Hierba del Tacón (Violet)

Hierba, Andina, Costa, $0-4000 \mathrm{~m}$, introducido y cultivado

Uso: Corazón, Enfermedad de Amor, Nervios, Insomnio, Olvidad Dolor, Susto, Mal Aire, Nervios, Epilepsia / Planta entera, fresco o seco / Oral / Hervir 1 litro de agua. Añadir 10g de Pensamiento Amarillo a 10 plantas de Corazón incluso Toronjil, Congona y Clavel. Tomar 3 tazas por día como se necesita.

VITACEAE - Vitis vinifera L.

Uva

Liana, Andina, Costa, 0-2000m, introducido y cultivado

Uso: Bronquitis, Laxante / Frutas, seco / Oral / Añadir 1/2 litro de leche fresca a 10g de pasas. Hervir la mezcla por 3-4 minutos. Tomar caliente. Tomar 1 vaso 3 veces por día por 2 semanas.

XANTHORROEACEAE - Aloe vera (L.) Burm $\mathrm{f}$.

Sábila, Zábila, Aloe, Hojas de Sábila, Aloe Vera

Hierba, Amazónico, Andino, Costa, 0-3000m, introducido y cultivado

Uso: 1. Inflamación (Externo), Inflamación Vaginal, Úlceras Vaginales, Cáncer Vaginal, Crecimiento de Cabello, Mejoramiento de piel, cataratas, Ojos, Heridas, Quemaduras / Hojas, fresco / Tópico / Tomar una hoja grande y remover espinas. Cortar la hoja longitudinal y remover baba. Calentar y poner en área inflamada como Emplasto 2 veces por día por 1 semana. por Inflamación Vaginal, injertar hoja 2-3 veces por día o como se necesita. Dejarlo dentro por 5 minutos. Por perdida de cabello aplicar por piel y cabello. El jugo puede ser aplicado a los ojos, 1 gota en cada ojo cada 2 días por 6 días. 2. Pérdida de Peso, Gastritis, Inflamación, Diabetes, Tos, Bronquitis, Riñones, Úlceras, Colesterol, Cáncer, Asma, Bilis / Hojas, fresco / Oral / Combinar $1 \mathrm{~kg}$ de Hierba, $1 / 2 \mathrm{~kg}$ de Miel, y 3 cucharas de pisco. Abrir hoja longitudinal y extraer baba. Consumir baba, 1-2 tazas por día por una semana hasta un mes. Hoja se puede macerar en una botella de alcohol. 3. Buena Suerte, Felicidad / Hojas, fresco / Amuleto / Colgar planta entera sobre puerta.

XIMENIACEAE - Ximenia americana L.

Limoncillo

Árbol, Amazónico, 0-1000m

Uso: Nervios, Estómago, Regulación Menstrual / Planta entera, fresco o seco / Oral / Hervir 1 litro de agua. Añadir $10 \mathrm{~g}$ total de Limoncillo, Panisara, Hinojo, Ajenjo, Toronjil y Pimpinela. Dejar mezcla por 3 minutos. Paciente puede tomar con cualquier temperatura. Tomar 1 taza, 3-4 veces por día por 1 mes.

XYRIDACEAE - Xyris subulata Ruiz \& Pav.

Hierba del Caballero, Chupaflor

Hierba, Andino, 2500-4500m

Uso: Incitar una mujer, Fragancia, Buena Suerte, Buenos Negocios, Protección, Buena Fortuna, Buena salud / Tallos, fresco / 1. Seguro / Mezcla Estándar para Seguro / 2. Tópico / Mezcla Estándar para Florecimiento.

ZINGIBERACEAE - Zingiber officinale Roscoe

Kion, Gengibre

Hierba, Amazónica, Andina, Costa, 0-2000m, introducido y cultivado

Uso: Resfrío, Tos, Bronquitis / Raíz, fresco / Oral / Cortar Kion en trozos pequeños y añadir 10g este a $10 \mathrm{~g}$ de cada uno de Matico, Nogal y Veronica. Hervir en $1 / 2$ litro de agua. Tomar 1 taza 3 veces por día por 1 semana. 


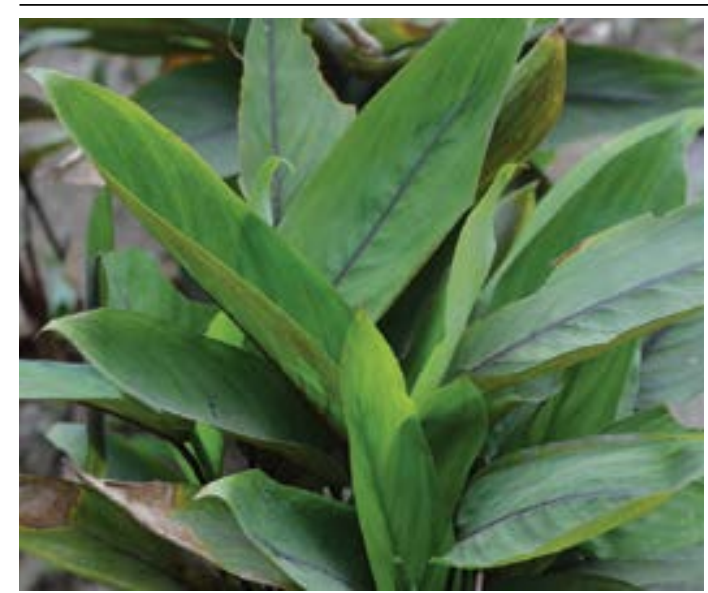

ZINGIBERACEAE

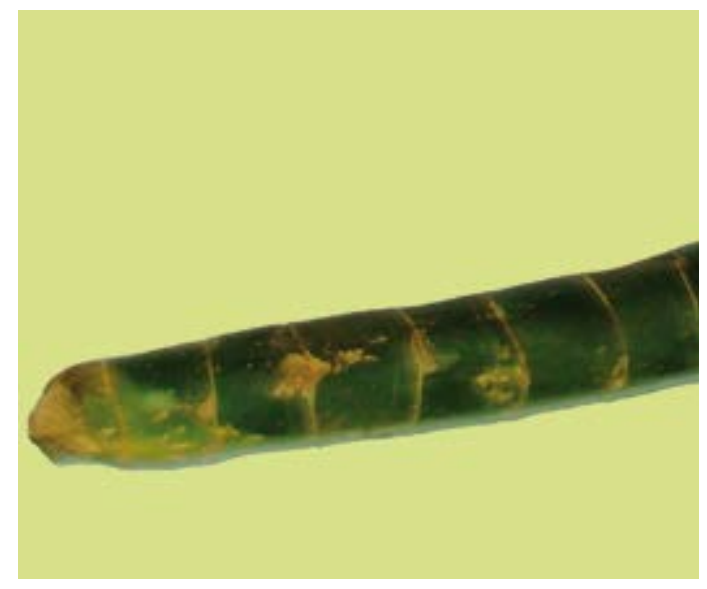

Anti Ajo

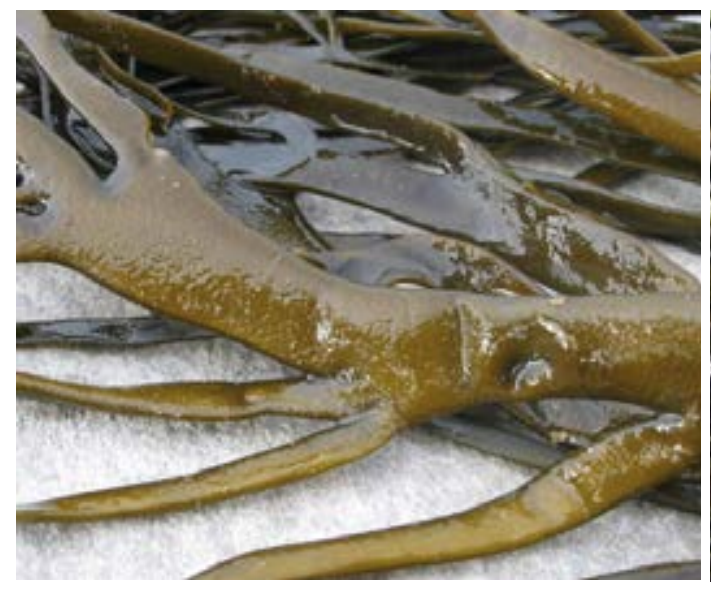

Giartina chamissoi, Giartina glomerata, Giartina paitensis

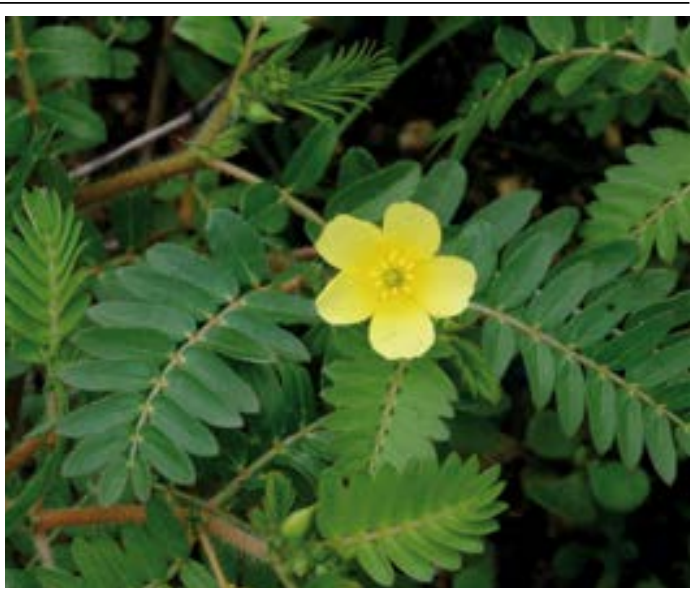

Tribulus terrestris

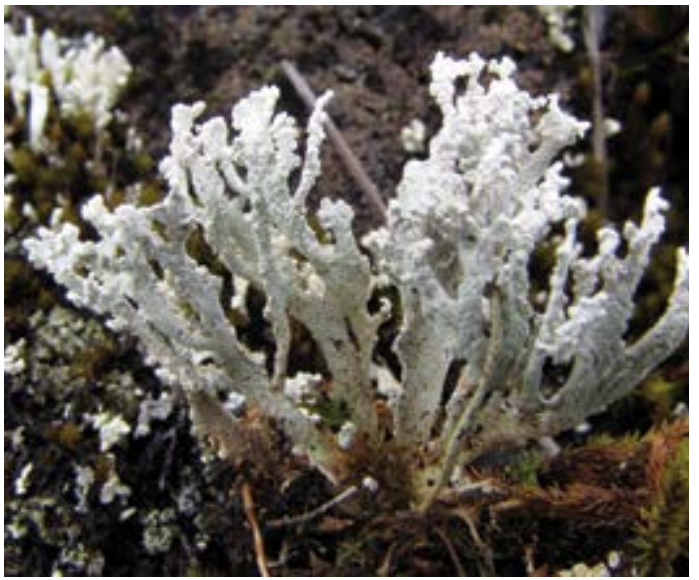

Siphula sp.

\section{ZINGIBERACEAE}

Chimapampana

Uso: Excitar sexualmente y atrapar miembro del sexo opuesto / fresco / Tópico / Usar tubérculo rojo o purpureo. Moler para crear perfume. Poner 1/2 tubérculos en contenedor de perfume. Mezclar con perfume Cariño. Friccionar Perfume sobre cuerpo como se necesita.

ZYGOPHYLLACEAE - Tribulus terrestris L.

Abrojo, Cadillo

Hierba, Andino, Costa, 0-2000m, maleza

Uso: Dolor fuerte de cuerpo, Inflamación (General), Piel, Intestinos, Enfermedad de Hígado, Enfermedad de Vesícula, Tumores, Enfermedades Urinarias / Planta entera, fresco / Oral / Hervir 10g cada uno de Abrojo, Amor Seco, Lampazo y Trinoso en 1/2 taza de agua por 3 minutos. Tomar 1/4 taza una vez por día por 3 días.

\section{NO IDENTIFICADO}

Anti Ajo

Uso: Hechicería en una casa / Tallos, fresco / Amuleto / Hervir $40 \mathrm{~cm}$ de Tallo de Anti Ajo en 2 litros de agua por 3 horas. Dejar por 5 minutos. Usar Ruda (Hembra y Macho) y distribuya mezcla en cada esquina de la casa, siempre de derecha hacía izquierda. Distribuir el resto de la mezcla por el frente de la casa.

\section{NO IDENTIFICADO}

\section{Hierba del Hongo}

Uso: Contusión, Anemia, Liquido en tejidos o Heridas, Riñones / Planta entera, fresco o seco / Tópico / Hervir $10 \mathrm{~g}$ por 5 minutos en 1 litro de agua o $5 \mathrm{~g}$ en 3 litros. Ańadir 2 cucharas de Vinagre, Jugo de Limón, Manzanilla Blanca, Laurel y Llantén. Lavar los pies, manos, cuerpo con mezcla, 1 lavada por día en la tarde, hasta síntomas se mejoren.

ALGAE - Giartina chamissoi, Giartina glomerata, Giartina paitensis

Cochayuyo, Mococho

Uso: Pérdida de Peso, Colesterol / Planta entera, fresco / Oral / Tallo 20g de material de planta en agua hervida. Mezclar el material con el jugo de 3-4 Naranjas. Tomar 1 vaso dos veces por día por 1 mes.

LICHENES - Siphula sp.

Papelillo, Papelilla, Palalio

Uso: Hígado / Hojas, fresco / Oral / Hervir 5g en 1 litro de agua por 10 minutos.

\section{MATERIALES NO PLANTAS}

Polen de Zapote, Polen de Espina Negra, Polen de Arboles, Polen de Ciachon (Heces de Insectos)

Uso: Bronquitis, Asma, Tuberculosis / Heces de Insectos / Oral / Poner 4g de Heces ("Polen") en 1 litro de agua hervida. Muy fuerte. Tomar 1 litro por día por 1 mes. 


\section{Mezcla Estándar de Seguro}

Mezclar todo del siguiente en una botella de perfume: 3 Tallos y Hojas de Hierba de la Señorita con algo de: Hierba del Buen Querer, Palmerilla, Destrencilla, Lanzetia, Hierba del Carpintero, Pega-Pega, Siempre Viva, Hierba de la Fortuna, Hierba del Tesoro, Hierba de la Plata, Hierba del Cariño, Guaime-Guaime, Piri- Piri, Hierba del Caballero y Hierba de la Justicia. Monto depende en tamaño de la botella. Añadir perfume "Carińo" y algo de los perfumes siguientes: Dios de la Huaringa, Dios de la Felicidad, San Antonio, Macumba Pusanga, Gran Jefe, Mil Flores, Llama Plata y Ekeko. El curandero vaya bendecir y soplar. Mantener el Seguro en la casa, o si esta pequeño llevarlo todo el tiempo.

\section{Mezcla Estándar por Florecimiento}

Hervir 3 litros de agua por 30 minutos con 10g de Chupaflor y 10g cada uno de Hierba del Buen Querer, Palmerilla, Destrencilla, Lanzetia, Hierba del Carpintero, Pega Pega, Siempre Viva, Hierba de la Fortuna, Hierba del Tesoro, Hierba de la Plata, Hierba del Cariño, Guaime Guaime, Piri Piri, Hierba de la Señorita, Hierba de la Justicia, Hierba de la Fortuna, El Dólar, Hierba de la Plata, Chupaflor, Hierba del Halago y Pétalos de Rosas Rojas, Blancas y Roja-Amarillas. También añadir Agua Florida, Tabú, Azucar Blanco, y jugo de Lima. Después de hervir añadir una botella de su perfume favorito. Bañar 3 veces: Martes, Viernes, Martes siguiente. Paciente puede repetir si se necesita. Friccionar cuerpo entero con todas las hierbas. Lavar con la mezcla y deja secar al aire. No usar jabón o toalla.

\section{Mezcla Alternativa por Florecimiento}

Hervir 3 litros de agua por 30 minutos con 3 Tallos y 1 Hoja de Hierba de la Seńorita y un poco de: Hierba del Buen Querer, Palmerilla, Destrencilla, Lanzetia, Hierba del Carpintero, Pega-Pega, Siempre Viva, Hierba de la Fortuna, Hierba del Tesoro, Hierba de la Plata, Hierba del Carińo, Guaime-Guaime, Piri-Piri, Hierba del Caballero y Hierba de la Justicia. Después de hervir añadir una botella de su perfume favorito. Friccionar cuerpo entero con todas las hierbas. Lavar con la mezcla y deja secar al aire. No usar jabón o toalla.

\section{Mezcla de Bańo para protección del mal}

Hervir 6 litros de agua por 5 minutos con 10g cada una de: Misha Blanca, Misha Colambo, Misha Galga, Misha Morada, Misha Roja, Misha Rosada y Toromaique. Recitar y orar. Bañar el paciente con la mezcla, friccionando con las hierbas. Después lava con agua y deja secar naturalmente al aire.

\section{Bibliografia}

Abad L (2003) Etnocidio y Resistencia en la Amazonia Peruana. Ediciones de la Universidad de Castilla-La Mancha, Cuenca-Spain.

Acosta J (1588-90) The Natural and Moral History of the Indies. Reprinted form the English edition of Edward Grimson (1604), vols. 1-2. Hakluyt Society, London; 1880

Agurto J (2005) Comentarios de Panelistas. In: Ferro P, Ruiz M (Eds) ¿Como prevenir la biopirateria en el Peru? Reflexiones y Propuestas pp. 70-73. Lerma Gomez E.I.R.L., Lima-Miraflores.

Alam G, Belt J (2009) Developing a medicinal plant value chain: Lessons from an initiative to cultivate kuti (Picrorbizakurrooa) in Northern India. KIT Working Papers Series pp. 1-14. The Royal Tropical Institute (KIT), The Netherlands.

Alarco de Zandra A (1988) Perú, el libro de las plantas mágicas. Concytec, Lima.

Alban C (1985) Un Registro de Datos Etnobotánicos. Boletín de Lima 7(39):93-96.

Alcedo A de (1786-89) Diccionario geográfico histórico de las indias occidentales o América. Madrid.

Alexiades MN (1996) Collecting ethnobotanical data: an introduction to basic concepts and techniques. In: Alexiades MN (Ed). Selected Guidelines for Ethnobotanical Research: A Field Manual pp. 53-94. The NewYork Botanical Garden, New York.

Alva W (1994) Sipán: descubrimiento e investigación. Cultura y artes del antiguo Perú. Backus \& Johnston, Lima.

Alva W, Donnan CB (1993) Royal Tombs of Sipán. Fowler Museum of Cultural History, University of California, Los Angeles.

Alva W, Donnan CB (1994) Tales from a Peruvian Crypt. Natural History 103(5):26-36.

Angulo P (2009) Nuevos enfoques en la investigación de plantas medicinales. In: Sánchez Garrafa R \& R (Eds) Medicina Tradicional Andina: Planteamientos y aproximaciones pp. 351-384. Centro de Estudios Regionales Andinos Bartolomé de las Casas (CBC)/Centro de Medicina Andina (CMA), Cuzco.

Baker J, Borris R, Carté B, Cordell G, Soejarto D, Cragg G, Gupta M, Iwo M, Madulid D, Tyler V (1995) Natural Product Discovery and Development, New Perspectives on International Collaboration. Journal of Natural Products 58(9):1325-1357.

Balick M, Mendelsohn R (1992) Assessing the Economic Value of Traditional Medicines from Tropical Forests. Conservation Biology 6:128-129.

Bannister K, Barrett K (2001) Challenging the Status Quo in Ethnobotany: A New Paradigm for Publication May Protect Cultural Knowledge and Traditional Resources. Cultural Survival Quarterly 24(4):10-12. 
Barve V, Bhatti R, Bussmann RW, Bye R, Chen J, Dulloo E, Giovannini P, Linares E, Magill R, Roguet D, Salick J, On TV, Vandebroek I, Wightman G, Wyse Jackson P (2013) A Global Program on Conservation of Useful Plants and Traditional Knowledge - A Call to Action. https://www. researchgate.net/publication/236633499_A_Global_Program_on_Conservation_of_Useful_Plants_ and_Traditional_Knowledge_A_Call_to_Action?ev=prf_pub

Bastien J (1987) Healers of the Andes: Kallawaya Herbalists and Their Medicinal Plants. University of Utah Press, Salt Lake City.

Bazán S (2005) Propiedad Intelectual: Conceptos Básicos. In: Ferro P, Ruiz M (Eds) Cómo prevenir la Biopiratería? Reflexiones y Propuestas pp 21-35. Lerma Gómez E.I.R.L, Lima-Miraflores.

Béjar E, Bussmann RW, Roa C, Sharon D (1997) Pharmacological Search for Active Ingredients in Medicinal Plants of Latin America. In: Shuman T, Garrett M, Wozniak L (Eds), International Symposium on Herbal Medicine, A Holistic Approach pp. 63-81, SDSU International Institute for Human Resources Development, San Diego.

Béjar E, Bussmann RW, Roa C, Sharon D (2001) Herbs of Southern Ecuador - Hierbas del Sur Ecuatoriano. Latin Herbal Press, San Diego.

Bermúdez A, Velásquez D (2002) Etnobotánica de una Comunidad Campesina del Estado de Trujillo: Un Estudio Preliminar Usando Técnicas Cuantitativas. Revista de la Facultad de Farmacia 44:2-6.

Bianchi A, Samorini G (1993) Plants in Associacion with Ayahasuca. Jahrbuch Ethnomedizin 1993:21-

Brack Egg A (1999) Diccionario enciclopédico de plantas útiles del Perú. PNUD - CBC, Cuzco.

Brack Egg A (2004) Biodiversidad, pobreza y bionegocios. PNUD, Lima.

Brako L, Zarucchi JL (Eds) (1993) Catalogue of the Flowering Plants and Gymnosperms of Peru. Missouri Botanical Garden, Saint Louis, MO.

Breevort P (1998) The Booming U. S. Botanical Market, A New Overview. HerbalGram 44.

Bristol ML (1969) Tree Datura drugs of the Columbian Sibundoy. Botanical Museum Leaflets 22:165227

Brown M (2003) Who Owns Native Culture? Harvard University Press, Cambridge.

Brüning HH (2004) Diccionario Mochica. Universidad de San Martin de Porres, Lima.

Brush S, Stabinsky D (Eds) (1996) Valuing Local Knowledge: Indigenous People and Intellectual Property Rights. Island Press, Washington, D.C.

Buitron X (1999) Ecuador, uso y comercio de plantas medicinales, situacion actual y aspectos importantes para su conservación. TRAFFIC International, Cambridge, UK.

Burger R (1992) Chavin and the Origins of Andean Civilization. Thames and Hudson, London.
Bussmann RW (2002) Ethnobotany and Biodiversity Conservation. In: Ambasht RS, Ambasht NK (Eds) Modern Trends in Applied Terrestrial Ecology pp. 345-362.

Bussmann RW (2006) Manteniendo el balance de naturaleza y hombre, La diversidad florística andina y su importancia por la diversidad cultural - ejemplos del Norte del Perú y Sur de Ecuador. Arnaldoa 13(2):382-397.

Bussmann RW (2013) The Globalization of Traditional Medicine in Northern Peru: From Shamanism to Molecules. Evidence-Based Complementary and Alternative Medicine, Volume 2013, Article ID 291903, 46pages, Hindawi Publishing Corporation, http://dx.doi.org/10.1155/2013/291903.

Bussmann RW, Glenn A (2010) Cooling the Heat - Traditional remedies for malaria and fever in Northern Peru. Ethobotany Research and Applications 8:125-134.

Bussmann RW, Glenn A (2011) Traditional medicinal plants used in Northern Peru for kidney problems and urinary infections / Plantas medicinales norperuanas usadas para enfermedades renales e infecciones urinarias. Arnaldoa 18(1):77-93.

Bussmann RW, Glenn A, Meyer K, Kuhlman A, Townesmith A (2010) Herbal mixtures in traditional medicine in Northern Peru. Journal of Ethnobiology and Ethnomedicine 6(10).

Bussmann RW, Glenn A, Meyer K, Rothrock A, Townesmith A, Sharon D, Castro M, Cardenas R, Regalado S, Toro R, Chait G, Malca G, Perez F (2009a) Antibacterial Activity of Medicinal Plants of Northern Peru-Part II. Arnaldoa 16(1):93-103.

Bussmann RW, Glenn A, Meyer K, Rothrock A, Townesmith A, Sharon D, Castro M, Cardenas R, Regalado S, Toro R, Chait G, Malca G, Perez F (2009b) Phyto-Chemical Analysis of Peruvian Medicinal Plants. Arnaldoa 16(1):105-110.

Bussmann RW, Glenn A, Sharon D, Chait G, Diaz D, Pourmand K, Jonat S, Somogy S, Guardado G, Aguirre C, Chan R, Meyer A, Townesmith A (2010) Proving that Traditional Knowledge Works, The antibacterial activity of Northern Peruvian medicinal plants. Ethnobotany Research and Applications 9:67-96.

Bussmann RW, Malca G, Glenn A, Sharon D, Chait G, Diaz D, Pourmand K, Jonat B, Somogny S, Guardado G, Aguirre C, Chan R, Meyer K, Kuhlman A, Townesmith A, Effio J, Frias F, Benito M (2010) Minimum inhibitory concentrations of medicinal plants used in Northern Peru as antibacterial remedies. Journal of Ethnopharmacology 132:101-108.

Bussmann RW, Malca G, Glenn A, Sharon D, Nilsen B, Parris B, Dubose D, Ruiz D, Saleda J, Martinez M, Carillo L, Kuhlman A, Townesmith A (2011) Toxicity of medicinal plants used in traditional medicine in Northern Peru. Journal of Ethnopharmacology 137:121-140.

Bussmann RW, Paniagua Zambrana N, Rivas Chamorro M, Molina Moreira N, Cuadros Negri ML, Olivera J (2013) Peril in the market - classification and dosage of species used as anti-diabetics in Lima, Peru. Journal of Ethnobiology and Ethnomedicine 9(37).

Bussmann RW, Sharon D (2006a) Traditional plant use in Loja province, Southern Ecuador. Journal of Ethnobiology and Ethnomedicine 2(44):1-11.

Bussmann RW, Sharon D (2006b) Traditional plant use in Northern Peru: Tracking two thousand years of healing culture. Journal of Ethnobiology and Ethnomedicine 2(47):1-18. 
Bussmann RW, Sharon D (2007a) Plants of longevity - The medicinal flora of Vilcabamba. Plantas de la longevidad - La flora medicinal de Vilcabamba. Graficart, Trujillo.

Bussmann RW, Sharon D (2007b) Plants of the four winds - The magic and medicinal flora of Peru. Plantas de los cuatro vientos - La flora mágica y medicinal del Perú. Graficart, Trujillo.

Bussmann RW, Sharon D (2009a) Shadows of the colonial past-diverging plant use in Northern Peru and Southern Ecuador. Journal of Ethnobiology and Ethnomedicine 5(4):1-17.

Bussmann RW, Sharon D (2009b) Naming a phantom-the quest to find the identity of Ulluchu, an unidentified ceremonial plant of the Moche culture in Northern Peru. Journal of Ethnobiology and Ethnomedicine 5(8):1-6.

Bussmann RW, Sharon D (2009c) From collection to market and cure-Traditional medicinal use in Northern Peru. In: Albuquerque U, Hanazaki N (Eds) Recent Development and Case Studies in Ethnobotany pp.184-207. Nupeea, Recife.

Bussmann RW, Sharon D, Diaz D, Barocio Y (2008) Peruvian plants canchalagua (Schkubria pinnata (Lam.) Kuntze), hercampuri (Gentianella alborosea (Gilg) Fabris), and corpus way (Gentianella bicolor (Wedd.) J. Pringle) prove to be effective in the treatment of acné. Arnaldoa 15(1):149-152.

Bussmann RW, Sharon D, Garcia M (2009) From Chamomile to Aspirin? Medicinal Plant use among clients at Laboratorios Beal in Trujillo, Peru. Ethnobotany Research and Applications 7:399-407.

Bussmann RW, Sharon D, Lopez A (2007) Blending Traditional and Western Medicine, Medicinal plant use among patients at Clinica Anticona in El Porvenir, Peru. Ethnobotany Research and Applications 5:185-199.

Bussmann RW, Sharon D, Perez F, Díaz D, Ford T, Rasheed T, Silva R (2008) Antibacterial activity of Northern-Peruvian Medicinal Plants - a low cost laboratory.approach to assess biological activity. Arnaldoa 15(1):127-148

Bussmann RW, Sharon D, Vandebroek I, Jones AA, Revene Z (2007) Health for sale, the medicinal plant markets in Trujillo and Chiclayo, Northern Peru. Journal of Ethnobiology and Ethnomedicine 3(37):1-9.

Cabieses Molina F (1990) The Magic Plants of Ancient Perú. Atti del V Congresso Nazionale della Società Italiana di Fitochimica, LP2.

Cabieses Molina F (1993) Apuntes de Medicina Tradicional: La racionalización de lo irracional. CONCYTEC, Lima.

Cabieses Molina F (1997) La Maca y la Puna. Universidad de San Martin de Porres, Lima.

Cabieses Molina F (2000) La Uńa de Gato u su entorno. De la Selva a la farmacia. Universidad de San Martin De Porres, Lima.

Cabieses Molina F (2003) Ayer y Hoy (Las Plantas Medicinales). Imprenta Luis Ramos Díaz, Lima.

Cabieses Molina F (2007) La Salud y los Dioses: La Medicina en el Antiguo Perú. Universidad Científica del Sur, Lima.
Caillaux J (2005) Acceso a los Recursos Genéticos. In: Ferro P, Ruiz M (Eds) ¿Cómo prevenir la Biopirateria en el Perú? Reflexiones y Propuestas pp. 36-47. Lerma Gómez E.I.R.L., Lima-Miraflores.

Camino L (1992/1999) Cerros, plantas y lagunas poderosas - la medicina al norte del Perú. Lluvia Editores, Lima.

Cano JH, Volpato G (2004) Herbal mixtures in the traditional medicine of Eastern Cuba. Journal of Ethnopharmacology 90:293-316.

Capasso A, De Feo V (2002) Central Nervous System Parmacological Effects of Plants from Northern Peruvian Andes: Valeriana adscendens, Iresine herbstii and Brugmansia arborea. Pharmaceutical Biology 40(4):274-293

Carrillo L (2012) Scientific Validation? How Bioprospecting Laboratory Practices Contribute to the Devaluation of Traditional Medicinal Knowledge. The Berkeley McNair Research Journal, vol. 19 , Spring, pp. 30-46.

Caselli I Ecuador hospital mixes folk and modern medicine. BBC News pp. 1-5; www.bbc.co.uk/ news/world - latin-america-18483584

Chiappe M, Lemlij M, Millones L (1985) Alucinógenos y Shamanismo en el Perú contemporáneo El Virrey, Lima.

Chumpitaz M (2009) De Su Propia Medicina. Somos 1164:28-31, 28 Marzo.

Cobo B (1653/1956) Historia del Nuevo Mundo. Obras del P. Bernabé Cobo, vols. 1 \& 2. P. Francisco Mateo (Ed). Biblioteca de Autores Españoles. Vols. 91 \& 92. Ediciones Atlas, Madrid.

Connally MPE, Fabiano E, Patel IH, Kinyanjui SM, Mberu EK, Watkins WM (1996) Antimalarial activity in crude extracts of Malawian medicinal plants. Annals of Tropical Medicine and Parasitology 90:597-602

Cox P, Balick M (1994) The Ethnobotanical Approach to Drug Discovery. Scientific American 270(6):82-87.

Crosby DM, McLaughlin JL (1973) Cactus alkaloids. XIX. Crystallization of mescaline $\mathbf{H C l}$ and 3-methoxytyramine $\mathrm{HCl}$ from Trichocereus pachanoi. Lloydia 36:416-418.

Cruz Sánchez G (1948) Informe sobre las aplicaciones populares de la címora en el norte del Perú. Revista de Farmacologia y Medicina Experimental 1:253-258.

D’Agostino M, Pizza C, De Simone F (1995a) Flavone and flavonol glycosides from Desmodium mollicum. Fitoterapia 66:384-385.

D’Agostino M, Pizza C, De Simone F, Tommasi N (1995b) Constituents of Culcitium canescens. Fitoterapia 66:550-551.

Data from Information Resources, Inc. Scanner Data (1998) Quoted in Herbal Gram, Journal of the American Botanical Council and the Herb Research Association 43:61. 
DeFeo V (1992) Medicinal and magical plants on northern Peruvian Andes. Fitoterapia 63:417-440.

DeFeo V (2003) Ethnomedicinal field study in northern Peruvian Andes with particular reference to divination practices. Journal of Ethnopharmacology 85:243-256.

DeFerreyra EC (1978) Plantas medicinales alto-andinas. Boletín de la Colonia Suiza en el Perú 1-6.

DeFerreyra EC (1981) Plantas que curan las heridas del hombre y los animales. Boletin de Lima 1-12.

Dobkin de Rios M (1968) Trichocereus pachanoi: a mescaline cactus used in folk healing in Peru. Economic Botany 22:191-194.

Dobkin de Rios M (1969) Folk curing with a psychedelic cactus in North Coast Peru. International Journal of Social Psychiatry 15:23-32

Dobkin de Rios M (1977) Plant hallucinogens and the religion of the Mochica, an ancient Peruvian people. Economic Botany 31:189-203.

Dobkin de Rios M, Cardenas M (1980) Plant hallucinogens, shamanism and Nazca ceramics. Journal of Ethnopharmacology 2:233-246.

Domenighetti G, Grilli R, Gutzwiller F, Quaglia J (2000) Usage personnel de pratiques relevant des médecines douce sou alternatives parmi les médecins suisses. Médecine \& Hygiène 58: 22-91.

Donnan CB, Castillo LJ (1994) Excavaciones de tumbas de sacerdotes Moche en San José de Moro, Jequetepeque. In: Uceda S, Mujica E (Eds) Moche: Propuestas y Perspectivas 5. Trujillo.

Downer CC (2006) Insights, Mining Peru's Andean Forest Puts Unique Species, Ecosystem at Risk. Environmental News Service, February 6.

Duke JA, Velazquez YR (1994) Amazonian ethnobotanical dictionary. CRC Press, Boca Raton.

Eisenberg DM, Davis RB, Ettner SL, Appel S, Wilkey S, Rompay M van, Kessler RC (1998) Trends in alternative medicine use in the United States, 1990-1997, results of a follow-up national survey. Journal of the American Medical Association 280(18):1569-1575.

El Kamali H, El Kijalifa KE (1997) Treatment of malaria through an herbal drug in the central Sudan. Fitoterapia 6:527-528.

Elizabetsky E (1988) Ethnopharmacology and drug development in South America. In: Trabajos del II Congreso Internacional de Medicinas Tradicionales. Junio 26/29, Lima.

Elisabetsky E, Castilhos C (1990) Plants used as analgesics by Amazonian caboclos as a basis for selecting plants for investigation. International Journal of Crude Drug Research 28:309-320.

EsSalud/Organización Panamericana de Salud (2000) Estudio Costo-Efectividad, Programa Nacional de Medicina Complementaria. Seguro Social de EsSalud (Study of Cost Effectiveness, National Program in Complementary Medicine. Social Security of EsSalud). Lima, EsSalud/Organización Panamericana de Salud.

Evans S, Tellez C, Vega C (2014) Traceability of Twenty Medicinal Plants in the Markets of Northern Peru. Acta Hort. ISHS 1030:143-149.
Fajardo S, Sours A (2012) Patient Surveys at EsSalud's Complementary Medicine Clinic in Trujillo, Peru. MHIRT-Peru 2012

FAO (1997) Medicinal Plants for Forest Conservation and Health Care: Global Initiative for Traditional Systems. Non-Wood Forest Products No. 11. Food and Agriculture Organization of the United Nations, Rome.

Farnsworth N, Akerele O, Bingel A, Soejarto D, Guo Z (1985) Medicinal plants in therapy. Bulletin of the World Health Organization 63(6):965-981.

Fernández G (2012) Hechiceros y Ministros del Diablo: Rituales, prácticas y patrimonio inmaterial en los Andes (siglos XVI-XXI). Ediciones Abya-Yala, Quito.

Fernández L (2009) Medicina Complementaria en la Seguridad Social: Avances, Retos y Perspectivas. In: Vergara E, Vásquez R (Eds) Medicina Tradicional: Conocimiento Milenario pp. 292-293. Museo de Arqueología, Antropología e Historia, Serie Antropologia No. 1, Facultad de Ciencias Sociales Universidad Nacional de Trujillo, Trujullo.

Fernández M (2005) La OMS y los sistemas médicos tradicionales. In: Garrafa R, Garrafa R (Eds) Medicina Tradicional, Planteamientos y aproximaciones pp. 325-337. CBC/CMA, Cuzco.

Fernandez Honores A, Rodriguez Rodriguez E. (2007) Ethnobótanica del Perú Prehispano. Ediciones Herbarium Truxillense (HUT), Universidad Nacional deTrujillo, Trujillo.

Ferro M, Ruiz P (Eds) (2005a) ¿Cómo prevenir la Biopiratería en el Perú? Reflexiones y Propuestas. Lerma Gómez E.I.R.L., Lima.

Ferro M, Ruiz P (Eds) (2005b) Apuntes sobre Agrobiodiversidad, Conservación, Biotecnología y Conocimientos Tradicionales. Lerma Gómez E.I.R.L., Lima-Miraflores.

Fisher P, Ward A (1971) Medicine in Europe, complementary medicine in Europe. British Medical Journal 309:107-111.

Franco R (2009) Breve Registro de Ejemplos de Curanderos y Oficiantes en la Cerámica Mochica del Complejo el Brujo, Costa Norte del Perú. In: Vergará E, Vasquez R. Medicina Tradicional: Conocimiento Milenerio pp. 29-43. Serie Antropología No. 1, Museo de Arqueología, Antropología e Historia, Facultad de Ciencias Sociales, Universidad Nacional de Trujillo, Trujillo.

Franquemont C, Plowman T, Franquemont E, Niezgoda C, King S, Sperling C, Davis W (1990) The Ethnobotany of Chinchero, an Andean Community in Southern Peru. Fieldiana Botany, New Series

Fung R (1967) Las Aldas: Su Ubicación dentro del Proceso Histórico del Perú. Dédalo 5(9-10): 205-207.

Gauksheim S, Nevarez M, Pon E, Sharon D (2013) Evaluation of Phyto-Therapy at EsSalud-Centro de Atención de Medicina Complementaria, Trujillo-Evaluación de la Fito-Terapia en el Centro de Medicina Complementaria, Trujillo. MHIRT-Peru, 2013.

Gbile ZO (1984) Vernacular Names of Nigerian Plants (Yoruba). FRIN, Ibadan. 
Galvez, C. (2014). Una mesa de curandero y la geografía sagrada del Valle de Chicama. In: Olvera $S$, Millones L (Eds.). Por la Mano del Hombre: Practicas y creencias sobre chamanismo y curandería en Mexico y el Peru, pp. 169-210. Fondo Editorial de la Asamblea Nacional de Rectores, Lima.

Gillett NA, Chan C (2000) Applications of immunohistochemistry in the evaluation of immune suppressive agents. Human \& Experimental Toxicology 19(4):251-254.

Girault L (1987) Kallawaya, Curanderos itinerantes de los Andes. UNICEF-OPS-OMS, La Paz.

Glass-Coffin B, Sharon D, Uceda S (2004) Curanderos a la sombra de la Huaca de la luna. Bulletin Institute francais d'Etudes Andines 33(1):81-95.

Global Industry Analysts Inc (2012) Herbal Supplements and Remedies, A Global Strategic Business Report. Global Industry Analysts, San Jose.

Gonzalez de la Cruz M, Malpartida SB, Beltrán H, Jullian V, Bourdy G (2014) Hot and Cold: Medicinal plant uses in Quechua communities in the high Andes (Callejón de Huaylas, Ancash, Perú). Journal of Ethnopharmacology (In press).

Greaves T (1995) Cultural Rights and Ethnography. General Anthropology 1(1): 3-6.

Hamilton A (Ed) (2013) Medicinal plants in conservation and development: case studies and lessons learnt. Plantlife International, Salisbury, UK.

Hammond GB, Fernández ID, Villegas L, Vaisberg AJ (1998) A survey of traditional medicinal plants from the Callejón de Huaylas, Department of Ancash, Perú. Journal of Ethnopharmacology 61:17-30.

Hay SI, Were EC, Renshaw M, Noor AM, Ochola SA, Olusanmi I, Alipui N, Snow RW (2003) Forecasting, warning, and detection of malaria epidemics, a case study. Lancet 361(9370):17051706 .

Hayden C (2003) When Nature Goes Public, The Making and Unmaking of Bioprospecting in Mexico. Princeton University Press, Princeton and Oxford.

Health Canada (2001) Perspectives on Complementary and Alternative Health Care. A Collection of Papers Prepared for Health Canada. Ottawa, Health Canada.

HerbalGram (1998). Quoted scanner data from Information Resources, Inc. HerbalGram 43:61.

Herrera F (1941) Sinopsis de la Flora del Cuzco, Tomo I, Parte Sistemática. Supremo Gobierno, Lima.

Hocquenghem AM (2008) Sacrifices and Ceremonial Calendars in Societies of the Central Andes: A Reconsideration. In: Bourget S, Jones KL (Eds): The Art and Archaeology of the Moche pp. 23-42. University of Texas Press, Austin.

Huaman L et al (2004). Flora Vascular de la Zona baja de los Valles Pativilca y Fortaleza. In: $X$ Congreso Nacional de Botánica, p. 149. Lima.

Hultin E, Wassén H, Bondeson W (1987) Papain in Moche Blood ceremonies. Journal of Ethnopharmacology 19(2):227-228.
Iwu M (1996) Implementing the Biodiversity Treaty, how to make international cooperative agreements work. Trends in Biotechnology 3-4(146):67-107.

Joralemon D, Sharon D (1993) Sorcery and Shamanism, Curanderos and Clients in Northern Peru. University of Utah Press, Salt Lake City.

Jørgensen PM, Ulloa Ulloa C (1994) Seed plants of the High Andes of Ecuador - a checklist. $A A U$ Reports 34:1-443.

Jovel EM, Cabanillas JH, Towers GHN (1996) An ethnobotanical study of the traditional medicine of the Mestizo people of Suni Mirafio, Loreto, Peru. Journal of Ethnopharmacology 53(3):149-56.

Kraemer H (1915) Scientific and Applied Pharmacognosy. Philadelphia.

La Torre M, Alban J (2006) Etnobotánica en los Andes del Perú. In: Morales M, Ollgaard L, Kvist L, Borchsenius B, Balslev H. Botánica Económica de los Andes Centrales. pp. 239-245. Universidád Mayor de San Andres, La Paz.

Lambert J, Srivastava J, Vietmeyer N (1997) Medicinal Plants: Rescuing a Global Heritage. The World Bank Technical Paper No. 355, Washington, D.C.

Larco Hoyle R (1938) Los mochicas I. Casa editora

Larco Hoyle R (1939) Los Mochicas II. Casa editora

Larco Herrera F (1940) Plantas que curan y plantas que matan de la Flora del Cusco. Revista del Museo Nacional IX(1):74-127.

León B (2006) El libro rojo de las plantas endémicas del Perú. Revista peruana de biologia (Numero especial) 13(2):9-22.

Léon, B, Young K, Cano A (1996) Observaciones sobre la flora vascular de la costa central del Perú. Arnaldoa 4(1):67-85

Lira JA (1985) Medicina Andina. Farmacopea y rituals. Centro Bartolomé de las Casas, Cuzco.

Lynch T (1980) Guitarrero Cave. Academic Press, New York

Macía JM, García E, Vidaurre PJ (2005) An ethnobotanical survey of medicinal plants commercialized in the markets of La Paz and El Alto, Bolivia. Journal of Ethnopharmacology 97:337-350.

Manek M, Lettington R (2001) Indigenous Knowledge Rituals: Recognizing Alternative Worldviews. Cultural Survival Quarterly 24(4): 8-9.

Marínez Compañón DB (1789) Razón de las especies de la naturaleza y del arte del obispado de Trujillo del Perú. Tomos III-V. Biblioteca del palacio real, Sevilla.

Martin RT (1970) The role of coca in the history, religion, and medicine of South American Indians. Economic Botany 24:422-438.

McBride JF (Ed) (1936) Flora of Peru. Fieldiana: Botany. Field Museum of Natural History, Chicago. 
McClelland D (1977) The Ulluchu: A Moche Symbolic Fruit. In: Cordy-Collins A, Stern J (Eds) PreColumbian Art History pp 435-452. Peek Publications, Palo Alto.

McClelland D (2008) Ulluchu - An elusive fruit. In: Bourget S, Jones KL (Eds) The Art and Archaeology of the Moche pp 43-65. University of Texas Press, Austin.

McKenna DJ, Luna LE, Towers CHN (1986) Ingredientes biodinámicos en las plantas que se mezclan al ayahuasca. Una farmacopea tradicional no identificada. América Indígena 46:73-98.

Meza E (Ed) (1999) “Sangre del Grado" y el Reto de su Producción Sustentable en el Perú. Universidad Nacional Mayor de San Marcos, Lima.

Milliken W (1997) Traditional anti-malarial medicine in Roraim, Brazil. Economic Botany 51(3):212237.

Minakawa N, Sonye G, Mogi M, Githeko A, Yan GY (2002) The effects of climatic factors on the distribution and abundance of malaria vectors in Kenya. Journal of Medical Entomology 39(6):833841

Monardes N (1574) Primera y segunda y tercera partes de la história medicinal de las cosas que se traen de nuestras Indias Occidentales, que sirven en medicina; Tratado de la piedra bezaar, y de la yerva escuerçonera; Diálogo de las grandezas del hierro, y de sus virtudes medicinales; Tratado de la nieve, y del beuer frio. Alonso Escrivano, Seville.

Monigatti M, Bussmann R, Wekerle CS (2012) Medicinal plant use in two Andean communities located at different altitudes in the Bolívar Province, Peru. Journal of Ethnopharmacology 145:450464

Mooney P (1993) Aprovechando la Diversidad, Una Nota Sobre la Diversidad Biológica y el Conocimiento Indígena. América Indigena 3:41-55.

Morales P (2005) Ley 28216: Ley de Proteccíon al Acceso a la Diversidad Biológica Peruana y los Conocimientos Colectivos de los Pueblos Indígenas. In: Ferro P, Ruiz M (Eds) Cómo prevenir la Biopiratería? Reflexiones y Propuestas pp.48-49. Lerma Gómez E.I.R.L., Lima-Miraflores.

Morales R (2012) Curanderos y Académicos: Una Experiencia en Trujillo (1994 y 1995). In: Paz E (Ed) Curanderismo, Medicina Tradicional pp. 11-109. Pueblo Continente 23(1):14-17.

Moran K, King SR, Carlson T (2001) Biodiversity prospecting, lessons and prospects. Annual Review of Anthropology 30:505-526.

Mostacero J, Castillo F, Mejía F, Gamarra O, Charcape J, Ramírez R (2011) Plantas Medicinales del Perú: Taxonomía, Ecogeografía, Fenología y Etnobotánica, Asamblea Nacional de Rectores: Instituto de Estudios Universitarios “José Antonio Encinas," Trujillo.

Naranjo P (1981): Social function of coca in pre-Columbian America. Journal of Ethnopharmacology 3:161-172.

Neto CC, Owens CW, Langfield RD, Comeau AB, St. Onge J, Vaisberg AJ, Hammond GB (2002) Antibacterial activity of some Peruvian medicinal plants from the Callejón de Huaylas. Journal of Ethnopharmacology 79:133-138.
Nuestra Farmacia (2004) La historia de la ética farmacia Makewelawen. Marzo/Abril, pp. 36-37.

Oblitas E (1992) Plantas medicinales de Bolivia. Editorial Los Amigos del Libro, La Paz.

Obregón L (1996) “UNA DE GATO” “Cat”s Claw.” Instituto de Fitoterapia Americano, $3^{\text {rd }}$ Ed, Lima.

Okuyama E, Umeyama K, Ohmori S, Yamazaki M, Satake M (1994) Pharmacologically active components from a Peruvian medicinal plant, Huira-Huira (Culcitium canescens H. \& B.) Chemical and Pharmaceutical Bulletin 42:2183-2186.

Pallardel Peralta TH (1988) Plantas útiles para emergencia y primeros auxilios. II Congreso Internacional de Plantas Tradicionales, Lima.

Paz E (Ed) (2012) Curanderismo, Medicina Tradicional. Pueblo Continente 23(1):11-109.

Perez F, Rodríguez F, León G, Sharon D, Bussmann RW, Willsky G, Guerrero G, Willner K, Castro I (2012) Estudio fitoquímico y antibacteriana de mezclas de plantas medicinales. En búsqueda de nuevos componentes. Pueblo continente 23(2):339-343.

Perez F, Rodríguez F, León M, Malca G (2010) Mezcla de extractos de plantas medicinales: isingerismo o reacción química? Pueblo Continente 21(1):239-242.

Perumal Samy R, Ignacimuthu S (2000) Antibacterial activity of some medicinal plants used by tribals in Western Ghats, India. Journal of Ethnopharmacology 69:63-71.

Pestalozzi HU (1998) Flora ilustrada alto andina. Herbario Nacional de Bolivia y Herbario Forestal Nacional Martín Cárdenas, Cochabamba.

Pietrillini F (2007) Las Plantas Medicinales en un Piso Alto y Mesoandino. GCP, Ayacucho.

Plotkin M (1993) Tales of a Shaman's Apprentice: An Ethnobotanist Searches for New Medicines in the Amazon Rain Forest. Viking, New York.

Plowman T (1981) Amazonian coca. Journal of Ethnopharmacology 3:195-225.

Plowman T (1984 a ) The ethnobotany of coca (Erythroxylum spp., Erythroxylaceae). Advances in Economic Botany 1:62-111.

Plowman T (1984 b) The origin, evolution, and diffusion of coca, Erythroxylum spp. in South and Central America. Papers of the Peabody Museum of Archaeology and Ethnology 76:125-163.

Polia M (1988) Las Lagunas de los Encantos - Medicina Tradicional Andina en el Perú septentrional. CePeSe, Lima.

Polia M (2000) Shamanismo Andino: Un Perfíl Cultural. In: Polia M (Ed) Shamán: La búsqueda.. pp. 45-134. Imprenta San Pablo, S.L., Córdoba.

Portillo Z (2009) Peru's patent win strikes blow against biopiracy. Science and Development Network. Retrieved from http://www.scidev.net/en/news/peru-s-patent-win-strikes-blow-against-biopiracy.html.

Prance GT (1972) Ethnobotanical notes from Amazonian Brazil. Economic Botany 26:221-233. 
Pummangura S, McLaughlin JL, Schiffendecker RC (1982) Cactus alkaloids. LI. Lack of mescaline translocation in grafted Trichocereus. Journal of Natural Products 45:215-216.

Raimondi A (1857) Elementos de Botánica aplicada a la medicina y la industria en los cuales se trata especialmente de las plantas del Perú. Mariano Murga, Lima.

Rätsch C (1998) Enzyklopädie der psychoaktiven Pflanzen. AT Verlag, Aarau.

Reid W (1993) The Economic Realities of Biodiversity. Issues in Science and Technology 10(2):48-55

Revene Z, Bussmann RW, Sharon D (2008) From Sierra to Coast, Tracing the supply of medicinal plants in northern Peru - A plant collector's tale. Ethnobotany Research \& Applications 6:15-22.

Rivier L, Lindgren JE (1971) An American hallucinogenic drink: An ethnobotanical and chemical investigation. Economic Botany 25:101-133.

Rodríguez F (2007) Plantas de Uso Etnobotánica de la Zona Baja de los Valles de Pativilca y Fortaleza, Provincia de Barranca, Lima. Tesis de Licenciado de Biología, Universidad Peruana Cayetano Heredia, Lima.

Rodriguez J, Pacheco P, Razmilic I, Loyola JI, Schmeda-Hirschmann G, Theoduloz C (1994) Hypotensive and diuretic effect of Equisetum bogotense and Fuchsia magellanica and micropropagation of $E$. bogotense. Phytotherapy Research 8:157-160.

Roersch C, Van der Hoogte YL (1998) Plantas medicinales del sur andino del Perú. II Congreso Internacional de Medicina Tradicional, Lima.

Roersch C (1994) Plantas Medicinales en el Sur Andino del Perú. Koeltz Scientific Books, Königstein.

Ruiz H (1777-1788/1998) Relación del viaje hecho a los reynos del Perú y Chile. Translated by Schultes ER, Nemry von Thenen de Jaramillo-Arango MJ as "The Journals of Hipólito Ruiz," Timber Press, Portland.

Ruiz H, Pavón J (1794-1802) Florae peruvianae et chilensis, Tomos 1-3. Typis Gabrielis, Madrid.

Rumiche Briceño J, De Valderrama YRB (1998) Las plantas medicinales en el Perú. II Congreso Internacional de Plantas Tradicionales, Lima.

Rutter RA (1990) Catálogo de plantas útiles de la Amazonia Peruana. Comunidades y Culturas Peruanas 22:1-349.

Sagástegui A, Sánchez I, Leiva S, Lezama P, Dillon M (1999) Diversidad Florística del Norte de Perú Tomo I. Graficart, Trujillo.

Sagástegui A, Sánchez I, Zapata M, Dillon M (2003) Diversidad Florística del Norte de Perú, Tomo II, Bosques Montanos. Graficart, Trujillo.

Sánchez Garrafa R, Sánchez Garrafa R (2009) 25 Aniversario del Centro de Medicina Andina. In: Sánchez Garrafa R, Sánchez Garrafa R (Eds) Medicina Tradicional: Planteamientos y Aproximaciones pp. 375-384. CBC/CMA, Cuzco.
Sánchez Garrafa R, Sánchez Garrafa R (Eds) (2009) Medicina Tradicional: Planteamientos y Aproximaciones. Centro de Medicina Andina (CMA) y Centro de Estudios Regionales Andinos Bartolomé de las Casas (CBC), Cuzco.

Schjellerup I, Espinoza C, Quipuscoa V, Samamé C (1999) La Morada - la gente y la biodiversidad/ La Morada - people and biodiversity. Centre for Research on the Cultural and Biological Diversity of Andean Rainforest Report No. 8. The Danish Environmental Research Programe, Copenhagen.

Schjellerup I, Sorensen K, Espinoza V, Quipuscoa V, Peńa V (2003) Los Valles Olvidados - Pasado y Presente en la Utilización de Recursos en Ceja de Selva, Perú. The Forgotten Valleys - Past and Present in the Utilization of Resources in the Ceja de Selva, Peru. The National Museum of Denmark, Ethnographic Monographs No. 1, Copenhagen. Graficart, Trujillo.

Schjellerup I, Quipuscoa V, Espinoza C, Peńa V, Sorensen MK (2005) Redescubriendo el Valle de los Chilchos: Condiciones de vida en la Ceja de Selva, Perú. The Chilchos Valley Revisted: Life Conditions in the Ceja de Selva, Peru. The National Museum of Denmark, Ethnographic Monographs, No. 2. Copenhagen. Graficart, Trujillo.

Schjellerup I (2009) Razon de las Especies de la Naturaleza y del Arte del Obispado de Trujillo del Peru del Obispo D. Baltazar Martinez Compagńón In: Vergara E, Vásquez R (Eds) Medicina Tradicional, Conocimento Milenario pp 128-152. Museo de Arqueología, Antropología e Historia, Serie Antropología 1, Facultad de Ciencias Sociales, Universidad Nacional de Trujillo, Trujllo.

Schultes RE (1994) Amazonian ethnobotany and the search for new drugs. In Ciba Foundation Symposium, vol. 185, pp 106-115. Wiley, Chichester.

Schultes RE, Hofmann A (1992a) Plants of the Gods. Healing Arts Press, Rochester, VT.

Schultes RE, Raffauf R (1990) The Healing Forest. Dioscorides Press, Portland, OR.

Schultes RE, Raffauf R (1992) Vine of the Soul. Synergetic Press, Oracle, Arizona.

Seguín CA (1979) Psiquiatría Folklórica: Shamanes y Curanderos. Ediciones Ermar, Lima.

Seguin CA (1982) La enfermedad el enfermo y el médico. Piramide, Madrid.

Seguin CA (1988) Medicinas tradicionales y medicina folkórica. Banco Central de Reserva Perú, Lima.

Segura N, Miranda J (1995) Curanderismo del complejo cultural costa norte: Un itinerario para la reflexión (a propósito de CHACMA 94). Revista del Museo de Arqueología, Antropología e Historia 5:343-360.

Sharon D (1978) Wizard of the Four Winds, A Shaman's Story. Free Press, New York.

Sharon D (1980) El Chamán de los Cuatro Vientos. Siglo veintiuno editores, México DF

Sharon D (1994) Tuno y sus colegas, notas comparativas. In: Millones L, Lemlij M (Eds) En el Nombre del Señor, Shamanes, demonios y curanderos del norte del Perú pp 128-147. Australis S.A., Lima.

Sharon D (2000) Shamanismo y el Cacto Sagrado - Shamanism and the Sacred Cactus. San Diego Museum Papers 37. 
Sharon D (2009) Tuno y sus colegas: Notas comparativas. In: Vergara E \& Vásquez R (Eds) Medicina Tradicional: Conocimiento Milenario pp 251-267. Serie Antropología No 1. Museo de Arqueología, Antropología e Historia, Facultad de Ciencias Sociales, Universidad Nacional de Trujillo.

Sharon D, Bussmann RW (2006) Plantas Medicinales en la Obra del Obispo Don Baltasar Jaime Martínez Compagnón (Siglo XVIUI). In: Millones L Kato T (Eds) Desde el exterior: El Perú y sus estudios pp 147-165. Tercer Congreso Internacional de Peruanistas, Nagoya, 2005, UNMSM, Lima.

Sharon D, Bussmann RW (2014). Medicina tradicional y medicina modern en México y el Perú: valorización y explotación. In: Limón S, Millones L (Eds) Por la mano del hombre: prácticas y creencias sobre chamanismo y curandería en México y el Perú. Fondo Editorial de la Asamblea Nacional de Rectores/ Punto \& Grafia S.A.C., Lima.

Sharon D, Galvez C (2009) La mesa de Leoncio Carrión. In: Vergara E \& Vásquez R (Eds.) Medicina Tradicional: Conocimiento Milenario pp 236-244. Serie Antropología, No 1. Museo de Arquelogía, Antropología e Historia, Facultad de Ciencias Sociales, Universidad Nacional de Trujillo.

Sharon D, Glass-Coffin B, Bussmann RW (2009) La mesa de Julia Calderón de Ávila. In: Vergara E, Vásquez R (Eds) Medicina Tradicional: Conocimiento Milenario. pp 245 -254. Serie Antropología, No 1. Museo de Arquelogía, Antropología e Historia, Facultad de Ciencias Sociales, Universidad Nacional de Trujillo.

Skoczen S, Bussmann RW (2006) ebDB International Ethnobotany Database. Lyonia 11:44.

Smallwood A (2011) The Effects of Biopiracy on the Natural Plant Product Market: A Peruvian Case History. M.A. Thesis, San Diego State Uuiversity/Latin American Studies, San Diego.

Soukup J (1970) Vocabulario de los Nombres vulgares de la Flora Peruana. Imprenta del Colegio Salesiano, Lima.

Soukup J (1987) Vocabulario de los Nombres tradicionales de la Flora Peruana y Catálogo de los Géneros. Editorial Salesiana, Lima.

Tilbert JC, Kaptchuk TJ (2008) Herbal medicine research and global health, an ethical analysis. Bulletin of the World Health Organization 86:594-599.

Torres CM (2008) Chavin's Psychoactive Parmacopoeia: The Iconographic Evidence. In: Conklin WJ, Quilter J (Eds.) Chavin: Art, Architecture, and Culture pp 239-260. Los Angeles: Cotsen Institute of Archaeology, UCLA

Towle MA (1961) The Ethnobotany of Peru. Wenner-Gren Foundation for Anthropological Research, Inc. Aldine Publishing Company, Chicago.

Ugent D, Ochoa C (2006) La Etnobotánica del Perú Desde la Prehistoria al Presente. Centro de Producción Editorial e Imprenta de la Universidad Nacional Mayor de San Marcos, Lima.

Ulloa C, Jørgensen PM (1993) Arboles y arbustos de los Andes del Ecuador. AAU Reports 30:1-263.

United Nations Conference on Trade and Development (2000) Systems and National Experiences for Protecting Traditional Knowledge, Innovations and Practices. Background Note by the UNCTAD Secretariat Geneva, United Nations Conference on Trade and Development, (document reference TD/B/COM.1/EM.13/2)
Unnikrishnan PM, Suneetha MS (2012) Biodiversity, Traditional Knowledge and Community Health: Strengthening Linkages. Yokohama, United Nations University, Institute of Advanced Studies.

Valdivia Ponce O (1975) Hampicamayoc. Medicina folklórica y su substrato aborígen en el Perú. Universidad Nacional Mayor de San Marcos, Lima.

Valdizán H, Maldonado YA (1922) La medicina popular peruana. Tomo 3. Torres Aguirre, Lima.

Van den Eynden V, Cueva C, Cabrera O (2004) Of "Climbing Peanuts" and "Dog's Testicles." Mestizo and Shuar plant nomenclature in Ecuador. Journal of Ethnobiology 24(2):279-306.

Vandebroek I, Balick MJ, Ososki A, Kronenberg F, Yukes J, Wade C, Jiménez F, Peguero B, Castilloin D (2010) The importance of botellas and other plant mixtures in Dominican traditional medicine. Journal of Ethnopharmacology 128:20-41.

Vázquez R (1989) Plantas útiles de la Amazonia Peruana. Iquitos, Perú.

Venero B (2005a) Componentes de la Diversidad Biológica Peruana Patentados en el Extranjero: La Experiencia de Maca. ¿Cómo combatir la biopiratería? In: Ferro P, Ruiz M (Eds) ¿Cómo prevenir la Biopiratería en el Perú? Reflexiones y Propuestas pp. 50-55 \& 74-78. Lerma Gómez E.I.R.L., LimaMiraflores.

Venero B (2005b) La protección legal de los conocimientos tradicionales en el Perú. In: Ferro P, Ruiz M (Eds) Apuntes sobre Agrobiodiversidad: Conservación, biotecnología y conocimientos tradicionales pp. 17-47. Lerma Gómez E.I.R.L., Lima-Miraflores.

Vergara E, Vásquez R (Eds) (2009) Medicina Tradicional: Conocimiento Milenario. Serie Antropología No. 1. Museo de Arqueología, Antropología e Historia, Facultad de Ciencias Sociales, Universidad Nacional de Trujillo, Trujillo.

Villar M, Villavicencio O (2001) Manual de Fitoterapia.Lima, OPS/OMS - EsSalud, Programa Nacional de Medicina Complementaria.

Villegas LF, Fernandez ID, Maldonado H, Torres R, Zavaleta A, Vaisberg AJ, Hammond GB (1997) Evaluation of the wound-healing activity of selected traditional medicinal plants from Peru. Journal of Ethnopharmacology 55:193-200.

Wassen H (1976) Was Espingo (Ispincu) of Psychotropic and Intoxicating Importance for Shamans in Peru? In: Agehananda Bharati (Ed) The Realm of the Extra-Human Agents and Audiences. Mouton Publishers, The Hague-Paris. Distributed in the United States and Canada by Aldine, Chicago.

Wassen H (1987) "Ulluchu" in Moche Iconography and Blood Ceremonies: The Search for Identification. Göteborg Etnografiska Museum, Annals 1985/86.

Weberbauer A (1945) El Mundo Vegetal de los Andes Peruanos. Estación experimental de agricultura La Molina, Ministerio de Agricultura, Lima.

Weil AT (1978) Coca leaf as therapeutic agent. American Journal of Drug and Alcohol Abuse 5(1):75-86.

World Health Organization (1977) Report: Promotion and Development of Traditional Medicine. Technical Report Series 622. Geneva 
World Health Organization (1978) Final Report: International Conference on Primary Health Care. Alma Ata, USSR.

World Health Organization (1998) Technical Briefing on Traditional Medicine. 49 ${ }^{\text {th }}$ Regional Committee Meeting, 18 September. WHO Regional Office for the Western Pacific, Manila.

World Health Organization (1999a) Consultation Meeting on TM and Modern Medicine, Harmonizing the Two Approaches. Document reference: (WP)TM/ICP/TM/001/RB/98-RS/99/ GE/32(CHN)). World Health Organization, Geneva.

World Health Organization (1999b) Traditional, Complementary and Alternative Medicines and Therapies. Washington DC, WHO Regional Office for the Americas/Pan American Health Organization (Working group OPS/OMS)

World Health Organization (2002a) Implementation of the WHO Strategy for Prevention and Control of Chronic Respiratory Diseases. WHO/MNC/CRA/O2.2, World Health Organization, Geneva.

World Health Organization (2002b) WHO Traditional Medicine Strategy 2002-2005. World Health Organization, Geneva.

World Health Organization (2002c) Foodborne disease. World Health Organization, Geneva.

World Health Organization (2005) Urinary Tract Infections in infants and children in developing countries in the context of IMCI. World Health Organization, Geneva.

World Health Organization (2007) Sexually transmitted infections fact sheet. World Health Organization, Geneva.

World Health Organization (2009a) Declaración de Alma Ata. World Health Organization, Geneva. In: Medicina Tradicional Andina: Planteamientos y aproximaciones. Sánchez Garrafa R, Sánchez Garrafa R (Eds) pp. 387-390. CBC/CMA, Cuzco.

World Health Organization (2009b) World health fact sheet. World Health Organization, Geneva.

Yacovleff E, Larco Herrera F (1935) El Mundo Vegetal de los antiguos peruanos. Revista del Museo Nacional 4: 31-102.

Zamora Pérez DI (2007) Creación de un Órgano Administrativo Especializado en imponer sanciones a los concesionarios mineros en caso de incumplimiento de sus obligaciones ambientales. Tesis de Abogado, Universidad Privada Antenor Orrego, Trujillo.

Zollman C, Vickers AJ (2000) ABC of Complementary Medicine. BMJ Books, London.

\section{Indice General}

Medicina Tradicional y Alternativa - Complementaria

Antecedentes - Investigación de Plantas Medicinales y la Medicina Tradicional en Perú

Asuntos de Actualidad en la Etnobotánica

Conservación de Biodiversidad y Medicina Tradiciona

Trabajo hasta la Fecha

Nomenclatura de Plantas en el Norte de Perú

Dos décadas de Etnobotánica en el norte de Perú y el sur de Ecuador

Usos Medicinales

Usos Mágico

Sistema Respiratorio

Sistema Urinario (Rińones, Vejiga)

Problemas reumáticos

Órganos Internos (Hígado, Vesícula)

Diarrea, Problemas del Estómago y otras Enfermedades de los Intestinos

Problemas Reproductivos y Salud Femenina

Corazón y Sistema Circulatorio

Inflamación e Infecciones Bacterianas

Paludismo y Fiebre

Cancer y Diabetes

Partes Usadas de las Plantas Medicinales y Modos de Aplicación

¿Funciona la Medicina Tradicional? Una Mirada a Plantas Antibacterianas en el Norte

Toxicidad en la Medicina Tradicional

Mercados y Sostenibilidad

El Caso de Ulluchu

Mercados cambiantes

La sostenibilidad - ¿Qué cantidad de planta y a qué precio?

Semillas Sagradas, el Protocolo de Nagoya y la Repatriación de los Conocimientos Tradicionales

Un Programa Global de Conservación de las Plantas Útiles y

los Conocimientos Tradicionales: Una Llamada a la Acción

Conclusiones

Agradecimientos

ACANTHACEAE - Aphelandra cirsioides Lindau

ADOXACEAE - Sambucus peruviana Kunth

AIZOACEAE - Tetragonia crystallina L'Héritie

ALSTROEMERIACEAE - Bomarea angulata Benth.

ALSTROEMERIACEAE - Bomarea dulcis (Hook.) Beauv.

AMARANTHACEAE - Alternanthera brasiliana (L) Kuntze

AMARANTHACEAE - Alternanthera halimifolia (Lam.) Standley \& Pittier

AMARANTHACEAE - Alternanthera porrigens (Jacquin) Kuntze

AMARANTHACEAE - Alternanthera villosa Kunth

AMARANTHACEAE - Amaranthus caudatus L. 
AMARANTHACEAE - Chenopodium quinoa Willd. (wild form) AMARANTHACEAE - Chenopodium quinoa Willd.

AMARANTHACEAE - Iresine diffusa Humb. \& Bonpl. ex Willd.

AMARANTHACEAE - Iresine herbstii Lindley

AMARYLLIDACEAE - Allium odorum L.

AMARYLLIDACEAE - Allium sativum $\mathrm{L}$.

AMARYLLIDACEAE - Eustephia coccinea Cav.

ANACARDIACEAE - Anacardium occidentale $\mathrm{L}$

ANACARDIACEAE - Loxopterygium huasango Spruce ex Engl.

ANACARDIACEAE - Mangifera indica L.

ANACARDIACEAE - Mauria heterophylla Kunth.

ANACARDIACEAE - Schinus molle L.

ANNONACEAE - Annona muricata L.

APIACEAE - Ammi visnaga (L.) Lam.

APIACEAE - Apium graveolens $\mathrm{L}$.

APIACEAE - Arracacia xanthorrhiza Bancrof

APIACEAE - Coriandrum sativum L.

APIACEAE - Daucus montanus Humb. \& Bonpl. ex Spreng.

APIACEAE - Foeniculum vulgare P. Miller

APIACEAE - Niphogeton dissecta (Benth.) J.F. Macbr.

APIACEAE - Petroselinum crispum (Miller) A.W. Hill

APIACEAE - Pimpinella anisum $\mathrm{L}$.

APOCYNACEAE - Mandevilla antennacea (A.DC.) Schum.

APOCYNACEAE - Mandevilla trianae Woodson

APOCYNACEAE - Nerium oleander $\mathrm{L}$.

APOCYNACEAE - Thevetia peruviana (Pers.) Schum.

APOCYNACEAE - Vallesia glabra (Cav.) Link.

AQUIFOLIACEAE - Ilex guayusa Loes

ARALIACEAE - Hydrocotyle bonariensis Commerson ex Lam.

ARALIACEAE - Hydrocotyle globiflora R. \& P.

ARALIACEAE - Oreopanax eriocephalus Harms

ARAUCARIACEAE - Araucaria heterophylla (Salisb.) Franco

ARECACEAE - Bactris gasipaes Kunth

ARECACEAE - Cocos nucifera L.

ARISTOLOCHIACEAE - Aristolochia ruiziana (Klotsch) Duch.

ASCLEPIADACEAE - Sarcostemma clausum (Jacquin) Schultes

ASPARAGACEAE - Dracaena fragrans Ker Gawl.

ASTERACEAE - Acanthoxanthium spinosum (L.) Fourreau

ASTERACEAE - Achillea millefolium L.

ASTERACEAE - Achyrocline alata (Kunth) DC.

ASTERACEAE - Acmella ciliata (Kunth) Cass.
ASTERACEAE - Ambrosia peruviana Willd.

ASTERACEAE - Arctium lappa L.

ASTERACEAE - Aristeguietia gayana (Wedd.) R.M. King \& H. Rob.

ASTERACEAE - Arnica montana L.

ASTERACEAE - Artemisia absinthium $\mathrm{L}$.

ASTERACEAE - Ayapana amygdalina (Lam.) R.M. King \& H. Rob.

ASTERACEAE - Baccharis caespitosa (Ruiz \& Pav.) Pers

ASTERACEAE - Baccharis chilco Kunth

ASTERACEAE - Baccharis genistelloides (Lam.) Pers.

ASTERACEAE - Baccharis latifolia (Ruiz \& Pav.) Pers.

ASTERACEAE - Baccharis pedunculata (Mill.) Cabr.

ASTERACEAE - Baccharis salicifolia (R. \& P.) Pers.

ASTERACEAE - Baccharis tricuneata (L.f.) Pers.

ASTERACEAE - Bidens pilosa L.

ASTERACEAE - Chuquiragua spinosa Lessing ssp. huamanpinta C. Ezcurra

ASTERACEAE - Chuquiragua weberbaueri Tovar

ASTERACEAE - Clibadium sylvestre (Aubl.) Baill.

ASTERACEAE - Cronquistianthus lavavandulaefolius (DC.) R.M. King \& H. Rob.

ASTERACEAE - Cynara cardunculus L.

ASTERACEAE - Diplostephium gynoxyoides Cuatrec.

ASTERACEAE - Diplostephium sagasteguii Cuatrec.

ASTERACEAE - Ferreyranthus verbascifolius (Kunth) H. Rob. \& Brettell

ASTERACEAE - Flaveria bidentis (L.) Kuntze

ASTERACEAE - Gamochaeta americana (Mill.) Wedd.

ASTERACEAE - Lactuca sativa L.

ASTERACEAE - Loricaria ferruginea (Ruiz \& Pav.) Wedd.

ASTERACEAE - Loricaria thyrsoidea (Cuatrec.) Dillon \& Sagástegui

ASTERACEAE - Matricaria chamomilla L.

ASTERACEAE - Matricaria recutita L.

ASTERACEAE - Mikania leiostachya Benth.

ASTERACEAE - Monactis flaverioides Kunth

ASTERACEAE - Munnozia lyrata (A. Gray.) H. Rob. \& Brettell

ASTERACEAE - Onoseris odorata (D. Don) Hooker \& Arnott

ASTERACEAE - Oritrophium peruvianum (Lam.) Cuatrec.

ASTERACEAE - Paranephelius uniflorus Poepp. \& Endl.

ASTERACEAE - Perezia multiflora (Humb. \& Bonpl.) Lessing

ASTERACEAE - Perezia pungens (Kunth) Cass.

ASTERACEAE - Picrosia longifolia D. Don

ASTERACEAE - Pluchea absinthioides Hook. \& Arn.) H. Rob. \& Cuatr.

ASTERACEAE - Porophyllum ruderale (Jacq.) Cass.

ASTERACEAE - Pseudogynoxys cordifolia (Cass.) Cabrera

ASTERACEAE - Schkuhria pinnata (Lam.) Kuntze 
\begin{tabular}{lr}
\hline ASTERACEAE - Senecio canescens (H.B.K.) Cuatrecasas & 109
\end{tabular}

ASTERACEAE - Senecio comosus Sch.-Bip. 109

ASTERACEAE - Senecio genisianus Cuatr. 109

$\begin{array}{lr}\text { ASTERACEAE - Senecio hypsiandinus Cuatr. } & 109\end{array}$

ASTERACEAE - Senecio otuscensis Cabrera 109

ASTERACEAE - Senecio tephrosioides Turcz. 109

ASTERACEAE - Smallanthus sonchifolius (Poepp. \& Endl) H. Rob. 111

ASTERACEAE - Sonchus oleraceus L.

ASTERACEAE - Spilanthes leiocarpa DC.

ASTERACEAE - Tagetes elliptica $\mathrm{Sm}$

ASTERACEAE - Tagetes erecta L.

ASTERACEAE - Tagetes filifolia Lag.

ASTERACEAE - Taraxacum officinale Wiggers

ASTERACEAE - Tessaria integrifolia R. \& P.

ASTERACEAE - Trixis cacalioides Kunth

ASTERACEAE - Weddelia latifolia DC.

ASTERACEAE - Werneria nubigena Kunth

ASTERACEAE - Werneria pygmaea Gillies ex Hook. \& Arn

ASTERACEAE - Werneria villosa A. Gray

BALANOPHORACEAE - Corynaea crassa Hook. f

BERBERIDACEAE - Berberis buceronis J.F. Macbride

BETULACEAE - Alnus acuminata Kunth

BIGNONIACEAE - Crescentia cujete L.

BIGNONIACEAE - Cydista aequinoctialis (L.) Miers

BIGNONIACEAE - Jacaranda acutifolia Humb. \& Bonpl.

BIGNONIACEAE - Tynanthus polyanthus (Bureau) Sandwith

BIXACEAE - Bixa orellana L.

BORAGINACEAE - Borago officinalis $\mathrm{L}$

BORAGINACEAE - Cordia alliodora (R. \& P.) Oken

BORAGINACEAE - Cordia lutea Lam.

BORAGINACEAE - Heliotropium curassavicum L.

BORAGINACEAE - Tiquilia paronychioides (Phil.) Rich.

BRASSICACEAE - Brassica oleracea L.

BRASSICACEAE - Brassica rapa $\mathrm{L}$

BRASSICACEAE - Capsella bursa-pastoris (L.) Medic

BRASSICACEAE - Lepidium virginicum L.

BRASSICACEAE - Raphanus sativus $\mathrm{L}$.

BRASSICACEAE - Rorippa nasturtium-aquaticum (L.) Hayek

BROMELIACEAE - Ananas comosus (L.) Merrill

BROMELIACEAE - Puya hamata L.B. Sm.

BROMELIACEAE - Puya weberbaueri Mez.

BROMELIACEAE - Tillandsia cacticola L.B. Sm.

BROMELIACEAE - Tillandsia multiflora Bentham var. decipiens (Andre) Sm.
BURSERACEAE - Bursera graveolens (Kunth) Triana \& Planchon

政

CACTACEAE - Echinopsis pachanoi (Britton \& Rose) Friedrich \& G. Rowley CACTACEAE - Opuntia ficus-indica (L.) Miller

CALCEOLARIACEAE - Calceolaria rugulosa Edwin

CALOPHYLLACEAE - Mammea americana L.

CAMPANULACEAE - Centropogon argutus E. Wimmer

CAMPANULACEAE - Centropogon cornutus (L.) Druce

CAMPANULACEAE - Centropogon rufus Wimm

CAMPANULACEAE - Lobelia decurrens Cavaniles

CAMPANULACEAE - Siphocampylus angustiflorus Schlechtendal

CAMPANULACEAE - Siphocampylus cutervensis A. Zahlbr.

CAMPANULACEAE - Siphocampylus tupaeiformis Zahlbr.

CANNABACEAE - Celtis pubescens (Humb. \& Bonpl.) Spreng.

CAPPARIDACEAE - Capparis crotonoides (Kunth) Iltis \& Cornejo

CAPPARIDACEAE - Capparis scabrida Kunth

CAPRIFOLIACEAE - Dipsacus jallonum $\mathrm{L}$

CAPRIFOLIAEAE - Lonicera japonica Thunberg

CAPRIFOLIACEAE - Scabiosa atropurpurea L.

CAPRIFOLIACEAE - Valeriana microphylla Kunth

CAPRIFOLIACEAE - Valeriana niphobia Briquet

CAPRIFOLIACEAE - Valeriana plantaginea Kunth

CAPRIFOLIACEAE - Valeriana rigida Ruiz. \& Pav.

CARICACEAE - Carica papaya L.

CARICACEAE - Jacartia digitata (Poepp. \& Endl.) Solms-Lang.

CARYOPHYLLACEAE - Dianthus caryophyllus L.

CARYOPHYLLACEAE - Dianthus caryophyllus L.

CARYOPHYLLACEAE - Stellaria media (L.) Criollo

CELASTRACEAE - Salacia multiflora (Lam.) DC.

CHLORANTHACEAE - Hedyosmum racemosum (R. \& P.) G. Don.

CHRYSOBALANACEAE - Couepia guianensis Aubl.

CLETHRACEAE - Clethra castaneifolia Meisn.

CLUSIACEAE - Clusia minor L

CONVOLVULACEAE - Cuscuta foetida H.B.K.

CONVOLVULACEAE - Ipomoea batatas (L.) Lamarck

CONVOLVULACEAE - Ipomoea pauciflora M. Martens \& Galeotti

CRASSULACEAE - Echeveria peruviana Meyen

CUCURBITACEAE - Citrullus lanatus (Thunberg) Matsumura \& Nakai

CUCURBITACEAE - Cucumis dipsaceus Ehrenb.

CUCURBITACEAE - Cucumis sativus $\mathrm{L}$

CUCURBITACEAE - Cucurbita maxima Duchesne

CUCURBITACEAE - Cucurbita moschata Duch.

CUCURBITACEAE - Cyclanthera pedata (L.) Schrad. 
CUCURBITACEAE - Sechium edule Swartz.

CUCURBITACEAE - Sicana odorifera (Vell.) Naud.

CUCURBITACEAE - Sycos baderoa H. et A

CUPRESSACEAE - Cupressus lusitanica Miller

CYPERACEAE - Cyperus articulatus $\mathrm{L}$.

CYPERACEAE - Kyllingia pumila Michx.

CYPERACEAE - Oreobolos obtusangulus T. Koyama

- Scirpus californicus (C.A. Meyer) Steudel subsp. tatora (Kunth) T. Koyama

DIOSCOREACEAE - Dioscorea tambillensis Kunth

DIOSCOREACEAE - Dioscorea trifida L.f.

ELAEOCARPACEAE - Vallea stipularis L.f.

EPHEDRACEAE - Ephedra americana Humb. \& Bonpl. ex Willd.

EQUISETACEAE - Equisetum bogotense H.B.K. (Kunth)

EQUISETACEAE - Equisetum giganteum (Wedd.) Ulbrich

ERICACEAE - Bejaria aestuans Mutis ex L.

ERICACEAE - Gaultheria erecta Vent.

ERICACEAE - Gaultheria reticulata Kunth

ERIOCAULACEAE - Paepalanthus ensifolius (Kunth) Kunth

ERYTHROXYLACEAE - Erytbroxylon coca Lam.

ESCALLONIACEAE - Escallonia pendula (R. \& P.) Pers.

EUPHORBIACEAE - Acalypha villosa Jacq.

EUPHORBIACEAE - Chamaesyce hypericifolia (L.) Millspaugh

EUPHORBIACEAE - Croton draconoides Müll.-Arg.

EUPHORBIACEAE - Croton lechleri Müll. Arg.

EUPHORBIACEAE - Hura crepitans $\mathrm{L}$.

EUPHORBIACEAE - Jatropa curcas L., Jatropa gossypiifolia L., Jatropa weberbaueri Pax \& Hoffman

EUPHORBIACEAE - Manihot esculenta Crantz

EUPHORBIACEAE - Phyllhonthus nimuri Lo Phyllanthus stipulatus (Raf) Webser, Phyllhethus wind

EUPHORBIACEAE - Ricinus communis $\mathrm{L}$

FABACEAE - Acacia macracantha Humb. \& Bonpl. ex Willd.

FABACEAE - Caesalpinia paipai Ruiz \& Pav

FABACEAE - Caesalpinia spinosa (Molina) Kuntze

FABACEAE - Cajanus cajan (L.) Millsp.

FABACEAE - Cassia fistula L.

FABACEAE - Cicer arietinum $\mathrm{L}$

FABACEAE - Desmodium molliculum (H.B.K.) DC.

FABACEAE - Desmodium triflorum (L.) DC

FABACEAE - Dioclea virgata (Rich.) Amsh.

FABACEAE - Erythrina amazonica Krukoff

FABACEAE - Erythrina velutina Willdenow

FABACEAE - Indigofera suffruticosa Miller

FABACEAE - Inga edulis C. Martius, Inga fenilleei DC

FABACEAE - Lathyrus odoratus $\mathrm{L}$.
FABACEAE - Lablab purpureus (L.) Sweet

FABACEAE - Lens culinaris Medikus

FABACEAE - Leucaena leucocephala (Lam.) De Wit

FABACEAE - Lupinus mutabilis Sweet

FABACEAE - Medicago sativa $\mathrm{L}$.

FABACEAE - Melilotus alba Medikus

FABACEAE - Mimosa albida H. \& B

FABACEAE - Mimosa nothacacia Barneby

FABACEAE - Myroxylon balsamum (L.) Harms.

FABACEAE - Otholobium mexicanum (L.f.) Grimes

FABACEAE - Ormosia sp.

FABACEAE - Pisum sativum L.

FABACEAE - Prosopis pallida (H. \& B. ex Willd.) H.B.K.

FABACEAE - Senna alexandrina Mill.

FABACEAE - Senna bicapsularis (L.) Roxburgh

FABACEAE - Senna occidentalis (L.) Link.

FABACEAE - Spartium junceum $\mathrm{L}$.

FABACEAE - Tamarindus indica $\mathrm{L}$

FABACEAE - Trifolium repens $\mathrm{L}$.

FABACEAE - Zornia piurensis Mohlenbrock

GENTIANACEAE - Coutoubea ramosa Aubl.

GENTIANACEAE - Gentianella bicolor (Wedd.) Fabris ex J.S.Pringle

GENTIANACEAE - Gentianella brunneotincta (Gilg) J.S.Pringle

GENTIANACEAE - Gentianella crassicaulis J.S.Pringle

GENTIANACEAE - Gentianella dianthoides (H.B.K.) Fabri

GENTIANACEAE - Gentianella graminea (H.B.K.) Fabris

GERANIACEAE - Erodium cicutarium (L.) L'Herit.

GERANIACEAE - Geranium ayavacense Willd ex H.B.K., Geranium sessiliflorum Cavanilles

GERANIACEAE - Pelargonium odoratissimum (L.) L'Herit.

GERANIACEAE - Pelargonium roseum Willd.

HYPERICACEAE - Hypericum aciculare Kunth.

HYPERICACEAE - Hypericum laricifolium Juss.

HYPERICACEAE - Hypericum silenoides Juss.

IRIDACEAE - Hesperoxiphion niveum (Rav.) Rav.

ISOETACEAE - Isoetes andina Spruce ex Hook.

JUGLANDACEAE - Juglans neotropica Diels

KRAMERIACEAE - Krameria lappacea (Dombey) Burdet \& B.B. Simpson

LAMIACEAE - Clerodendrum philippinum Schauer

LAMIACEAE - Hyptis sidifolia (L'Her.) Briq.

LAMIACEAE - Lavandula angustifolia Miller

LAMIACEAE - Lepechinia meyenii (Walp.) Epling

LAMIACEAE - Marrubium vulgare L.

LAMIACEAE - Melissa officinalis L. 
LAMIACEAE - Minthostachys mollis (Benth.) Griseb.

MALVACEAE - Malva parviflora L.

LAMIACEAE - Ocimum basilicum L.

MALVACEAE - Malva sylvestris L.

LAMIACEAE - Origanum majorana L.

MALVACEAE - Theobroma cacao L.

LAMIACEAE - Origanum vulgare L.

LAMIACEAE - Rosmarinus officinalis $\mathrm{L}$.

MALVACEAE - Tilia platyphyllos Scop.

MALVACEAE - Urena lobata L.

LAMIACEAE - Salvia ayavacensis Kunth

LAMIACEAE - Salvia cuspidata R. \& P. 169

LAMIACEAE - Salvia discolor H.B.K. 169

LAMIACEAE - Salvia macrophylla Benth. 169

LAMIACEAE - Salvia officinalis L. 169

LAMIACEAE - Salvia officinalis subsp. lavandulifolia (Vahl) Gams

LAMIACEAE - Salvia sagitatta Ruiz \& Pav.

LAMIACEAE - Salvia tubiflora R. \& P.

LAMIACEAE - Satureja pulchella (Kunth) Briquet

MELASTOMATACEAE - Brachyotum tyrianthinum J.F Macbr.

MELASTOMATACEAE - Miconia salicifolia (Bonpl. Ex Naud.) Naud.

MELASTOMATACEAE - Tibouchina laxa (Des.) Cog.

MENISPERMACEAE - Abuta grandifolia (Mart.) Sandwith.

MONIMIACEAE - Peumus boldus Molina

MORACEAE - Brosimum rubescens (Aublet) Huber

MORACEAE - Ficus carica L.

MORACEAE - Ficus spp.

MORACEAE - Morus alba L.

MUNTINGIACEAE - Muntingia calabura L.

MUSACEAE - Musa $x$ paradisiaca L.

MYRICACEAE - Myrica pubescens H. \& B. ex Wild.

LAMIACEAE - Stachys lanata Jacq.

LAMIACEAE - Thymus vulgaris $\mathrm{L}$.

LAURACEAE - Aiouea dubia (Kunth) Mez

LAURACEAE - Cinnamonum verum J. Presl.

LAURACEAE - Nectandra reticulata (Ruiz \& Pav.) Mez.

MYRISTICACEAE - Myristica fragrans $\mathrm{L}$

MYRTACEAE - Eucalyptus citriodora Hooker

MYRTACEAE - Eucalyptus globulus Labill.

MYRTACEAE - Eugenia punicifolia (Kunth) DC.

MYRTACEAE - Myrcianthes discolor (Kunth) Vaughn; Myrcianthes fragrans (Sw) McVaugh

MYRTACEAE - Psidium guajava $\mathrm{L}$

MYRTACEAE - Syzygium aromaticum (L.) Merr. \& Perry

MYRTACEAE - Syzygium jambos (L.) Alston

NYCTAGINACEAE - Boerhavia coccinea Mill.

NYCTAGINACEAE - Mirabilis jalapa L.

OLACACEAE - Heisteria acuminata (Humb. \& Bonpl.) Engler

OLEACEAE - Olea europaea L.

ONAGRACEAE - Epilobium denticulatum Ruiz \& Pav.

ONAGRACEAE - Fuchsia ayavacensis H.B.K.

ONAGRACEAE - Oenothera rosea Aiton

ORCHIDACEAE - Aa paleacea (Kunth) Rchb.f.

ORCHIDACEAE - Epidendrum calanthum Rchb. $f$

ORCHIDACEAE - Lycaste gigantea Lindl.

ORCHIDACEAE - Pachyphyllum crystallinum Lindley

ORCHIDACEAE - Stelis flexuosa Lindley

ORCHIDACEAE - Stelis sp.

OROBANCHACEAE - Escobedia grandiffora (L.f.) Kuntze

OXALIDACEAE - Oxalis bulbigera Knuth.

YTHRACEAE - Cuphea strigulosa H.B.K.

MALPIGHIACEAE - Banisteriopsis caapi (Spruce ex Grieseb.) Morton 
PASSIFLORACEAE - Malesherbia ardens J.F. Macbr. 195

PASSIFLORACEAE - Passiflora caerulea L. 195

$\begin{array}{ll}\text { PASSIFLORACEAE - Passiflora edulis Sims. } & 195\end{array}$

PASSIFLORACEAE - Passiflora ligularis Juss. 195

PASSIFLORACEAE - Passiflora punctata L. 195

PASSIFLORACEAE - Passiflora quadrangularis L 197

PASSIFLORACEAE - Passiflora sp. 197

PHYTOLACCACEAE - Gallesia integrifolia (Spreng.) Harms. 197

PHYTOLACCACEAE - Petiveria alliacea L.

PHYTOLACCACEAE - Phytolacca bogotensis H.B.K.

PINACEAE - Pinus patula Schldl. \& Cham., Pinus radiata D. Don. 197

PIPERACEAE - Peperomia fraseri C. DC.

PIPERACEAE - Peperomia galioides H.B.K.

PIPERACEAE - Peperomia hartwegiana Miq. $\quad 199$

PIPERACEAE - Peperomia inaequalifolia R. \& P. 199

PIPERACEAE - Peperomia quadrifolia Trel. 199

PIPERACEAE - Piper aduncum L. 199

PIPERACEAE - Piper aequale Vahl. 201

PIPERACEAE - Piper nigrum L. 201

PLANTAGINACEAE - Galvesia fruticosa J. Gmelin 201

PLANTAGINACEAE - Plantago linearis Kunth 201

PLANTAGINACEAE - Plantago major L. 201

PLANTAGINACEAE - Plantago sericea Ruiz \& Pav. var. sericea 201

PLANTAGINACEAE - Plantago sericea R. \& P. var. lanuginosa Grieseb. 203

PLANTAGINACEAE - Plantago sericea subsp. sericans (Pilg.) Rahn 203

POACEAE - Arundo donax L. 203

POACEAE - Cenchrus echinatus L.

POACEAE - Cymbopogon citratus (DC.) Stapf.

POACEAE - Cynodon dactylon (L.) Persoon

POACEAE - Digitaria ciliaris (Retz.) Koehler.

POACEAE - Gynerium sagittatum (Aublet.) P. Beauvois

POACEAE - Hordeum vulgare $\mathrm{L}$.

POACEAE - Oryza sativa L.

POACEAE - Saccharum officinarum L.

POACEAE - Triticum aestivum $\mathrm{L}$.

POACEAE - Zea mays L.

POLEMONIACEAE - Cantua buxifolia Jus. ex Lam.

POLEMONIACEAE - Cantua quercifolia Jus.

POLYGALACEAE - Monnina pterocarpa Ruiz \& Pav.

POLYGALACEAE - Polygala paniculata L.

POLYGONACEAE - Mueblenbeckia tamnifolia (Kunth) Meisner

POLYGONACEAE - Polygonum hydropiperoides Michaux
POLYPODIACEAE - Grammitis moniliformis (Lag. ex Sw.) Proctor

POLYPODIACEAE - Polypodium crassifolium L.

PORTULACACEAE - Portulaca oleracea L. subsp. tuberculata Danin \& H.G. Baker

PORTULACACEAE - Portulaca pilosa L.

PROTEACEAE - Oreocallis grandiflora (Lam.) R.Br.

PTERIDACEAE - Adiantum concinnum Humb. \& Bonpl. ex Willd.

PTERIDACEAE - Cheilanthes myriophylla Desv.

PTERIDACEAE - Jamesonia goudotii (Hieron) C. Chr.

PTERIDACEAE - Jamesonia rotundifolia Fée

PTERIDACEAE - Pellaea ternifolia (Cav.) Link.

RANUNCULACEAE - Laccopetalum giganteum (Wedd.) Ulbrich

RANUNCULACEAE - Thalictrum decipiens B. Boivin

RHAMNACEAE - Scutia spicata (H. \& B. ex Schultes) Weberb. var. spicata

ROSACEAE - Cydonia oblonga Miller

ROSACEAE - Fragaria vesca $\mathrm{L}$.

ROSACEAE - Geum peruvianum Focke

ROSACEAE - Lachemilla nivalis Kunth

ROSACEAE - Polylepis racemosa $\mathrm{R}$. \& P.

ROSACEAE - Prunus serotina Ehrh.

ROSACEAE - Prunus serotina Ehrhart subsp. capuli (Cav.) McVough

ROSACEAE - Rosa centifolia L.

ROSACEAE - Rubus robustus C. Presl.

ROSACEAE - Sanguisorba minor Scop.

RUBIACEAE - Arcytophyllum filiforme (Ruiz \& Pav.) Standl.

RUBIACEAE - Cinchona officinalis L.

RUBIACEAE - Coffea arabica L

RUBIACEAE - Gardenia augusta (L.) Merr.

RUBIACEAE - Uncaria guianensis (Aublet) Gmelin

RUTACEAE - Citrus aurantium (Christmann) Swingle

RUTACEAE - Citrus grandis (L.) Osbeck

RUTACEAE - Citrus limetta Riso

RUTACEAE - Citrus reticulata Blanco

RUTACEAE - Citrus limon (L.) Burm. f.

RUTACEAE - Citrus sinensis (L.) Osbeck

RUTACEAE - Ruta graveolens $\mathrm{L}$.

SALICACEAE - Populus deltoides Bartram

SALICACEAE - Salix chilensis Molina

SAPINDACEAE - Serjania brachyptera Radlk.

SAPOTACEAE - Pouteria lucuma (R. \& P.) Kuntze.

SCHISANDRACEAE - Illicium verum Hook. f.

SCROPHULARIACEAE - Buddleja coriacea Remy

SCROPHULARIACEAE - Capraria peruviana Bentham 
SMILACACEAE - Smilax febrifuga Kunth

ZINGIBERACEAE

SMILACACEAE - Smilax kunthii Killip \& Morton

ZYGOPHYLLACEAE - Tribulus terrestris L.

SOLANACEAE - Brugmansia arborea (L.) Lagerheim

NO IDENTIFICADA

SOLANACEAE - Brugmansia candida Persoon

NO IDENTIFICADA

SOLANACEAE - Brugmansia sanguinea (R. \& P.) D. Don. 225

SOLANACEAE - Capsicum annuum L

ALGAE - Giartina chamissoi, Giartina glomerata, Giartina paitensis

LICHENES - Siphula sp.

MATERIAL - NO PLANTAS

SOLANACEAE - Cestrum auriculatum L'Herit

SOLANACEAE - Cestrum nocturnum L.

SOLANACEAE - Cestrum strigilatum R. \& P., Cestrum undulatum R. \& P.

OLANACEAE - Datura inoxia Miller

SOLANACEAE - Jaltomata sp.

SOLANACEAE - Juanulloa ochracea Cuatrecasas

SOLANACEAE - Lycopersicon esculentum Mill.

SOLANACEAE - Lycopersicon hirsutum Dunal

SOLANACEAE - Lycopersicum peruvianum $\mathrm{L}$.

SOLANACEAE - Nicotiana tabacum L.

SOLANACEAE - Solanum americanum Mill.

SOLANACEAE - Solanum mammosum L.

SOLANACEAE - Solanum melongena $\mathrm{L}$.

SOLANACEAE - Solanum tuberosum L.

SOLANACEAE - Solanum sp.

SOLANACEAE - Solanum sp.

THEACEAE - Camellia sinensis (L.) Kuntze

THELYPTERIDACEAE - Thelypteris scalaris (Christ.) Alton

THYMELEACEAE - Daphnopsis weberbaueri Domke

TROPAEOLACEAE - Tropaeolum minus L.

TYPHACEAE - Typha angustifolia $\mathrm{L}$.

URTICACEAE - Pilea microphylla (L.) Lieberman

URTICACEAE - Urtica magellanica A. Jussieu ex Poiret

VERBENACEAE

URTICACEAE - Urtica urens $\mathrm{L}$

VERBENACEAE - Aloysia triphylla (L'Her.) Britt.

VERBENACEAE - Lantana scabiosaeflora Kunth

VERBENACEAE - Lippia alba (Miller) N.E. Brown

VERBENACEAE - Verbena litoralis Kunth

VERBENACEAE

VIOLACEAE - Viola tricolor L.

VITACEAE - Vitis vinifera L

XANTHORROEACEAE - Aloe vera (L.) Burm $\mathrm{f}$.

XIMENIACEAE - Ximenia americana $\mathrm{L}$. 


\section{Indice de Especies}

Aa paleacea (Kunth) Rchb.f.

Abuta grandifolia (Mart.) Sandwith.

Acacia macracantha Humb. \& Bonpl. ex Willd.

191

Acalypha villosa Jacq.

Acanthoxanthium spinosum (L.) Fourreau

Achillea millefolium $\mathrm{L}$.

Achyrocline alata (Kunth) DC.

Acmella ciliata (Kunth) Cass.

Adiantum concinnum Humb. \& Bonpl. ex Willd.

Aiouea dubia (Kunth) Mez

Alcea rosea (L.) Cavanilles

Allium odorum $\mathrm{L}$

Allium sativum $\mathrm{L}$.

Alnus acuminata Kunth

Aloe vera (L.) Burm f.

Aloysia triphylla (L'Her.) Britt.

Alternanthera brasiliana (L.) Kuntze

Alternanthera halimifolia (Lam.) Standley \& Pittier

Alternanthera porrigens (Jacquin) Kuntze

Alternanthera villosa Kunth

Amaranthus caudatus $\mathrm{L}$

Amaranthus hybridus $\mathrm{L}$

Ambrosia arborescens Mill.

Ambrosia peruviana Willd.

Ammi visnaga (L.) Lam.

Anacardium occidentale $\mathrm{L}$.

Ananas comosus (L.) Merril

Annona muricata L.

Aphelandra cirsioides Lindau

Apium graveolens $\mathrm{L}$.

Araucaria heterophylla (Salisb.) Franco

Arctium lappa L.

Arcytophyllum filiforme (Ruiz \& Pav.) Standl.

Argemone mexicana $\mathrm{L}$.

Aristeguietia gayana (Wedd.) R.M. King \& H. Rob

Aristolochia ruiziana (Klotsch) Duch.

Arnica montana $\mathrm{L}$.

Arracacia xanthorrbiza Bancroft

Artemisia absinthium L.
Arundo donax L.

Ayapand amygdalina (Lam.) R.M. King \& H. Rob.

Baccharis caespitosa (Ruiz \& Pav.) Pers

Baccharis chilco Kunth

Baccharis genistelloides (Lam.) Pers.

Baccharis latifolia (Ruiz \& Pav.) Pers.

Baccharis pedunculata (Mill.) Cabr.

Baccharis salicifolia (R. \& P.) Pers.

Baccharis tricuneata (L.f.) Pers.

Bactris gasipaes Kunth

Banisteriopsis caapi (Spruce ex Grieseb.) Morton

Bejaria aestuans Mutis ex L.

Berberis buceronis J.F. Macbride

Bidens pilosa $\mathrm{L}$

Bixa orellana $\mathrm{L}$

Boerhavia coccinea Mill.

Bomarea angulata Benth

Bomarea dulcis (Hook.) Beauv.

Borago officinalis $\mathrm{L}$.

Brachyotum tyrianthinum J.F. Macbr.

Brassica oleracea $\mathrm{L}$.

Brassica rapa $\mathrm{L}$.

Brosimum rubescens (Aublet) Huber

Brugmansia arborea (L.) Lagerheim

Brugmansia candida Persoon

Brugmansia sanguinea (R. \& P.) D. Don.

Buddleja coriacea Remy

Bursera graveolens (Kunth) Triana \& Planchon

Caesalpinia paipai Ruiz \& Pav.

Caesalpinia spinosa (Molina) Kuntze

Cajanus cajan (L.) Millsp.

Calceolaria rugulosa Edwin

Camellia sinensis (L.) Kuntze

Cantua buxifolia Jus. ex Lam.

Cantua quercifolia Jus.

Capparis crotonoides (Kunth) Iltis \& Cornejo

Capparis scabrida Kunth

Capraria peruviana Bentham

Capsella bursa-pastoris (L.) Medic.

Capsicum annuит $\mathrm{L}$.

Capsicum rhomboideum (Dunal) Kunze.

Carica papaya $\mathrm{L}$. 
Cenchrus echinatus L.

Cucumis dipsaceus Ehrenb.

Centropogon argutus $\mathrm{E}$. Wimmer

Cucumis sativus $\mathrm{L}$.

Centropogon cornutus (L.) Druce

Cucurbita maxima Duchesne

Cucurbita moschata Duch.

Centropogon rufus Wimm

Cuphea strigulosa H.B.K.

Cestrum auriculatum L'Heri

Cupressus lusitanica Miller

Cestrum nocturnum $\mathrm{L}$.

Cestrum strigilatum R. \& P., Cestrum undulatum R. \& P.

Chamaesyce hypericifolia (L.) Millspaugh 143

Cheilanthes myriophylla Desv.

Chenopodium ambrosioides $\mathrm{L}$.

Cuscuta foetida H.B.K.

Cyclanthera pedata (L.) Schrad.

Cydista aequinoctialis (L.) Miers

Cydonia oblonga Miller

Cymbopogon citratus (DC.) Stapf.

Cynara cardunculus $\mathrm{L}$.

Cynodon dactylon (L.) Persoon

Chenopodium quinoa Willd. (wild form)

Chuquiragua spinosa Lessing ssp. huamanpinta C. Ezcurra

Cyperus articulatus $\mathrm{L}$.

Daphnopsis weberbaueri Domke

Cicer arietinum $\mathrm{L}$

Cinchona officinalis $\mathrm{L}$.

Cinnamonum verum J. Presl.

Datura inoxia Miller

Daucus montanus Humb. \& Bonpl. ex Spreng.

Desmodium molliculum (H.B.K.) DC.

Desmodium triflorum (L.) DC

Dianthus caryophyllus L.

Dianthus caryophyllus L.

Digitaria ciliaris (Retz.) Koehler.

Dioclea virgata (Rich.) Amsh.

Dioscorea tambillensis Kunth

Dioscorea trifida L.f.

Diplostephium gynoxyoides Cuatrec.

Diplostephium sagasteguii Cuatrec.

Dipsacus jallonum L.

Dracaena fragrans Ker Gawl.

Echeveria peruviana Meyen

Echinopsis pachanoi (Britton \& Rose) Friedrich \& G. Rowley

Ephedra americana Humb. \& Bonpl. ex Willd.

Epidendrum calanthum Rchb. f.

Epilobium denticulatum Ruiz \& Pav.

Equisetum bogotense H.B.K. (Kunth)

Equisetum giganteum (Wedd.) Ulbrich

Erodium cicutarium (L.) L'Herit.

Erythrina amazonica Krukoff

Erythrina velutina Willdenow

Erythroxylon coca Lam.

Escallonia pendula (R. \& P.) Pers. 
Escobedia grandiflora (L.f.) Kuntze

Eucalyptus citriodora Hooke

Eucalyptus globulus Labill.

Eugenia punicifolia (Kunth) DC.

Eustephia coccinea Cav.

Ferreyranthus verbascifolius (Kunth) H. Rob. \& Brettell

Ficus carica L.

Ficus spp

Flaveria bidentis (L.) Kuntze

Foeniculum vulgare P. Miller

Fragaria vesca $\mathrm{L}$.

Fuchsia ayavacensis H.B.K.

Gallesia integrifolia (Spreng.) Harms.

Galvesia fruticosa J. Gmelin

Gamochaeta americana (Mill.) Wedd.

Gardenia augusta (L.) Merr.

Gaultheria erecta Vent.

Gaultheria reticulata Kunth

Gentianella bicolor (Wedd.) Fabris ex J.S.Pringle

Gentianella brunneotincta (Gilg) J.S.Pringle

Gentianella crassicaulis J.S.Pringle

Gentianella dianthoides (H.B.K.) Fabris

Gentianella graminea (H.B.K.) Fabris

Geranium ayavacense Willd ex H.B.K., Geranium sessiliflorum Cavanilles

\section{Geum peruvianum Focke}

Giartina chamissoi, Giartina glomerata, Giartina paitensis

Gossypium barbadense L.

Grammitis moniliformis (Lag. ex Sw.) Proctor

Gustavia augusta L.

Gynerium sagittatum (Aublet.) P. Beauvois

Hedyosmum racemosum (R. \& P.) G. Don.

Heisteria acuminata (Humb. \& Bonpl.) Engler

Heliotropium curassavicum $\mathrm{L}$.

Hesperoxiphion niveum (Rav.) Rav.

Hordeum vulgare $\mathrm{L}$.

Huperzia columnaris B. Øllg.

Huperzia crassa (H. \& B. ex Willd.) Rothm.

Huperzia hohenackeri (Herter) Holub

Huperzia kuesteri (Nessel) B. Øllg.

Huperzia reflexa (Lam.) Trevis.

Huperzia sellifolia B. Olls.

Huperzia tetragona (Hook. \& Grev.) Trevis.
Hura crepitans $\mathrm{L}$.

Hydrocotyle bonariensis Commerson ex Lam.

Hydrocotyle globiflora R. \& P

Hypericum aciculare Kunth.

Hypericum laricifolium Juss.

Hypericum silenoides Juss.

Hyptis sidifolia (L’Her.) Briq.

Ilex guayusa Loes

Illicium verum Hook. f.

Indigofera suffruticosa Miller

Inga edulis C. Martius, Inga feuilleei DC

Ipomoea batatas (L.) Lamarck

Ipomoea pauciflora M. Martens \& Galeotti

Iresine diffusa Humb. \& Bonpl. ex Willd.

Iresine herbstii Lindley

Isoetes andina Spruce ex Hook.

Jacaranda acutifolia Humb. \& Bonpl.

Jacartia digitata (Poepp. \& Endl.) Solms-Lang.

Jaltomata sp.

Jamesonia goudotii (Hieron) C. Chr.

Jamesonia rotundifolia Fée

Jatropa curcas L., Jatropa gossypiifolia L., Jatropa weberbaueri Pax \& Hoffman

Juanulloa ochracea Cuatrecasas

Juglans neotropica Diels

Krameria lappacea (Dombey) Burdet \& B.B. Simpson

Kyllingia pumila Michx.

Lablab purpureus (L.) Sweet

Laccopetalum giganteum (Wedd.) Ulbrich

Lachemilla nivalis Kunth

Lactuca sativa $\mathrm{L}$.

Lantana scabiosaeflora Kunth

Lathyrus odoratus $\mathrm{L}$.

Lavandula angustifolia Miller

Lemna minuta Kunth

Lens culinaris Medikus

Lepechinia meyenii (Walp.) Epling

Lepidium virginicum $\mathrm{L}$.

Leucaena leucocephala (Lam.) De Wit

Linum sativum L., Linum usitatissimum $\mathrm{L}$

Lippia alba (Miller) N.E. Brown

Lobelia decurrens Cavaniles

Lonicera japonica Thunberg 
Loricaria ferruginea (Ruiz \& Pav.) Wedd.

Loricaria thyrsoidea (Cuatrec.) Dillon \& Sagástegui

Loxopterygium huasango Spruce ex Engl.

Lupinus mutabilis Sweet

Lycaste gigantea Lindl.

Lycopersicon esculentum Mill.

Lycopersicon hirsutum Duna

Lycopersicum peruvianum $\mathrm{L}$.

Lycopodium clavatum $\mathrm{L}$.

Lycopodium jussiaei Desv. ex Poir

Lycopodium thyoides H. \& B. ex Willd.

Malesherbia ardens J.F. Macbr.

Malva parviflora $\mathrm{L}$.

Malva sylvestris $\mathrm{L}$.

Mammea americana $\mathrm{L}$

Mandevilla antennacea (A.DC.) Schum.

Mandevilla trianae Woodson

Mangifera indica $\mathrm{L}$.

Manihot esculenta Crantz

Marrubium vulgare $\mathrm{L}$.

MATERIALES NO PLANTAS

Matricaria chamomilla $\mathrm{L}$

Matricaria recutita $\mathrm{L}$.

Mauria heterophylla Kunth.

Medicago sativa $\mathrm{L}$

Melilotus alba Medikus

Melissa officinalis $\mathrm{L}$

Mentha piperita L.

Mentha spicata $\mathrm{L}$.

Miconia salicifolia (Bonpl. Ex Naud.) Naud.

Mikania leiostachya Benth.

Mimosa albida H. \& B.

Mimosa nothacacia Barneby

Minthostachys mollis (Benth.) Griseb.

Mirabilis jalapa $\mathrm{L}$.

Monactis flaverioides Kunth

Monnina pterocarpa Ruiz \& Pav.

Morus alba L.

Mueblenbeckia tamnifolia (Kunth) Meisner

Munnozia lyrata (A. Gray.) H. Rob. \& Brettel

Muntingia calabura L.

Musa $x$ paradisiaca $\mathrm{L}$.
Myrcianthes discolor (Kunth) Vaughn; Myrcianthes fragrans (Sw) McVaugh

Myrica pubescens H. \& B. ex Wild.

Myristica fragrans $\mathrm{L}$.

Myroxylon balsamum (L.) Harms.

Nectandra reticulata (Ruiz \& Pav.) Mez.

Nectandra sp.

Nerium oleander L.

Nicotiana tabacum $\mathrm{L}$.

Niphogeton dissecta (Benth.) J.F. Macbr.

No Identificado

No Identificado

Ocimum basilicum L.

Ocotea floribunda (Sw.) Mez

Oenothera rosea Aiton

Olea europaea L.

Onoseris odorata (D. Don) Hooker \& Arnott

Opuntia ficus-indica (L.) Miller

Oreobolos obtusangulus T. Koyama

Oreocallis grandiflora (Lam.) R.Br.

Oreopanax eriocephalus Harms

Origanum majorana L.

Origanum vulgare $\mathrm{L}$.

Oritrophium peruvianum (Lam.) Cuatrec.

Ormosia sp.

Oryza sativa L.

Otholobium mexicanum (L.f.) Grimes

Oxalis bulbigera Knuth.

Oxalis tuberosa Molina

Pachyphyllum crystallinum Lindley

Paepalanthus ensifolius (Kunth) Kunth

Paranephelius uniflorus Poepp. \& Endl.

Passiftora caerulea $\mathrm{L}$.

Passiflora edulis Sims.

Passiflora ligularis Juss.

Passiflora punctata L.

Passiflora quadrangularis $\mathrm{L}$

Passiflora sp.

Pelargonium odoratissimum (L.) L'Herit.

Pelargonium roseum Willd.

Pellaea ternifolia (Cav.) Link.

Peperomia fraseri C. DC.

Peperomia galioides H.B.K. 
Peperomia quadrifolia Trel.

Raphanus sativus $\mathrm{L}$.

Perezia multiflora (Humb. \& Bonpl.) Lessing

Ricinus communis $\mathrm{L}$.

Perezia pungens (Kunth) Cass.

Rorippa nasturtium-aquaticum (L.) Hayek

Rosa centifolia L.

Rosmarinus officinalis $\mathrm{L}$.

Rubus robustus $\mathrm{C}$. Presl.

Petiveria alliacea $\mathrm{L}$.

Petroselinum crispum (Miller) A.W. Hill

Rumex crispus $\mathrm{L}$.

Ruta graveolens $\mathrm{L}$.

Phyllanthus niruri L., Phyllanthus stipulatus (Raf.) Webster, Phyllanthus urinaria L.

Saccharum officinarum $\mathrm{L}$.

Salacia multiflora (Lam.) DC.

Salix chilensis Molina

Salvia ayavacensis Kunth

Salvia cuspidata R. \& P.

Salvia discolor H.B.K.

Salvia macrophylla Benth.

Salvia officinalis $\mathrm{L}$.

Salvia officinalis subsp. lavandulifolia (Vahl) Gams

Salvia sagitatta Ruiz \& Pav.

Salvia tubiflora R. \& P.

Sambucus peruviana Kunth

Sanguisorba minor Scop.

Sarcostemma clausum (Jacquin) Schultes

Satureja pulchella (Kunth) Briquet

Scabiosa atropurpurea $\mathrm{L}$

Schinus molle L.

Schkuhria pinnata (Lam.) Kuntze

Scirpus californicus (C.A. Meyer) Steudel subsp. tatora (Kunth) T. Koyama

Scutellatia scutellarioides (Kunth) R. Harley

Scutia spicata (H. \& B. ex Schultes) Weberb. var. spicata

Sechium edule Swartz.

Senecio canescens (H.B.K.) Cuatrecasas

Senecio comosus Sch.-Bip.

Senecio genisianus Cuatr.

Senecio hypsiandinus Cuatr.

Senecio otuscensis Cabrera

Senecio tephrosioides Turcz

Senna alexandrina Mill.

Senna bicapsularis (L.) Roxburgh

Senna occidentalis (L.) Link.

Serjania brachyptera Radlk.

Sicana odorifera (Vell.) Naud.

Pouteria lucuma (R \& P) Kuntze.

Prunus serotina Ehrh.

Pseudorynoxys cordifolia (Cass.) Cabrera

Psidium guajava $\mathrm{L}$.

Punica granatum $\mathrm{L}$. 
Siparuna muricata (R. \& P.) A. DC.

223

Siparuna tomentosa (Ruiz \& Pav) A. DC.

Siphocampylus angustiflorus Schlechtendal

Siphocampylus cutervensis A. Zahlbr.

Siphocampylus tupaeiformis Zahlbr.

Siphula sp.

Smallanthus sonchifolius (Poepp. \& Endl) H. Rob.

Smilax febrifuga Kunth

Smilax kunthii Killip \& Morton

Solanum americanum Mill.

Solanum mammosum $\mathrm{L}$.

Solanum melongena $\mathrm{L}$.

Solanum sp.

Solanum sp.

Solanum tuberosum $\mathrm{L}$

Sonchus oleraceus L.

Spartium junceum L.

Spilanthes leiocarpa DC.

Stachys lanata Jacq.

Stelis flexuosa Lindley

Stelis sp.

Stellaria media (L.) Criollo

Sycos baderoa $\mathrm{H}$. et $\mathrm{A}$.

Syzygium aromaticum (L.) Merr. \& Perry

Syzygium jambos (L.) Alston

Tagetes elliptica Sm.

Tagetes erecta $\mathrm{L}$

Tagetes filifolia Lag.

Tamarindus indica L.

Taraxacum offcinale Wiggers

Tessaria integrifolia R. \& P.

Tetragonia crystallina L'Héritier

Thalictrum decipiens $\mathrm{B}$. Boivin

Thelypteris scalaris (Christ.) Alton

Theobroma cacao $\mathrm{L}$

Thevetia peruviana (Pers.) Schum.

Thymus vulgaris $\mathrm{L}$.

Tibouchina laxa (Des.) Cog.

Tilia platyphyllos Scop.

Tillandsia cacticola L.B. Sm.

Tillandsia multiflora Bentham var. decipiens (Andre) Sm.

Tiquilia paronychioides (Phil.) Rich.
Tribulus terrestris $\mathrm{L}$.

Trifolium repens

Tristerix longebracteatus (Desr.) Barlow \& Wiens

Triticum aestivum $\mathrm{L}$.

Trixis cacalioides Kunth

Tropaeolum minus $\mathrm{L}$.

Tynanthus polyanthus (Bureau) Sandwith

Typha angustifolia $\mathrm{L}$.

Uncaria guianensis (Aublet) Gmelin

Urena lobata $\mathrm{L}$.

Urtica magellanica A. Jussieu ex Poiret

Urtica urens $\mathrm{L}$.

Valeriana microphylla Kunth

Valeriana niphobia Briquet

Valeriana plantaginea Kunth

Valeriana rigida Ruiz. \& Pav.

Vallea stipularis L.f.

Vallesia glabra (Cav.) Link.

Verbena litoralis Kunth

VERBENACEAE

Viola tricolor $\mathrm{L}$.

Vitis vinifera $\mathrm{L}$.

Weddelia latifolia DC.

Werneria nubigena Kunth

Werneria pygmaea Gillies ex Hook. \& Arn

Werneria villosa A. Gray

Ximenia americana $\mathrm{L}$.

Xyris subulata Ruiz \& Pav.

Zea mays $\mathrm{L}$.

Zingiber officinale Roscoe

ZINGIBERACEAE

Zornia piurensis Mohlenbrock 


\section{Indice de Nombres Comunes}

Abrojo, Cadillo: ZYGOPHYLLACEAE - Tribulus terrestris L.

Abuta (Macho and Hembra): MENISPERMACEAE - Abuta grandifolia (Mart.) Sandwith.

Acelga, Lengua de Vaca, Hojas de Mala Hierba: POLYGONACEAE - Rumex crispus L.

Acharachango, Charachango, Ashango: CHRYSOBALANACEAE - Couepia guianensis Aubl.

Achicoria, Chicoria: ASTERACEAE - Picrosia longifolia D. Don

Achiote, Hoja de Achiote: BIXACEAE - Bixa orellana L.

Agujilla Blanca, Auguilla.: GERANIACEAE - Erodium cicutarium (L.) L'Herit.

Ajenco: ASTERACEAE - Artemisia absinthium L.

Aji Colorado: SOLANACEAE - Capsicum rhomboideum (Dunal) Kunze.

Aji Panca: SOLANACEAE - Capsicum annuum L.

Ajo (Garlic): AMARYLLIDACEAE - Allium sativum L

225
81

DACEAE - Cordia alliodora (R. \& P.) Oken $\quad 117$

Alacrán, Alacrancillo: BORAGINACEAE - Heliotropium curassavicum L.

Alamo (Poplar): SALICACEAE - Populus deltoides Bartram 221

Albaca, Albaca Mixtura, Albaca Negra, Albaca Morada (Basil): LAMIACEAE -Ocimum basilicum L. 167

Alcachofa (Artichoke): ASTERACEAE - Cynara cardunculus L.

Alcanfor (Camphor), Eucalipto Serrano, Eucalipto (Eucalyptus): MYRTACEAE-Eucalyptus globulus Labill.187

Alcaparrilla, Alpacaquilla: FABACEAE - Senna bicapsularis (L.) Roxburgh 155

Alfalfa: FABACEAE - Medicago sativa $\mathrm{L}$.

Alfalfilla: FABACEAE - Melilotus alba Medikus

Algarrobo (Carob): FABACEAE - Prosopis pallida (H. \& B. ex Willd.) H.B.K.

Algodón Pardo, (Brown Cotton): MALVACEAE - Gossypium barbadense L.

$\begin{array}{ll}\text { Algodon Pardo, (Brown Cotton): MALVACEAE - Gossypium barbadense L. } & 181 \\ \text { Aliso Blanco (Liso), Aliso Colorado (Arrugado): BETULACEAE - Alnus acuminata Kunth } & 115\end{array}$

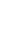

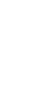

Altamisa, Marco, Artamisa, Manzanilla del Muerto, Marcos, Alta Misa, Ajenco, Altamis, Llatama Negra

Malera, Llatama Roja Malera: ASTERACEAE - Ambrosia peruviana Willd.

Alucema, Labanda: LAMIACEAE - Lavandula angustifolia Miller 165

Amaro Amaro: ASTERACEAE - Chuquiragua weberbaueri Tovar

$\begin{array}{ll}\text { Ambarina, Ambarina Negra, Flor de Ambarina, Ambarindas: CAPRIFOLIACEAE } & 129 \\ \text { - Scabiosa atropurpurea L. } & 93\end{array}$

Ambrosia: ASTERACEAE - Ambrosia arborescens Mill.

Ambulluco del Muerto: SOLANACEAE - Lycopersicon hirsutum Dunal 229

Amor Seco, Cadillo, Tres Esquinas, Carqueja: ASTERACEAE - Bidens pilosa L. 99

Anga Macha: GENTIANACEAE - Gentianella brunneotincta (Gilg) J.S.Pringle 159

Anis Criollo, Anís: APIACEAE - Pimpinella anisum L.

Anis Estrella: SCHISANDRACEAE - Illicium verum Hook. f. 221

Anís, Anís Serrano: ASTERACEAE - Tagetes filifolia Lag. 111

Anti Ajo: UNIDENTIFIED 239

Añasquero Chico: ASTERACEAE - Trixis cacalioides Kunth 113

Añasquero, Hojas de Añasquero, Añasquero (Grande): SIPARUNACEAE - Siparuna muricata (R. \& P.) A. DC. 223

Añil: FABACEAE - Indigofera suffruticosa Miller

Apio Cimarrón, Apio: APIACEAE - Apium graveolens L.

Arabisca, Huaba Bruja: FABACEAE - Leucaena leucocephala (Lam.) De Wit

Arabisca, Yarabisca: BIGNONIACEAE - Jacaranda acutifolia Humb. \& Bonpl.

Arbejas, Arvejas (Pea): FABACEAE - Pisum sativum L.

Arnica: ASTERACEAE - Arnica montana L.

Árnica: ASTERACEAE - Senecio otuscensis Cabrera

Arroz (Rice): POACEAE - Oryza sativa L.

Asma Chilca, Asma Chica: ASTERACEAE - Aristeguietia gajana (Wedd.) R.M. King \& H. Rob.

Ayahuasca, Ayahuasca Verde, Ayahuasca Amarilla: MALPIGHIACEAE - Banisteriopsis caapi (Spruce ex Grieseb.) Morton

Azafrán: OROBANCHACEAE - Escobedia grandiflora (L.f.) Kuntze

Balsa, Totora: CYPERACEAE - Scirpus californicus (C.A. Meyer) Steudel subsp. tatora (Kunth) T.

Koyama

Barbón: MELASTOMATACEAE - Tibouchina laxa (Des.) Cog.

Bastón de San José, Varita de San José, Pura Pura: CYPERACEAE - Cyperus articulatus L.

Bejuco Amarillo: BIGNONIACEAE - Cydista aequinoctialis (L.) Miers

Bejuco Colambo Negro: APOCYNACEAE - Mandevilla antennacea (A.DC.) Schum.

Bejuco de Contra-Aire: ARISTOLOCHIACEAE - Aristolochia ruiziana (Klotsch) Duch.

Bejuco de Montaña: CELASTRACEAE - Salacia multiflora (Lam.) DC.

Bejuco, Bejuco Negro (Grande), Bejuco Negro (Chico): APOCYNACEAE - Mandevilla trianae

Woodson

Berenjena (Eggplant): SOLANACEAE - Solanum melongena L.

Berros (Watercress): BRASSICACEAE - Rorippa nasturtium-aquaticum (L.) Hayek

Boldo: MONIMIACEAE - Peumus boldus Molina

Bolsita del Pastor, Hierba del Pastor, Bolsa de Pastor (Sheppard's purse): BRASSICACEAE - Capsella bursapastoris (L.) Medic.

Borraja (Borage): BORAGINACEAE - Borago officinalis L.

Botón de Oro, Trencilla Amarilla, Hierba del Oso, Bonito de Oro, Bastonn del Inca: PTE

Botón de Oro: CAPRIFOLIACEAE - Valeriana niphobia Briquet

Brochamelia: LAMIACEAE - Clerodendrum philippinum Schauer

Buenas Horas: MALVACEAE - Urena lobata L.

Buenas Tardes: NYCTAGINACEAE - Mirabilis jalapa $\mathrm{L}$.

Cacao: MALVACEAE - Theobroma cacao L.

Cachujillo: ALSTROEMERIACEAE - Bomarea angulata Benth.

Cadillo, Abrojo: POACEAE - Cenchrus echinatus L.

ERICACEAE - Bejaria aestuans Mutis ex L.

Café (Coffee): RUBIACEAE - Coffea arabica L

Caihua Chilena, Mochera, Caihua: CUCURBITACEAE - Sechium edule Swartz.

Caihua: CUCURBITACEAE - Cyclanthera pedata (L.) Schrad.

Camote (Sweet potato): CONVOLVULACEAE - Ipomoea batatas (L.) Lamarck

Canchalagua, Canchalagua Chica: ASTERACEAE - Schkuhria pinnata (Lam.) Kuntze

Canchalagua: POLYGALACEAE - Polygala paniculata L.

Candu: POLEMONIACEAE - Cantua buxifolia Jus. ex Lam.

Canela (Cinammon): LAURACEAE - Cinnamonum verum J. Presl.

Canillahuanga: ASTERACEAE - Munnozia lyrata (A. Gray.) H. Rob. \& Brettell

Caña Brava: POACEAE - Gynerium sagittatum (Aublet.) P. Beauvois

Caña Cańa: ORCHIDACEAE - Lycaste gigantea Lindl.

Caña de Azucar, Caña Dulce (Sugarcane): POACEAE - Saccharum officinarum L.

Caña Fistula: FABACEAE - Cassia fistula L.

Capuli: ROSACEAE - Prunus serotina Ehrhart subsp. capuli (Cav.) McVough

Cardo Santo: CAPRIFOLIACEAE - Dipsacus jallonum L.

Cardo Santo: PAPAVERACEAE - Argemone mexicana L.

Carrizo, Caña Hueca: POACEAE - Arundo donax L.

Cebada (Barley): POACEAE - Hordeum vulgare $\mathrm{L}$.

Cebolla China, Cebolla (Onion): AMARYLLIDACEAE - Allium odorum L.

Cedrón, Pepas de Cedrón: VERBENACEAE - Aloysia triphylla (L'Her.) Britt.

Cerezo Cimarrón: MUNTINGIACEAE - Muntingia calabura L. 
Cerraja, Serraja, Zeraja: ASTERACEAE - Sonchus oleraceus L.

Chamico: SOLANACEAE - Datura inoxia Miller 227 urinaria $\mathrm{L}$.

Chante (Cattail): TYPHACEAE - Typha angustifolia L.

Chilca Chica, Chilca Grande: ASTERACEAE - Baccharis latifolia (Ruiz \& Pav.) Pers.

Chilco Hembra: ASTERACEAE - Ayapana amygdalina (Lam.) R.M. King \& H. Rob.

Chimapampana: ZINGIBERACEAE

Chivato: FABACEAE - Cajanus cajan (L.) Millsp.

Chocho, Tarhui: FABACEAE - Lupinus mutabilis Sweet

Cholitos (Macho and Hembra): THYMELEACEAE - Daphnopsis weberbaueri Domke

Chonta: ARECACEAE - Bactris gasipaes Kunth

Chontilla (Chica): RANUNCULACEAE - Thalictrum decipiens B. Boivin

Chope: LECYTIDACEAE - Gustavia augusta L.

Chuchuhuasi: OLACACEAE - Heisteria acuminata (Humb. \& Bonpl.) Engler

Chuingue: ELAEOCARPACEAE - Vallea stipularis L.f.

Chulgan, Cuchalman: ASTERACEAE - Weddelia latifolia DC.

Chulgán: PASSIFLORACEAE - Passiflora sp.

Chumbiauri, Chumbiauria: POLYGONACEAE - Muehlenbeckia tamnifolia (Kunth) Meisner

Chuño de Papa (Potato): SOLANACEAE - Solanum tuberosum L.

Chuque: ESCALLONIACEAE - Escallonia pendula (R \& P.) Pers.

Pessing ssp. hudmanpinta C. Ezcurra 99

Chusgón: CLUSIACEAE - Clusia minor $\mathrm{L}$.

Címora Negra, Címora Curandera: ORCHIDACEAE - Epidendrum calanthum Rchb. f.

Cinta de Novia, Sauco, Saucotillo, Tilo: ADOXACEAE - Sambucus peruviana Kunth

Cintaura: HYPERICACEAE - Hypericum silenoides Juss.

Cipre, Cipres: CUPRESSACEAE - Cupressus lusitanica Miller

Citrodora: MYRTACEAE - Eucalyptus citriodora Hooker

Clarín: POLYGALACEAE - Monnina pterocarpa Ruiz \& Pav.

Clavel Serrano: CARYOPHYLLACEAE - Dianthus caryophyllus L.

Clavel, Clavelina, Clavel de la Costa: CARYOPHYLLACEAE - Dianthus caryophyllus L.

Clavelillo, Espino de Hoja, Pulmonária: ASTERACEAE - Cronquistianthus lavavandulaefolius (DC.) R.M.

King \& H. Rob.

Clavo de Olor (Clove): MYRTACEAE - Syzygium aromaticum (L.) Merr. \& Perry

Clavo Huasca: BIGNONIACEAE - Tynanthus polyanthus (Bureau) Sandwith

Coca: ERYTHROXYLACEAE - Erythroxylon coca Lam.

Cochaya: CAMPANULACEAE - Siphocampylus tupaeiformis Zahlbr

Cochayuyo, Mococho: ALGAE - Giartina chamissoi, Giartina glomerata, Giartina paitensis

Coco: ARECACEAE - Cocos nucifera L.

Col, Repollo (Cabbage): BRASSICACEAE - Brassica oleracea L.

Cola de Caballo: EQUISETACEAE - Equisetum bogotense H.B.K. (Kunth)

Colores, Timoras, Zangurache: AMARANTHACEAE - Iresine herbstii Lindley

Conchalay Blanco, Conchalalay Blanco: CAMPANULACEAE - Siphocampylus cuterne

Conchalay, Conchalalay: CAMPANULACEAE - Centropogon argutus E. Wimmer

Conchalay, Conchalay Colorado: ONAGRACEAE - Fuchsia ayavacensis H.B.K. 191

Condor Crespo: LYCOPODIACEAE - Huperzia sellifolia B. Ollo.

Condor Lasio, Trensa Hermosa, Condor Crespo, Condor Cimuro, Condor: LYCOPODIACEAE - Huperzic kuesteri (Nessel) B. Øllg.

Condor Mulato, Enredadera: LYCOPODIACEAE - Huperzia reflexa (Lam.) Trevis.
Condor, Condor Amarillo, Condorcillo, Condorcilla, Condor Rojo, Condor Verde: LYCOPODIACEAE - Huperzia crassa (H. \& B. ex Willd.) Rothm.

Congona: PIPERACEAE - Peperomia inaequalifolia R. \& P.

Congonilla: PIPERACEAE - Peperomia galioides H.B.K.

Contolla: CAMPANULACEAE - Lobelia decurrens Cavaniles 125

Contoya, Hierba de Envidia, Contolla: CAMPANULACEAE - Siphocampylus angustiflorus Schlechtendal 125

$\begin{array}{ll}\text { Contra Hechizo: CARICACEAE - Jacartia digitata (Poepp. \& Endl.) Solms-Lang. } & 131 \\ \text { Contra Hierba: URTICACEAE - Pilea microphylla (L.) Lieberman } & 233\end{array}$

Cordón del Muerto, Chanca de Comida, Chancas del Muerto: LAMIACEAE - Marrubium vulgare L. 165

Corpus Way, Hórnamo León: GENTIANACEAE - Gentianella bicolor (Wedd.) Fabris ex J.S.Pringle 159

Corzonera, Escorcionera, Escorzonera: ASTERACEAE - Perezia multiflora (Humb. \& Bonpl.) Lessing 105

Cuchichara: LAMIACEAE - Salvia macrophylla Benth.

Culantrillo del Pozo, Culantrillo: PTERIDACEAE - Adiantum concinnum Humb. \& Bonpl. ex Willd. 211

Culantrillo Serrano: ASTERACEAE - Tagetes elliptica Sm

Culantro: APIACEAE - Coriandrum sativum L.

Culén: FABACEAE - Otholobium mexicanum (L.f.) Grimes

Cuncuno, Cun Cun: APOCYNACEAE - Vallesia glabra (Cav.) Link.

Curil, Machacha: PLANTAGINACEAE - Galvesia fruticosa J. Gmelin

Cuti Cuti, Cuti Cuti Amarillo: PTERIDACEAE - Pellaea ternifolia (Cav.) Link.

Cuya Cuya: SOLANACEAE - Juanulloa ochracea Cuatrecasas

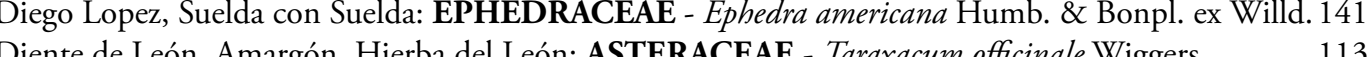

Dormidera Hierba Adormecedora Tutapure Morado (Chico): POLFMONIACEAE - Co Wiggers 113

Enredadera: ASTERACEAE - Mikania leiostachya Benth.

Espiga de Maíz, Chuño de Maíz, Maíz (Corn): POACEAE - Zea mays L.

Espina de Hoja: ACANTHACEAE - Aphelandra cirsioides Lindau

Espuela de Gallo: ALSTROEMERIACEAE - Bomarea dulcis (Hook.) Beauv.

Faique, Espino, Huarango: FABACEAE - Acacia macracantha Humb. \& Bonpl. ex Willd.

Flor Blanca: SCROPHULARIACEAE - Buddleja coriacea Remy

Flor de Agua: LEMNACEAE - Lemna minuta Kunth

Flor de Are Dija de Lag

Flor de Arenilla, Té de Indio: SCROPHULARIACEAE - Capraria peruviana Bentham 223

Flor de Azares: SOLANACEAE - Cestrum nocturnum L.

Flor de Dracena: ASPARAGACEAE - Dracaena fragrans Ker Gawl.

Flor de Novia: ASTERACEAE - Clibadium sylvestre (Aubl.) Baill.

Flor del Muerto, Clavel Chino, Flor de Muerto: ASTERACEAE - Tagetes erecta L

(L.) Lagerheim

Fresa (Strawberries): ROSACEAE - Fragaria vesca L.

Frijol Chileno: FABACEAE - Lablab purpureus (L.) Sweet

Fuque: CUCURBITACEAE - Sycos baderoa H. et A.

Garbanzo (Chickpea): FABACFAE - Cicer arietimum L.

Genciana, Egenciana, Amargón, Campanilla: GENTIANACEAE - Gentianella dianthoides (H.B.K.) Fabris 159

Genciana: GENTIANACEAE - Coutoubea ramosa Aubl.

Geranio (Geranium): GERANIACEAE - Pelargonium roseum Willd.

Grama Dulce: POACEAE - Cynodon dactylon (L.) Persoon

Granada (Pomegranate): LYTHRACEAE - Punica granatum L.

Granadilla, Hoja de Granadilla: PASSIFLORACEAE - Passiflora ligularis Juss.

Guaimi Guaimi, Huaime Huaime: ORCHIDACEAE - Pachyphyllum crystallinum Lindley

Guaminga, Huaminga: LYCOPODIACEAE - Huperzia hohenackeri (Herter) Holub

Guanábana, Graviola: ANNONACEAE - Annona muricata L. 
Guava, Huaba, Pacae, Pacai: FABACEAE - Inga edulis C. Martius, Inga feuilleei DC

Guayusa, Agracejo, Citrodora: AQUIFOLIACEAE - Ilex guayusa Loes

Habilla: EUPHORBIACEAE - Hura crepitans L.

Helecho Macho: THELYPTERIDACEAE - Thelypteris scalaris (Christ.) Alton Helialiso: ROSACEAE - Prunus serotina Ehrh.

Hierba Buena, Hierba Buena Silvestre, Menta (Mint): LAMIACEAE - Mentha spicata L.

Hierba Chupaflor, Hierba de la Suerte, Hierba del Carpintero: CYPERACEAE - Oreobolos obtusangulus T. Koyama 139

Hierba de la Fortuna: CAPRIFOLIACEAE - Valeriana microphylla Kunth

Hierba de la Golondrina: CYPERACEAE - Kyllingia pumila Michx.

Hierba de la Justicia, Piri Piri, Totorilla: IRIDACEAE - Hesperoxiphion niveum (Rav.) Rav.

Hierba de la Madriguera: RUBIACEAE - Arcytophyllum fliforme (Ruiz \& Pav.) Standl.

Hierba de la Plata, Chilco Hembra, Chilco Macho: ASTERACEAE - Baccharis salicifolia (R. \& P.) Pers. 97

Hierba de la Plata, Dolar (Dollar): PIPERACEAE - Peperomia fraseri C. DC.

Hierba de la Plata, Hierba del Tesoro: PIPERACEAE - Peperomia hartwegiana Miq.

Hierba de la Recaida, Hierba del Aire, Cutiquero, Yuca del Aire, Paja del Aire: LAMIACEAE - Salvia tubiflora R. \& P.

Hierba de la Reina: ASTERACEAE - Onoseris odorata (D. Don) Hooker \& Arnott

Hierba de la Señorita: ASTERACEAE - Werneria nubigena Kunth

Hierba de la Soledad, Hierba Sola: ORCHIDACEAE - Aa paleacea (Kunth) Rchb.f.

L'Héritier

Hierba de la Víbora: FABACEAE - Zornia piurensis Mohlenbrock

157

aciculare Kunth. 161

Hierba de los Sievientos. POACEAE - Digitaria cilhas (Rez.) Koehler. 205

Hierba del Caballero, Chupaflor: XYRIDACEAE - Xyris subulata Ruiz \& Pav. 237

Hierba del Cariño, Hierba de la Fortuna, Solitario, Chinchango, Abrecaminos: HYPERICACEAE -

Hypericum laricifolium Juss.

Hierba del Carnero, Hierba de Borrego: BROMELIACEAE - Puya hamata L.B. Sm.

Hierba del Carpintero: PTERIDACEAE - Jamesonia goudotii (Hieron) C. Chr.

Hierba del Dominio: ONAGRACEAE - Oenothera rosea Aiton

Hierba del Dominio: PTERIDACEAE - Cheilanthes myriophylla Desv.

Hierba del Halago: ASTERACEAE - Werneria pygmaea Gillies ex Hook. \& Arn

Hierba del Hombre, Rastrera: LYCOPODIACEAE - Lycopodium jussiaei Desv. ex Poir

Hierba del Hongo: UNIDENTIFIED

Hierba del Olvido: CLETHRACEAE - Clethra castaneifolia Meisn.

Hierba del Oro, Botón de Oro: ORCHIDACEAE - Stelis flexuosa Lindley

Hierba del Oro: ASTERACEAE - Werneria villosa A. Gray

Hierba del Oso, Veronica (Hembra), Moradilla de Cerro: AMARANTHACEAE - Alternanthera brasiliana

(L.) Kuntze

Hierba del Oso: AMARANTHACEAE - Alternanthera villosa Kunth

Hierba del Oso: ROSACEAE - Lachemilla nivalis Kunth

flaverioides Kunth

Hierba del Tigre: ASTERACEAE - Diplostephium sagasteguii Cuatrec.

Hierba del Tigre: SOLANACEAE - Jaltomata sp.

Hierba Gallinazo, Hierba del Gallinazo: ASTERACEAE - Porophyllum ruderale (Jacq.) Cass.

Hierba Luisa, Cedrón, Maria Luisa (Lemongrass): POACEAE - Cymbopogon citratus (DC.) Stapf.

Hierba Mora, Hierba del Susto, Baja del Espanto: SOLANACEAE - Solanum americanum Mill.

Hierba Rabia: ONAGRACEAE - Epilobium denticulatum Ruiz \& Pav.

Hierba Santa, Agrasejo: SOLANACEAE - Cestrum auriculatum L'Herit

Higo (Fig): MORACEAE - Ficus carica L.
Higrillo, Higrilla, Piñon, Higuerilla, Llonque: EUPHORBIACEAE - Ricinus communis L.

Higuerón: BIGNONIACEAE - Crescentia cujete L.

Higuerón: MORACEAE - Ficus sp.

Hinojo, Anís Criollo: APIACEAE - Foeniculum vulgare P. Miller

Hoja de Guanabana (Soursop), Graviola (Guava): MYRTACEAE - Psidium guajava L.

Hojas de Naranja (Bitter Orange): RUTACEAE - Citrus aurantium (Christmann) Swingle

Hojas de Olivo, Olivo (Olive): OLEACEAE - Olea europaea L.

Hojas de Sen: FABACEAE - Senna alexandrina Mill.

Hojas de Tumbo: PASSIFLORACEAE - Passiflora quadrangularis $\mathrm{L}$

Hojas de Yacón, Llacón: ASTERACEAE - Smallanthus sonchifolius (Poepp. \& Endl) H. Rob.

Hórnamo Blanco: ASTERACEAE - Senecio hypsiandinus Cuatr.

Hórnamo Cimuro: SOLANACEAE - Solanum sp.

Hórnamo Condor Purga: LYCOPODIACEAE - Huperzia columnaris B. Øllg.

Hórnamo Estrella, Siete Sábios, Valeriana Estrella, Valeriana, Hierba de la Estrella: CA

- Valeriana rigida Ruiz. \& Pav.

Hórnamo Leon Amarillo: ASTERACEAE - Senecio comosus Sch.-Bip.

Hórnamo Morado, Hórnamo Caballo: CAPRIFOLIACEAE - Valeriana plantaginea Kunth

Hórnamo Toro: APIACEAE - Niphogeton dissecta (Benth.) J.F. Macbr.

Huaime-Huaime, Cucharilla: ORCHIDACEAE - Stelis sp.

Hualtaco: ANACARDIACEAE - Loxopterygium huasango Spruce ex Engl.

Vira, Hónnamo, Hierba del Sol, Maguanmarica, Hierba del

109

Huamanripa, Pacra, Flor de Guarmayra: RANUNCULACEAE - Laccopetalum giganteum (Wedd.) Ulbrich213

Huanarpo (Hembra and Macho): BALANOPHORACEAE - Corynaea crassa Hook. f.

Huanarpo: CONVOLVULACEAE - Ipomoea pauciflora M. Martens \& Galeotti $\quad 135$

Huarate: SAPINDACEAE - Serjania brachyptera Radlk.

Huayruro, Huairuro: FABACEAE - Erythrina amazonica Krukoff

Huayruro, Huairuro: FABACEAE - Ormosia sp.

Ishpingo, Espingo-blanco, Espingo: LAURACEAE - Nectandra reticulata (Ruiz \& Pav.) Mez. 173

Ishpingo: LAURACEAE - Aiouea dubia (Kunth) Mez

Ishpinguillo, Ishpingo, Flor de Ishpingo: ASTERACEAE - Achyrocline alata (Kunth) DC.

Ishpino, Flor de Ishpingo, Hierba de Ishpingo: LAURACEAE - Ocotea floribunda (Sw.) Mez

mis dipsaceus Ehrenb. 135

Juan Alonso, Espina de Perro, Corona de Cristo: ASTERACEAE - Acanthoxanthium spinosum (L.) Fourreau 93

Kion, Gengibre (Ginger): ZINGIBERACEAE - Zingiber officinale Roscoe

Lampazo: ASTERACEAE - Arctium lappa L.

Lancetilla, Sanguinaria, Hierba del Toro: LYTHRACEAE - Cuphea strigulosa H.B.K.

McVaugh

Laurel, Laurel Rosa: APOCYNACEAE - Nerium oleander L.

Laurel: MYRICACEAE - Myrica pubescens H. \& B. ex Wild.

Laylambo, Ilambo: PHYTOLACCACEAE - Phytolacca bogotensis H.B.K.

Lecherita, Lechera: EUPHORBIACEAE - Chamaesyce hypericifolia (L.) Millspaugh

Lechuga (Lettuce): ASTERACEAE - Lactuca sativa L.

Lechuguilla: ASTERACEAE - Gamochaeta americana (Mill.) Wedd.

Lengua de Vaca: ASTERACEAE - Perezia pungens (Kunth) Cass.

Lenteja (Lentil): FABACEAE - Lens culinaris Medikus

Lima (Lime): RUTACEAE - Citrus limetta Riso 
\begin{tabular}{lr}
\hline Limón (Lemon): RUTACEAE - Citrus limon (L.) Burm. f. & 219
\end{tabular}

Limoncillo: XIMENIACEAE - Ximenia americana L. 237

Limpia Plata, Cola de Caballo, Tembladera: EQUISETACEAE - Equisetum giganteum (Wedd.) Ulbrich 141

Linoza (Linseed): LINACEAE - Limum sationm L., Linum usitatissimum L.

Llantama Blanca: VERBENACEAE

Llantén, Llantén de la Costa, Llantén Serrano: PLANTAGINACEAE - Plantago linearis Kunth

Llantén: PLANTAGINACEAE - Plantago major L.

Llatama Roja: MELASTOMATACEAE - Miconia salicifolia (Bonpl. Ex Naud.) Naud.

Lucuma: SAPOTACEAE - Pouteria lucuma (R. \& P.) Kuntze.

Madre Selva: CAPRIFOLIAEAE - Lonicera japonica Thunberg

Madriguera: ERIOCAULACEAE - Paepalanthus ensifolius (Kunth) Kunth

Mailchin, Maichil, Camalonga, Cabalonga: APOCYNACEAE - Thevetia peruviana (Pers.) Schum. 89

Maipa: BRASSICACEAE - Lepidium virginicum $\mathrm{L}$.

Malva (Chica), Malva Blanca: MALVACEAE - Malva sylvestris L.

Malva Blanca, Malva Morada: MALVACEAE - Alcea rosea (L.) Cavanilles

Malva de Oro, Malva Olorosa: GERANIACEAE - Pelargonium odoratissimum (L.) L'Herit.

Malva Rosa, Malva Real: MALVACEAE - Malva parviflora L.

Mamey: CALOPHYLLACEAE - Mammea americana L.

Mandarina (Mandarin Orange): RUTACEAE - Citrus reticulata Blanco

Mango: ANACARDIACEAE - Mangifera indica L.

Manzanilla (Camomille): ASTERACEAE - Matricaria chamomilla L. Matricaria recutita $\mathrm{L}$.

Cota L.

Maque Maque, Mano de León: ARALIACEAE - Oreopanax eriocephalus Harms

Maracuya: PASSIFLORACEAE - Passiflora edulis Sims.

Marañon, Cayu (Cashew): ANACARDIACEAE - Anacardium occidentale L.

Marrajudio: ASCLEPIADACEAE - Sarcostemma clausum (Jacquin) Schultes

Masamoche, Asancito, Asarcito, Asarquiro, Choleta: CHLORANTHACEAE - Hedyosmum racemosum (R

$\&$ P.) G. Don.

Mastrando, Mastrante: VERBENACEAE - Lantana scabiosaeflora Kunth

Mastuerzo: TROPAEOLACEAE - Tropaeolum minus L.

Mata Gusano: ASTERACEAE - Flaveria bidentis (L.) Kuntze

Mejorana: LAMIACEAE - Origanum majorana L.

Membrillo (Quince): ROSACEAE - Cydonia oblonga Miller

Milenrama, Chonchon: ASTERACEAE - Achillea millefolium L.

Mirra (Myrrh): BURSERACEAE - Commiphora myrrha (T. Nees) Engl.

Misha Amarilla, Misha Galga: SOLANACEAE - Brugmansia candida Persoon

(R. \& P.) D. Don

Mocura, Mucura: PHYTOLACCACEAE - Petiveria alliacea L.

Modoquero, Mogoquero: PIPERACEAE - Piper aequale Vahl.

Molle, Moy: ANACARDIACEAE - Schinus molle L

Morera (Mulberry): MORACEAE - Morus alba L

Mullaca Mistura, Mullaca, Mullaca Real: ERICACEAE - Gaultheria erecta Vent.
Muña, Chancas de Comida: LAMIACEAE - Minthostachys mollis (Benth.) Griseb.

Nabo (Raddish): BRASSICACEAE - Brassica rapa L.

Naranja (Orange): RUTACEAE - Citrus sinensis (L.) Osbeck

Nogal (Walnut): JUGLANDACEAE - Juglans neotropica Diels

Nuez Moscada, Ajonjolí (Nutmeg): MYRISTICACEAE - Myristica fragrans L.

Oca Rosada: OXALIDACEAE - Oxalis tuberosa Molina

Oregano: LAMIACEAE - Origanum vulgare L.
Ortiga: URTICACEAE - Urtica urens L.

Ortiga, Ortiga (Chica), Ortiga de Oveja, Ortiga Negra: URTICACEAE - Urtica magellanica A. Jussieu ex Poiret

Overo, Flor de Overo, Overal: BORAGINACEAE - Cordia lutea Lam.

Pacha Rosa, Carapa de Chancho: ASTERACEAE - Paranephelius uniflorus Poepp. \& Endl.

Paico: AMARANTHACEAE - Chenopodium ambrosioides $\mathrm{L}$.

Paja Amargoza: ASTERACEAE - Baccharis caespitosa (Ruiz \& Pav.) Pers

Paja Blanca, Sanguinaria: AMARANTHACEAE - Iresine diffusa Humb. \& Bonpl. ex Willd.

Paja Blanca: PLANTAGINACEAE - Plantago sericea subsp. sericans (Pilg.) Rahn

Paja Blanca: PLANTAGINACEAE - Plantago sericea subsp. sericans (Pilg.) Rahn
Paja Morada (Colores), Lenguetilla, Sanguinario, Lengua de Pájaro, Sanguinaria, Moradilla, Hierba Morada

Pájaro Bobo: ASTERACEAE - Tessaria integrifolia R. \& P.

Pajilla Blanca: PLANTAGINACEAE - Plantago sericea R. \& P. var. lanuginosa Grieseb.

Palmeras (Chica), Llatama, Yatama: LAMIACEAE - Salvia discolor H.B.K.

Palmerilla, Palmita, Pata de Gallina, Palmera, Trensilla, Palmilla, Patita de Gallo, Palmia Pina, Palmera

Blanca, Destrensilla: ASTERACEAE - Loricaria ferruginea (Ruiz \& Pav.) Wedd.

Palmilla Ancha, Palmilla Verde, Palma Bendita: ASTERACEAE - Loricaria thyrsoidea (Cuatrec.) Dillon \&

Sagástegui

Palo Amarillo: BERBERIDACEAE - Berberis buceronis J.F. Macbride

Palo de Ajo: PHYTOLACCACEAE - Gallesia integrifolia (Spreng.) Harms.

Palo de la China (Blanco): SMILACACEAE - Smilax febrifuga Kunth

Palo Huaco, Palo Blanco: CANNABACEAE - Celtis pubescens (Humb. \& Bonpl.) Spreng.

Palo Sangre, Palo de Sangre, Ablita: MORACEAE - Brosimum rubescens (Aublet) Huber

Palo Santo: BURSERACEAE - Bursera graveolens (Kunth) Triana \& Planchon

Palta (Avocado): LAURACEAE - Persea americana Mill.

Panisara: LAMIACEAE - Satureja pulchella (Kunth) Briquet

Papa Madre, Papa Pacta: DIOSCOREACEAE - Dioscorea trifida L.f.

Papa Semitona DIOSCOREACEAE - Dioscored tambillensis Kun

Papaya: CARICACEAE - Carica papaya L

Papelillo, Papelilla, Palalio: LICHENES - Siphula sp.

Parrano: ASTERACEAE - Diplostephium gynoxyoides Cuatrec.

Pasionara: PASSIFLORACEAE - Passiflora caerulea L.

Pasto Miel: ASTERACEAE - Baccharis pedunculata (Mill.) Cabr.

Pata de Gallina: ASTERACEAE - Baccharis chilco Kunth

Pata de Gallina: ASTERACEAE - Pluchea absinthioides Hook. \& Arn.) H. Rob. \& Cuatr.

Pay Pay: FABACEAE - Caesalpinia paipai Ruiz \& Pav.

LAMIACEAE - Hyptis sidifolia (L’Her.) Briq.

Pega Pega: FABACEAE - Desmodium triflorum (L.) DC

Pega Pega: NYCTAGINACEAE - Boerhavia coccinea Mill.

Pensamiento Amarillo, Hierba del Pensamiento, Hierba del Tacón (Violet): VIOLACEAE - Viola tricolor L. 237

Pepinillo: CUCURBITACEAE - Cucumis sativus $\mathrm{L}$.

Perejil: APIACEAE - Petroselinum crispum (Miller) A.W. Hill

Pial, Pus: RHAMNACEAE - Scutia spicata (H. \& B. ex Schultes) Weberb. var. spicat

Pica Pica: POLYGONACEAE - Polygonum hydropiperoides Michaux

(H.B.K.) DC.

Pimienta Negra (Black pepper): PIPERACEAE - Piper nigrum L.

Pimpinela, Flor de Overa: ROSACEAE - Sanguisorba minor Scop.

Pino (Pine): PINACEAE - Pinus patula Schldl. \& Cham., Pinus radiata D. Don. 
Pino: ARAUCARIACEAE - Araucaria heterophylla (Salisb.) Franco

Pinpin, Siempre Viva, Rosa Berta, Haya Rosa: CRASSULACEAE - Echeveria peruviana Meyen 135

Piña (Pineapple): BROMELIACEAE - Ananas comosus (L.) Merrill

Piñones: EUPHORBIACEAE - Jatropa curcas L Jatropa gossypiifolia L, Jatropa weberbaueri Pax \& Hoffman 145 Piri Piri (Macho and Hembra): PIPERACEAE - Peperomia quadrifolia Trel. 199

Piri Piri: ISOETACEAE - Isoetes andina Spruce ex Hook.

$\begin{array}{lc}\text { Piri Piri: ISOETACEAE - Isoetes andina Spruce ex Hook. } & 163 \\ \text { Plátano (Banana): MUSACEAE - Musa x paradisiaca L. } & 185\end{array}$

Polen de Zapote, Polen de Espina Negra, Polen de Arboles, Polen de Ciachon (Insect Feces): NON-PLANT MATERIAL 239

Poleo (Peppermint): LAMIACEAE - Mentha piperita L. 165

Poleo de Gentil: LAMIACEAE - Scutellatia scutellarioides (Kunth) R. Harley 171

Poleo del Inca: VERBENACEAE - Lippia alba (Miller) N.E. Brown 235

$\begin{array}{ll}\text { Poma Rosa: MYRTACEAE - Syzygium jambos (L.) Alston } & 189\end{array}$

Porotillo: FABACEAE - Erythrina velutina Willdenow

Potito: CALCEOLARIACEAE - Calceolaria rugulosa Edwin

Puli Punchi, Pasuchaca, Pachuchaca, Miscamisca: GERANIACEAE - Geranium ayavacense Willd ex H.B.K.

Geranium sessiliflorum Cavanilles

Quihuicha, Kiwicha: AMARANTHACEAE - Amaranthus caudatus L.

Quina Quina, Kina Kina: FABACEAE - Myroxylon balsamum (L.) Harms.

Quinua Amarga: AMARANTHACEAE - Chenopodium quinoa Willd. (wild form)

Quinua, Cascarilla: RUBIACEAE - Cinchona officinalis L.

Quinua: AMARANTHACEAE - Chenopodium quinoa Willd.

Quinual: ROSACEAE - Polylepis racemosa R. \& P.

Rabanito (Raddish): BRASSICACEAE - Raphanus sativus $\mathrm{L}$

121

Rabo de Paloma, Hierba del Susto (de Cerro): PLANTAGINACEAE - Plantago sericea Ruiz \& Pav. var. sericea 201

Racacha, Racacha Cimarrona: APIACEAE - Arracacia xanthorrhiza Bancroft $\quad 85$

$\begin{array}{lr}\text { Raínga: CAMPANULACEAE - Centropogon cornutus (L.) Druce } & 125 \\ & 177\end{array}$

Rastera: LYCOPODIACEAE - Lycopodium clavatum L. 177

\begin{tabular}{ll} 
Ratania: KRAMERIACEAE - Krameria lappacea (Dombey) Burdet \& B.B. Simpson & 163 \\
\hline & 157
\end{tabular}

$\begin{array}{ll}\text { Retama, Retania: FABACEAE - Senna occidentalis (L.) Link. } & 157 \\ \text { Retama: FABACEAE - Spartium junceum L } & 157\end{array}$

$\begin{array}{ll}\text { Retama: FABACEAE - Spartium junceum L. } & 157 \\ \text { Rinchinchin, Chinchin: SIPARUNACEAE - Siparuna tomentosa (Ruiz \& Pav.) A. DC. } & 223\end{array}$

$\begin{array}{ll}\text { Rinchinchin, Chinchin: SIPARUNACEAE - Siparuna tomentosa (Ruiz \& Pav.) A. DC. } & 223 \\ \text { Romero del Campo, Romero Blanco, Romero Serrano: LAMIACEAE - Salvia officinalis subsp. lavandulifolia (Vahl) Gams } & 169\end{array}$ Romero, Romero Castilla (Rosemary): LAMIACEAE - Rosmarinus officinalis L. 167

Rosa de Castilla, Rosa (Rose): ROSACEAE - Rosa centifolia L.

Ruda, Ruda (Macho y Hembra), Hierba del Quinde: RUTACEAE - Ruta graveolens $\mathrm{L}$.

Rumilanche, Huaminga: PROTEACEAE - Oreocallis grandiflora (Lam.) R.Br.

Sábila, Zábila, Aloe, Hojas de Sábila, Aloe Vera: XANTHORROEACEAE - Aloe vera (L.) Burm f. 237

Salvia (Sage): LAMIACEAE - Salvia officinalis L.

Salvia Blanca: LAMIACEAE - Salvia cuspidata R. \& P.

Salvia Negra: LAMIACEAE - Salvia sagitatta Ruiz \& Pav.

Salvia, Salvia Real: LAMIACEAE - Lepechinia mevenii (Walp.) Epling

165

San Juan: ASTERACEAE - Pseudogynoxys cordifolia (Cass.) Cabrera 107

San Pedro, Huachuma: CACTACEAE - Echinopsis pachanoi (Britton \& Rose) Friedrich \& G. Rowley 123

Sandía (Watermelon): CUCURBITACEAE - Citrullus lanatus (Thunberg) Matsumura \& Nakai 135

Sangre de Grado, Sangre de Drago: EUPHORBIACEAE - Croton draconoides Müll.-Arg. $\quad 145$

Sangre de Grado, Sangre de Drago: EUPHORBIACEAE - Croton lechleri Müll. Arg.

Sanguinaria, Moradilla, Lancetilla: AMARANTHACEAE - Alternanthera porrigens (Jacquin) Kuntze 79

Santa María: SOLANACEAE - Cestrum strigilatum R. \& P., Cestrum undulatum R. \& P. 227

Sarcilleja: MELASTOMATACEAE - Brachyotum tyrianthinum J.F. Macbr.
Sauce (Willow): SALICACEAE - Salix chilensis Molina

Secana: CUCURBITACEAE - Sicana odorifera (Vell.) Naud.

Shimir, Tres Hojas, Trinidad, Chacur, Ahimir, Feregreco: ANACARDIACEAE - Mauria heterophylla Kunth. 83

Siempre Viva, Siempre Viva Roju: BROMELIACEAE - Tillandsia multiflora Bentham var decipiens (Andre) Sm. 123

PACEAE - Baccharis tricuneata (L.f) Pers.

Sombristis (Lam.) Pess.

Sombrerito: ARALIACEAE - Hydrocotyle globiflora R. \& P.

Suelda con Suelda: LORANTHACEAE - Psittacanthus chanduyensis Eichler

Suelda con Suelda: LORANTHACEAE - Tristerix longebracteatus (Desr.) Barlow \& Wiens

Sumarán, Chinchimali, Corpushuay: GENTIANACEAE - Gentianella graminea (H.B.K.) Fabris

Tabaco (Tobacco): SOLANACEAE - Nicotiana tabacum L.

Tacón Blanco, Pensamiento Blanco: FABACEAE - Lathyrus odoratus L.

Tamarindo: FABACEAE - Tamarindus indica L.

Tapa Tapa: FABACEAE - Mimosa albida H. \& B.

Tara, Talla, Chanchalagua: FABACEAE - Caesalpinia spinosa (Molina) Kuntze

Té (Tea): THEACEAE - Camellia sinensis (L.) Kuntze

Ticra: LAMIACEAE - Salvia ayavacensis Kunth

Ticta, Tifta: BROMELIACEAE - Puya weberbaueri Mez.

Tilo (Linden): MALVACEAE - Tilia platyphyllos Scop.

Tomate (Tomato): SOLANACEAE - Lycopersicon esculentum Mill.

Tomate de Monte: SOLANACEAE - Lycopersicum peruvianum L.

Tomillo (Thyme): LAMIACEAE - Thymus vulgaris L.

Toromaique, Maique, Maique Candela, Toromaique Amarillo, Toromaique Verde, Gavilán Maique Amarillo,

Gavilán Maique Verde: ERICACEAE - Gaultheria reticulata Kunth

Toronja (Grapefruit): RUTACEAE - Citrus grandis (L.) Osbeck

Toronjil, Melissa: LAMIACEAE - Melissa officinalis L.

Trebol, Trebol de Agua (Clover): FABACEAE - Trifolium repens $\mathrm{L}$.

Trébol: OXALIDACEAE - Oxalis bulbigera Knuth.

Trencilla Pequeña: POLYPODIACEAE - Grammitis moniliformis (Lag. ex Sw.) Proctor

Trencilla Roja: LYCOPODIACEAE - Huperzia tetragona (Hook. \& Grev.) Trevis.

Trencilla Roja: LYCOPODIACEAE - Lycopodium thyoides H. \& B. ex Willd.

Trigo (Wheat): POACEAE - Triticum aestivum $\mathrm{L}$.

Trinoso: CAMPANULACEAE - Centropogon rufus Wimm

Tripa de Cuy: CARYOPHYLLACEAE - Stellaria media (L.) Criollo

Tumapara, Pomanpara, Puma Para, Para Para: AMARYLLIDACEAE - Eustephia coccinea Cav.

Tumbillo: PASSIFLORACEAE - Passiflora punctata L.

Tuna: CACTACEAE - Opuntia ficus-indica (L.) Miller

Turre: ASTERACEAE - Spilanthes leiocarpa DC.

Rob. \& Brettell

Tutapure Blanco: ASTERACEAE - Senecio genisianus Cuatr.

Tutapure Chico: SOLANACEAE - Solanum sp.

Tutapure de Estrella: ARALIACEAE - Hydrocotyle bonariensis Commerson ex Lam.

Ufla: ASTERACEAE - Acmella ciliata (Kunth) Cass.

Unquia Real, Rumilanchi: MYRTACEAE - Eugenia punicifolia (Kunth) DC.

Uńa de Gato de la Costa: FABACEAE - Mimosa nothacacia Barneby

Uńa de Gato, Uncaria Tomentosa

(Aublet) Gmelin

Uva (Grape): VITACEAE - Vitis vinifera L.

Valeriana: ROSACEAE - Geum peruvianum Focke 
Verbena: VERBENACEAE - Verbena litoralis Kunth

Verdolaga: PORTULACACEAE - Portulaca oleracea L. subsp. tuberculata Danin \& H.G. Baker 209

Verdolaga: PORTULACACEAE - Portulaca pilosa L. 209

Veronica (Macho): LAMIACEAE - Stachys lanata Jacq. $\quad 171$

Veronica: PASSIFLORACEAE - Malesherbia ardens J.F. Macbr. 195

Violeta Genciana: GENTIANACEAE - Gentianella crassicaulis J.S.Pringle 159

Vira Vira, Oreja de Conejo: ASTERACEAE - Senecio canescens (H.B.K.) Cuatrecasas 109

Visnaga: APIACEAE - Ammi visnaga (L.) Lam.

Yerba del Soldado, Tilonga, Matico, Mogo-Mogo: PIPERACEAE - Piper aduncum L. 199

Yin Yin: FABACEAE - Dioclea virgata (Rich.) Amsh. 149

Yodo: CONVOLVULACEAE - Cuscuta foetida H.B.K. 133

Yuca (Manihot): EUPHORBIACEAE - Manihot esculenta Crantz 145

Yuyo: AMARANTHACEAE - Amaranthus hybridus L. 79

Zanahoria de Zorro, Zanahoria de Gentil, Zanahoria: APIACEAE - Daucus montanus Humb. \& Bonpl. ex Spreng. 85

Zapallo: CUCURBITACEAE - Cucurbita maxima Duchesne 135

Zapallo: CUCURBITACEAE - Cucurbita moschata Duch. 137

Zapote: CAPPARIDACEAE - Capparis scabrida Kunth 127

Zarzamora, Moyaca, Zarza, Zarza Parrilla, Mora, Cushai (Blackberry): ROSACEAE - Rubus robustus C. Presl.215

Zarzaparilla, Zarza Parilla: SMILACACEAE - Smilax kunthii Killip \& Morton 223 
